University of Rhode Island

DigitalCommons@URI

Open Access Dissertations

1972

\title{
A Dynamic Study of a Pilot Eckey Horizontal Fractionator
}

Robert Kingsley Andren

University of Rhode Island

Follow this and additional works at: https://digitalcommons.uri.edu/oa_diss

\section{Recommended Citation}

Andren, Robert Kingsley, "A Dynamic Study of a Pilot Eckey Horizontal Fractionator" (1972). Open Access Dissertations. Paper 773.

https://digitalcommons.uri.edu/oa_diss/773

This Dissertation is brought to you for free and open access by DigitalCommons@URI. It has been accepted for inclusion in Open Access Dissertations by an authorized administrator of DigitalCommons@URI. For more information, please contact digitalcommons-group@uri.edu. 


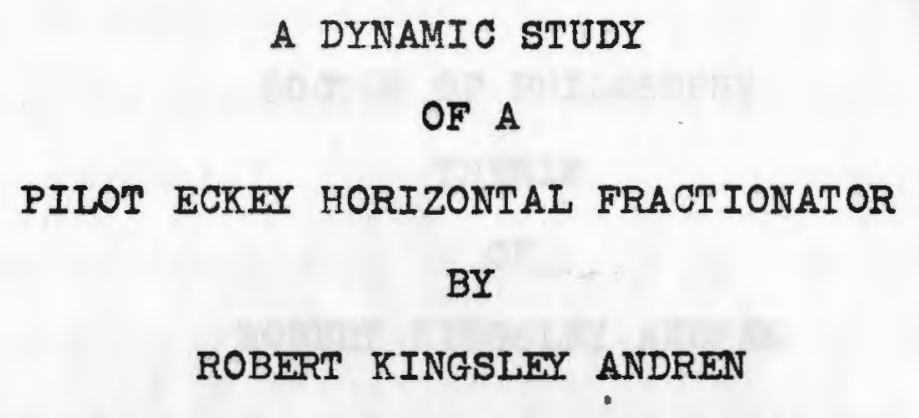

A THESIS SUBMITTED IN PARTIAL FULFILLMENT OF THE REQUIREMENTS FOR THE DEGREE OF DOCTOR OF PHILOSOPHY

IN

CHEMICAL ENGINEERING

UNIVERSITY OF RHODE ISLAND 1972 
DOCTOR OF PHILOSOPHY

THESIS

OF

ROBERT KINGSLEY ANDREW

Approved:

Thesis committee: G. David Shilling

Frank m. White

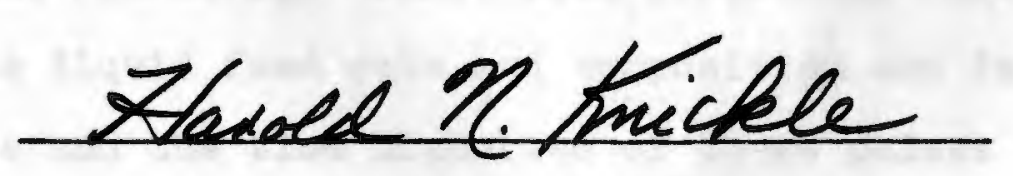

$$
\frac{\text { A. G. Michel }}{\text { Dean of the Graduate school }}
$$

UNIVERSITY OF RHODE ISLAND

1972 


\section{ABSTRACT}

In order that the automatic control of a process system be optimal, the dynamics of the equipment involved must be throughly understood. Distillation is a complex non-linear process and as such, many of the dynamic system parameters are diffleult to predict accurately and must be determined experimentally. The purpose of this study was to develop a series of dynamic models which characterize the response of the liquid temperature on the plates of a pllot Eckey Horlzontal Fractionator, to variations in liquid feed rate, liquld feed composition, and vapor feed rate. Th1s was done by experimentally determining the frequency response of the column indirectly, using the pulse technique.

The elght 1nch, 32 plate column was run as a stripper using the binary methanol-water system. Llquid feeds were introduced at the top with raw steam being fed into the bottom of the column. The column was run at pressures of one atmosphere and about $200 \mathrm{~mm}$ Hg. Pulse-like varlations were introduced into the liquid feed rate and composition and in the vapor feed rate and the time historles of these pulses and the column responses on several plates were recorded. From these data, values for the system frequeney response were calculated numerically using the computerized TAFT routine. This data was then plotted on Bode diagrams. The 
Bode plots were analyzed to determine the form of the dynamic models of the column and their parameters.

It was found that 11 quid rate and composition disturbances showed flrst order responses plus delays which increased with distance from the feed plate. Vapor rate responses also showed first order dynamics but without delays. The major first order time constants were relatively constant on all plates for the liquid and vapor rate responses but Increased with distance from the feed plate for liquid composition responseg. Of considerable interest was the presence of resonance peaks in the frequency response curveg. These are thought to be the result of oscillating composition transients traveling down the column in the liquid and up in the vapor flow. A term to account for resonance was included in the models. It was found that the time delays and first order time constants could be related to the liquid residence time and scale-up equations are developed for applying the results of this study to other Eckey horlzontal columns. 


\section{ACKNOWLEDGMENT}

At this time, I would like to take the opportunity to thank those whose generous ald was given to the author Dr. G. David Shlliling whose advice, councel, and patience were greatly appreclated; Dr. Pasquale Marino who originated the concept of th1s study; and the Vulcan Manufacturing Company and Mr. Larry Nisbet for providing the Eckey Fractionator.

I am grateful to NDEA, NSF, the Department of Chemlcal Engineering - U.R.I., W1lliam M. Jette \& Son Inc., and my wife Susan for financial support during this study. I would also like to express my warmest thanks to my wife for her devotion, understanding, patience, and endurance and thank Krlcket for her moral support. 


\section{TABLE OF CONTENTS}

I. INTRODUCT ION.............................. 1

The Literature......................... 4

Distillation Dynamios...................... I1

II. THEORY OF PULSE TESTING................... 15

III. EXPERIMENTAL WORK..................... 25

Equipment......................... 25

Experimental Procedure.................... $\quad 39$

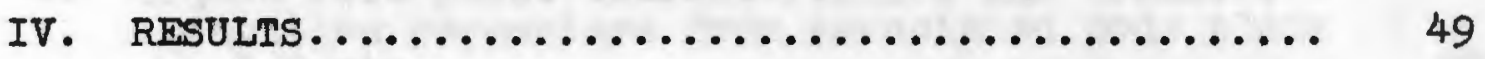

v. DISCUSSION.......................... 77

VI. CONCLUSIONS.......................... 86

BIBLIOGRAPHY......................... 89 APPENDIX

A. Equipment Specifications............... 96

B. Computer Program..................... 99

C. Experimental Frequency Response Plots.... 106 


\section{LIST OF TABLES}

Table

Page

1. Operating conditions - steady state experimental

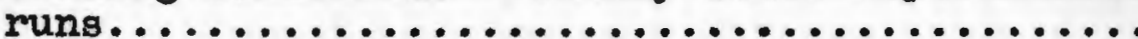

42

2. Steady state operating conditions for pulse runs

3. Vapor rate pulse characteristics and transfer function parameters from associated Bode plots

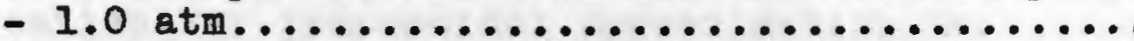

4. Liquid rate pulse characterlstics and transfer function parameters from assoclated Bode plots

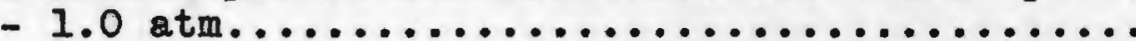

5. Liquid concentration pulse characteristics and transfer function parameters from assoclated Bode plots - $1.0 \mathrm{~atm} . . . \ldots \ldots \ldots \ldots \ldots \ldots . . . . .$.

6. Vapor rate pulse characteristics and transfer function parameters from associated Bode plots - .26 atm...........................

7. Llquid rate pulse characterlstics and transfer function parameters from associated Bode plots

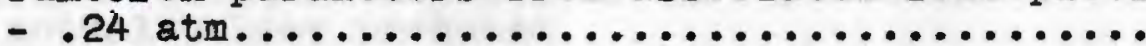

8. Iiquid concentration pulse characteriatics and transfer function parameters from assoclated

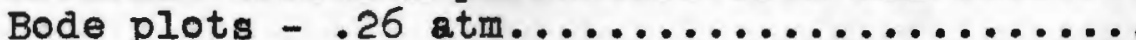

9. Final column transfer function model parameters. 
LIST OF FIGURES

Figure

Page

1. Internal views of Eckey column.............

2. Sinusoldal forced response of typical linear

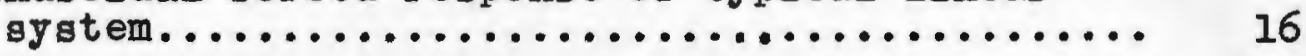

3. Frequency spectrum for rectangular pulse trains. 18

4. Notation for Trapezo1dal Approximation to Fourler Trañsorm - (TAFT routine)......... 22

5. Overall equipment setup................. 26

6. Eckey column........................ 34

7. Hquld feed system....................... 35

8. Vapor feed and bottoms liquid systems......... 36

9. D1st1llate collection and vacuum systems....... 37

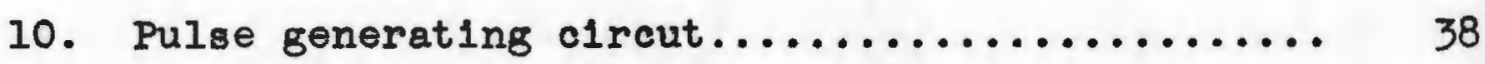

11. Illustration of theoretical flow pulses and actual pulses produced.................. 46

12. Illustration of notation used for calculation of transfer function parameters $A$ and B...... 55

13. Plot of L/RT versus plate number for liquid rate

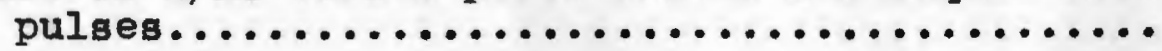

81

14. Plot of L/RT versus plate number for liquid composition pulses.

Appendix C - Bode Plots

Vapor rate responses -1.0 atm............. 108

Liquid rate responses -1.0 atm............ 157

Liquid concentration responses - $1.0 \mathrm{~atm} . . . \ldots . .192$

Vapor rate responses - .26 atm............. 213 
Liquid rate responses -.24 atm............ 256

Liquid concentration responses - .26 atm...... 281 


\section{INTRODUCTION}

The optimum use of proven equipment and the development of new designs remain continuing challenges to the chemlcal process 1ndustry. The Eckey Horlzontal Fractionator is a horlzontal, rapor-liquid contact column recently developed for use in low pressure distillation, absorption, strlpping, and evaporation operations. Although performing the same functions as conventional sleve tray or bubble cap distillation units, phase contact is accomplished by passing rapor countercurrent to curtalns of llquid droplets providing effective interfaces for mass and heat transfer. This results In efflolent liquid-vapor contact for even highly viscous materlals. Combined with an extremely low pressure drop per theoretical stage of the order .05 to $.2 \mathrm{~mm} \mathrm{Hg}$, the column is 1deal for performing separations involving high bolling, heat sensltive materials under high vacuum. The horizontally mounted elght inch diameter column contains 32 phase contact stages. A section of the column is shown in Figure 1. Liquid flows from stage to stage, but only after it has been sprayed by the 1mpeller located in that stage. The impellers are mounted on a rotating shaft extending lengthwise through the column below the axis. They are fabricated from a serles of "sleve plates" and "spacer rings" and designed so that large volumes of liquid 


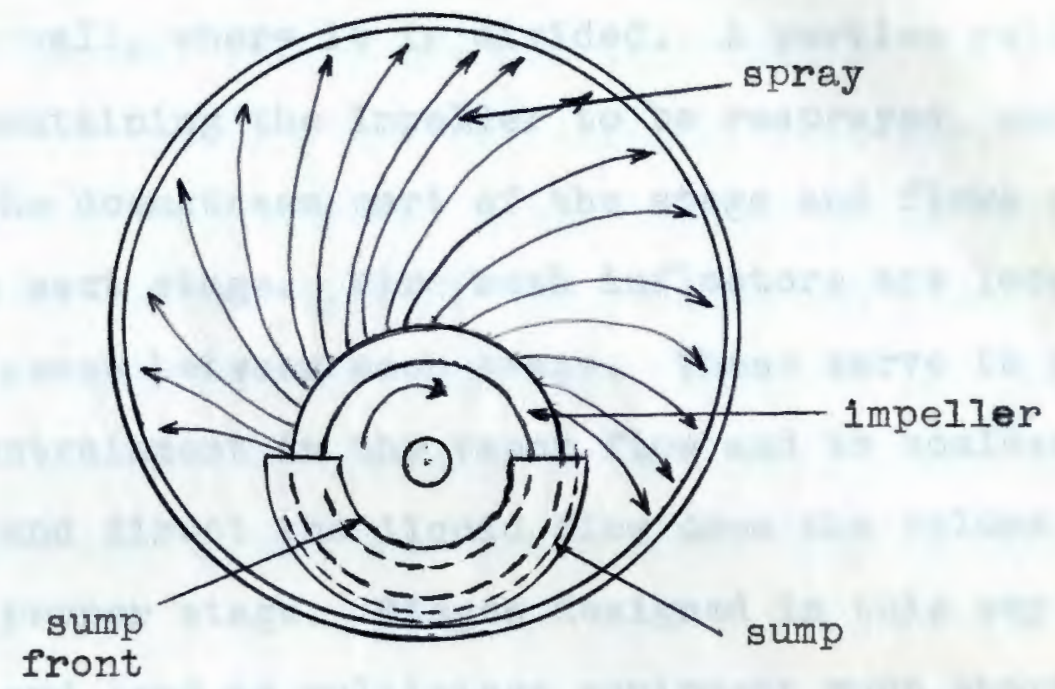

Cross section

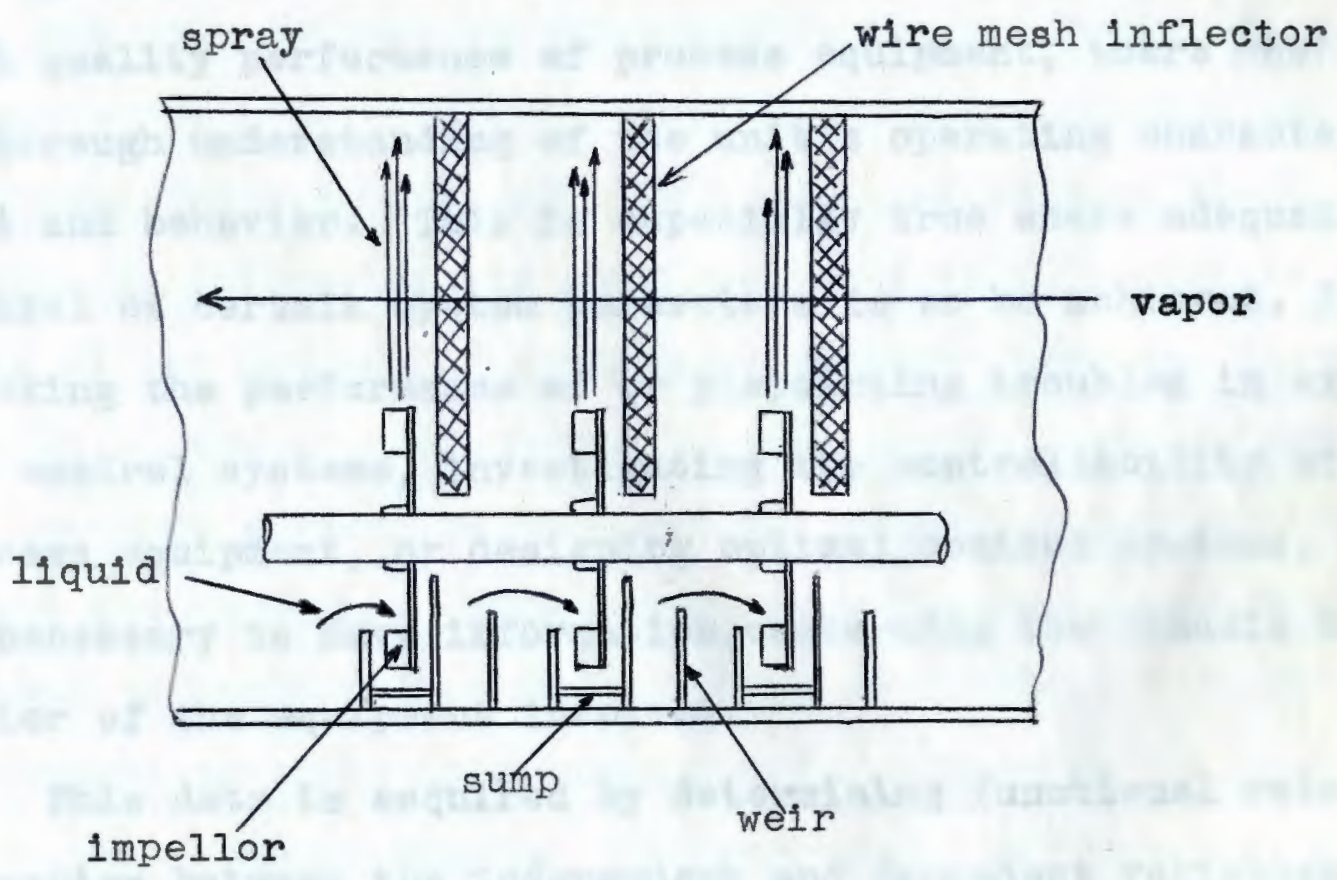

Longitudinal section

Figure 1 -- Internal views of Eckey Column 
entering the inside periphery are sprayed out forming a pattern of unfform drop size and density. The spray then inpinges on the shell of the column above the Impeller and runs back down the wall, where 1 t is divided. A portion returns to the sump containing the impeller to be resprayed, and the rest enters the downstream part of the stage and flows over a weir to the next stage. W1re mesh inflectors are located in the vapor space between each stage. These serve to prevent liquid entralnment in the vapor flow and to corlesce the droplets and direct the liquid flow down the column walls to 1ts proper stage. Stages designed in this way are very compact and lead to multistage equipment much shorter in length than conventional distillation columns.

In order to insure efficlent and economical design and hlgh quality performance of process equipment, there must be a thorough understanding of the unit's operating characterlstics and behavior. This is especially true where adequate control of certain system parameters is to be achleved. In checking the performance of or pinpointing troubles in existIng control systems, investigating the controllability of process equipment, or designing opt1mal control systems, it is necessary to have information concerning the dynamio behavior of the equipment involved.

Th1s data is acquired by determining functional relat1onsh1ps between the independent and dependent variables of the system. A dynamic model may be rigorously derived if the physical laws describing the action and interaction of 
these variables are completely understood. Often however, the system is of such complexity that only an approximate model can be constructed and experimental information is required to determine the parameters occuring in this model and to verify its accuracy and reliablilty. The experimental testing usually consists of subjecting an input (1ndependent variable to some type of disturbance and measuring the response of some output (dependent) variable to that disturbance. Appropriate analysis of the forcing and the system response will then gleld the desired dynamic informat1on.

\section{THE LITERATURE}

Two main methods for determining dynamic properties, as discussed by Lees (58) are translent response testing and frequeney response testing. Both of these methods jield sufficient information to construct or test a linearized model of the system. In transient response response testing, usually a ramp or atep change in some system input 18 made and the time history of this and the system outputs of interest are recorded. These data are analyzed by standard methods to yield values for the time constants and other parameters occuring in a dynamic model. However for higher order more complex syatems, interpretation of transient data becomes diffcult. Also, a permanent change in the system variables is produced which in practical situations may not be desirable. 
Frequency response testing involves the technique of applying a steady sinusoldal variation to a system input and measuring the output response. This is a technique that has been long used in electrical englneering applications. Theoretically the forcing can cover an infinite range of frequencles, but actually, data of interest usually lie in a more narrow range. By proper analysis of amplitude ratios and phase angle shifts between input forcing and the system's response over a range of input frequencles, it is possible to accurately determine values for the parameters occuring in a dynamic model of the system. From this information, one could then predict the response of the system to any disturbance in the range of linear operation. Frequency response data also yleld Information regarding stabllity of the system, reveal resonance effects, and are more useful for higher order systems than translent data.

The direct method of obtaining this data is to actually vary a system input sinusoldally and measure the response over a wlde range of input frequencles. Thls however can be a very time consuming process and may require a large amount of expensive testing apparatus. Also if the equipment being tested is in use, the experimentation could cause dangerous side effects or result in the production of large quantities of off-specification product. Fortunately there are simpler Indirect methods of obtalning frequency response data which are arallable. Gallier (37) and Lees (58) discuss methods of obtaining frequency response data by statistically analyzing 
random variations in input and output varlables using correlation techniques. However a more practical and widely applicable method is pulse testing.

It has been shown by Hougen $(45,47)$, clements and schnelle (22), and Draper et al (28) that by subjecting a system to a single pulse-like disturbance, the same frequency response information can be acquired as that determined by forcing the syatem sinusoldally over a range of frequenc1es. The experimental testing time then is much shorter than that required for direct frequency response testing. since an exact sinusoidal variation in an input variable is not needed, the testing equipment can often be simpler. The pulse is made by varying the input from its steady-state value for some fintte period of time and then returning it to this value. The time history of the input and the system response are recorded. The pulse must be large enough to generate a messurable response but should not be so large as to excite the system beyond Iinear operation. It may have a precise shape, such as triangular, rectangular, or half sine, but this is not a requirement.

Driefke (29) has made a detalled investigation into the effect of pulse helght, width and shape on the accuracy of frequency response data derived from experimental pulse test1ng. Thls study involved analog testing of firgt, second, third, and higher order systems by forcing them with many different pulses. He concluded that several different pulses gave good results, and in general, longer pulses gave more 
rellable low frequency data and shorter pulses more rellable high frequency data. It was found that half sine pulses geve better results than rectangular pulses and that the spectral content of the input pulse was very 1mportant. Accuracy was also affected by the data reduction process, conflrming earlier work.

Some of the earliest applications of pulse testing were In the area of alrcraft stability and control. Smith and Triplett (78) and Eggleston and Mathows (32) discuss several methods of obtalning frequency response data from pulse information gotten during flight tests. In recent years this technique has been applied in many areas of the chemieal process Industry. Hougen and Lees (46) pulse tested a condenser to determine the response of the outlet 11quid temperature to changes in the inlet liquid flow rate. The frequency response was then calculated, compared to the sinusoldal forced response, and fltted to a dynamic model of the process. Hougen and Walsh (47) discuss the application of the pulse testing method to ten systems incluaing servomechanisms, analog models, heat exchangers and mixing chambers. The frequency response data obtained were found to be in excellent agreement with those acquired by direct sinusoldal forcing.

There have been numerous studies made of the dynamics of fractionating equipment. A distillation column consists of a complex sequence of interacting heat and masg transfer stages. A serles of non-linear differential equations 
describing the distillation process can be written for each stage, but the simultaneous solution of these becomes quite difficult. Attempts to solve simplified versions of these have been made and the results compared with experimentally determined transient and frequenoy response data.

Williams (83) and Archer and Rothfus (4) have completed extensive literature survejs of recent work done in the area of distillation dynamics. Rosenbrock (64) discusses a digital computer routine used to numerically solve the theoret1cal equations.

A five plate benzene-carbon tetrachloride column was studied at total reflux by Armstrong and w1lkson $(5,6)$ to determine the transient response to step changes in vapor composition. An analytical solution of simplified modeling equations showed good comparison with the experimental data for the initial portion of the response. In further studies, Armstrong et al $(7,9)$ investigated the transient response of the plate liquid composition of a 22 plate four inch benzene-carbon tetrachloride column to step changes in feed composition and reflux rat10. Predicted responses showed good comparison with the experimental work and the authors suggested that the response could be characterized by a time delay followed by a firgt order lag.

Lamb and P1gford (57) made a theoretical study of transient behavior of five, 16, and 21 plate columns by solving the differential perturbation equations describing the column. An analog circult was set up simulate changes in feed 
rate and composition. An osclllating transient was noticed in the Ilquid composition on each plate and attributed to wavelike disturbances moving up in the rapor and down in the 11quid. They seemed to originate at the point of upset and be reflected at the ends of the column. It was also felt that the responses at low frequency could be simply characterized by delays and first order lags.

In a series of papers, Gerster et al $(10,11,36,38)$ conducted experimental transient response studies on a pilot plant distillation column. Step changes in liquid feed rate, vapor rate, and reflux rate were made for five plate and ten plate, two foot diameter benzene-acetone columns. The results, when compared w1th analog solutions to the perturbation equations of Lamb and Plgford, showed good agreement. Approximate first order responses were noted, with disturbances in vapor rates belng felt almost immediately throughout the column.

More complex equations were developed by Franke et al (34), and their solutions were compared with experimental tests performed on a twelve plate methanol-tertlary butyl alcohol column. The response to step changes in reflux rate showed approximately equal first order lags on each plate.

Wahl and Harriot (81), in analyzing a computer-simulated column, felt changes in vapor rates showed first order responses on any plate while responses to liquid rate and concentration changes were nth order at a distance of $n$ plates from the point of upset. 
Wood and Amstrong $(8,84)$ have developed and solved mathematical models of theoretical columns to study the frequency response to sinusoldal changes in liquid feed composition and reflux rate. The presence of possible oscillatory effects is noted.

The frequency response of a 20 plate gasoline splitting column was studied by Alkman (1) in order to provide a high quality control sjstem. Sinusoidal variations in the vapor and reflux rates were made, with the outlet vapor temperature measured. The response was characterized by time delays and first order time constants.

Pell (68) compared a mathematical model with exper1mental data for the frequency reaponse of a multiplate column. Direct sinusoidal forcing was used for changes in liquld feed rate, and the response to feed composition changes was determined by pulse methods. Good agreement was obtained, but the author noted some deviation between computed and experimental phase lags.

Marino and stutzman $(62,63)$ have made frequency response tests using both sinusoldal and pulse forcings on a 24 plate, elght 1nch benzene-acetone column. Rectangular and cosine pulses were introduced in the reflux flow, with the plate liquid temperature at several polnts belng recorded. The pulse technique is shown to give reliable data, with the response approximating f1rat order plus a delay term. Recommendations are also given regarding maxium pulse width. 
DIST ILIATION DYNAMICS

During the actual operation of distillation columns, upsetg are most likely to be introduced because of changes in liquid (or possibly vapor) feed rate and composition. Control of the rate or concentration of some product stream(s) 1s usually maintained by sultable mantpulation of liquid reflux flow or vapor flow to the bottom of the column from the reboller. It therefore becomes necessary to understand how variations in these parameters affect the operation of the column. In this study, the frequency response of the Eckey Horizontal Fractionator was studied using pulse techniques. The column was subjected to pulse-like disturbances In the liquid feed rate, liquid feed composition, and vapor rate. The time histories of the input pulse and of the responses of the liquid temperature on several plates were recorded. Methanol-water solutlons were used as the working fluid and the column was run at both atmospheric and reduced pressure. The input and response data were processed to yield frequency response information, which was analyzed to determine the parameters occurring in the transfer functions showing how the liquid composition at several points in the column would respond to variations in vapor flow and feed liquid flow and concentration.

Effect of Ifquid and Vapor Flow Disturbances

The propagation of flow and concentration disturbances 
within a column is a very complicated process. A change in the liquid feed rate to one stage is eventually felt by each successive downstream stage as a new hydraulic equllibrium is approached. Th1s results in a change in the Ilquid concentration in each stage, which in turn causes a change in the concentration of the vapor passing countercurrently through the liquid spray above each plate. Thege changes are propagated upstream in the vapor flow and act further to affect the liquid composition on the upstream plates. If the liquid's feed rate remains constant but its composition Is changed, a dsturbance is also propagated down the column by the liquid flow. As before, the compositions of the vapor above each plate start to change, which in turn affects the plate liquid compositions as the vapor travels through the column.

A change in the flow rate of the vapor to an Eckey column is felt almost immediately at each gtage. This is because the column 18 deslgned to give little reslstance to vapor flow, hence the extremely low pressure drop across the column. As mixing occurs on each stage, the plate liquid compositions begin to change. The liquid composition on each plate is then also affected by other upstream plates as the liquid flows through the column.

Since there is a great deal of interaction between the flow streams, the response of the column to liquid and vapor perturbations becomes quite complex. Sinusoldal disturbances belng propagated up and down the column in the liquid 
and vapor flows also lead to the posslbillty of reinforcement and Inhibition of composition changes, resulting in resonance effects. It would be extremely diffcult to develop a workable model which involved all of the mechanisms present in the distillation process. It is possible however, to construct simpler Iinearlzed models from frequency response data which characterlze well the response of the system. This is common practice in dynamic analys1s, (1, 38, $39,46,53,59,62,65)$.

System Transfer Function

These models are often conveniently written in the form of a transfer function, which is the ratio of the Laplace transforms of the system response and the input forcing. Consistent with results from dynamic response tests performed on other distillation units, the modeling equation for the Eckey Fractionator will be of the form:

$$
G(s)=\frac{\mathcal{L}(\text { OUTPUT })}{\mathcal{L}(\text { INPUT })}=\frac{e^{-L s}\left(1-A e^{-B s}\right)}{(\tau s+1)}
$$

where $G(s)$ defines the transfer funotion as the ratio of LaPlace transforms and $\mathrm{s}$ is the LaPlacian operator. The response of a system to any input forcing can be found simply by multiplying the gystem transfer function by the Laplace transform of the forcing and taking the inverse transformation. 
When a change is made in the liquid feed rate or concentration to a column, there is usually a period of time before a response is noted on the other plates in the column. This time $I$ is represented in the transfer function by the expression for delay, $e^{-L s}$. It should be possible to relate I to the time it takes the Ilquid to flow from the point of disturbance to the plate at which the response is measured. The quantity $\tau$ represents the major time constant assoesated with a first order model of the response. If more accuracy were warranted, a second order model could be used. The major time constant is sometimes estimated from the liquld residence time in the whole column and a minor one from a single plate. These methods are often inaccurate though and useful only in estimating the order of magnitude of these parameters. The possibility of reourring resonance peaks in the Irequency response is taken into account by including in the transfer function the term $\left(1-\mathrm{Ae}^{-\mathrm{Bg}}\right)$ where $A$ and $B$ are related to the magnitude and period of the peaks. Koppel (53), Kuemmel (56) and Ifm (59) have found resonance effects present in both experimental and theoret1cal studies of several distributed systems. Process models which they have developed, when simplifled, have shown this term to represent these resonance effects with good accuracy. Although this model is fairly simple in nature, it can, within limits, represent the complex non-linear distillation process with good accuracy. 


\section{THEORY OF PULSE TESTING}

The frequency response of a system is a set of forced responses to sinusoldal variations in some input covering a wide range of frequencles. If the relationships between the dependent and independent varlables of the system can be defined by a set of linear differential equations with constant coefficients, the system is sald to be linear. When an input to such a system is varled sinusoldally at some frequency, the forced response of the system will also be a sinusoid and of the same frequency. Figure 2 show the forced response, $y(t)$, of a typlcal Inear system to a sinusoldal variation in input, $x(t)$. The frequency response information deduced from a set of plots like this are the phase shift, $\phi$, between the input and output, and the ratio of their amplitudes, $\mathbf{A}_{\mathbf{y}} / \mathbf{A}_{x^{*}}$ A different set of values of the phase angle and amplitude ratio will be obtalned for each value of the frequency of the input forcing.

A convenient and useful way of presenting frequency response data is through the use of Bode diagrams. In this method a log-log plot of the amplitude ratios versus frequency 18 made accompanled by a seml-log plot of the phase angles versus the $\mathrm{log}$ of the frequency. Often the plot of amplitude ratios is normatized with respect to the amplitude 


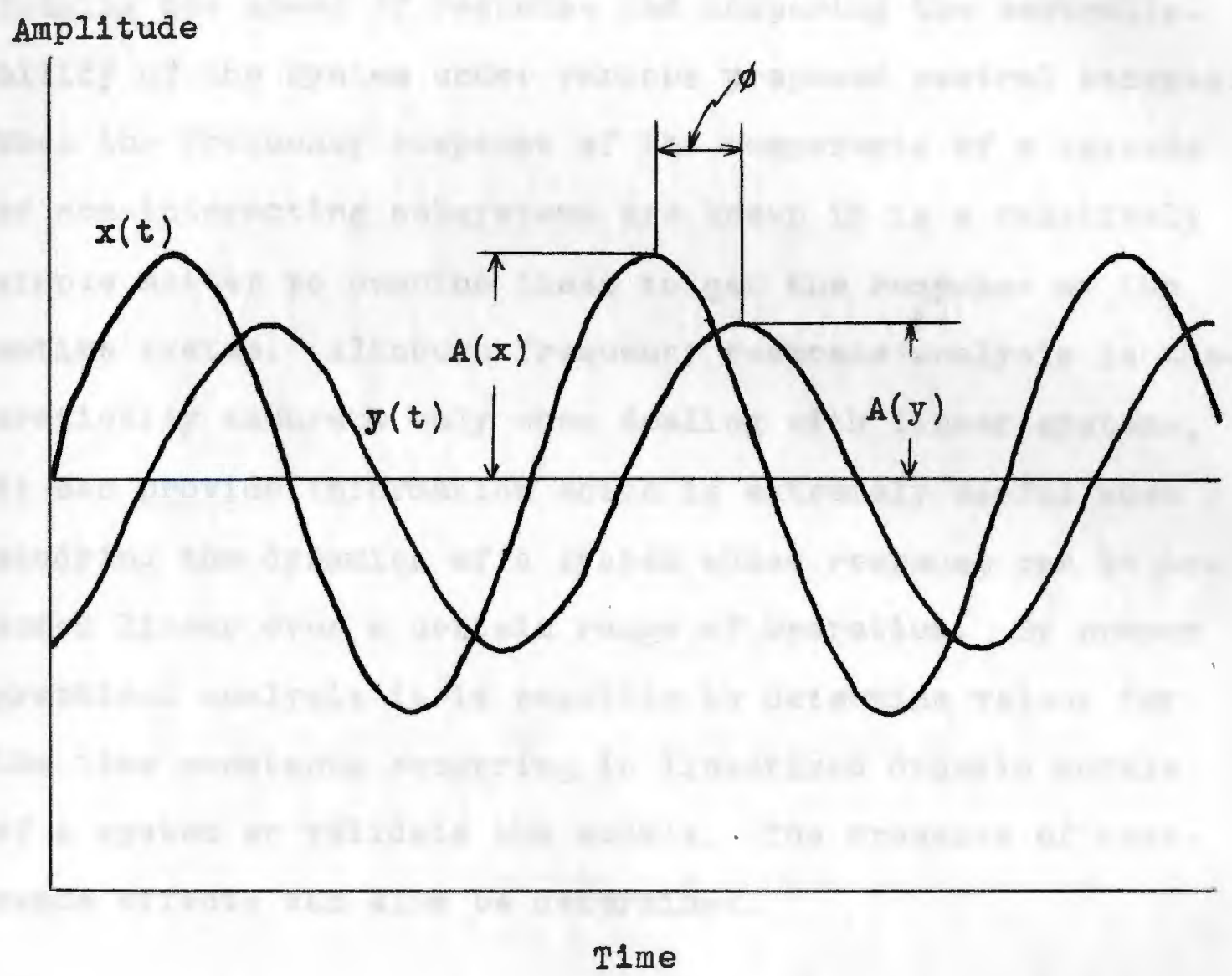

Figure 2- Sinusoldal forced response of typical linear system 
rat10 at zero frequency, 1.e. the steady-state gain. From these plots it is possible to determine the maximum gain for stable operation, if the system is put under feedback control, and the critical frequency of the system. This information is useful in determining optimum controller settings, judging the speed of response and comparing the controllabllity of the system under various proposed control schemes. When the frequency response of the components of a cascade of non-1nteracting subsystems are known it is a relatively simple matter to combine these to get the response of the entire system. Although frequency response analysis is theoretically accurate only when dealing with linear systems, it can provide information which is extremely useful when studying the dynamics of a system whose responge can be assumed linear over a certain range of operation. By proper graphical analysis it is possible to determine values for the time constants occurring in linearized dynamic models of a system or validate the models. The presence of resonance effects can also be determined.

The Pulse Method

Frequency response information can be extracted from the time response of a system to a pulse-like disturbance in some system input. A perlodic function such as a sequence of pulses can be written as a Fourler serles of sinusoidal waves of different frequencles and amplitudes. Flgure $3 a$ shows a sequence of rectangular pulses of period $P$ together 


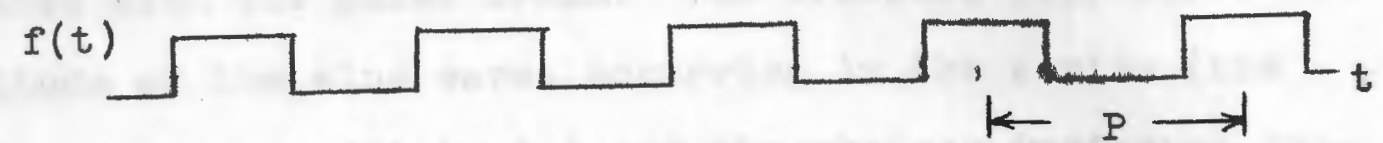

(a) Periodic rectangular pulse with period $P$.

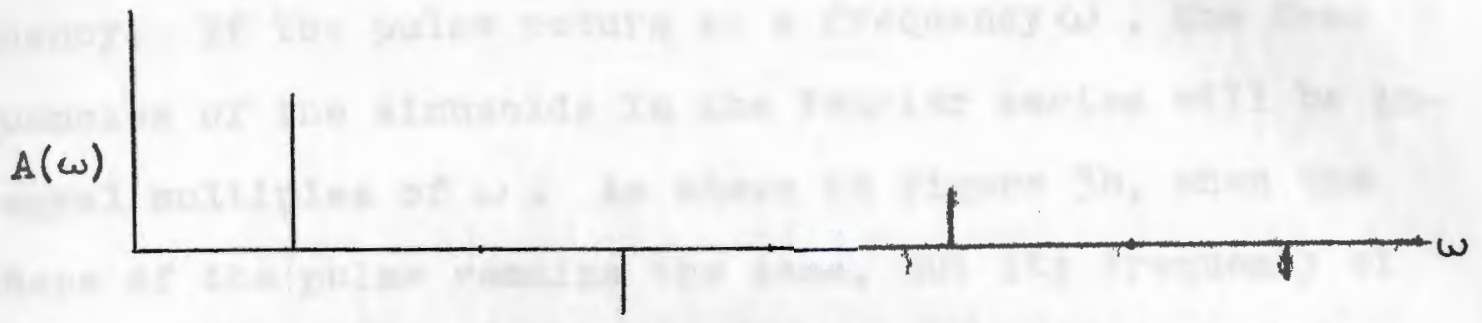

Fourler series coeficients associated with (a)

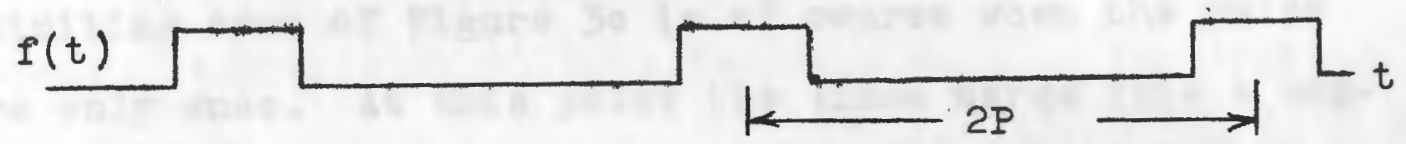

(b) Periodic rectangular pulse with period $2 P$

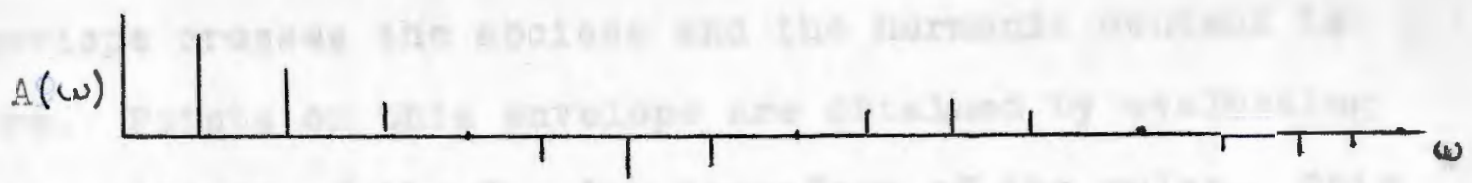

Fourier series coefficients associated with (b)

$f(t)$

(c) Single rectangular pulse

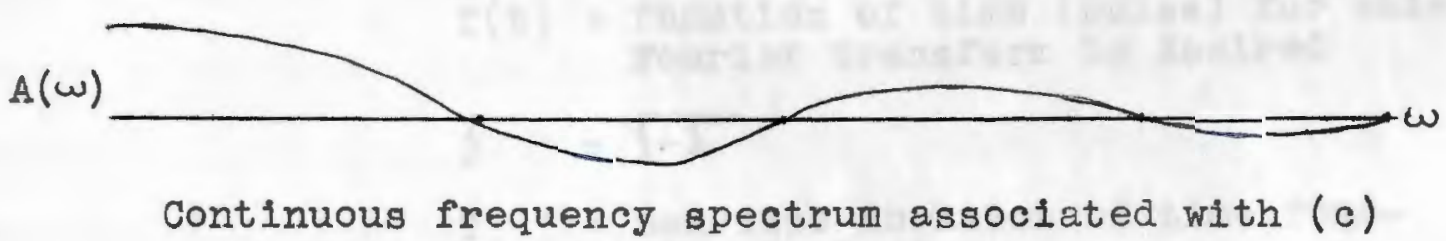

Figure 3-- Frequency spectrum for reetangular pulse trains showing effect of decreasing rate of repltition of pulse. 
with a line spectrum of the Fourler series coefficients assoclated with the pulse train. The ordinate represents the amplitude of the sine waves occurring in the serles (the Fourler series coefficlents) and the abcissa indicates frequency. If the pulse occurs at a frequency $\omega$, the frequencies of the sinusolds in the Fourler series will be integral multiples of $w$. As shown in Figure 3b, when the shape of the pulse remalns the same, but its frequency of repetion decreases, more lines appear in the line spectrum. The limiting case of Figure $3 \mathrm{c}$ is of course when the pulse occurs only once. At this point the lines merge into a continuous spectrum. Thus, a single pulse contains sinusoidal components at all frequencles, except those at which the envelope crosses the abcissa and the harmonic content is zero. Points on this envelope are obtained by evaluating the amplitude of the Fourler transform of the pulse. This is determined from the Fourler Integral:

$$
\begin{aligned}
& F[f(t)]=\int_{0}^{T} f(t) e^{-g \omega t} d t \\
& \text { where } F \text { = Fourler transform } \\
& f(t)=\text { function of time (pulse) for which } \\
& \text { Fourler transform is desired } \\
& 1=\sqrt{-1} \\
& \mathrm{~T}=\text { non-zero duration of time func- } \\
& \text { tion (pulse) } \\
& \omega=\text { frequency, radians/time, for which } \\
& \text { Fourler transform 1s desired }
\end{aligned}
$$

If the exact Fourler transform of the input pulse to a 
system is known together with the exact value of the Fourler transform of the response of the system to that pulse, the frequency response of the system is by definition:

$$
G(j \omega)=\frac{F(y)}{F(x)}=\frac{\int_{0}^{T_{y}} y(t) e^{-j \omega t} d t}{\int_{0}^{T_{x}} x(t) e^{-j \omega t} d t}
$$

where $x(t)$ and $y(t)$ are the input pulse and output reaponse time histories respectively and $T_{x}$ and $T_{y}$ are the duration of $x(t)$ and $y(t)$.

The complex variable $G(j \omega)$ is a function of $\omega$. The magnitudes and phase angles associated with this number can be determined over the range of frequencies of interest and the results displajed on a Bode plot.

The TAFT Routine

If precise mathematical expressions are known for the input pulse and output response, the evaluation of the Fourier integrals in the equation for the frequency response can be done by calculus. Howerer, in most cases, evaluation must be done by operating mathematically on experimental pulse input-output time histories. Several methods for determining numerical Fourler transform approximations from experimental data are discussed in the literature. Draper, McKay and Lees (28) have developed a simple stepped-curvo approximation and also discuss a type of trapezoldal method. clements and schnelle (22) discuss the use of F1lon's quad- 
rature formula, where experimental time hlstories are approximated by parabollc line segments. In this study, a trapezoldal method, known as the TAFT (Irapozo1dal Approximation to Fourier Iransform) routine, was used to determine numerical approximations to the Fourler transforms of the Input pulses and output responses of the system. Th1s method has been used in recent works by Driefke (29), Marino (62) and Hougen (45).

In the development of the TAFT routine operating on a typlcal time function which differs from zero for a period of time T, (see Figure 4 for notation) it is first necessary to write the equation for the straight line connecting the ordinates $I_{1}$ and $I_{1+1}$ over the interval $\Delta T$ :

$$
f(t)=f_{1}\left(1-\frac{t}{\Delta T}\right)+I_{1+1}\left(\frac{t}{\Delta T}+1-1\right)
$$

The transform of the function can now be evaluated in the 1th interval from the definition.

$$
\begin{aligned}
& F_{1}[f(t)] \approx \operatorname{TAFT}_{1}(j \omega)=\int(1-1) \Delta T+f(t) e^{-j \omega t} d t \\
& =\frac{P_{1} j}{\omega}\left[\frac{1}{\Delta T \omega} e^{-j \omega(1 \Delta T)}-\left(\frac{1}{\omega \Delta T}+1\right) e^{-j \omega(1-1) \Delta T}\right]
\end{aligned}
$$

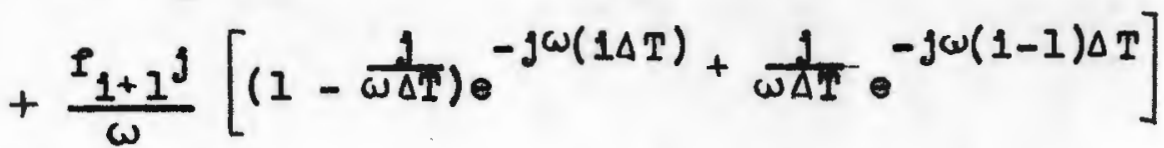

To determine the Fourier transform of the entire function, the integrals for the trapezoldal intervals must now 


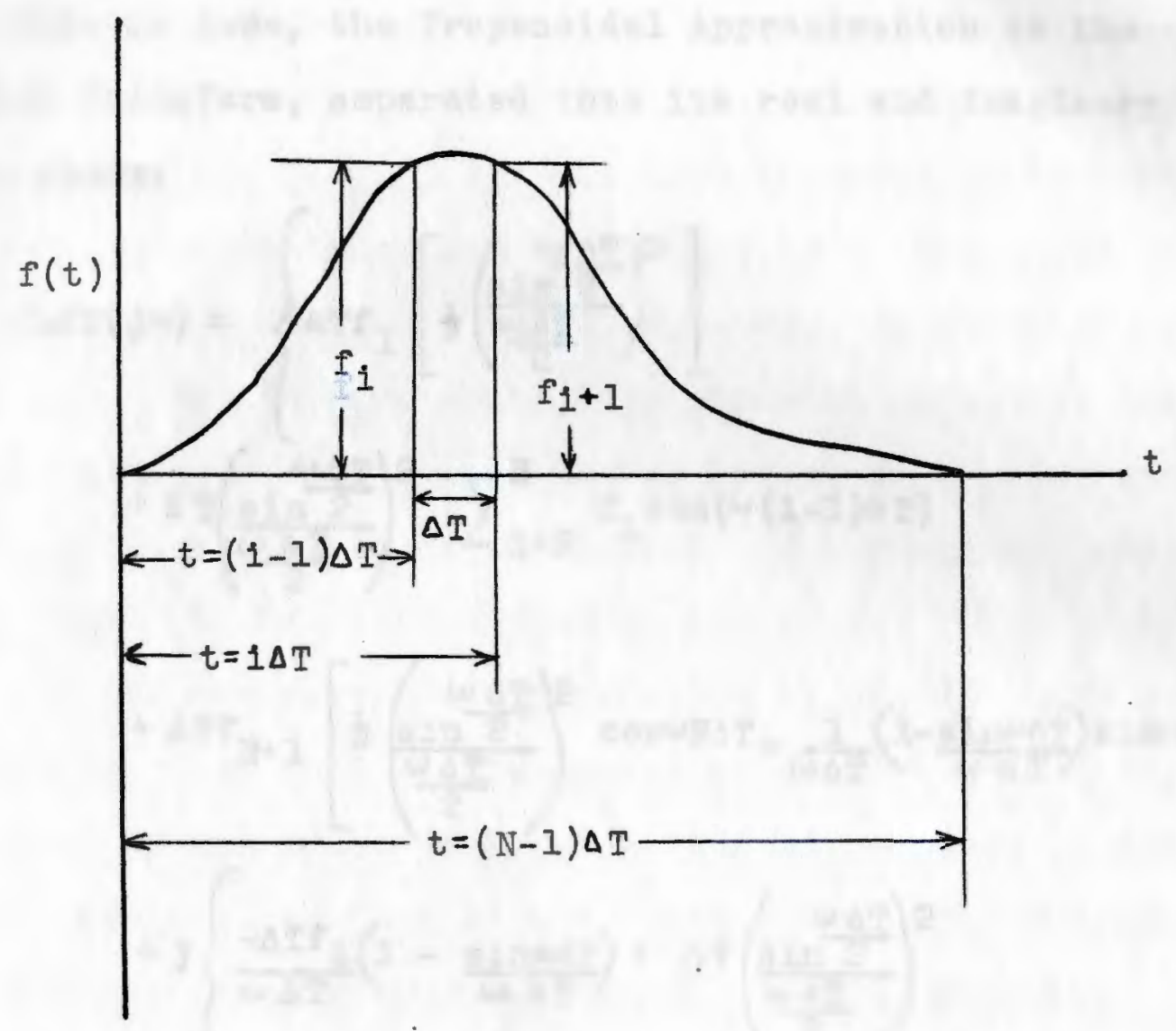

Figure 4 -- Notation for Trapezoidal Approximation to Fourier Transform-( TAFT routiñe) 
be summed over the time perlod from 0 to $T$ (1.e. $1=1$ to $N$ ).

$$
\operatorname{TAFT}_{T}(j \omega)=\sum_{1}^{\pi} \operatorname{TAFT}_{1}(j \omega)
$$

When this is done, the Trapezoldal Approximation to the Fourier Transform, separated into 1ts real and Imaginary parts reads:

$$
\begin{aligned}
& \operatorname{TAFT}(j \omega)=\left\{\Delta T r _ { 1 } \left[\frac{\left.\frac{1}{2}\left(\frac{\sin \frac{\omega \Delta}{2}}{\frac{\omega \Delta T}{2}}\right)^{2}\right]}{}\right.\right. \\
& +\Delta T\left(\frac{\frac{s i n}{2} \frac{\omega \Delta T}{\omega \Delta T}}{2}\right)^{2} \quad \sum_{1=2}^{N} I_{1} \cos (\omega(1-1) \Delta T)
\end{aligned}
$$

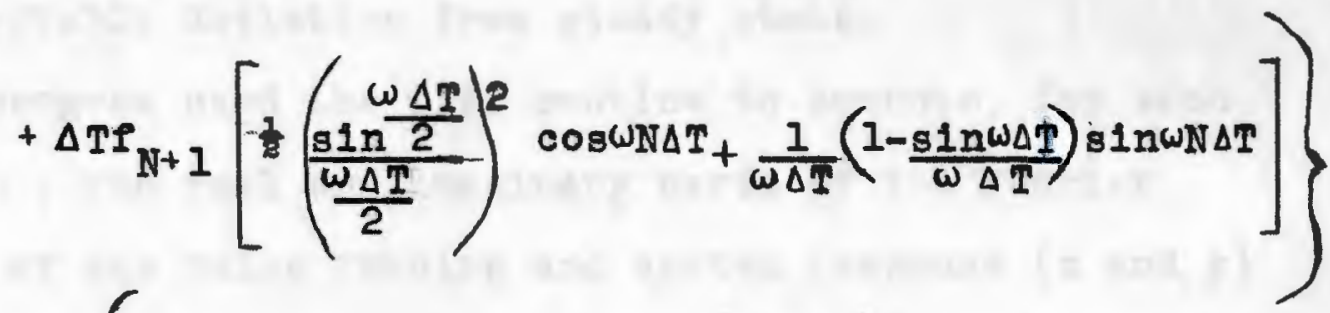

$$
\begin{aligned}
& +j\left\{\frac{-\Delta T I_{1}}{\omega \Delta T}\left(1-\frac{\operatorname{gin} \omega \Delta T}{\omega \Delta T}\right)+\Delta T\left(\frac{\frac{\sin \frac{\omega \Delta T}{2}}{\omega \Delta T}}{2}\right)^{2}\right. \\
& \sum_{1=2}^{N}-I_{1} \sin (\omega(1-1) \Delta T) \\
& \left.+\Delta T f_{N+1}\left[-\frac{1}{2}\left(\frac{\frac{\omega \Delta}{\omega} \frac{\Delta T}{2}}{\frac{\omega \Delta T}{2}}\right)^{2} \sin (\omega N \Delta T)+\frac{1}{\omega \Delta T}\left(1-\frac{\sin \omega \Delta T}{\omega \Delta T}\right) \cos \omega N \Delta T\right]\right\}
\end{aligned}
$$

From the above equation, the Fourler transform of the input pulse or of the output response can be numerloally computed 
from the experimental time histories.

Because of the large amount of calculating involved, processing of the experimental pulse data was done using the University of Rhode Island IBM $360 / 50$ digltal computer. Data supplied to the computer were l1sts of numbers representing the time histories of the pulse forcing and the system response $\left(x, y, T_{x}, T_{y}\right)$, the time interval to be used in the TAFT approximation, and the values of $w$ for which frequency response data were to be computed. To simplify data processing and interpretation, any apparent pure time delays In the responses were accounted for before data reduction by shlfting the zero time of the output to the point of the first observable deviation from steady state.

The program used the TAFT routine to compute, for each value of $\omega$, the real and 1maginary parts of the Fourier transform of the pulse forcing and system response ( $x$ and $y$ ) and the spectral content of the input pulse. The erequency response was then determined from the complex function $F(y) / F(x)$, as values for each frequency; of the phase angle (arctan $\operatorname{Im}(F(y) / F(x)) / \operatorname{Re}(F(y) / F(x))$ ) and magnitude (square root $\left.(\operatorname{Im}(F(y) / F(x)))^{2}+(\operatorname{Re}(F(y) / F(x)))^{2}\right)$. The magnitude was then normalized by dividing each value by the magnitude at zero Irequency. The frequency response data was then in a form suitable for plotting on a Bode diagram. A copy of the computer program used and simplified data processing flow sheet are found in Appendix B. 
EXPERIMENTAL WORK

\section{EQUIPMENT}

The orerall equipment setup for the experimental work 1s shown in Flgure 5. The 32 stage Eckey Fractionator was run as a stripping column with liquid feed, at room temperature, entering on plate 30 , two plates from the "top". Using terminology consistent w1th vertical columns, vapor is considered to enter the "bottom" and exit at the "top" of this horizontal column. Binary methanol-water liquid feeds were used and flow control was maintalned using constant head tanks. The liquid product exited from the bottom of the column into a storage tank. Pure steam, whlch stripped the alcohol from the incoming liquid, was fed into the bottom of the column. The methanol rich vapor product left the top of the column, was condensed, and stored in holding tanks. Provislons were made for sampling all feed and produot streams. When desired, reduced pressure in the system was established by pulling a vacuum on the condenser. For economy, black iron plpe was used throughout the system. All liquid lines and the steam inlet line were $\frac{1}{2}$ inch, sch-40, with 2 inch, sch-40 being used for the vapor exit line, to insure a low pressure drop between the column and condenser. 


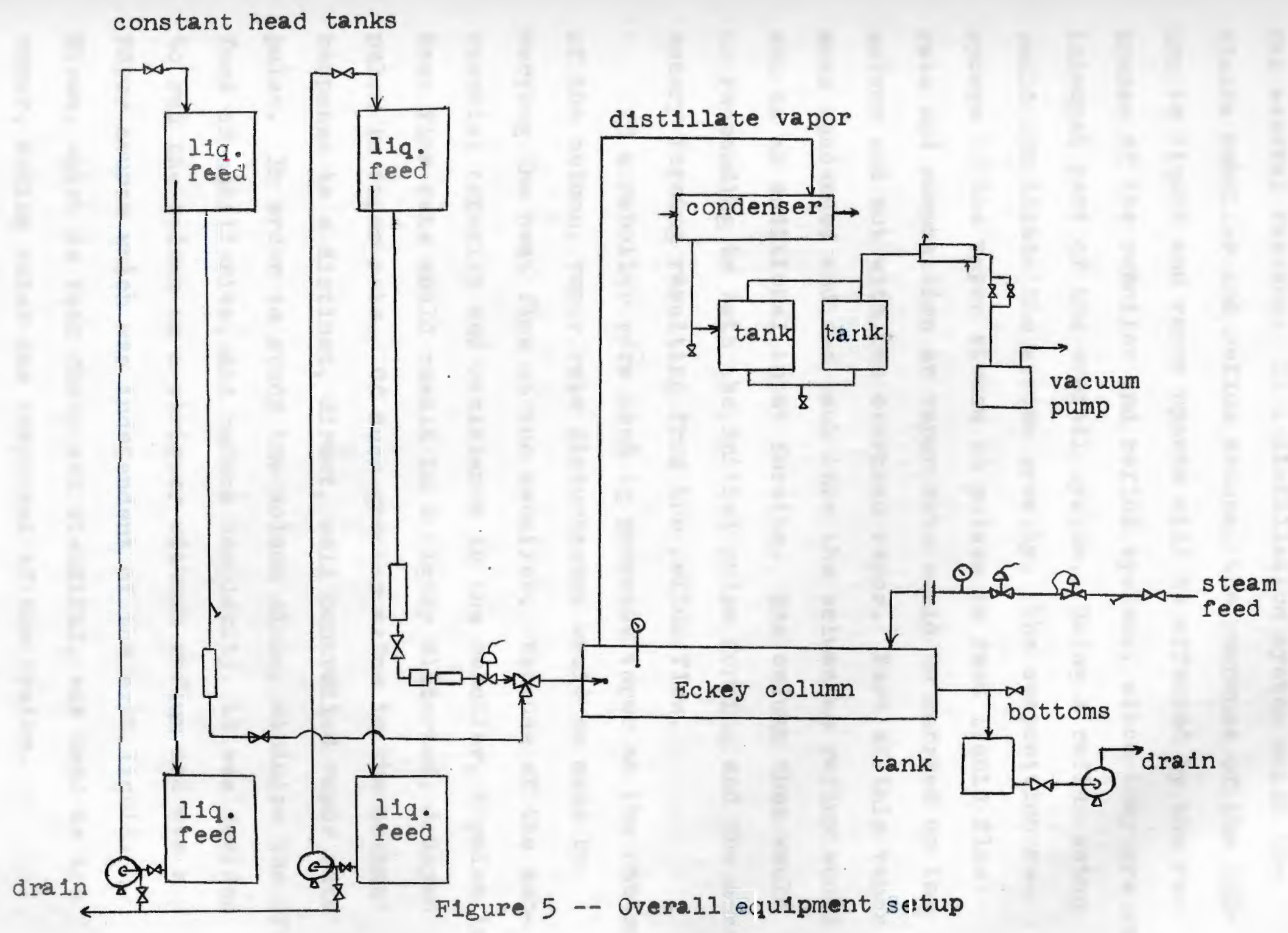


The column was run as a stripper using methanol-water for several reasons. In a distillation system which includes reboller and reflux setups, the response of the colunn to liquid and vapor upsets w1ll be affected by the response of the reboller and reflux systems, since they are an Integral part of the overall system. Using a reflux setup would complicate the system greatly. The composition response of the vapor stream to pulses in feed liquid flow rate and composition or vapor rate would be carried up the column and out with the overhead vapor. Part of this vapor when condensed and fed back into the column as reflux would act as an additional 1nput forcing. The column then would be responding to both the initial pulse forcing and the secondary forcing resulting from the reflux flow.

If a reboller were used to generate vapor at the bottom of the column, vapor rate disturbances would be made by varying the heat flow to the reboller. Because of the substantial capaolty and resiatance in the reboller, a pulse in heat flow rate would result in a highly distorted, delayed pulse in vapor rate. Of much greater value is the column response to a distinct, direot, well controlled vapor rate pulse. In order to study the oolumn alone, minimize the effect of auxiliaries, and reduce complexity, 1t was decided to run the column as a stripper without reflux and use a vapor souree whlch was independent of the exit liquid. Steam, which 1s both cheap and plentiful, was used as the vapor, making water one component of the system. 
In this study, the dynamic response of the column was studied by making pulse-like changes in an independent variable (Ilquid feed rate, liquid feed composition, vapor feed rate) and measuring the response of the various plate liquid temperatures to these changes. In order for th1s method to be feastble, the response must be measurable. When the column is pulsed, the regulting changes in plate liquid composition and saturated liquid temperature must be large enough to be accurately measured by recording devices. One criteria then of the binary system to be used was that there be a relatively large change in bolling point with composition. However in order to study the column response on sereral plates, the vapor-liquid equilibrium relationships between the two components must be such that complete separation of the components by distillation requires several equilibrium stages. The methanol-water syatem with a pure component bolling point difference of about $60^{\circ} \mathrm{F}$ satisfled these conditions. Also, methanol-water solutions are economical in cost, safe to handle, and relatively non-toxic. Copper-constantan thermocouples were used to measure plate liquid temperatures because of their chemical inertness to the methanol-water system and their relatively large change in emf with temperature (about $.025 \mathrm{mv} /{ }^{\circ} \mathrm{F}$ ).

For simplification, the equipment and instrumentation setups w1ll be broken into sections for discussion. The major pleces of equipment in the accompanying figures are numbered with reference to Appendix A where detalled manu- 
facturers spec1floations are found.

I. The Eckey Column

The elght 1nch, 32-atage Eckey fractionator is approximately elght feet long and was mounted, for optimum eff1clency, at a 1.5 degree angle from the horlzontal, as shown in Figure 6. This unit was capable of handling liquid loads up to $0.5 \mathrm{gpm}$. The motor-driven longltudual shaft on which the impellers are mounted 1 s supported by four main bearings and rotated at a speed of $1730 \mathrm{rpm}$. The shaft enters the column shell through an 01l-cooled shaft seal (John Crane Chemlon). Motor o1l was clrculated by a small gear pump at $20 \mathrm{psig}$ through the seal for lubrication and to maintain the temperature at a value less than $300^{\circ} \mathrm{F}$. Sight glasses are present at the top and bottom of the column, and above the 13th and 26th plates. Thermocouples measured the inlet and outlet vapor temperatures, and a vacuum gauge located above plate 30 indlcated column pressure. Copper-constantan bare wire thermocouples were mounted in the liquid pools, on plates $28,26,21,16,11$, and 2 , to measure the 11quid temperatures. During pulse runs, time histories of these temperatures were recorded using two Honeywell ELECTRONIK 19 strip chart emf recorders. The sensitivity of the liquid temperature recording system was such that a one inch change in chart width represented about a $2^{\circ} \mathrm{F}$ temperature change. 
II. Liquid Feed system

Llquid feed entered the column on plate 30 from either the main or auxiliary feed system. In both systems, the feed was pumped from stalnless-steel storage tanks to ten gallon constant-head tanks mounted approximately ten feet above the column. To maintain a constant head, overflow plpes were mounted in the overhead tanks to carry excess feed back to storage. The feeds from both head tanks were f1ltered and passed through rotometers for flow rate measurement as shown in Figure 7. The capacities for the main and auxillary feed systems were 100 and 60 gallons respectively. Flow was controlled in the auxiliary system by means of a hand operated needle valve, and switching between the feeds was accomplished using a 3-way solenold valve.

Liquid flow rate disturbances were introduced into the system in the main feed line. A pulse in liquid rate resulted from a similar pulse in the air pressure signal to a Foxboro pnuematic control valve. The pulsed liquid flow rate was recorded using a Foxboro magnetic turbine flow transmitter. Th1s instrument generates an oscillating voltage slgnal whose frequency is converted to an output voltage directly proportional to volumetric flow rate.

Rectangular pulseg in feed Ilquid composition were made by switching from the main feed to the auxiliary feed of a different composition but the same flow rate for a flxed period of time. The duration of these pulses was recorded using an electric timer. 
III. Vapor Feed and Bottoms Itquid systems

Pure steam at 90-100 psig was avallable as vapor feed to the bottom of the column from the University high pressure steam line shown in Figure 8. With the Foxboro pneumatic control valve set to full open, the vapor flow rate during steady state operation was set using a Malsonelion pressure regulating valve. A negative pulse-like change in the vapor feed was made by introducing a pulse in the air pressure signal to a Foxboro pneumatic control valve. This pulse acted to decrease the vapor rate for a perlod of time and then return it to the steady state value. The vapor rate was measured using a critical flow convergent nozzle designed so that the mass flow rate was directly proportional to the upstream steam pressure. This pressure was sensed by a Foxboro electronic pressure transmitter, to yleld a recorded voltage which varied Iinearly with mass flow.

Liquid product leaving the bottom of the column passed into a small holding tank. After specific gravity measurements showed this to be essentially alcohol free, it was discarded.

IV. Condensate Collection system

Figure 9 1llustrateg the condensate collection and vaouum control systems. The methanol rich vapor product leaving the top of the column was condensed in a horizontally mounted, stainless-steel, 47 sq. ft., 1-1, shell and tube, 
heat exchanger. Cooling water passed through the tubes and vapor entered the shell. Provislons were made for withdrawing samples from the condensate effluent line for composition analysis. The distillate was collected in two forty gallon recelvers, which were vented during atmospheric pressure operation.

When required, reduced pressure was maintained in the system by pulling a partial vacuum on the vapor space above the Ilquid in the recelvers, using an NCR rotary gag-ballast pump. A small condenser in the vacuum line prevented volat1les from entering the pump. System pressure was measured using a column mounted vacuum gauge.

V. Pulse Generating system

The purpose of the pulse generating clrcult was to produce an air pregsure signal pulsed in the range 3 to 15 psig for a finite perlod of time. Th1s slgnal was used to actuate pneumatic control valves producing similar pulse-like changes in elther liquid or vapor feed rate. The princlpal plece of equipment used was a Hewlett-Packard 202A low frequency function generator. This instrument, in normal operation, is capable of producing sinusoldal, triangular, and rectangular waves over a wlde range of frequencles and amplitudes. But $1 t$ can be modifled to produce single pulses of triangular, rectangular, or half-sine shape. This is done by externally driving the 202A with a pulse activator powered by a 300 volt D.C. source. Th1s activator produces 
a fast rising trigger pulse of sufficlent helght and duration to Initiate one cycle of operation of the function generator, which, in turn produces a single pulse of chosen shape, amplitude and duration.

It was possible to produce pulses up to 150 seconds in length. The pulsed roltage algnal was recelved by a Flsher electro-pneumatic transducer where it was converted to a pulsed pressure signal uged to actuate the pneumatic control valves. This clrcuit is shown in Figure 10. 


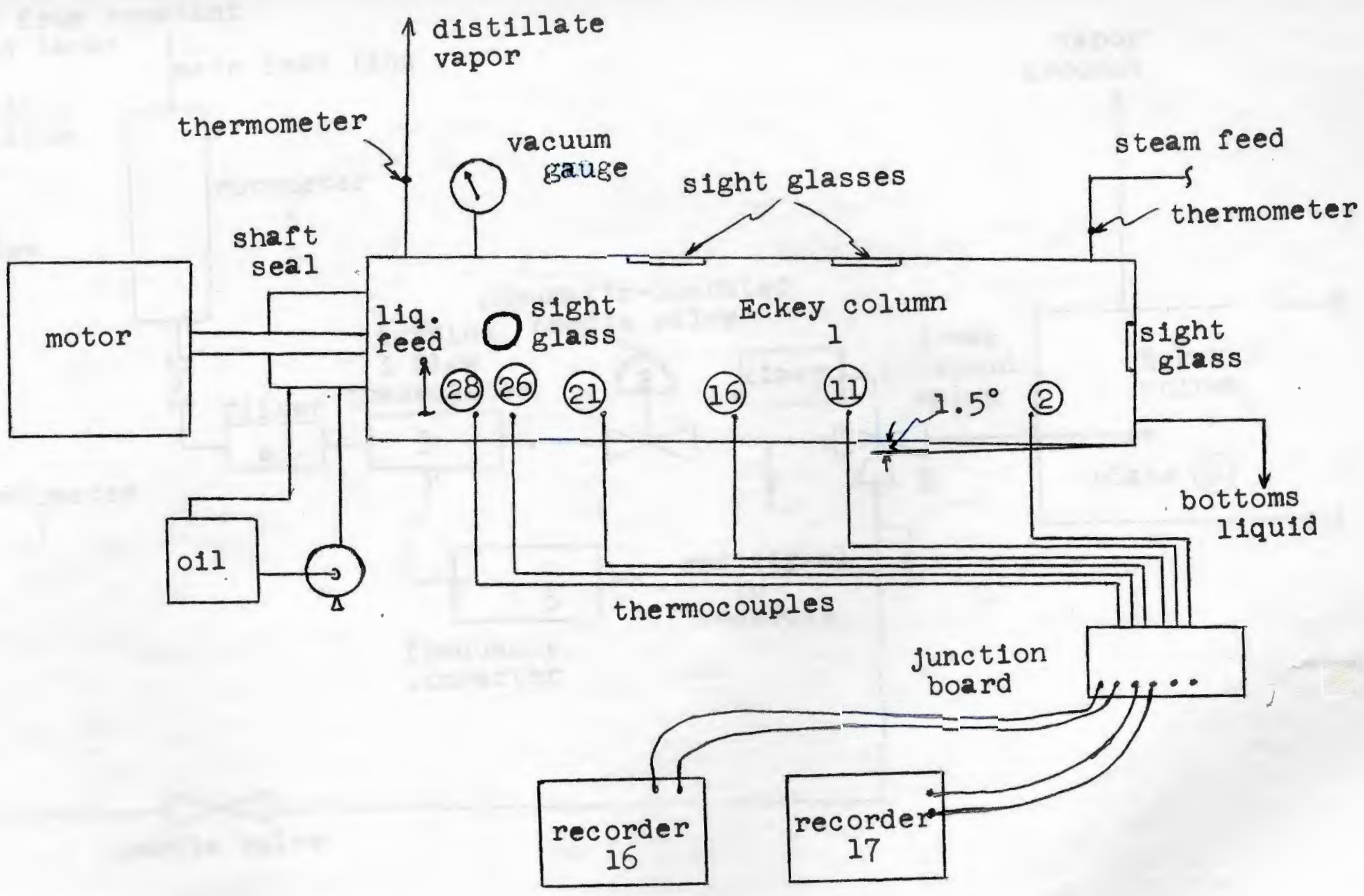

Figure 6 -- Eckey column 


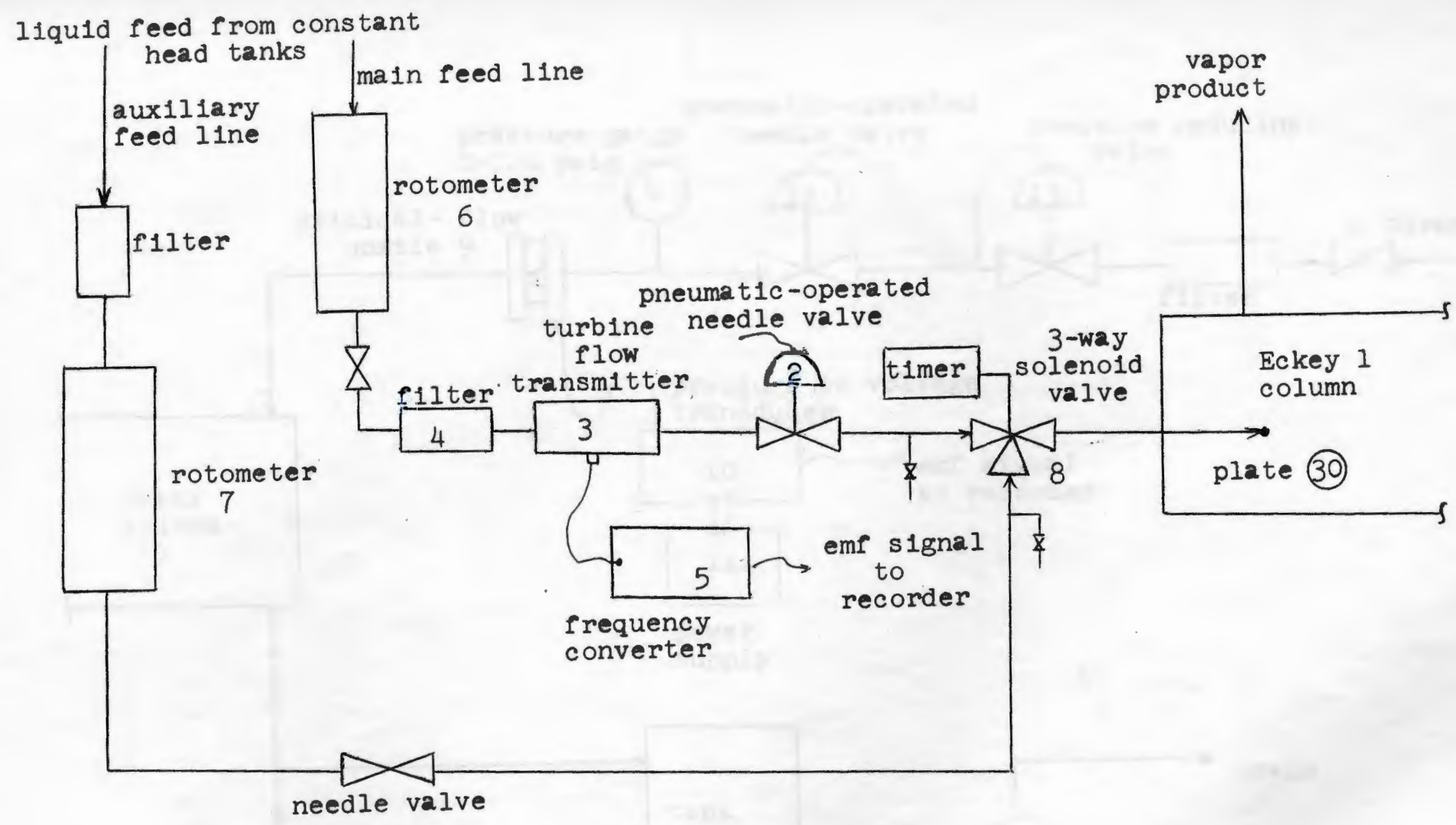




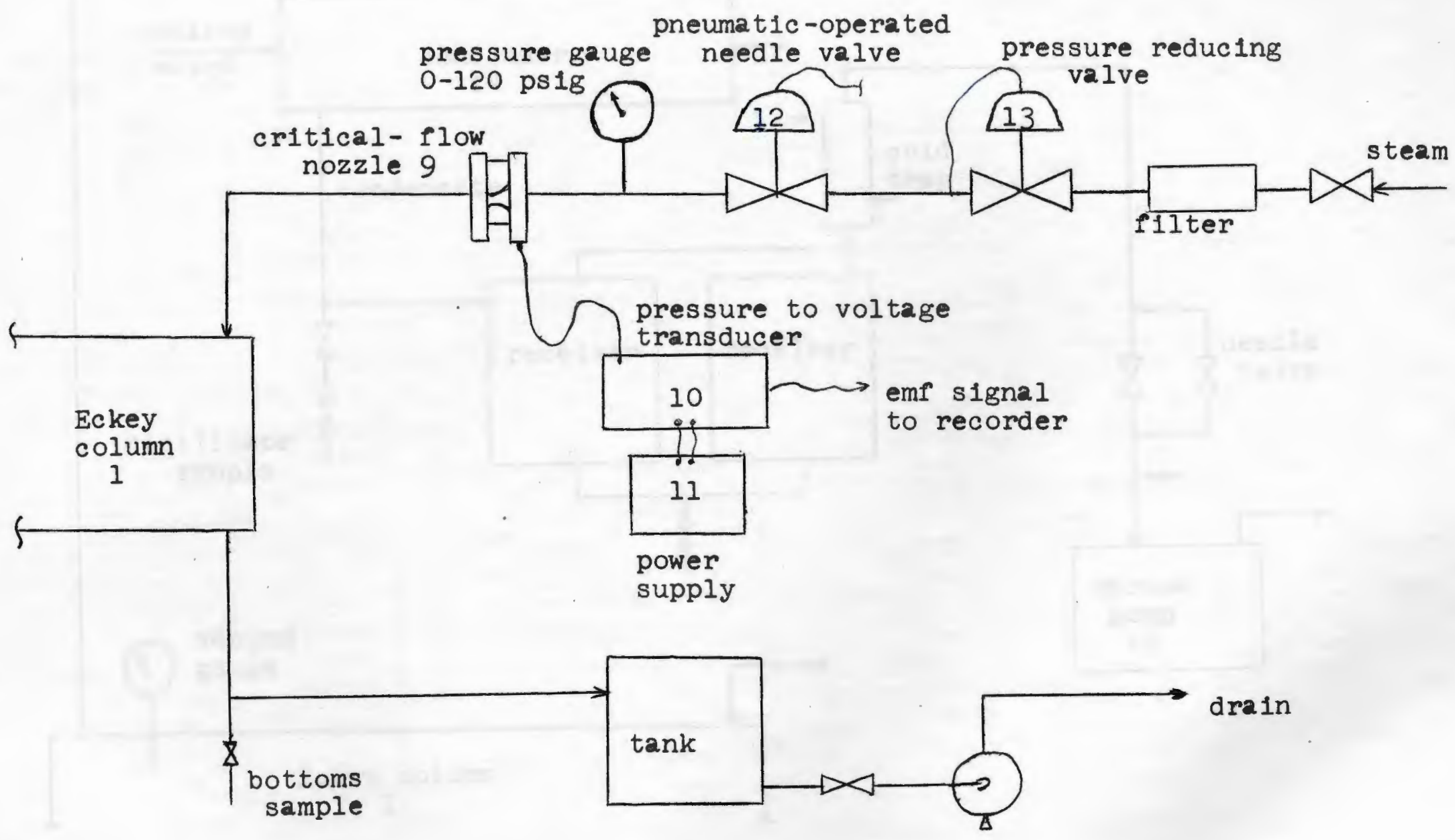

Figure 8 -- Vapor feed and bottoms liquid systems 


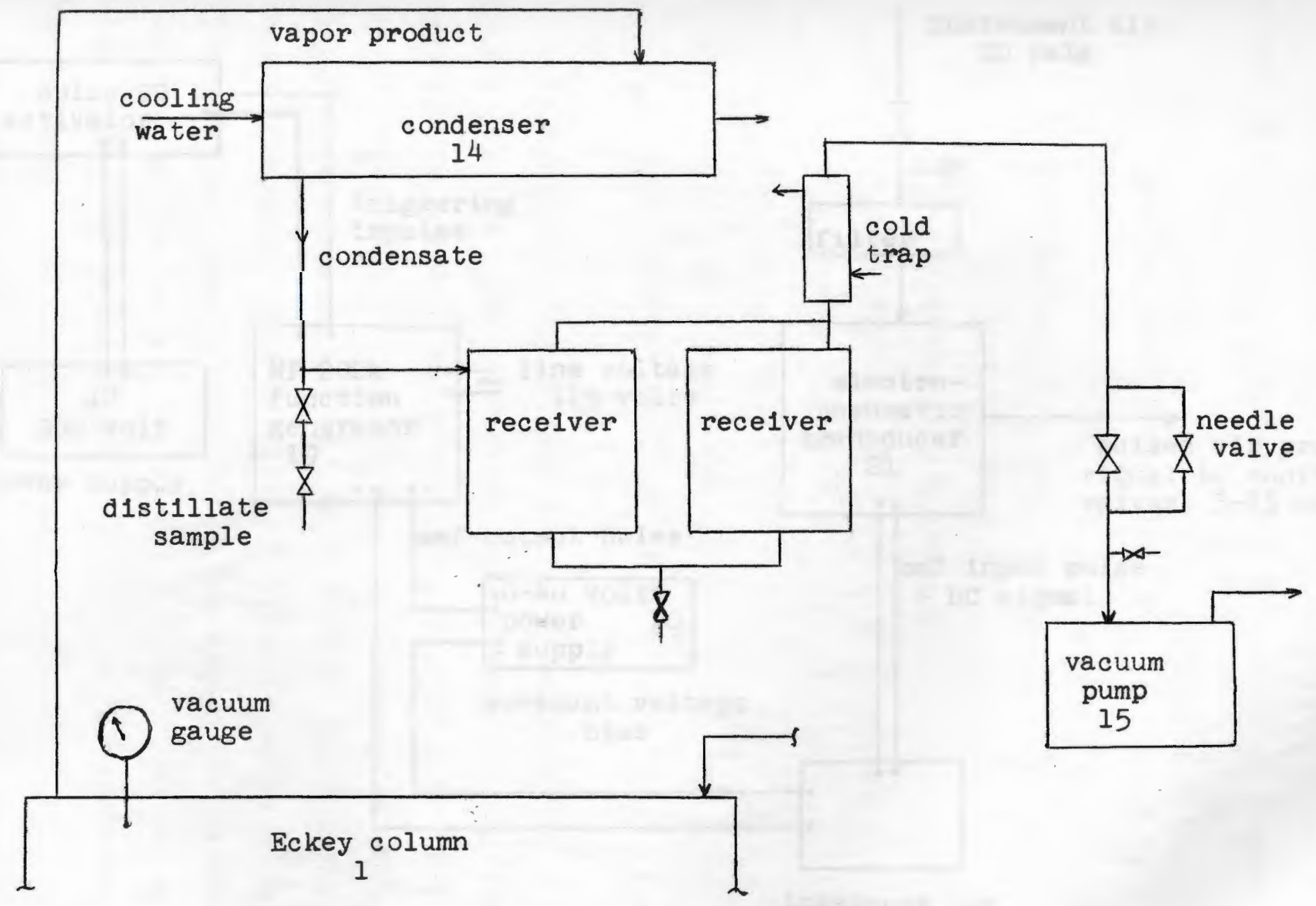

Figure 9 -- Distillate collection and vacuum systems 


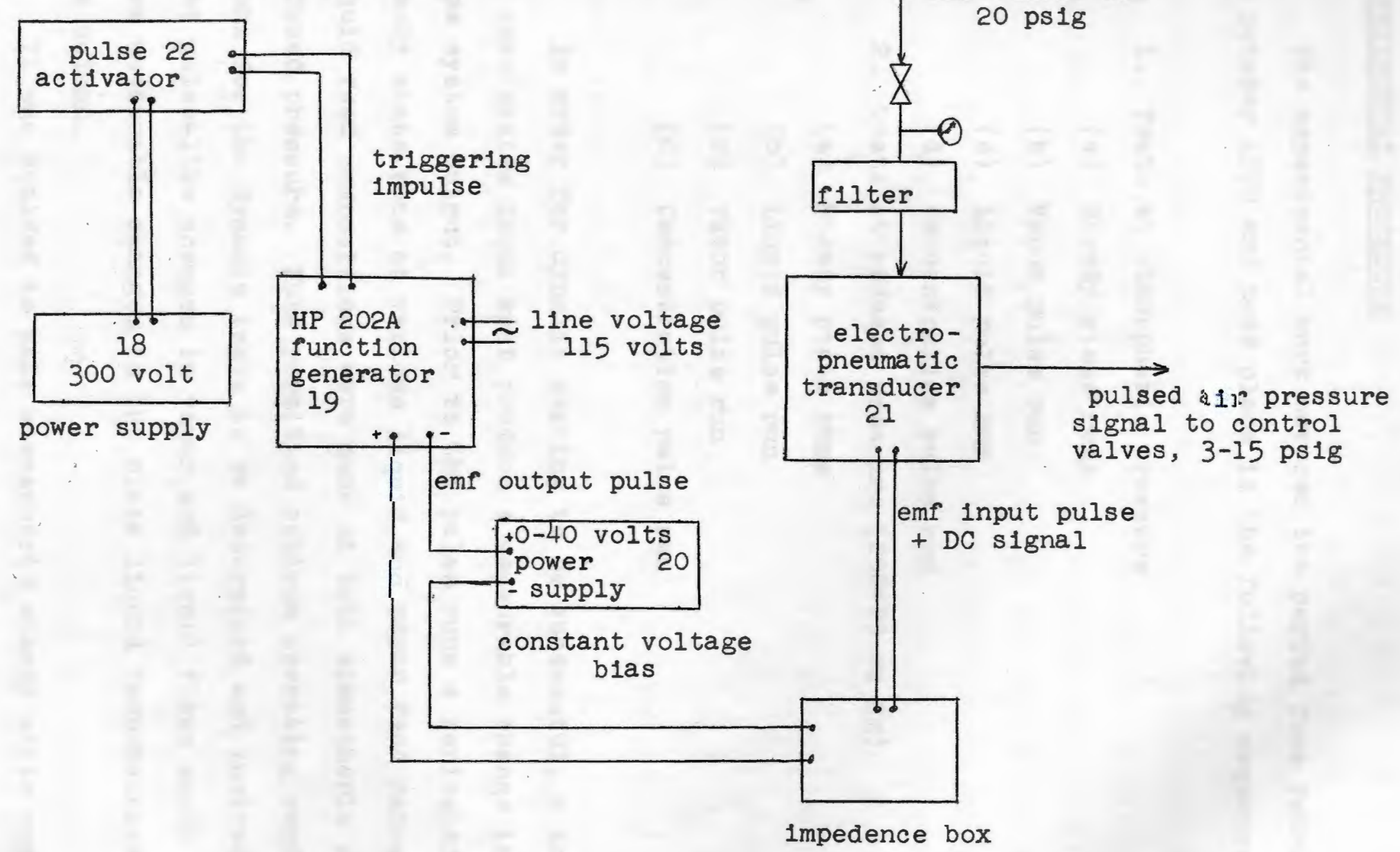

F1gure 10 -- Pulse generating clrcut 


\section{EXPERIMENTAL PROCEDURE}

The experimental work covered the perlod from February to october 1970 and took place in the following sequence:

1. Tests at atmospheric pressure

(a) Steady state runs

(b) Vapor pulse run

(c) Ifquid pulse run

(d) Concentration pulse run

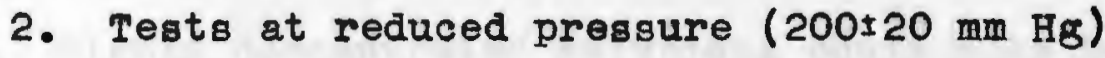

(a) Steady state rune

(b) Liquid pulse run

(c) Vapor pulse run

(d) Concentration pulse run

In order for dynamic testing to be successful, a change in some system input must produce a measurable change in some system output. Prior to the pulse runs a series of steady state muns at various $11 q u 1 d$ and vapor feed rates and liquid feed compositions were made at both atmospheric and reduced pressure. This permitted opt1mum operating cond1tions for the dynamic tests to be determined and insured that pulse-like changes in vapor and liquid flows would produce measurable changes in the plate liquid temperatures in the column.

It was decided to make atmospheric steady state runs using feed liquid concentrations of about 30,40 and 50 mole 
percent methanol. It was felt that the optimum feed liquid concentration for the pulse runs to follow would 1 all somewhere in this range. From inspection of the methanol-water vapor liquid equilibrium diagram, it can be seen that several equilibrium stages will be needed to strip the alcohol from I1quid feeds of the above compositions. Using feeds of lower methanol concentrations would result in methanol removal occurring in only a few stages at the top of the column. Using a highly concentrated feed would not appreclably increase the number of equilibrium atages required for stripping. Highly concentrated solutions could also be extremely dangerous to handle and would require large amounts of the limited supply of methanol avallable. Actual liquid feed composition used during these runs were 29.9, 42.1 and 50.3 mole percent methanol. During each run, several liquid to vapor ratios were used.

To conserve feed, the column was first heated unt1l a thermal equilibrium had been reached by feeding steam in the bottom and using pure water as liquid feed. Equilibrium was reached when the plate liquid reached the saturation temperature at column pressure. Following this, the methanol-water feed solution was introduced into the column. Liquid bottoms product and condensate samples, together with plate liquid temperature readings, were taken at various time intervals until steady state conditions were reached. At this point the liquid to vapor ratio was changed and product samples and temperature readings were again taken unt1l the 
next steady state was reached. This procedure was followed for each run using a different liquid feed composition. Another serles of steady state runs was made, prior to the reduced pressure pulse tests, at column pressure of about $200 \mathrm{~mm} \mathrm{Hg}$. Iiquid feed concentrations used were 39.5 and 47.5 mole percent methanol. For each feed, various liquld to vapor ratios were tried with the sampling procedure identical to that for atmospheric steady state runs.

The compositions of the distillate and bottoms products were determined from speciflc gravity measurements made on a Christian Becker balance. The plate liquid compositions were found from their liquid temperatures assuming saturation at column pressure. This is justified on the basis that when pure water was used as the liquid feed, the plate liquids did Indeed reach and maintain their saturation temperatures. Using thege measurements, plate liquid temperature and composition profiles throughout the column were constructed. The operating conditions and results of the steady state runs are shown in Table 1 . From these results, the approximate optimum operating conditions for the dynamic pulse tests to follow were determined. The actual operating conditions for the pulse runs are shown in Table 2. Dynamic testing is primarily concerned with changes in variables changes in output caused by changes in input. Extremely accurate measurements of the absolute values of system variables is often not important. Values of the liquid feed rate, vapor rate, and liquid feed composition were chosen 
TABLE I

\section{OPERATING CONDITIONS - STEADY STATE EXPERIMENTAL RUNS}

\begin{tabular}{|c|c|c|c|c|c|c|c|}
\hline $\begin{array}{l}\text { Steady } \\
\text { State } \\
\text { Run No. }\end{array}$ & $\begin{array}{l}\text { Column } \\
\text { Pressure } \\
\text { Atm. }\end{array}$ & $\begin{array}{l}\text { Feed Liq. } \\
\text { Comp. } \\
\% \text { MeOH }\end{array}$ & $\begin{array}{c}\text { Feed IIq. } \\
\text { Rate } \\
\text { GPM }\end{array}$ & $\begin{array}{l}\text { Feed Vapor } \\
\text { Rate } \\
\text { LE/HR }\end{array}$ & $\begin{array}{l}\text { Liquid to } \\
\text { Vapor } \\
\text { Ratio }\end{array}$ & $\begin{array}{c}\text { Dist.Comp. } \\
\text { Mole } \\
\text { To MeOH }\end{array}$ & $\begin{array}{l}\text { Bot. Comp. } \\
\text { Mole } \\
\text { \% MeOH }\end{array}$ \\
\hline $\begin{array}{l}1 \\
2 \\
3 \\
4 \\
5 \\
6 \\
7 \\
8 \\
9 \\
10 \\
11 \\
12 \\
13 \\
14 \\
15 \\
16\end{array}$ & $\begin{array}{l}1.0 \\
1.0 \\
1.0 \\
1.0 \\
1.0 \\
1.0 \\
1.0 \\
1.0 \\
1.0 \\
1.0 \\
.26 \\
.26 \\
.26 \\
.28 \\
.27 \\
.26\end{array}$ & $\begin{array}{l}29.9 \\
29.9 \\
29.9 \\
29.9 \\
42.1 \\
42.1 \\
42.1 \\
50.3 \\
50.3 \\
50.3 \\
39.5 \\
39.5 \\
39.5 \\
47.5 \\
47.5 \\
47.5\end{array}$ & $\begin{array}{l}.33 \\
.19 \\
.25 \\
.20 \\
.35 \\
.28 \\
.22 \\
.34 \\
.29 \\
.23 \\
.26 \\
.26 \\
.25 \\
.27 \\
.27 \\
.27\end{array}$ & $\begin{array}{l}84 . \\
56 . \\
84 . \\
55 . \\
84 . \\
83 . \\
82 . \\
83 . \\
83 . \\
83 . \\
47 . \\
59 . \\
88 . \\
44 . \\
60 . \\
75 .\end{array}$ & $\begin{array}{l}1.7 \\
1.3 \\
1.3 \\
1.1 \\
1.7 \\
1.3 \\
.99 \\
1.5 \\
1.2 \\
.96 \\
1.9 \\
1.5 \\
1.0 \\
2.0 \\
1.4 \\
1.2\end{array}$ & $\begin{array}{l}56.0 \\
41.7 \\
35.9 \\
34.4 \\
75.6 \\
55.5 \\
41.2 \\
78.6 \\
60.6 \\
47.8 \\
77.0 \\
61.9 \\
39.8 \\
81.1 \\
67.0 \\
55.0\end{array}$ & $\begin{array}{l}0.0 \\
0.0 \\
0.0 \\
0.0 \\
0.0 \\
0.0 \\
0.0 \\
0.0 \\
0.0 \\
0.0 \\
0.0 \\
0.0 \\
0.0 \\
0.0 \\
0.0 \\
0.0\end{array}$ \\
\hline
\end{tabular}


TABLE 2

STEADY STATE OPERATING CONDITIONS FOR PULSE RUNS

\begin{tabular}{|c|c|c|c|c|c|c|c|}
\hline $\begin{array}{l}\text { Puise } \\
\text { Type }\end{array}$ & $\begin{array}{l}\text { Column } \\
\text { Pressure } \\
\text { Atm. }\end{array}$ & $\begin{array}{c}\text { Feed Liq. } \\
\text { Comp. } \\
\text { of MeOH }\end{array}$ & $\begin{array}{l}\text { Feed Iid. } \\
\text { Rate } \\
\text { GPM }\end{array}$ & $\begin{array}{l}\text { feed Vapor } \\
\text { Rate } \\
\text { LB/HR }\end{array}$ & $\begin{array}{l}\text { Liquid to } \\
\text { Vapor } \\
\text { Ratio }\end{array}$ & $\begin{array}{l}\text { Dist.Comp. } \\
\text { Mole } \\
\% \text { MeOH }\end{array}$ & $\begin{array}{l}\text { Bot. Comp. } \\
\text { Mole } \\
\% \mathrm{MeOH}\end{array}$ \\
\hline $\begin{array}{l}\text { Vapor } \\
\text { rate }\end{array}$ & 1.0 & 44.3 & .29 & 92. & 1.1 & 48.0 & 0.0 \\
\hline $\begin{array}{l}\text { Liquid } \\
\text { rate }\end{array}$ & 1.0 & 45.5 & .30 & 78.0 & 1.3 & 60.0 & 0.0 \\
\hline $\begin{array}{l}\text { Liquid } \\
\text { conc. }\end{array}$ & 1.0 & 49.9 & .30 & 63. & 1.5 & 79.0 & 0.0 \\
\hline $\begin{array}{l}\text { Vapor } \\
\text { rate }\end{array}$ & .26 & 42.0 & .27 & 73. & 1.2 & 51.0 & 0.0 \\
\hline $\begin{array}{l}\text { Liquid } \\
\text { rate }\end{array}$ & .24 & 40.6 & .25 & 73. & 1.2 & 48.6 & 0.0 \\
\hline $\begin{array}{l}\text { Liquid } \\
\text { conc. }\end{array}$ & .26 & 45.5 & .25 & 48. & 1.6 & 75.5 & 0.0 \\
\hline
\end{tabular}


such that pulse-like changes in these values would produce measurable changes in plate liquid temperatures in the column. Measurement of the actual value of the liquid and vapor rate to more than two figure accuracy was not necessary. It was also possible to estimate the maximum column response which might be expected when changes were made in vapor rate and liquid rate and composition.

It was found that the feed liquid was stripped of 1ts alcohol in the top two thirds of the column and was essent1ally pure water at this polnt, regardless of the feed used. Therefore no column response would be felt by the thermocouples in the liquid on plates 11 and 2. During the pulse runs the 11quid temperatures on these plates were not recorded.

The dynamic testing was done during six experimental sessions, one each for liquid rate, liquid composition, and vapor rate pulses at atmospheric pressure and again for low pressure column operation. The total liquid feed storage oapacity was 100 gallons, and liquid rates were kept between .25 and .3 gpm allowing 5-6 hours of operation for each pulse session. Th1s was ample time to permit the use of pulses of different shapes, amplitudes, and duration.

Ifquid and Vapor Rate Pulses

Pulses in liquid feed rate were made by applying a pulsed pressure signal to the pneumatic control valve in the liquid feed line. The colum was first brought to a steady 
state. A pulse-like change was then made in llquid rate with the pulse and the responses of the liquid temperatures on plates 28, 26, 21 and 16 being recorded. After the column had returned to steady state again, additional pulses could be made.

The procedure for pulsing the vapor flow was similar to that for liquid flow, except that the air pressure signal was applied to the pneumatic operated valve in the steam line. After the column had reached steady state, a pulse in the vapor rate was made and the column was allowed to return to steady state with the input and responses being recorded.

A variety of triangular, half-sine and rectangular pulses were tried during both the high and low pressure runs. Because of non-linearities inherent in the pulse circult, transducer and control valve, the resulting pulses in liquid rate became somewhat deformed (see Figure 11) and the triangular and half-sine pulses appeared quite simllar in shape. Th1s was also true for the pulses made in the vapor flow rate to the bottom of the column. The effect is to partialIy smooth out any discontinuities in the pulse (e.g. to round off the point of the triangular pulses). It was possible to make more vapor pulses than liquid pulses during equal testing perlods because the column responded more rapldiy to rapor disturbances.

Ifquid Composition Pulses 


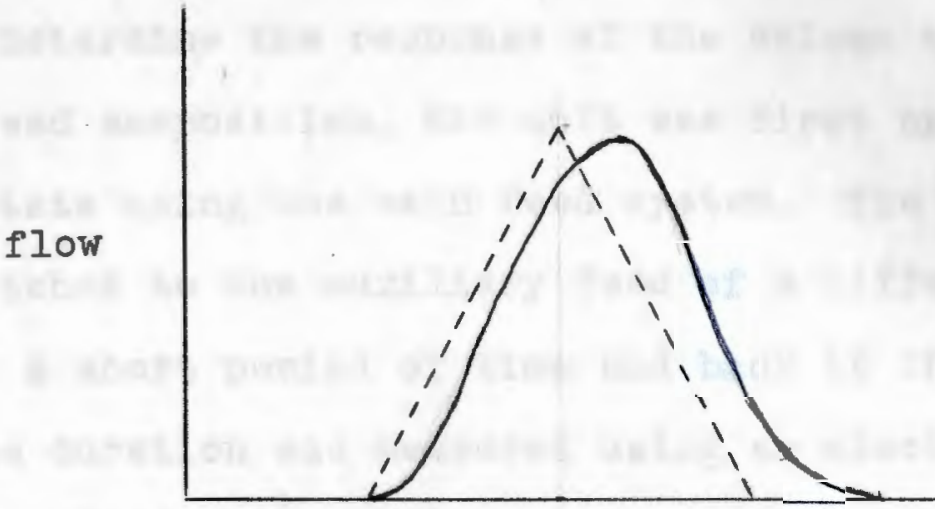

t1me

(a) Triangular Pulse

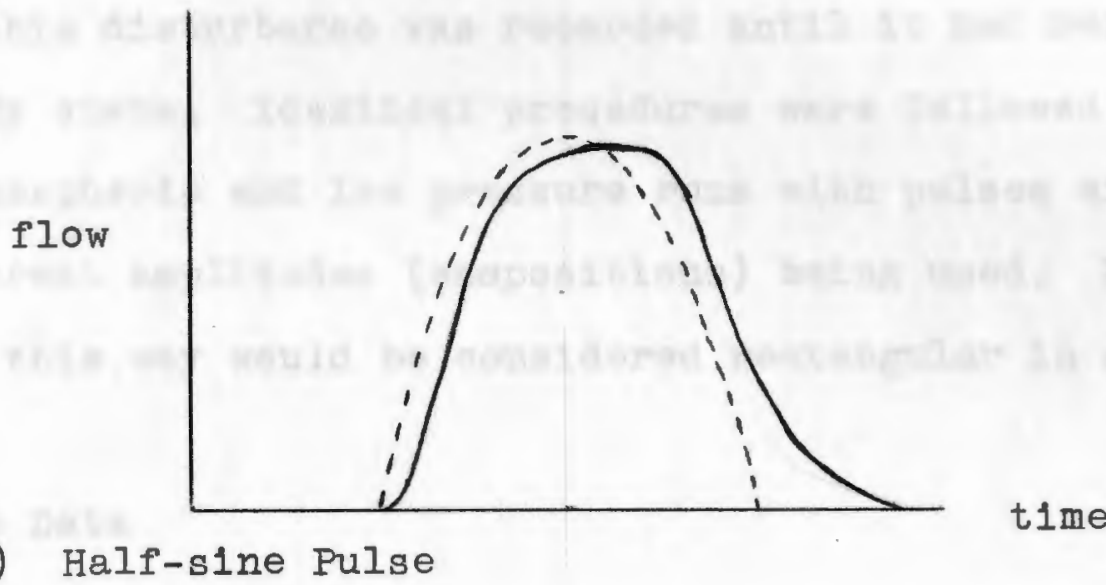

(b) Half-sine Pulse

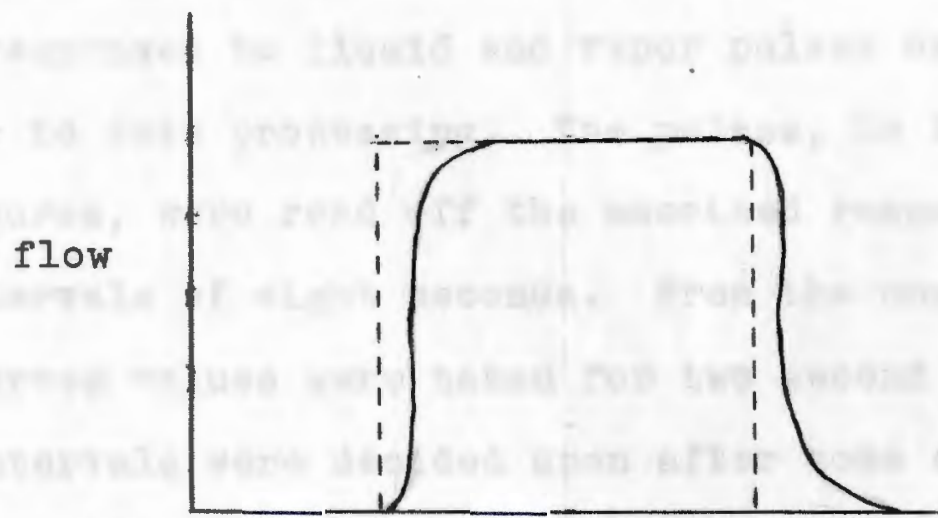

(c) Rectangular Pulse

time

Figure 11 - - Illustration of theoretical vapor and liquid flow rate pulses and actual pulses produced showing distortions caused by system nonIinearities 
To determine the response of the column to pulses in 11quid feed composition, the unit was first brought to steady state using the main feed system. The column was then swltched to the auxiliary feed of a different composition for a short period of time and back to the main feed. The pulse duration was measured using an electric timer accurate to .1 seconds. During this period, the volumetric flow rate was maintained constant. The response of the column to this disturbance was recorded until it had returned to steady state. Identical procedures were followed for both atmospheric and low pressure runs with pulses of several different amplitudes (compositions) being used. Pulses made in this way would be considered rectangular in shape.

Response Data

The thermocouple emf recordings representing the plate liquid responses to liquid and vapor pulses were hand smoothed prior to data processing. The pulses, to three signif1cant figures, were read off the smoothed response curves for time intervals of eight seconds. From the unsmoothed input pulse curves values were taken for two second intervals. These intervals were decided upon after some experimentation indicated that using smaller time intervals (more data points), while requiring more processing time, would not 1mprove the accuracy of the results. Using much larger time intervals would have unduly distorted the functions being approximated. When pure time delays were apparent in the 
response curves, these were recorded, and the zero point was shifted to the point of first deviation from the steady state. The rectangular concentration pulses were all assigned an amplitude of unity for their duration. The input-response data were then processed by the TAFT routine which calculates the input and output Fourler transforms and from these, standard frequenoy response information. Mile producing a printed output, the program also ut111zed the computer plotting system to automatically construct and plot the regults as Bode diagrams. 


\section{RESULTS}

A system subjected to a pulse forcing will be excited at all frequencies expect those at whlch the frequency content (the amplitude of the Fourler transform) of the input pulse becomes zero. At these polnts the expression for the amplitude and phase angle of the frequency response are reduced to the indeterminate form $0 / 0$. In practical computations however, small inaccuracies arising from point reading and roundoff errors inherent in numerical approximations will result in highly erroneous values if calculation is attempted.

As might be expected, there 1s often noticable scatter In the computed frequency response curves as these "zero frequencies" are approached. However the experimental curves usually remain smooth and scattering does not become apparent unt1l after the onset of error. It has been widely shown experimentally that the computed data deviate from the true system frequency response well before a frequency value equal to the first zero of the frequency content of the input pulse.

Hougen and Walsh (47), as a result of pulse testing many experimental systems, have observed that the calculated frequency response information can be considered reliable up to 70-80 percent of the first zero frequency. Although it 
was sometimes possible to recover useful information between zeros, th1s was not recommended. Driefke (29) in his study on the effect of pulse helght and width reached similar conclustons. After experience with many experimental and analytically computed pulse tests, Clements and schnelle (22) concluded that deviation from true response sets in when frequency content of the input pulse, normalized at $\omega=0$, drops to $.2-.3$.

Consistent with these findinge, the experimentally determined frequency response data in this study were calculated and consldered rellable below frequencles at which the normalized input pulse frequency content equaled .25. These data expressed as the amplitude ratio and phase angle are plotted on Bode diagrams, and found in Appendix C. These plots were analyzed to determine values for the parameters occurring in the transfer functions showing the response of 11quid temperature on plates 16, 21, 26 and 28 to changes in vapor rate, liquid feed rate and liquid composition.

Determination of First order Time Constants

Although it was possible to characterize the column responses by first, second or higher order approximations, after careful examination of the experimental Bode diagrams, 1t was decided that determination of more than a major first order time constant would be unwarranted. There were several reasons for this. The response of distillation units to 
changes in liquid flows (rate and composition) is often estimated to be first order on each plate in the column, making the total response nth order at a distance $n$ plates from the point of disturbance. It is common practice in cases such as this for the resulting response to be est1mated by a time delay and a first order time constant $(1,7$, $9,10,36,57)$. In this study, as previously mentioned, time delays were extracted from the experimental time histories of the responses to liquid rate and composition pulses before data processing by the TAFT routine.

The approximate first order time constants were determined by superimposing on the amplitude ratio curves of each Bode diagram, transparencles on which were plotted similar curves for known first order systems. Thus an observable best flt was obtalned which would be considered accurate enough for engineering applications. The experimental amplitude ratio curves showed good agreement with first order dynamics at low frequencles but the.true higher order nature of the responses became evident because of the more rapid attenuation of the curves at high frequencles. The phase lage also showed lower values at the corner frequencles (reciprocal of the first order time constants) than the $-45^{\circ}$ predicted from first order dynamies. It was felt howerer that any attempt to calculate a second time constant would produce values highly inaccurate and of little significance. Because of the extremely low pressure drop in the column, a vapor pulse is felt almost immediately on each plate. 
The response then contains no time delay. In this case a first order approximation to the response 1s more viable, although again at high frequencles, the higher order nature of the response 18 evident.

Characterization of Resonance Peaks

Perhaps the most distinct characteristic of the experimentally determined frequency response curves is presence of resonance peaks. Lamb and P1gford (57) and Wood (84) have both noted the posslbility of this occurrence. The Eckey column is basically a countercurrent phase contact unit. Sinusoldal composition transients in the liquid moving down the column interact with the vapor on each plate causing osclllating varlations in the composition of the vapor moring up the column. The reverse is also true. Because of the column's design for low pressure drop, the vapor composition osclllations are unlikely to be broken up by passing through the plates, as in conventional columns. When the sinusoidal Ilquid and vapor composition transients are in phase, reinforcement of the wares would occur, producing a peak in the amplitude ratio and phase plots. Inhibition occurring when the disturbances are $180^{\circ}$ out of phase would produce a corresponding trough.

In theory, these peaks should occur on all plates at the same frequencies. The experimental curves bear this out. As expected, the resonance frequencles were not noticeably affected by the shape, helght or duration of the input pulse. 
In addition, resonance peaks were evident in the frequency response curves for all liquid and vapor forclngs at both atmosphertc and reduced pressure.

The quantity $B$ in the experimental transfer functions was calculated from the perlod of the resonance peaks occurring in the amplitude ratio curves of the frequency response plots. The quantity $A$ is related to the amplitude of the resonance peaks and was calculated, where possible from the phase angle curves. Detalls of the methods of calculation of these parameters are shown below with reference to F1gure 12.

Determination of Parameters $A$ and $B$

Let the transfer function for a system which shows resonance peaks in the frequency response be of the form:

$$
G(s)=D(s) R(s)
$$

where $G(s)=$ total system transfer function

$$
\text { (2) } \begin{aligned}
k(s) & =\left(1-A e^{-B s}\right)-\begin{array}{c}
\text { component accounting for } \\
\text { resonance }
\end{array} \\
D(s) & =\text { remaining part of } G(s)
\end{aligned}
$$

To obtain the frequency response, let $s=j \omega$, where $j=\sqrt{-1}$

$$
\omega=\text { erequency, } \mathrm{rad} / \mathrm{sec}
$$

$$
\begin{aligned}
G(j) & =D(j \omega)\left(1-A e^{-j \omega B}\right) \\
& =D(j \omega)(1-A \cos B \omega+j A \sin B \omega) \\
(3) & =D(j \omega)[(1-A \cos B \omega)+j(A \sin B \omega)]
\end{aligned}
$$

Calculation of B

Obtain magnitude of $G(j(\omega)$

(4) $\operatorname{Mag}(G)=\operatorname{Mag}(D)\left(1-2 A \cos B \omega+A^{2} \cos ^{2} B \omega+A^{2} \sin ^{2} B \omega\right)^{\frac{1}{2}}$ 


$$
=\operatorname{Mag}(D)\left(1-2 A \cos B \omega+A^{2}\right)^{\frac{1}{2}}
$$

Obtain amplitude ratio by division by $\operatorname{Mag}(G)$ at $\omega=0$

(5) $\operatorname{AR}(G)=\frac{\operatorname{Mag}(G)}{\operatorname{Mag}(G(0))}=\frac{\operatorname{Mag}(D)}{\operatorname{Mag}(D(0))} \frac{1}{(1-\Lambda)}\left(1-2 A \cos B \omega+A^{2}\right)^{\frac{1}{2}}$

oscillations in a plot of $\mathrm{AR}(G)$ versus $\log \omega$ as shown in Figure 12 are caused by the term, $-2 A \cos B \omega$. Thls oscillates with a "period", $P=\frac{2 \pi}{B}$. From Figure 12, the "period" is the difference between successive peakg or troughs. Therefore $B$ is determined from the relation:

(6) $B=\frac{2 \pi}{P}=\frac{2 \pi}{\omega_{2}-\omega_{1}}$

Calculation 으 $\mathrm{A}$

(7) $\angle R(j \omega)=\angle G(j \omega)-\angle D(j \omega)$

from equation (3)

(8) $\angle R(j \omega)=\angle[(1-A \cos B \omega)+J(A \sin B \omega)]$

$$
=\tan ^{-1} \frac{A \sin B \omega}{(1-A \cos B \omega)}
$$

This term is oscillatory as seen from the table below.

\begin{tabular}{c|l} 
Bw & $L \mathrm{R}$ \\
\hline 0 & 0 \\
$\pi / 2$ & $\tan ^{-1} \mathrm{~A}$ \\
$\pi$ & 0 \\
$\pi / 2$ & $\tan ^{-1}-\mathrm{A}$ \\
$2 \pi$ & 0
\end{tabular}

Table I.

From Figure 12, $\angle R=\phi_{1}-\phi_{2}$.

From Table I, $\left|\left(\phi_{1}-\phi_{2}\right)\right|_{\max }=\tan ^{-1} A$ or $-\tan ^{-1}-A$

Therefore,

$$
A=\tan \left|\left(\phi_{1}-\phi_{2}\right)\right|_{\max }
$$


Bode Plot for Typlcal system showlng Resonance Peaks
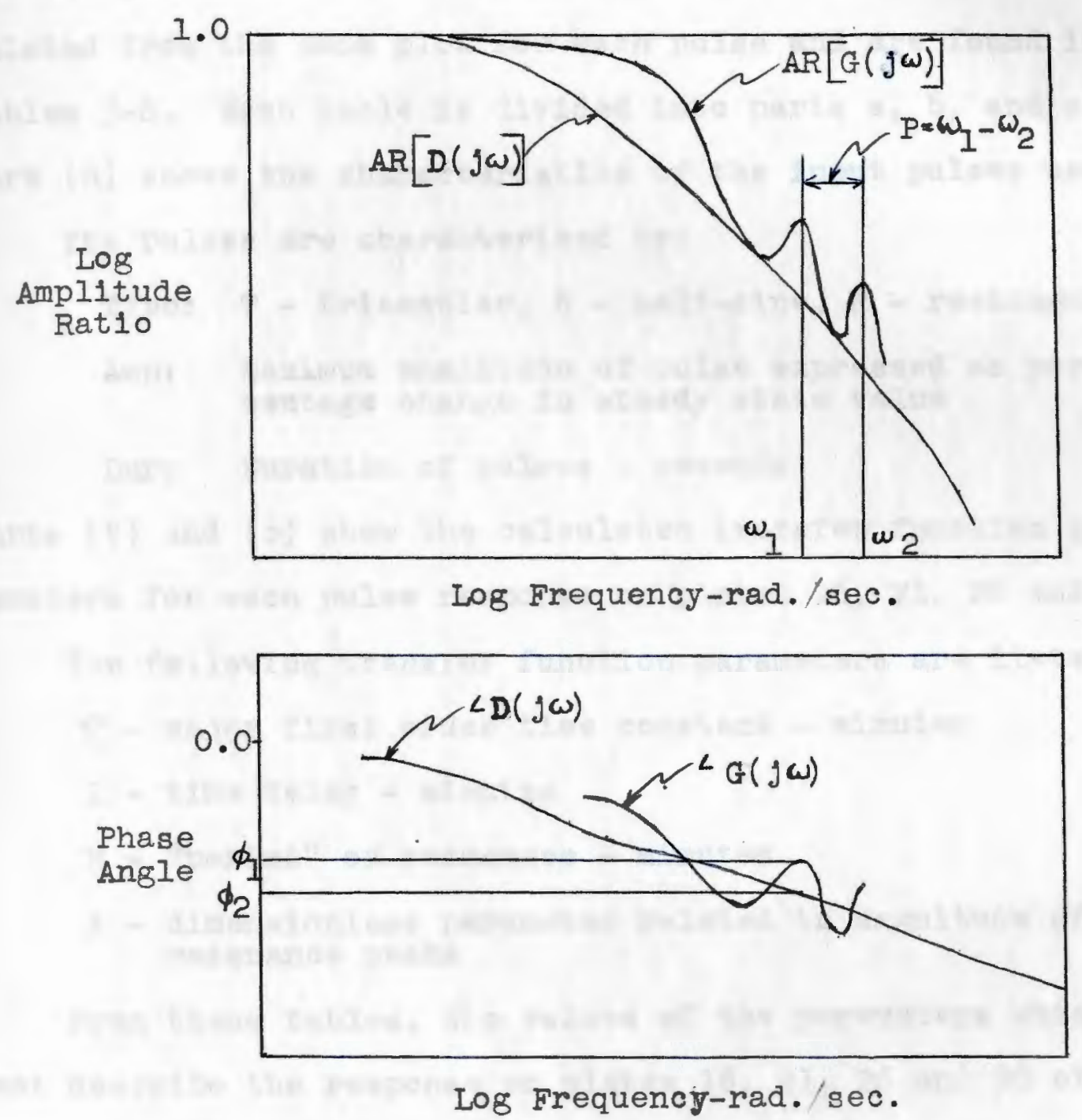

Figure 12 - Illustration of notation used for calculation of transfer function parameters $A$ and $B$. 
Summary of Calculated Transfer Function Parameters

Appendix C contains the experimentally determined Bode Diagrams and is divided into six sections according to the nature of the forcing and the system pressure. The values for the parameters in the transfer function model were calculated from the Bode plot for each pulse and are found in Tables 3-8. Each table is divided into parts $a, b$, and $c$. Part (a) shows the characteriatics of the input pulses used. The pulses are characterized by: Type: T - triangular, S - half-sine, $R$ - rectangular Amp: Maximum amplitude of pulse expressed as percentage change in steady state value

Dur: Duration of pulses - seconds

Parts (b) and (c) show the calculated transfer function parameters for each pulse response on plates $16,21,26$ and 28 . The following transfer function parameters are listed. $T$ - major first order time constant - minutes L - time delaj - minutes B - "period" of resonance - minutes

A - dimensionless parameter related to magnitude of resonance peaks

From these tables, the values of the parameters which best describe the response on plates 16, 21, 26 and 28 of the Eckey column to varlations in vapor rate, llquid rate, and Ilquid composition at both atmospheric and reduced pressure were determined and are shown in Table 9. 
TABLE $3 \mathrm{a}$

VAPOR RATE PULSE

COLUMN PRESSURE- 1 ATM.

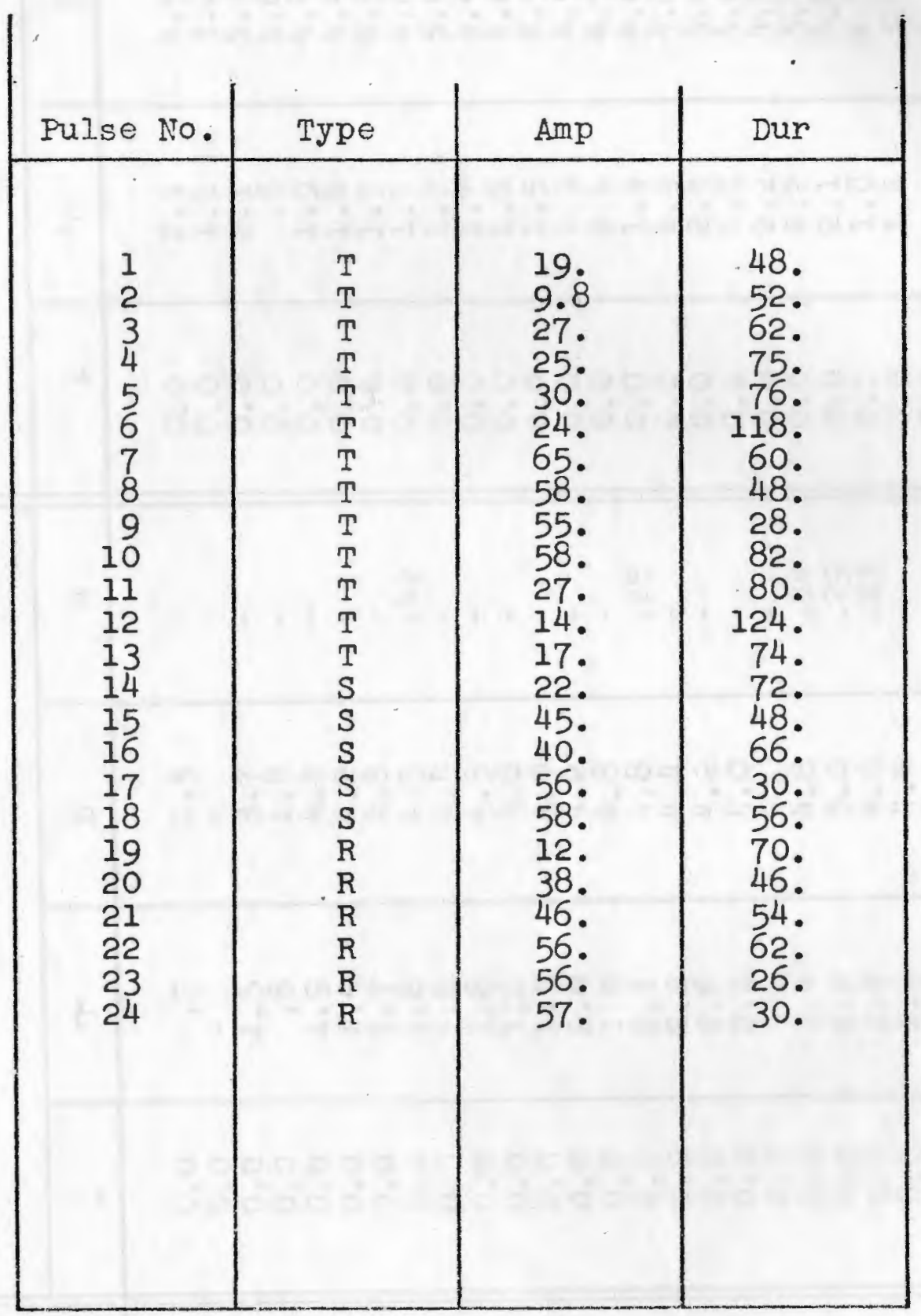




\begin{tabular}{|c|c|c|c|c|c|c|c|c|}
\hline \multirow[b]{2}{*}{ Pulse No } & \multicolumn{4}{|c|}{ Plate 16} & \multicolumn{4}{|c|}{ Plate 21} \\
\hline & L & $\tau$ & $B$ & A & L & $\tau$ & $B$ & A \\
\hline $\begin{array}{r}1 \\
2 \\
3 \\
4 \\
5 \\
6 \\
7 \\
8 \\
9 \\
10 \\
11 \\
12 \\
13 \\
14 \\
15 \\
16 \\
17 \\
18 \\
19 \\
20 \\
21 \\
22 \\
23 \\
24\end{array}$ & $\begin{array}{l}0.0 \\
0.0 \\
0.0 \\
0.0 \\
0.0 \\
0.0 \\
0.0 \\
0.0 \\
0.0 \\
0.0 \\
0.0 \\
0.0 \\
0.0 \\
0.0 \\
0.0 \\
0.0 \\
0.0 \\
0.0 \\
0.0 \\
0.0 \\
0.0 \\
0.0 \\
0.0 \\
0.0\end{array}$ & $\begin{array}{l}.7 \\
-1.5 \\
.8 \\
1.9 \\
1.4 \\
1.7 \\
1.8 \\
1.8 \\
1.8 \\
1.6 \\
1.5 \\
2.0 \\
1.9 \\
2.1 \\
2.2 \\
2.6 \\
2.2 \\
-2 \\
2.4 \\
2.2 \\
2.4 \\
1.4 \\
1.8\end{array}$ & $\begin{array}{l}1.5 \\
-3.7 \\
1.8 \\
4.4 \\
4.2 \\
4.8 \\
4.5 \\
4.5 \\
4.5 \\
3.5 \\
3.9 \\
4.2 \\
4.8 \\
4.8 \\
4.4 \\
4.2 \\
4.0 \\
-7.8 \\
5.8 \\
4.0 \\
4.4 \\
5.0\end{array}$ & $\begin{array}{l}- \\
- \\
- \\
- \\
- \\
- \\
- \\
.42 \\
- \\
- \\
- \\
- \\
- \\
- \\
.25 \\
- \\
- \\
- \\
-84 \\
.29 \\
.23 \\
- \\
-\end{array}$ & $\begin{array}{l}0.0 \\
0.0 \\
0.0 \\
0.0 \\
0.0 \\
0.0 \\
0.0 \\
0.0 \\
0.0 \\
0.0 \\
0.0 \\
0.0 \\
0.0 \\
0.0 \\
0.0 \\
0.0 \\
0.0 \\
0.0 \\
0.0 \\
0.0 \\
0.0 \\
0.0 \\
0.0 \\
0.0\end{array}$ & $\begin{array}{l}2.1 \\
1.2 \\
2.1 \\
.8 \\
1.9 \\
1.4 \\
1.7 \\
1.7 \\
1.7 \\
1.7 \\
1.6 \\
1.5 \\
1.9 \\
2.1 \\
1.9 \\
1.9 \\
2.4 \\
1.8 \\
2.2 \\
2.2 \\
2.1 \\
1.8 \\
1.4 \\
-\end{array}$ & $\begin{array}{l}4.5 \\
3.2 \\
5.0 \\
1.6 \\
4.4 \\
4.4 \\
4.5 \\
4.8 \\
5.0 \\
4.4 \\
4.0 \\
4.5 \\
4.5 \\
4.5 \\
4.8 \\
4.8 \\
5.0 \\
4.0 \\
4.5 \\
5.0 \\
4.8 \\
4.5 \\
3.0 \\
-\end{array}$ & $\begin{array}{l}- \\
- \\
- \\
- \\
- \\
- \\
.18 \\
- \\
- \\
.18 \\
.3 \\
.32 \\
.23 \\
- \\
.18 \\
.27 \\
- \\
.58 \\
.14 \\
.21 \\
- \\
- \\
-\end{array}$ \\
\hline
\end{tabular}




\begin{tabular}{|c|c|c|c|c|c|c|c|c|}
\hline \multirow[b]{2}{*}{ Pulse No } & \multicolumn{4}{|c|}{ Plate 26} & \multicolumn{4}{|c|}{ Plate 28} \\
\hline & L & $\tau$ & B & A & I & $\tau$ & $B$ & A \\
\hline $\begin{array}{r}1 \\
2 \\
3 \\
4 \\
5 \\
6 \\
7 \\
8 \\
9 \\
10 \\
11 \\
12 \\
13 \\
14 \\
15 \\
16 \\
17 \\
18 \\
19 \\
20 \\
21 \\
22 \\
23 \\
24\end{array}$ & $\begin{array}{l}0.0 \\
0.0 \\
0.0 \\
0.0 \\
0.0 \\
0.0 \\
0.0 \\
0.0 \\
0.0 \\
0.0 \\
0.0 \\
0.0 \\
0.0\end{array}$ & $\begin{array}{l}2.1 \\
.6 \\
2.1 \\
.6 \\
1.9 \\
1.3 \\
1.5 \\
1.8 \\
1.8 \\
1.3 \\
1.6 \\
1.5 \\
1.7\end{array}$ & $\begin{array}{l}4.4 \\
3.2 \\
4.2 \\
- \\
3.9 \\
4.4 \\
4.5 \\
4.4 \\
4.5 \\
4.5 \\
3.6 \\
3.9 \\
-\end{array}$ & $\begin{array}{l}.32 \\
- \\
- \\
- \\
- \\
- \\
.19 \\
.27 \\
-23 \\
- \\
-\end{array}$ & $\begin{array}{l}0.0 \\
0.0 \\
0.0 \\
0.0 \\
0.0 \\
0.0 \\
0.0 \\
0.0 \\
0.0 \\
0.0\end{array}$ & $\begin{array}{r}2.1 \\
.7 \\
1.0 \\
1.4 \\
.6 \\
-1.5 \\
2.1 \\
1.0 \\
1.8\end{array}$ & $\begin{array}{l}4.5 \\
2.6 \\
- \\
5.2 \\
3.6 \\
-5.0 \\
4.8 \\
4.4 \\
3.4\end{array}$ & $\begin{array}{l}.58 \\
- \\
- \\
.18 \\
- \\
.19 \\
-\end{array}$ \\
\hline & 0.0 & $\cdot 9$ & & & & & & \\
\hline
\end{tabular}


60

TABLE $4 a$

LIQUID RATE PULSE

COLUMN PRESSURE- 1 ATM.

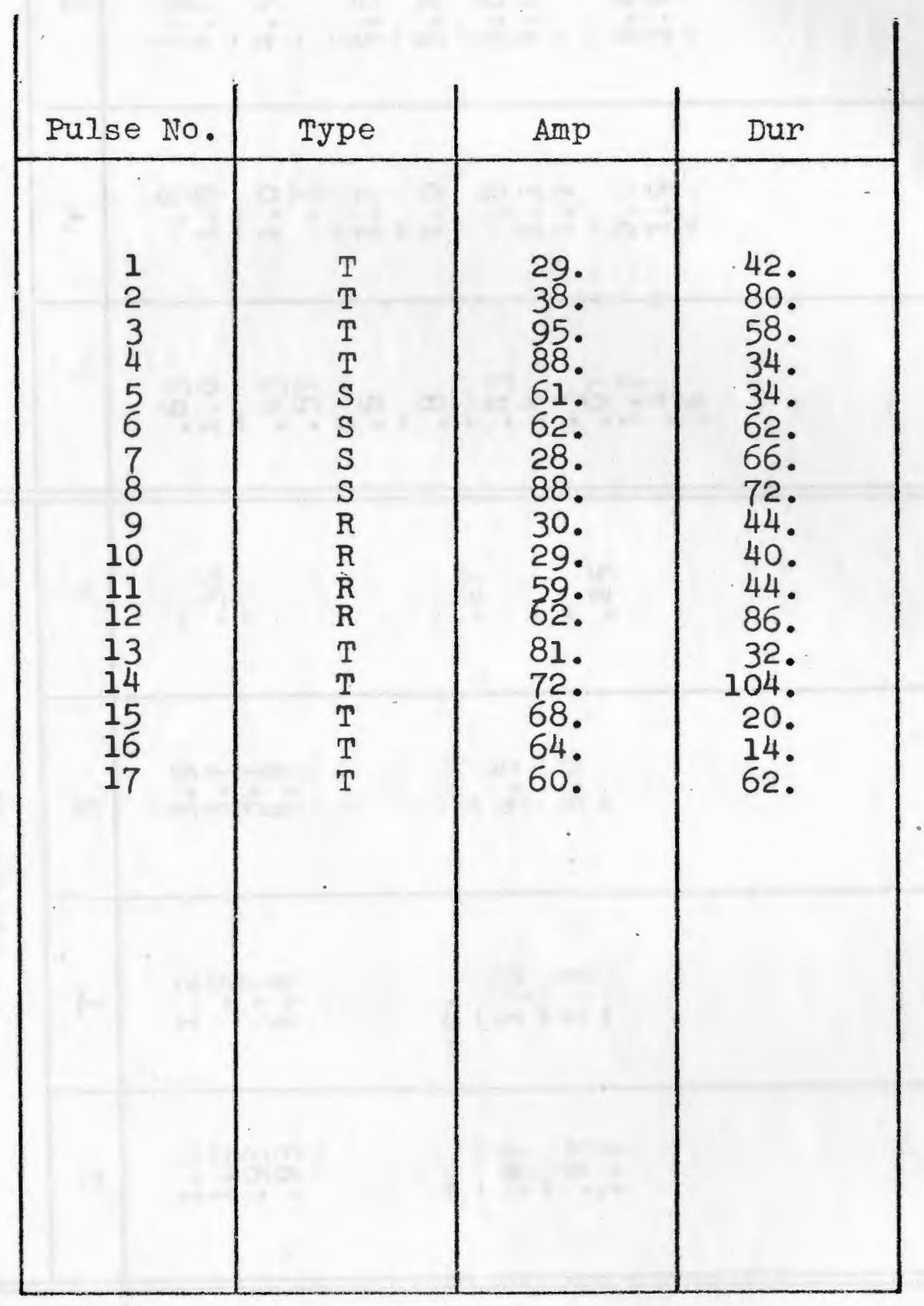




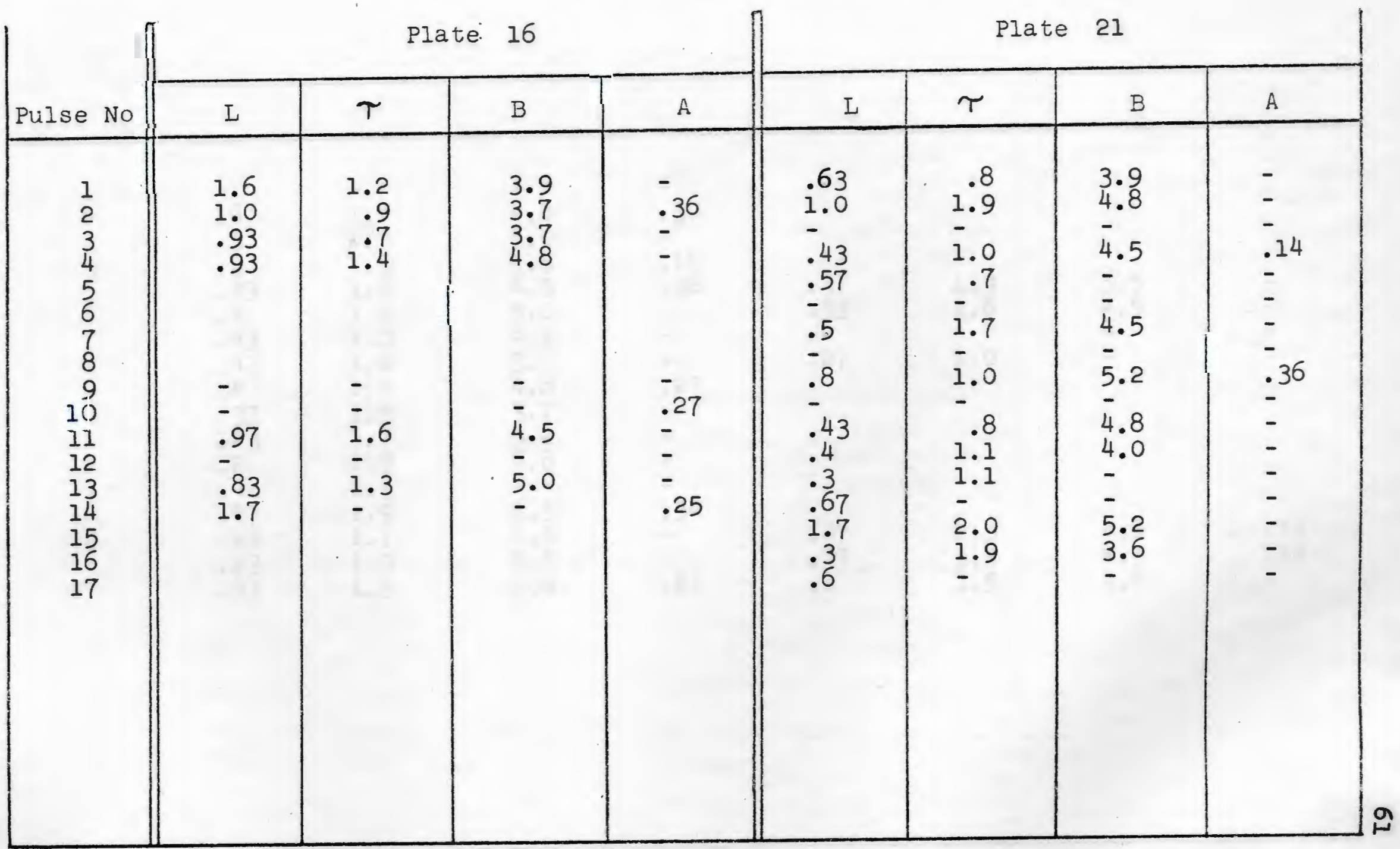




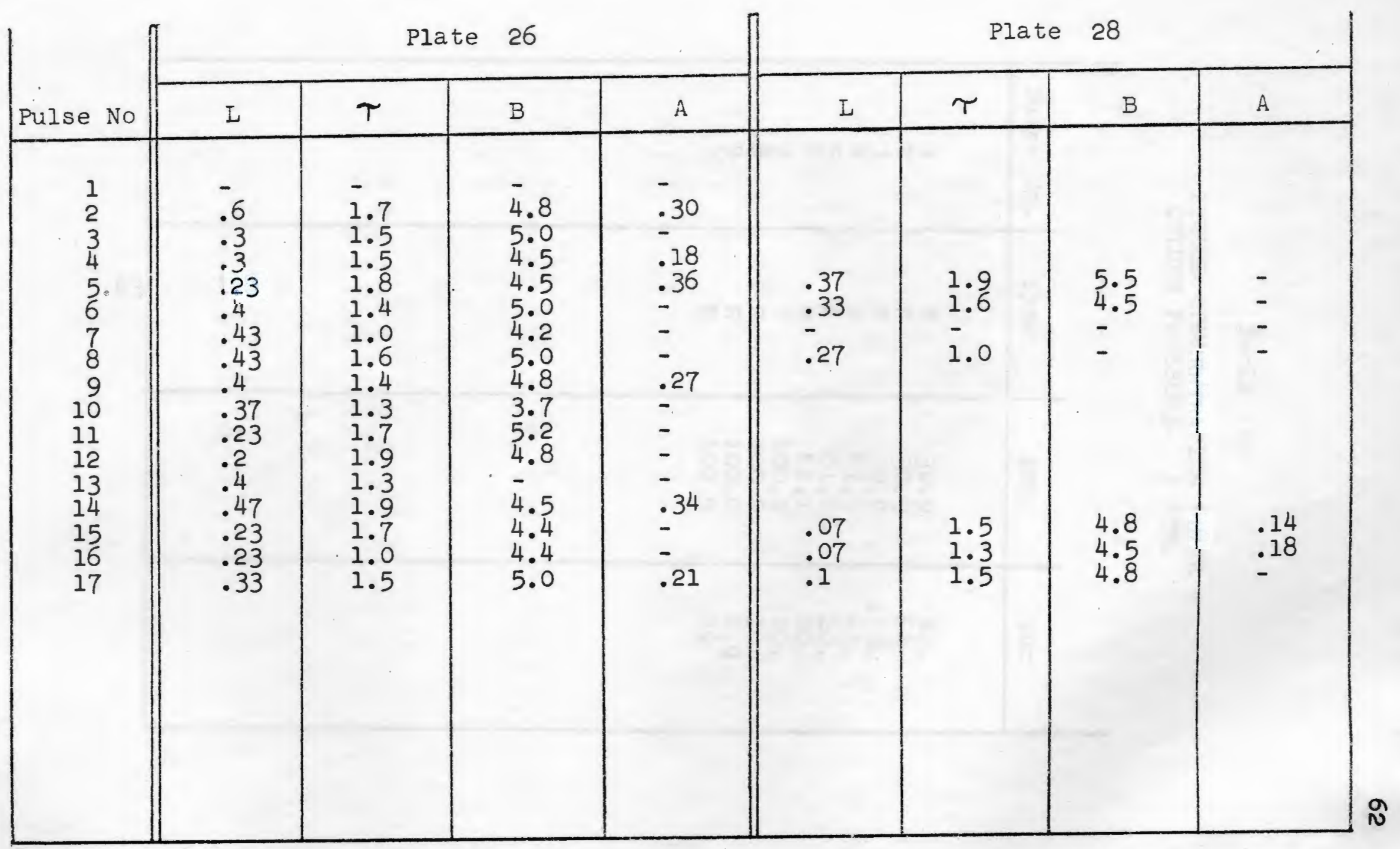


TABLE $5 \mathrm{a}$

LIQUID CONCENTRATION PULSE

COLUMN PRESSURE- 1 ATM.

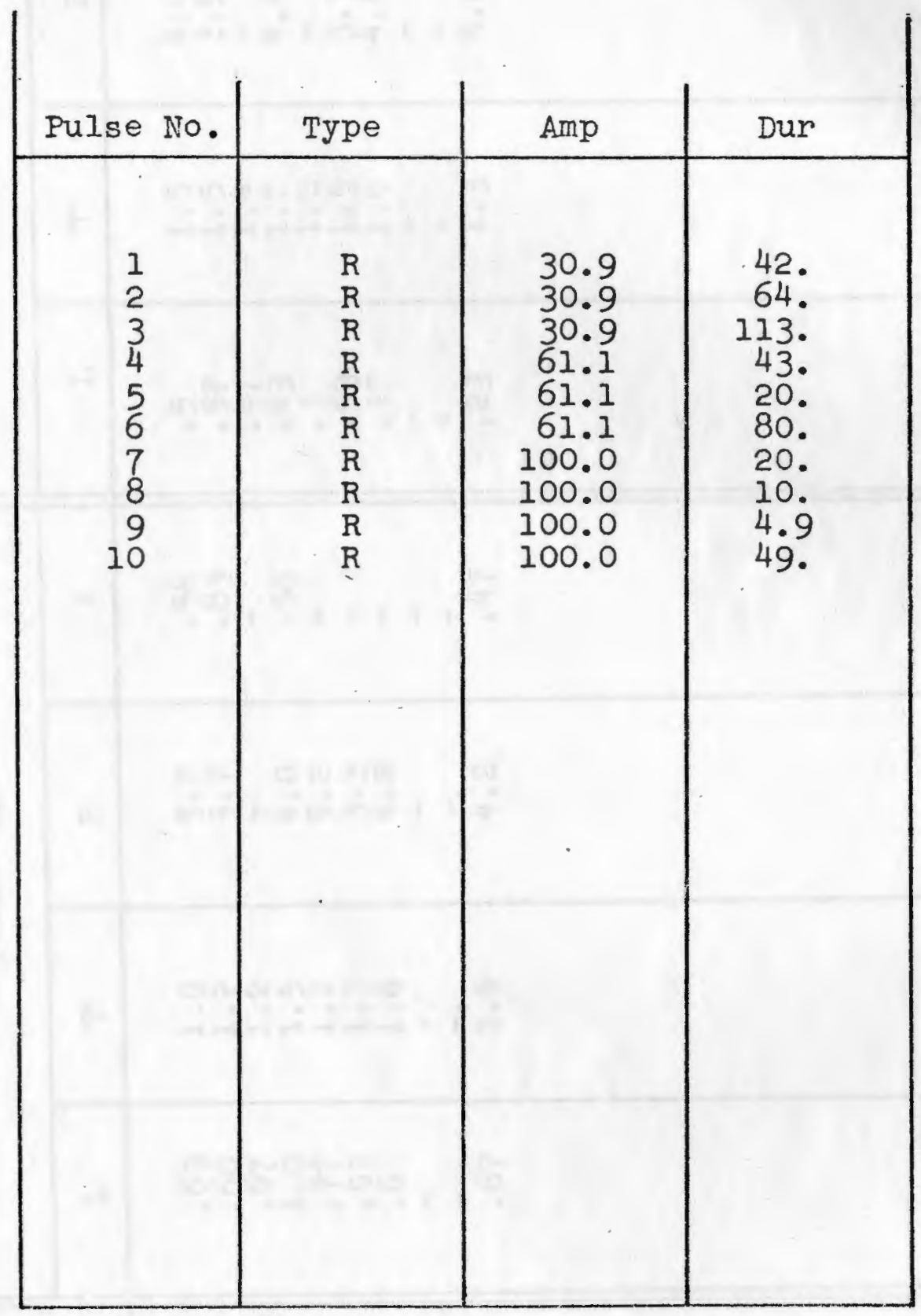


TRANSFER FUNCTION PARAMERERS FROM BODE PLOTS

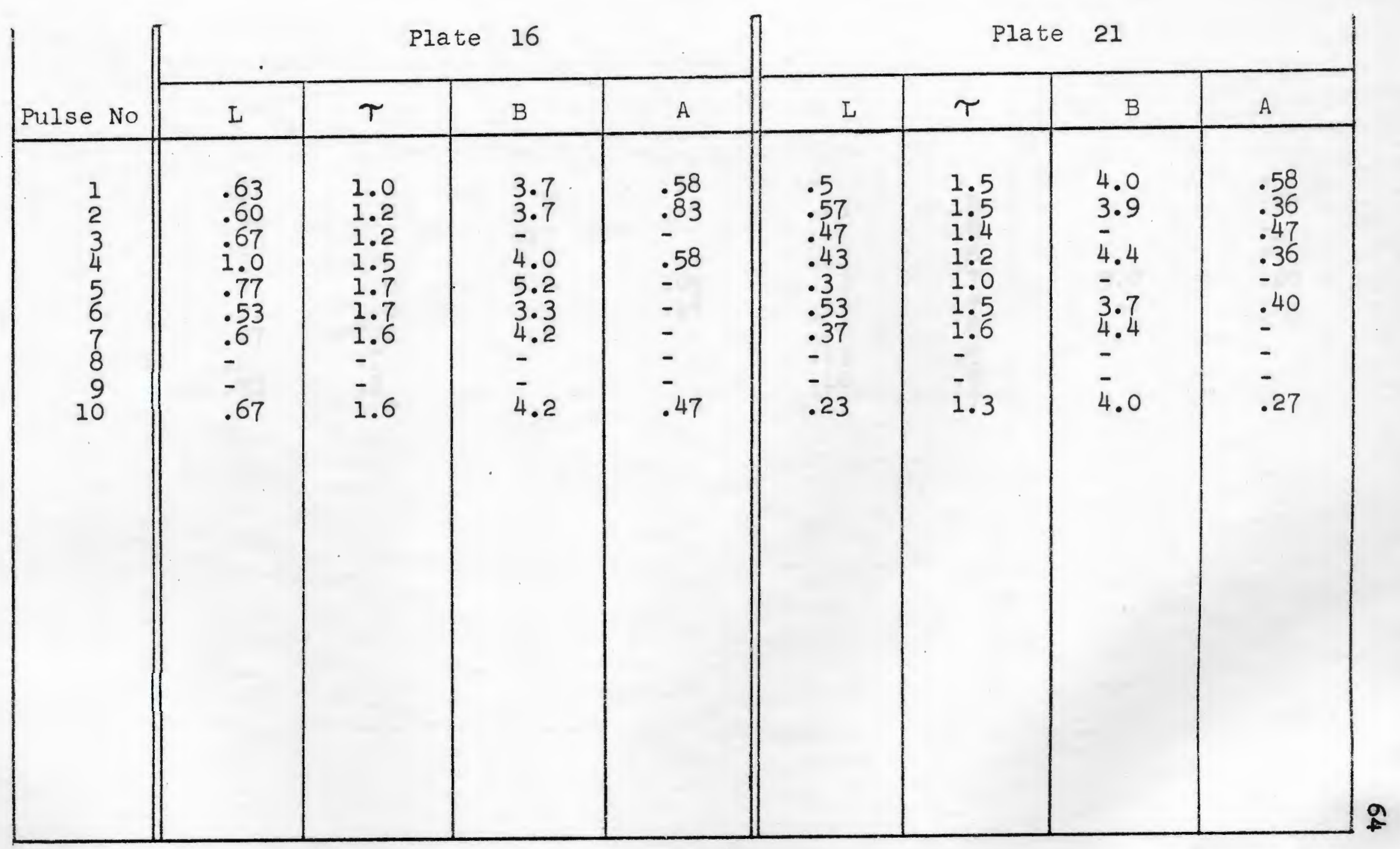


TRANSFER FUNCTION PARAMETERS FROM BODE PLOTS

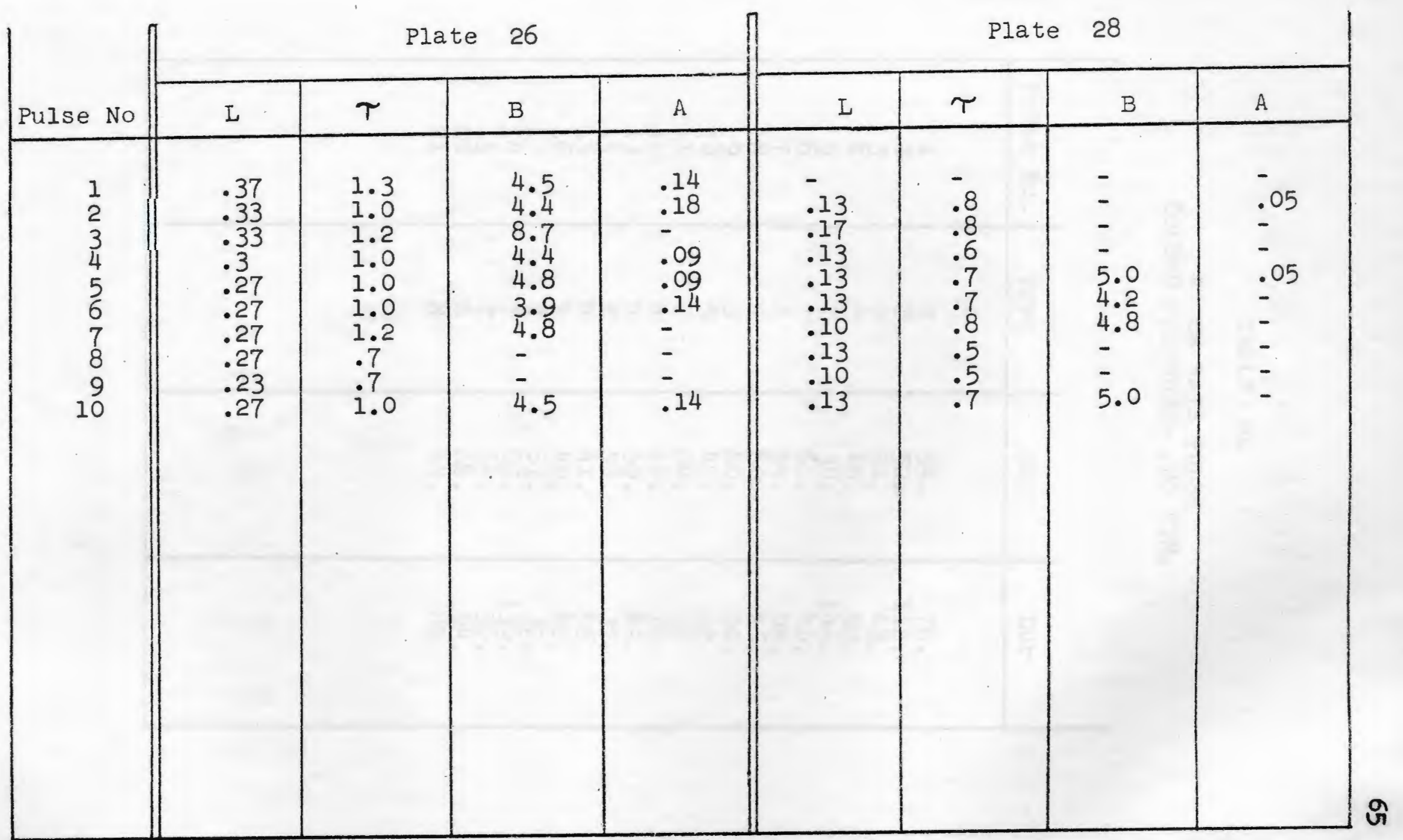


TABLE $6 a$

VAPOR RATE PULSE

COLUMN PRESSURE- .26 ATM.

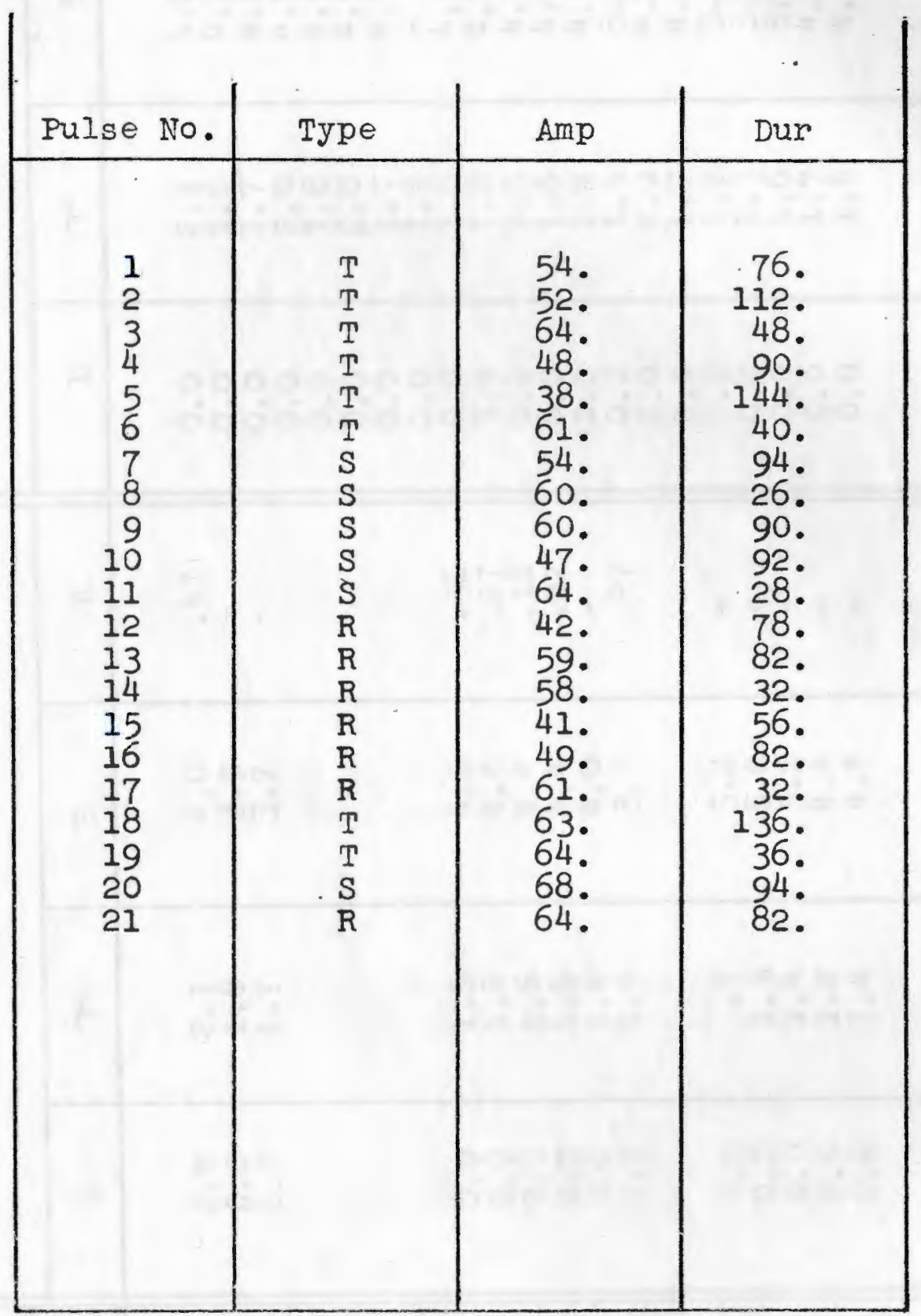


TRANSFER FUNCTION PARAMETERS FROM BODE PLOTS

\begin{tabular}{|c|c|c|c|c|c|c|c|c|}
\hline \multirow[b]{2}{*}{ Pulse No } & \multicolumn{4}{|c|}{ Plate 16} & \multicolumn{4}{|c|}{ Plate 21} \\
\hline & L & $\tau$ & $B$ & A & $I$ & $\tau$ & $B$ & $\mathrm{~A}$ \\
\hline $\begin{array}{r}1 \\
2 \\
3 \\
4 \\
5 \\
6 \\
7 \\
8 \\
9 \\
10 \\
11 \\
12 \\
13 \\
14 \\
15 \\
16 \\
17 \\
18 \\
19 \\
20 \\
21\end{array}$ & $\begin{array}{l}0.0 \\
0.0 \\
0.0 \\
\\
\\
\\
0.0 \\
0.0 \\
0.0 \\
0.0 \\
0.0 \\
0.0 \\
\\
0.0 \\
0.0 \\
0.0 \\
0.0 \\
0.0\end{array}$ & $\begin{array}{l}2.1 \\
1.8 \\
1.7 \\
\\
\\
1.8 \\
1.8 \\
1.6 \\
1.6 \\
1.9 \\
1.5 \\
\\
.7 \\
1.3 \\
1.4 \\
1.2 \\
1.4\end{array}$ & $\begin{array}{l}4.0 \\
3.9 \\
3.7 \\
\\
\\
4.0 \\
4.5 \\
4.4 \\
4.4 \\
4.0 \\
3.7 \\
\\
5.2 \\
5.2 \\
5.2 \\
4.4 \\
4.5\end{array}$ & $\begin{array}{l}.47 \\
- \\
\\
.36 \\
.27 \\
.18 \\
.27 \\
.27 \\
.2 \\
- \\
- \\
- \\
-\end{array}$ & $\begin{array}{l}0.0 \\
0.0 \\
0.0 \\
0.0 \\
0.0 \\
0.0 \\
0.0 \\
0.0 \\
0.0 \\
0.0 \\
0.0 \\
0.0 \\
0.0 \\
0.0 \\
0.0 \\
0.0 \\
0.0 \\
0.0 \\
0.0 \\
0.0 \\
0.0\end{array}$ & $\begin{array}{l}2.1 \\
1.6 \\
1.7 \\
2.0 \\
1.8 \\
2.0 \\
1.7 \\
1.2 \\
1.6 \\
1.8 \\
1.6 \\
1.6 \\
1.9 \\
1.5 \\
2.0 \\
1.7 \\
1.2 \\
1.3 \\
1.6 \\
1.7 \\
1.8\end{array}$ & $\begin{array}{l}4.2 \\
4.0 \\
4.8 \\
4.0 \\
4.0 \\
4.5 \\
4.0 \\
-4.0 \\
4.0 \\
4.8 \\
4.4 \\
4.4 \\
4.8 \\
3.9 \\
4.5 \\
4.4 \\
5.8 \\
3.5 \\
5.2 \\
4.0 \\
4.8\end{array}$ & $\begin{array}{l}.36 \\
-27 \\
.36 \\
-3 \\
.42 \\
.36 \\
- \\
.27 \\
.21 \\
.18 \\
-29 \\
.29 \\
.19 \\
.23 \\
-21 \\
- \\
- \\
- \\
-\end{array}$ \\
\hline
\end{tabular}




\begin{tabular}{|c|c|c|c|c|c|c|c|c|}
\hline \multirow[b]{2}{*}{ Pulse No } & \multicolumn{4}{|c|}{ Plate 26} & \multicolumn{4}{|c|}{ Plate 28} \\
\hline & L & $T$ & $B$ & $\Lambda$ & I & $\tau$ & $B$ & $\mathrm{~A}$ \\
\hline $\begin{array}{r}1 \\
2 \\
3 \\
4 \\
5 \\
6 \\
7 \\
8 \\
9 \\
10 \\
11 \\
12 \\
13 \\
14 \\
15 \\
16 \\
17 \\
18 \\
19 \\
20 \\
21\end{array}$ & $\begin{array}{l}0.0 \\
0.0 \\
0.0 \\
0.0 \\
0.0 \\
0.0 \\
0.0 \\
0.0 \\
0.0 \\
0.0 \\
0.0 \\
0.0 \\
0.0 \\
0.0 \\
0.0 \\
0.0 \\
0.0 \\
0.0 \\
0.0 \\
0.0 \\
0.0\end{array}$ & $\begin{array}{l}1.4 \\
1.3 \\
1.5 \\
1.3 \\
1.3 \\
1.4 \\
1.3 \\
1.1 \\
1.2 \\
1.2 \\
1.3 \\
1.4 \\
1.4 \\
1.0 \\
1.7 \\
1.4 \\
1.6 \\
1.3 \\
1.2 \\
1.2 \\
1.3\end{array}$ & $\begin{array}{l}4.4 \\
3.4 \\
4.5 \\
3.9 \\
3.6 \\
4.5 \\
3.7 \\
\overline{4} .2 \\
\overline{3} .5 \\
4.8 \\
3.7 \\
4.4 \\
4.8 \\
4.0 \\
-7.9 \\
2.9 \\
\overline{4} .4 \\
4.8\end{array}$ & $\begin{array}{l}.25 \\
.21 \\
.23 \\
.21 \\
- \\
.27 \\
.25 \\
- \\
- \\
- \\
.18 \\
- \\
- \\
.23 \\
- \\
- \\
- \\
- \\
- \\
-\end{array}$ & $\begin{array}{l}0.0 \\
0.0 \\
0.0 \\
0.0 \\
0.0\end{array}$ & $\begin{array}{r}1.3 \\
1.3 \\
1.8 \\
1.3 \\
.7\end{array}$ & $\begin{array}{l}4.0 \\
3.7 \\
4.5 \\
4.0 \\
-\end{array}$ & $\begin{array}{l}.18 \\
.27 \\
.27 \\
.18 \\
-\end{array}$ \\
\hline
\end{tabular}




$$
\begin{gathered}
\text { TABLE } 7 \mathrm{a} \\
\text { LIQUID RATE PULSE } \\
\text { COLUMN PRESSURE- } .24 \mathrm{ATM} \text {. }
\end{gathered}
$$

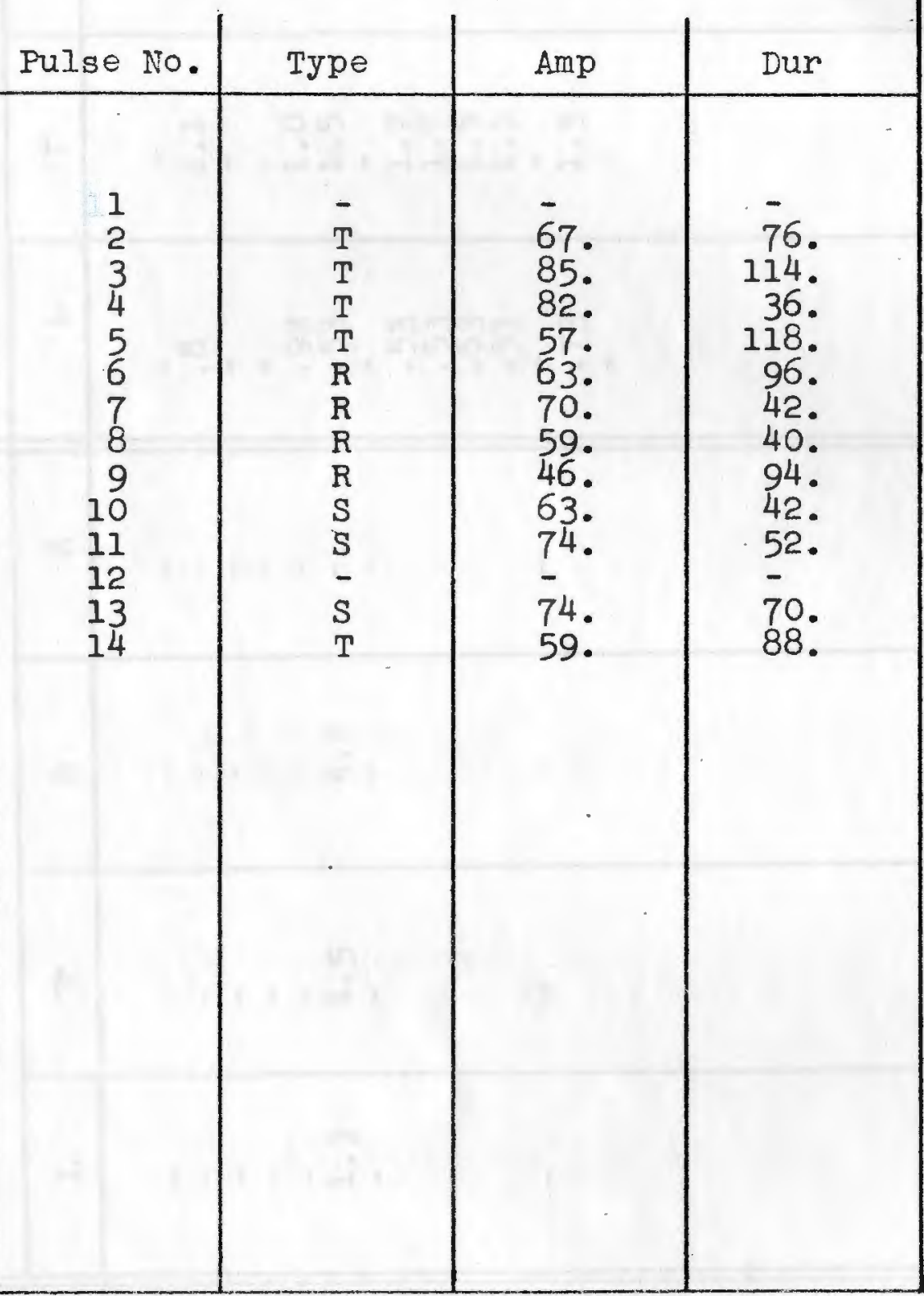




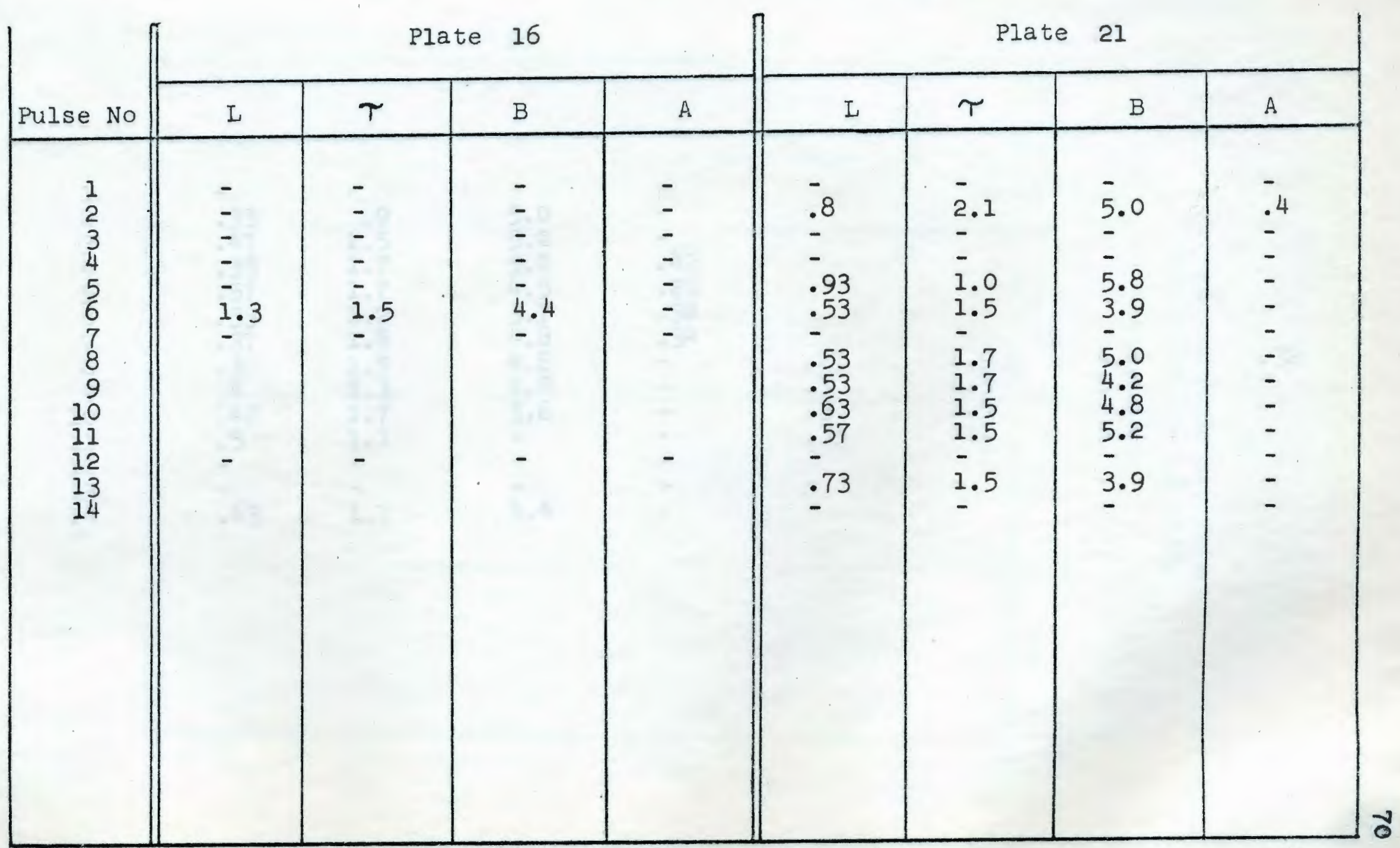




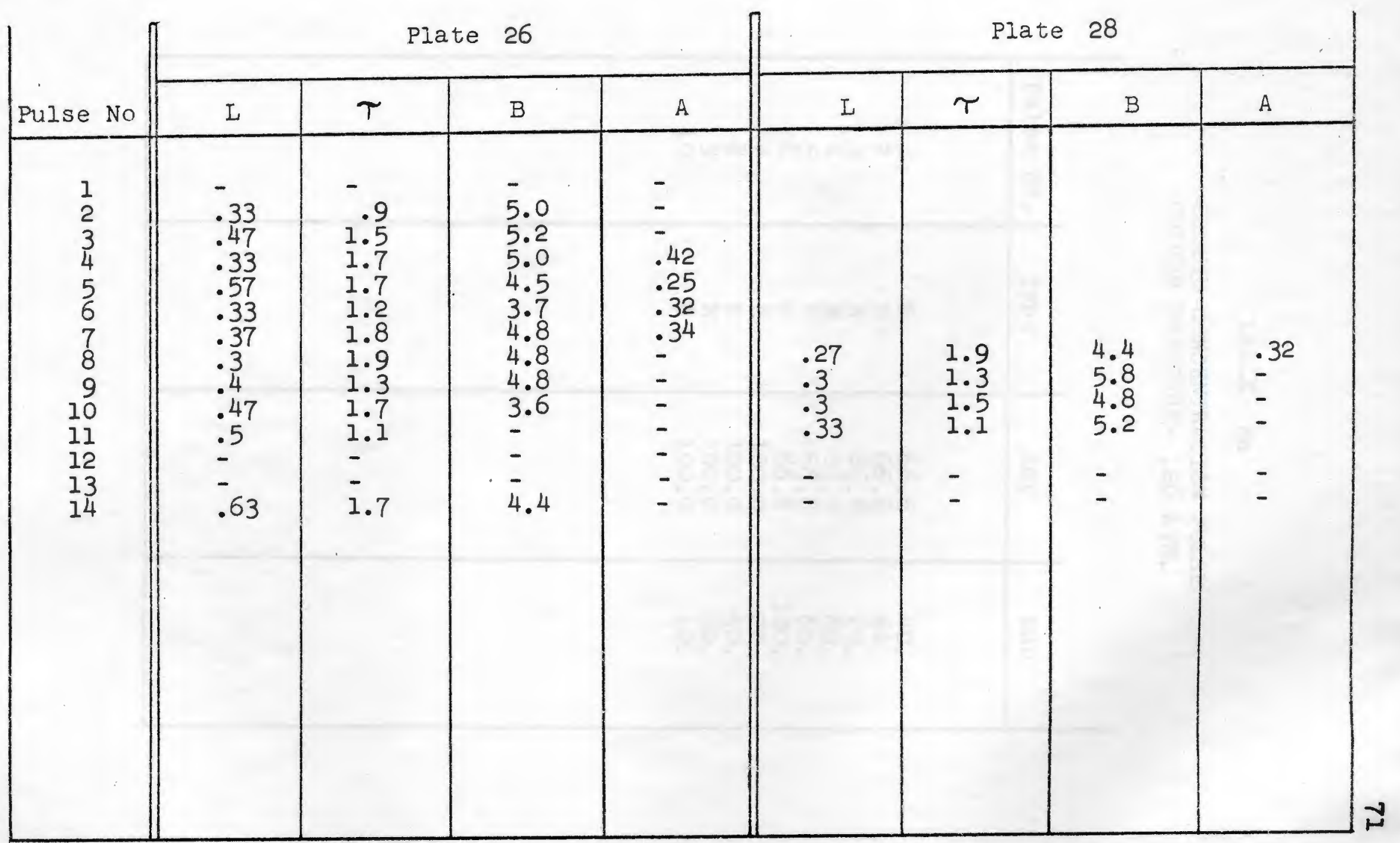


TABLE $8 a$

LIQUID CONCENTRATION PULSE

COLUMN PRESSURE- .26 ATM.

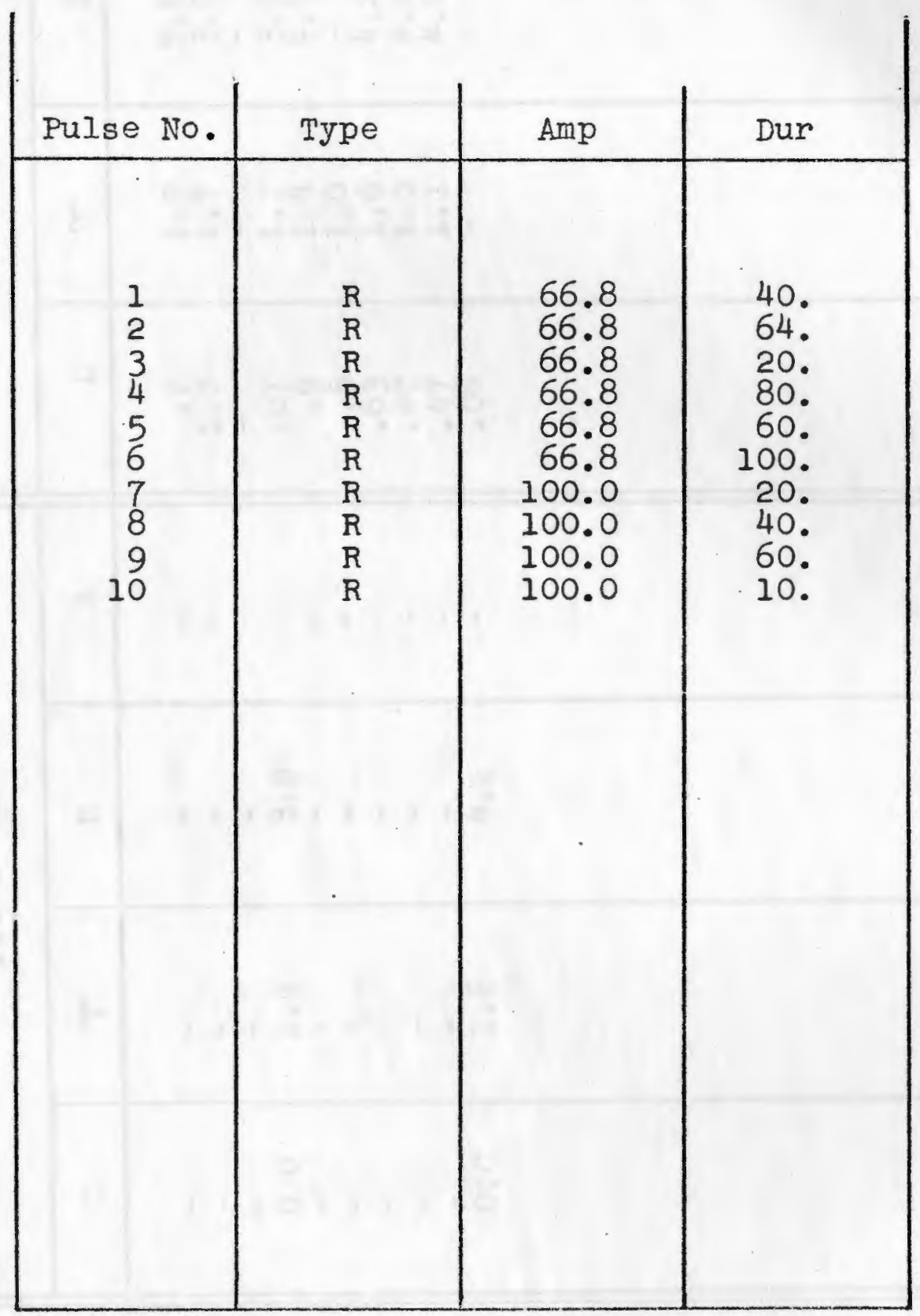




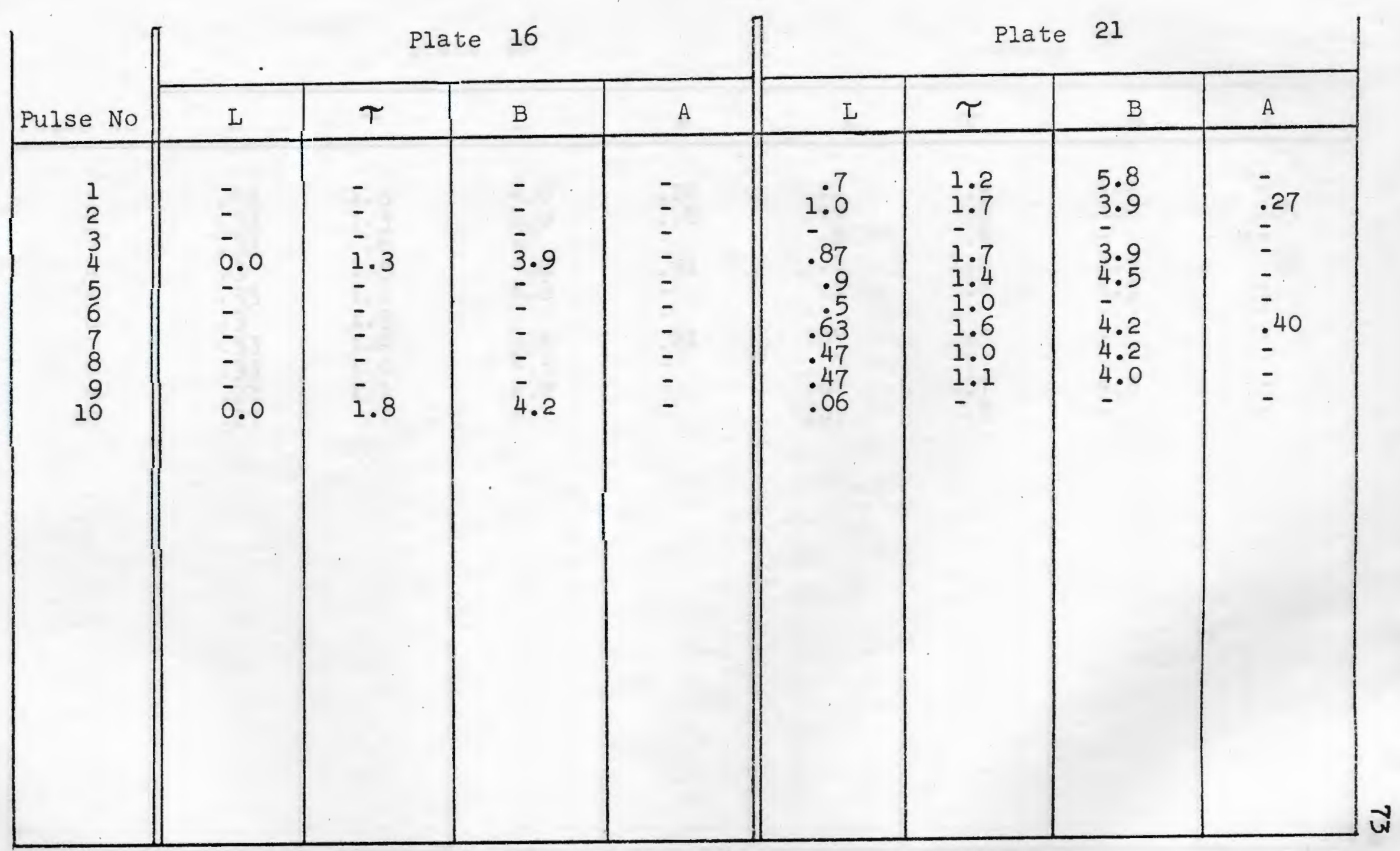


TABLE $8 \mathrm{c}$

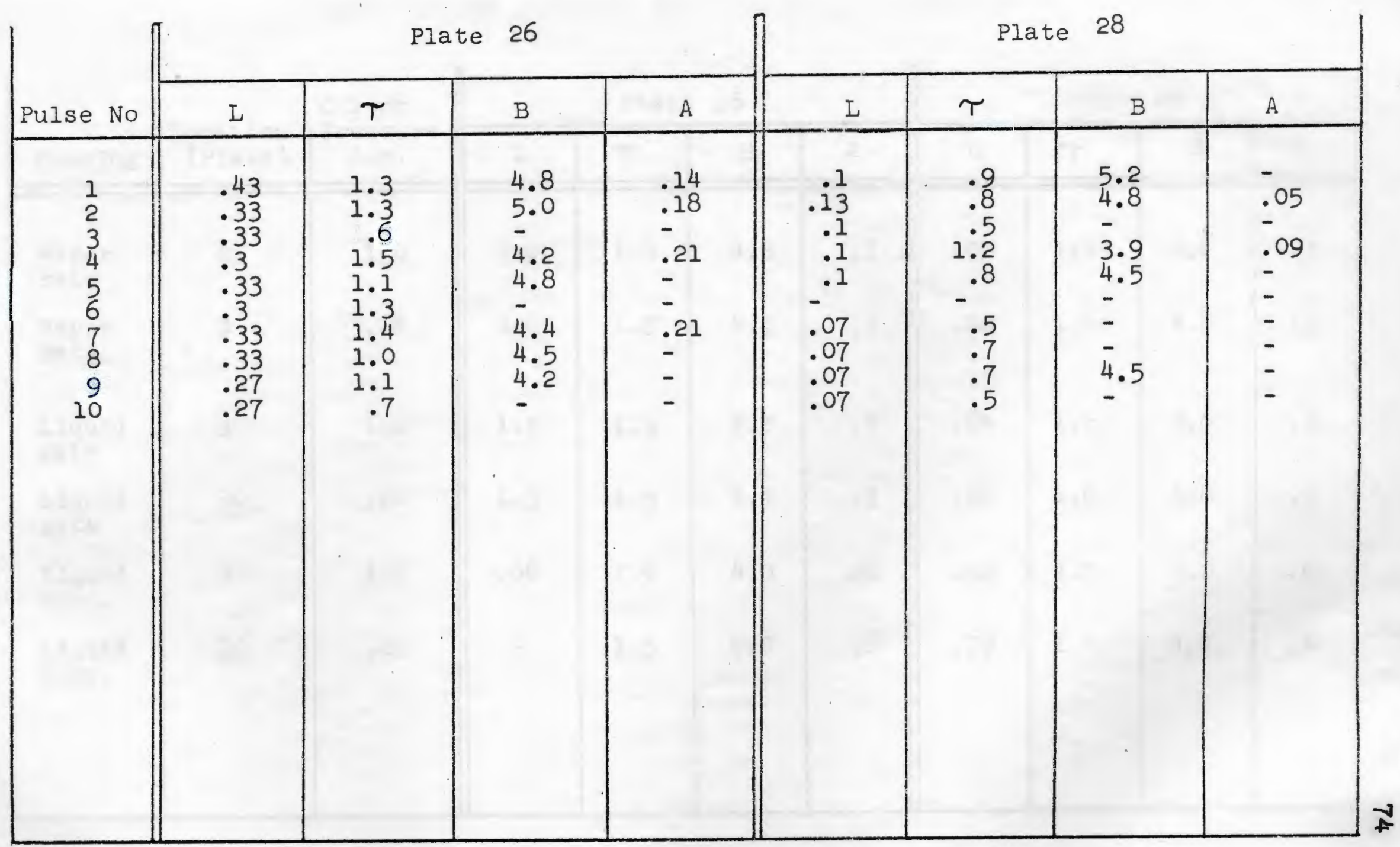




\section{TABLE $9 a$}

FINAL COLUMN TRANSFER FUNCTION MODEL PARAMETERS

\begin{tabular}{|c|c|c|c|c|c|c|c|c|c|c|}
\hline \multirow[b]{2}{*}{ Forcing } & \multirow{2}{*}{$\mid \begin{array}{c}\text { Location } \\
\text { (Plate) }\end{array}$} & \multirow{2}{*}{$\begin{array}{l}\text { Column } \\
\text { Pressure } \\
\text { Atm. }\end{array}$} & \multicolumn{4}{|c|}{ Plate 16} & \multicolumn{4}{|c|}{ Plate 21} \\
\hline & & & $\mathrm{L}$ & $\tau$ & B & A & L & $\tau$ & B & A \\
\hline $\begin{array}{l}\text { Vapor } \\
\text { rate }\end{array}$ & 0 & 1.0 & 0.0 & 1.9 & 4.5 & .3 & .00 & 1.9 & 4.6 & $\cdot 3$ \\
\hline $\begin{array}{l}\text { Vapor } \\
\text { rate }\end{array}$ & 0 & .26 & 0.0 & 1.7 & 4.5 & .3 & .00 & 1.8 & 4.5 & $\cdot 3$ \\
\hline $\begin{array}{l}\text { Liquid } \\
\text { rate }\end{array}$ & 30 & 1.0 & 1.1 & 1.3 & 4.2 & .3 & .64 & 1.5 & 4.6 & $\cdot 3$ \\
\hline $\begin{array}{l}\text { Liquid } \\
\text { rate }\end{array}$ & 30 & .24 & 1.3 & 1.5 & 4.4 & .3 & .66 & 1.6 & 4.8 & $\cdot 3$ \\
\hline $\begin{array}{l}\text { L1quid } \\
\text { conc. }\end{array}$ & 30 & 1.0 & .68 & 1.6 & 4.0 & .6 & .42 & 1.5 & 4.0 & .4 \\
\hline $\begin{array}{l}\text { Liquid } \\
\text { conc. }\end{array}$ & 30 & .26 & - & 1.5 & 4.0 & .6 & .79 & 1.4 & 4.2 & .4 \\
\hline
\end{tabular}


TABLE 9b

FINAL COLUMN TRANSFER FUNCTION MODEL PARAMETERS

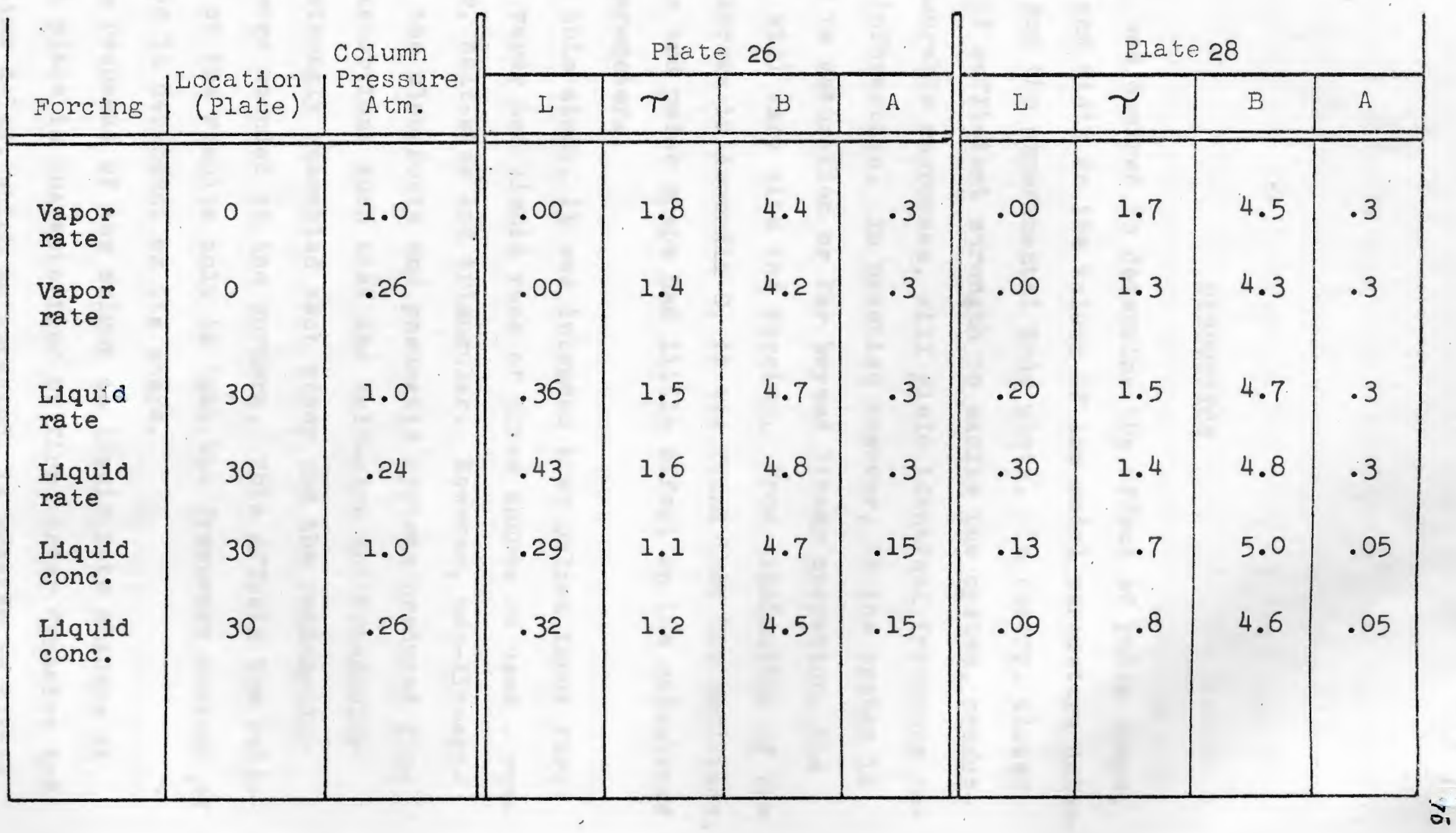




\section{DISCUSSION}

It was desired to determine the effect of pulse shape, height and width on the values of the model parameters determined from the experimental Bode plots. In thoory, closed pulses of sufflolent strength to exclte the system, producIng measurable responses, w1ll yield ldentical frequency responge information. In practice however, if the system 1s excited to saturation or far beyond Inear operation, the results will vary with the forelng. From examination of the Bode Dlagrams in Appendix C, it was found that the amplitude, duration and pulse shape had little effect on the calculated model parameters.

In this study, it was intended that pulsed input forcIngs in vapor and liquid rate of three shapes be used - rectangular, half-sine and triangular. However, non-linearities in the electronic and pneumatic systems produced flow pulse distortions such that the half-sine and triangular pulses strongly resembled each other and the rectangular pulses were rounded at the corners. This affects the rellablilty of the results only in that the frequency content of the pulse is dependent on 1ts shape.

The response of the column to Ilquid rate changes at the feed plate is characterized by first order dynamics and a pure time delay, which as expected, is greater on plates 
farther from the orlgin of the disturbance. The values of the first order time congtant for the different plates were very close, with any differences probably attributable to experimental errors. It would seem that once the disturbence is felt, the response of the liquid composition and temperature is the same on all plates.

A similar situation is encountered with the response to vapor rate changes, except there was no delay noted because of the rapid propagation of vapor disturbances through the column. Again the major first order time constants were about the same on each plate, and are very close to those characterizing the response to liquid flow changes. The time constants in the responses for both forcings, shown in Table 9, range from 1.3 to 1.9 minutes, with an average of about 1.7 minuteg. By changing the liquid or vapor rate on a particular plate, the contact time between the liquid and vapor phases is changed. This in turn affects the mass transfer between the phases and the composition and bolling point of the liquid pools on each plate. Thus, liquid and vapor rate disturbance which change this contact time should effect a similar response from the column.

A feed liquid composition pulse is a more powerful forcing since it directly causes a change in the plate liquld composition. Because of this, the response differed from that of the liquid and vapor rate pulses. Time delajs were noted which increased with distance from the feed plate. However, as seen in Table 9, they were shorter than those 
which occurred in the responses to liquid rate pulses. The major time constant varied with position in the column from about .75 minute on plate 28 to 1.6 minutes on plate 16 . The column also seemed to respond with slightly smaller delays and time constants as the amplitude of the composition pulse increased. The response, at reduced pressure, of plate 16 to composition pulses was very small in magnitude and produced results which are probably not reliable.

The time delays found in the liquid rate and composition pulse responses should be related to the everage time required for the liquid to pass from the feed plate through the column - the liquid residence time. This is determined by dividing the 11quid holdup below the feed plate by the volumetric liquid flow rate. For the pilot elght inch column used in this study, the holdup was about two gallons. Figures 13 and 14 show plots of the ratio of delay to total residence time versus plate number for liquid rate and liquld composition pulses respectively: Thls data was taken from the experimental response time historles and is tabulated in Tables 4, 5, 7 and 8 . Although some scatter is noted, it was found that the time delays varied Inearly with distance from the feed plate and could be approximated with reasonable accuracy from the equation:

(1) $L_{1}=K(R T)\left(\frac{N P_{1}}{T P}\right)$

where 1 plate on which response is being determined

$$
L_{1}=\text { time delay }
$$




$$
\begin{aligned}
& \mathrm{RT}=\text { total residence time of liquid below feed } \\
& \text { plate }
\end{aligned}
$$

.35 for respones to liquid rate forcings

.3 for responses to liquid concentration foreings

$$
\begin{aligned}
& \mathrm{TP}=\text { total number of plates below feed plate } \\
& \mathrm{NP}_{1}=\begin{array}{l}
\text { number of plates between feed plate and } \\
\text { plate } 1
\end{array}
\end{aligned}
$$

The empirical constant being less than 1. Indicates that the disturbances are belng carried down the column in the I1quid flow faster than might be predicted using an average flow rate.

The quantity B, which was calculated from the period of the resonance peaks in the amplitude ratio curves, varled from 4.0 to 5.0 minutes with an average of about 4.5 minutes. Values in this range were consistently found regardless of the type of input forcling used. The dimensionless quantity A is related to the magnitude of the resonance peaks and was calculated, where possible, from the phase angle plot of the experimental Bode diagrams. Although there was little variation in the period of resonance, the magnitudes were often inconsistent and erratic, making calculation of meaningful values of A extremely difficult. This was especially true at higher frequencles. It is felt that the technique of extracting frequency response information from transient pulse responses, which involves considerable data processing and numerical approximations, may not be accurate enough to produce reliable information regarding the magnitude of 


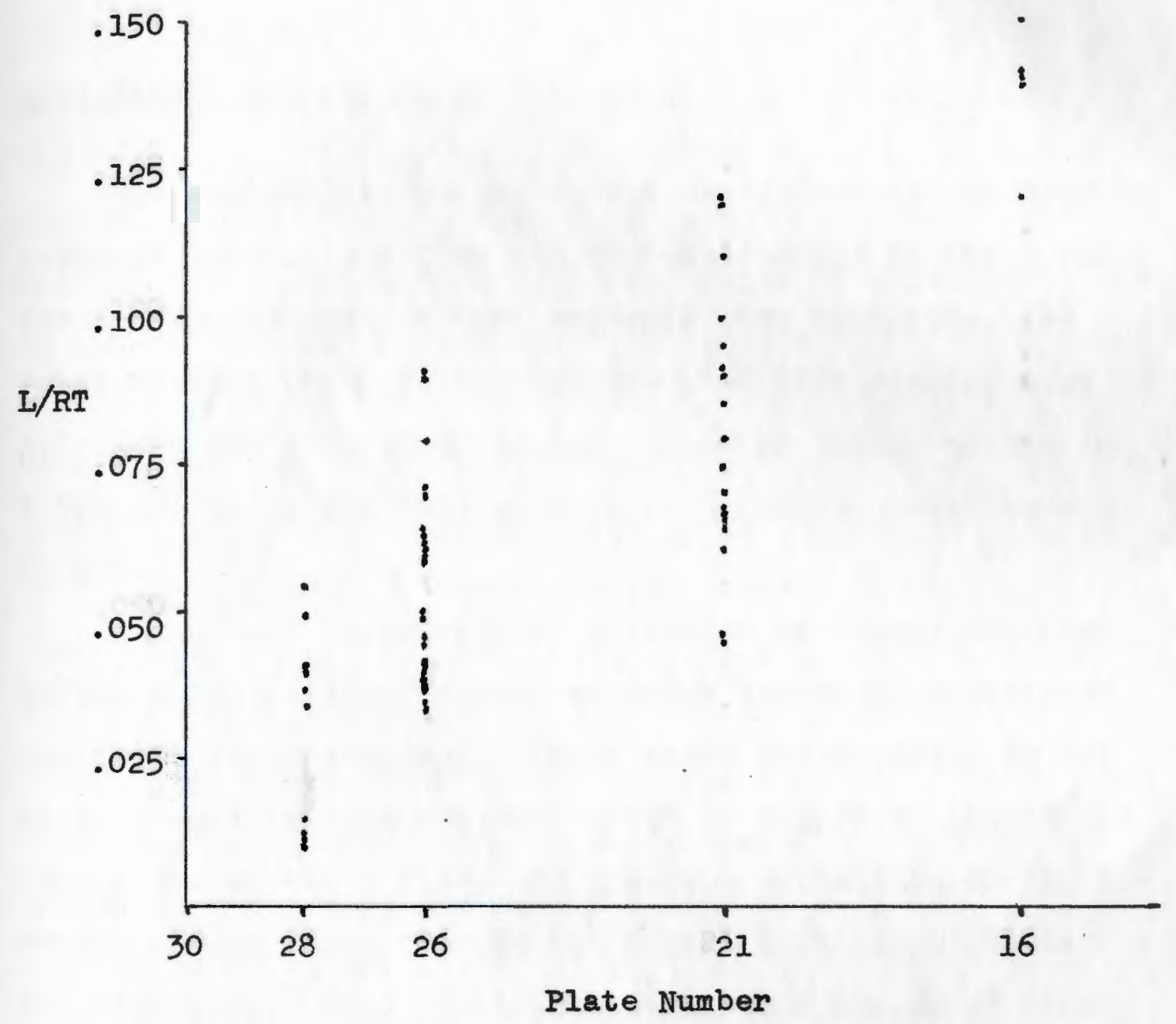

Figure 13 -- Plot of the ratio of delay to total residence time ( L/RT) vergus plate number for liquid rate pulses 


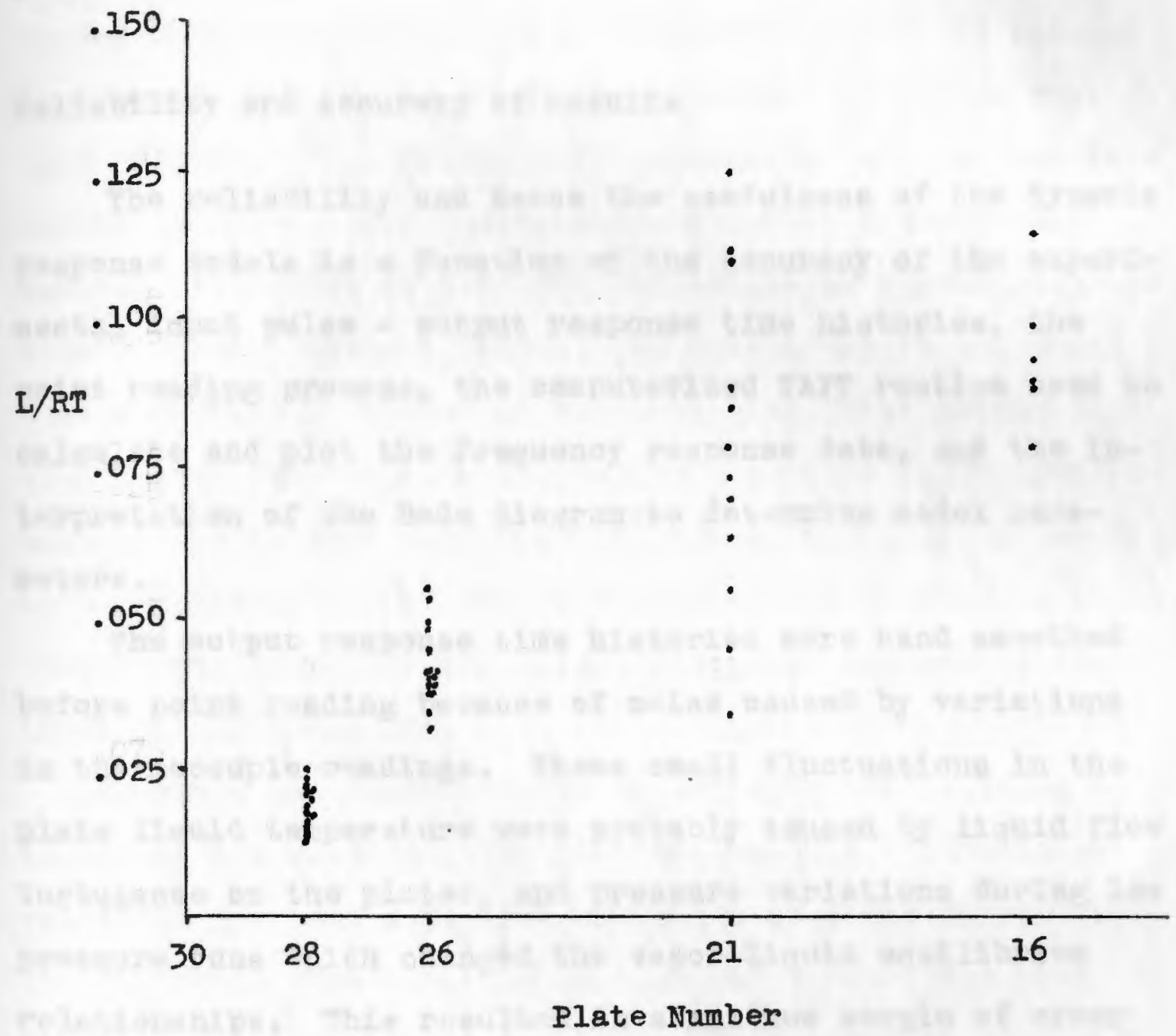

Flgure 14 -- Plot of the rat10 of delay to total residence time ( L/RT) versus plate number for liquid composition pulses 
these resonance peaks. For the response to liquid and vapor rate forcings, A seemed to vary from .15 to .4 with an average of about .3 on all plates. For the liquid concentration responses, A varied from about .05 on plate 28 to .6 on plate 16.

Rellability and Accuracy of Results

The rellablilty and hence the usefulness of the dynamic response models is a function of the accuracy of the experimental input pulse - output response time histories, the point reading process, the computerized TAFT routine used to calculate and plot the frequency response data, and the interpretation of the Bode diagram to determine model parameters.

The output response t1me histories were hand smoothed before point reading because of nolse caused by variations in thermocouple readings. These small fluctuations in the plate liquid temperature were probably caused by liquid flow turbulence on the plates, and pressure variations during low pressure runs which changed the vapor-liquid equilibrium relationships. This resulted in a maximum margin of error In the amplitude of the polnts read of about $\pm .4^{\circ} \mathrm{F}$.

It is often convient to truncate the output pulse responses to facllitate data processing. This is done when the response decays at a very slow rate or does not return to zero, as was often the case when very strong input forcings were used. When this is done, the low frequency part 
of the amplitude ratio curve is flattened while the high frequenoy part is attenuated too sharply. However Drlefke (29) found that moderate truncation (up to 25-50 percent of the time history) had negligible deterimental effect.

It has been shown that calculation of frequency response data numerically, using the TAFT routine, is extremeIy accurate as long as a sufficient number of polnts are used $(22,29,47)$. Hougen (47) recommends at least ten data points to approximate the input pulse while clements and Schnelle (22) feel it is rarely necessary to approximate the output by more than 50 points. In this study it was found that a maximum 5 minutes of response time, with points taken at 8 second intervals, sufficiently described the output response. It is felt that the data processing routine contributes little in the way of errors to the results up to frequencies where the normalized frequenoy content of the input pulse equals .25.

Perhapg the begt estimate of accuracy can be found by examining the reproducibility of the results. Calculated values of $B$ showed a maximum variation of about 15 percent for all runs. The determination of the first order time constant from any single amplitude ratio curre by comparison with standard curves w1ll naturally be subject to the experience and bias of the interpreter. However it is felt that the value determined would be within 10 percent of that of the author's. For the response on one plate, the variation In the values of $\tau$, calculated from the amplitude ratio 
curves, was about 25 percent. The time delays, L, for liquid rate and concentration pulses were taken directly from the pulse response time histories. Variations in these values for a particular plate ranged from 15 percent to 35 percent, with the data belng less consistent on plates farther from the feed plate. It was very difficult to determine values of $A$. As previously mentioned, it is doubtful that frequeney response data extracted from transient pulse data can give very accurate information regarding the amplitude of the resonance peaks. Those values of $\mathrm{A}$ stated can be assumed to have a margin of error of about 50 percent. 


\section{CONCLUSIONS}

1. The pulge technique was shown to be an excellent method of experimentally determining the frequency response of the elght inch pilot Eckey Fractionator to upsets in liquld rate, liquid composition and vapor rate. Using properly executed pulses, this information can be found in a fraction of the time required for direot sinusoidal forcings.

2. The data, plotted on Bode diagram, was analyzed to determine the parameters occurring in dynamic models of the system. Approximate first order behavior on all plates was noted with time delays evident in the responses to liquid rate and composition forcings. Resonance peaks were found in all responses. Good consistency in the calculated model parameters was obtalned, whlle many pulses of different amplitude, duration and shape were used as input forcings. The results appear to be of sufficlent accuracy to be useful in most engineering applications and in the deglgn of feedback control systems.

3. The column operating pressure had no noticeable effect on the model parameters. Varying the pressure, changes only the vapor rate and dengity which would in turn change the vapor holdup and residence time. However, since the vapor holdup is very small relative to the liquid holdup, 
little effect on the column response is expected.

4. It 1s felt that the results of this study can be applied to other Eckey columns of different sizes. Values of time delajs for different liquid rates and column holdups can be estimated from equation (1), page 79. The first order time constants can be considered to be proportional to the total liquid residence time - total liquid holdup divided by liquid flow rate. From the results of this study, the estimate, $\tau=.25(\mathrm{RT})$, for responses to liquid and vapor rate forclngs seems reasonable. For response to liquid composition disturbances, $T$ varied from. $I(R T)$ on plate 28 to $.2(R T)$ on plate 16. Unt1l the resonance effects are more clearly understood there appears to be no simple method of scaling the parameters $A$ and $B$ for other units.

5. Further work can be suggested in several areas: The effect on the column dynamics of (1) using alfferent binary or multicomponent systems, (2) running at high vacuum, (3) uging reboller and reflux setups should be investigated.

Further investigation into the resonance effects using direct sinusoidal forcings or carefully selected pulse would be interesting.

An attempt should be made to mathematically derive and solve a set of modeling equations for the col- 
umn. The validity of these could then be checked using the experimental results.

Additional investigation into the applications and Iimitations of pulse testing for dynamic analysis are needed. This would include study of (1) reliability, (2) accuracy, (3) onset of errors, (4) data processing routines, and (5) input pulse selection based on frequency content. 


\section{BIBLIOGRAPHY}

1. Alkman, A. R. "Frequency Response of a Fractionating Column." I. S. A. Journal, 3 (Oct., 1956), 412.

2. Anderssen, Ashley S, and White, Edward T. "Parameter Estimation by the Transfer Function Method." Chem. Eng. Se1., 25(6), (1970), 1015-21.

3. Anisimov, I. V.; Bodrov, V.I.; and Pokrovski1, V. B. "Method of Determining Transfer Functions for Mult1-Plate Distillation Columns." Teor. Osn. Khim. Tekhnol., 1(6), (1967), 866-75.

4. Archer, D. H., and Rothfus, R. R. "The Dynamic Control of Dist1liation Units and other Mass Transfer Equilpment." Chem. Eng. Prog. Sym. Ser., 36(57), 2.

5. Armstrong, W. D., and Wlikinson, W. L. "An Approximate Method of Predicting Composition Response of a Fractionating Column." Chem. Eng. Sci., 7(1957), 1.

6. Armstrong, W. D., Wilkinson, W. L. "An Invest1gation of the Transient Response of a Distillation Column." Plant and Process Dynamic Characteristics. New York: Academ1c Press, 1957, 56.

7. Armstrong, W. D., and Wlikinson, W. L. "An Investigation of the Transient Response of a Distillation Column, Part II: Experimental Work and Theory." Trans. Inst. Chem. Fng. (London), 35(1957), 352.

8. Armstrong, W. D., and Wood, R. M. "An Introduction to the Theoretical Evaluation of the Frequency Response of a Distillation Column to a Change in Reflux Flow Rate." Trans. Inst. Chem. Eng. (London), 39 (1961), 80.

9. Armstrong, W. D., and Wood, R. M. "The Dynamic Response of a Distillation Column to Changes in the Reflux and Vapor Flow Rates." Trans. Inst. Chem. Bng. (London), 39(1961), 65.

10. Baber, M:; Edwards, L.; Harper, W.; W1tte, M.; and Gerster, J. "Experimental Transient Response of a P1lot Plant Dist1llation Column." Chem. Eng. Pros. Sym. Ser., 136(57), 148-59. 
11. Baber, M. F., and Gerster, J. "Experimental Transient Response of a P1lot Plant Distillation Column, Part II: Response to Liquid and Vapor Rate Perturbat1ons." AIChE Journal, (July, 1962), 407.

12. Bailey, R. V., and Law, V. J. "A Method for the Determination of System Transfer Functions." Chemical Fngineering, (March, 1963), 189-99.

13. Barnes, J., and Gardner, M. F. Transients in Linear Systems. Vol. I: Lumped constant Systems. New York: John Wiley and Sons Inc., 1942.

14. Bird, J. B.; Draffen, J. F.; and Jansen, J. B. "Moblle Data Loggers." Chem. Eng. Prog., 57, (March, 1961).

15. Bracewel1, R. N. The Fourler Transform and 1ts Appl1cations. New York: McGraw-H111, 1965.

16. Brown, G. S., and Campbell, D. P. Principles of Servomechaniams. New York: John Wiley and Sons Inc., 1948.

17. Burman, L. K., and Maddox, R. N. "Dynamic Control of D1stillation Columns." Ind. Eng. Ohem. Proc. Des. Der., 8(4), (1969), 433-38.

18. Ceaglske, N. H. "Transient vs. Frequency Response in Analyzing Chemlcal Process Systems." Chem. Eng. Pros. Symp. Ser., 36(57), 53.

19. Chestnut, H., and Mayer R. W. Serromechanisms and Regulating System Design. New York: John Wlley and Sons Ine., 1951.

20. Churchill, Ruel V. Fourler Series and Boundary Velue Problems. New York: MoGraw-H111 Book Co. Ine., 1941.

21. Clements, C. C.; Harris, T. R.; and Hays, J. R. "The Frequency Domain Evaluation of Mathematical Models for Dynamic systems." AIChE Journal, $(13,2)$, (1967), 374-78.

22. Clements, W. C., and Schnelle, K. B. "Pulse Testing for Dynam1c Analys1s." Ind. Ens. Proc. Des. Dev., 2(2), (1963), 94-102.

23. Cohen, H. C., and Johnson, E. F. "Distributed Parameter Process Dynam1cs." Chem. Eng. Pros. Sym. Ser., $36(57)$, 86-99.

24. Donnegan, J. J., and Huss, C. R. Comparison of Several Methods for obtaining the Time Response of Linear Systems to Either a Unit Impulse of Arbitrary Input 
From Frequency Response Data, NACA Report 1324, Waghington, D. C., 195\%.

25. Donnegan, J.J., and Huss, C. R. Incomplete Time Response to a Unit Impulse and Its Application to Lightly Damped Linear Systems, NACA Technical Note 3897, Washington, D. C., 1956.

26. Donnegan, J. J., and Huss, C. R. Method and Tables for Determining the rime Response to a Unit Impulse from Frequency Response Data and for Determining the Fourler Transform of a Function of Time, NACA Technical Note 3598, Waghington, D. C., 1956.

27. Douglas, J.M., and RItter, A. B. "Frequency Response of Nonllnear Systems." Ind. Eng. Chem. Fund., 9(1), (1970), 21-78.

28. Draper, C.; McKay, W.; and Lees, Sidney. Instrument Englneering, Volume II. New York: MoGraw-Hill Book Company Inc., 1953.

29. Driefke, G. E. "Effects of Pulse Shape and W1dth on Accuracy of Dynamic System Analysis from Experimental Pulse Data." Unpublished D.Sc. Thesis, Washington University, Sever Institute of Technology, 1961.

30. Driefke, G. E.; Grantom, R. L.; and Hougen, J. 0. "Streem Analyser Dynamics." Control Englneering, (July, 1960), 104.

31. Driefke, G. E., and Hougen, J. O. "Experimental Determination of System Dynamics by Pulse Methods" (Proceedings of the Fourth Joint Automatic Control Conference, University of Minnesota, Minneapolis, Minnesota, June 19-21, 1963), 608.

32. Eggleston, J. M., and Mathews, C. W. Application of Several Methods for Determining Transfer Functiong and Frequency Response of Aircraft from Flight Data, NACA Report 1204, Waghington, D. C., 1954.

33. Falrchlld, B. T.; Franke, F. R.; Huckaba, C. E.; and May, F. P. "Experimental Confirmation of a Predictive Model for Dynamic Dist1llation." Chem. Ens. Prog. Sym. Ser., 55(61), 126.

34. Franke, F. R.; Huckaba, C. E.; and May, F. P. " An Analysis of Transient Conditions in Continuous Distillation Operations." Chem. Eng. Prog. Sym. Ser., 46(59), 39.

35. Frlediy, John C. "Use of Transfer Coefficients in 
Dynamic Process Modëls." Chem. Ing. Sc1., 25(1), (1970), 119-29.

36. Gerster, J.A., and Sproul, J. S. "Experimental Translent Response of a Pilot Plant Distillation Column, Part III: Condensing and Reboling Systems." Chem. Eng. Prog. Sym. Ser., 46(59), 21.

37. Gallier, P. W.; Puckett, T. H.; and Sllepcevich, C. M. "Some Practical Ilimitations of Correlation Techniques in Determining Process Frequency Response." Chem. Eng. Prog. Sym. Ser., 36(57), 59.

38. Gerster, J. A.; Luyben, W. L.; and Vernevil, V. S. "Experimental Transient Responge of a Pllot Plant Distillation Column." AIChE Journal, (May, 1964), 357.

39. Gibllaro, L. G., and Lees, F. P. "Reduction of Complex Transfer Function Models to simple Models using the Method of Moments." Chem. Eng. Sc1., 24(1), (1969), 85-93.

40. Gllath, Chaim; Naphtal1, Leonard M.; and Resnick, William. "Transient Response of a Packed Column to Changes in Liquid and Gas Flow Rate." Ind. Ing. Chem. Proc. Des. Der., 8(3), (1969), 324-33.

41. Gilliland, E. R., and Mohr, C. M. "Translent Behavior in Plate-Tower Distiliation." Chem. Fng. Prog. Sym. Ser., 46(59), 33.

42. Grover, S. S., and Pelser, A. M. "Dynamic Simulation of a Distillation Tower." Chem. Eng. Prog., 58, (sept., 1962), 65.

43. Guiliemin, Ernst $\dot{A}$. Theory of Linear Physical Systems. New York: John Wiley and Sons Inc., 1963.

44. Haagensen, A. J. and Lees, F. P. "Frequency Responge of a Plate Gas Absorption Column." Chem. Eng. Sc1., 21(1), (1966), 77-86.

45. Hougen, J. Experiences and Experiments with Process Dynam1cs. Chem. Eng. Prog. Mono. Ser., 4(60), 19-34.

46. Hougen, J. O., and Lees, S. "Pulge Testing a Model Heat Exchanger Process." Ind. Eng. Chem., 48, $(1956), 1064-70$.

47. Hougen, J. O., and Walsh, R. "Pulse Testing Method." Chem. Eng.Prog., 57, (1961), 69-79. 
48. Hoyt, P. R., and stanton, B. D. "Analyzing Process Control Syatems." Petroleum Refiner, (October, 1953), 115.

49. Hoerner, G. M., and Schiesser, W. M. "Simultaneous Optimization and Transient Response Evaluation of Packed Tower Absorption." Chem. Eng. Prog. Brm. Ser., 61(55), (1965), 115-25.

50. Jeffreson, C. P. "Dynamics of Packed Beds with Interphase Heat or Mass Transfer." Chem. Eng. So1., 24(30), (1969), 613-14.

51. Jeffreson, C. P. "Dynamic Testing - A Unification." Chem. Eng. So1., 25(8), (1970), 1319-29.

52. Johnson, E. F. Automat10 Process Control. New York: MeGrew-Hill Book Co., 1967.

53. Koppel, Lowell B. "Optimum Control of a Class of Distributed Parameter Processes." Ind. Eng. Chem. Fund., 6(2), (1967), 299-303.

54. Koppel, L. B.; Shin, Yen-Ping; and Couganowr, D. R. "Optimal Feedback Control of a Class of Distributed Parameter Systems with space-Independent Controls." Ind. Fng. Chem. Fund., 7(2), (1968), 286-95.

55. Kropholler, Hendrikus W. "Determination of Relative Variance and Other Moments for Generalized Flow Networks or System Transfer Functions." Ind. Eng. Chem. Fund., 9(3), (1970), 329-33.

56. Kuemmel, M. "Analog Simulation and Control of a Distributed Parameter System." Chem. Eng. Sc1., 24 (7), (1969), 1055-62.

57. Lamb, D. E.; P1gford, R. L.; and Rippin, D. W. "Dynamic Characteristics and Analogue simulation of Distillation Columns." Chem. Ens. Prog. S7m. Ser., 36(57), 132-47.

58. Lees, S. "Interpreting Dynamic Measurements of Phys1 cal Systems." American Soc1ety of Mechanical Engineers' Transactions, LXXX (1958), 833.

59. Lim, Henry C. Mrime Optimal Control of a Class of Linear D1stributed Parameter Processes." Ind. Eng. Chem. Fund., 8(4), (1969), 758-66.

60. Lin, Keh Kuang. "Discharge Coefficients of Control Valves." Unpublished M.S. Thesis, University of Rhode Island. 
61. Luyben, W. L., and Shunta, J. P. "Comparison of Stepping and General Complex Matrix Inversion Techniques in Calculating the Frequency Response of Binary Distillation Columns." Ind. Eng. Chem. Fund., 8(4), (1969), 838-40.

62. Marino, P. A.; Perna, A.; and Stutzman, L. "Sinuso1dal and Pulse Response of a Plate D1stillation Column by Reflux Upset." AIChE Journal, (Nov., 1968), 866.

63. Marino, P.A., and Stutzman, L. "Distillation Column Dynamics with the Use of the Pulse Technique." AIChE Journal, (12, 1966), 603-4.

64. MoDaniel, Ronald, and Holland, Charles D. "Modeling of Packed Absorbers at Unsteady State Operation." Chem. Eng. Se1., 25(8), (1970), 1283-96.

65. Moczek, J. S.; Otto, R. E.; and Will1ams, T. J. "Approximate Models for the Dynam1c Response of Large D1stillat1on Columns." Chem. Bng. Prog. Srm. Ser., 55(61), (1965), 136.

66. Moskowttz, Sidney, and Racker, Joseph. Pulse Technlques. New York: Prent1ce Hall, Inc., 1951.

67. Paynter, J. D.; Dranoff, J.s.; and Bankoff, S. G. "Application of a Suboptimal Design Method to a D1stributed Parameter Reactor Problom." Ind. Ing. Chem. Proc. Des. Der., 9(2), 1970, 303-9.

68. Pell, T. M. "Response of a Plate Dist1llation Column to Perlodic Varlations in the Feed stream." Unpublished M.S. Thesis, University of Florida,1964.

69. Pohjola, V. J., and Norden, H. V. "Process Dynamics of Binary Dist1llation." Chem. Eng. S01., 24(11), (1969), 1687-98.

70. Rosenbrock, H. H. "An Invest1gation of the Transient Response of a Distillation Column, Part I: Solution of the Equations." Transactions of the Institution of Chemicel mingineers (London). 35 , $(1957), 347$.

71. Rosenbrock, H. H. "D1stinctive Problems of Process Control." Chem. Ens. Prog., 58, (Sept., 1962), 43.

72. Sallaly, M., and Reynier, J. P. "D1spersed Phase DYnamics in Packed Column for Concurrent ItquidLiquid Down-Flow." Chem. Ens. Se1., 25(11), (1970), 1709-17. 
73. Samuels, H.; Ansell, L. S.; and Frishe, W. C. "Enthalpy - Concentration Chart for Methanol Water Solutions." Chem. Eng., 58, (April, 1957), 133.

74. Sauter, W. A., and Ward, T.J. "Use of Time Delays in Packed Gas Absorption Column Simulation." AIChE Journal, 13(6), (1967), 1211-13.

75. Sealy, C. J. "Introduction to Linear Control Theory." Brit. Chem. Bng., 14(8), (1969), 1063-69.

76. Selnfeld, John H. "Nonlinear Estimation Theory." Ind. Eng. Chem., 62(1), (1970), 32-42.

77. Shu, L. W.; Chu, J. C.; Sherman, L. L.; and Rajenore, P. Vapor - Ilquid Equilibrium Data. Michigan: J. W. Edwards Publisher Inc.

78. Smith, G. A., and Triplett, W.C. "Experimental Flight Methods for Evaluating Frequency Response Characteristics of Alroraft." Amerlcan Society of Mechanicel Engineers' Transctions, LXXVI (1954), 1383.

79. Tommas1, Giul1o, and Rice, Ph1lip. "Dynamics of Packed Tower Distillation." Ind. Eng. Chem. Proc. Des. Dev., $9(2),(1970), 234-43$.

80. Voetter, H. "Response of Concentrations in a Dist11lation Column to Disturbances in the Feed Composition." Plant and Process Dynamic Character1st1cs, New York: Acsdemic Pres8, 1957, 73.

81. Wah1, Edward F., and Harriot, Peter. "Understanding and Predicting the Dynamic Behavior of Distillation Columns." Ind. Eng. Chem. Proc. Des. Dev., 9(3), (1970), 396-407.

82. W1ll1ams, John A.; Adler, R. J.; and Zolner, William. "Parameter Est1mation of Unsteady State Distributed Models in the LaPlace Domain." Ind. Eng. Chem. Fund., 9(2), (1970), 193-7.

83. Williams, T. J. "The Status of the Dynamics of Mass Transfer Operations - A Review and Commentary." Chem. Ing. Prog. Sym. Ser., 46(59), (1963), 1 .

84. Wood, R. M. "Frequency Response of Mult1component Distillation Columns." Trans. Inst. Chem. Ing., (London), 45(5), 190-195. 
APPENDIX A

Equipment

Speciflcations 


\section{Equipment Specifications}

1. Eckey Pllot Horlzontal Fractionator, 8 foot length, 8 inch diameter, 32 stages, stainless steel, Vulcan Manufacturing Company, serial \#10542.

2. Foxboro Pneumatic Control Valve, \#238485, 3/8 inch needle valve, reversible motor.

3. Foxboro $1 / 2$ inch turbine flow transmitter, model $1 / 2-$ 2-81F5 $5 \mathrm{Cl}, 0-.5 \mathrm{gpm}$.

4. Number 100 mesh wire screen f1lter.

5. Foxboro Frequency to DC Converter, model FR-305-5-2, Input: $10-2700 \mathrm{HZ}$, Output: 0-5 volts DC.

6. Schutte and Hoerting Rotometer, serial \#63-01-627-M, $0-.575 \mathrm{gpm} ., 0-250 \mathrm{~mm}$.

7. Sohutte and Koert1ng Rotometer, ser1al \#53-9-204-T, $0-.5 \mathrm{gpm} ., 0-250 \mathrm{~mm}$.

8. Automatic switch Company, 3-way solenold valve, model \#8320All, serlal \#682935.

9. Danlel $1 / 2$ inch, \#300, ralsed face threaded ortfles rlange, model \#30-RT. Critical Flow Oriflce Plates:

Plate l: $0-85 \mathrm{psia}, 0-85 \mathrm{lb} / \mathrm{hr}$ steam

Plate 2: $0-85 \mathrm{psia}, 0-140 \mathrm{lb} / \mathrm{hr}$ steam

10. Foxboro Electronlc Pressure Transmitter, model \#6-11-GM, ser1al \#1435208, Input 0-100 ps18, Output 10-50 ma.

11. Foxboro Power Supply, part \#NI21AT, Output: 65 volts DC at 70 ma.

12. Foxboro Pneumatic Control Valve, \#2944093, 1/4 inch needle valve, reversible motor.

13. Masonellan Steam Pressure Reducing Valve, model \#17-1, serial \#279, 25-125 ps1.

14. Stainless steel, $1-1$ shell and tube condenser, $47 \mathrm{sq}$. It. Perry Products Company. 
15. N.C.R. Rotary Gas Ballast Pump, type 15-D, serial \#1402.

16. Honeywell Electronik 19 Mult1range Lab/Test W1de Chart Recorder, model \#194 112-002-002-001-01, serlal \#I8245974001.

17. Honeywell Electronlk 19 Multirange Lab/Test Narrow Chart Recorder, model\# 19302-11-01, serial \#E6757710001.

18. Everedy Min1-Max 300 volt battery, no.493.

19. Hewlett-Packard Low Frequency Function Generator, model 202A, range .008-1,200 $\mathrm{Hz}, 0-30$ volts.

20. Hewlett-Packard Harrison 6204B DC Power Supply, 0-40 volts, .3amps.

21. F1sher Electro-Pneumat1c Transducer, serial \#4362320, Input: 1-9 volts DC, Output: $3-15$ psig., F1sher Governor Company.

22. Pulse Act1vator, circut constructed as per HewlettPackard Application Note 31: Externaliy Driving the 202A Low Frequency Function Generator. 


\section{APPENDIX B}

Computer

Program 
Computer Program

This Appendix contalns the computer program used to calculate frequency response information from pulsed 1nput and output response time historles, and a general flow diagram of the logic 1nvolved. The values of the pulse forcling, sampling interval and number of data points were input to the program together with values for the response, response sampling interval and number of data points. Frequeney values at whlch the frequency response was calculated were also specifled. At a particular frequency, the program ut1lized the TAFT routine to calculate the Fourler transforms of the Input pulse and output response. The output transform was then divided by the input transform to give the real and Imaginary parts of the frequency response. The magnitude and phase angle of this complex number was then found and the magnitude was normalized by the magnitude at zero frequency. The program printed out the frequency specified, the real and 1maginary parts of the Fourler transforms of the input pulse and system response, the real and Imaginary parts of the frequeney response, and the normalized ampl1tude and phase angle.

Important nomenclature is shown below.

NP - number of pulse data points

DTI - sampling interral of pulse forclng 


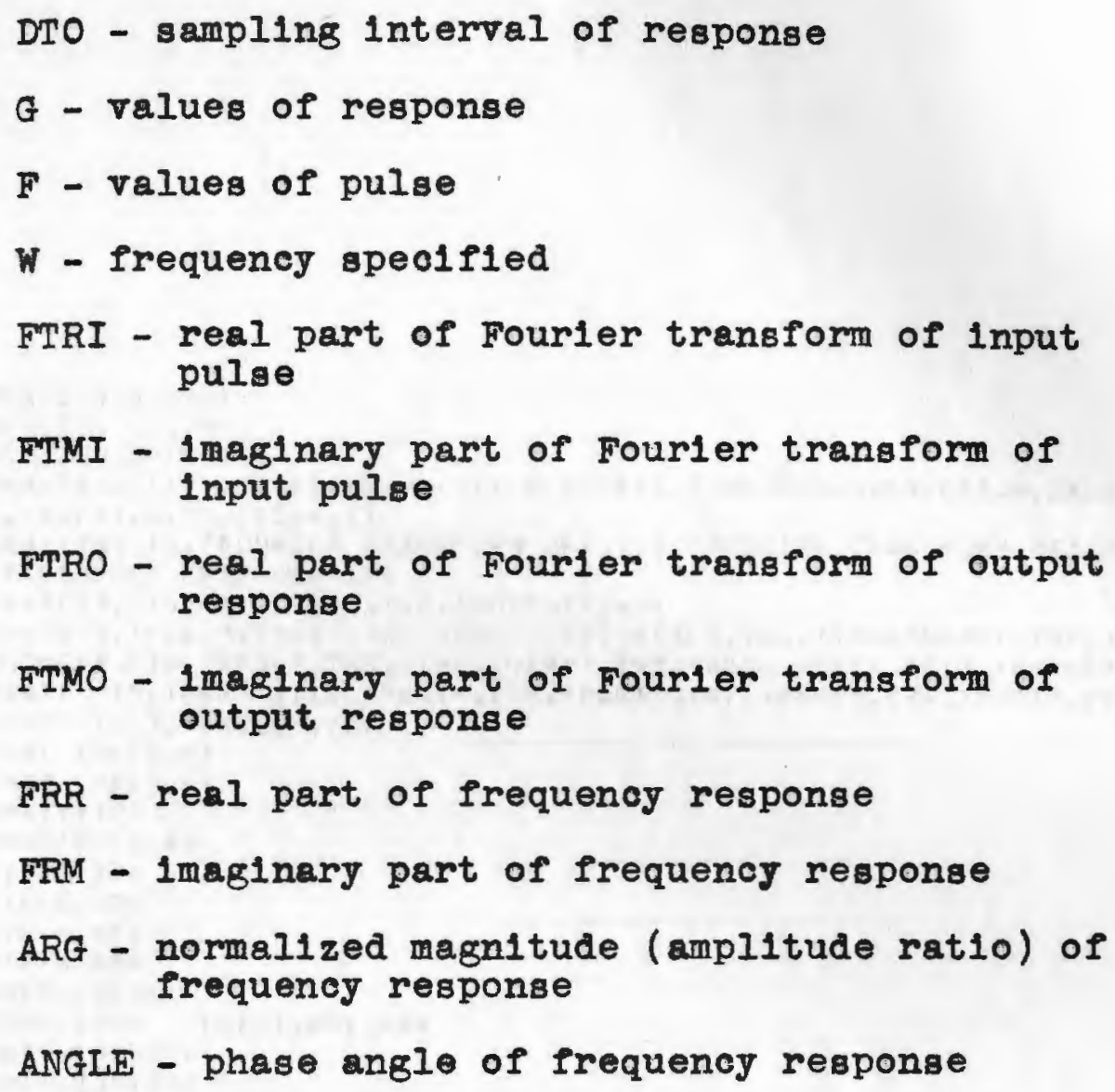


DIMENSITN WIIOOI

DIMENS: JN $\mathrm{F}(1,00)$

DIMENSIJN G(IOD)

1 FORMATI $1 X, E 11,4,2 X, E 11,4,4 X, E 11,4,2 X, E 11,4,4 X, E 11,4,2 X, E 11,4,2 X, E 1$ $11.4,2 X, E 11,4,2 X, E 11,4,11$

20 FORMATIIHI,T3, 'FUURIEK TRANSFORM OF', T31, 'FOURIER TRANSFORM OF', TR 10 , 'FREQUENCY PESP'JNSE 1,11

30 FORMATIT7, 'INPUT PULSE', T38, 'OUTPUT', $/ 11$

40 FJRMAT TT5, 'REAL', T16, ' IMAGINARY',T33, 'REAL, T44, 'I MAGINARY', T59, 'F IREQUENCY', T74, 'REAL', T85,'IMAGINARY', T98, 'ARGUFMENT', TI13, 'PHASE'I 50 FJRMATI T5, 'PART',T18, 'PART',T33, 'PART',T47, 'PART',T74, 'PART', T 87 1.'PART', T113,'ANGLE',//1

100 FORMAT $(5 E 15.4)$

110 FORMAT (5E 15.4)

120 FORMAT( 110$)$

130 FORMAT ( TE 15.4$)$

WRITE $(6,20)$

WRITE $(6,30)$

WRITE $(5,40)$

ARITE $(6.50)$

READ $(5,120) K K$

READ $(5,100) \quad(W(K), K=1, K K)$

READ $(5,13$ C) I I

READ $(5,130) D T O$

READ $(5,120) N P$

READ $(5,11 C) \quad(F(I), I=1, N P)$

READ (5, 120)MP

READ $(5,110) \quad(G(I), I=1, M P)$

$N I=N P-I$

$M I=M P-I$

$A 1=0.0$

DO $700 \mathrm{~K}=1, \mathrm{KK}$

SD21 $=((S I N I W(K)+D T I / 2)) /.(W(K) * D T I / 2)) *$.

$S S I=S I N(W(K) \neq(N I * D T I+A I))$

$\operatorname{CSI}=\operatorname{COS}(W(K) *(N I * D T I+A I))$

SDI $=(S I N(W(K) * D T I)) / N(K) * D T I)$

CALCULATE REAL PART OF INPUT FOURIER TRANSFORM

SUM $=$ ก. 0

D() $380 \quad I=2, \mathrm{NI}$

DSUiA $=F(I) * \operatorname{COS}(h(K) *(1 I-1) * D T I+A 1)$

SUM $=$ SUM + DSUM

390 CONTINUE

390 FIRI $=D I T * F(1) *(S D 2 I *(\operatorname{COS}(W(K) * A 1)) / 2 .-11 .-50 I) /(W(K) * D T I) *$

ISIN(N(K) $\# A 1)]$

$5+D I I \leqslant S D ? I * S, J M$

$3+D T I * F(V P) *(S D 2 I / 2 * C S I+(1 .-S D I) / W(K) * D T I) * S S I)$ 
CALCULATE I HAGINARY PART OF INPUT FOURIER TRANSFORM SU.Y $=0.0$

DO $490 \quad I=2, N I$

DSU.M $=F(I) *(-S I N(W(K) *((I-1) * D T I+A I))$

SUY $=$ SU:1 + DSU:A

480 CONTINUT

490 FTMI $=D T I * F(1) * \quad$ (SD2I/2, *SIN(W(K)*A1)-(1,-SDI)/(WIK)*DTI)*

$1 \operatorname{COS}(n(K) \div A 1) !$

$2+U T I * 502 I * S U M+$

$3 D T I * F(N P) *(-S D 21 / 2 * S S I+(1 .-S D I) /(W(K) \neq D T I) \neq C S I)$

$S D 20=(1 S I N(W(K) * 0 T 0 / 2)) /.(W(K) * D T O / 2)) *$.

SSO = SIN $=\operatorname{CWIK)*(MI*0TO+AII)}$

CSO $=\operatorname{COS}(W(K) *(M) * 0 T O+A 1))$

SDO $=$ (SIN(W(K)*DTO) )/ *A(K)*DTO)

CALCULATE REAL PART OF OUTPUT FOURIER TRANSFORM

SU.Y $=0.0$

DO $580 \quad I=2, M I$

DSUM =G(I)*COS $(W(K) *(1-1) * D T O+\Delta I))$

SUM $=$ SUM + DSUM

580 CONTINUE

590 FTRO=OTO*O(1)* $($ SD20*(COS $(W(K) * A 1)) / 2 .-(1 .-S D C) /(W(K) * D T O) *$

$1 \operatorname{SIN}(W(K) * A I))$

$2+U T O * S D 20 *$ SUIT

$3+D T D * G(M P) *(S O 20 / 2 . * S O+(1 .-S D O) /(W(K) * 0 T O) \neq S S O)$

CALCULATE IMAGINARY PART OF OUTPUT FOURIER TRANSFORM

SUM $=0.0$

DO $6.80 \quad I=2, M I$

DSUM $=G(1) * 1-S I N(W(K) *(\mid I-1) * 0 T 0 * A 1) 1)$

SUM $=$ SUPA+DSUM

680 CONTINUE

$690 \mathrm{FTMO}=0 \mathrm{TD} * \mathrm{G}(1) * \quad(5020 / 2$ * SIN(W(K)*AI)-(1.-SDOI/ $(W(K) * 0 T 0) *$

$1 \operatorname{Cos}(w(K) \neq A 1))$

$5+0 T 0 * S D ? 0 * 5 U M+$

3DTO*G(MP)* $(-S 020 / 2 *$ *SSO+(1.-SDO)/(W $(K) * D T O) * C S O)$

$F R R=(F T R I * F T R \cap+F T M I * F T M O) /(F T R I * 2+F T M I * 2)$

$F R M=(F T R I * F T M O-F T M I * F T R O) /(F T R I * 2+F T$ I I *2)

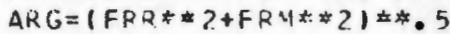

$\triangle N G L E=A T A N(F R M / F R R)$

WRIIE $(6,1)$ FTR I, F TMI, FTR[],FIIN,W(K),FRR, FRM, ARG, ANGLE

700 CONTINUE

WRITE $(6,100)(W(K), K=1, K K)$

WRITE(G,IICI (F(I),I =1, NP)

WRITF $(0,11 C)(G(I), I=1,4 P)$

CALL EXIT

END 
Flow sheet of computer program $\log 10$ for calculation of frequency response from pulse input and output response data

Read In input pulse and output response data, sampling interval, and number of sampling points for each.

Specify range of frequencles, $\omega$, at which it is desired to calculate frequency response and let $\omega=\omega$ initial.

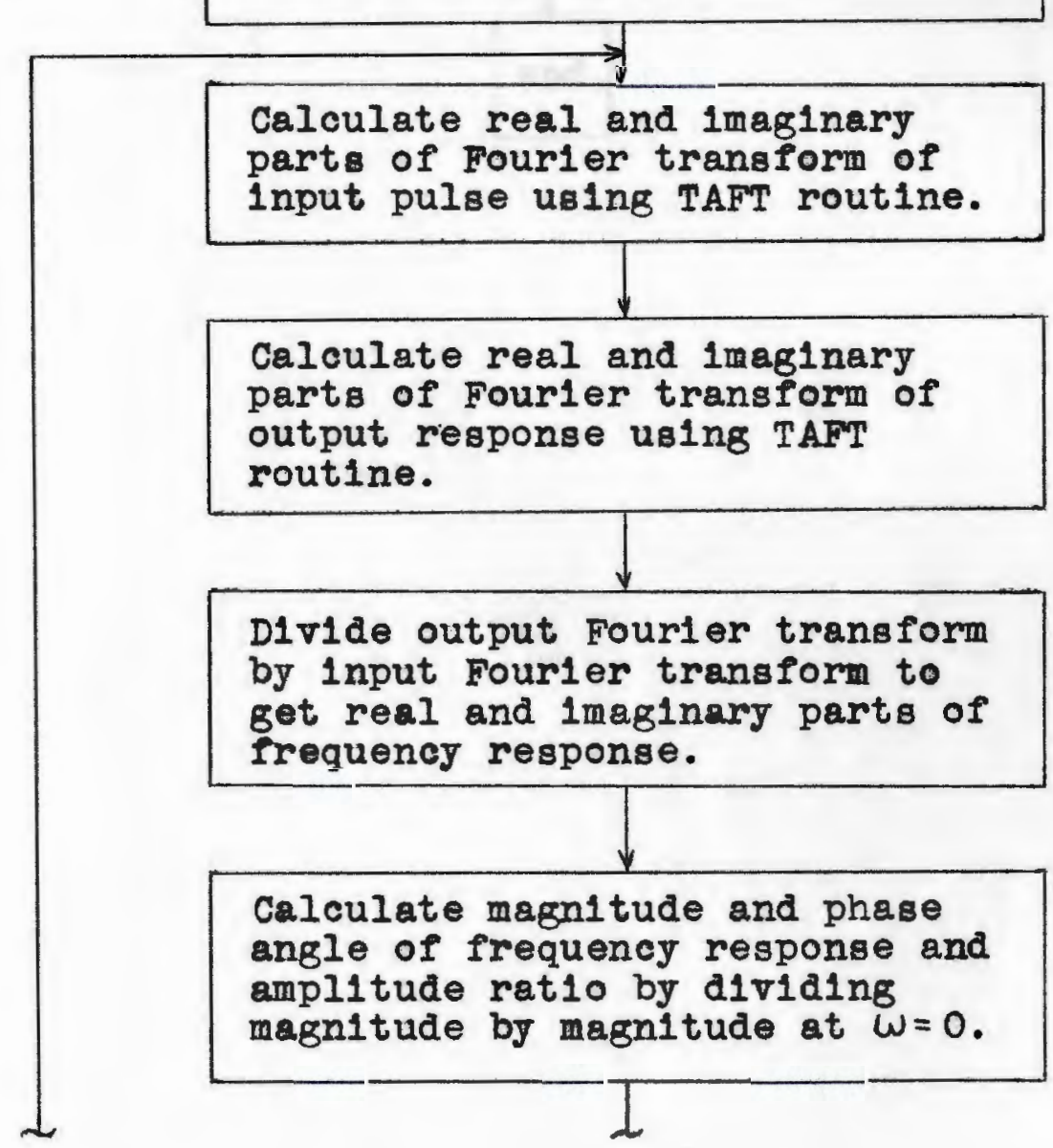




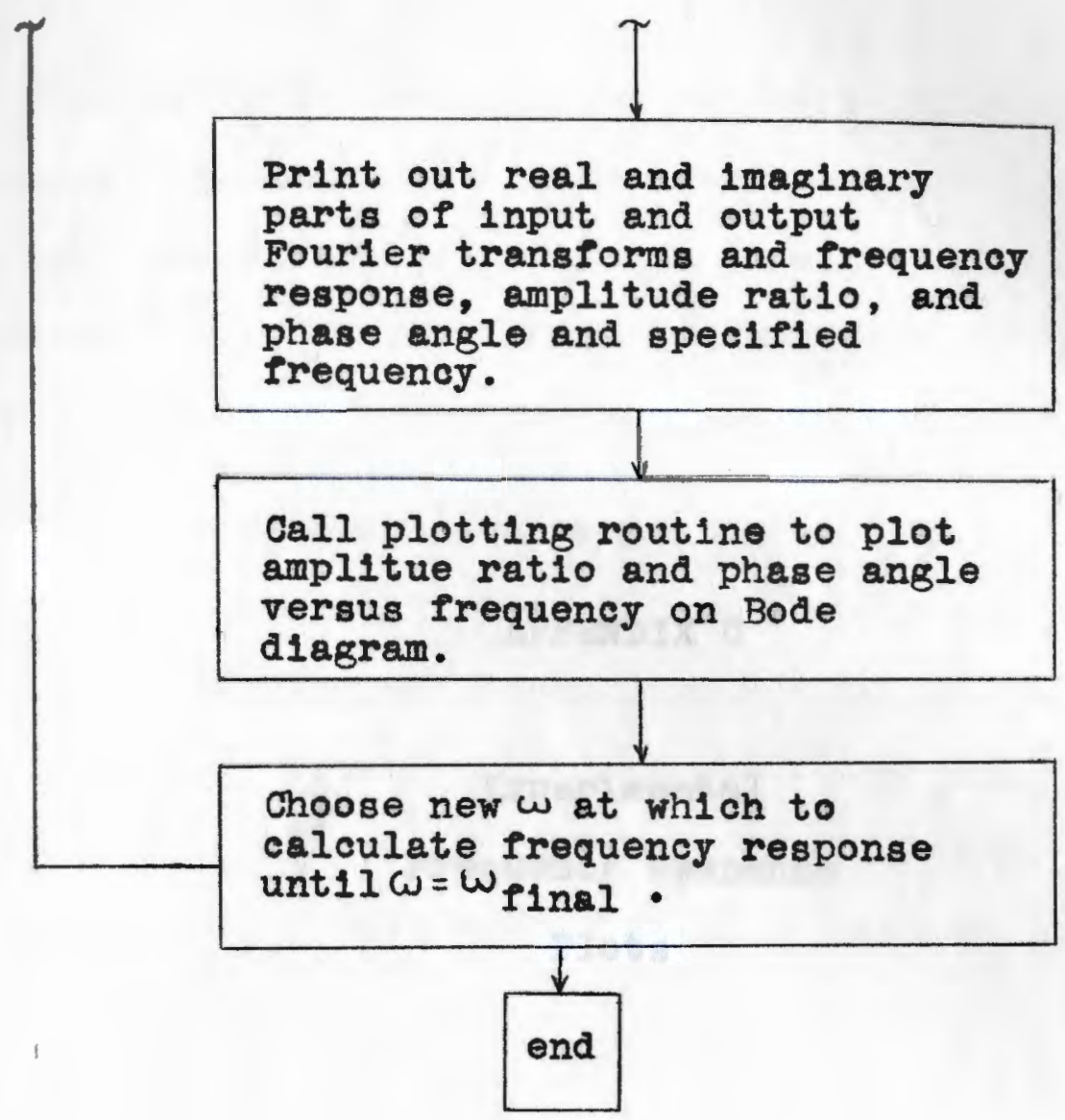


APPENDIX C

Experimental

Frequency Response

Plots 
This Appendix contalns the experimentally determined frequency response plots (Bode dlagrams) calculated from the input pulse - output response data by means of the computerized TAFT routine. It is divided into six sections according to input pulse forcing and column pressure:

Vapor rate responses - 1.0 atm.

Ilquid rate responses - 1.0 atm.

Liquid concentration responses - 1.0 atm.

Vapor rate responses - .26 atm.

Liquid rate responses - .24 atm.

Liquid concentration responses - .26 atm. 
Bode Plots

Vapor Rate Responses

Column Pressure - $1.0 \mathrm{~atm}$. 


\section{BODE PLOT}

VAPOR PULSE 1 AT COLUMN PRESSURE OF 1.000 ATM.

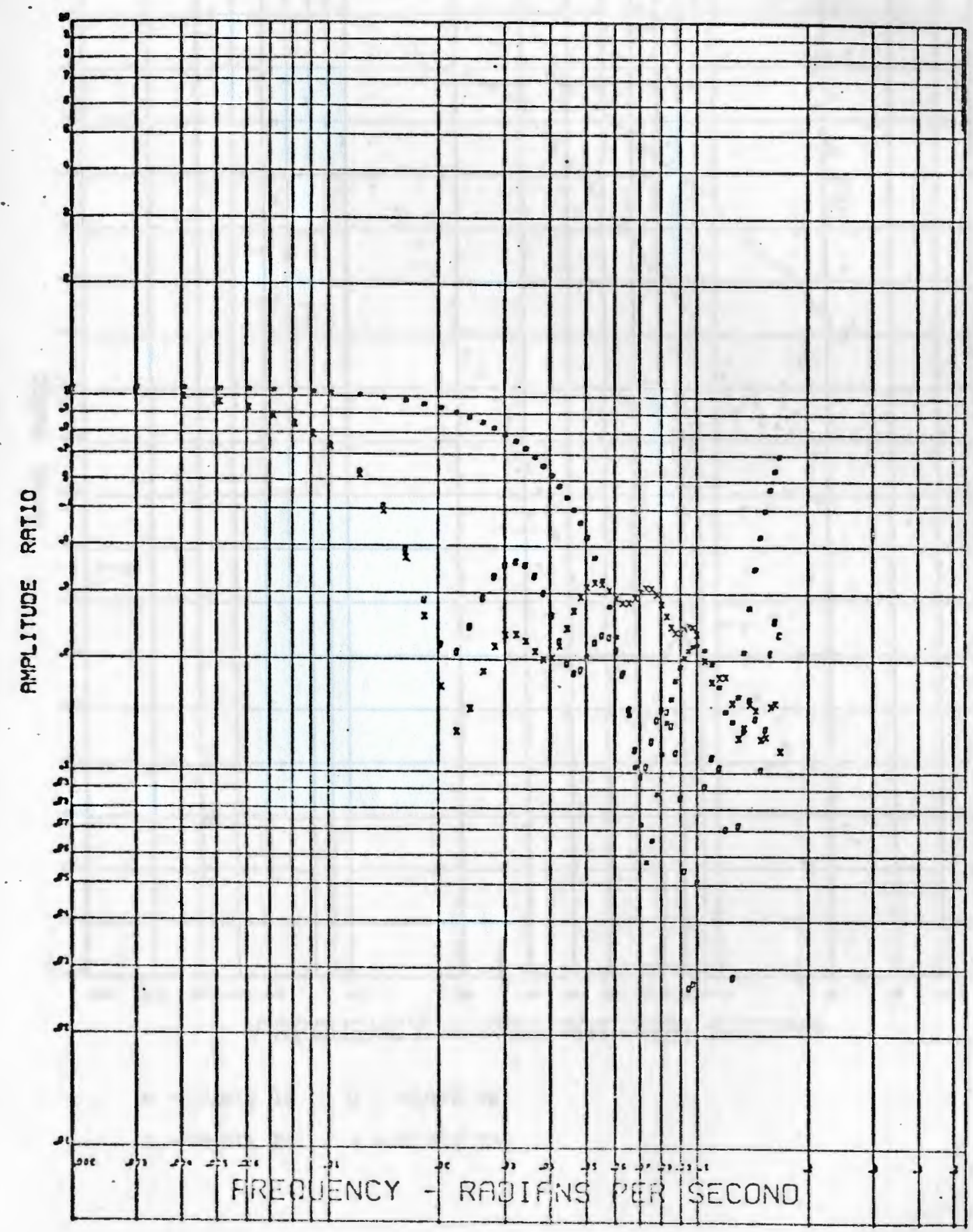


5

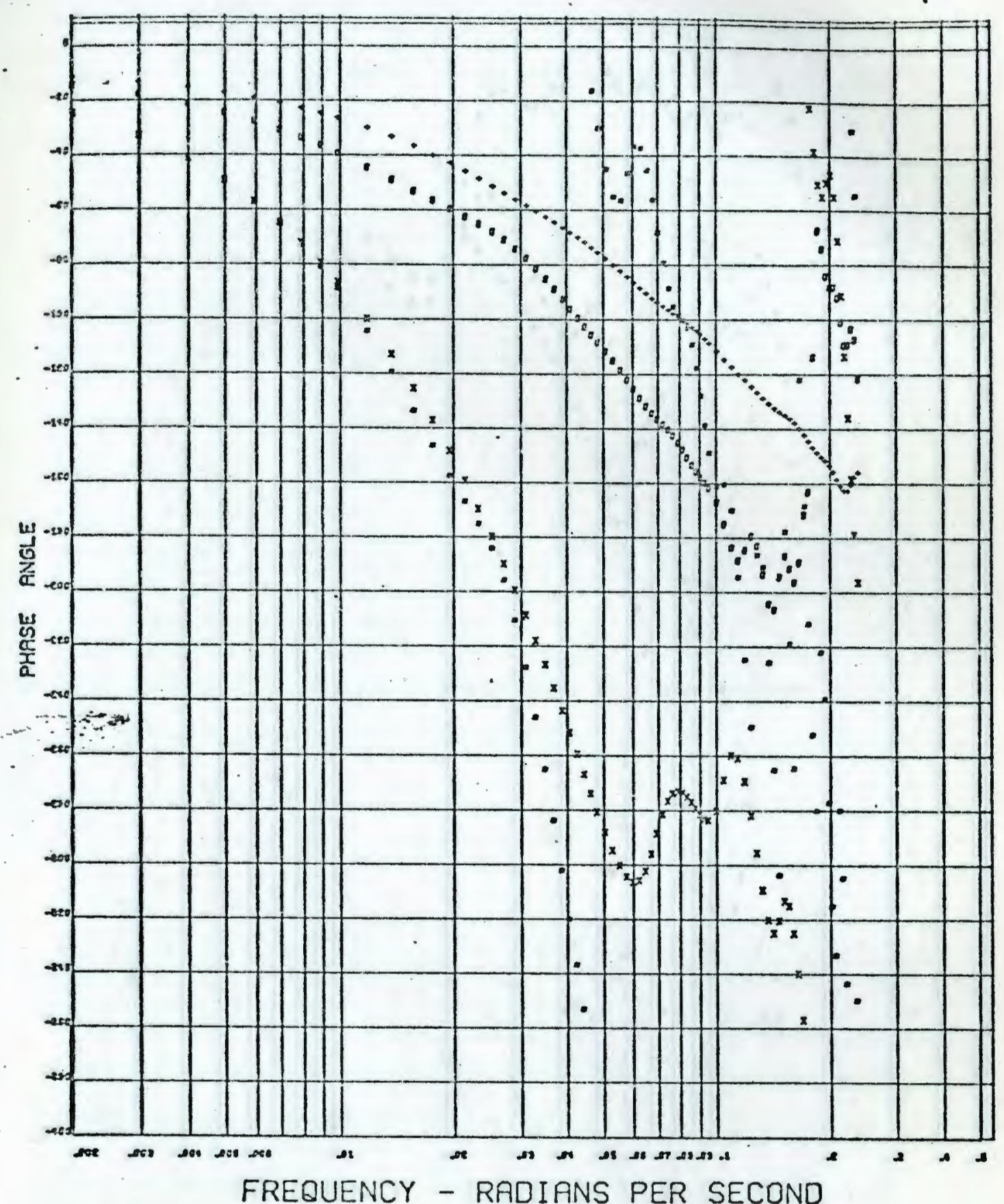

* - plate 16 o - plate 26

X-plate 21. + - plate 28 


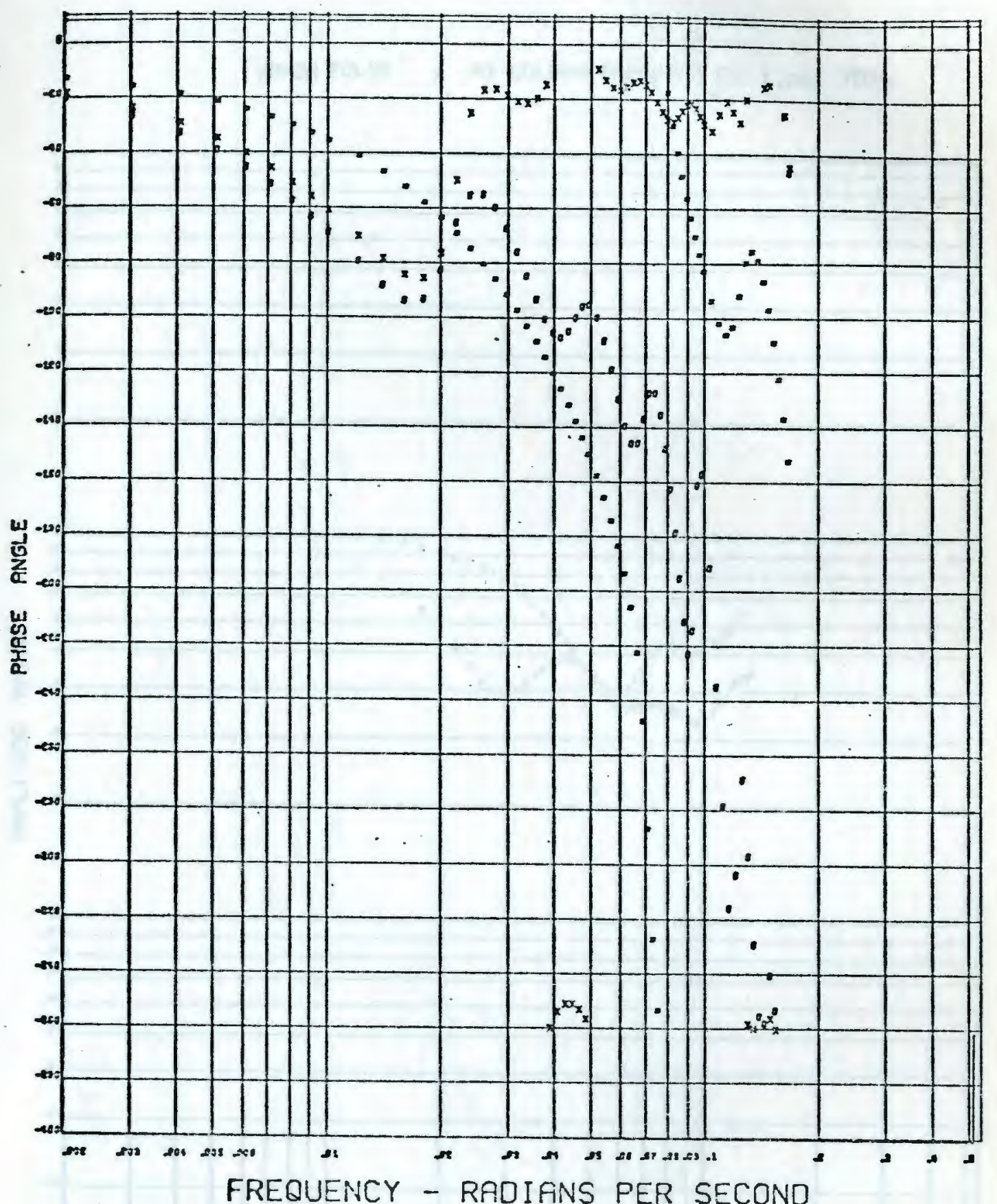

- plate is. o- plate 26

$x$ - PLATE 21. * PLATE 28 


\section{BODE PLOT}

VAPOR PULSE 2 AT COLUMN PRESSURE OF 1.000 ATM.

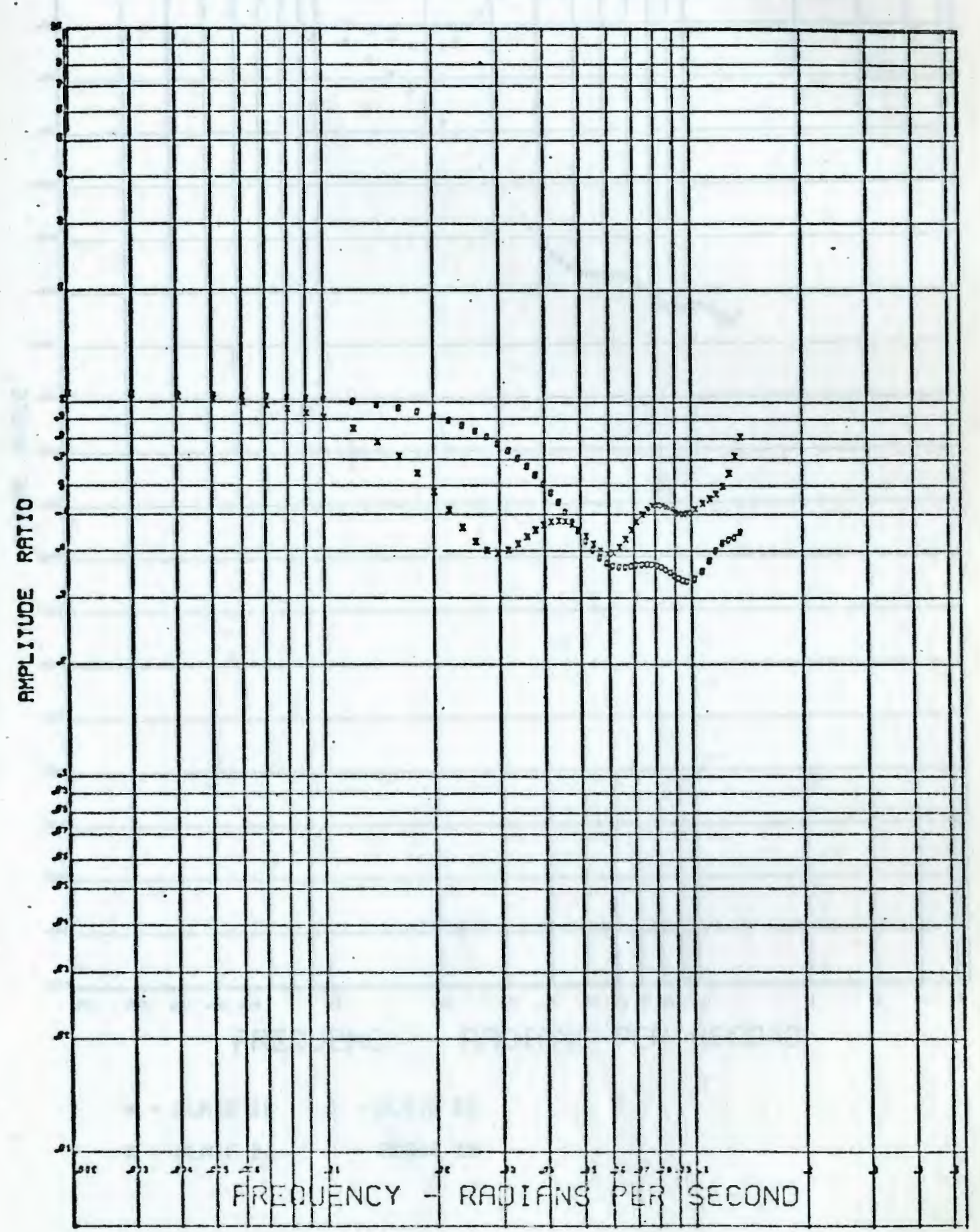




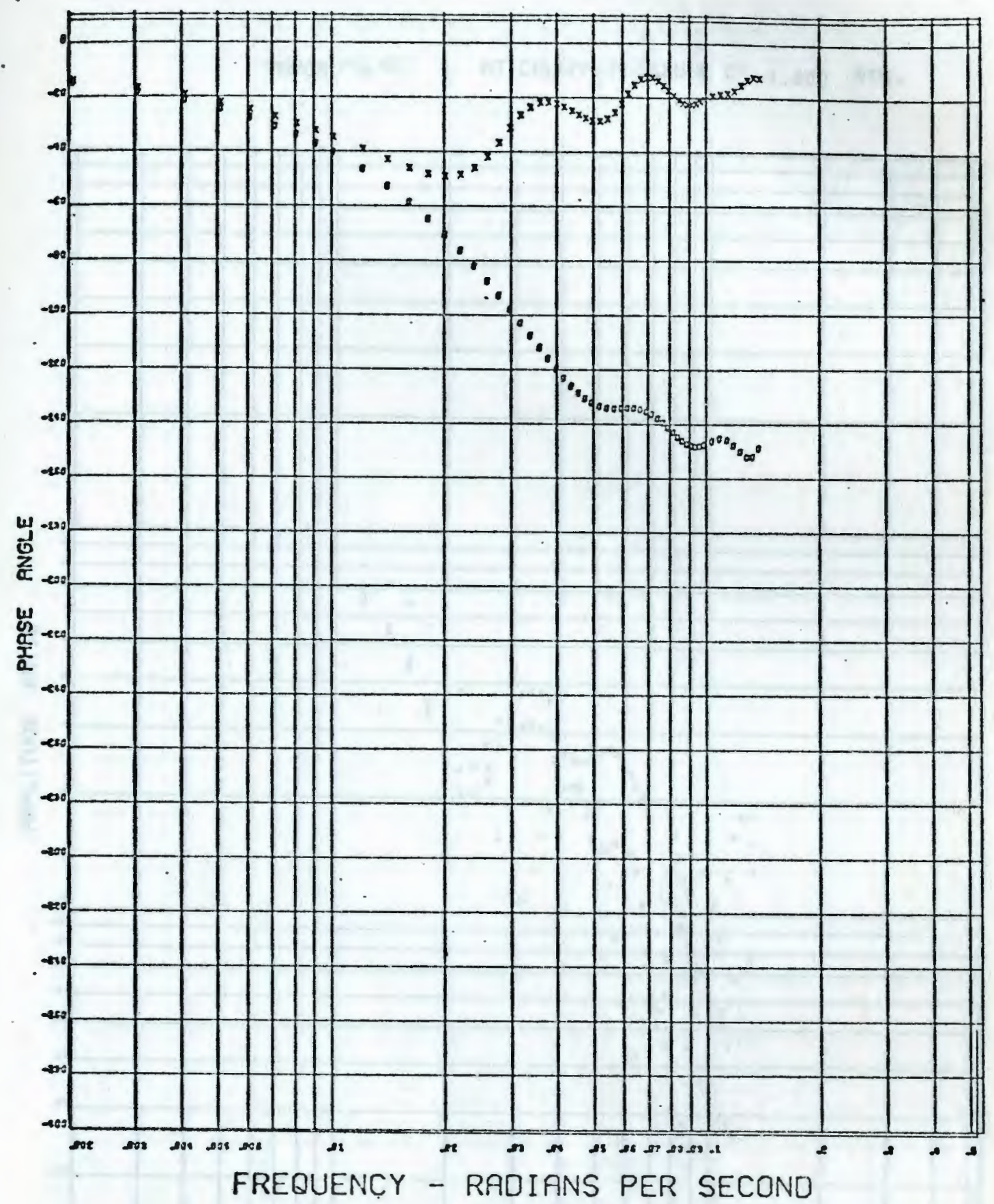

- plate 16 0 - plate 26

$x$ - PLATE 21 + PLATE 28 


\section{BODE PLOT}

VAPOR PULSE 3 AT COLUMN PRESSURE OF 1.000 ATM.

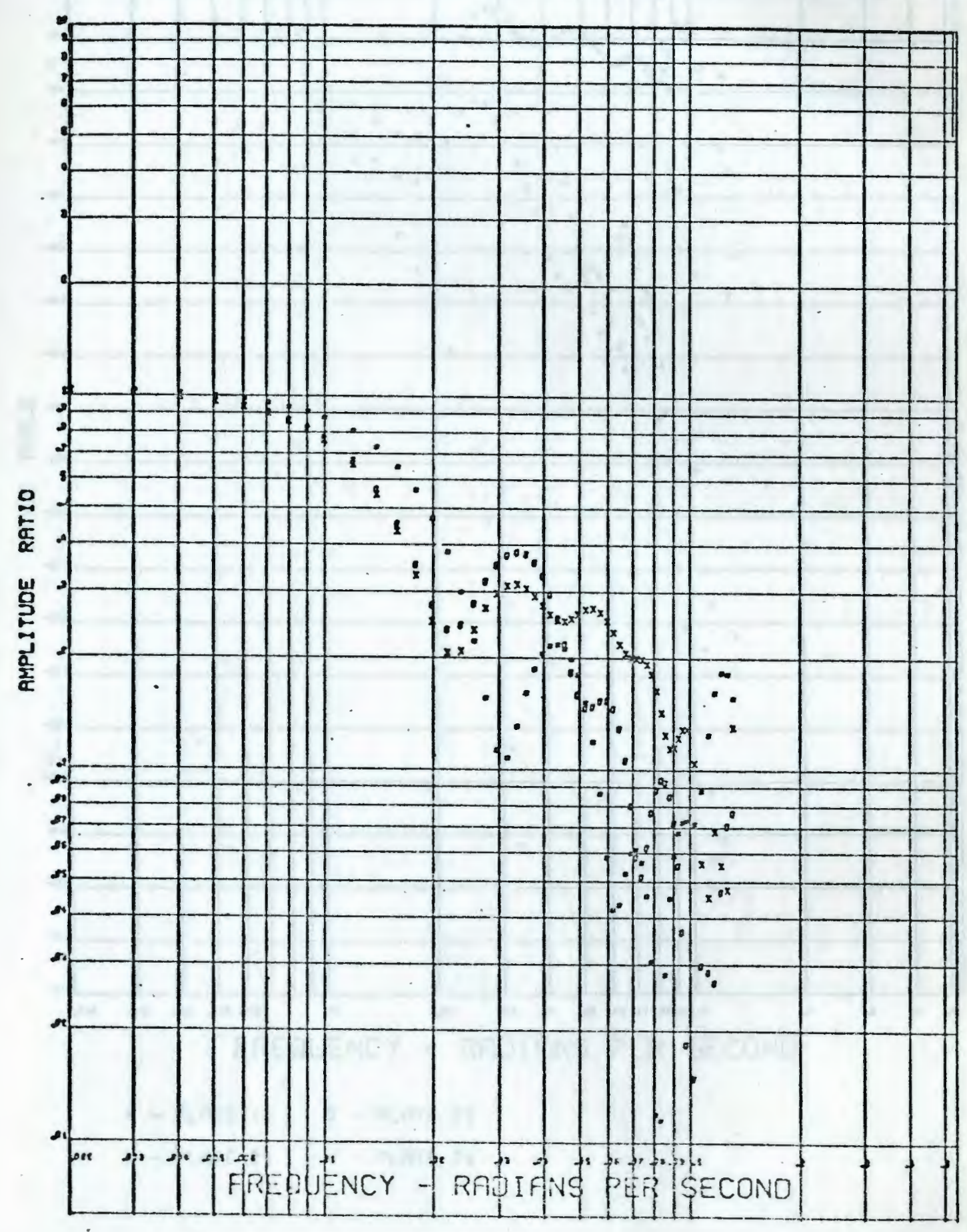




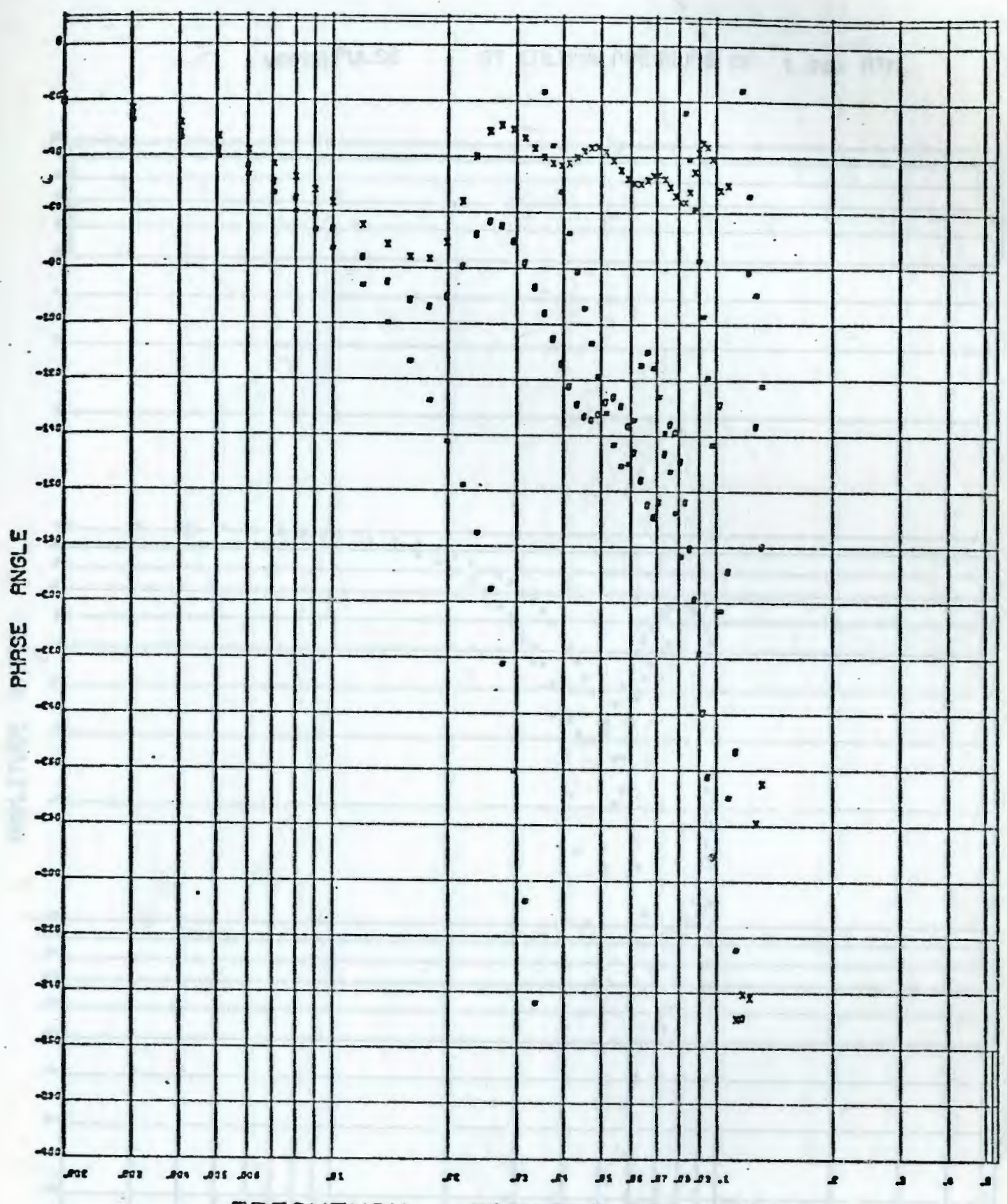

FREQUENCY - RADIANS PER SECOND

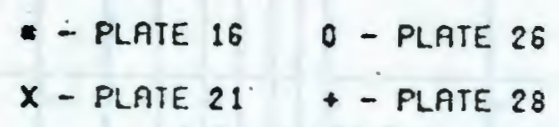




\section{BODE PLOT}

VAPORPULSE 4 AT COLUMN PRESSURE OF 1.000 ATM.

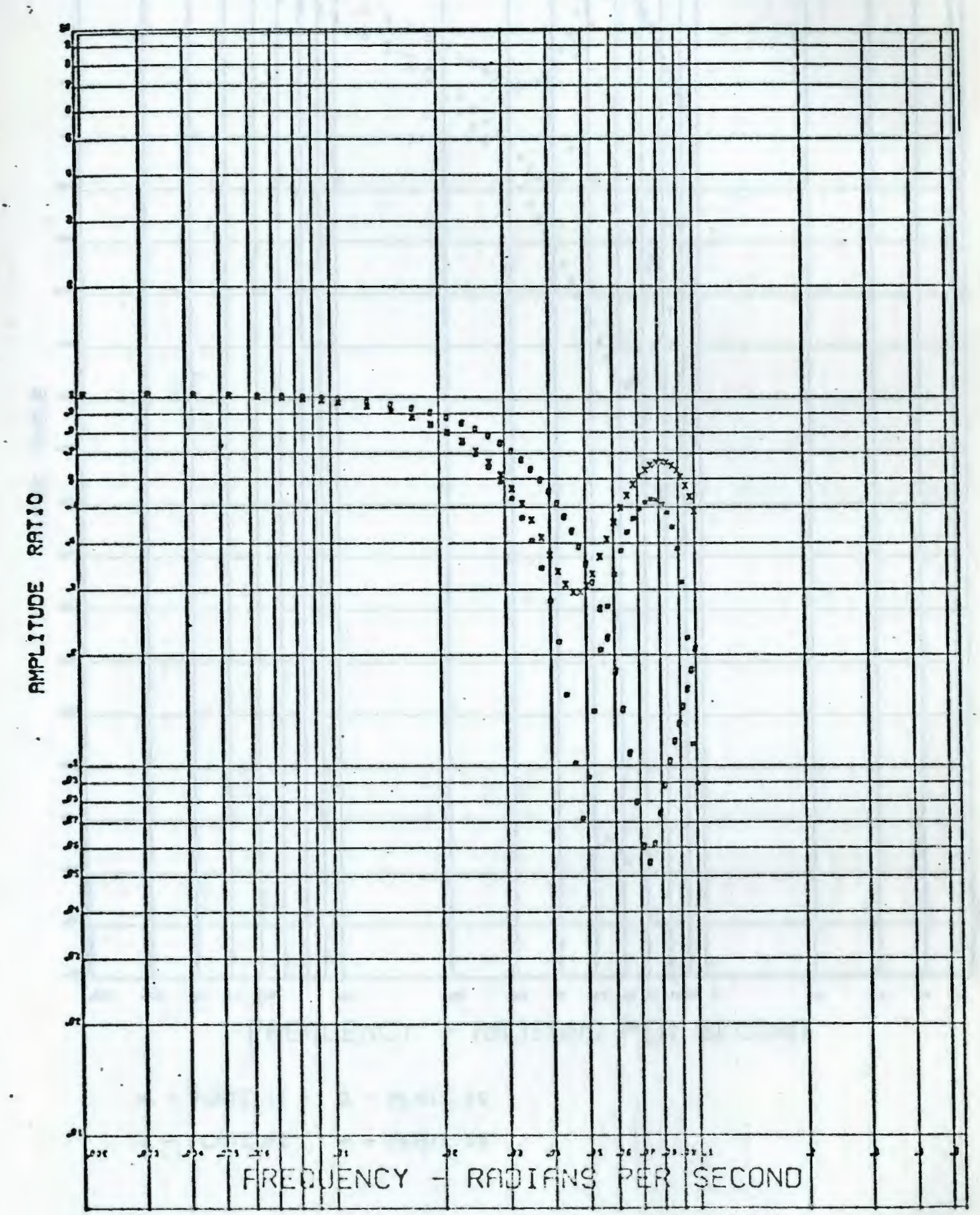




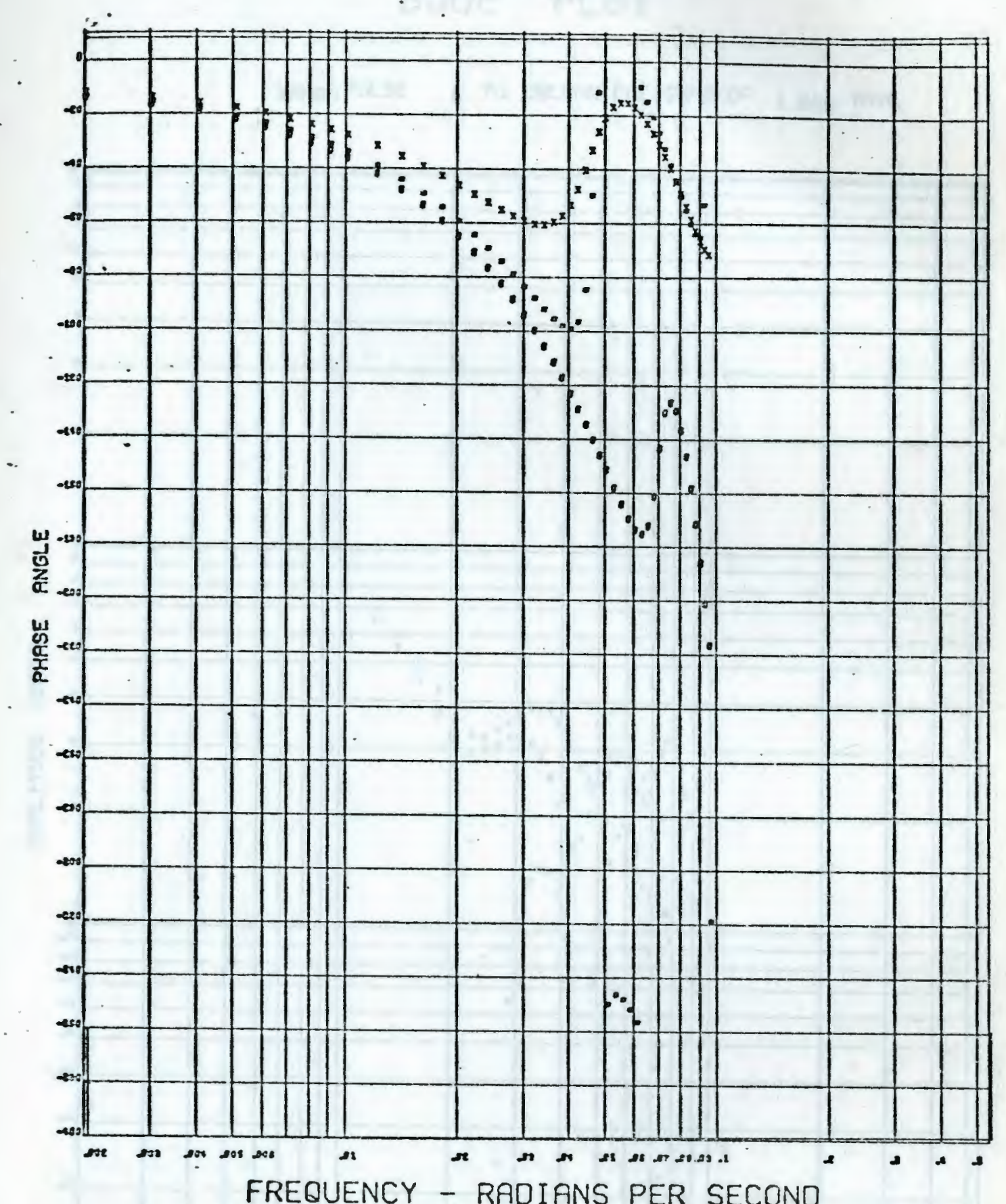

FREQUENCY - RADIANS PER SECOND

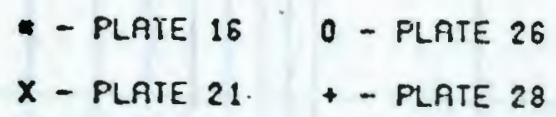


BODE PLOT

VAPOR PULSE 5 AT COLUMN PRESSURE OF 1.000 ATM.

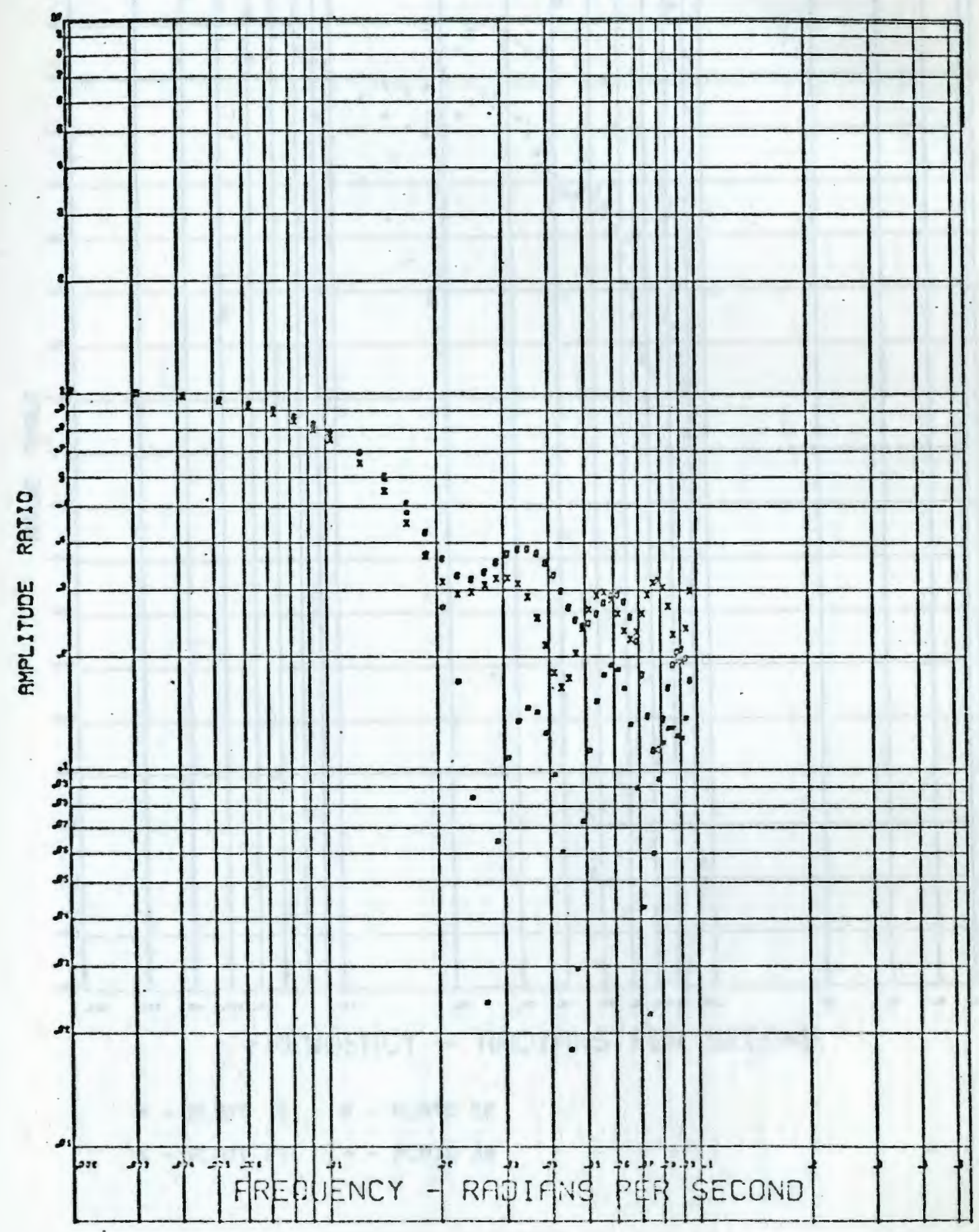




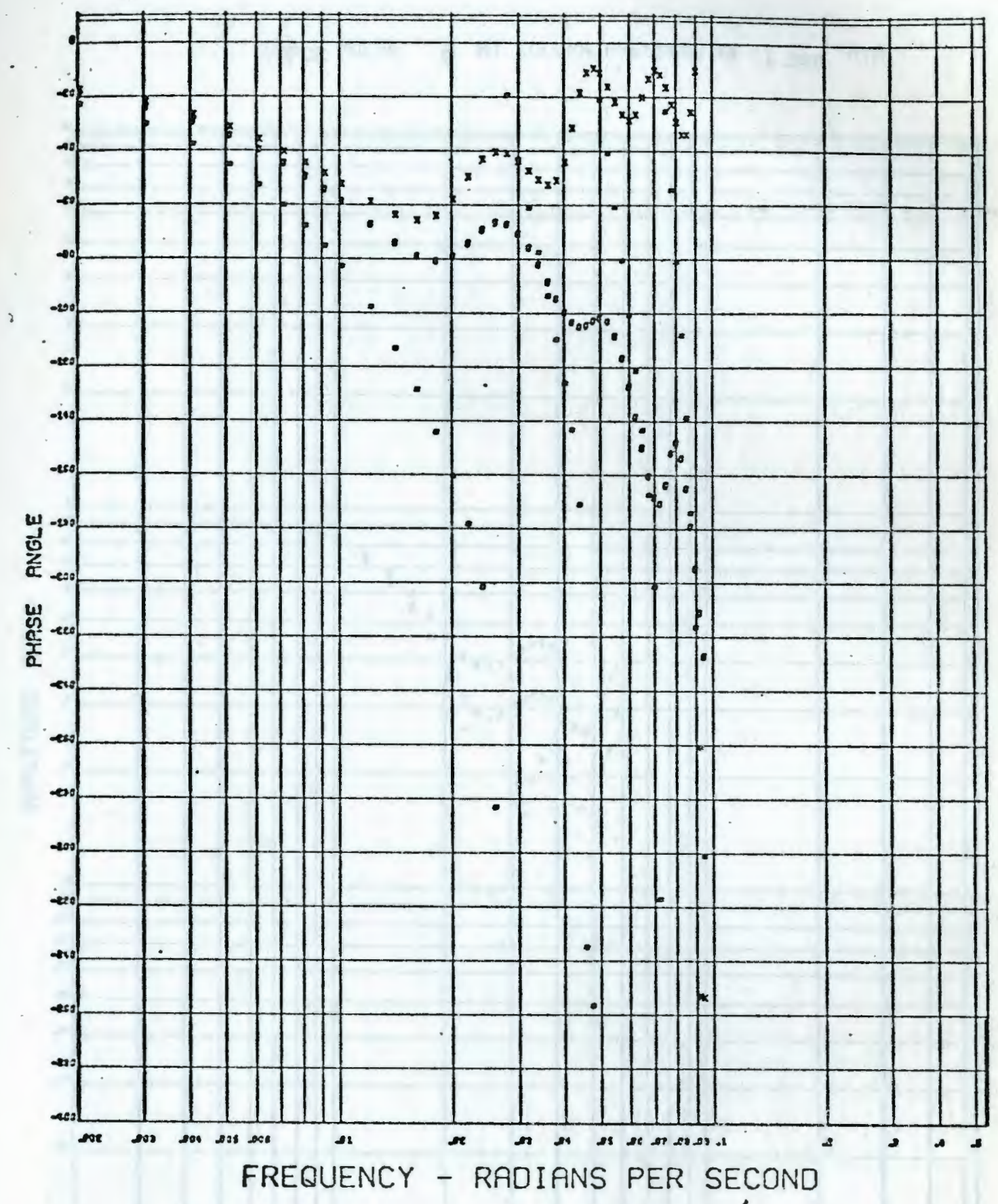

* plate 16 0-plate 26

x - Plate $21^{\circ}+$ - Plate 28 


\section{BODE PLOT}

VAPOR PULSE 6 AT COLUMN PRESSURE OF 1.000 ATM.

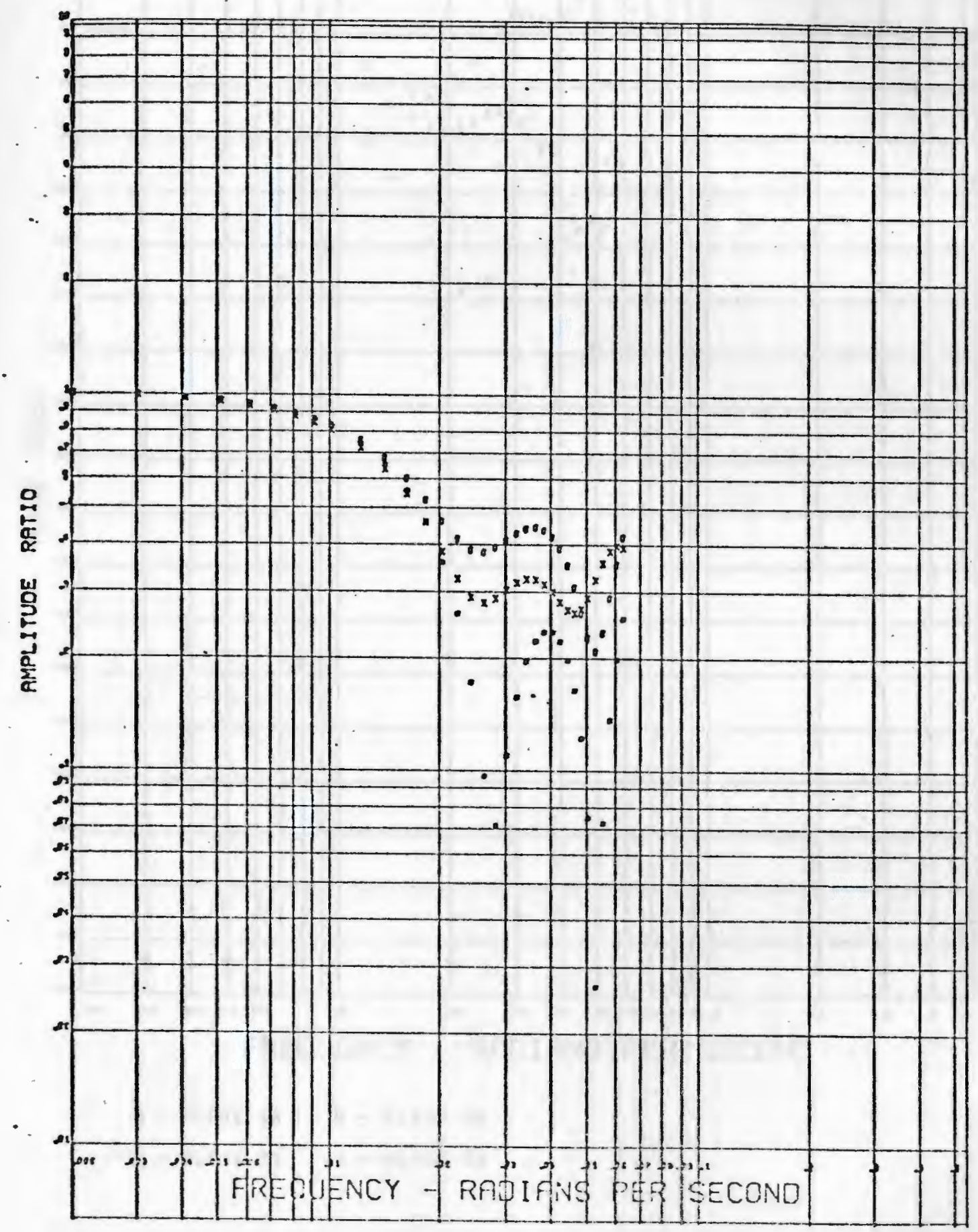




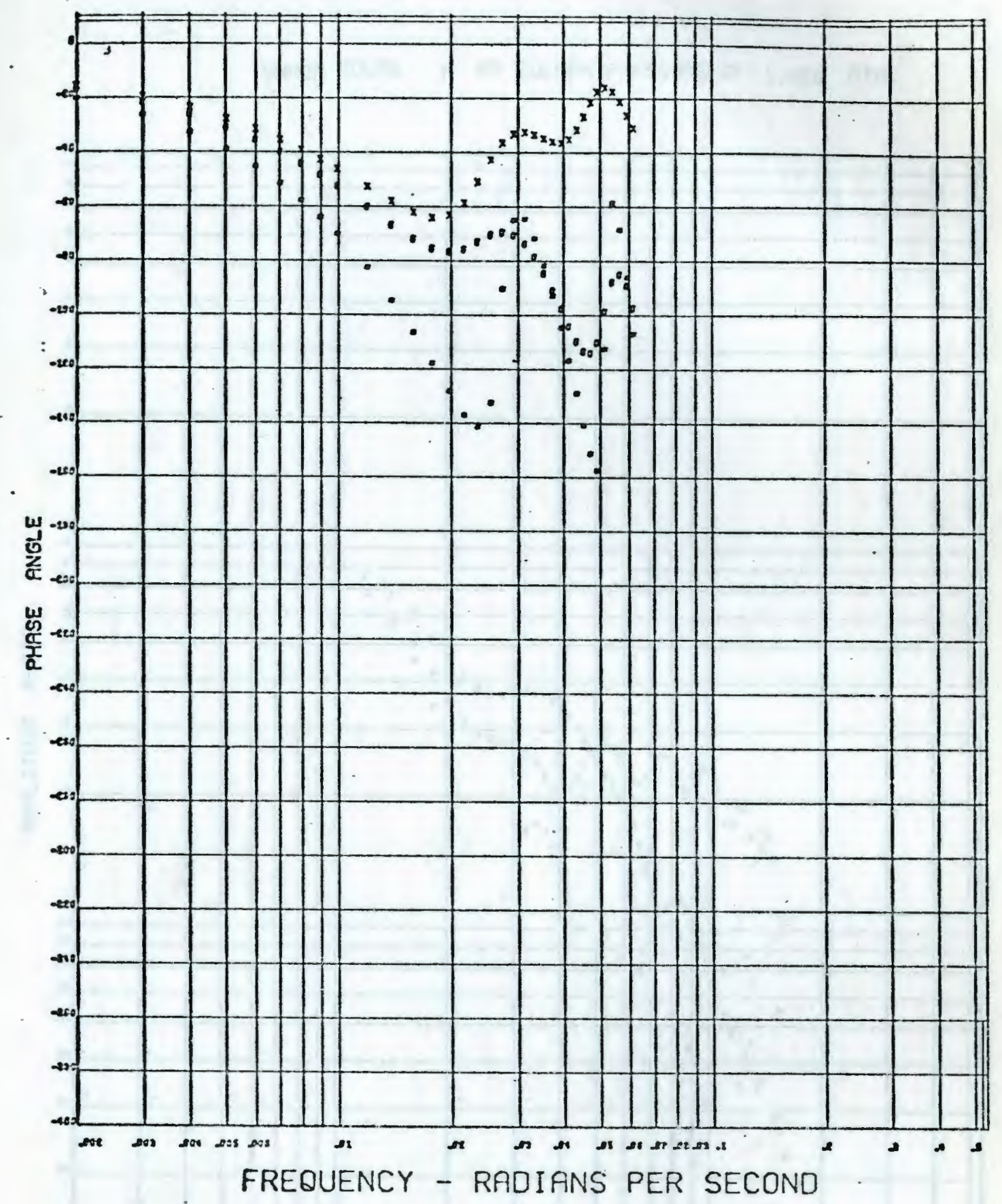

* - plate 16 0-plate 26

$X$ - PLATE 21 + PLATE 28 


\section{BODE PLOT}

VAPOR PULSE ? AT COLUMN PRESSURE OF 1.000 ATM.

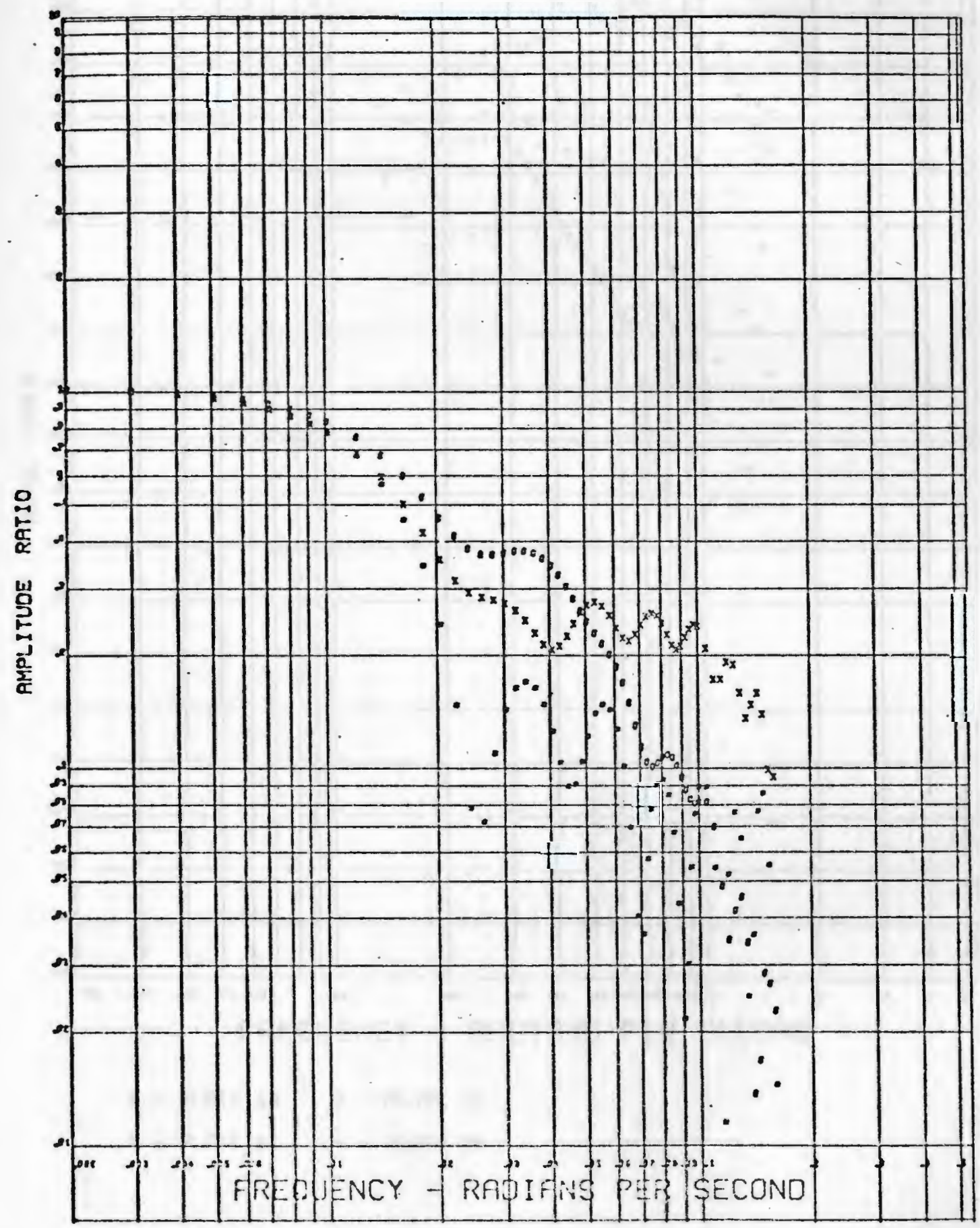




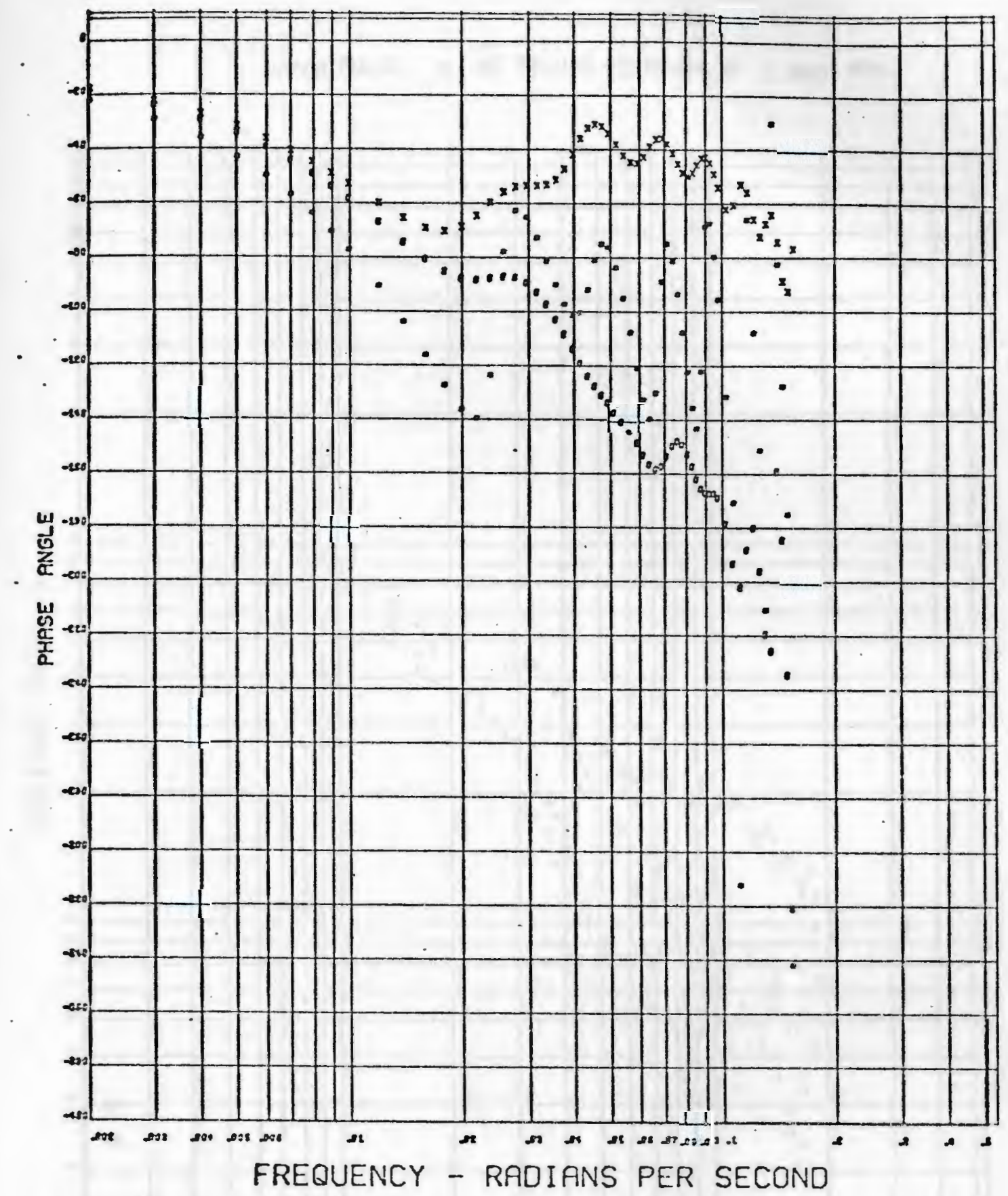

- plate 16 0-plate 26

$x$ - PLATE 21 + - PLATE 28 


\section{BODE PLOT}

VAPOR PULSE 8 AT COLUMN PRESSURE OF 1.000 ATM.

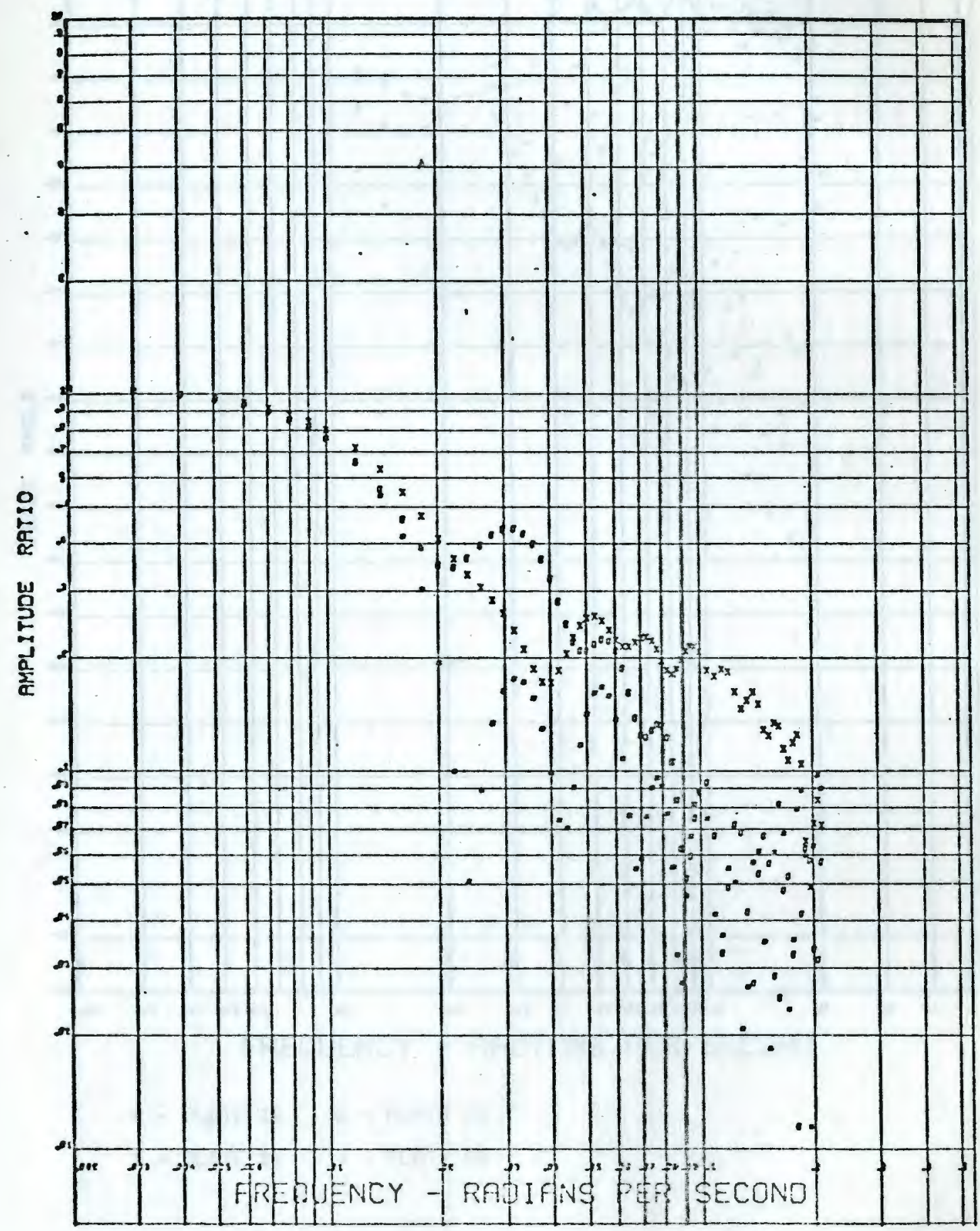




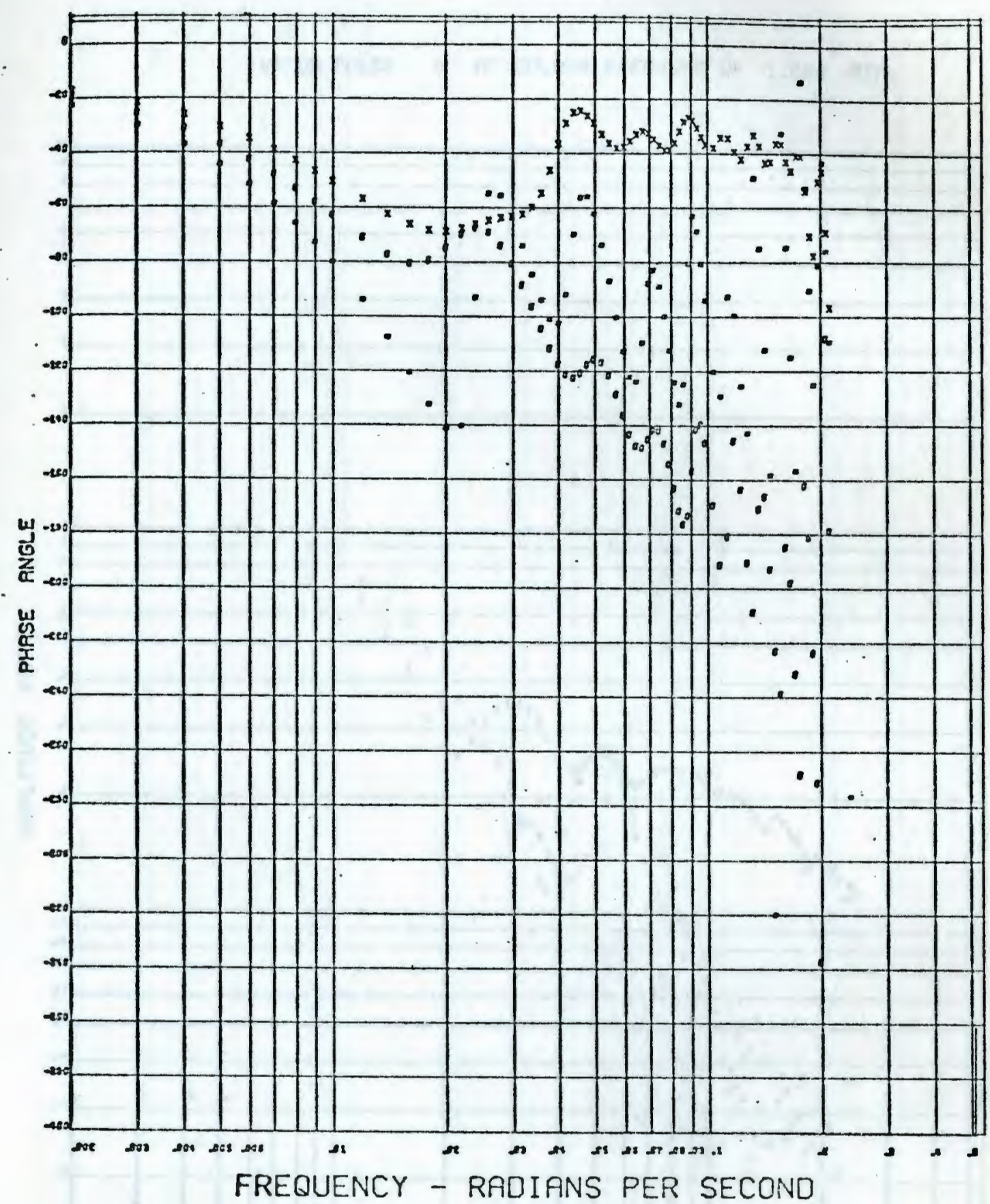

- Plate 16 0-plate 26

$X$ - PLATE 21 + - PLATE 28 


\section{BODE PLOT}

VAPOR PULSE 9 AT COLUMN PRESSURE OF 1.000 ATM.

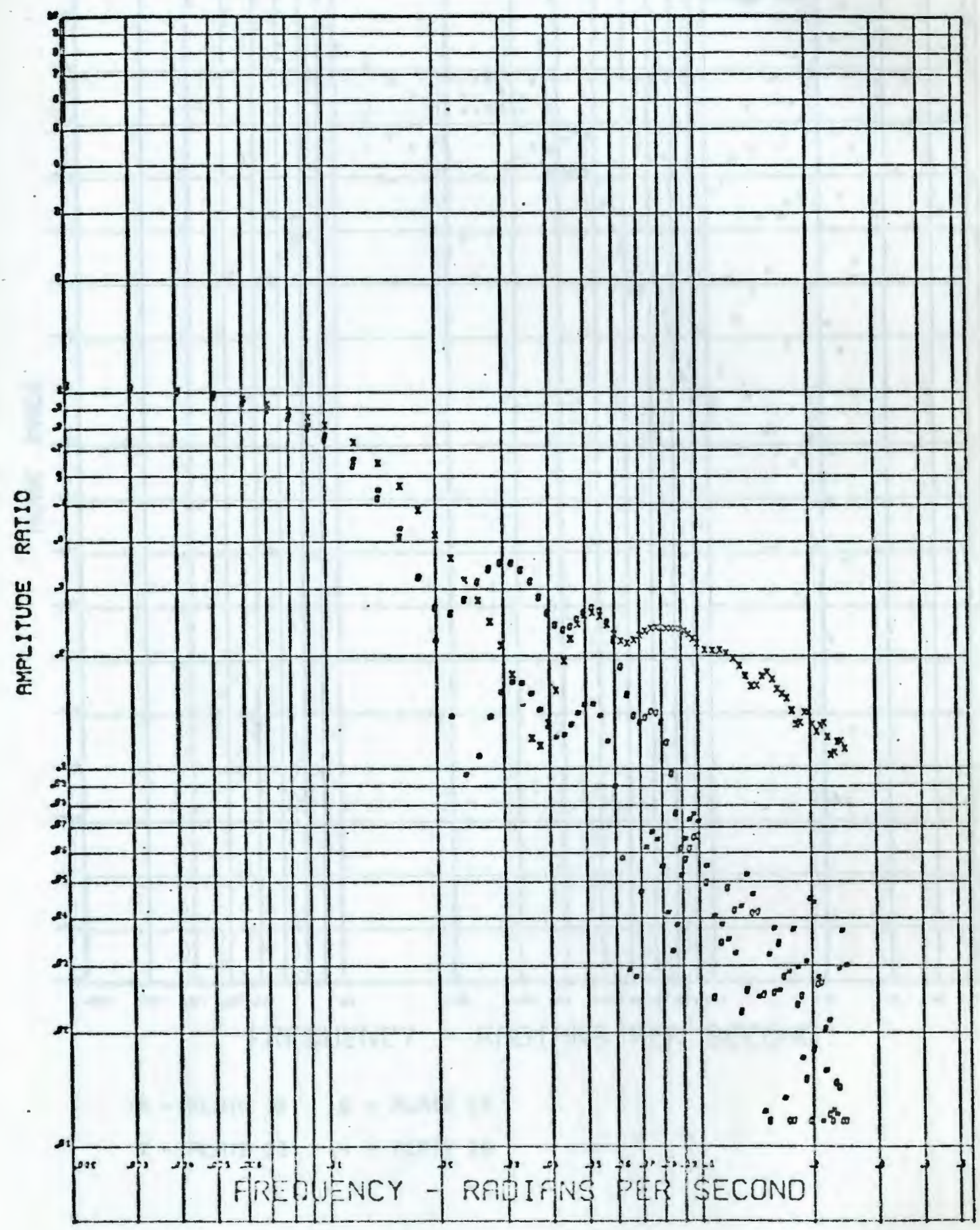




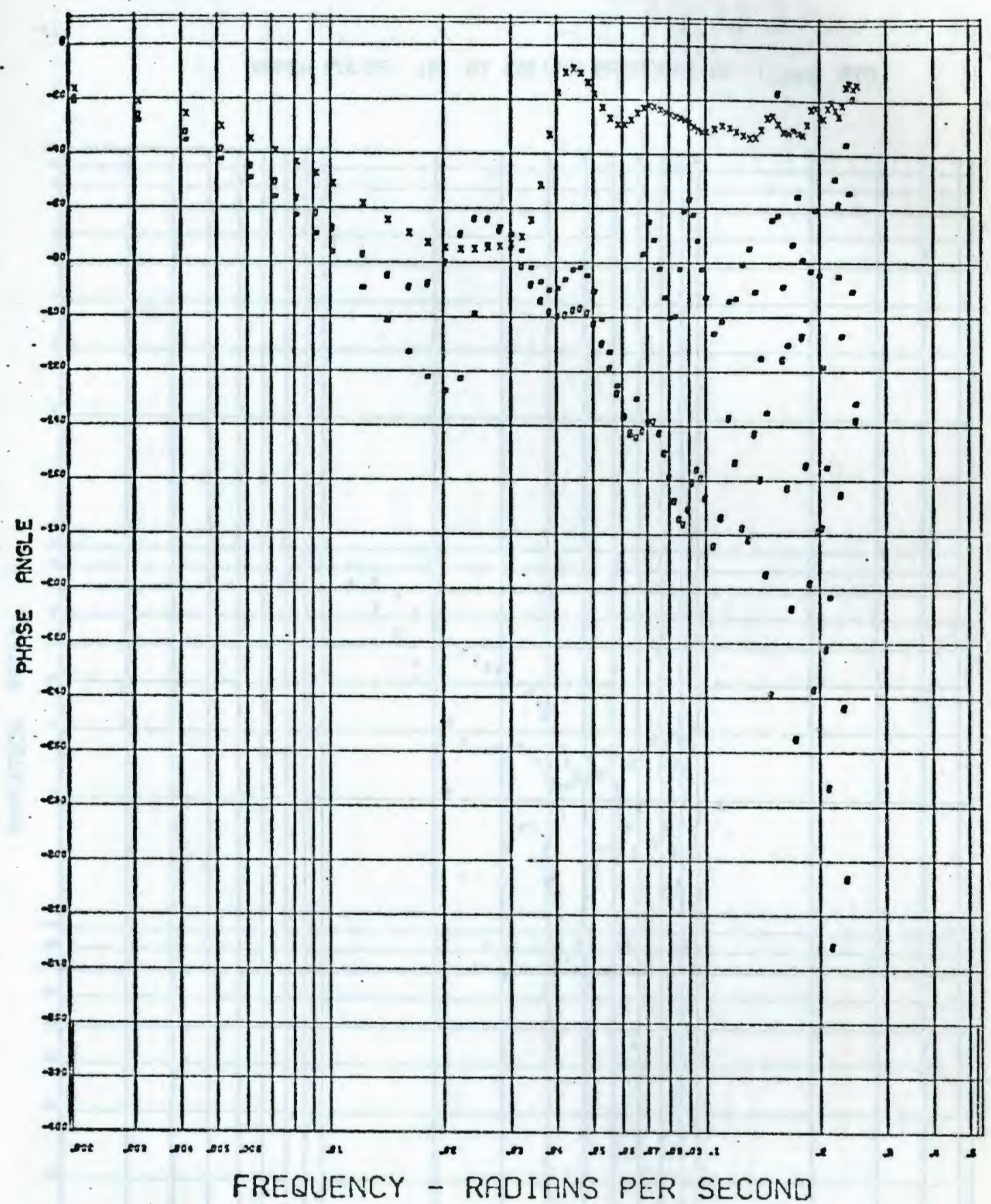

- Plate 16 0-plate 26

X- Plate 21 + plate 28 


\section{BODE PLOT}

VRPOR PULSE 10 AT COLUMN PRESSURE OF 1.000 ATM.

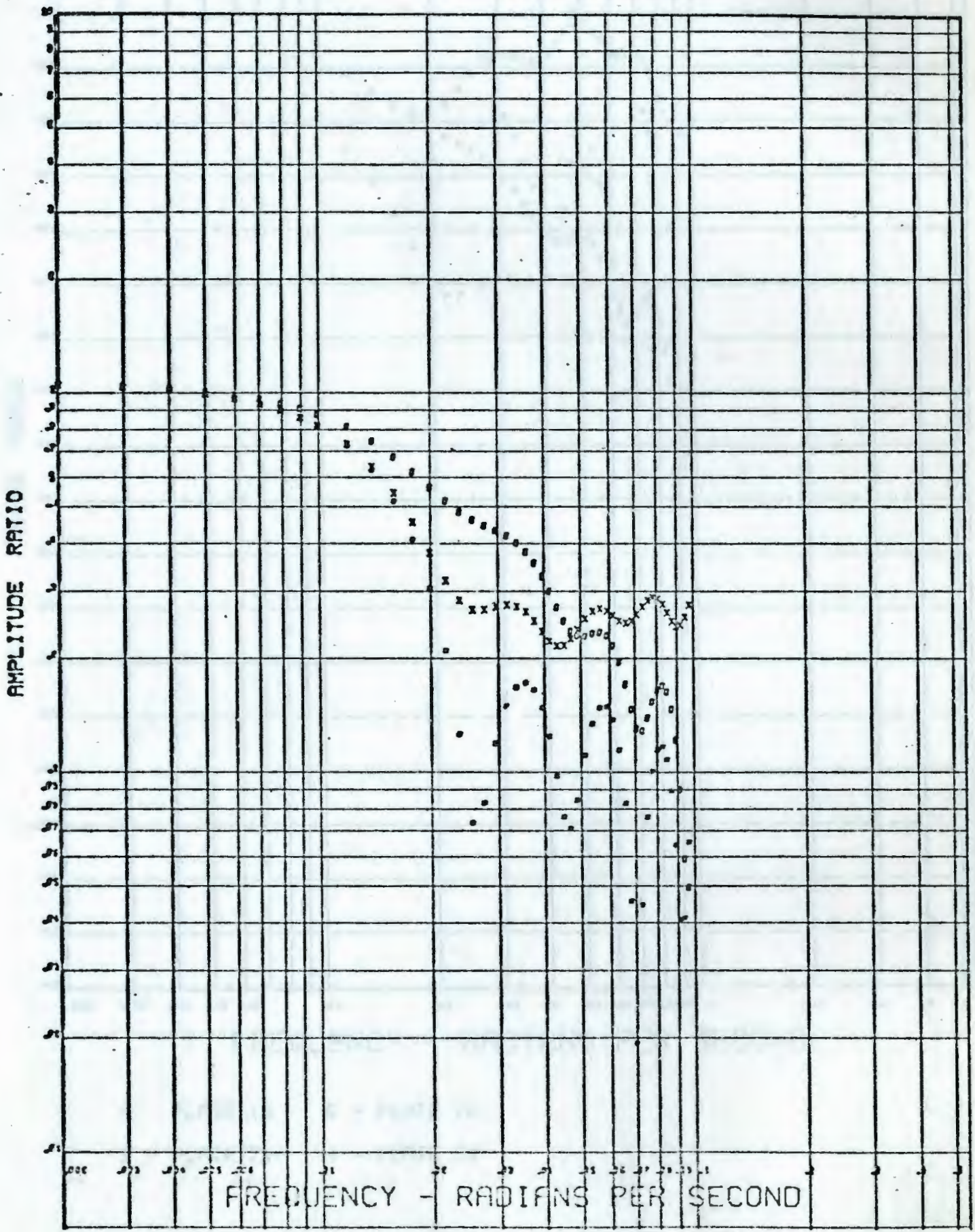


$\because$

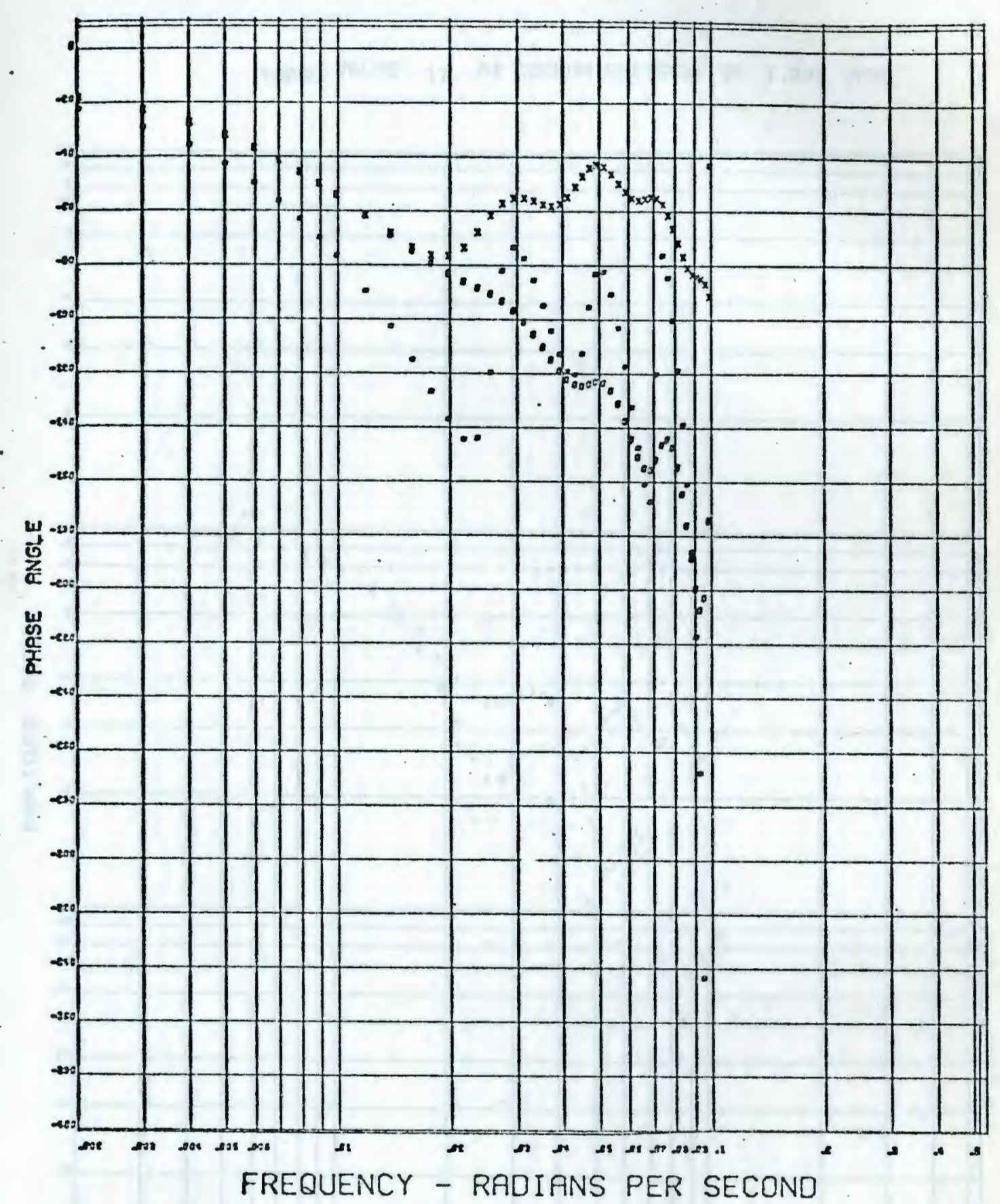

- plate ie o - plate 26

$X$ - PLATE 21 + - PLATE 28 


\section{BODE PEOT}

VAPOR PULSE - 11: AT COLUMA PRESSURE = OF: 1.000 ATM.

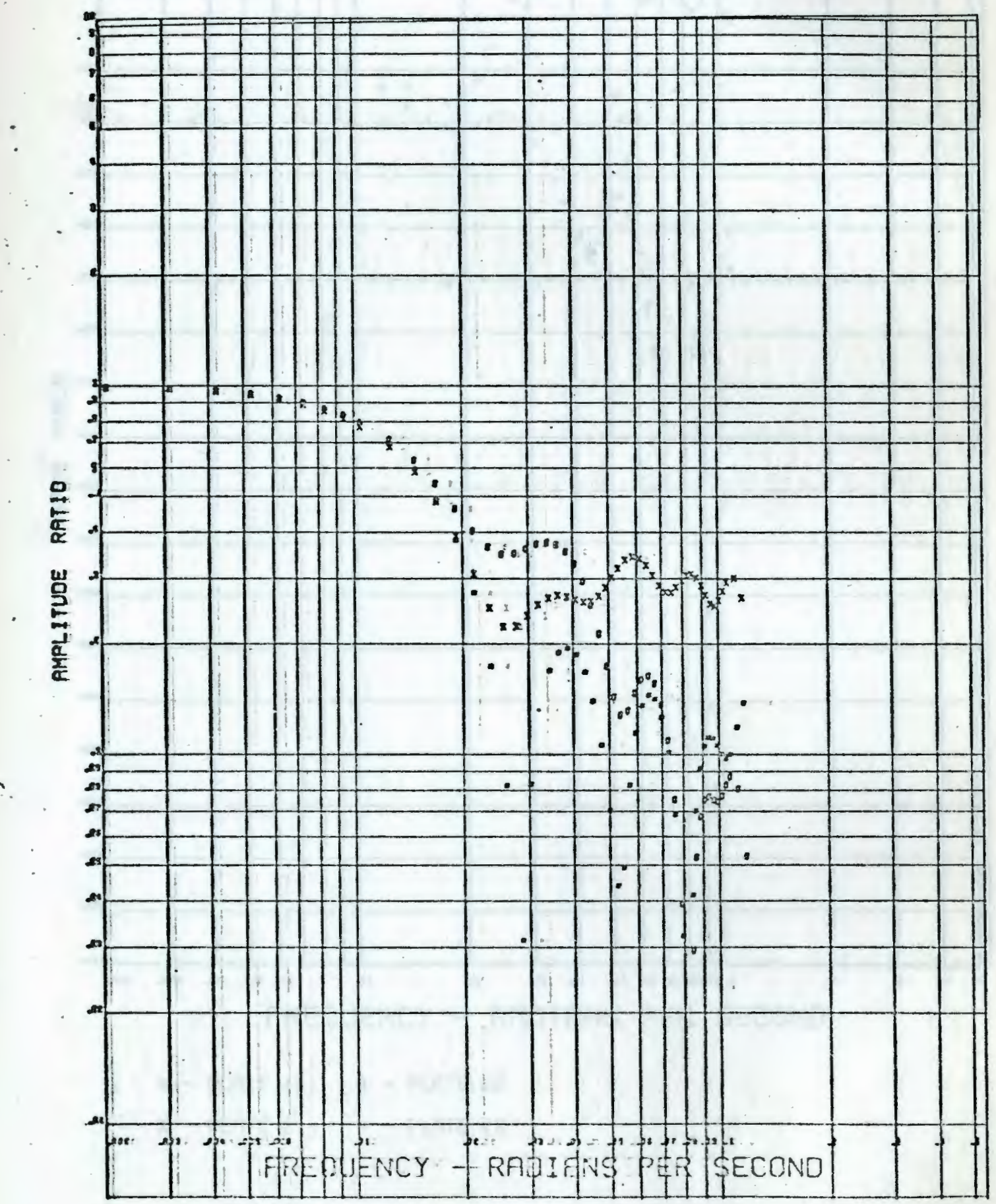




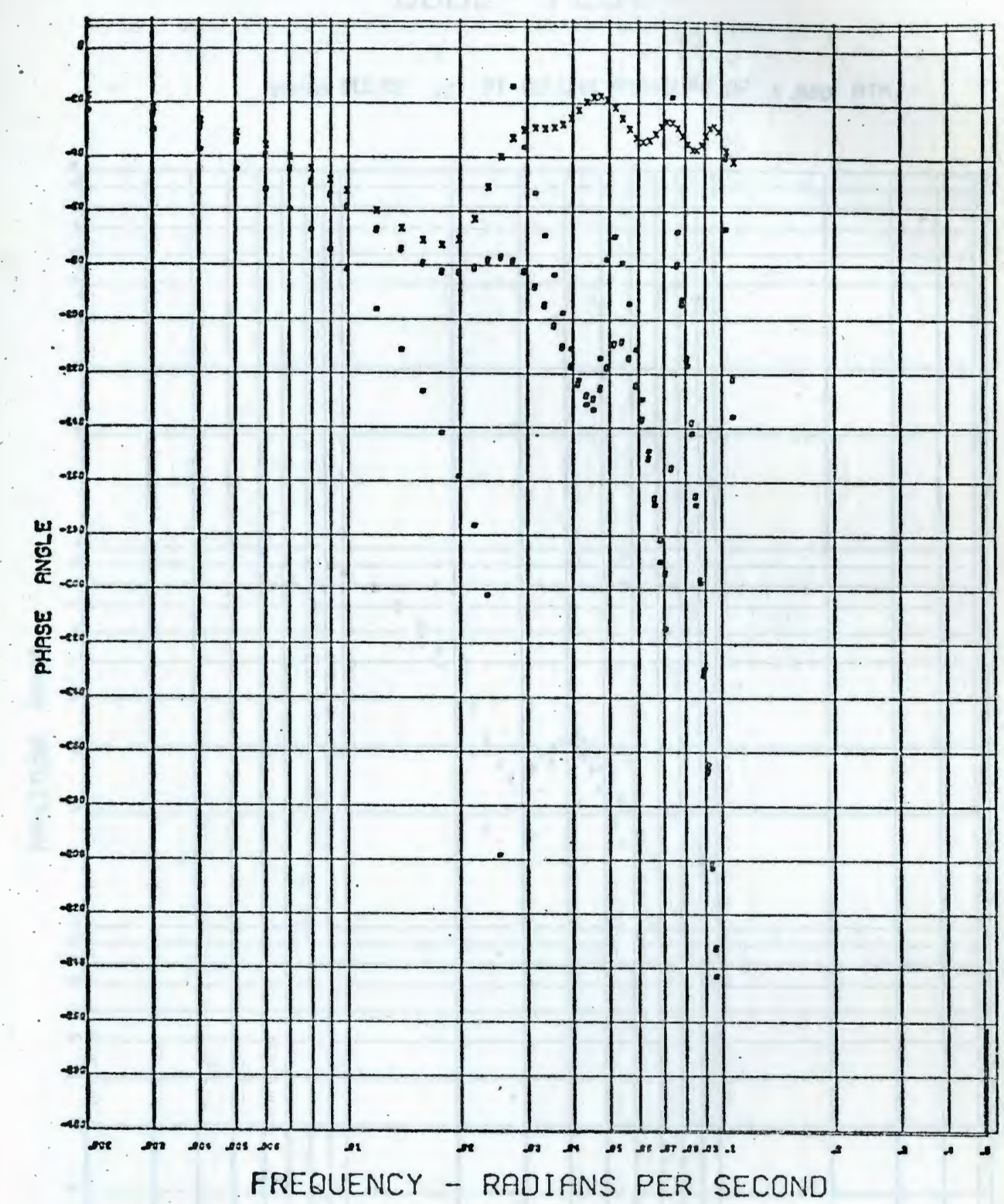

- plate 16 0-plate 26

X - PLATE 21 + PLATE 28 


\section{BODE PLOT}

VAPOR PULSE 12 AT COLUMN PRESSURE OF 1.000 ATM.

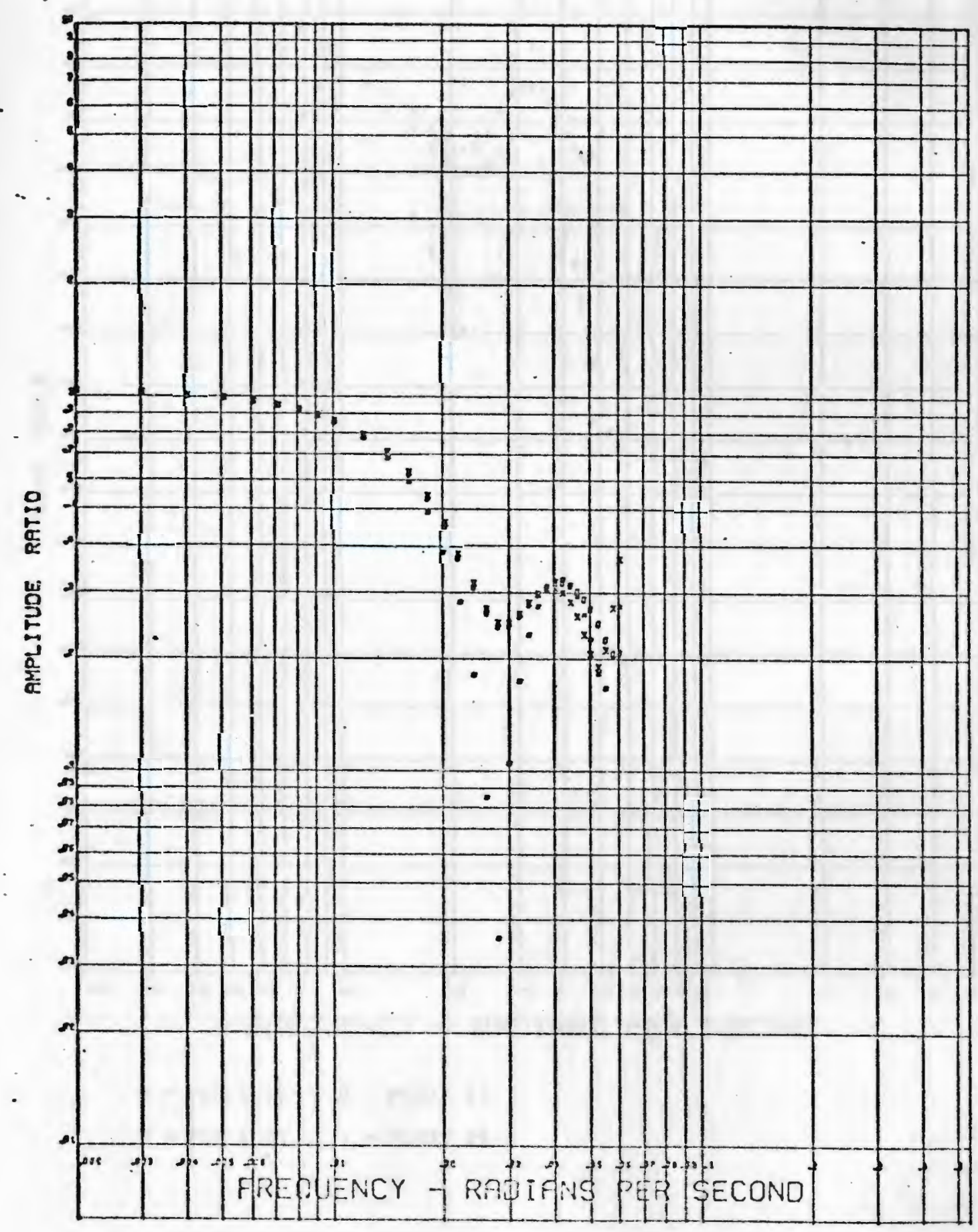




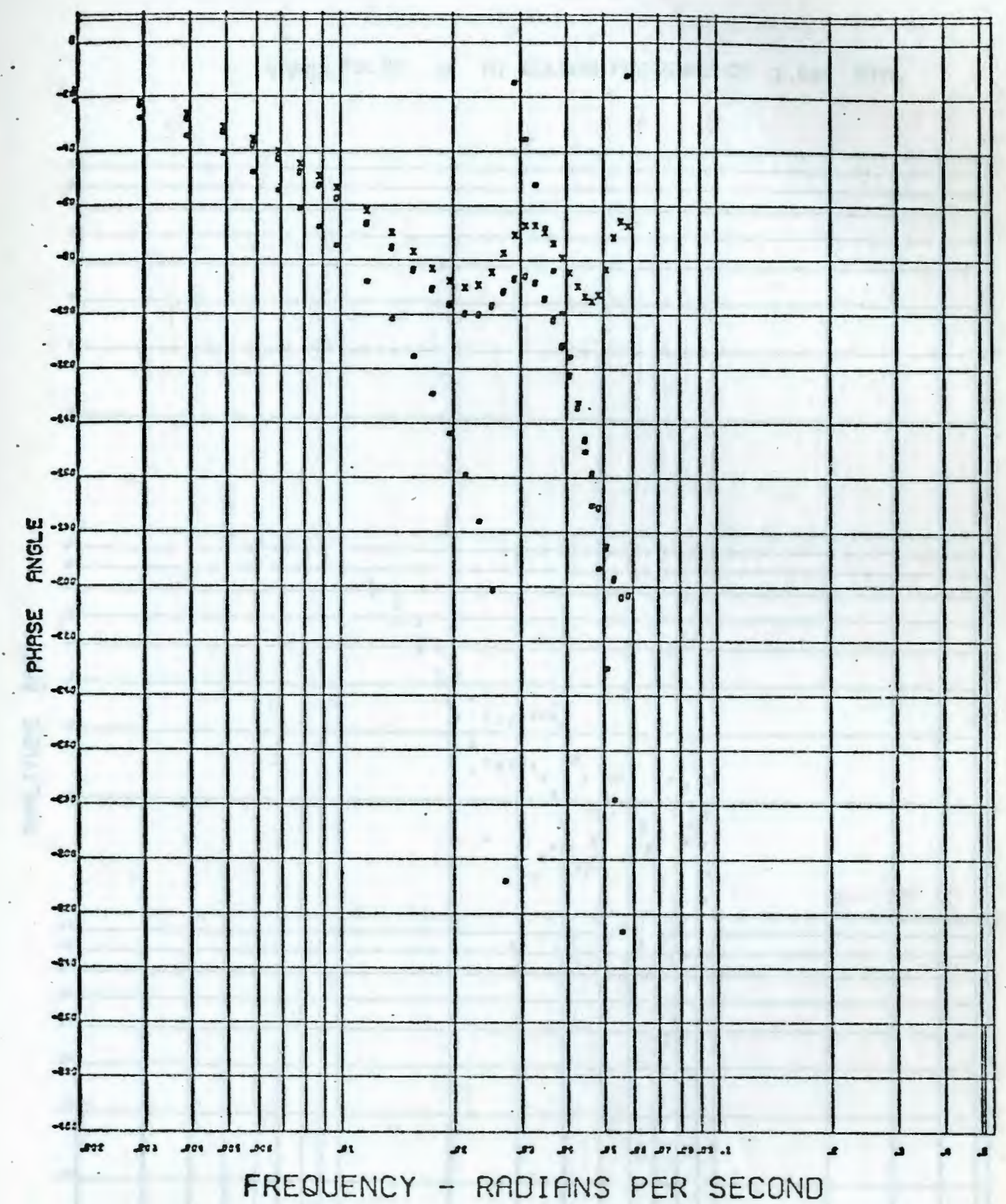

- plate 16 0 - plate 26

X- plate 21 + - plate 28 


\section{BODE PLOT}

VAPOR PULSE 13 AT COLUMN PRESSURE OF 1.000 ATM.

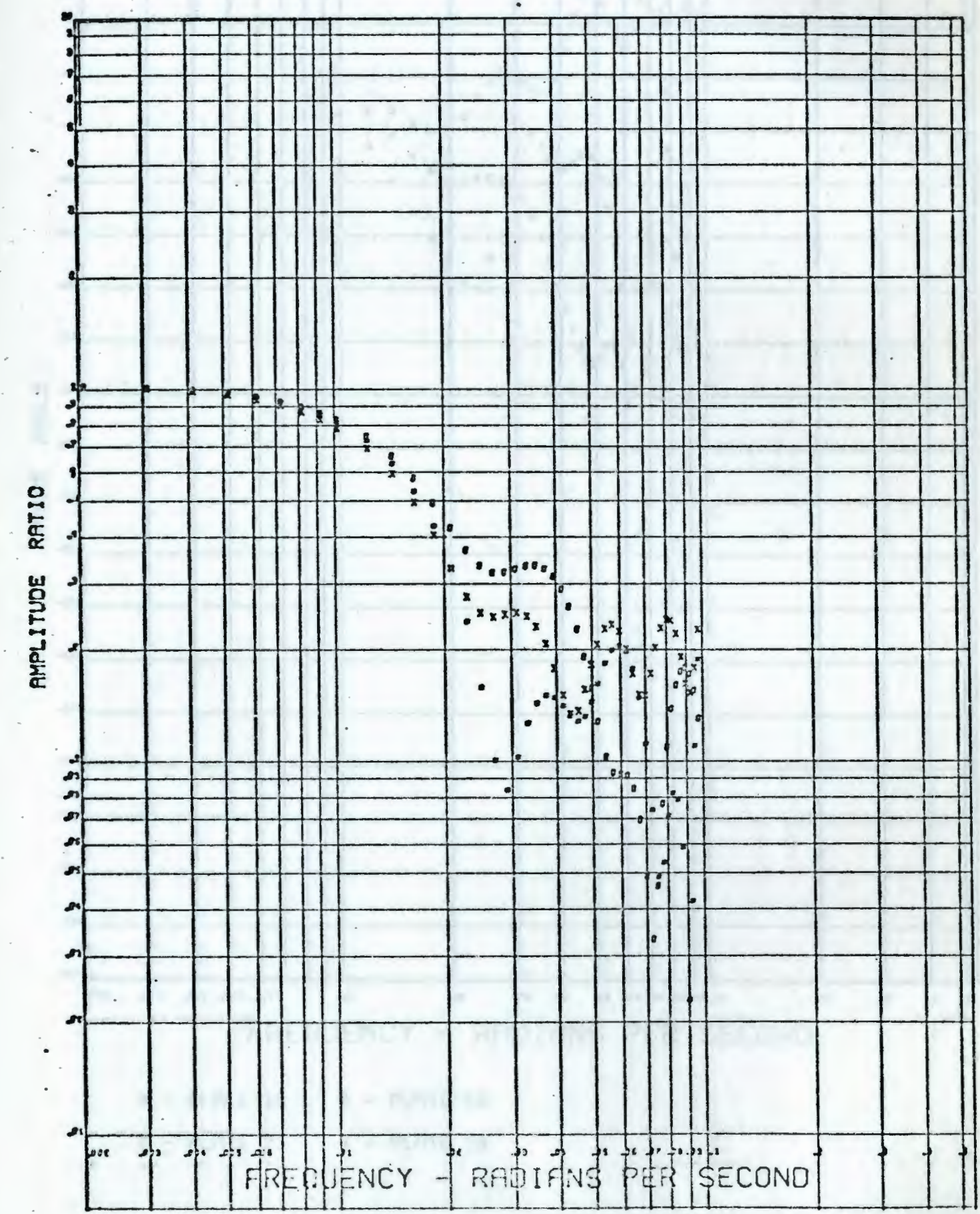




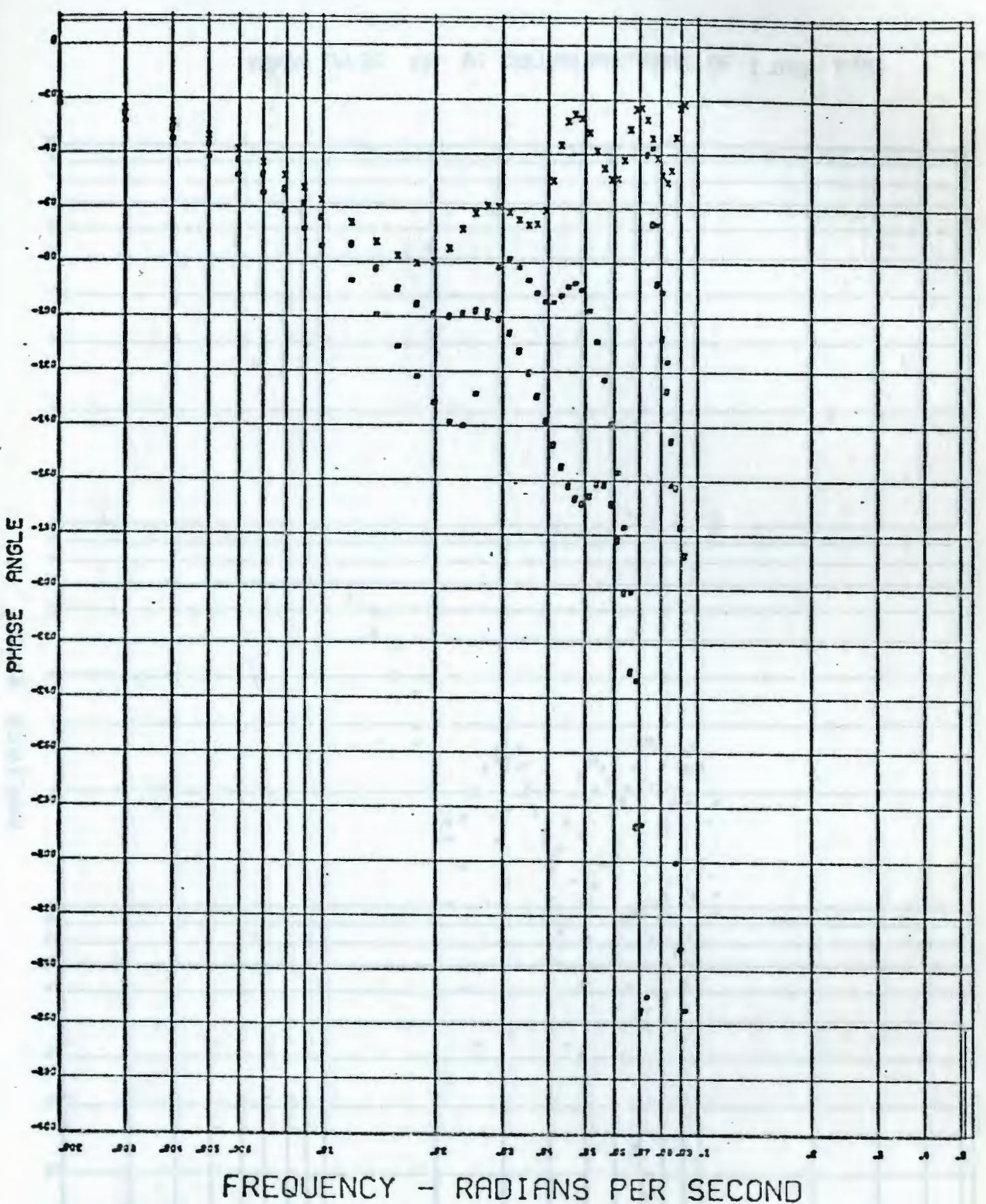

- plate 16 0-plate 26

X- PLATE 21 + - PLATE 28 


\section{BODE PLOT}

VAPOR PULSE 14 AT COLUMN PRESSURE OF 1.000 ATM.

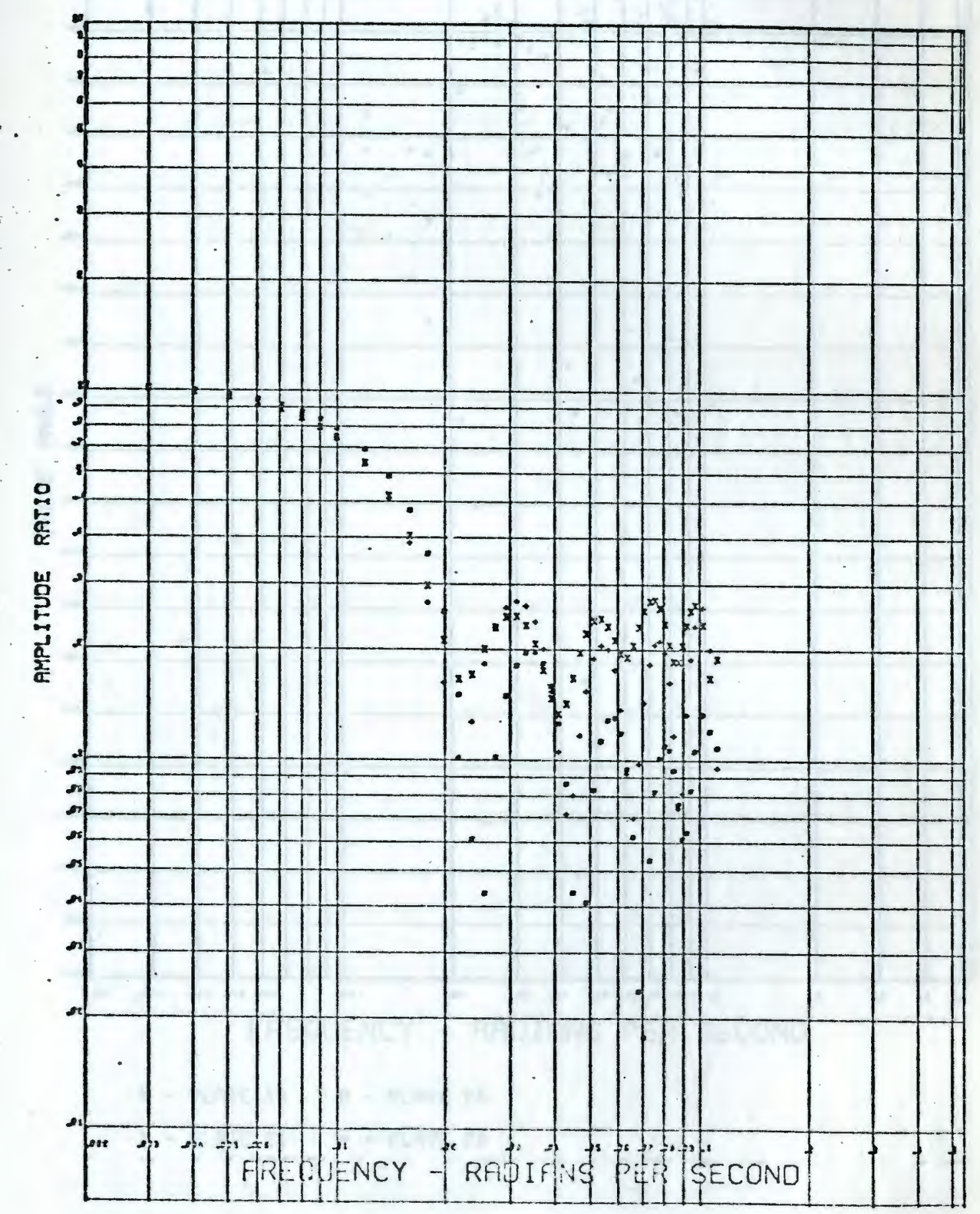




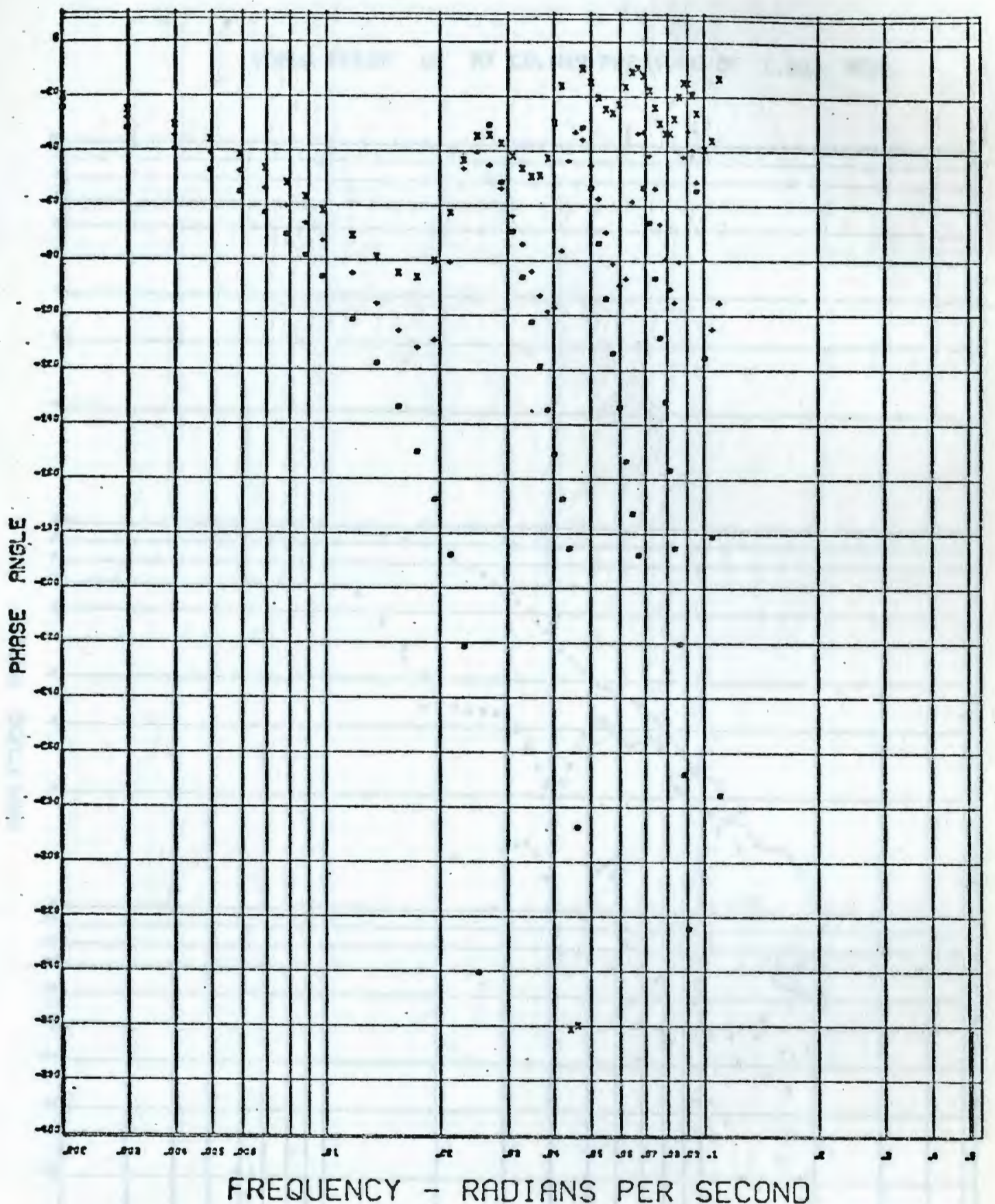

* plate 16 o-plate 26

X - PLITE 21 + PLATE 28 


\section{BODE PLOT}

VAPOR PULSE 15 AT COLUMN PRESSURE OF 1.000 ATM.

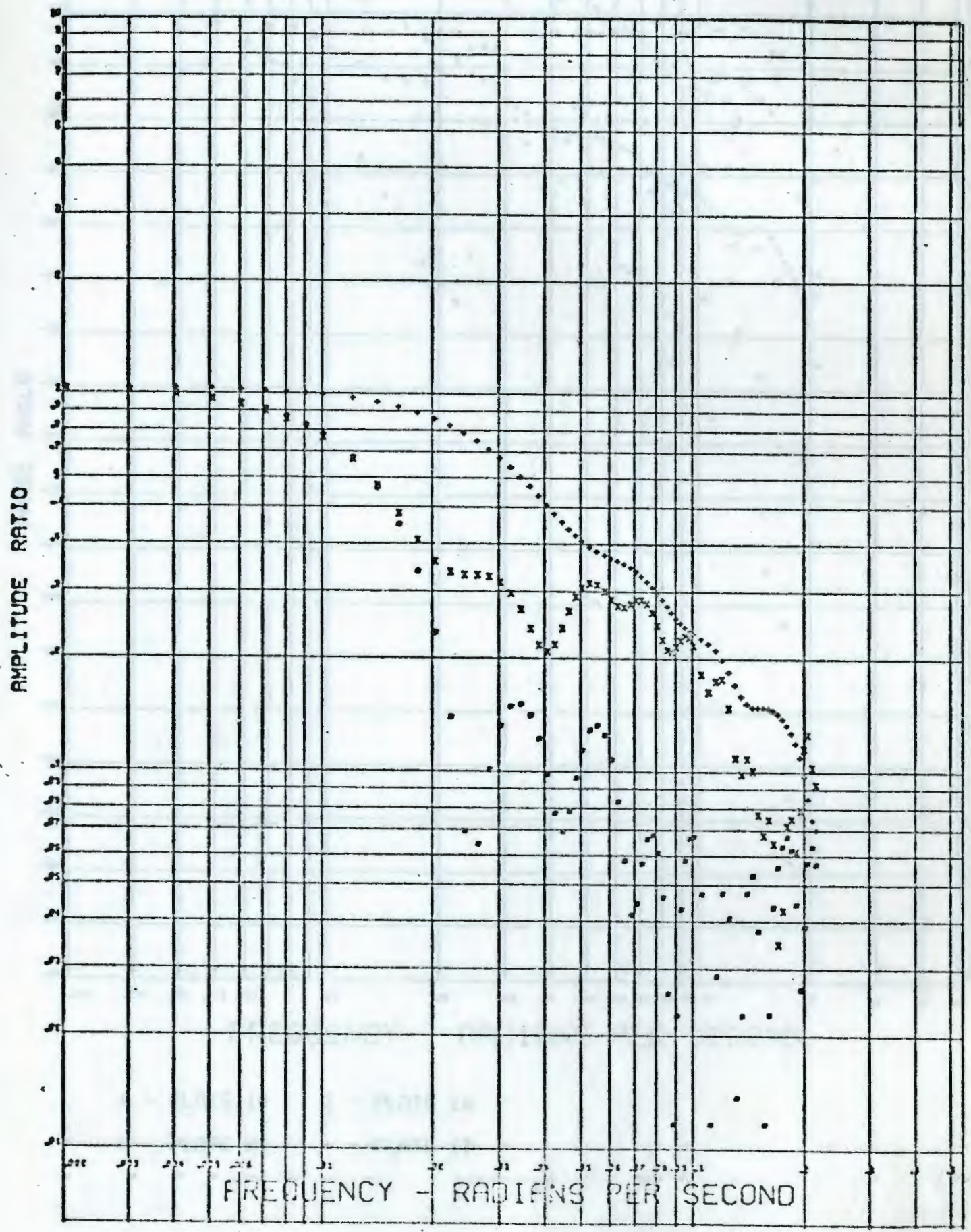




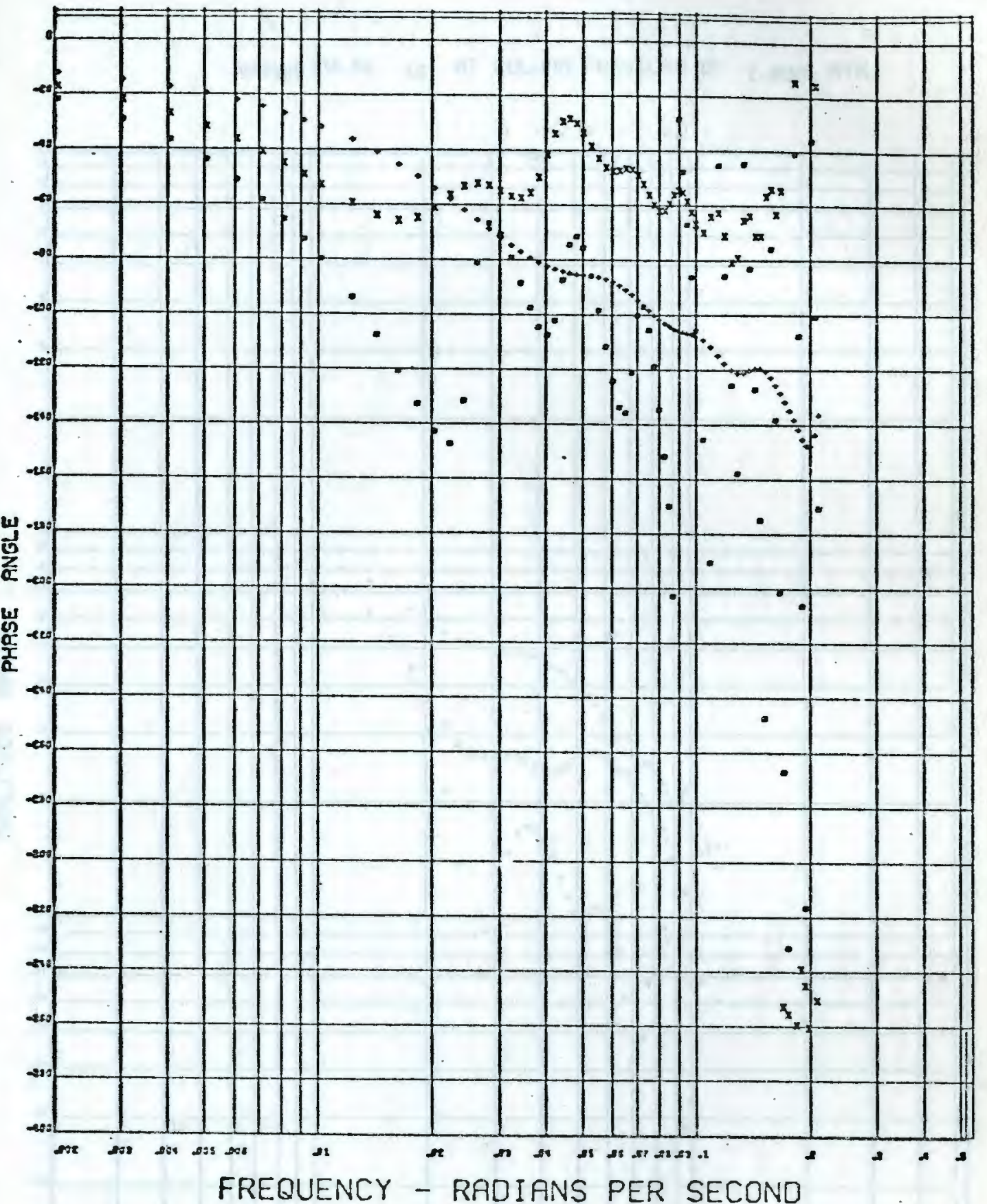

- plate 160 - plate 26

X - plate 21 + - plate 28 


\section{BODE PLOT}

VAPOR PULSE 16 AT COLUMN PRESSURE OF 1.000 ATM.

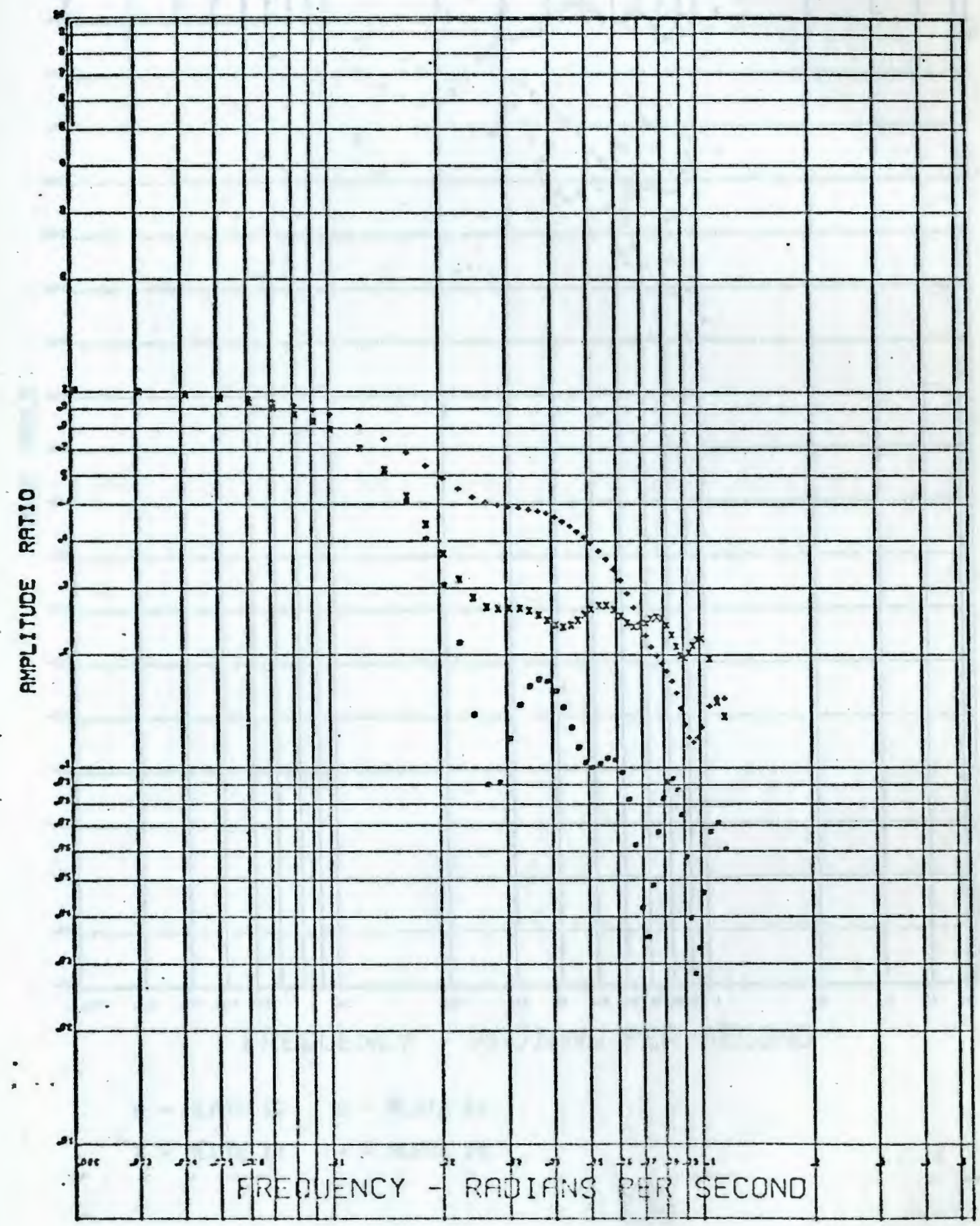




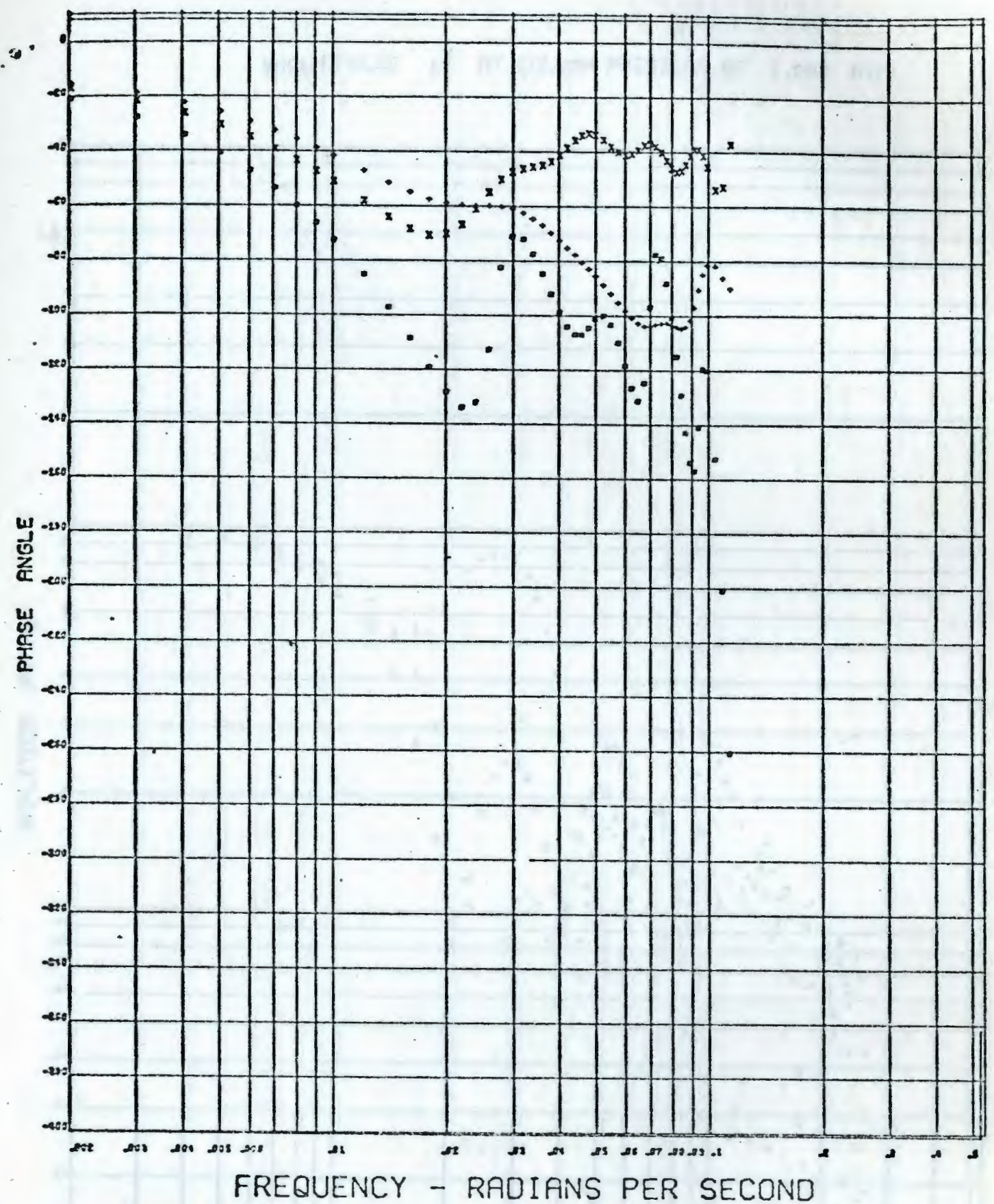

- plate 160 - plate 26

X- Plate 21. + Plate 28 


\section{BODE PLOT}

VAPOR PULSE 17 AT COLUMN PRESSURE OF 1.000 ATM.

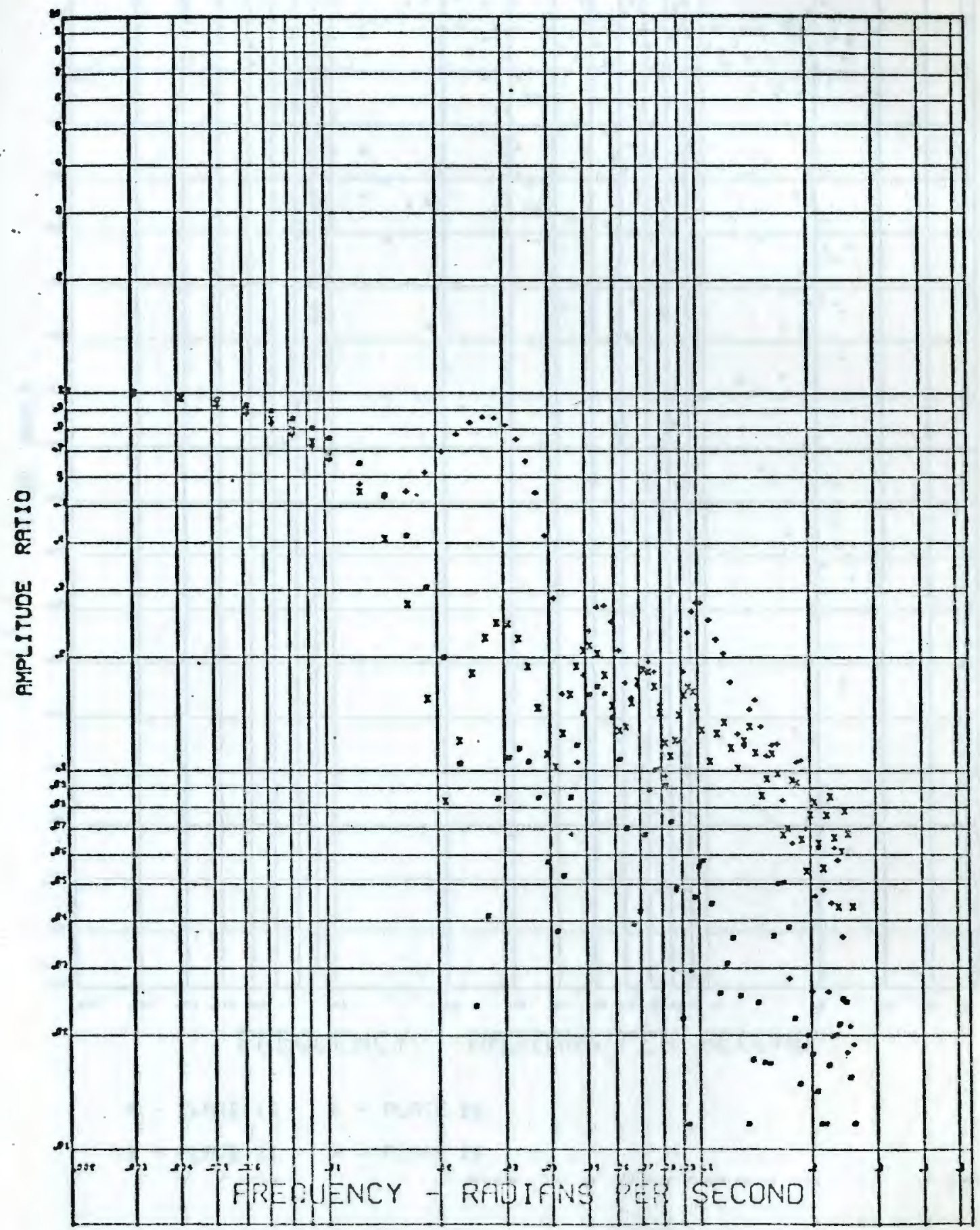




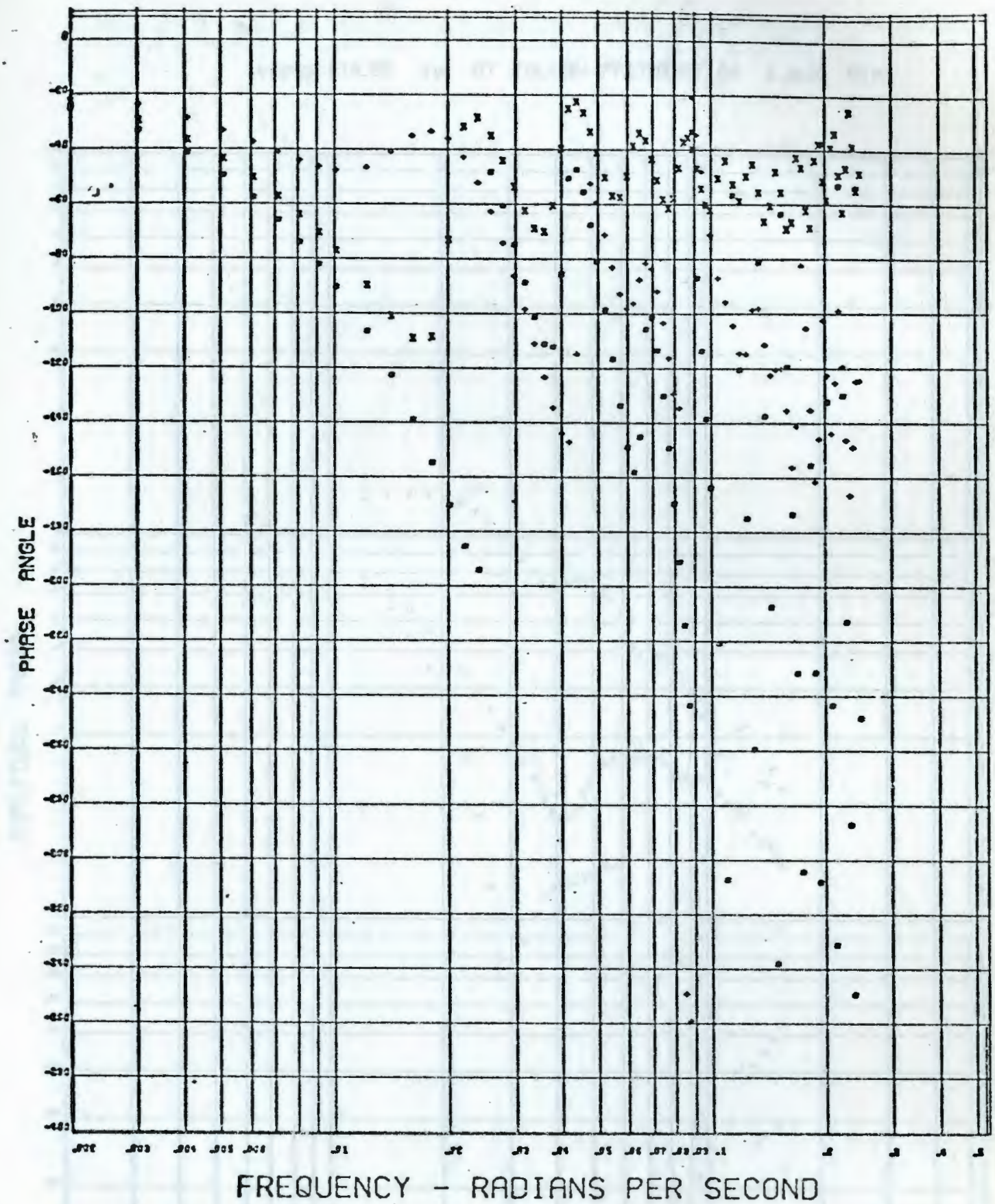

- Plate 160 - plate 26

X- Plate 21 + Plate 20 
BODE PLOT

a. VAPOR PULSE 18 AT COLUMN PRESSURE OF 1.000 ATM.

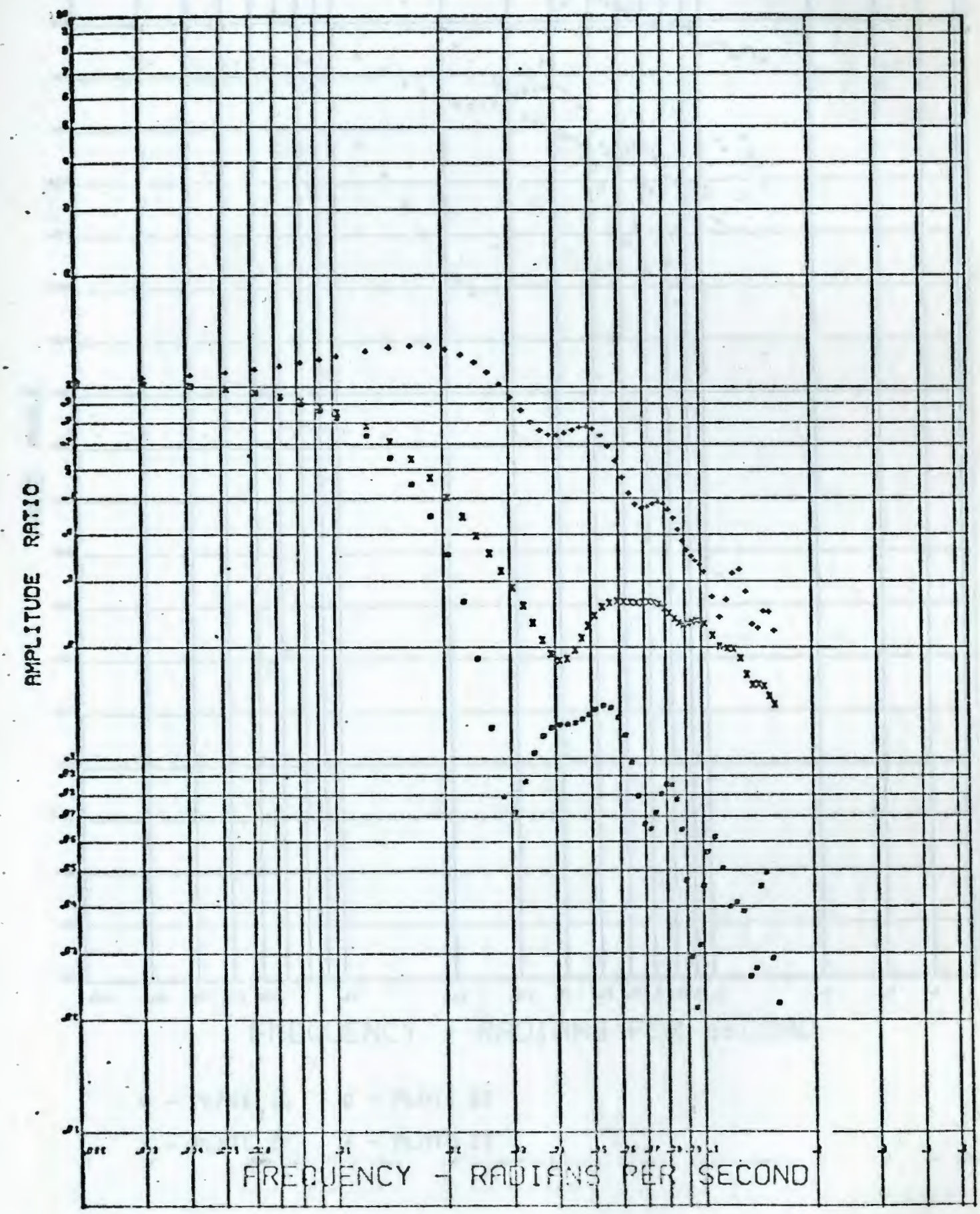




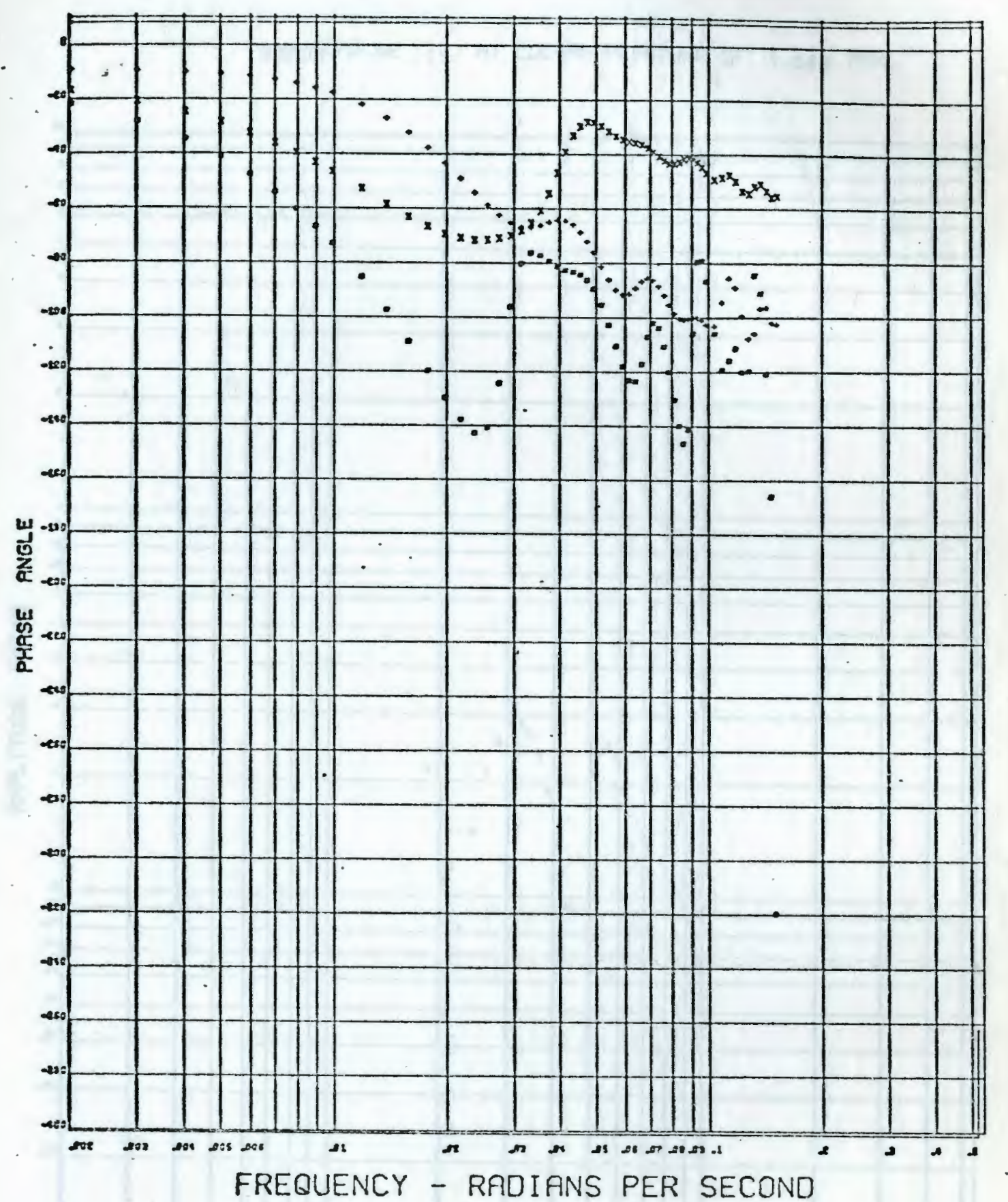

- plate 16 o-plate 26

$X$ - PLATE 21 + PLATE 28 


\section{BODE PLOT}

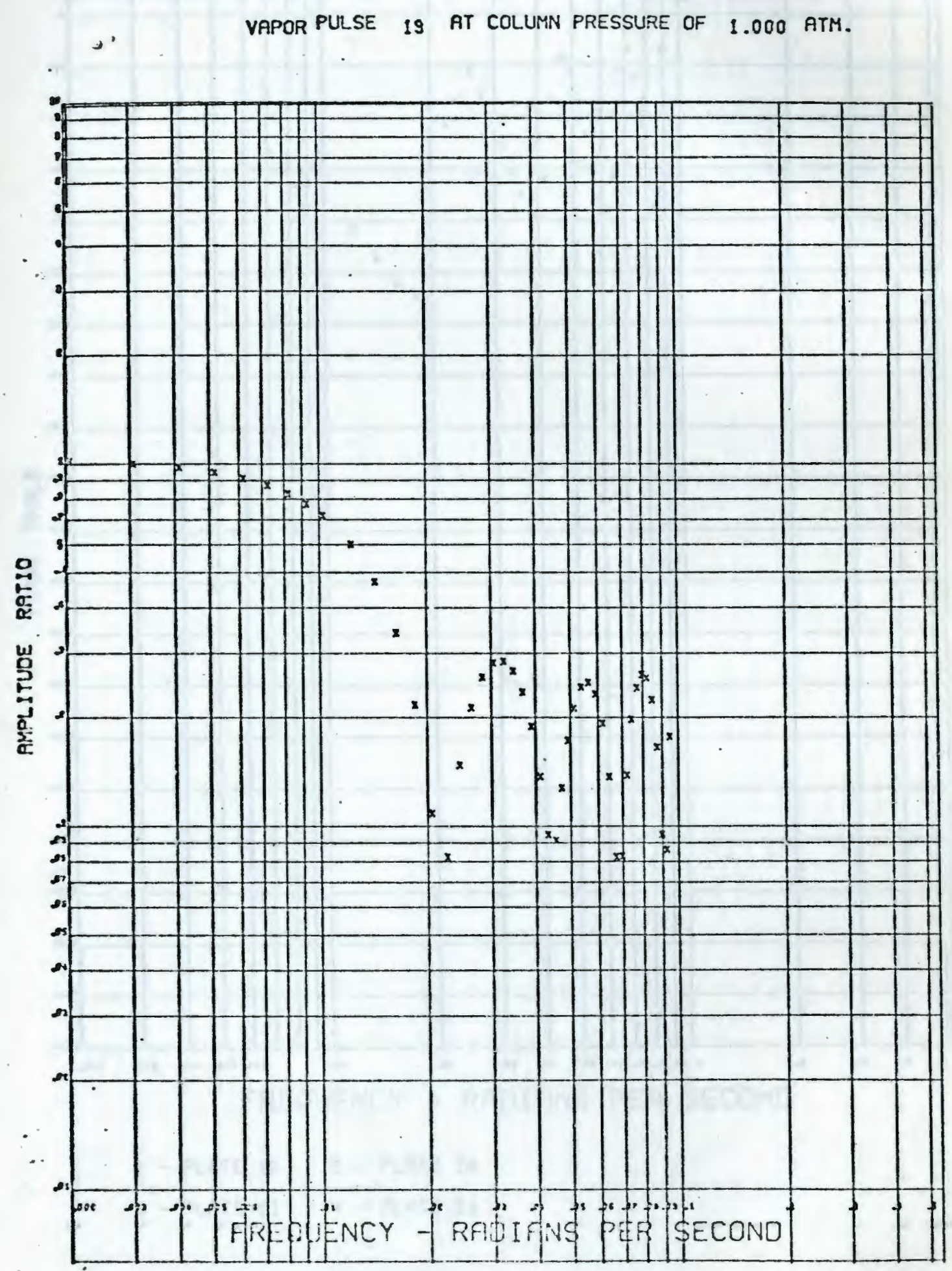



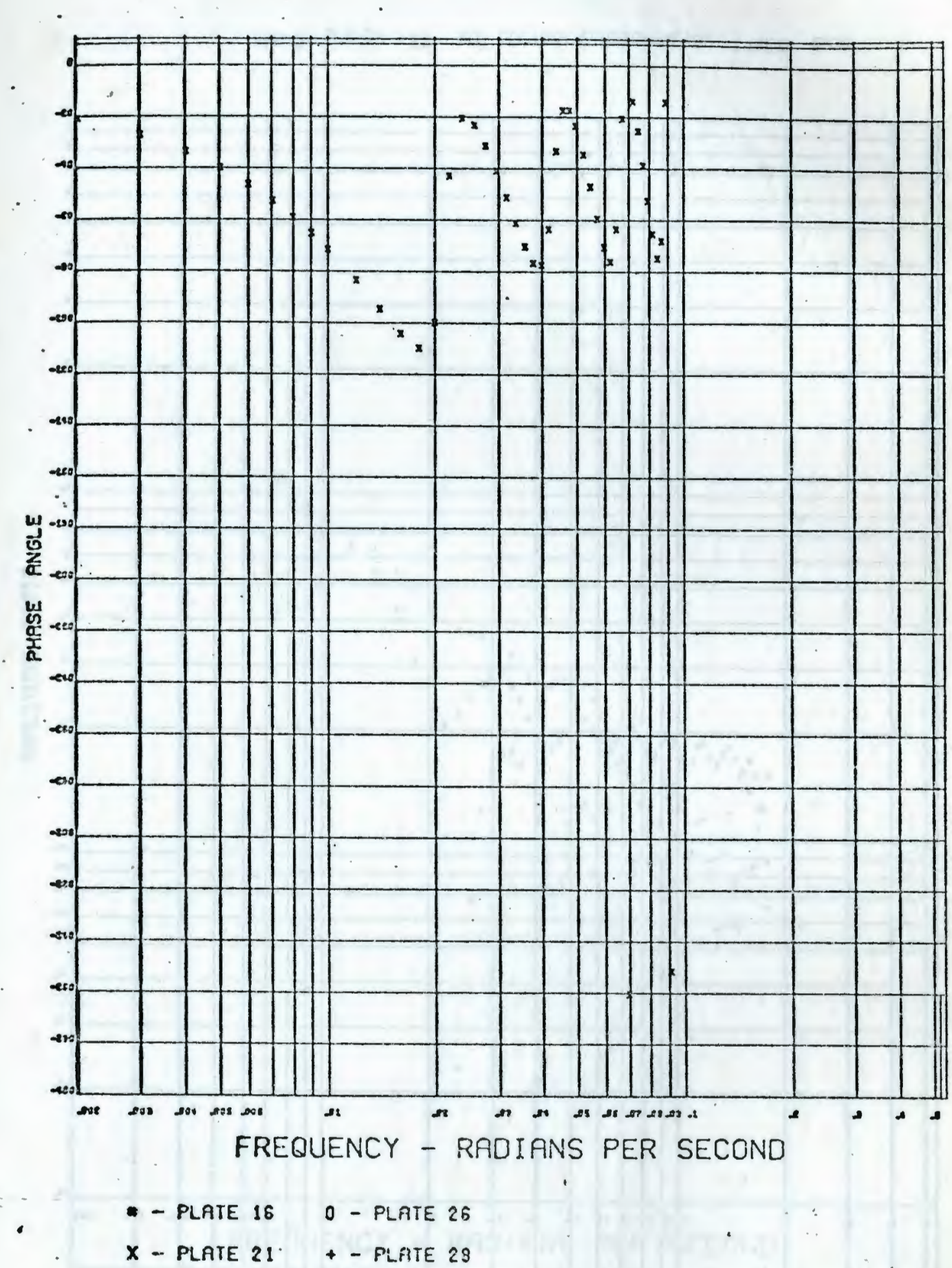


\section{BODE PLOT}

VAPOR PULSE 20 AT COLUMN PRESSURE OF 1.000 ATM.

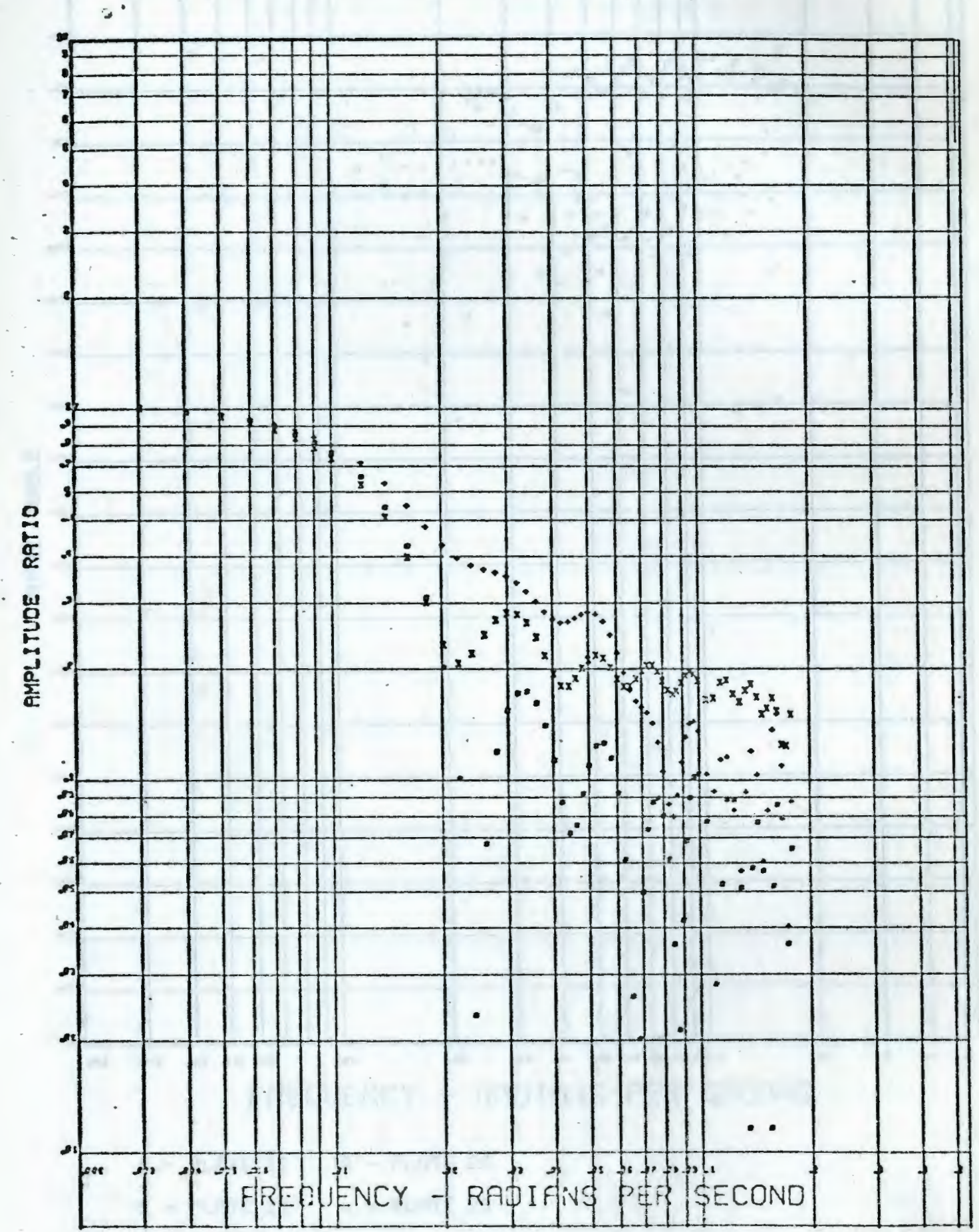




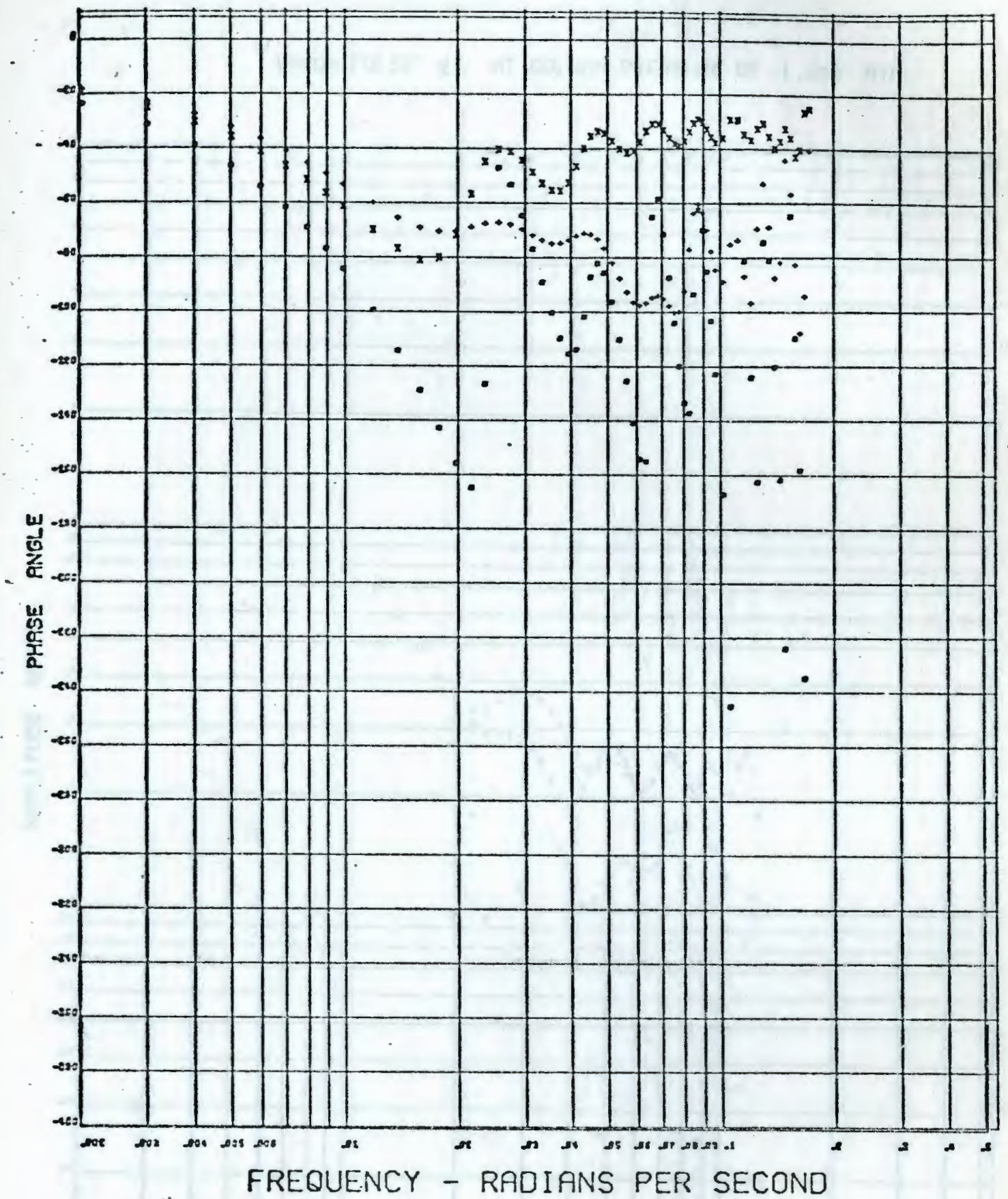

* plate 16 o-plate 28

X - plate 21. + plate 28 


\section{BODE PLOT}

YAPOR PULSE 21 AT COLUMN PRESSURE OF 1.000 ATM.

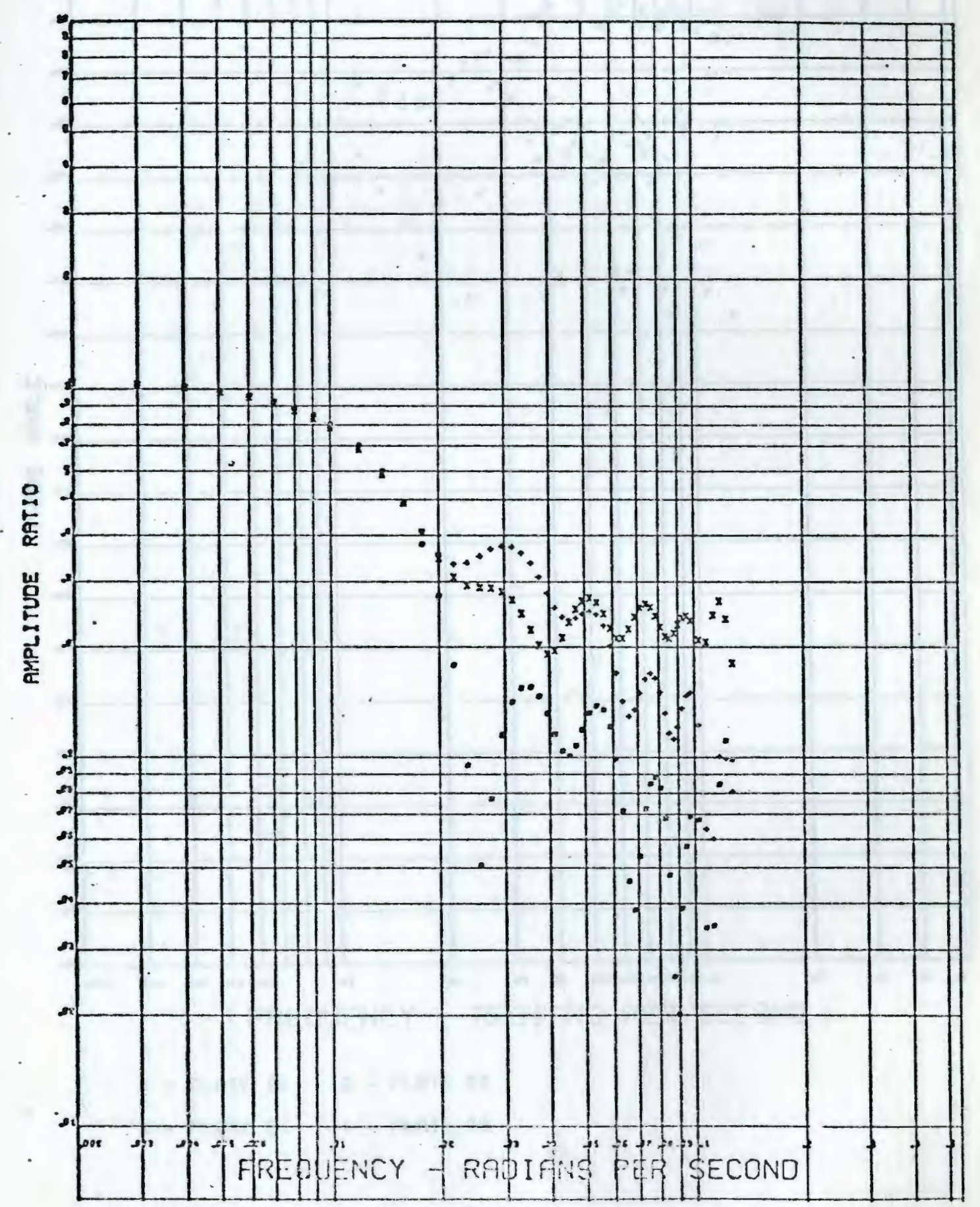




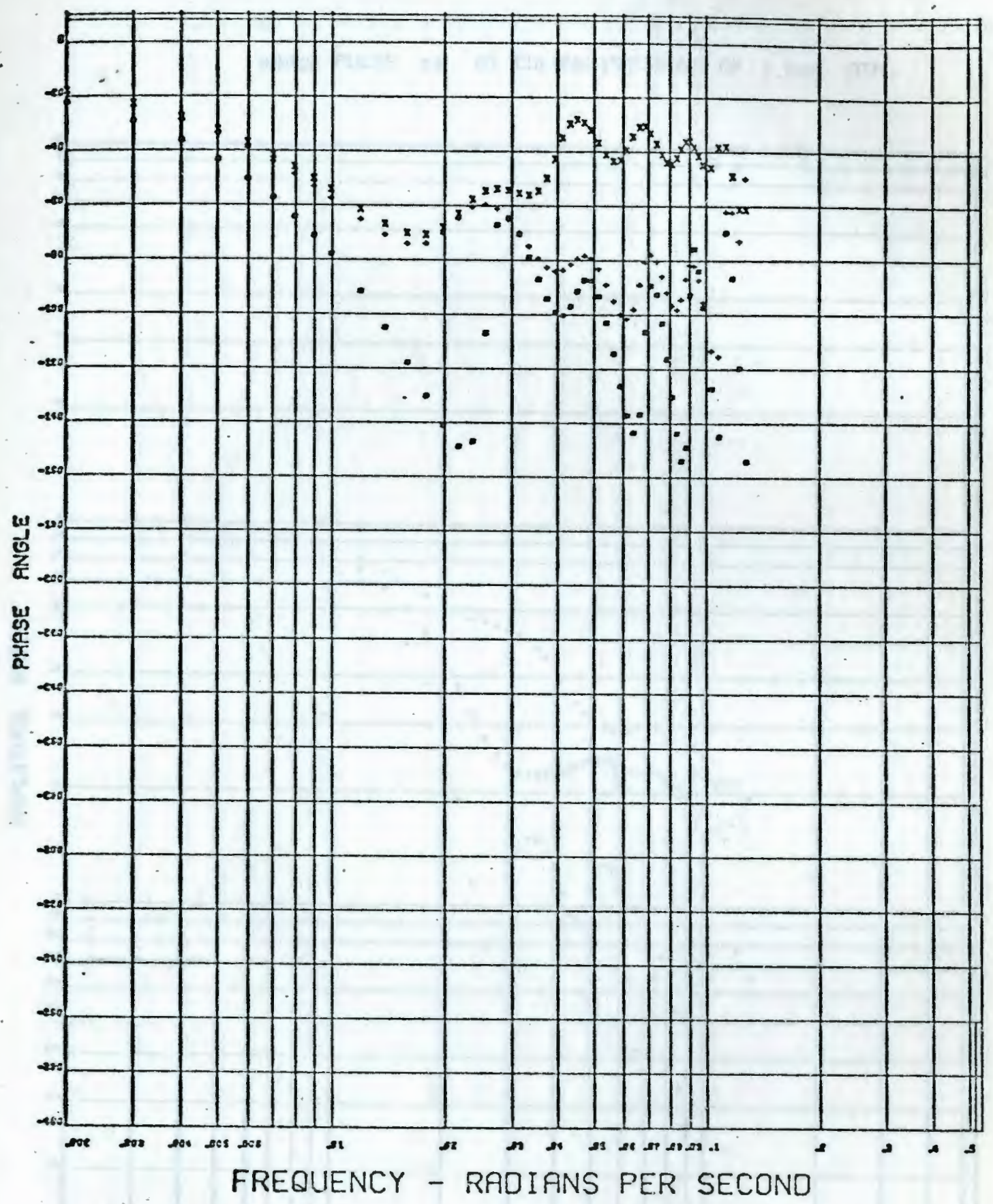

$\quad: \quad$ - Plate 18.0 - plate 26
X-PLate 21. 


\section{BODE . PLOT}

3. VAPOR PULSE 22 AT COLUMN PRESSURE OF 1.000 atM.

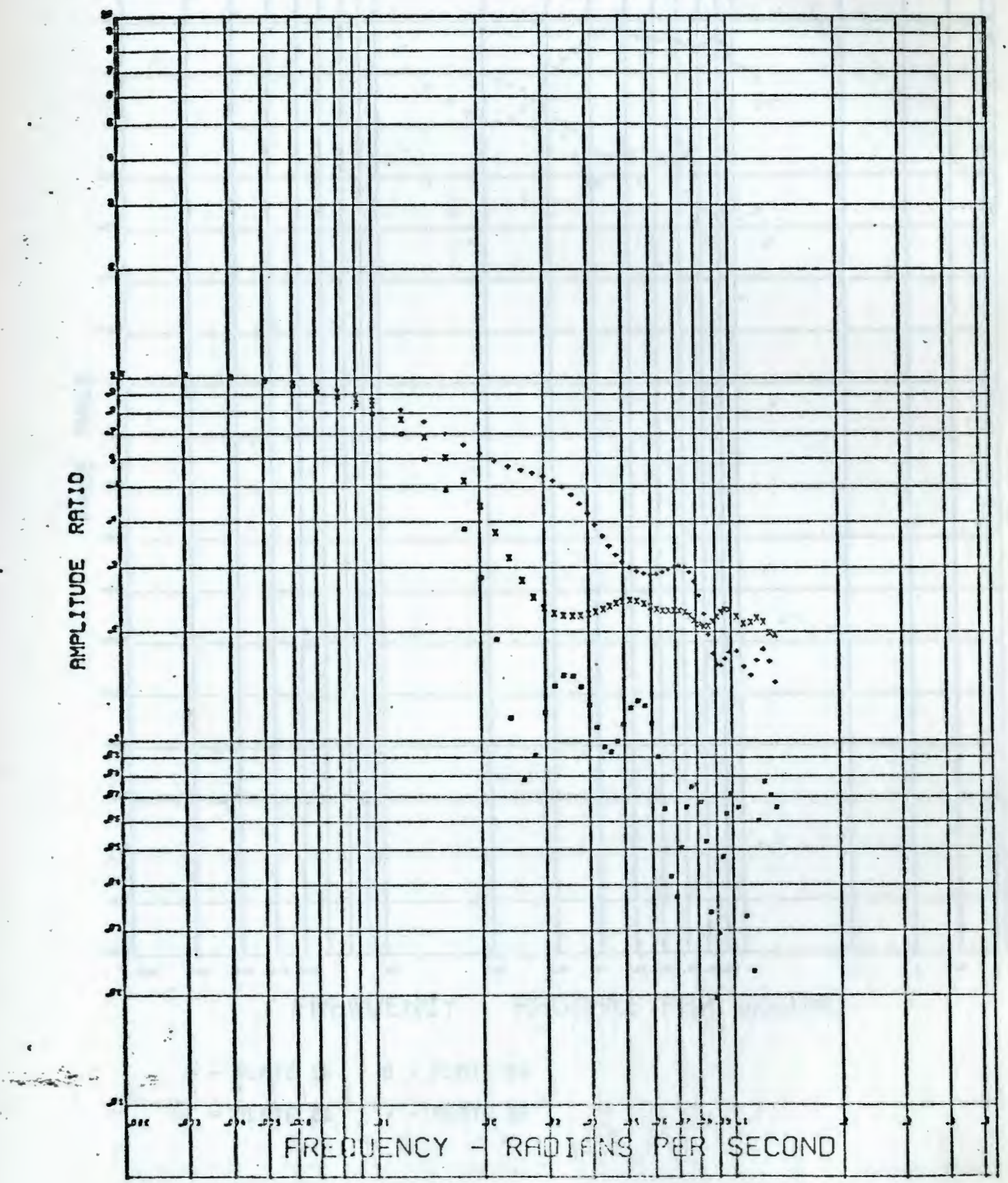




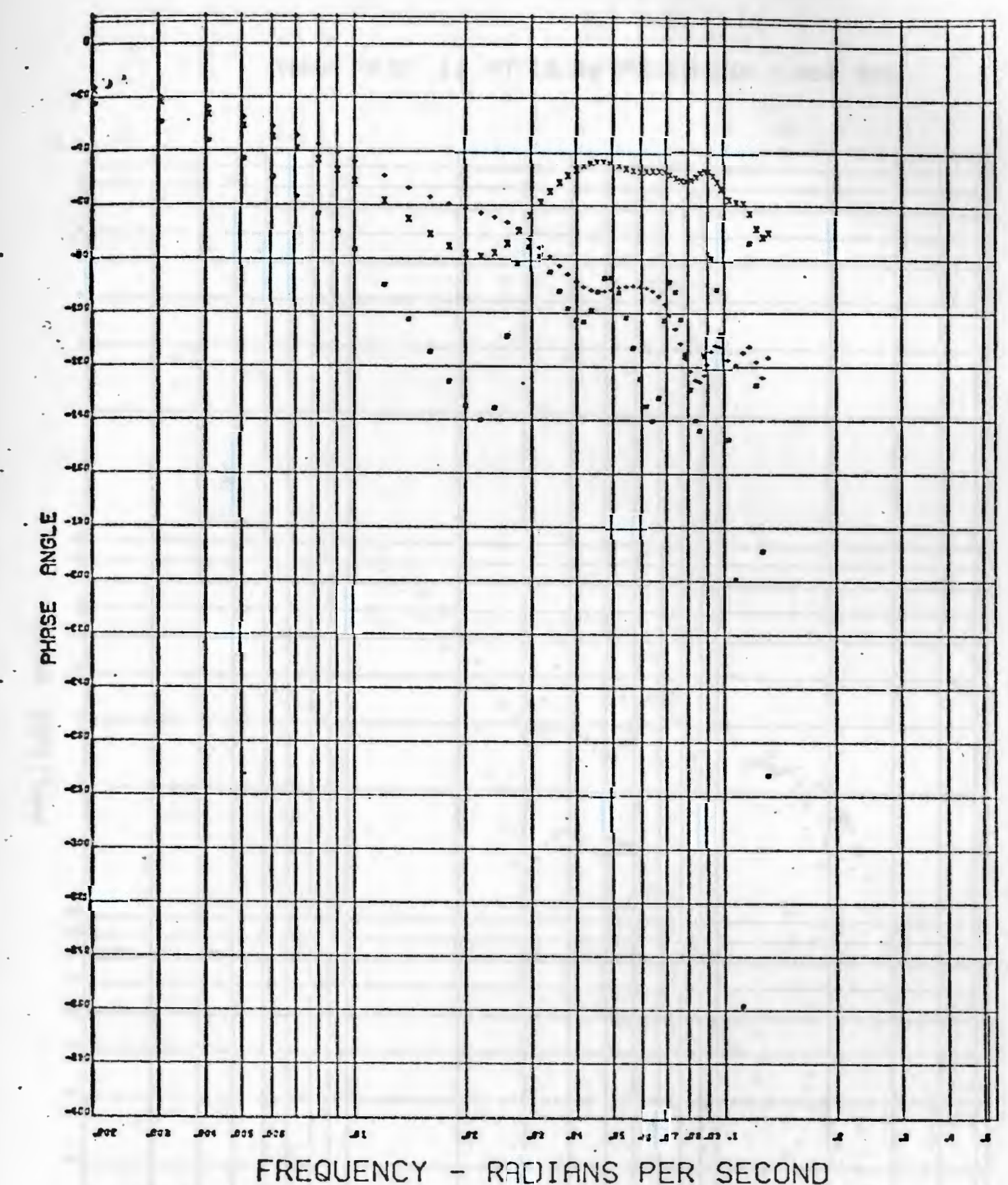

- plate 18 o-plate 28

X- plate 21. + - plate 28 


\section{BODE PLOT}

VAPOR PULSE 23 AT COLUMN PRESSURE DF 1.000 ATM.

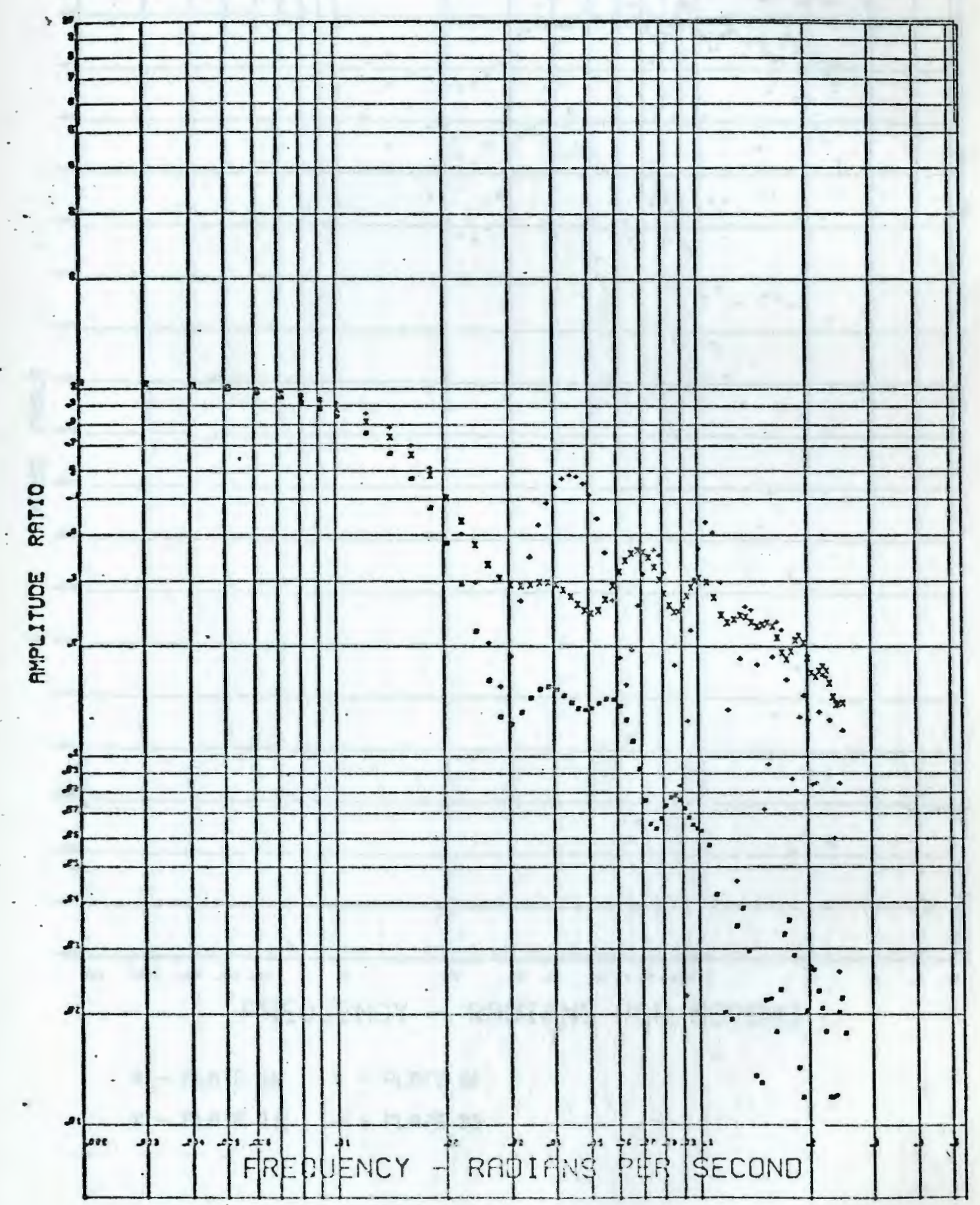




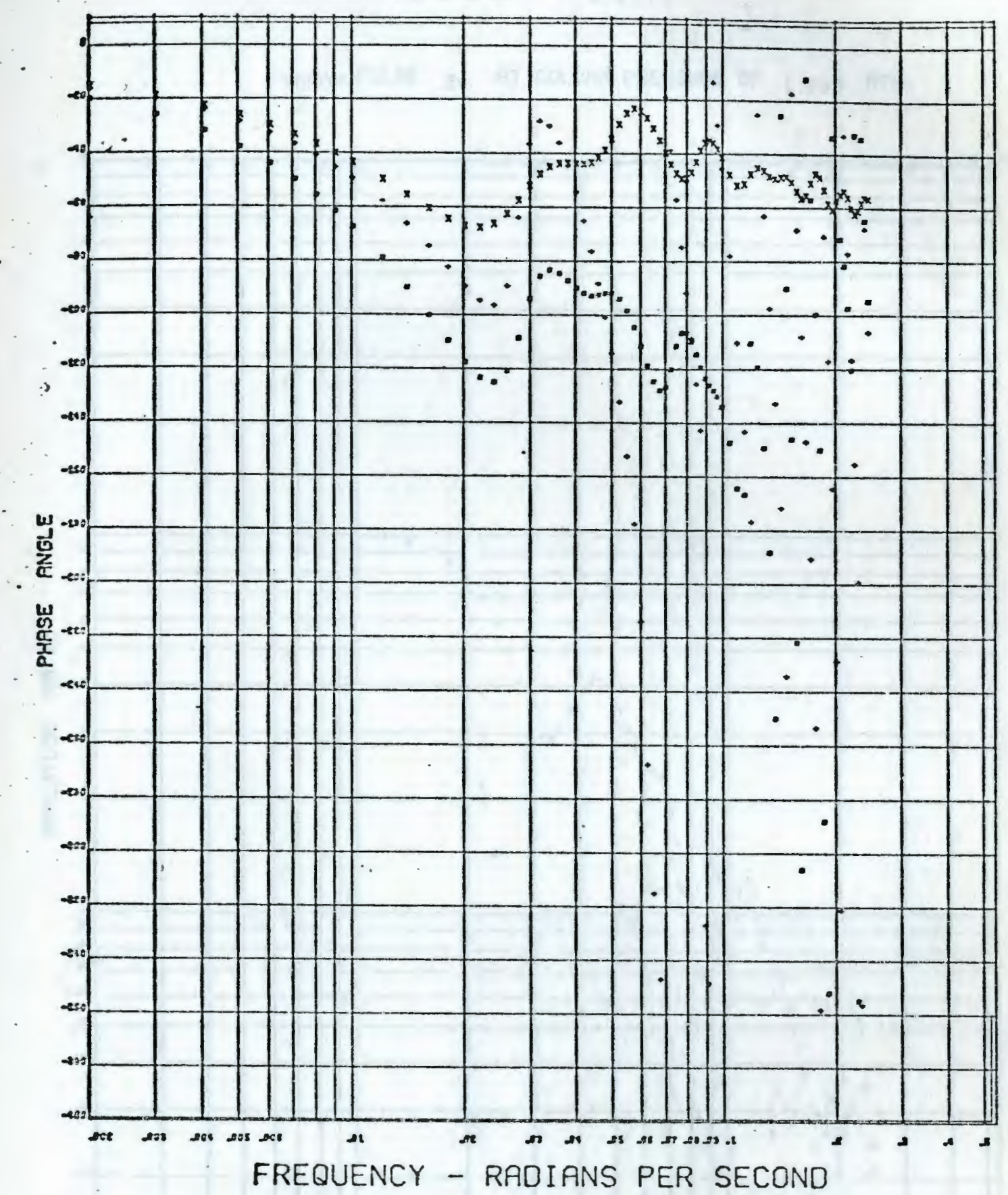

- plate 16 o-plate 26

X - PLATE $21 .+$ - plate 28 


\section{BODE PLOT}

$\therefore$ VAPOR PULSE 24 AT COLUMN PRESSURE OF 1.000 ATM.

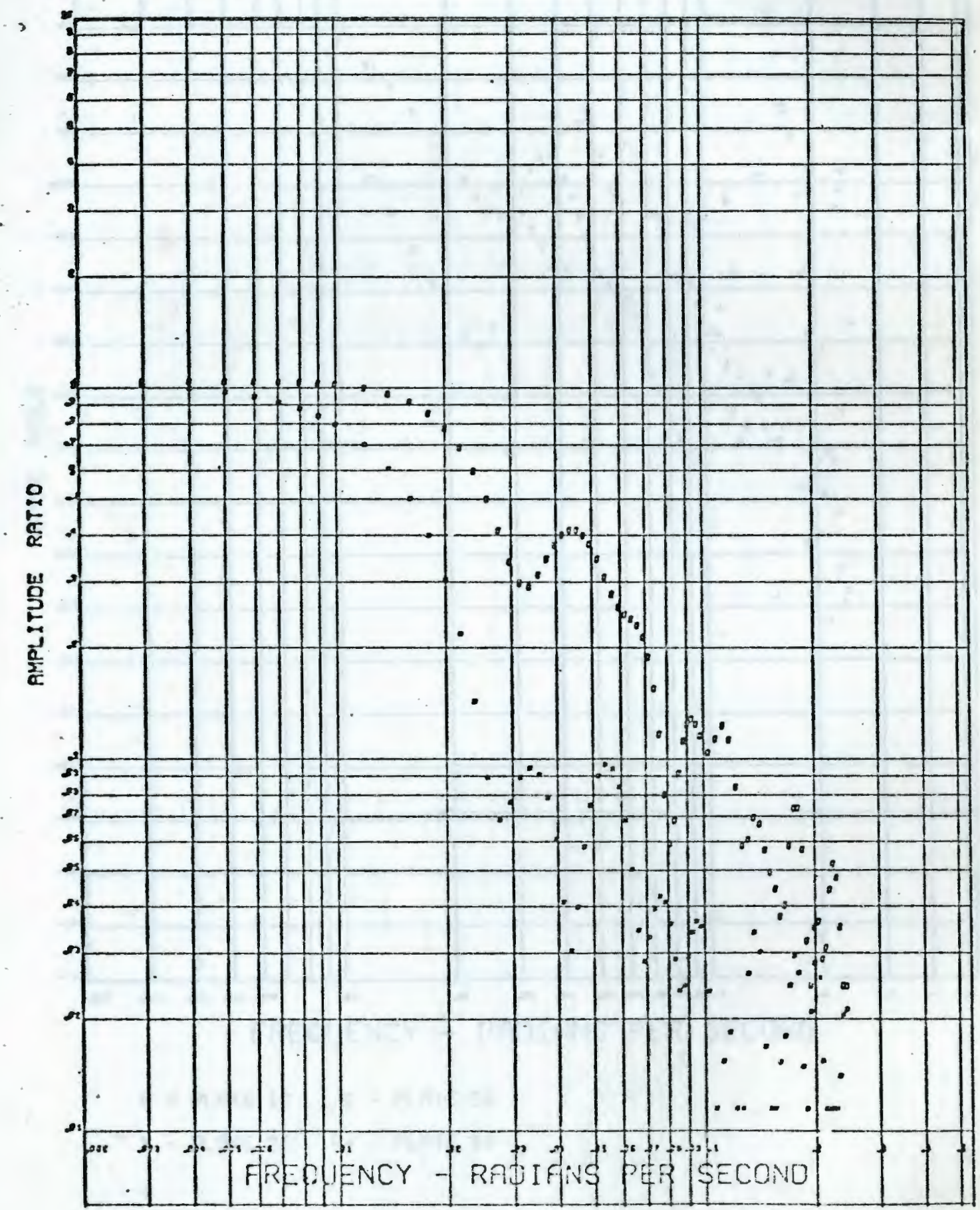



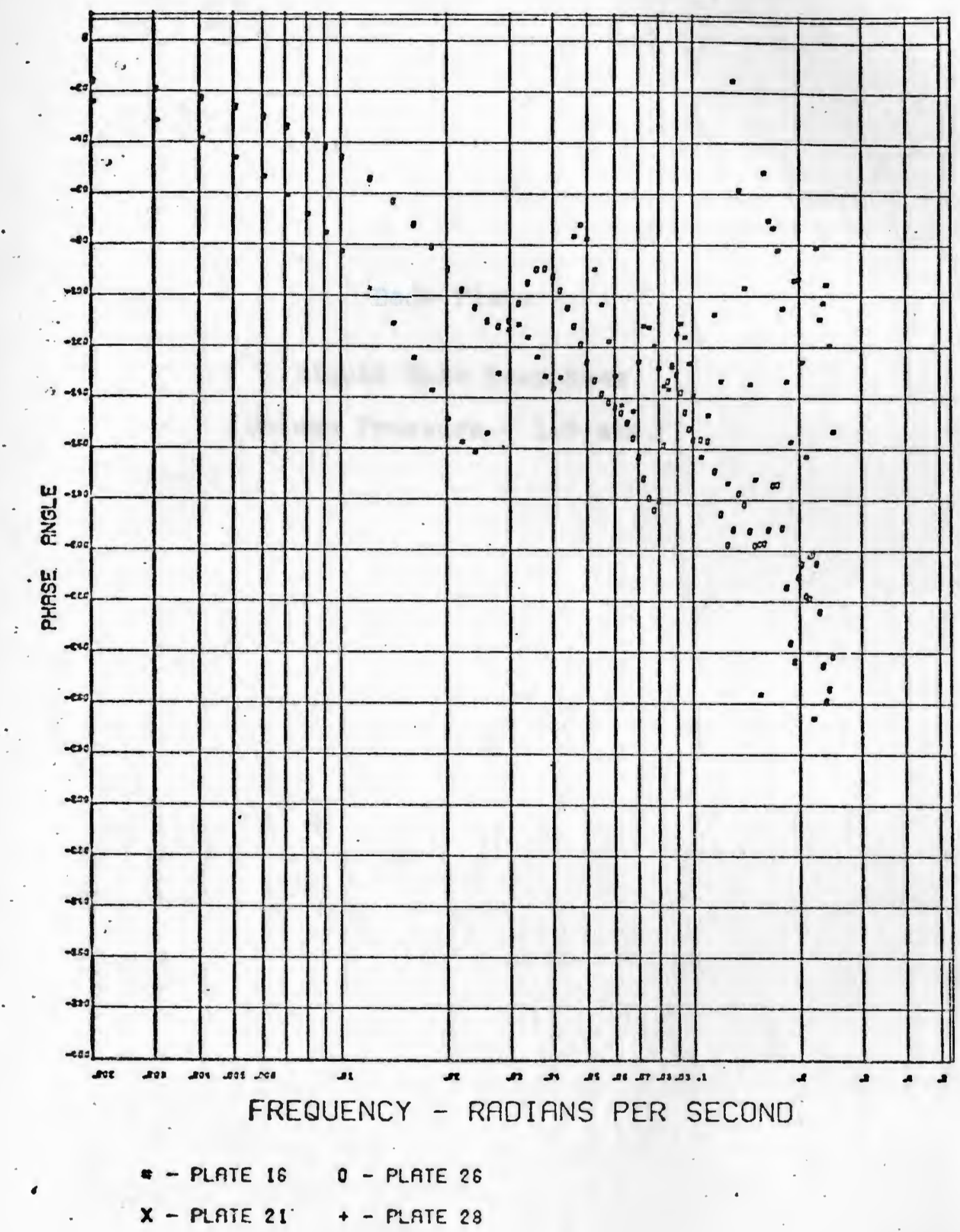
Bode Plots

Liquid Rate Responses

Column Pressure - 1.0 atm. 


\section{BODE PLOT}

LIQUID FULSE 1 AT COLUMN PRESSURE OF 1.000 ATM.

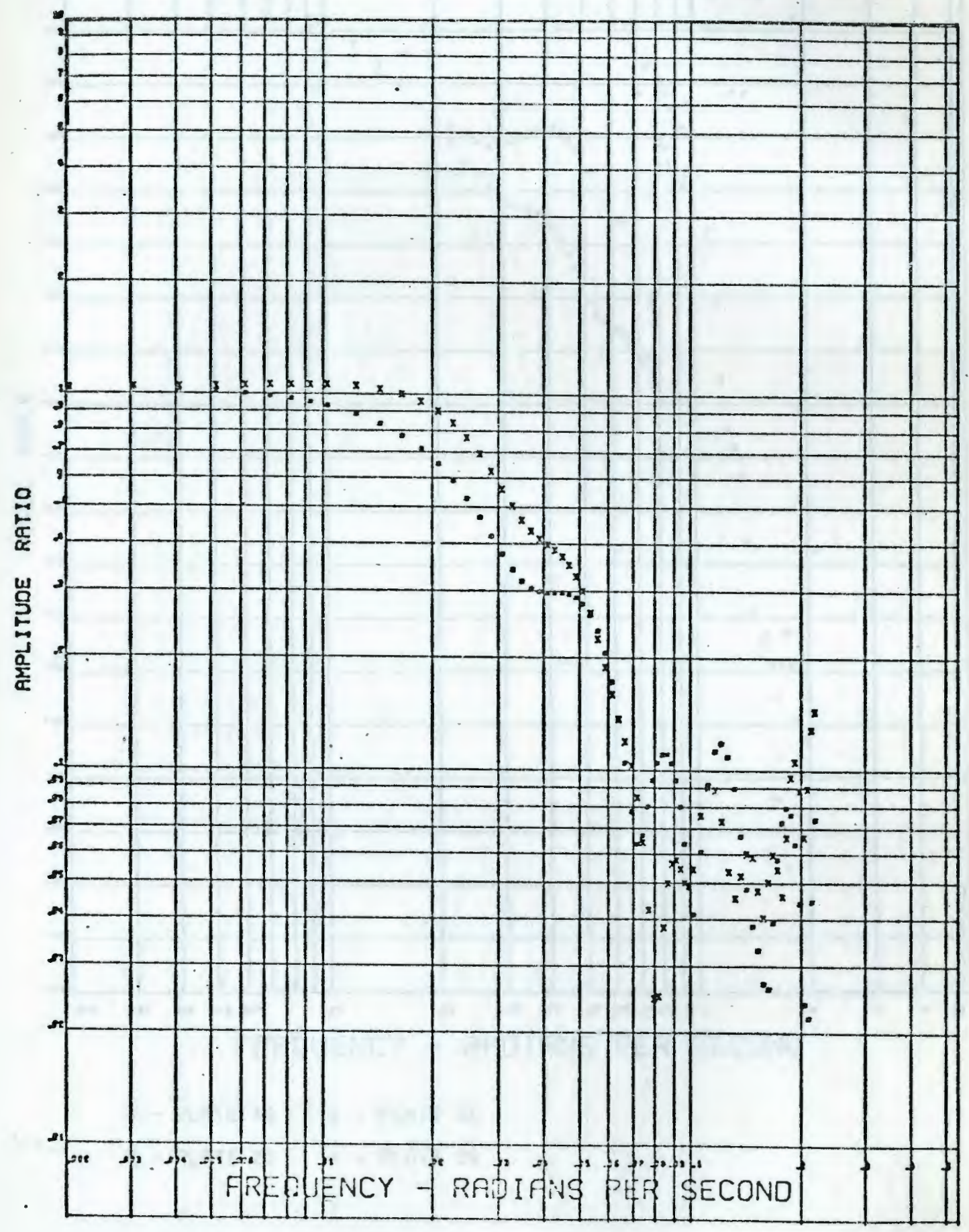



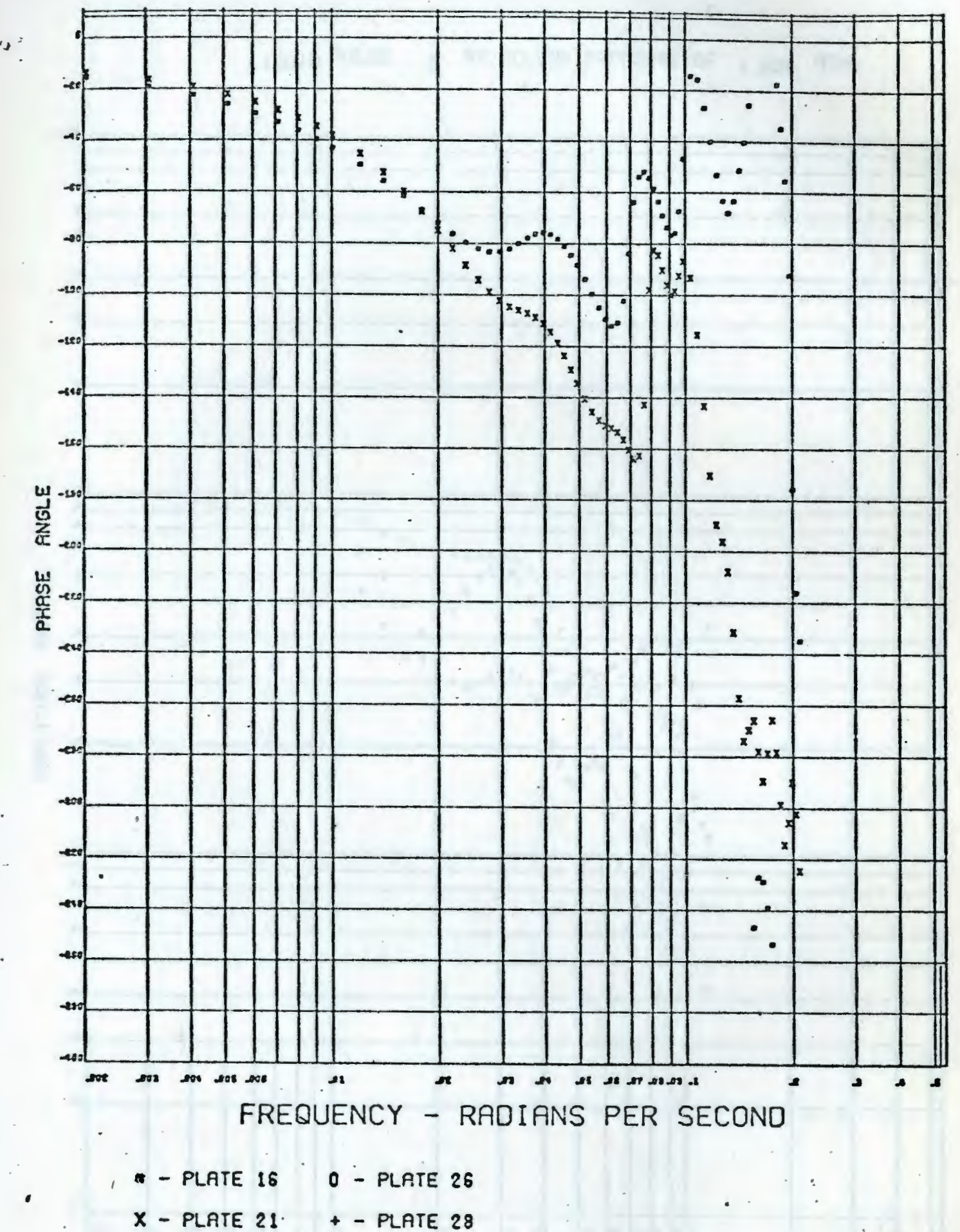


\section{BODE PLOT}

LIQUIO PULSE 2 AT COLUMN PRESSURE OF 1.000 ATM.

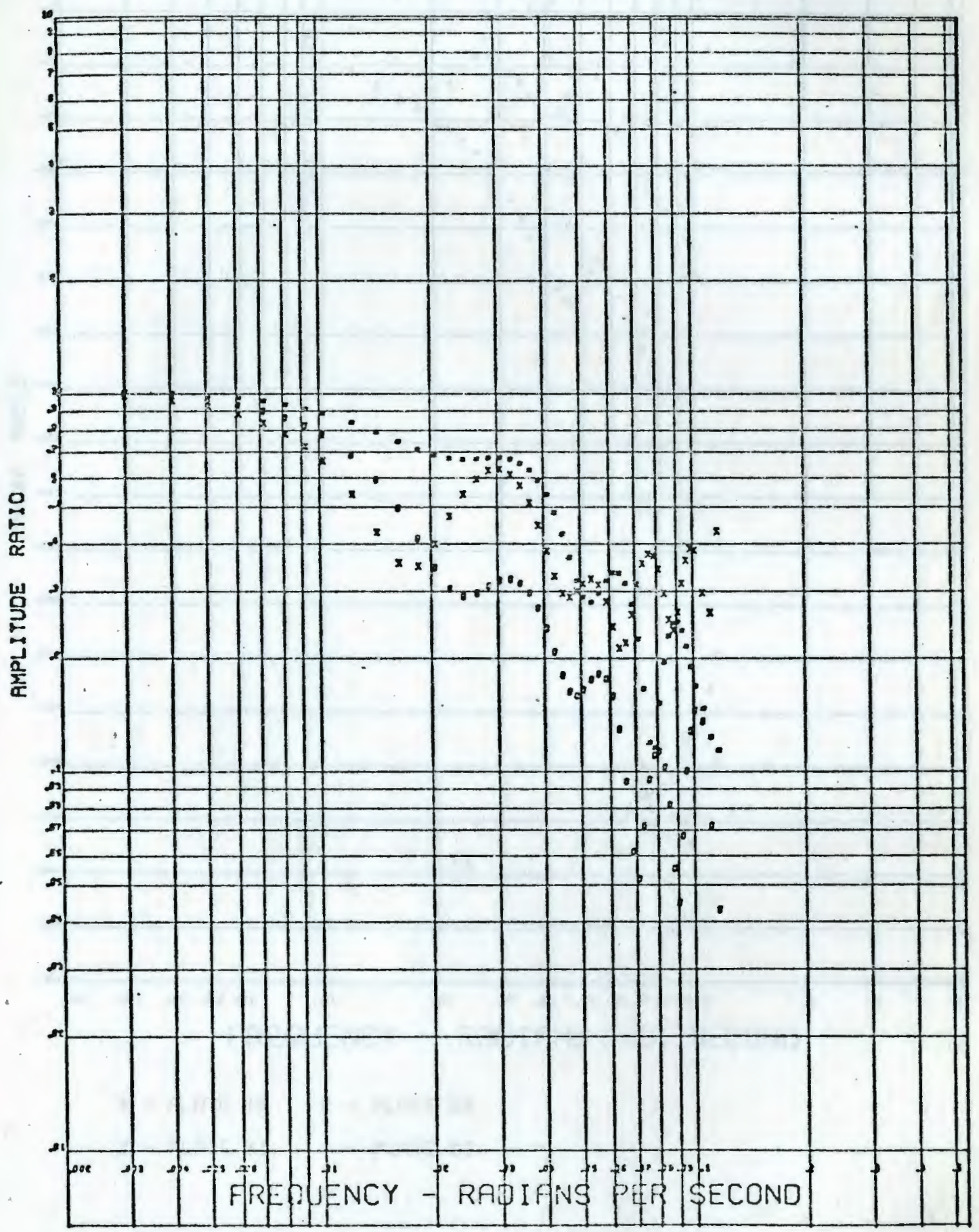




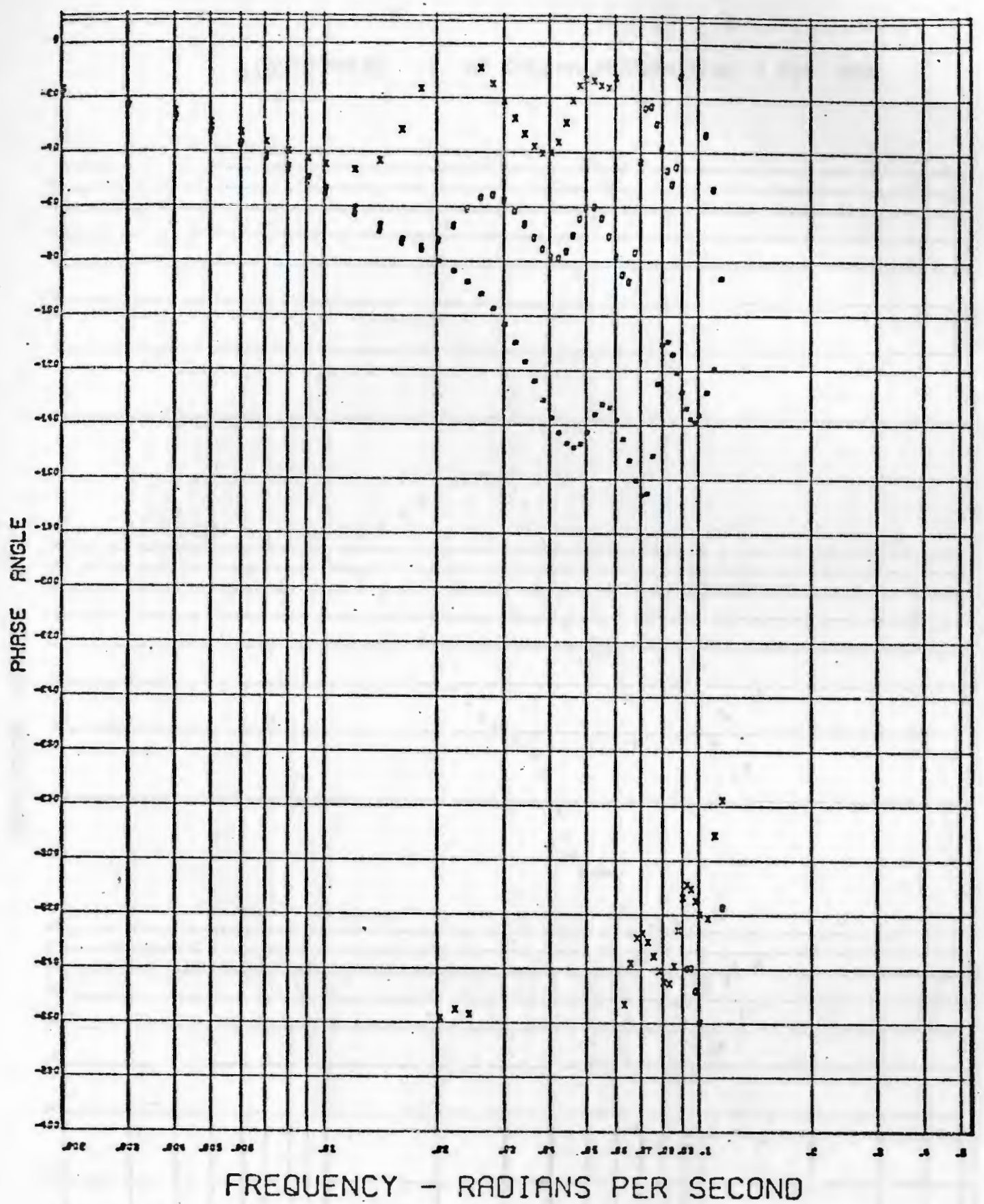

- plate 16 o-plate 26

X - plate $21 .+$ - plate 28 


\section{BODE PLOT}

LIOUID PULSE 3 AT COLUMN PRESSURE OF 1.000 ATM.

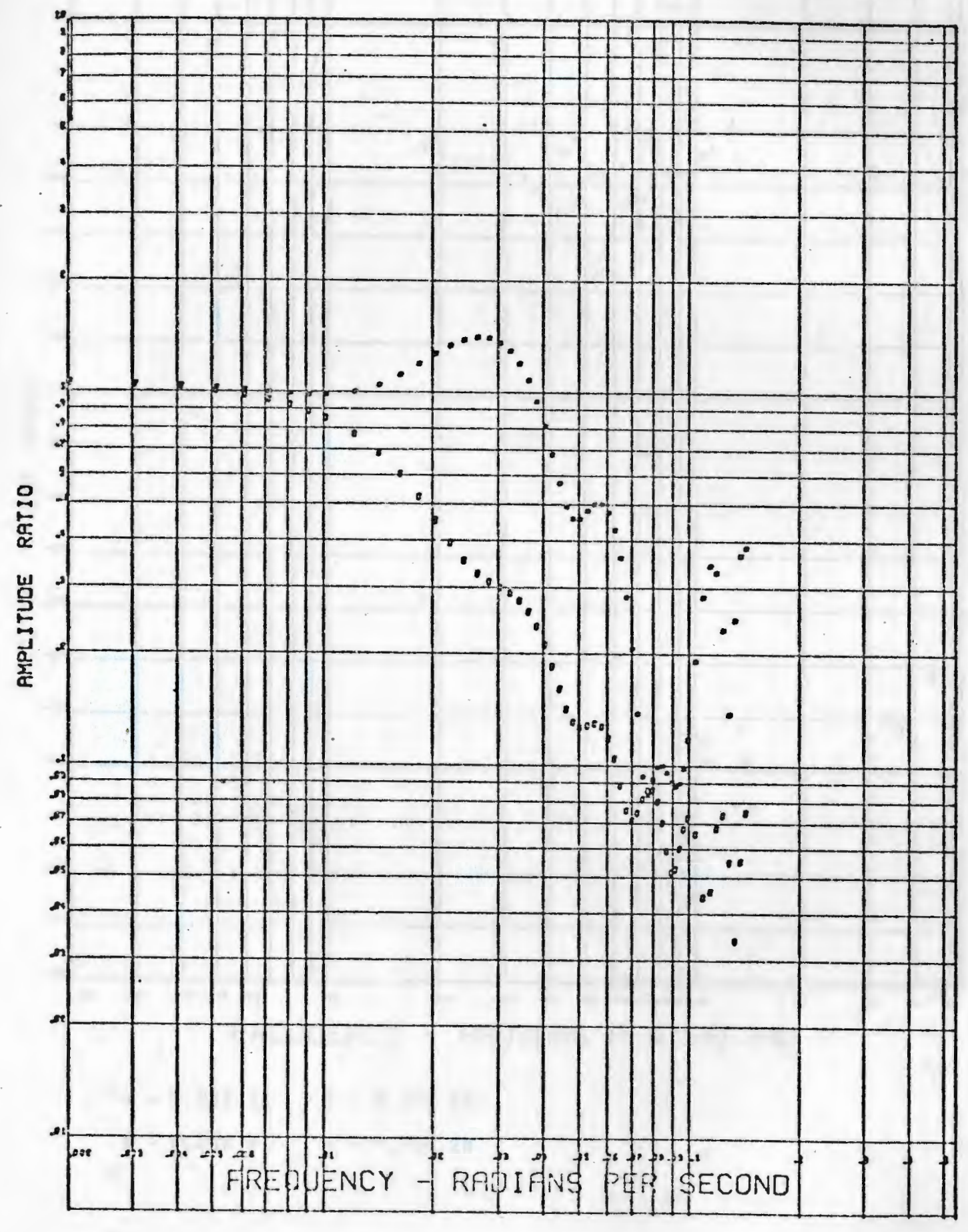




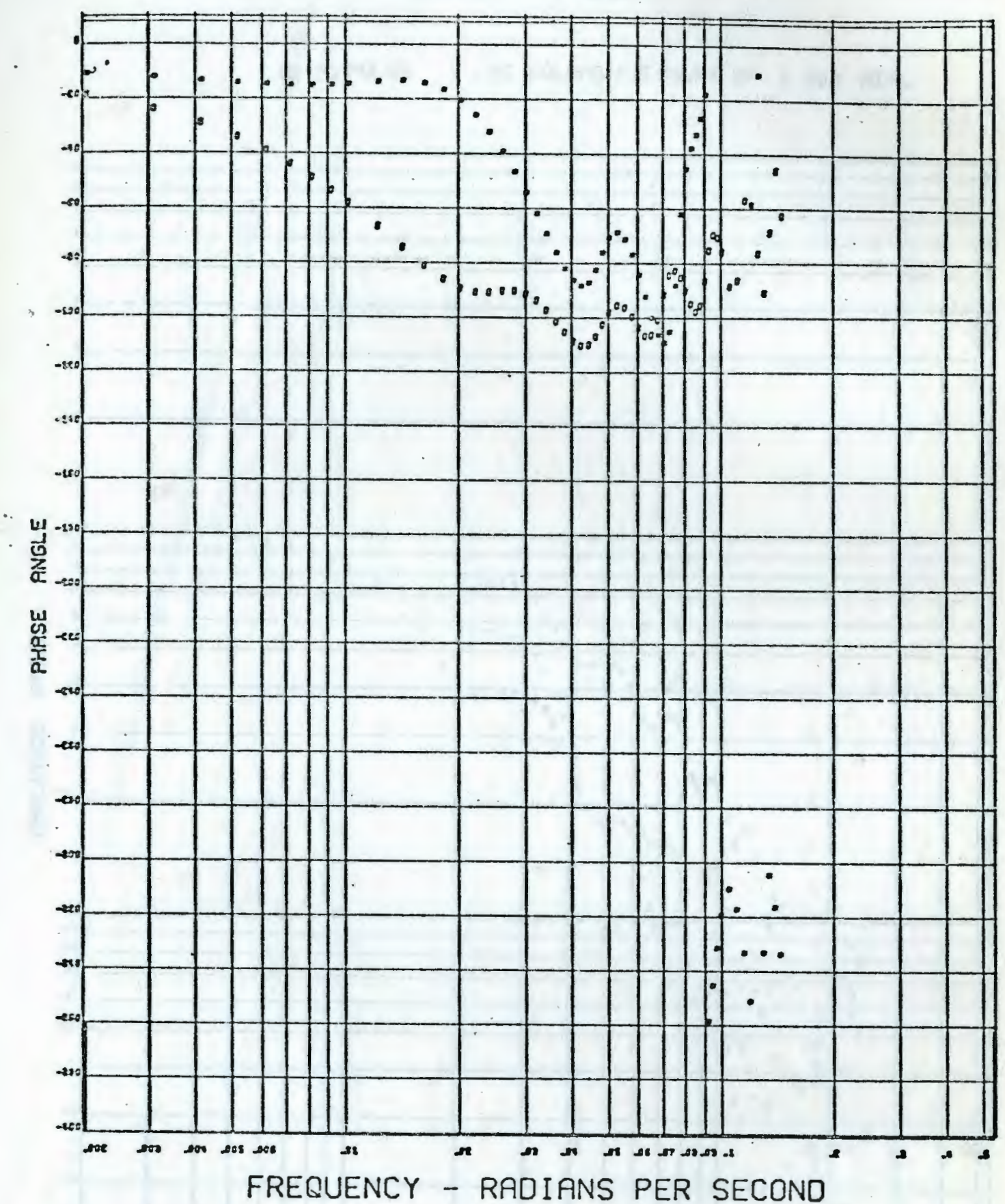

- plate 16 - plate 25

X - plate 21 + - plate 28 


\section{BODE PLOT}

LIQUID PULSE 4 AT COLUMN PRESSURE OF 1.000 ATM.

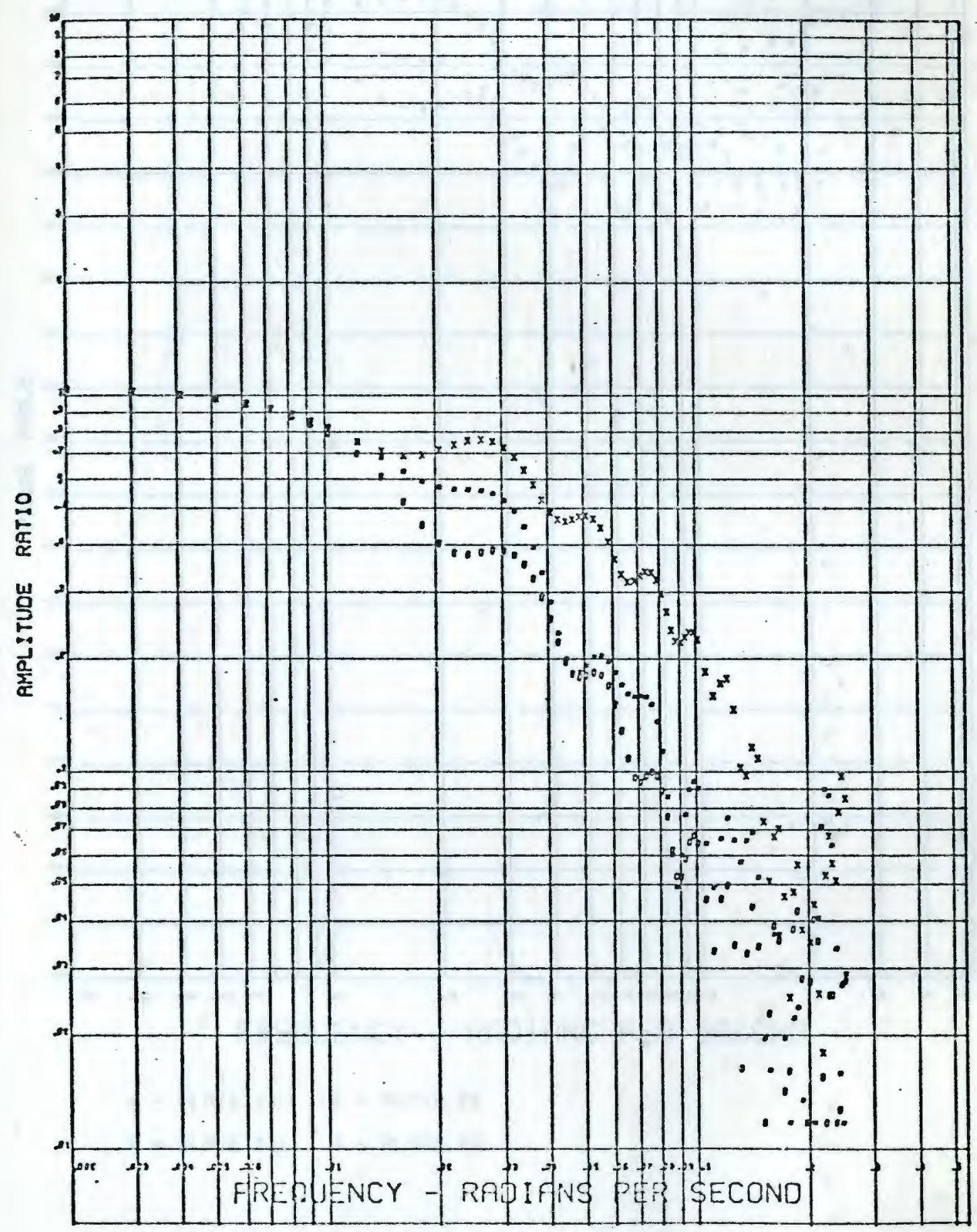




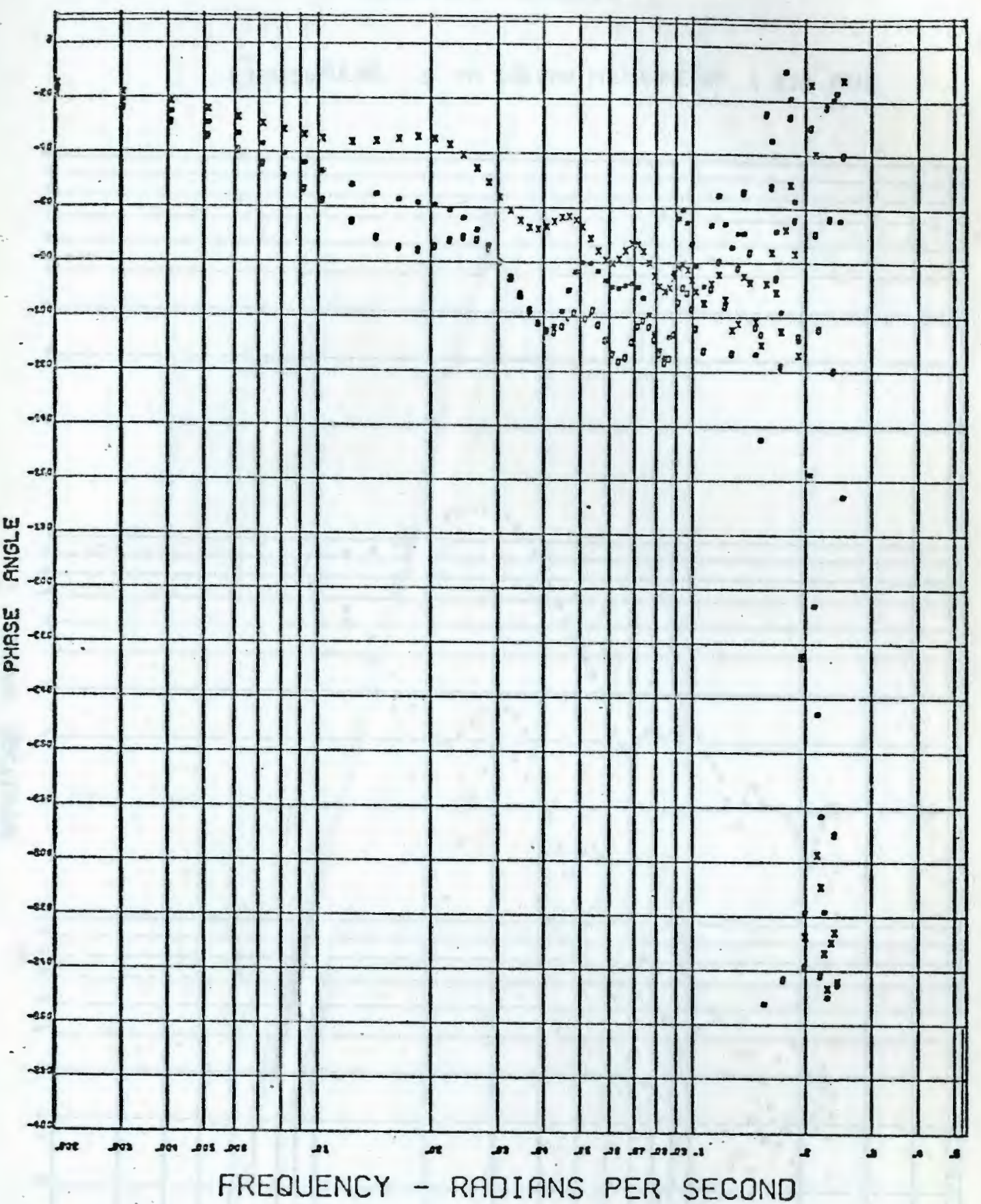

- plate 16 - plate 26

X - plate 21 + - plate 28 


\section{BODE PLOT}

LIQUJOPULSE 5 AT COLUMN PRESSURE OF 1.000 FITM.

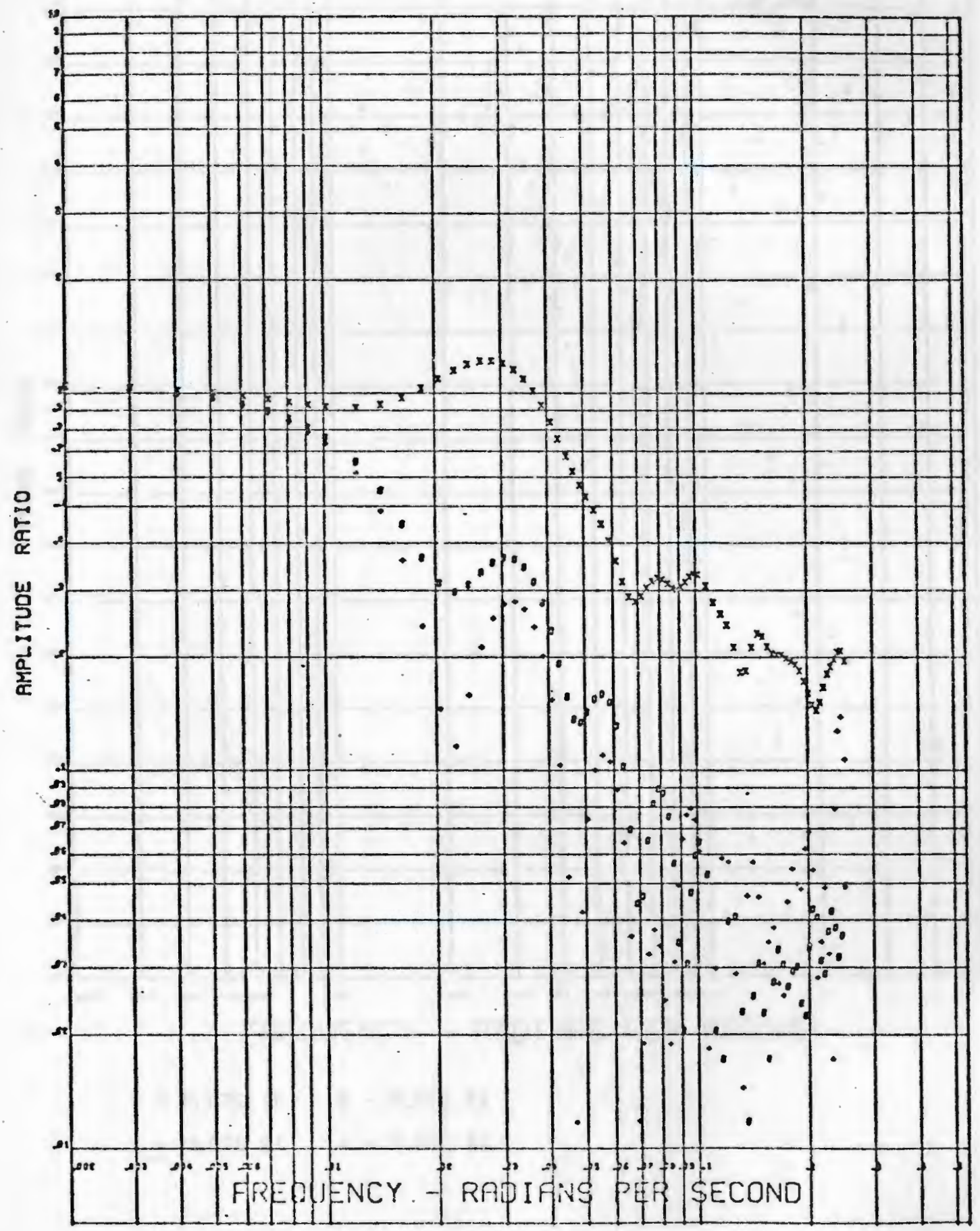




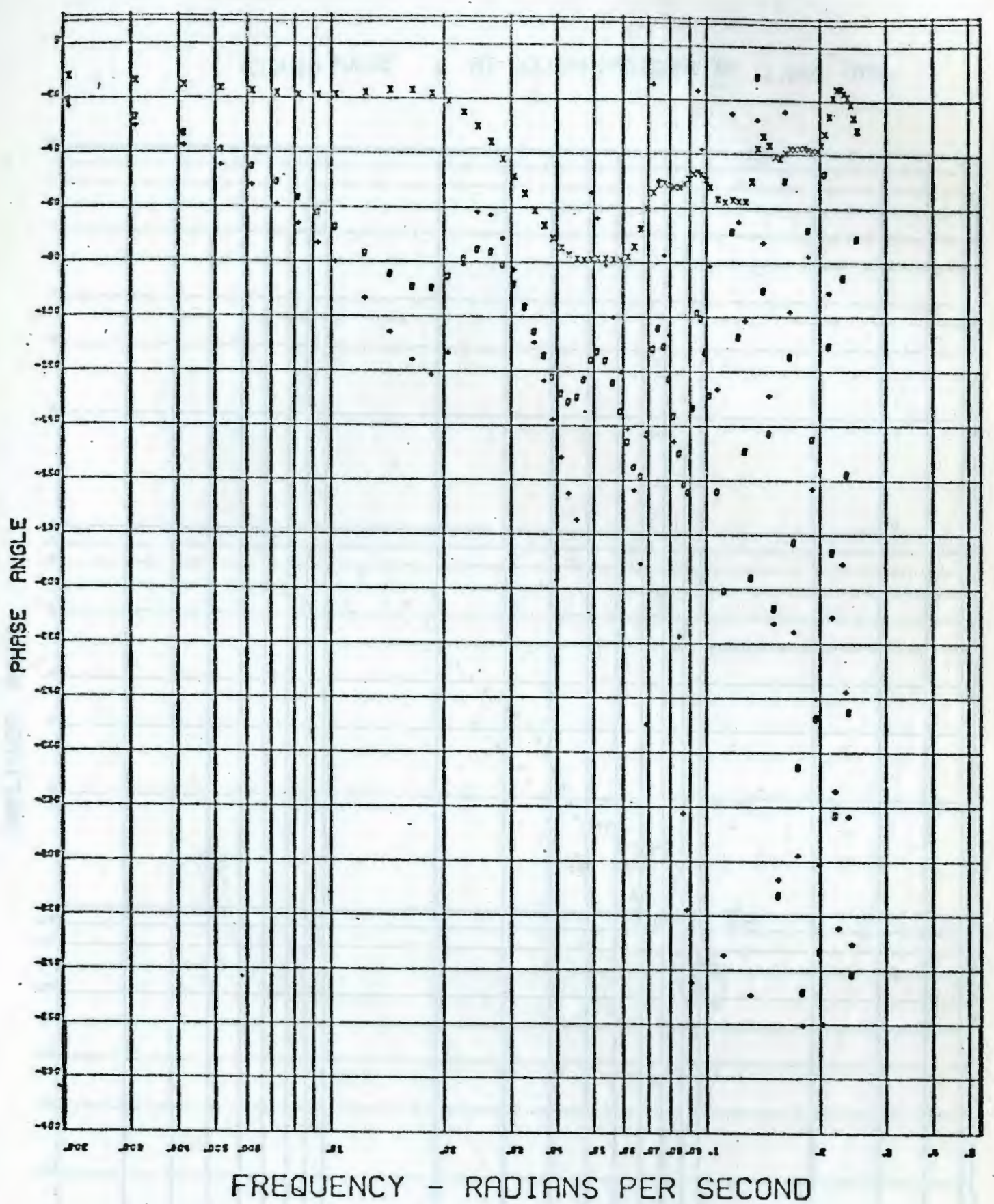

- plate 16 0 - plate 26

$x$ - plate 21. + plate 28 


\section{BODE PLOT}

LIQUIO PULSE 6 AT COLUMN PRESSURE OF 1.000 ATM.

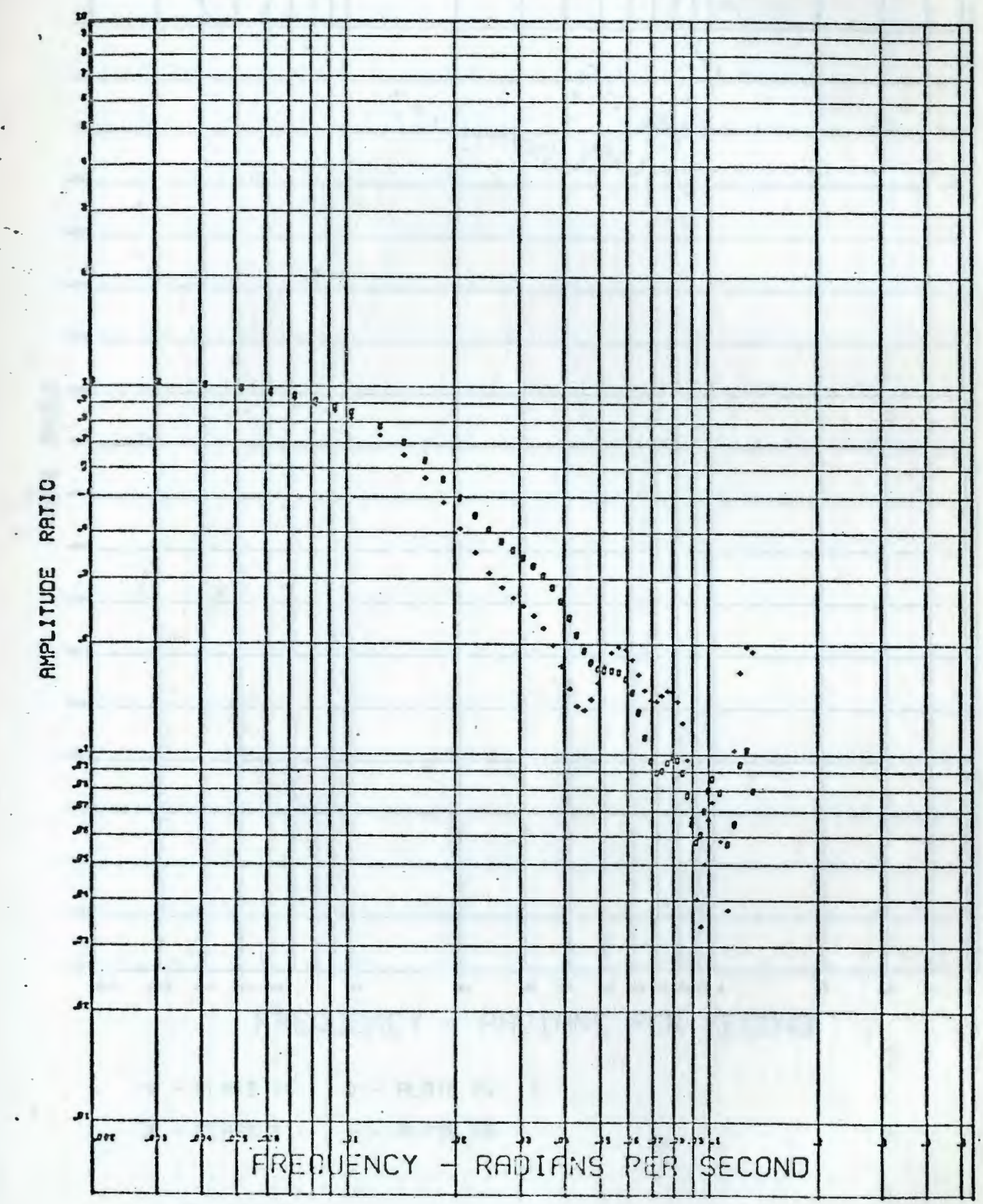




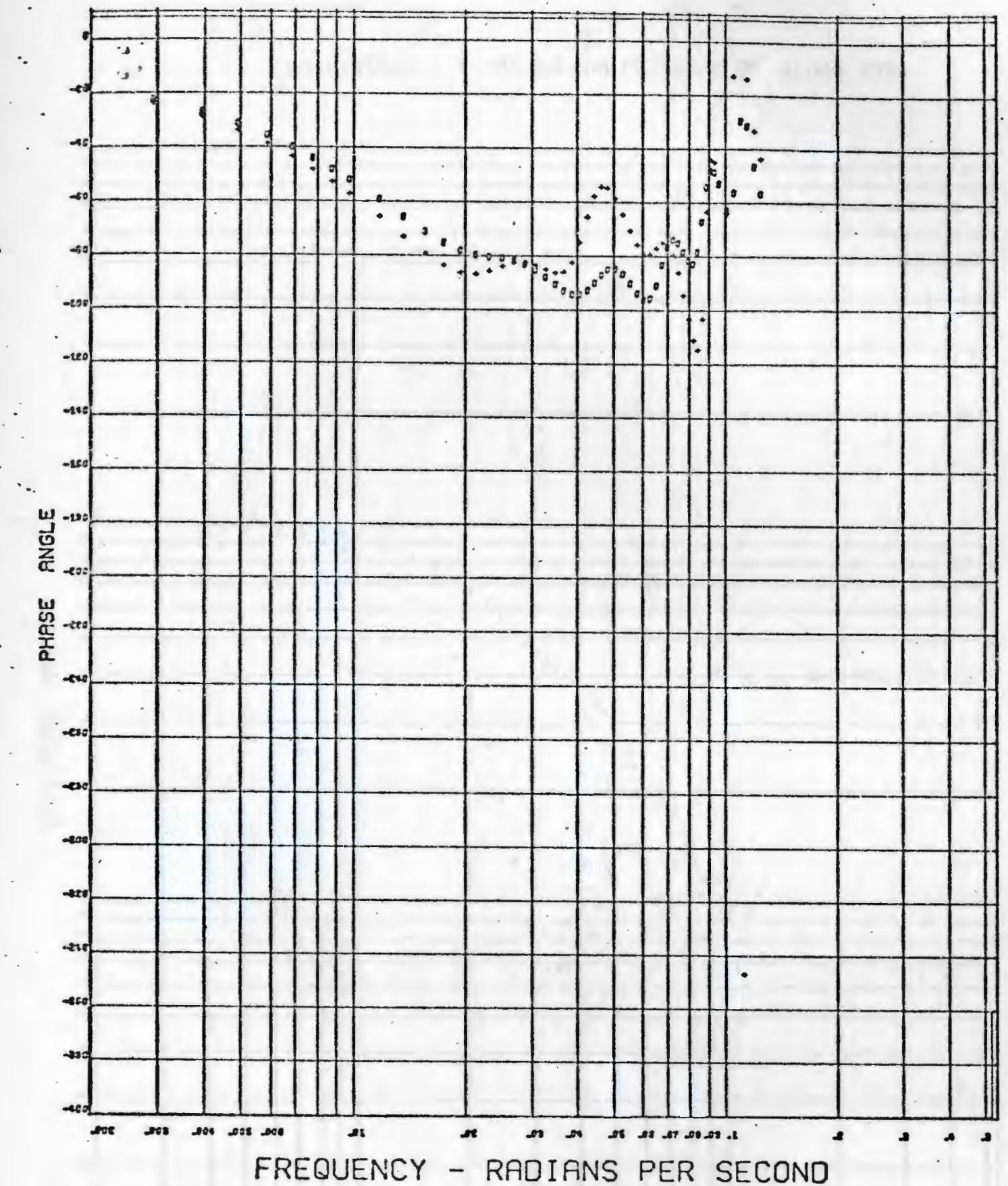

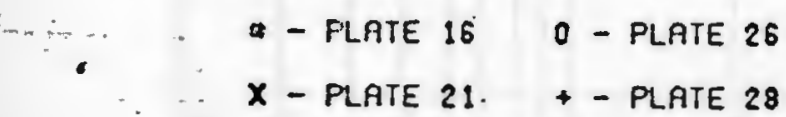




\section{BODE PLOT}

- Lieuid PULSE 7 at COlum pressure of 1.000 ath.

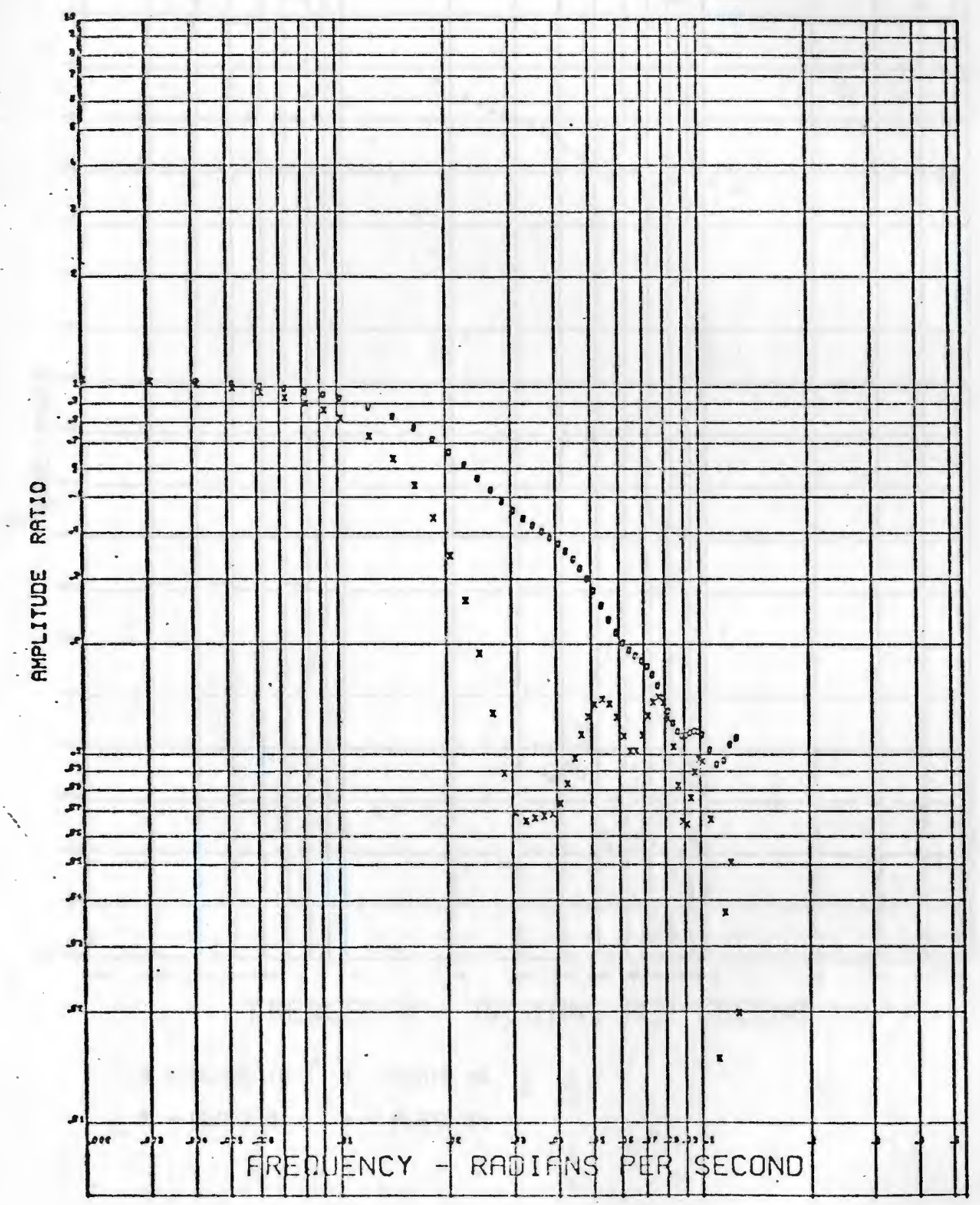




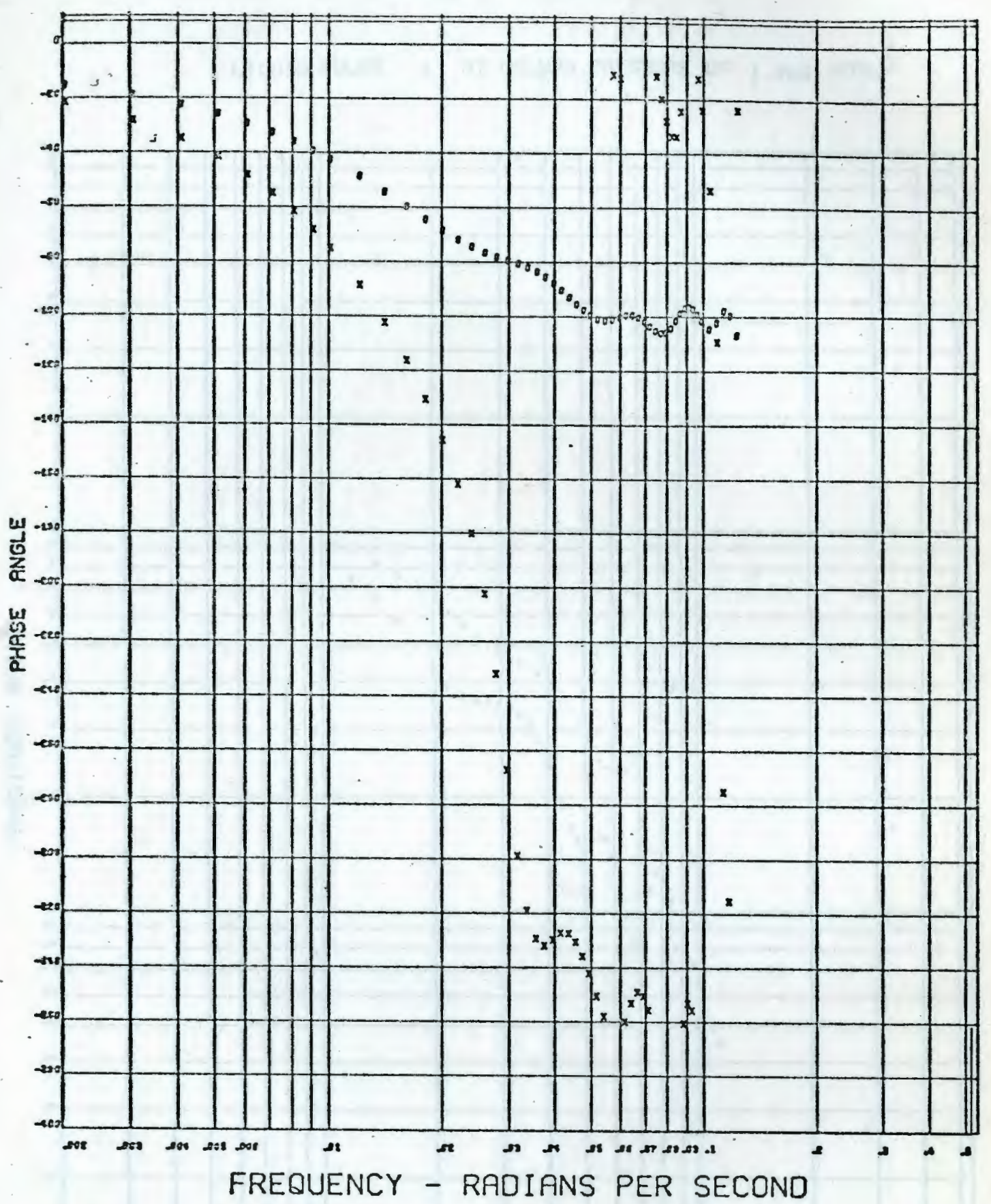

$-1$

- plate 16 o-plate 26

$\therefore X$ - Plate 21 + - PI.ate 28 


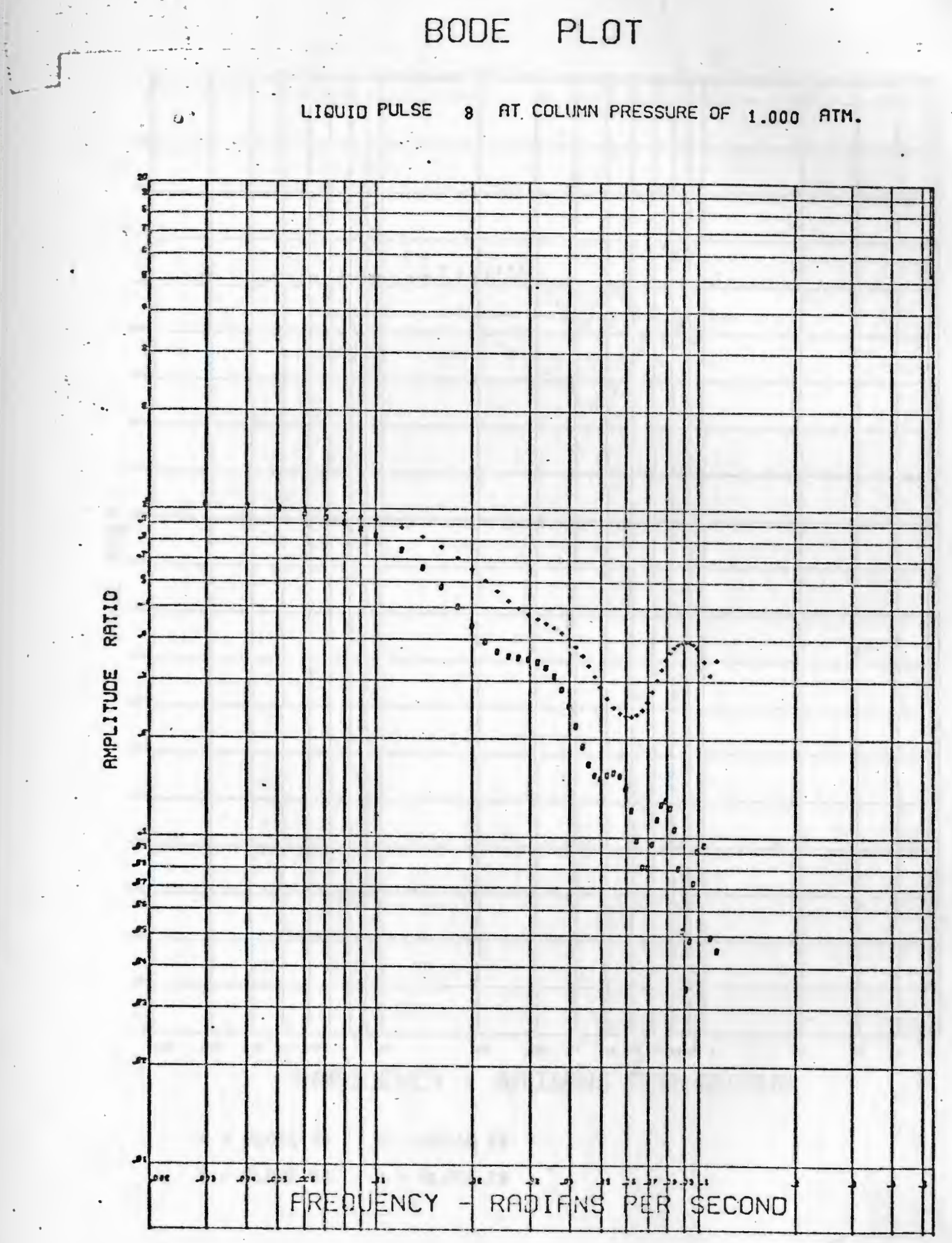



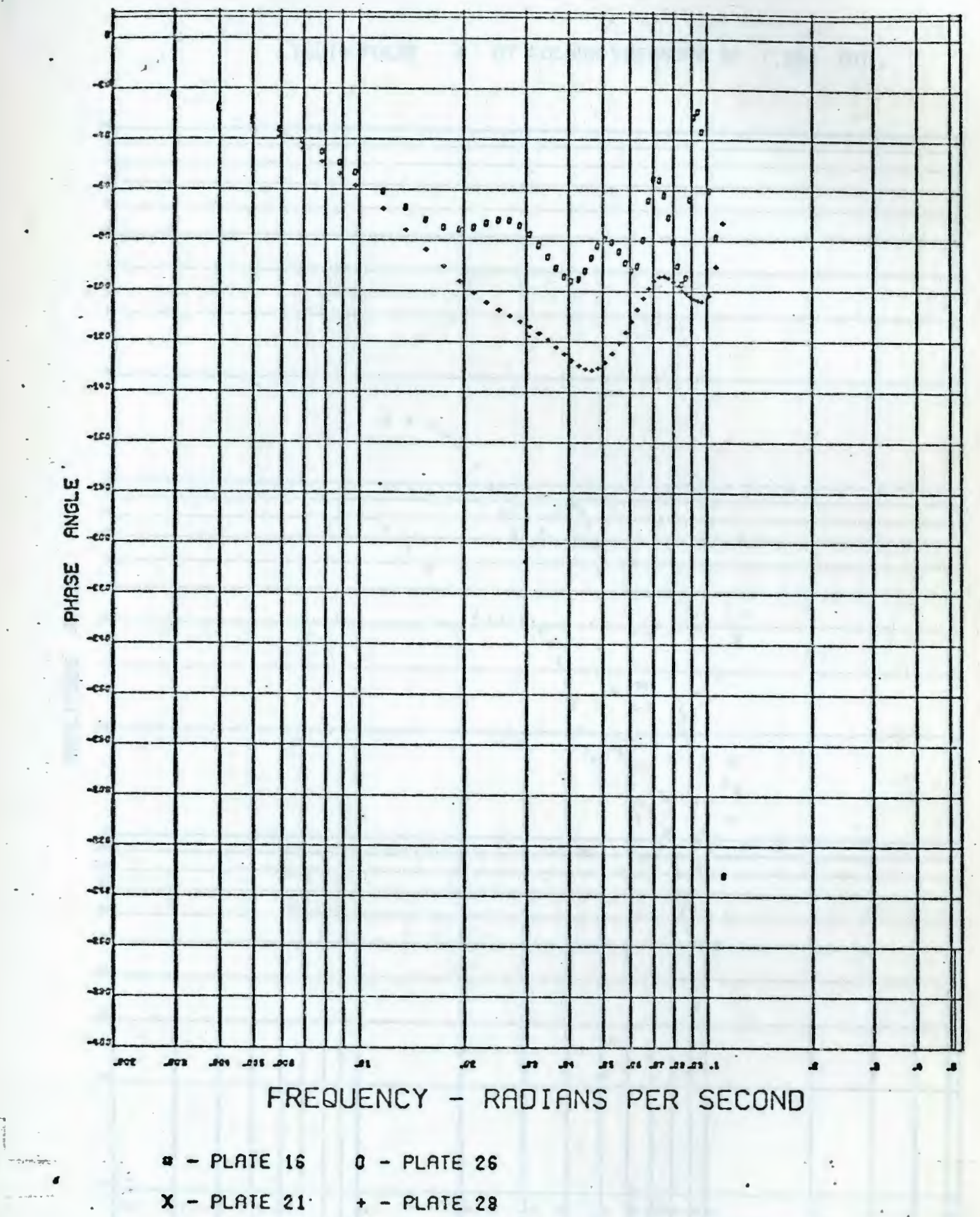


\section{BODE PLOT}

LIQUID PULSE 9 AT COLUMN PRESSURE OF 1.000 ATM.

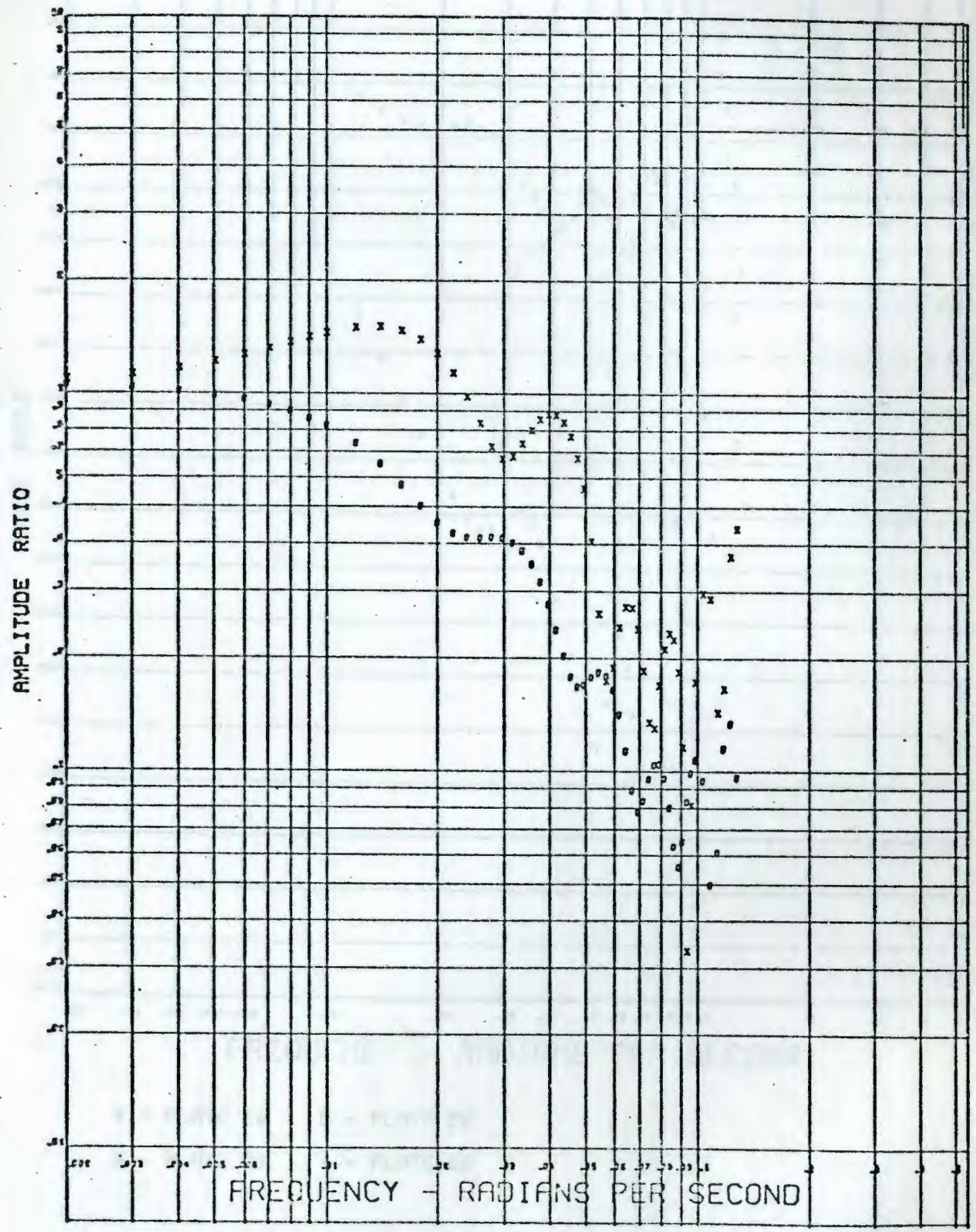




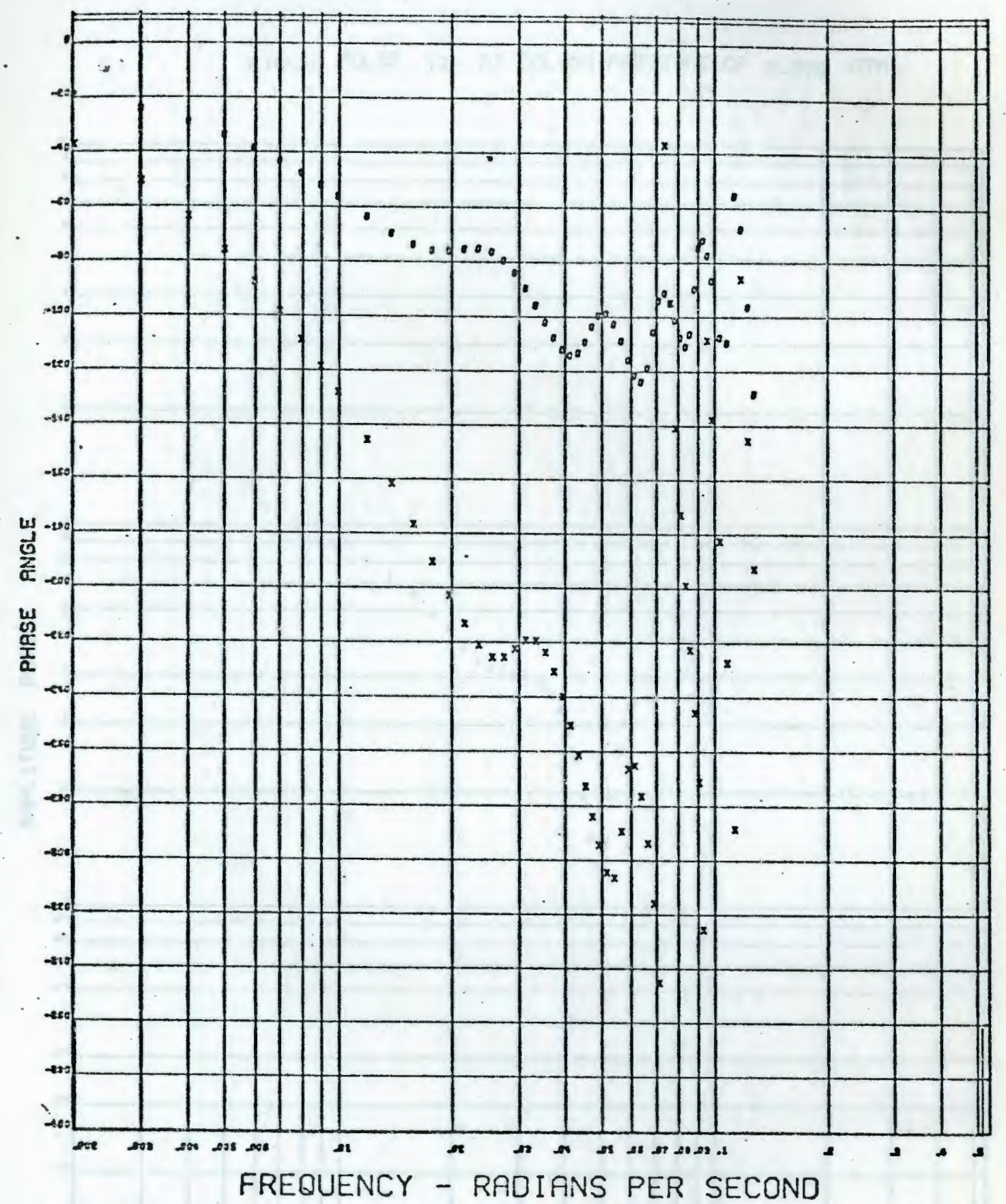

- plate 16 0-plate 26

X-plate $21^{\circ}$ + - plate 28 


\section{BODE PLOT}

- Liguid pulse 10 at colum pressure of 1.000 atm.

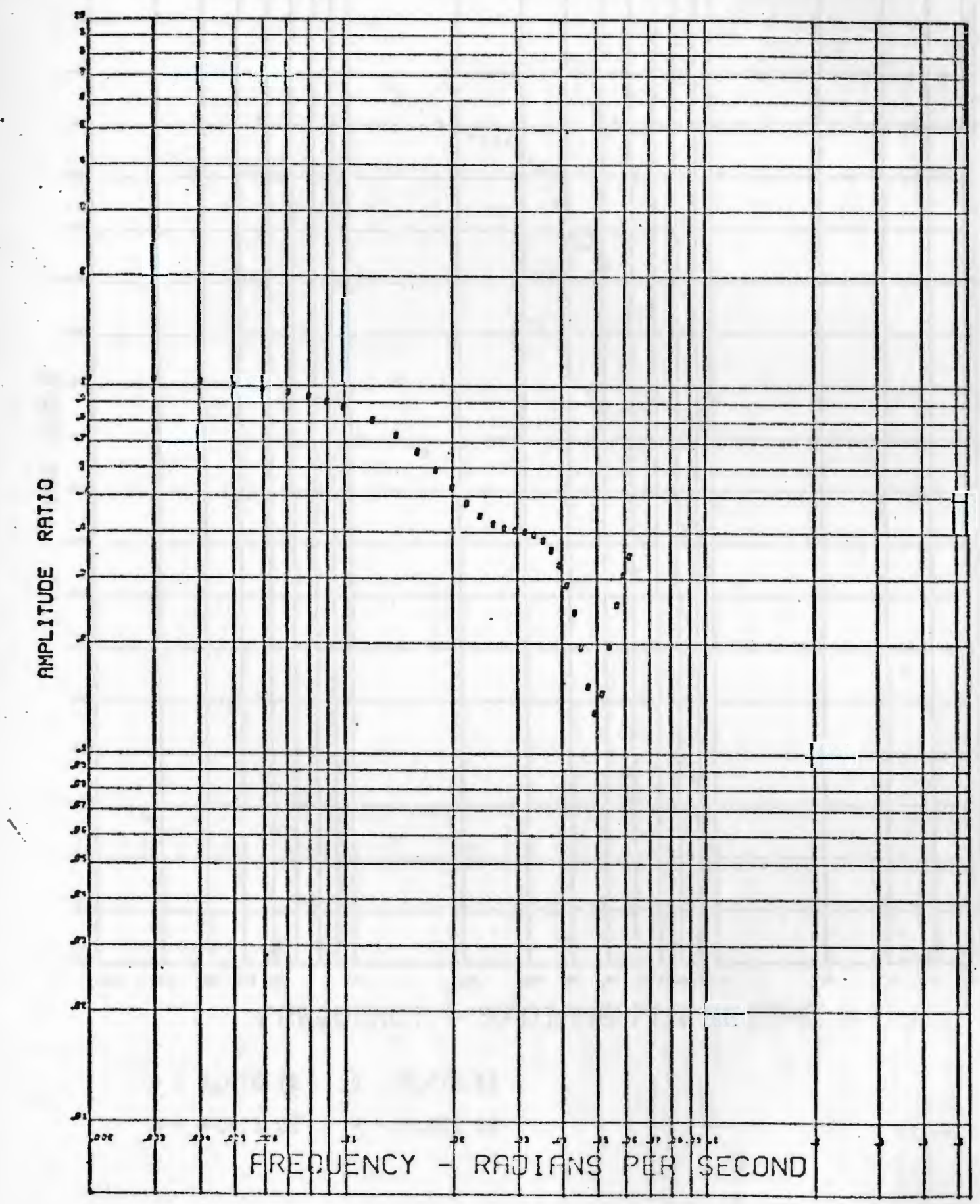



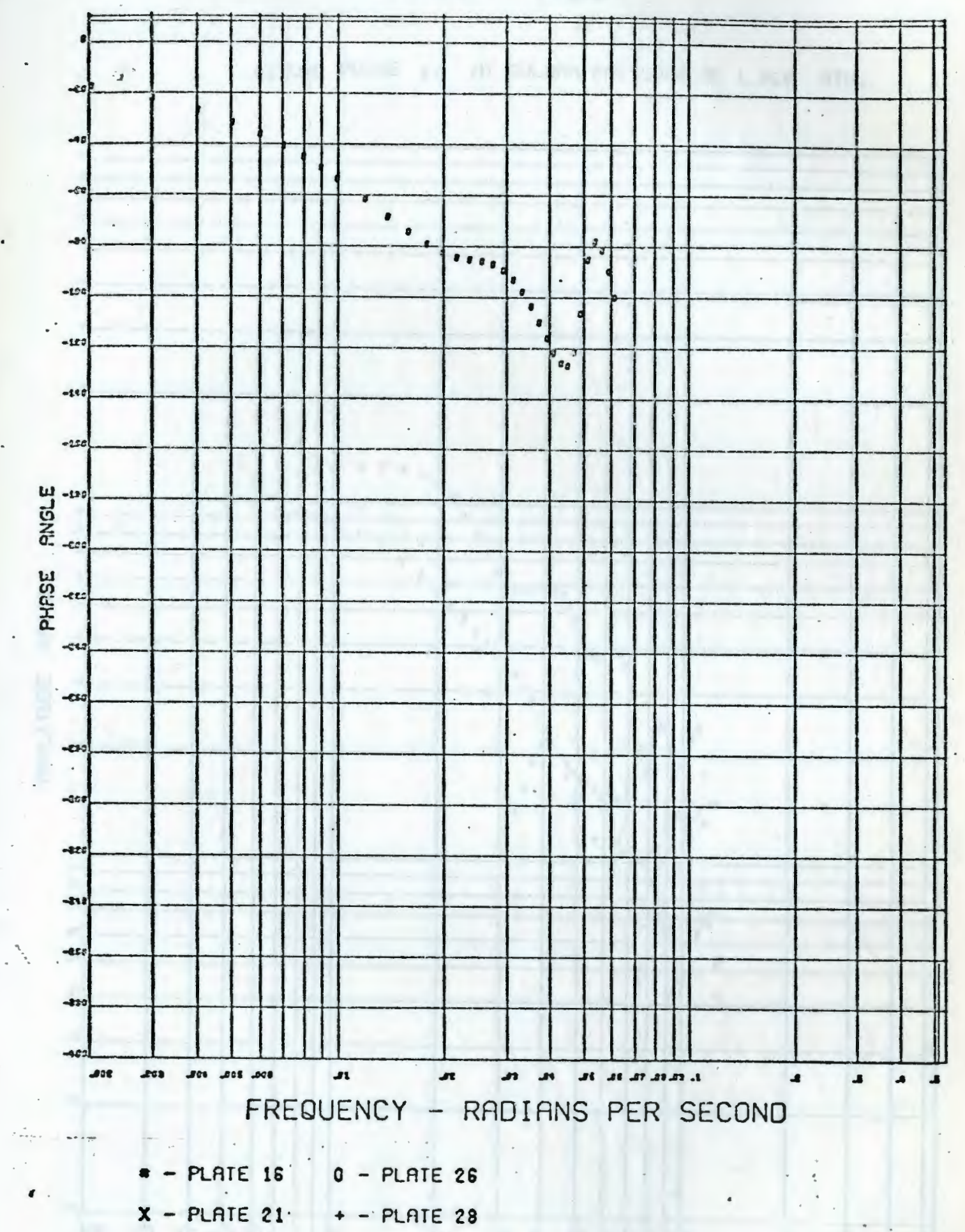


\section{BODE PLOT}

liguio pulse 11 at columa pressure of 1.000 atm.

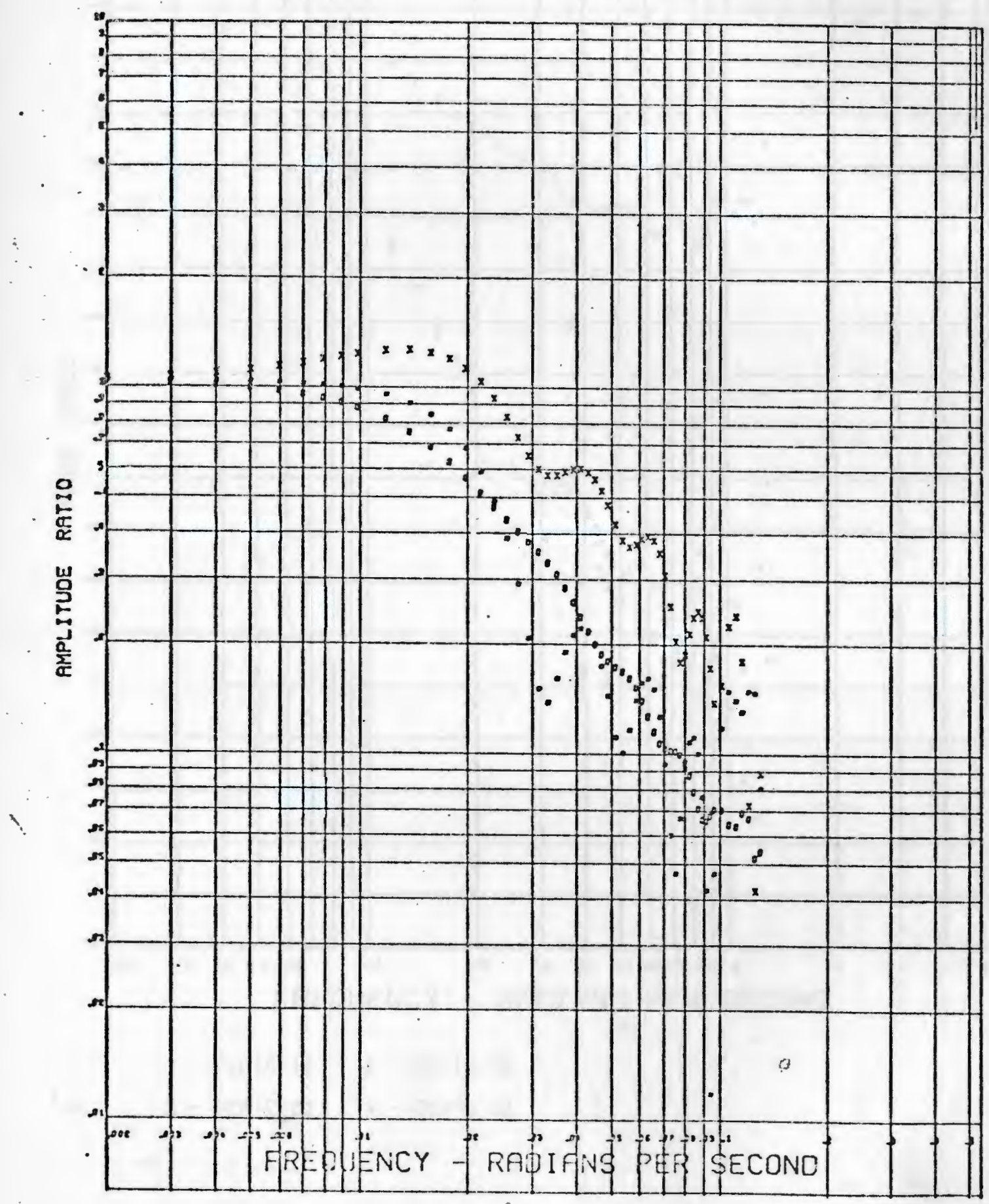




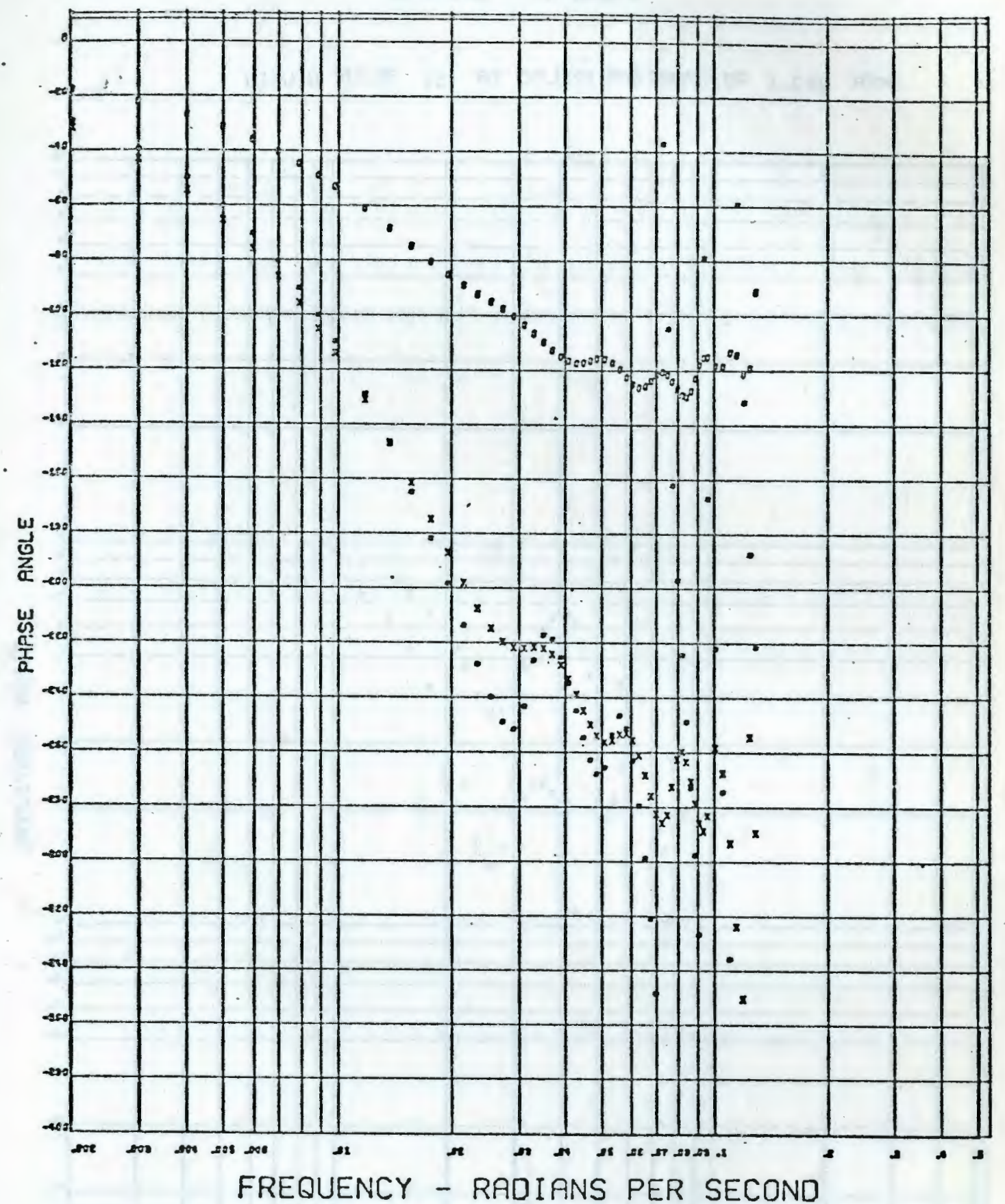

- plate 16 0 - plate 26

X - plate 21. + - plate 28 


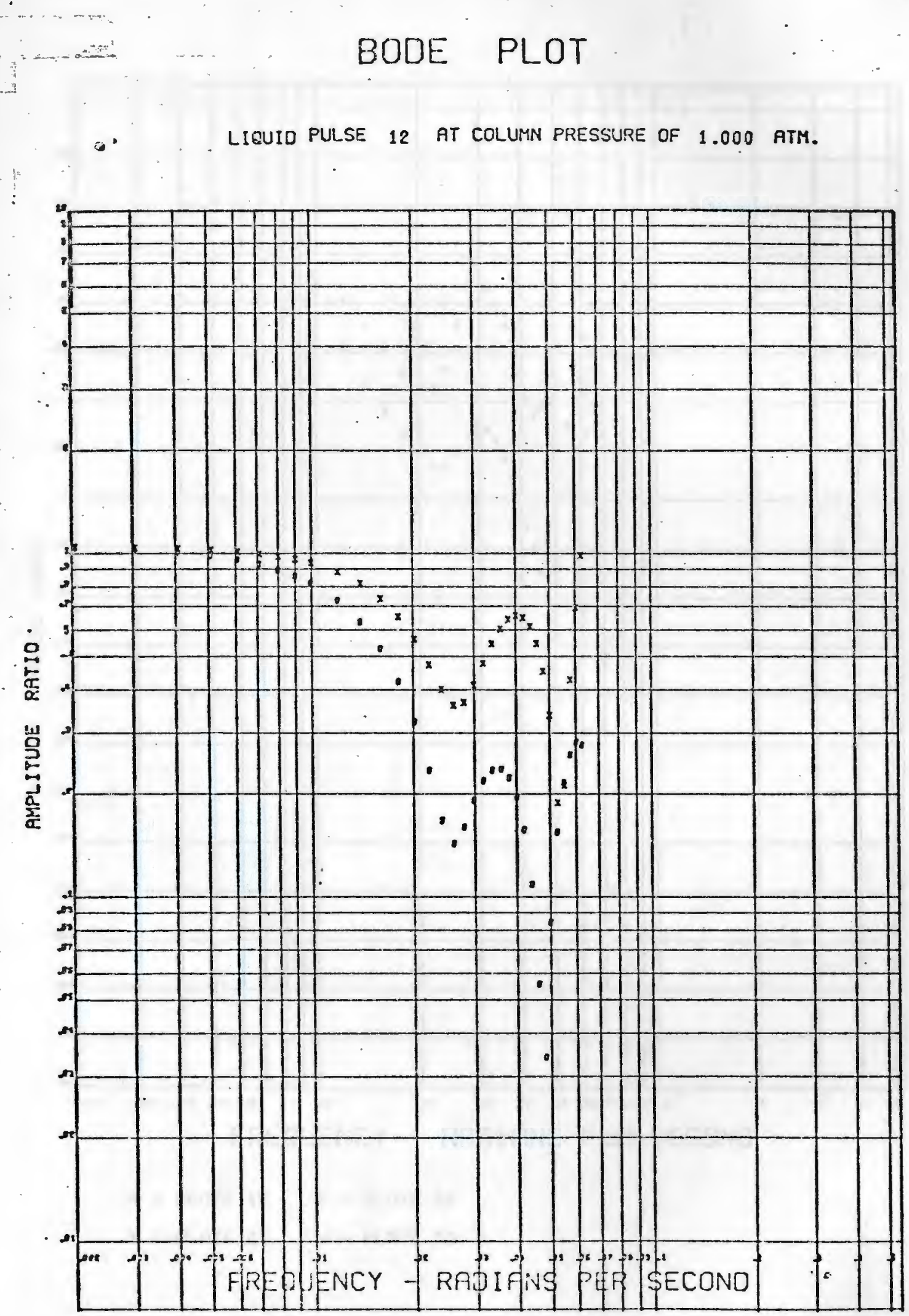




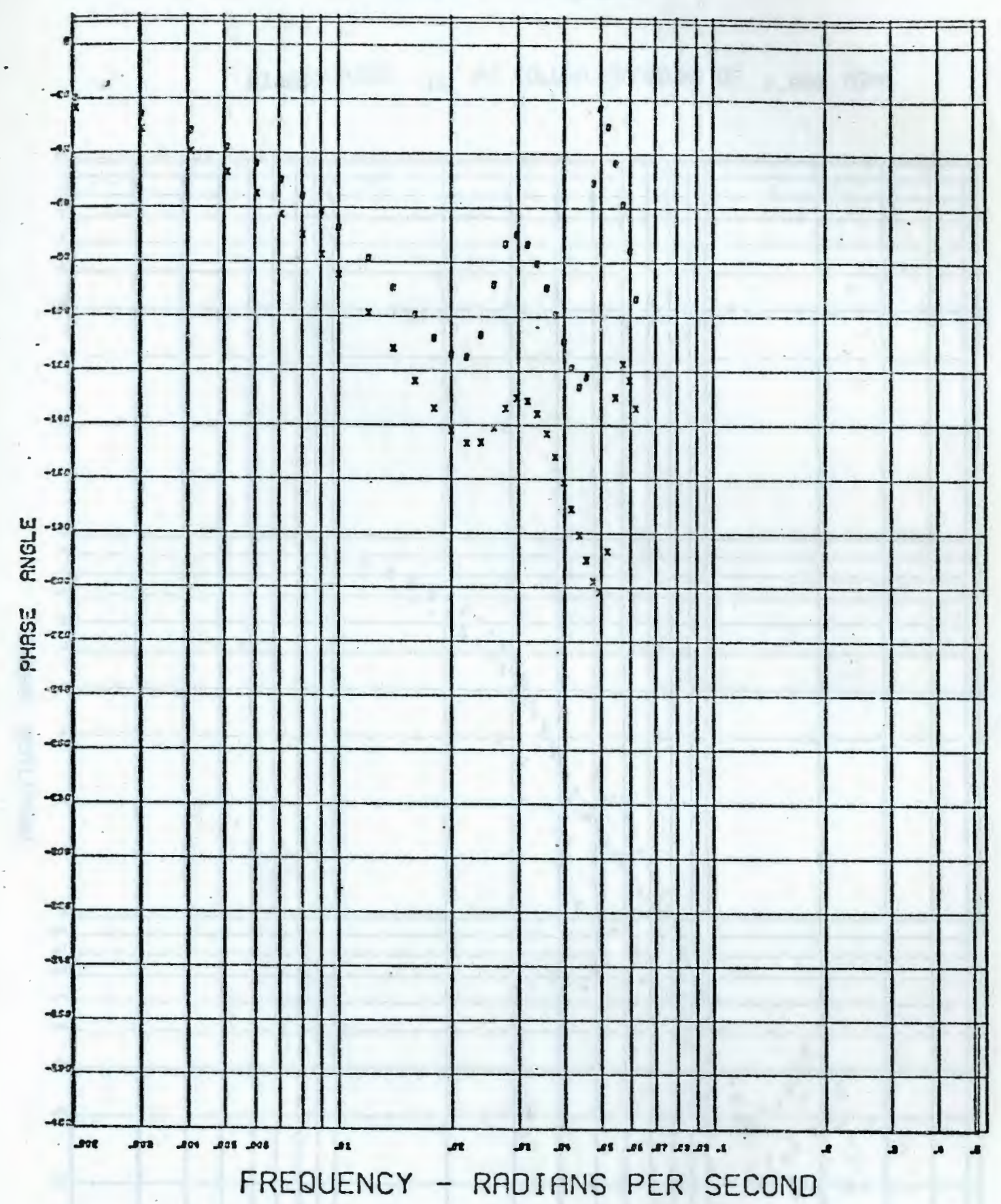

* - Plate 16 o- plate 26

X - plate 21. + plate 28 
BODE PLOT

LIQUTD PULSE 13 AT COLUMN PRESSURE OF 1.000 ATM.

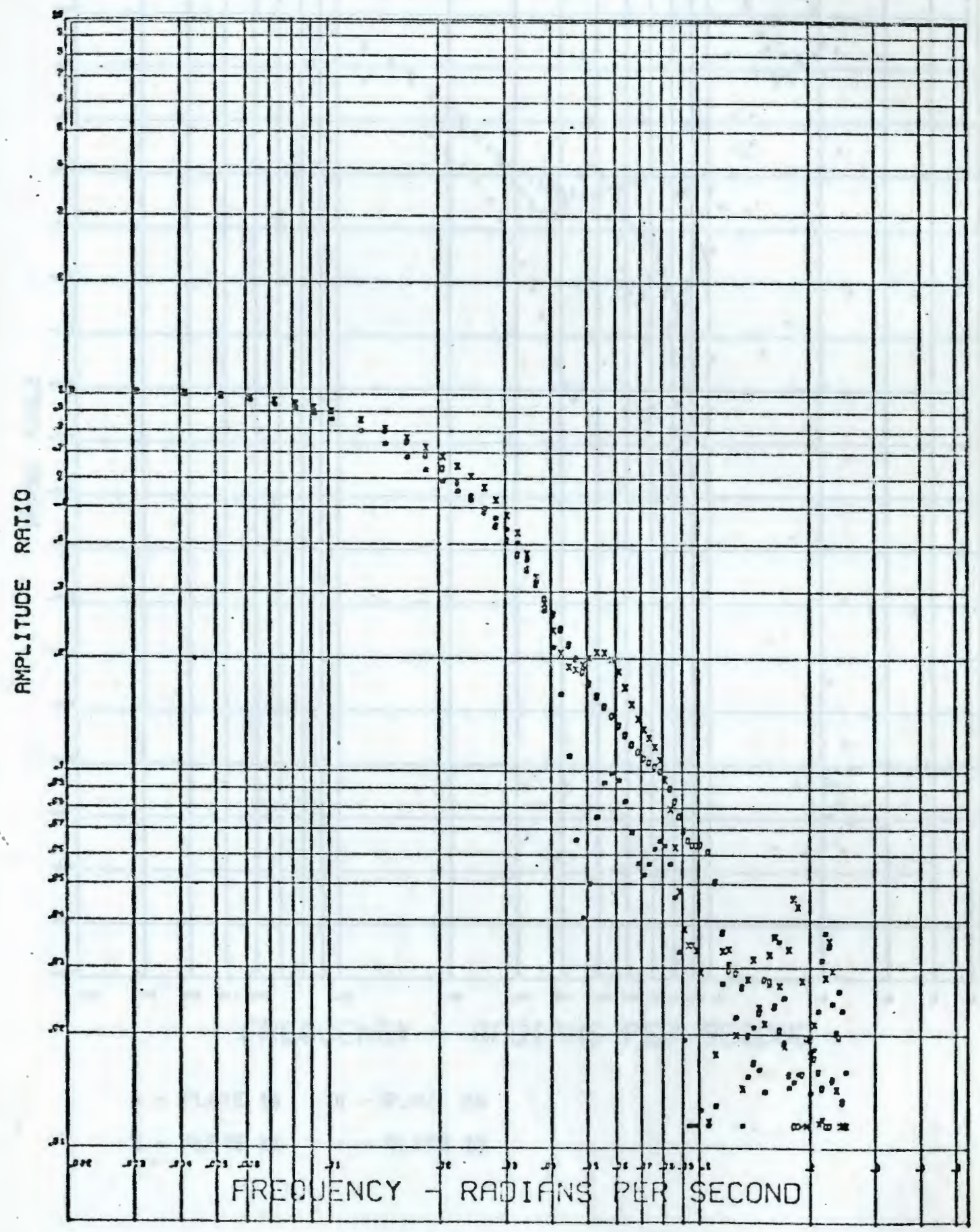




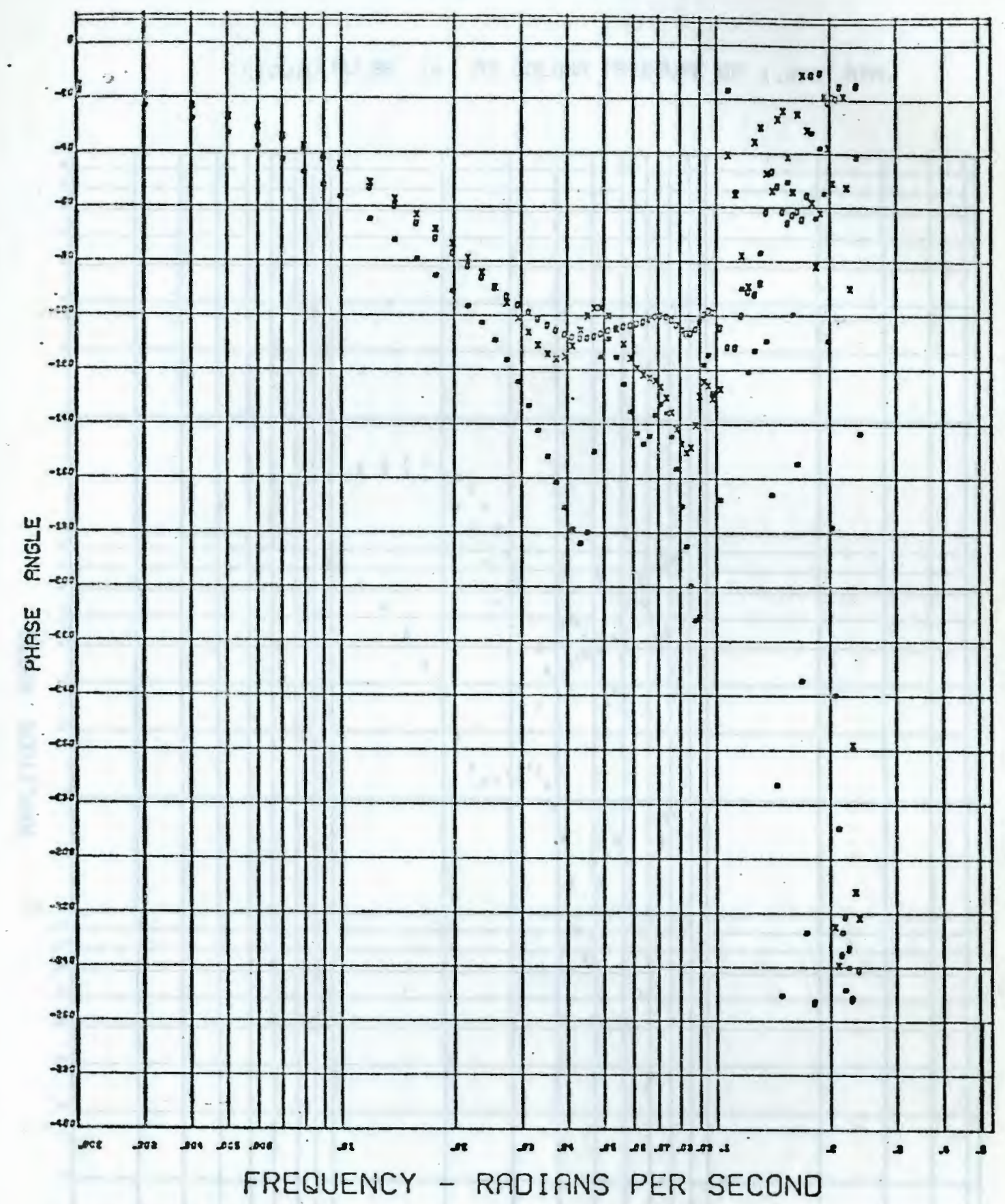

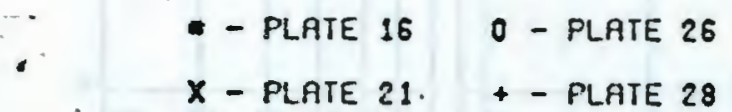




\section{BODE PLOT}

LIQUID PULSE 14 AT COLUMN PRESSURE OF 1.000 ATM.

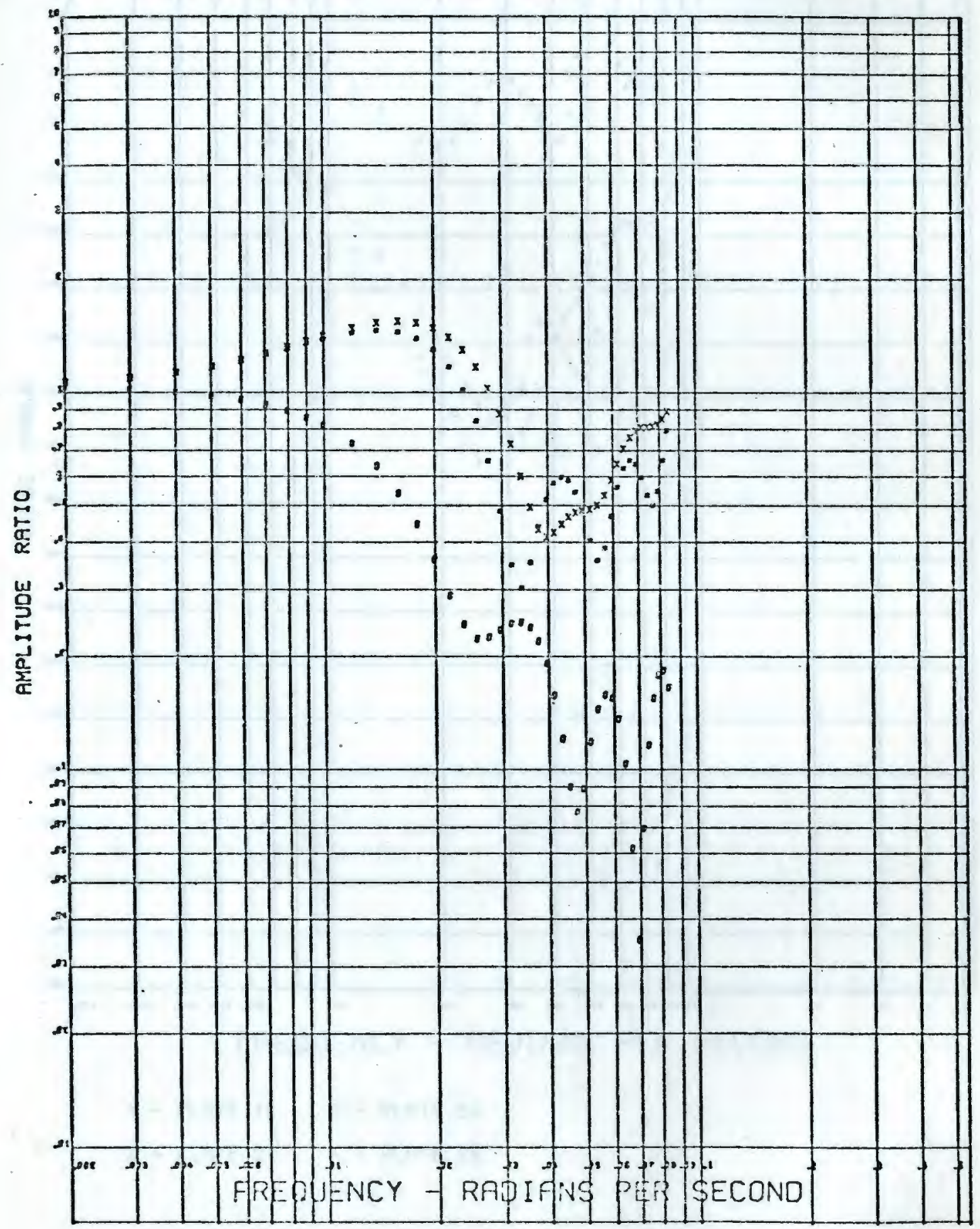




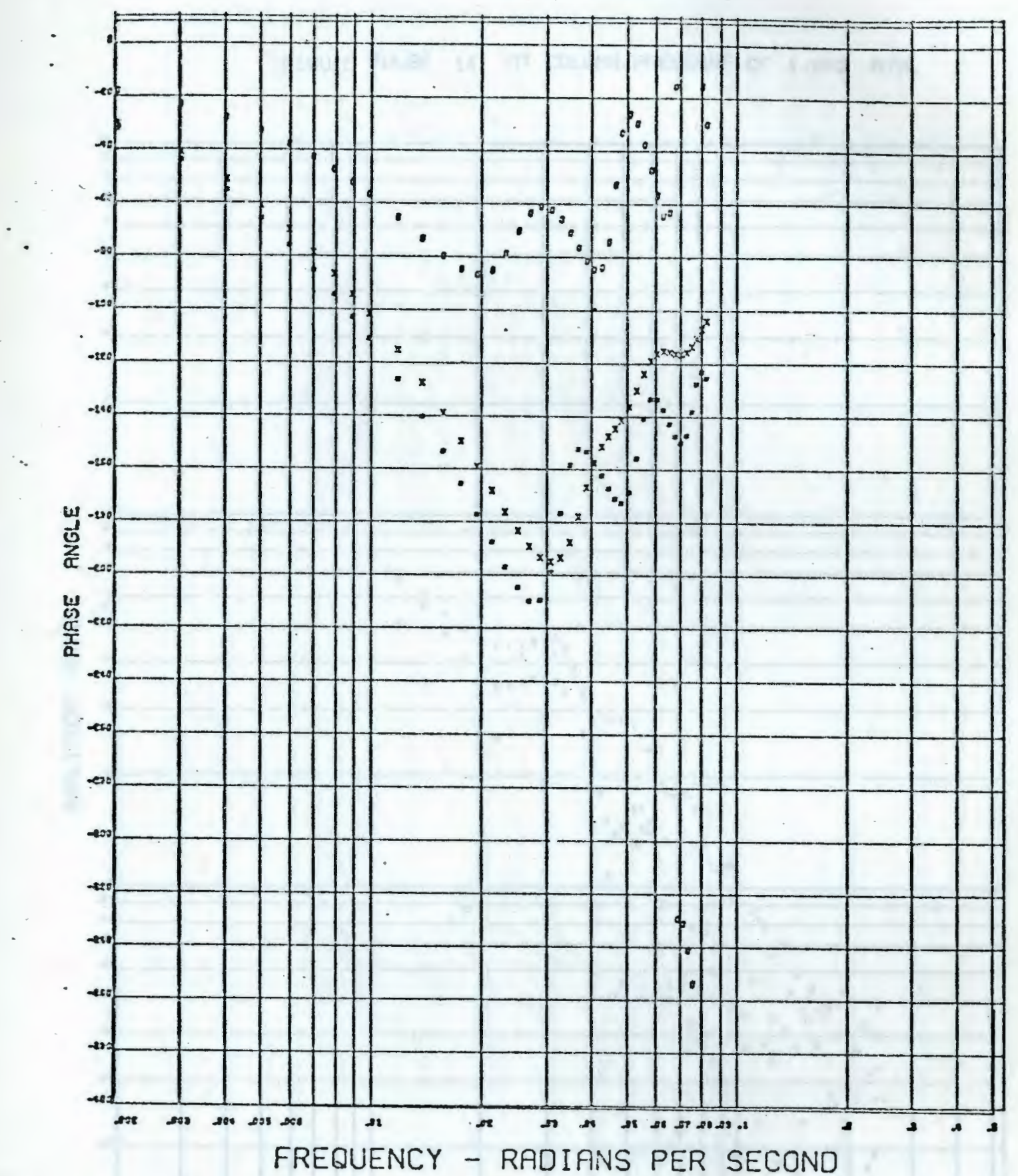

- plate 16 o-plate 26

X - plate 21 + + plate 28 
BODE PLOT

LIOUID PULSE 15 AT COLUMN FRESSURE OF 1.000 ATM.

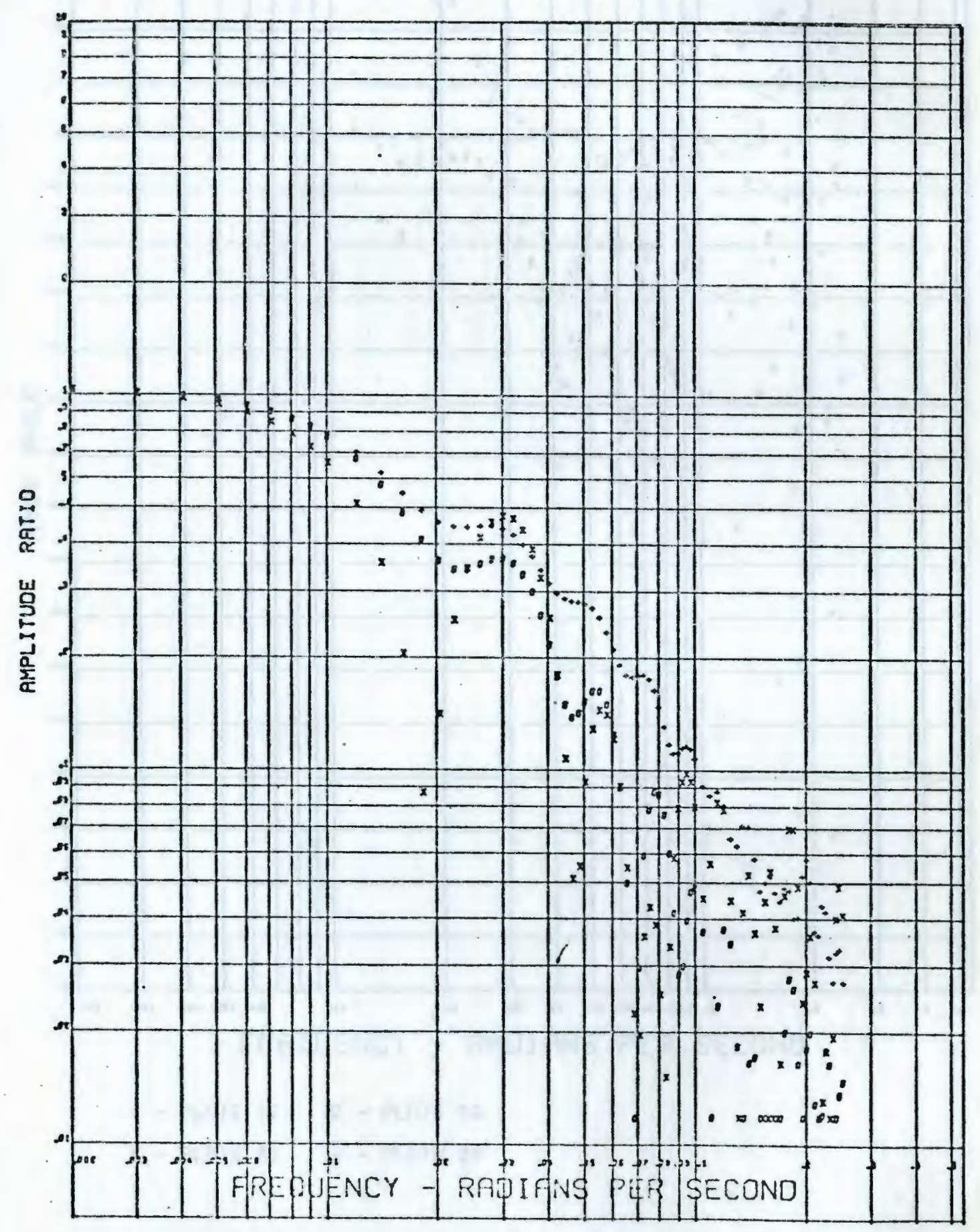




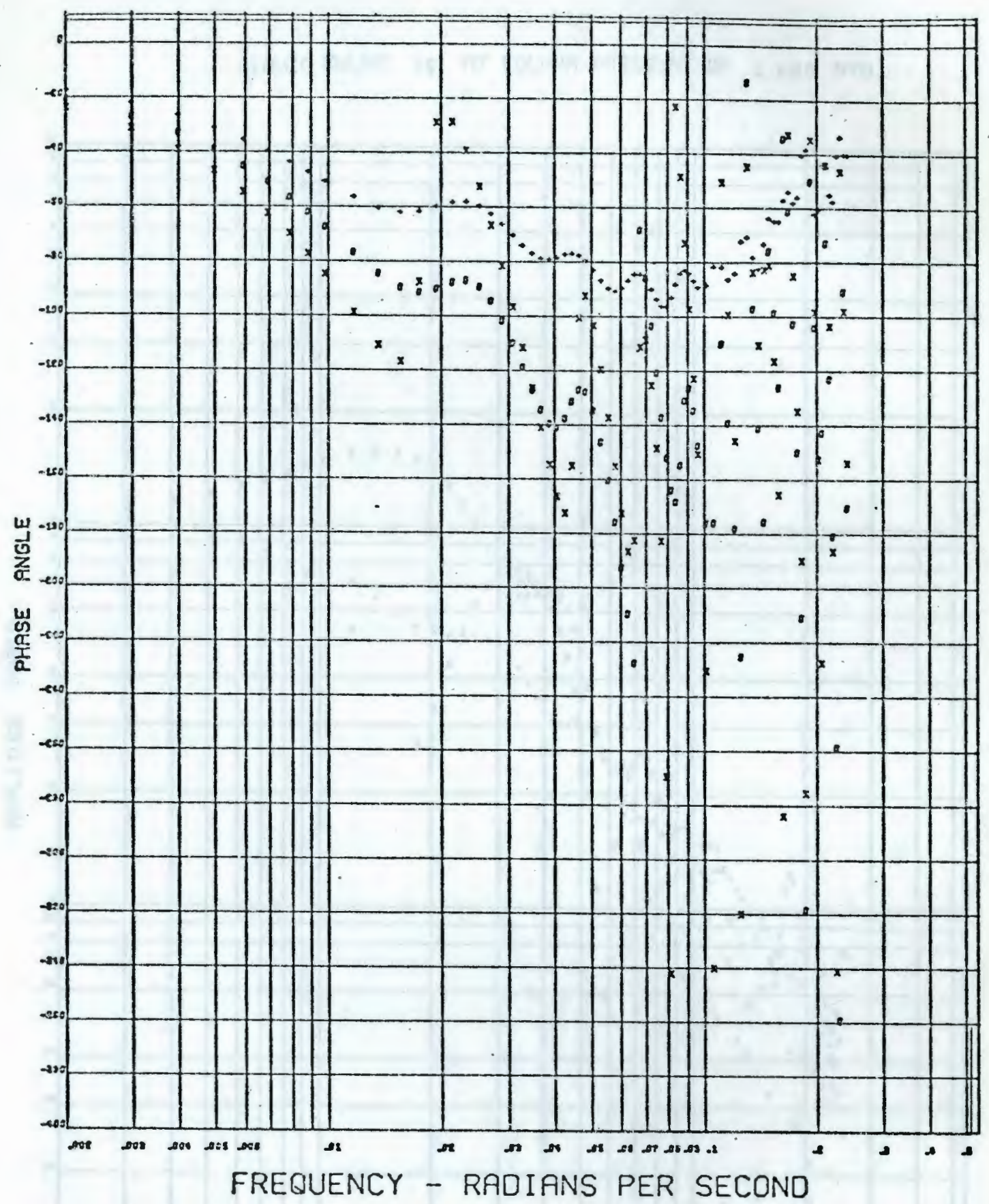

- plate 16 0-plate 26

X - PLATE 2! + - Plate 28 
BODE PLOT

LIQUID PULSE 16 AT COLUMN PRESSURE OF 1.000 ATM.

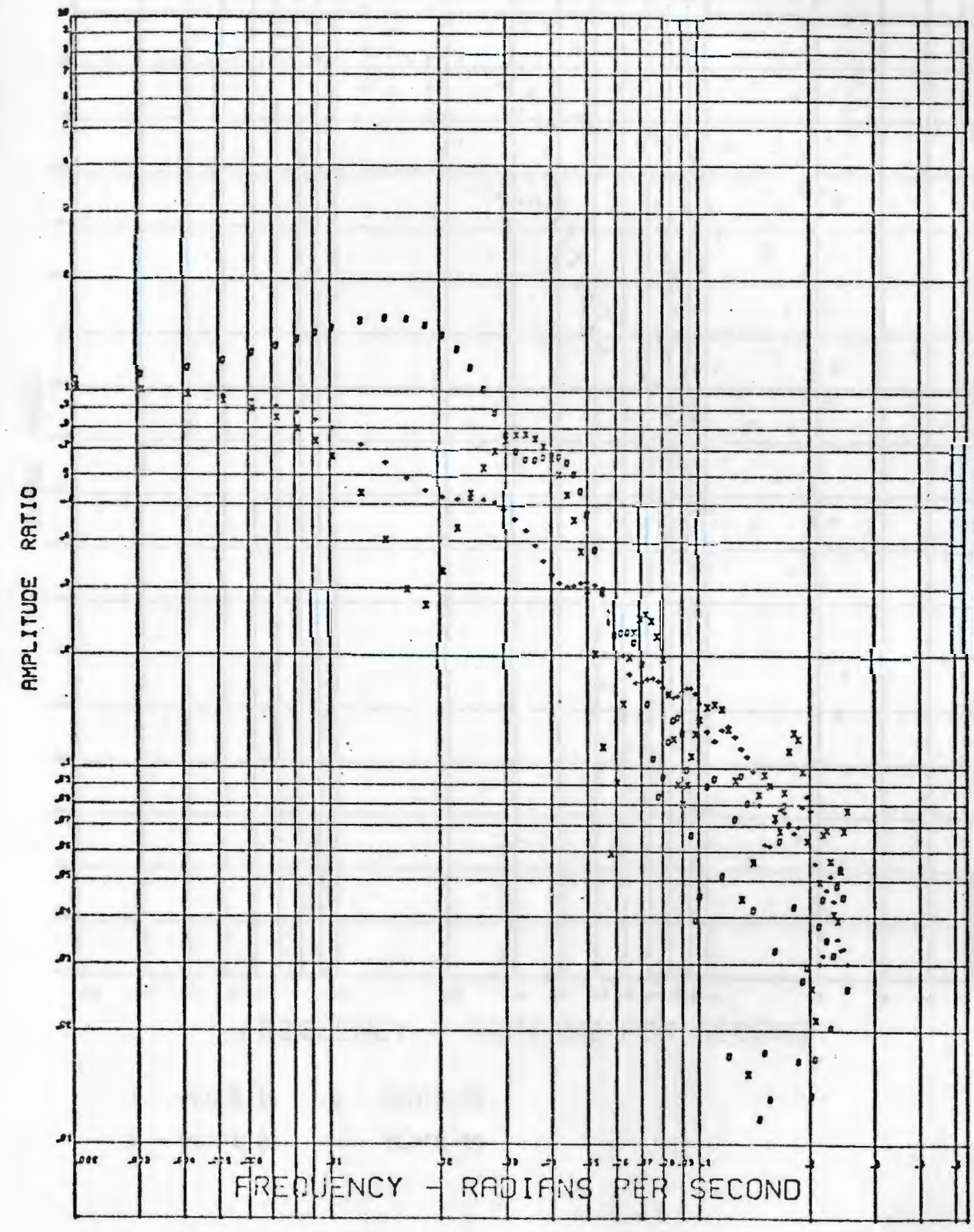




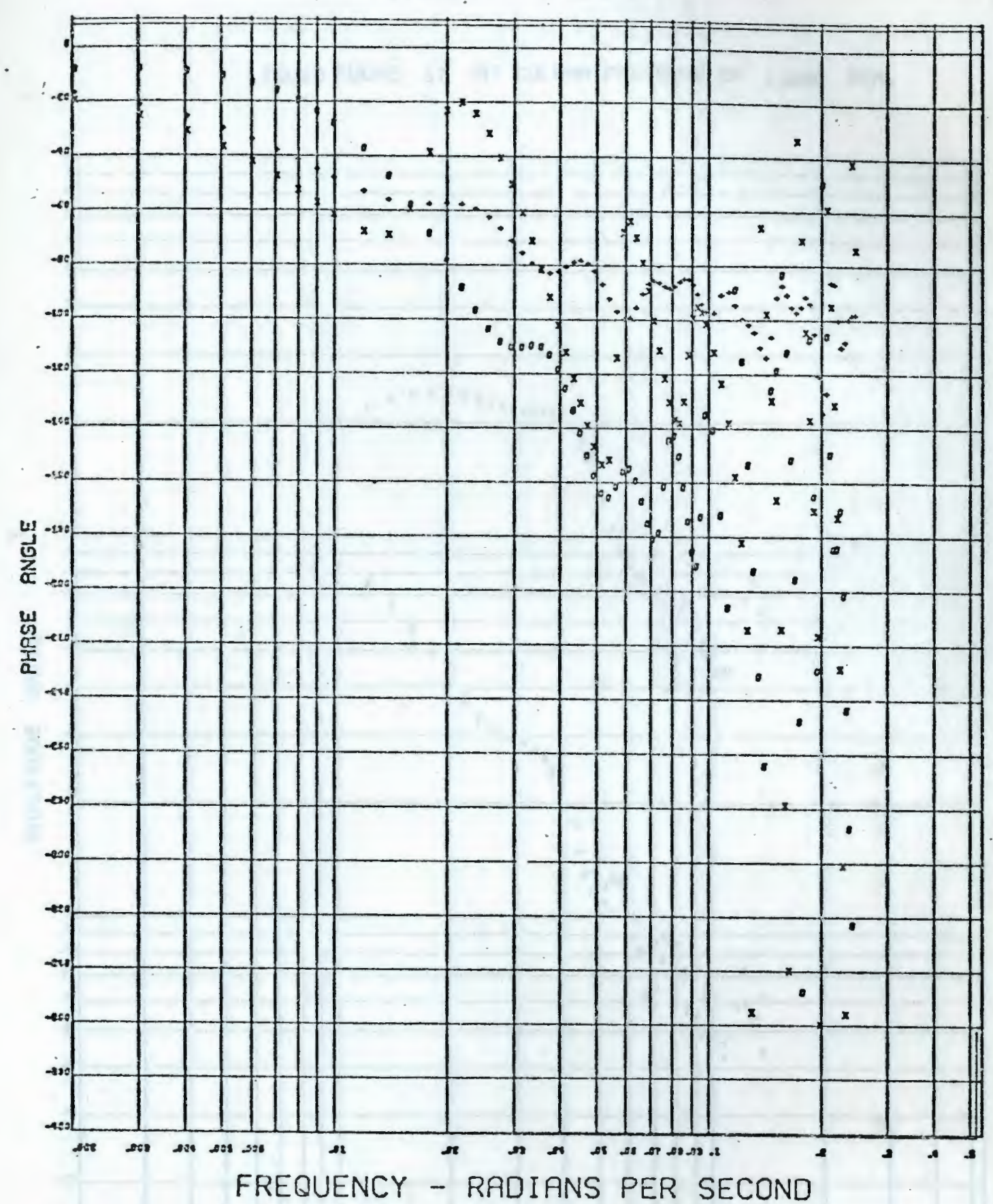

- plate 16 0-plate 26

$x$ - PLATE $21+$ - PLATE 28 
BODE PLOT

LIQUID PULSE 17 AT COLUMN PRESSURE OF 1.000 RTM.

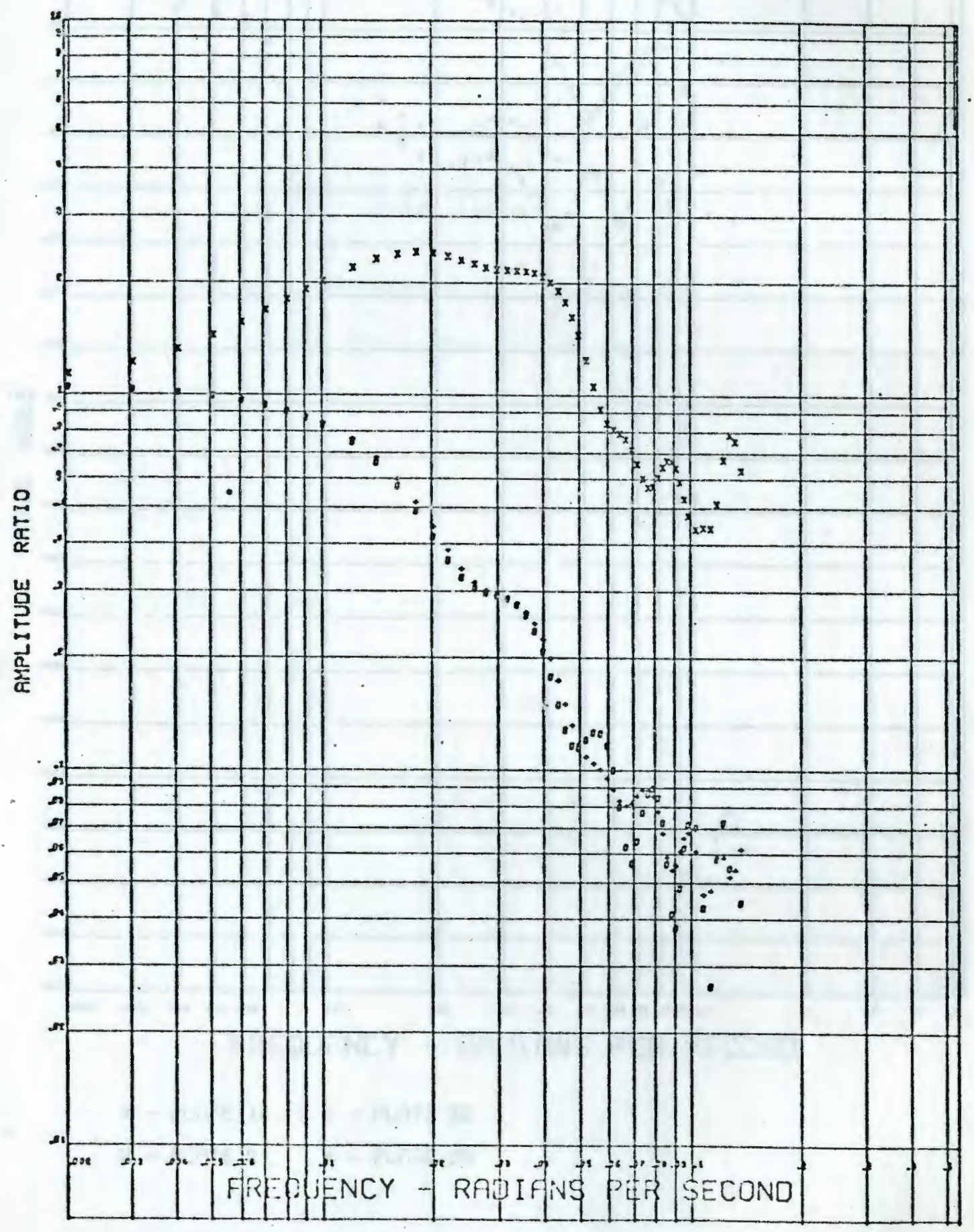




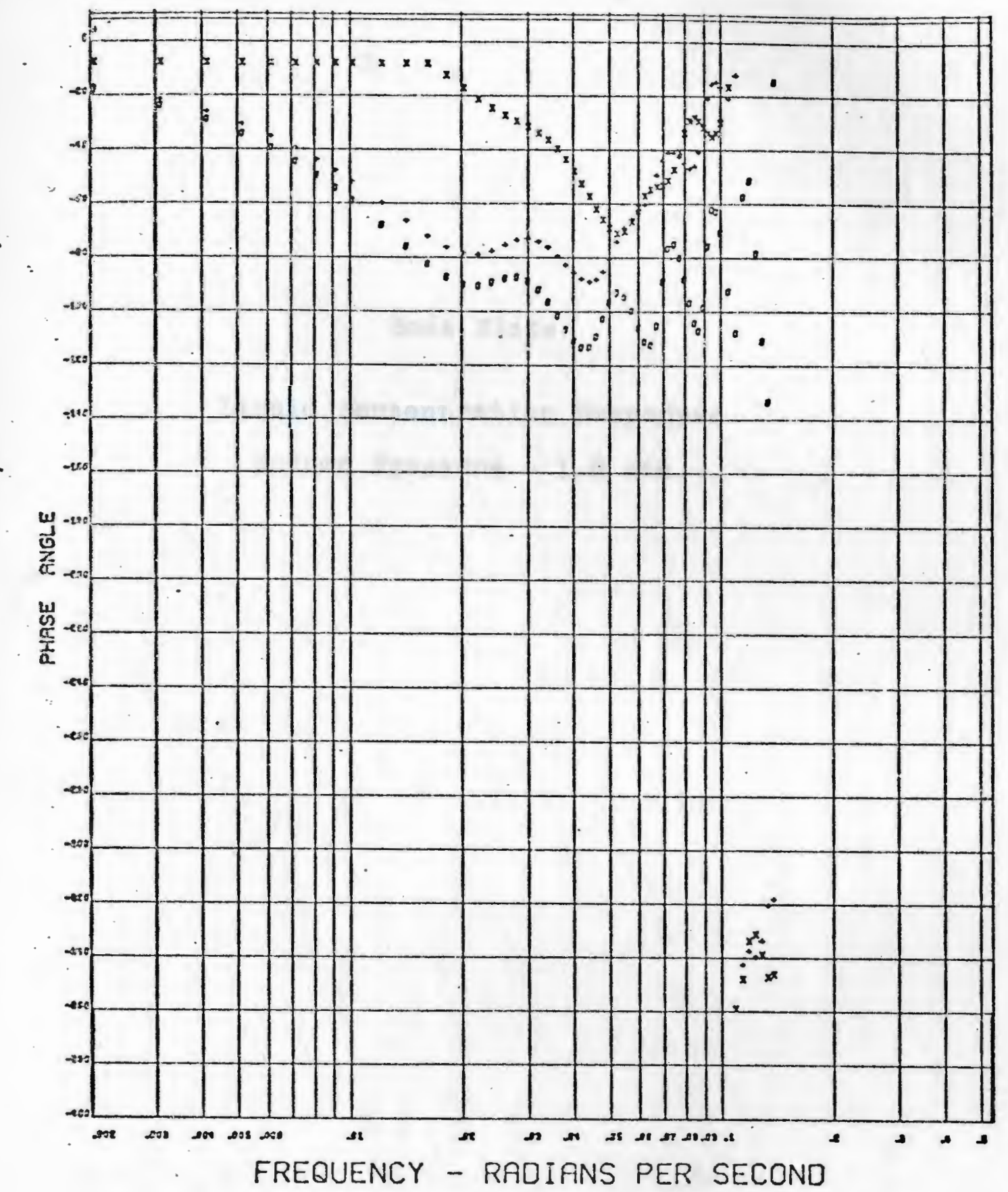




\section{Bode Plots}

Ifquid Concentration Responses

$$
\text { Column Pressure - } 1.0 \text { atm. }
$$


BODE PLOT

CONCENTRATION PULSE I AT COLUMN PRESSURE OF 1.000 ATM.

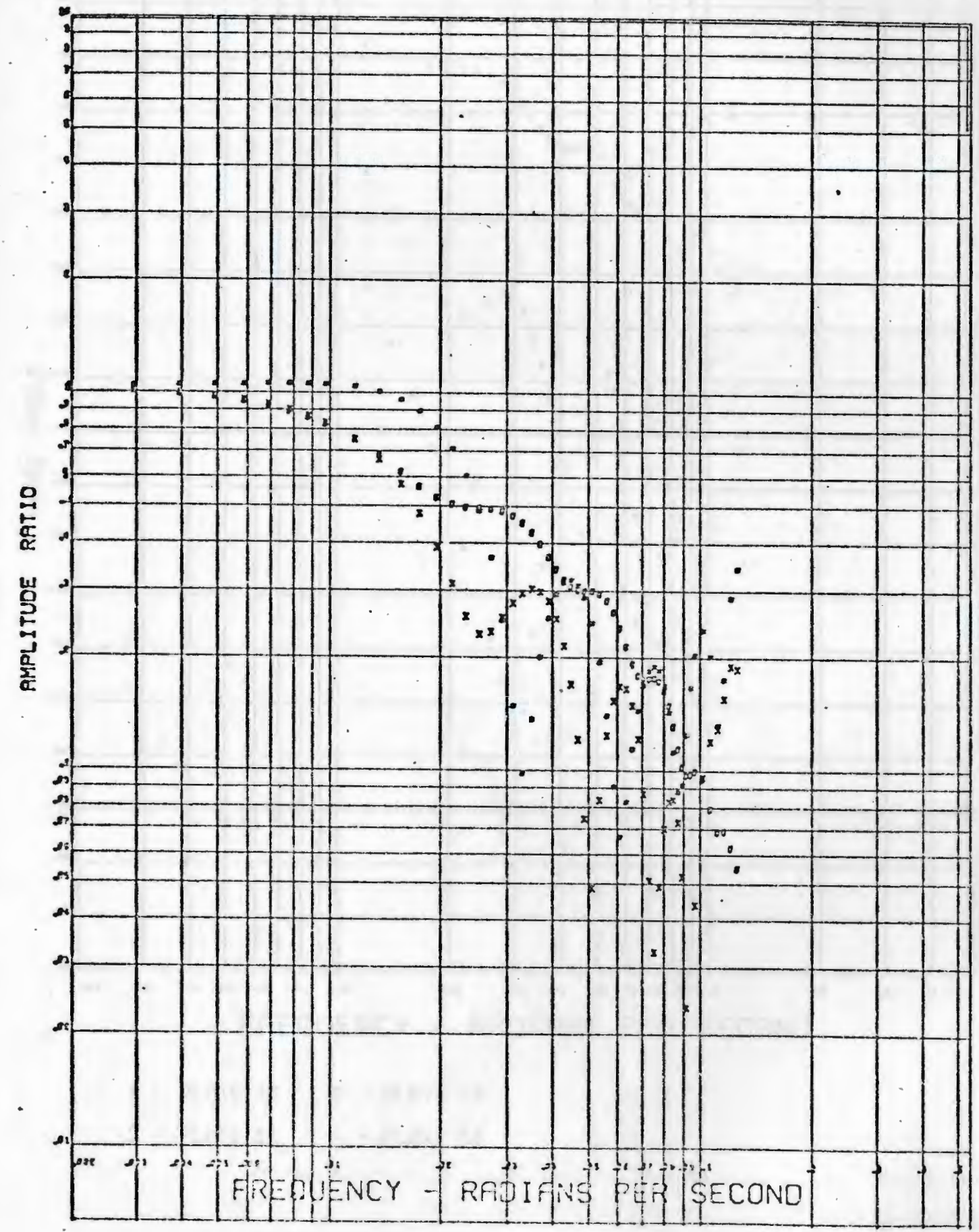




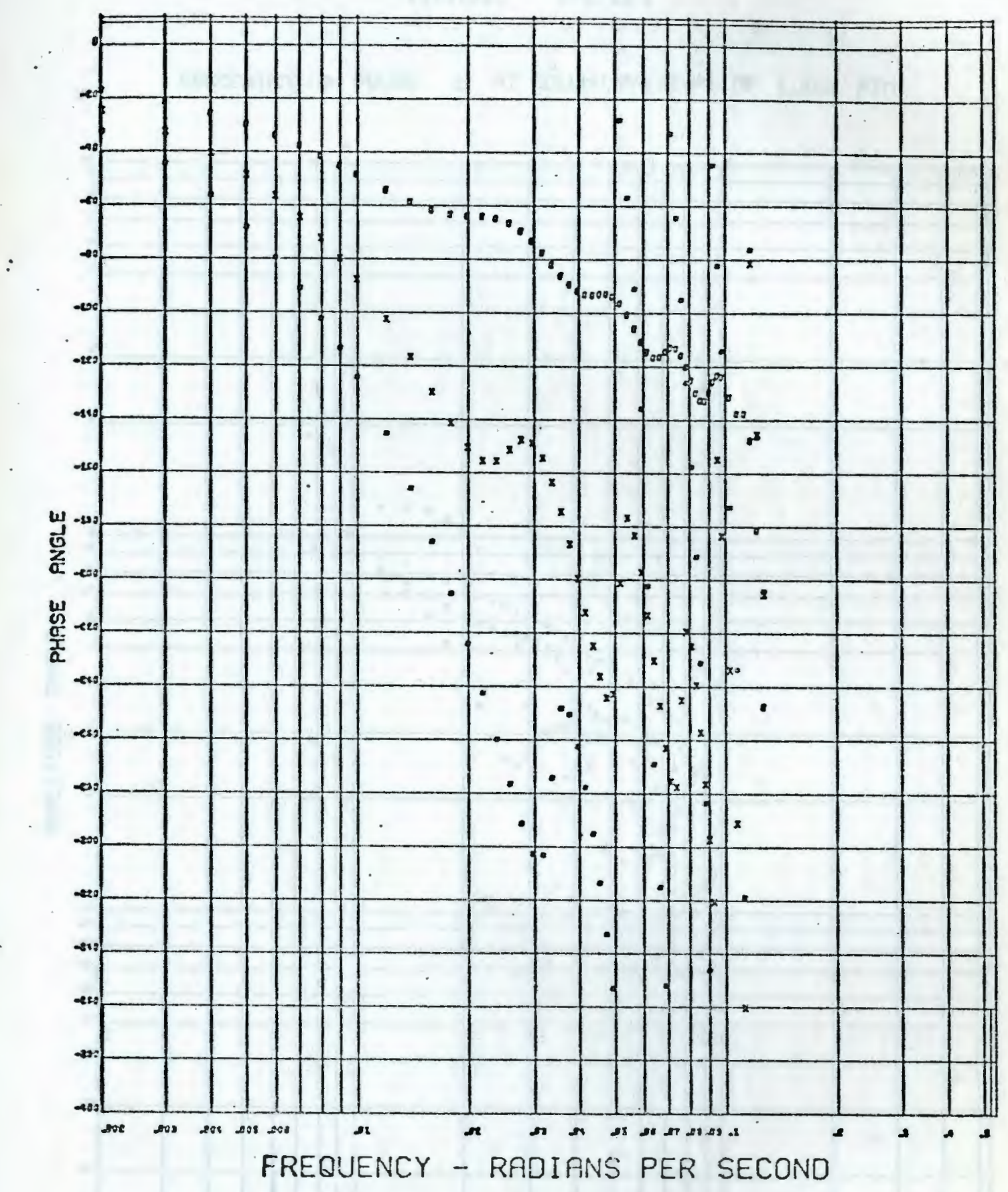

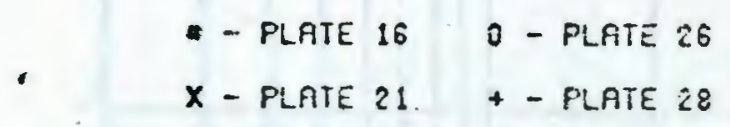




\section{BODE PLOT}

CONCENTRATION PULSE 2 AT CGLUMN PRESSURE OF 1.000 ATM.

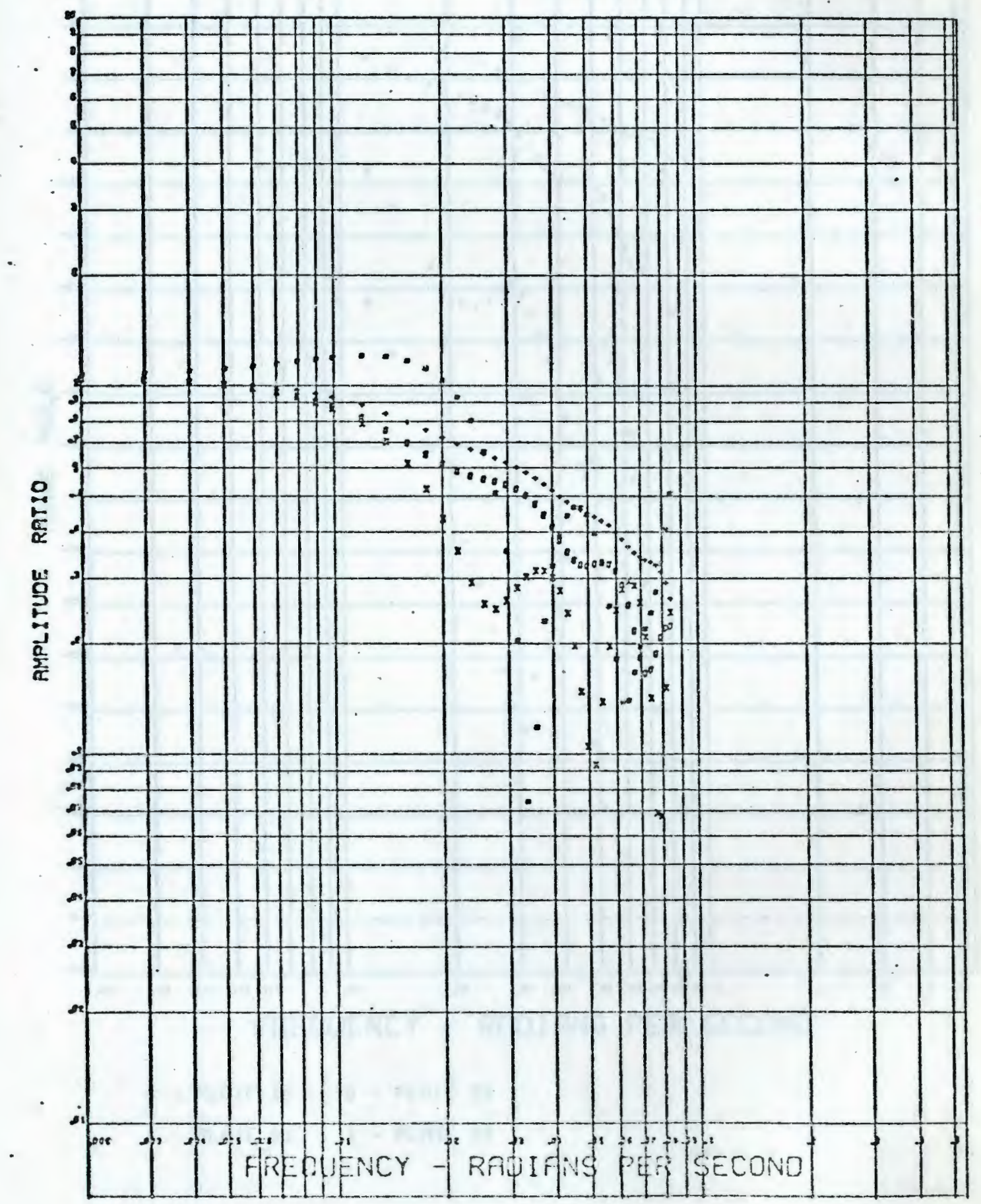


$-5$

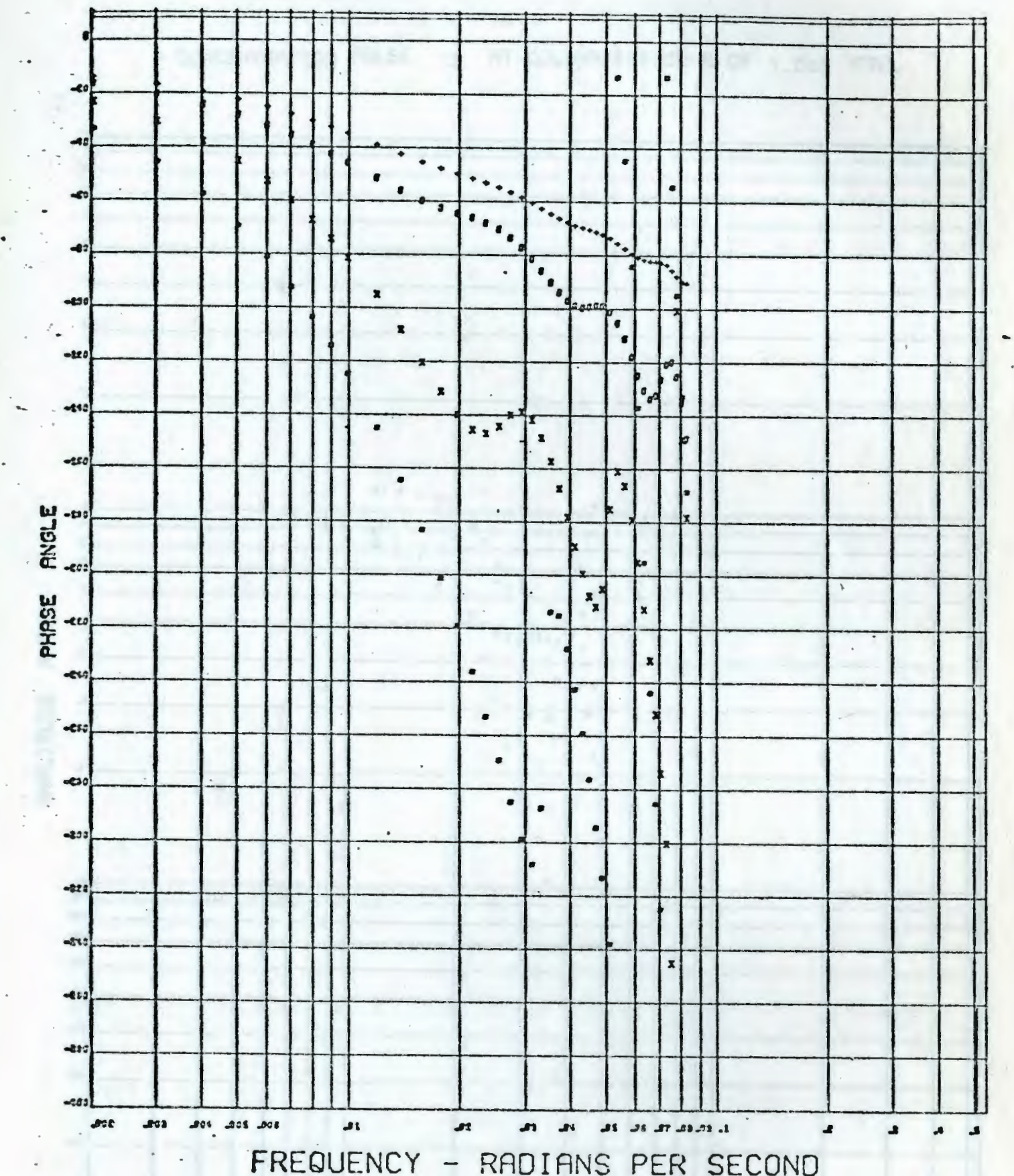




\section{BODE PLOT}

CONCENTRATION PULSE 3 AT COLUMN PRESSURE OF 1.000 ATM.

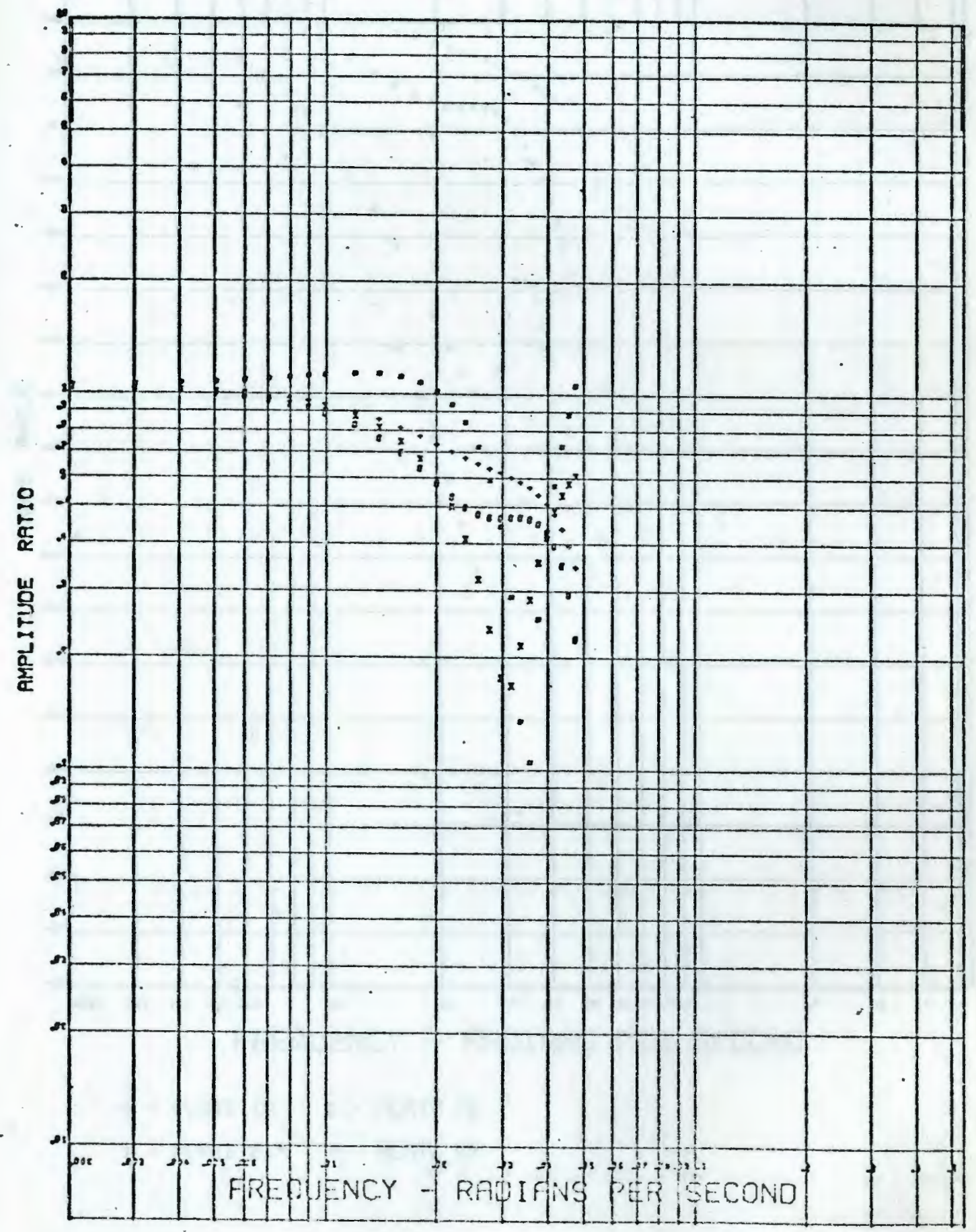




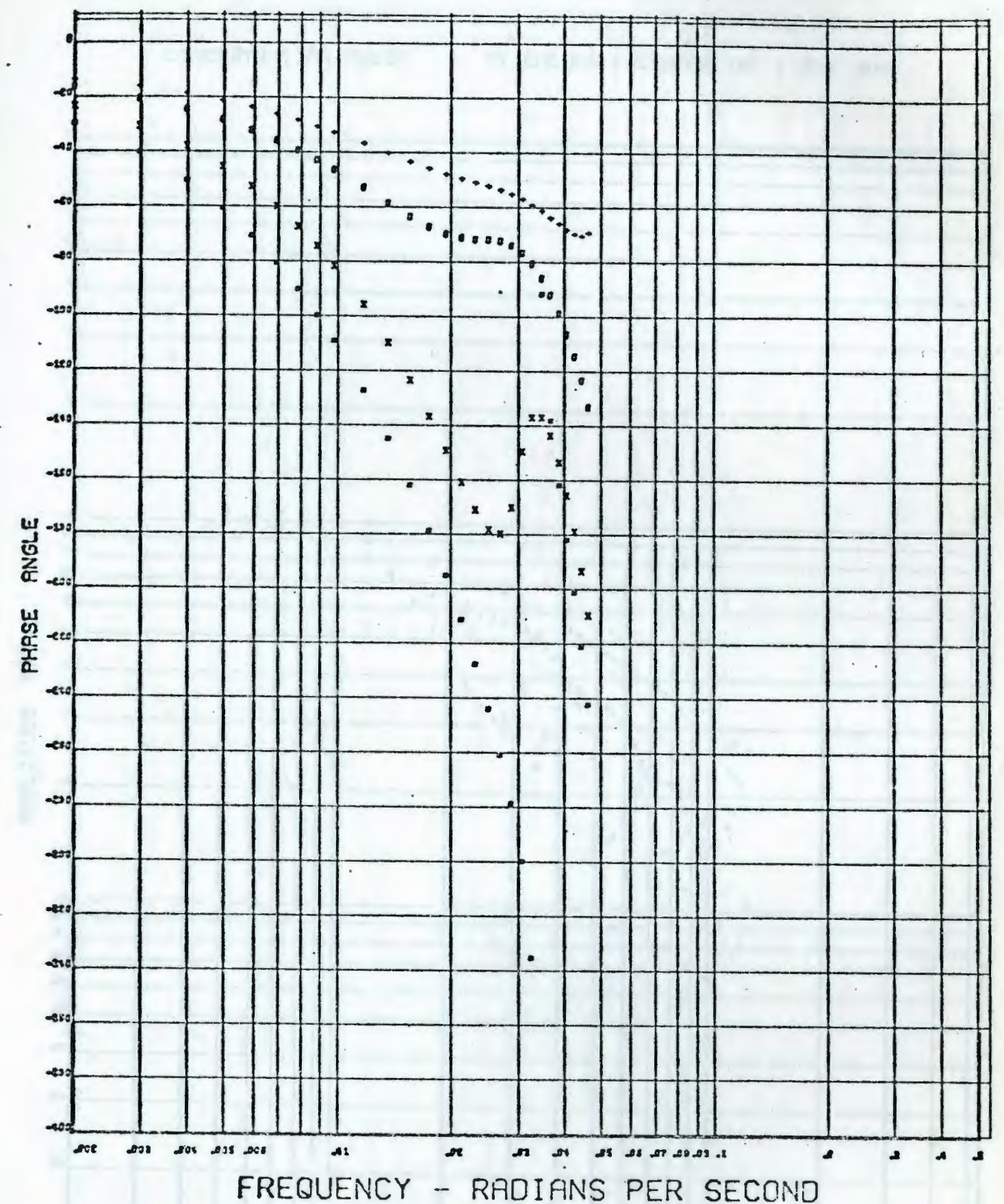

\footnotetext{
* - plate 16 - plate 26

X - Plate $21 .+$ - Plfite 28
} 


\section{. BODE PLOT}

CONCENTRATION PULSE 4 AT COLUMN PRESSURE OF 1.000 ATM.

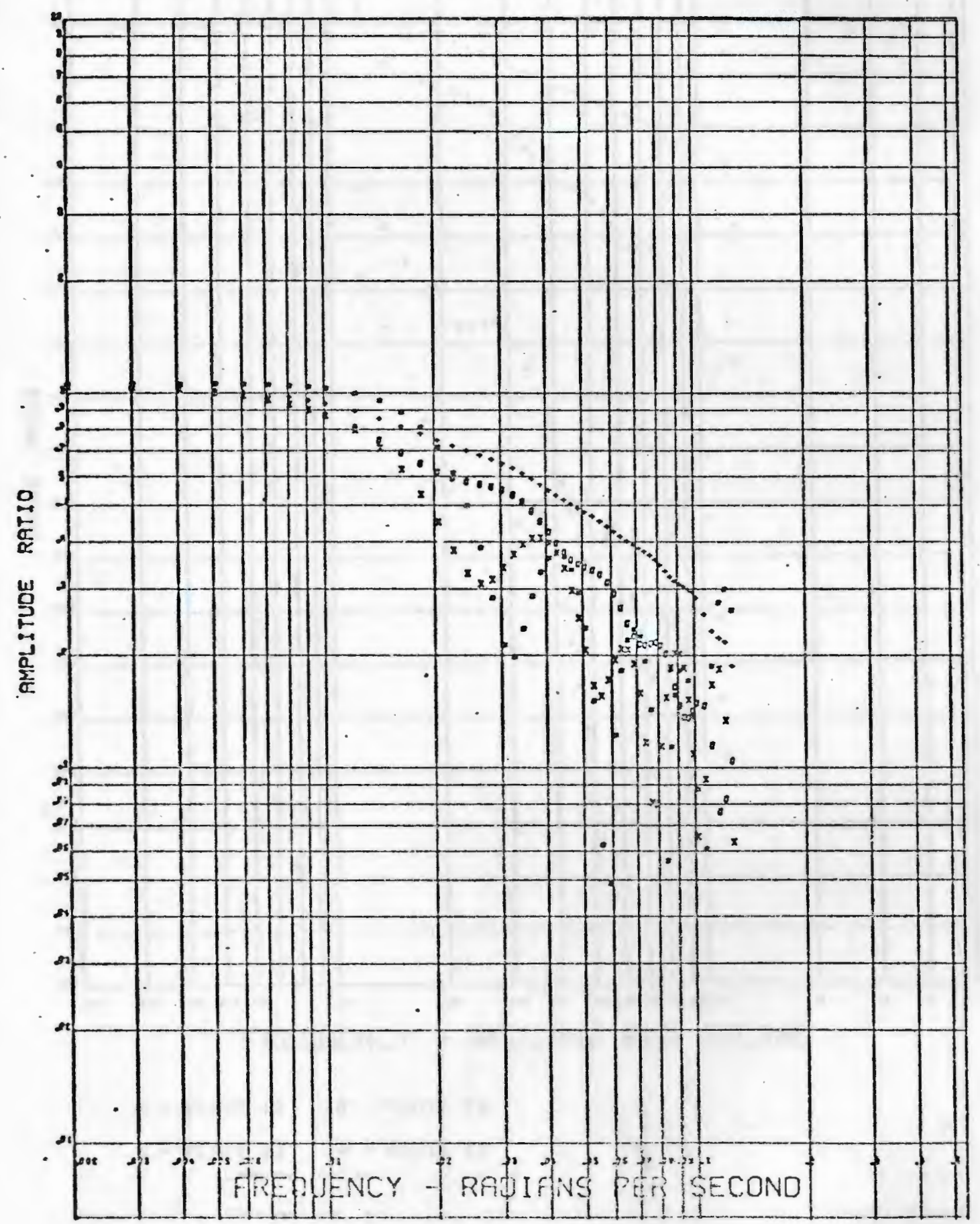




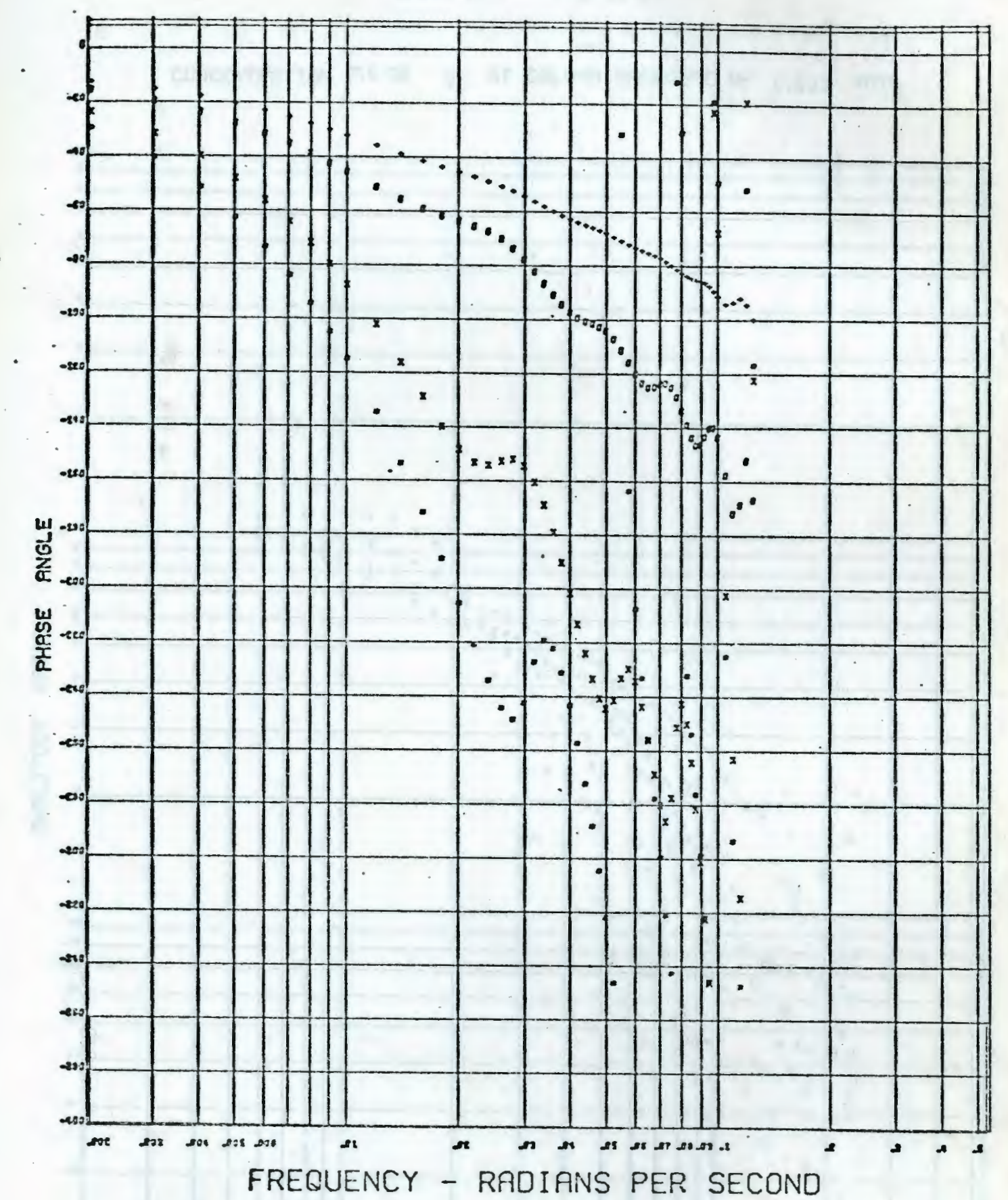

- plate is 0-plate 26

$X$ - PLATE 21 + PLATE 28 


\section{BODE PLOT}

CONCENTRATION PULSE 5 AT COLUMN PRESSURE OF 1.000 ATM.

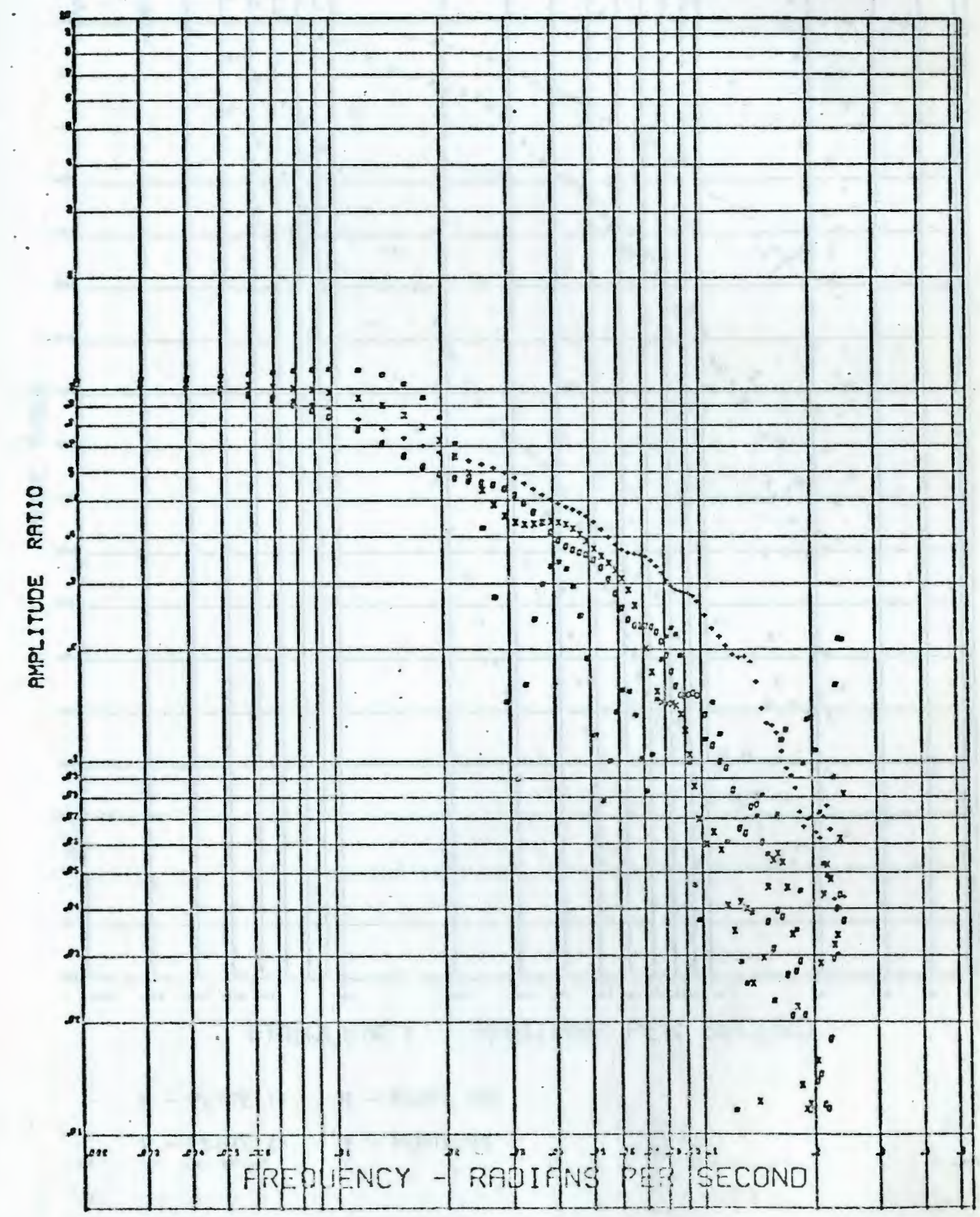




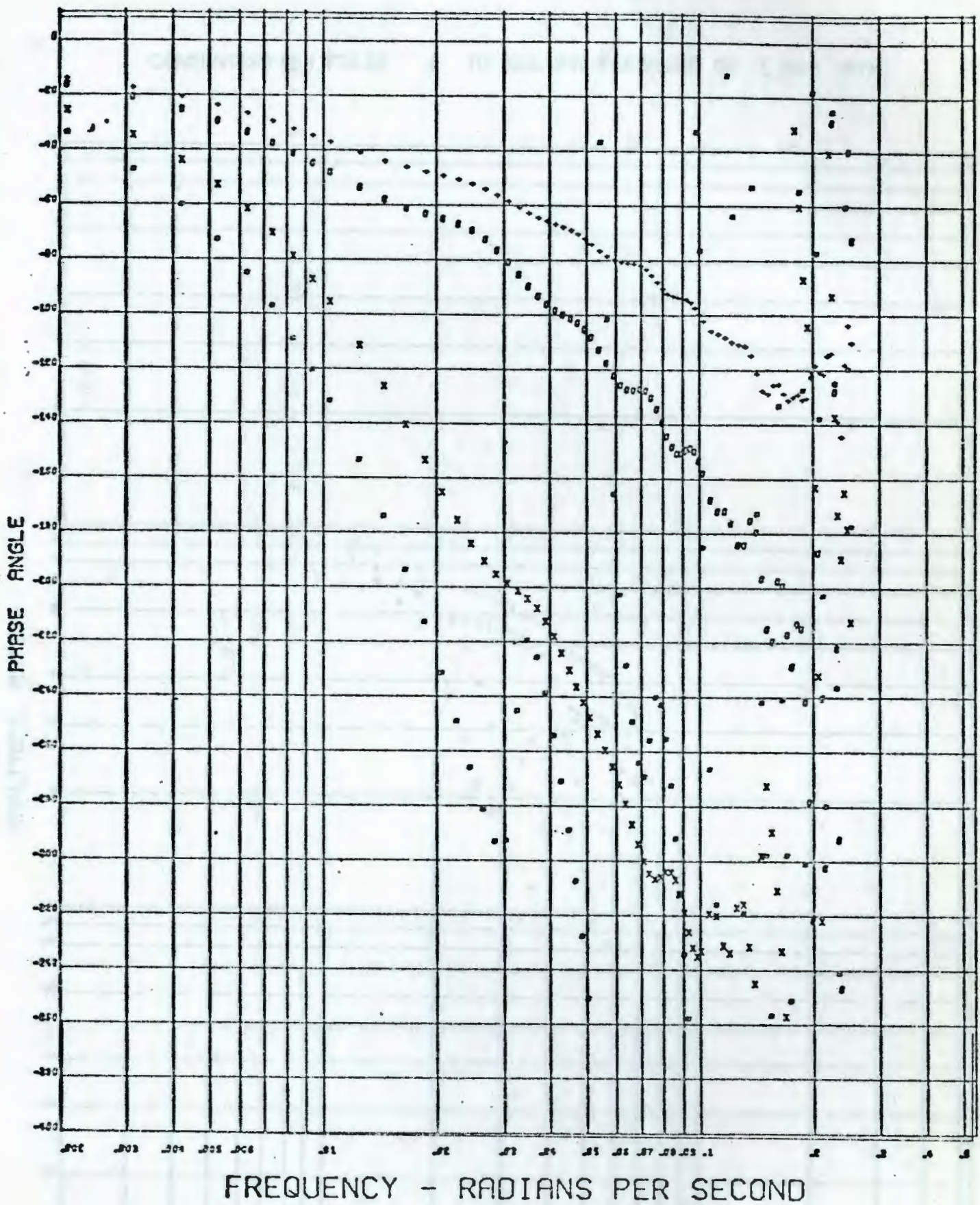

- plate 16 o-plate 26

X - PLATE 21 + PLATE 28 


\section{BODE PLOT}

CONCENTRATION PULSE 6 AT COLUMN PRESSURE OF 1.000 ATM.

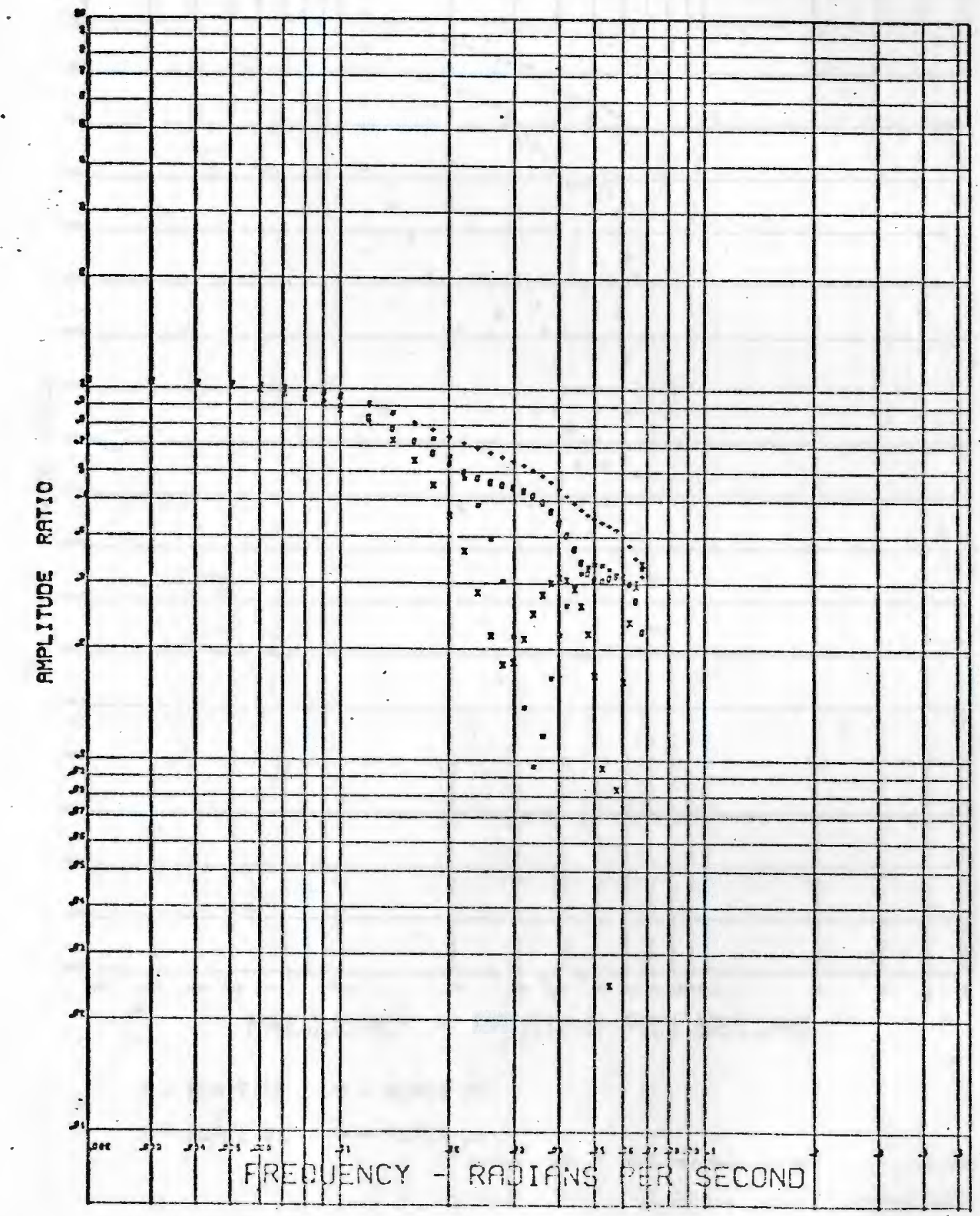



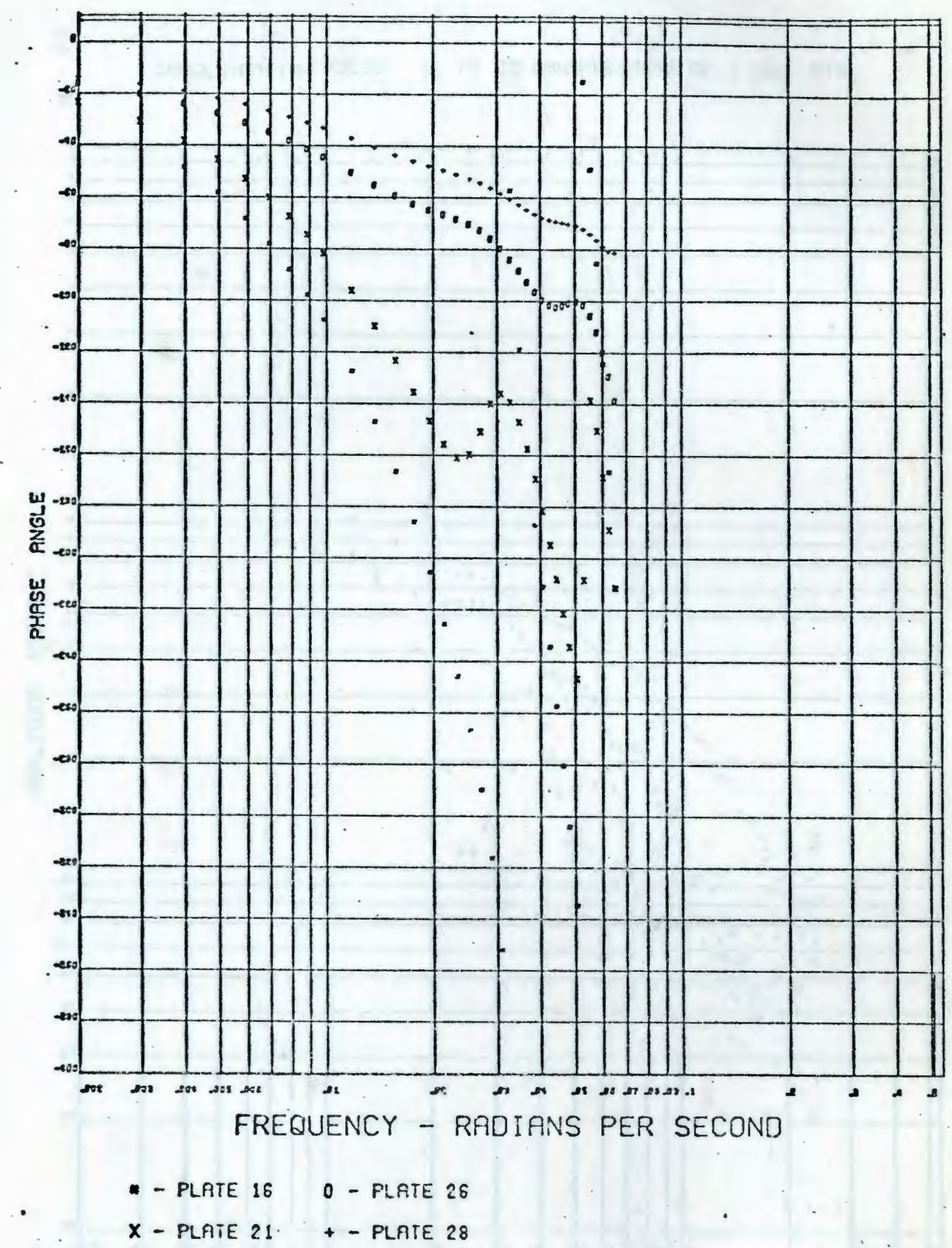


\section{BODE PLOT}

CONCENTRATION PULSE $?$ AT COL.UMN PRESSURE OF 1.000 ATM.

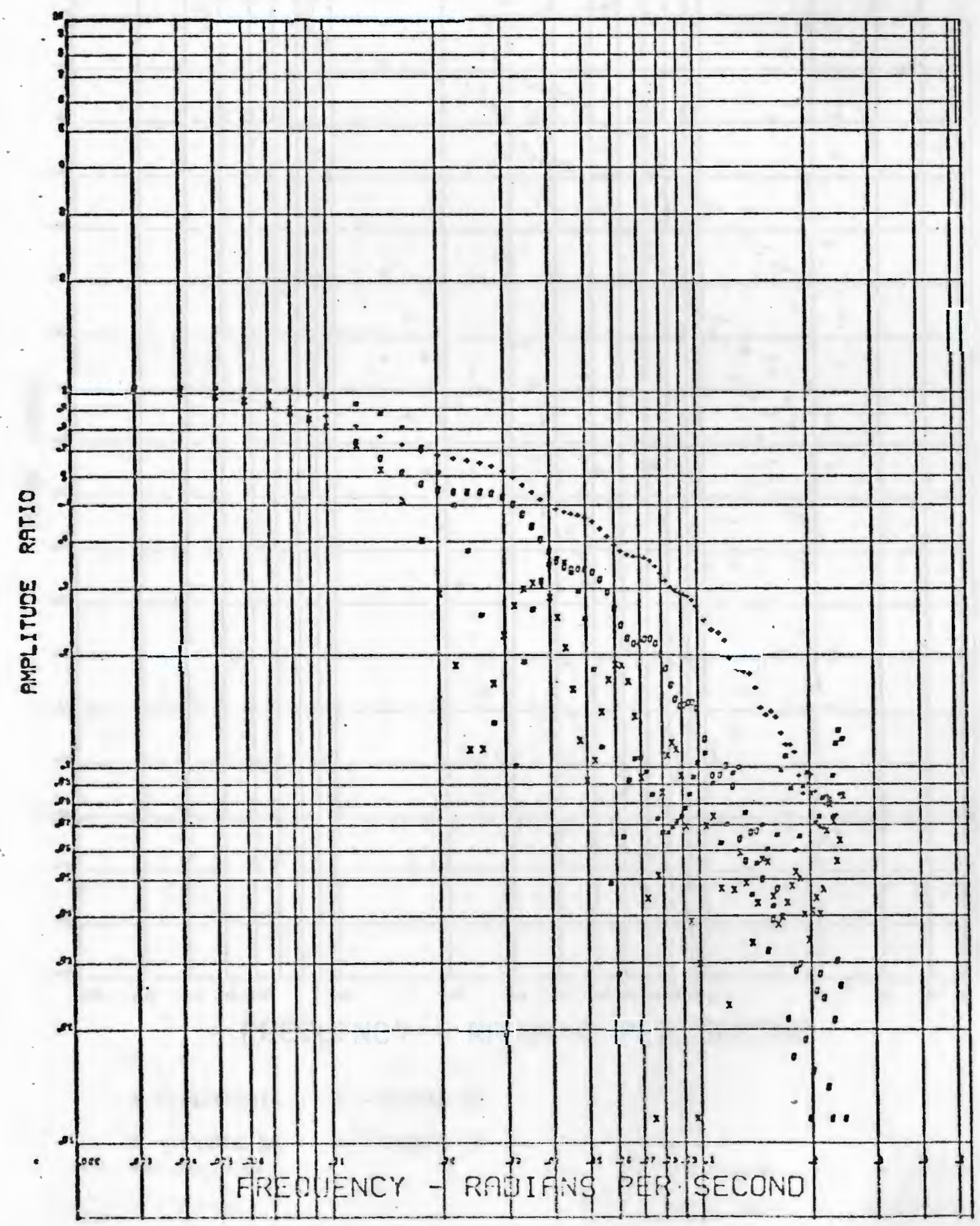




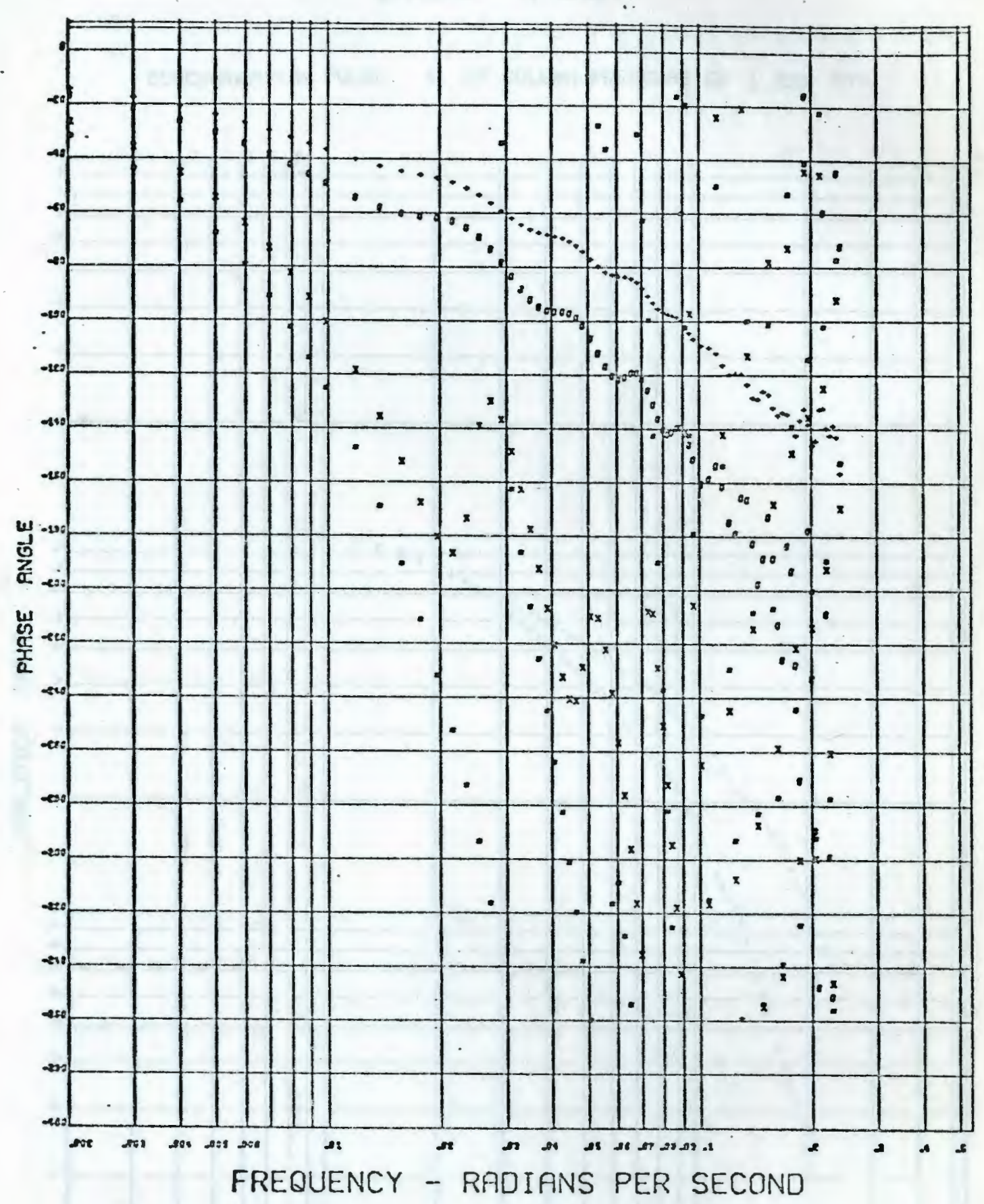

- plate 16 o-plate 26

x- Plate 21 + PLRTE 28 


\section{BODE PLOT}

CONCENTRATION PULSE \& AT COLUMN PRESSURE OF 1.000 ATM.

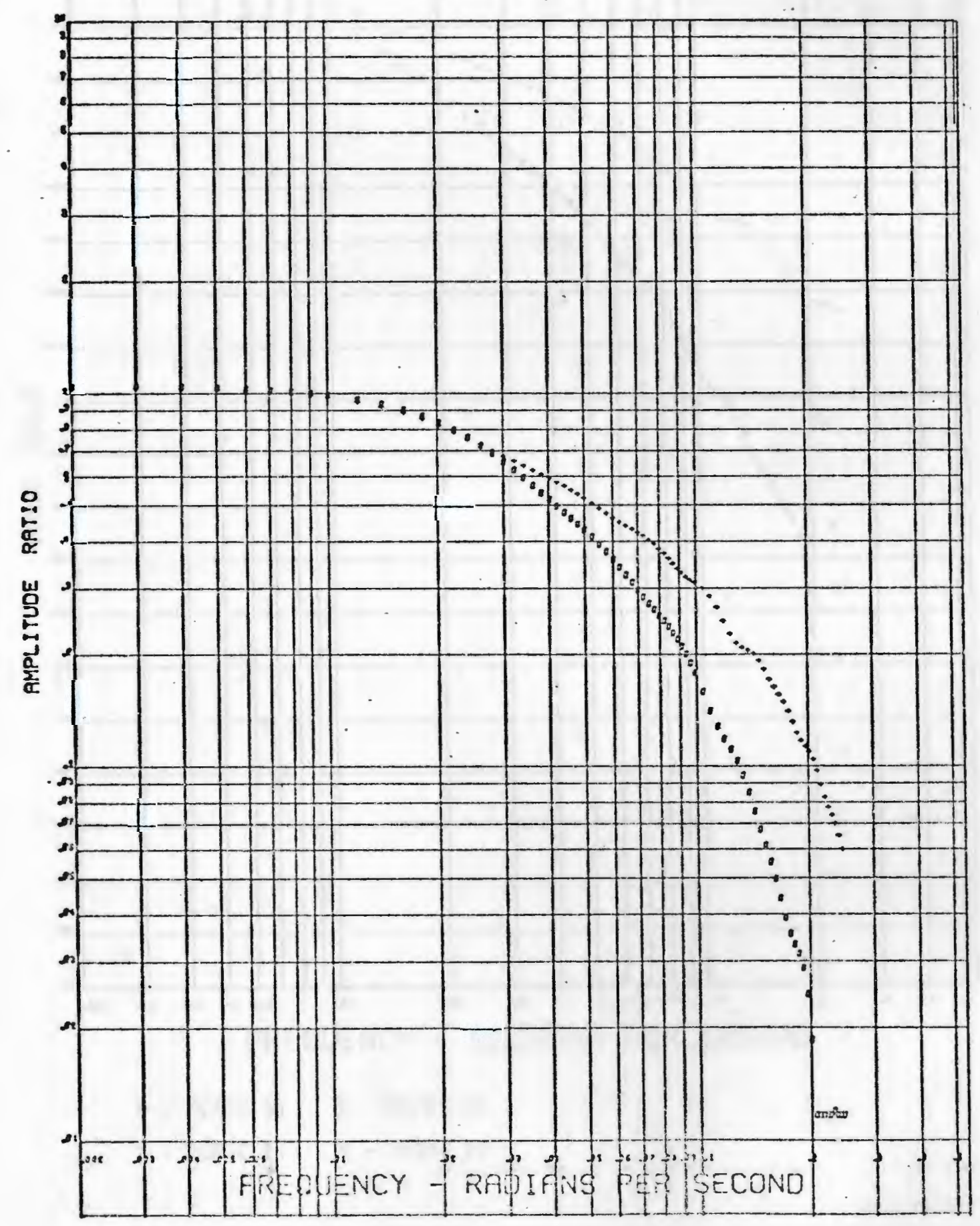




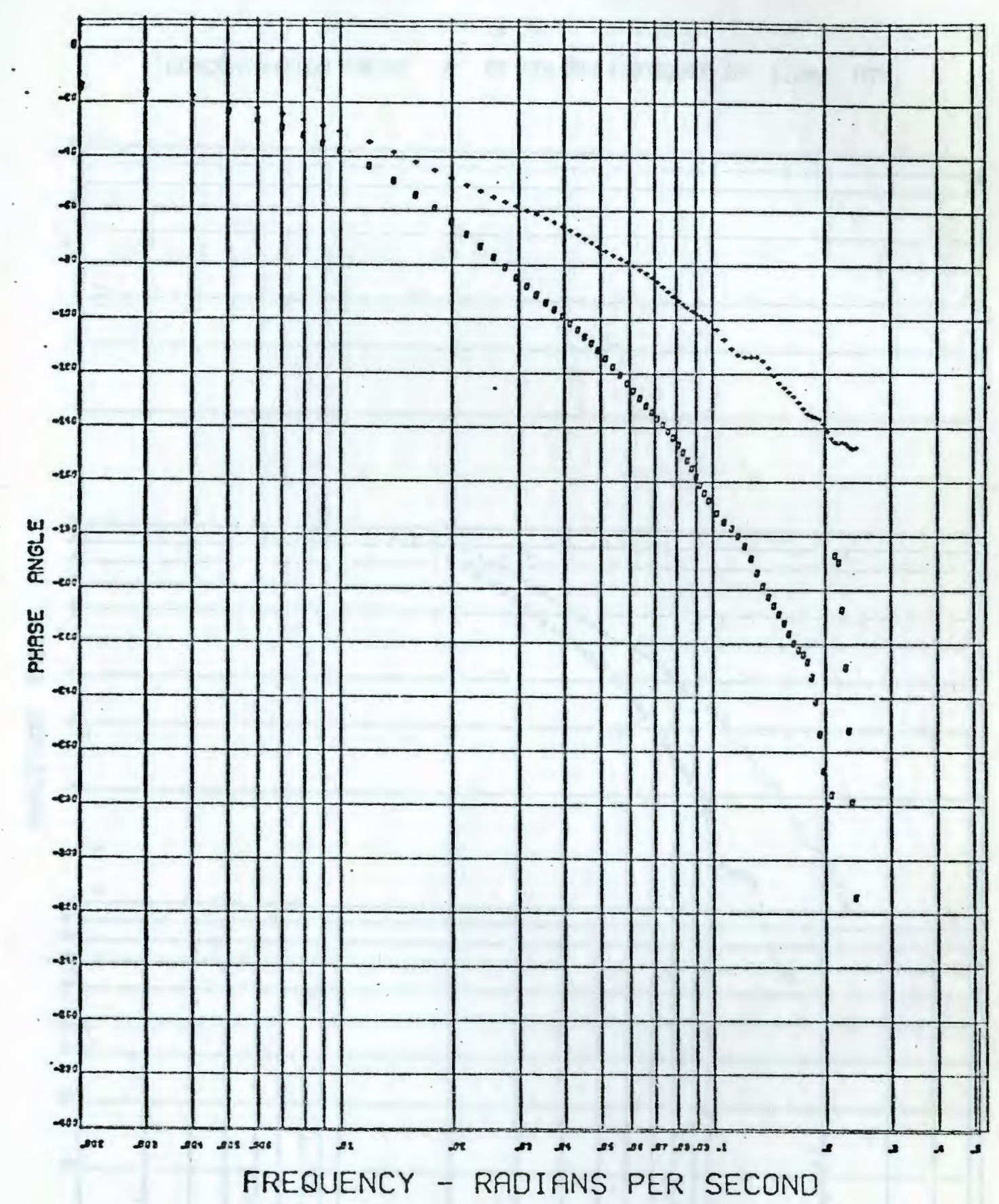

- plate 16 o-plate 26

$x$ - PLATE 21 \& PLATE 


\section{BODE PLOT}

CONCENTRATION PULSE \& AT COLUMN PRESSURE OF 1.000 ATM.

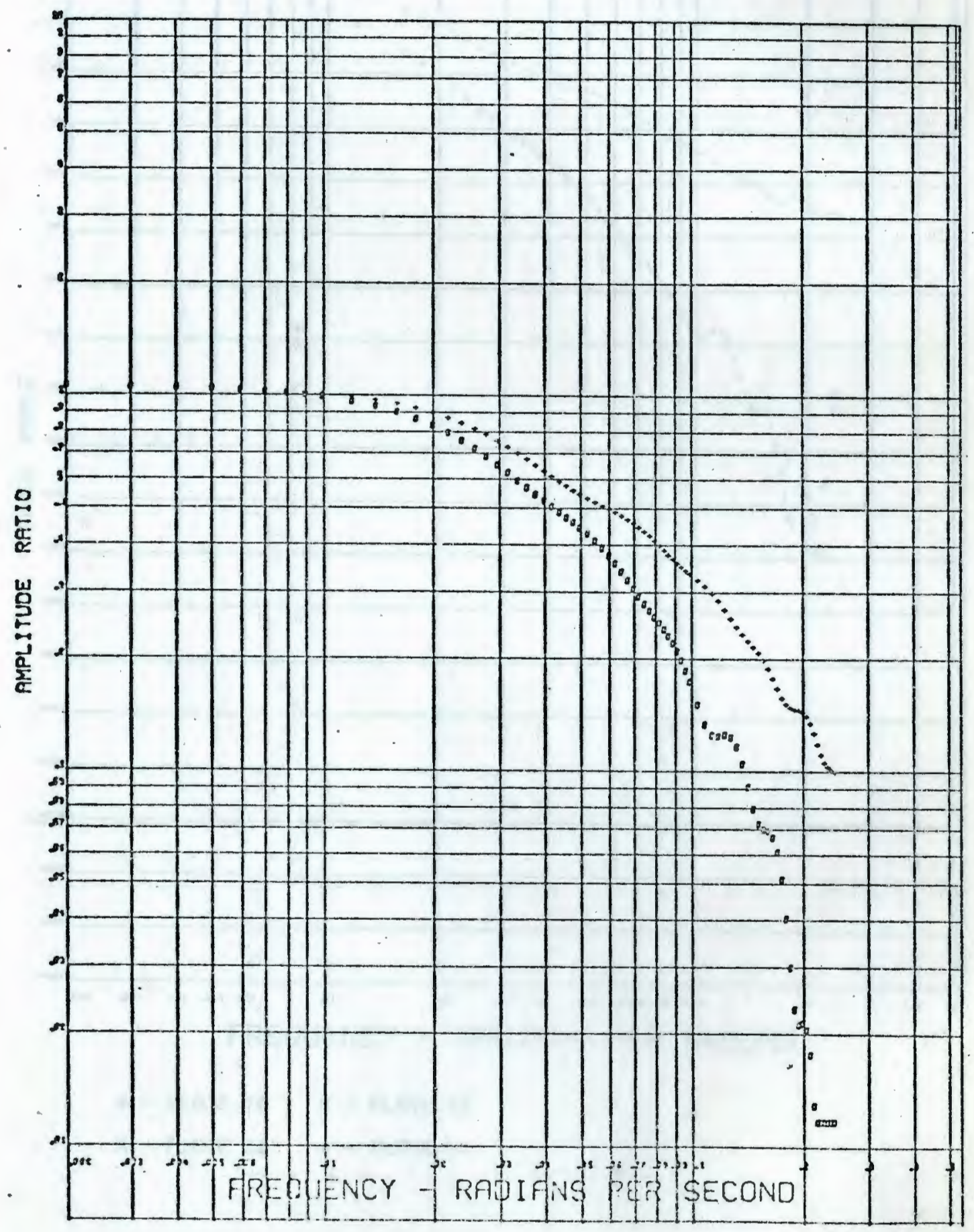




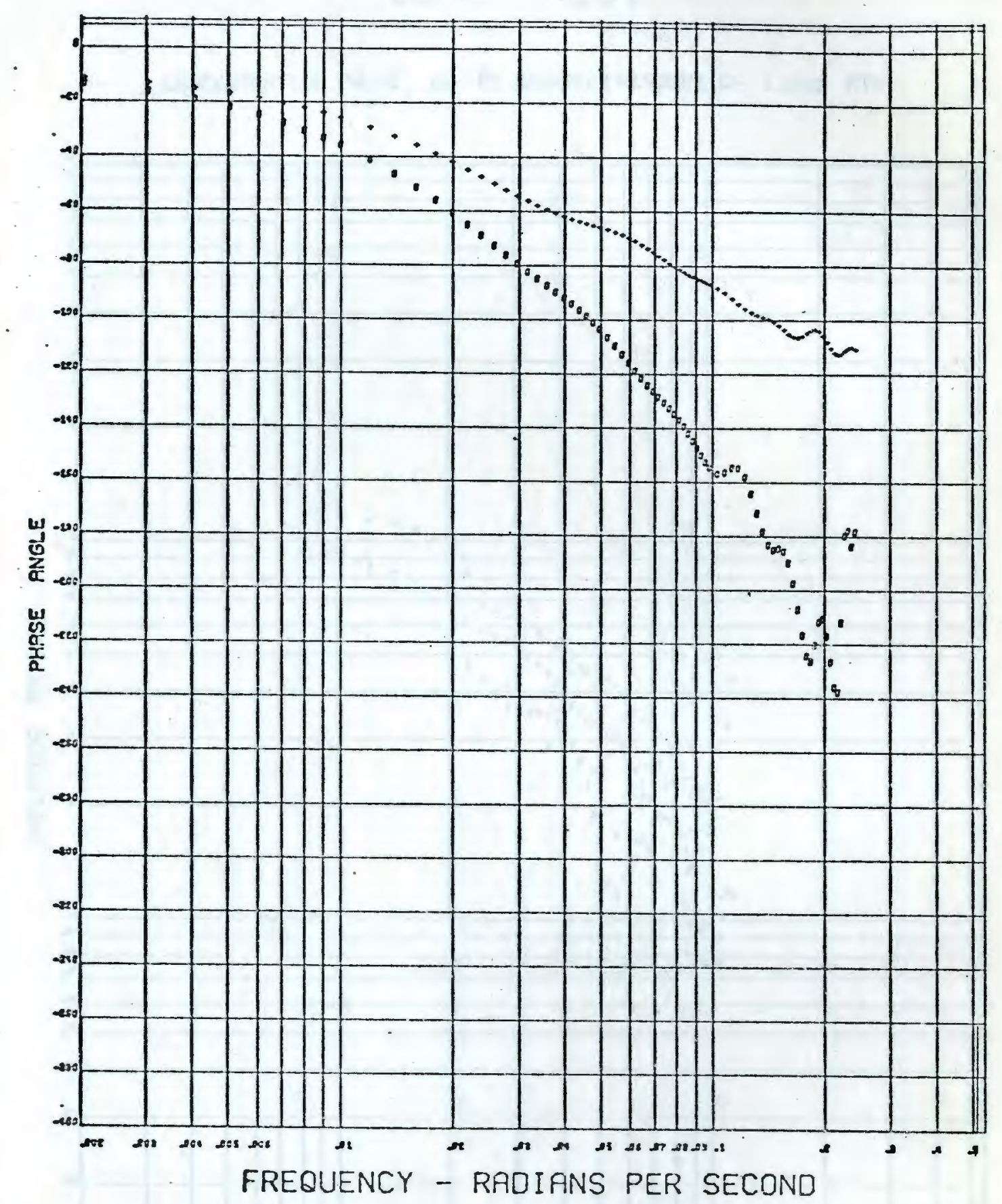

- plate 16 0-plate 26

X - plate 21 + - plate 28 


\section{BODE PLOT}

CONCENTRATION PULSE 10 Át COLUMN PRESSURE OF 1.000 ATM.

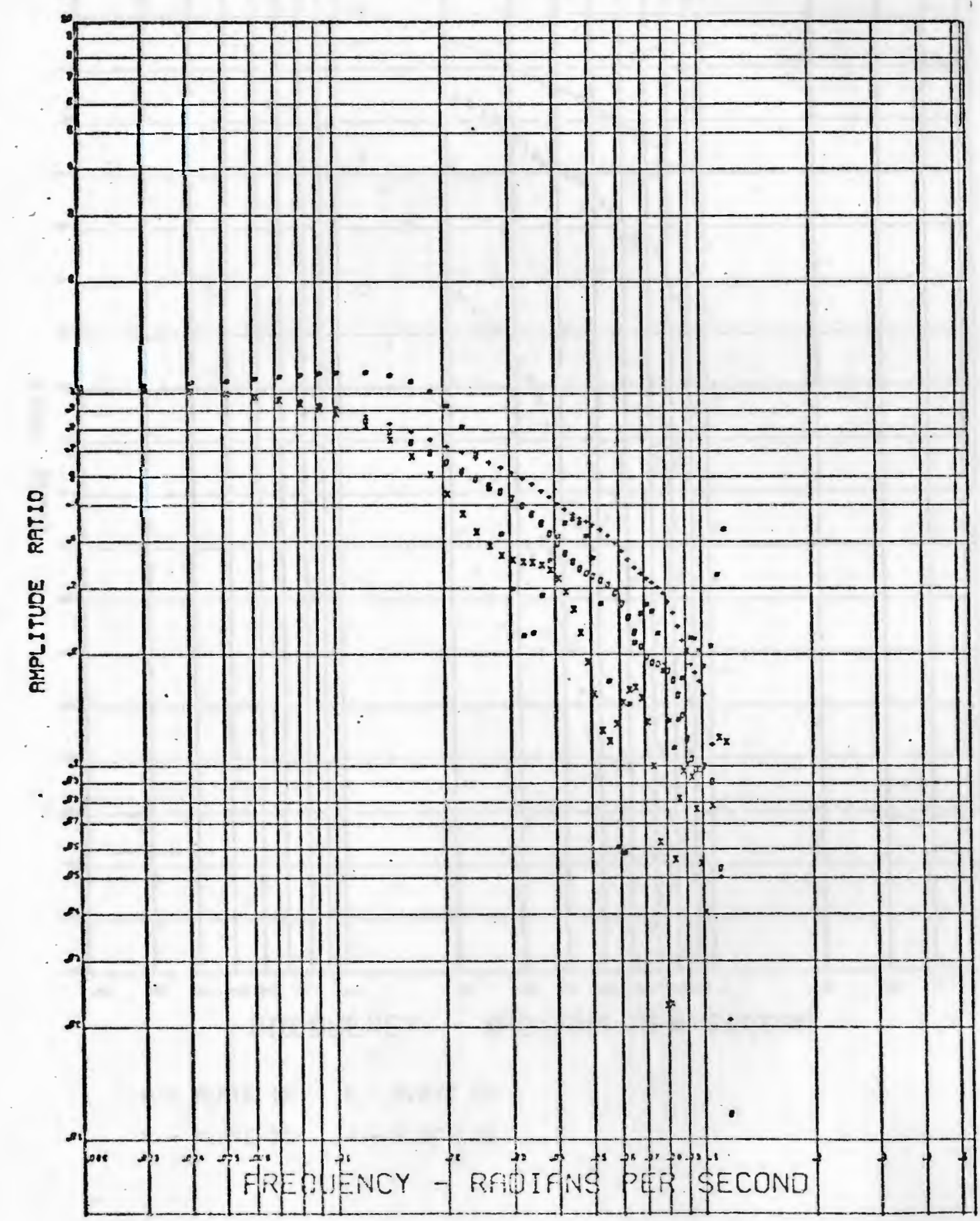




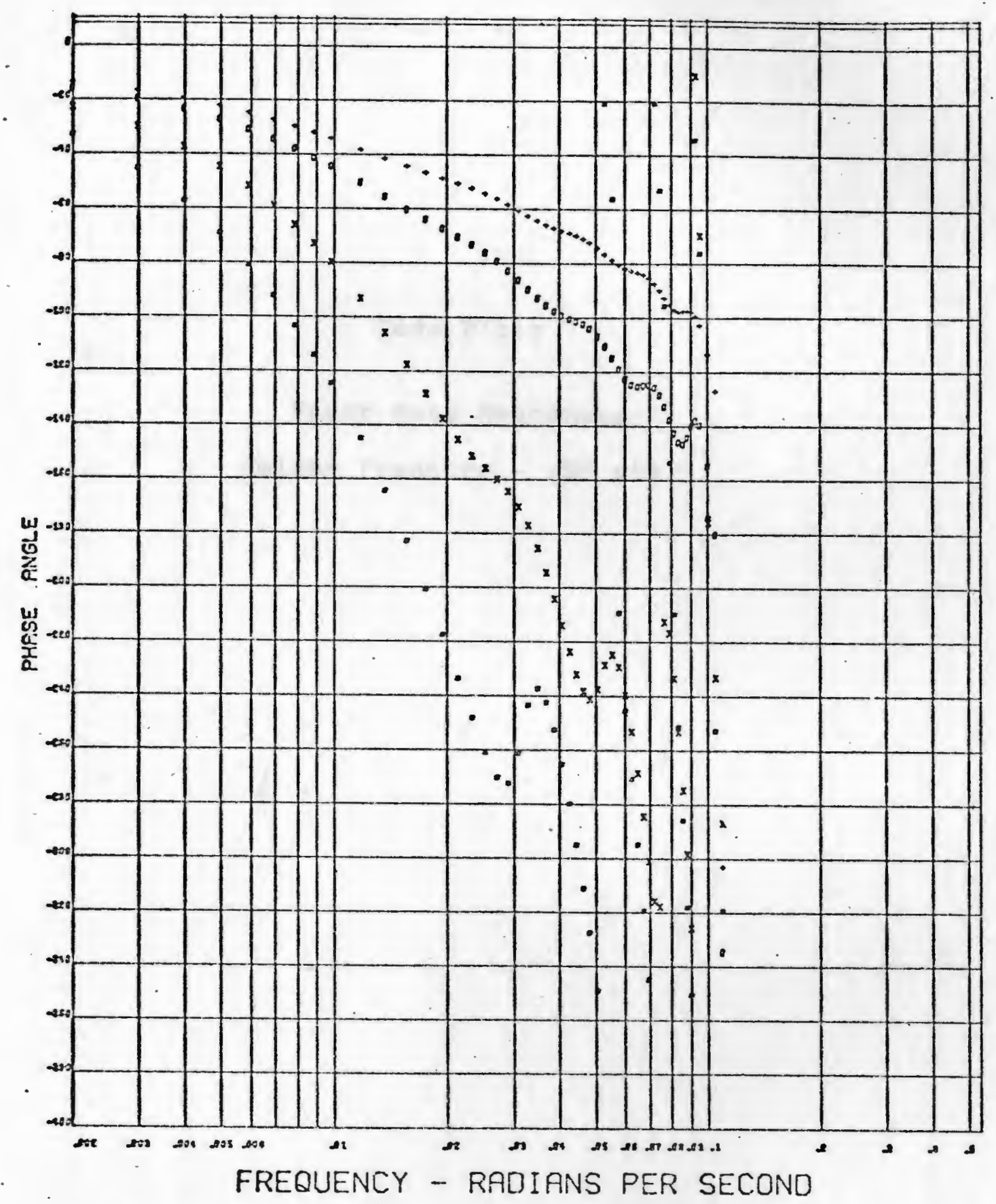

* plate 16 o-plate 26

X- PLATE 21 . + PLATE 28 
Bode Plots

Vapor Rate Responses

Column Pressure - .26 atm. 


\section{BODE PLOT}

VAPOR PULSE 1 AT COLUMN PRESSURE OF 0.263 ATM.

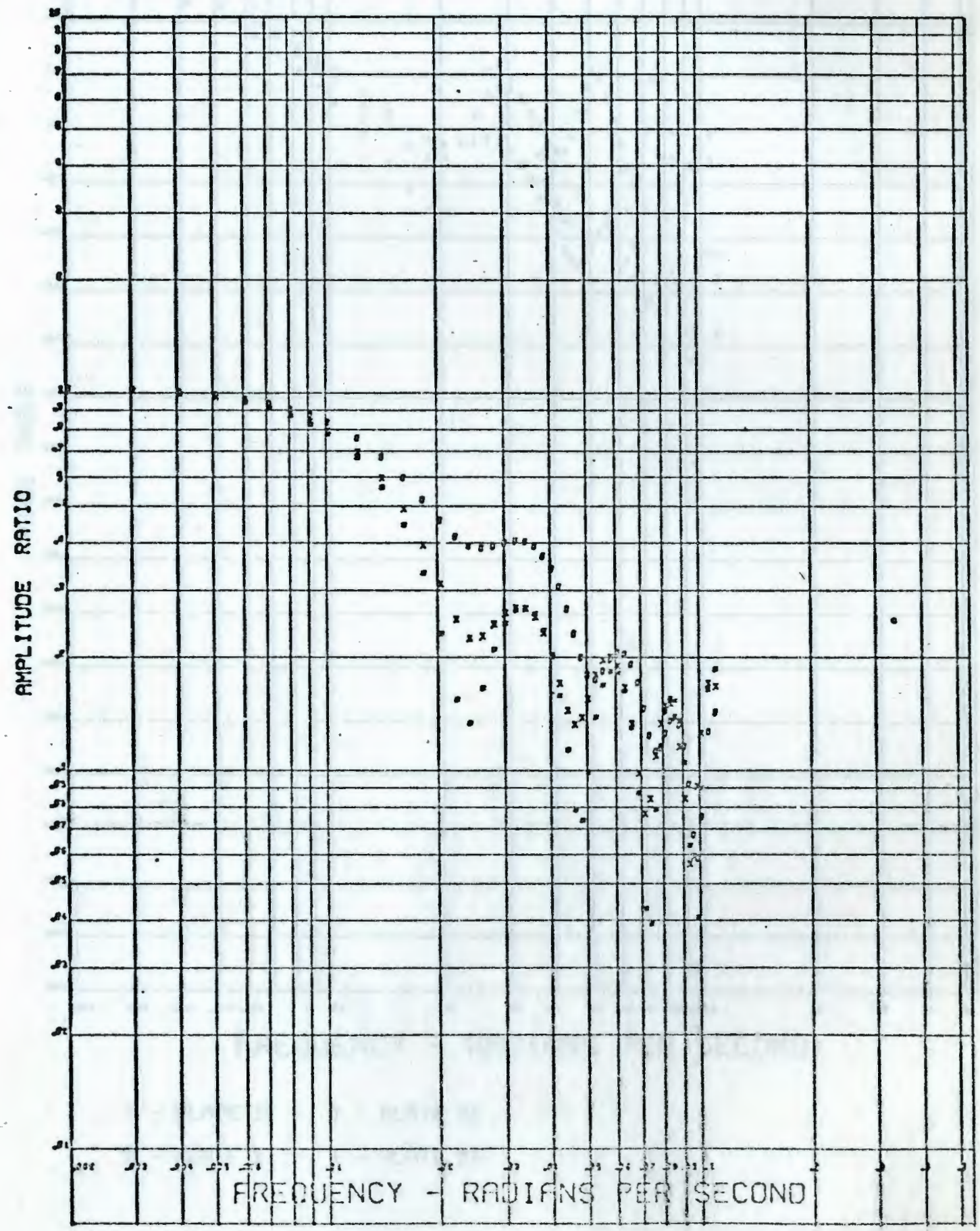




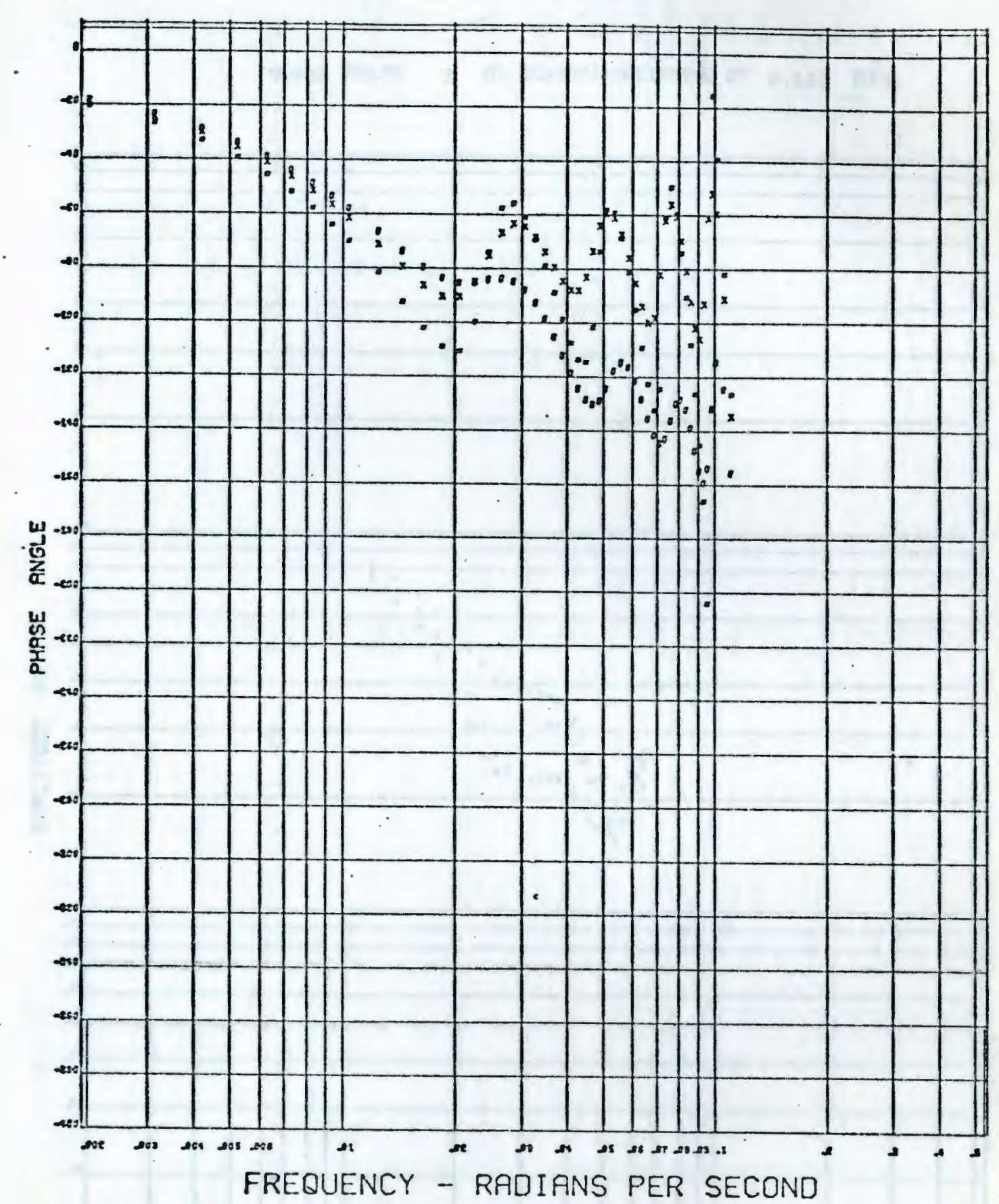

- plate 16 o-plate 26

x - plate 21. + plate 28 


\section{BODE PLOT}

VAPOR PULSE 2 AT COLUMN PRESSURE OF 0.263 ATM.

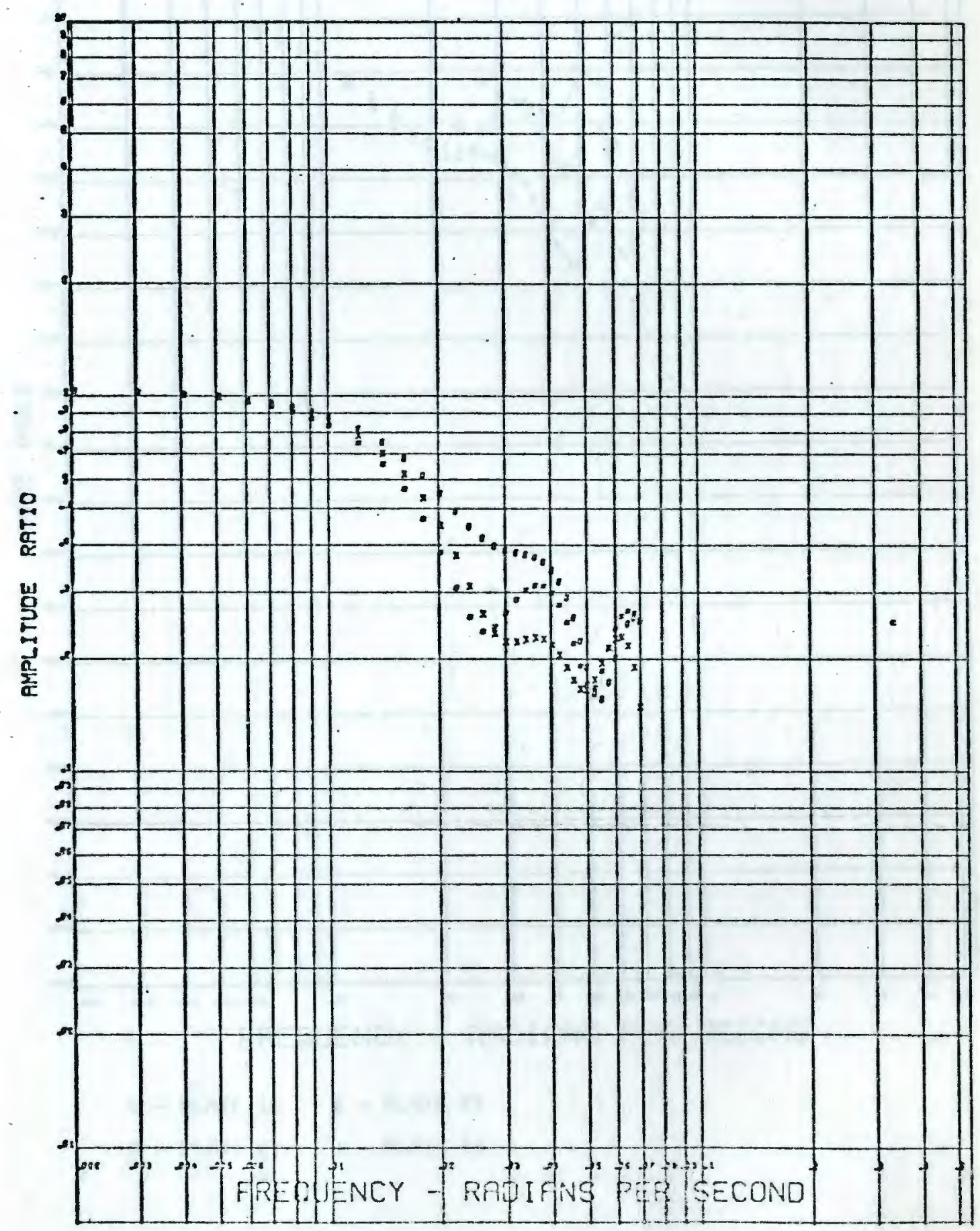




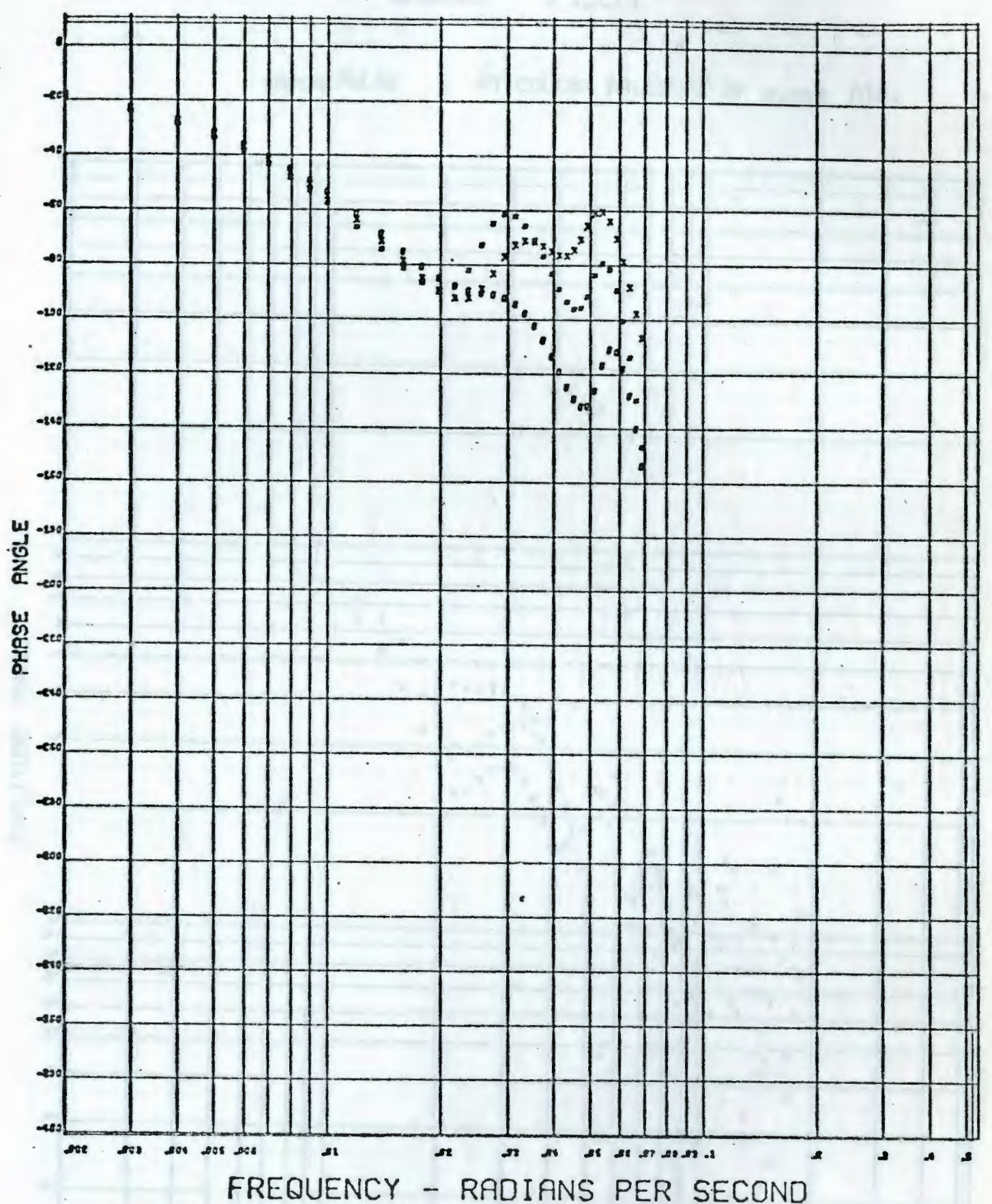

- plate 16 0-plate 26

$X$ - PLATE $2 !$ + PLATE 28 


\section{BODE PLOT}

VAPOR PULSE 3 AT COLUMN PRESSURE OF 0.263 ATM.

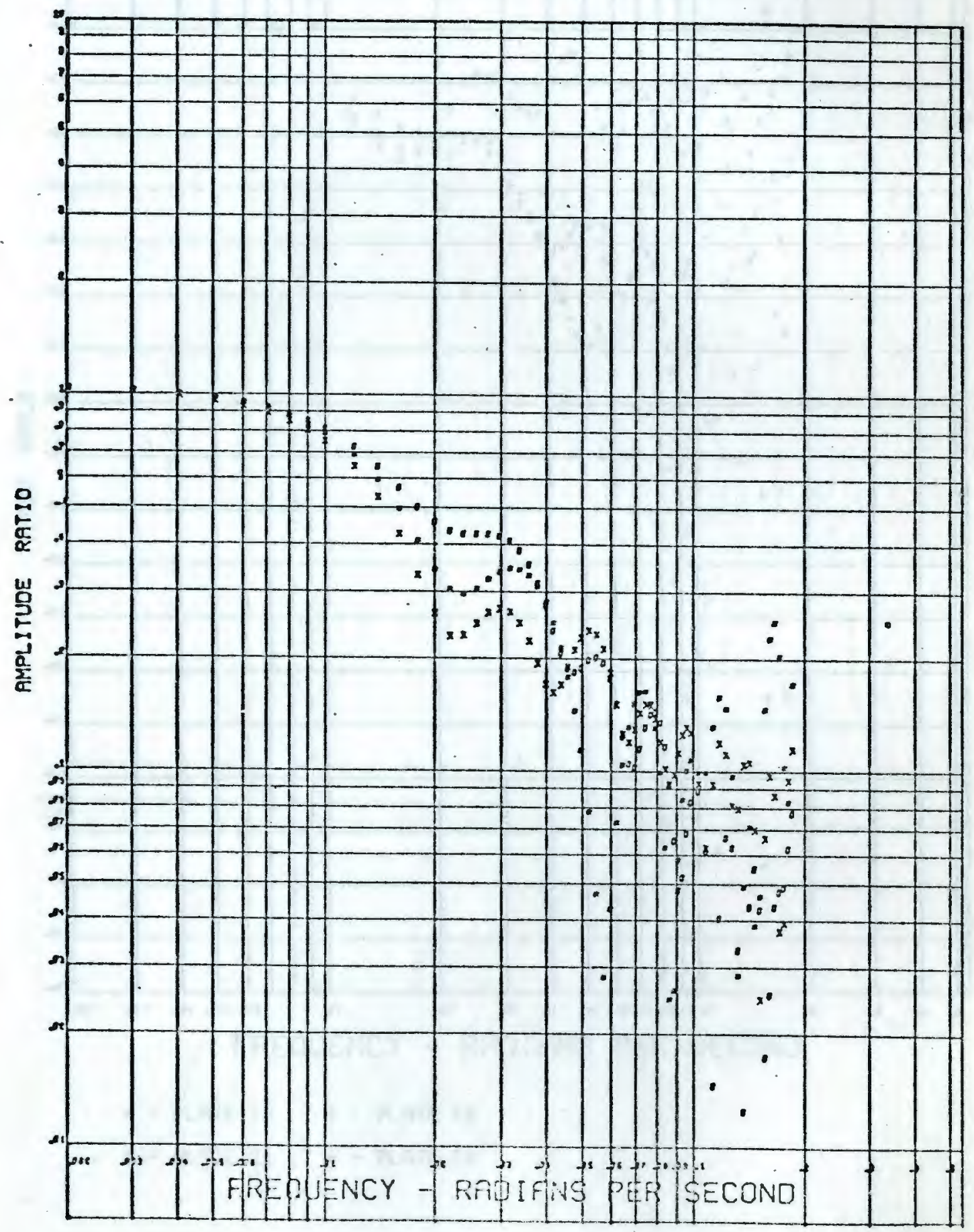




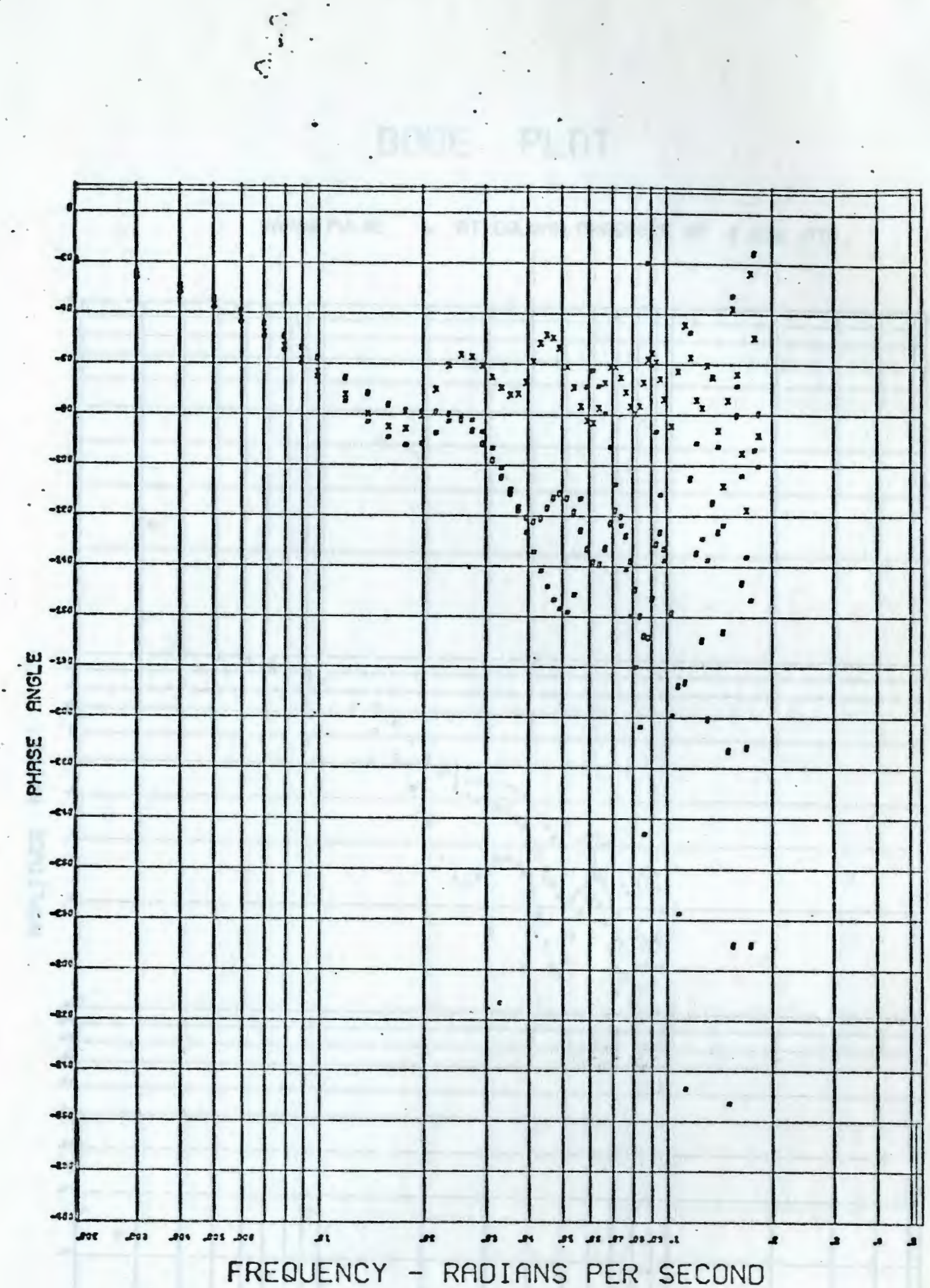

* - plate 16 o- plate 26

X-PLATE $21+$ - Plate 28 


\section{BODE PLOT}

VAPOR PULSE \& AT COLUMN PRESSURE OF 0.263 ATM.

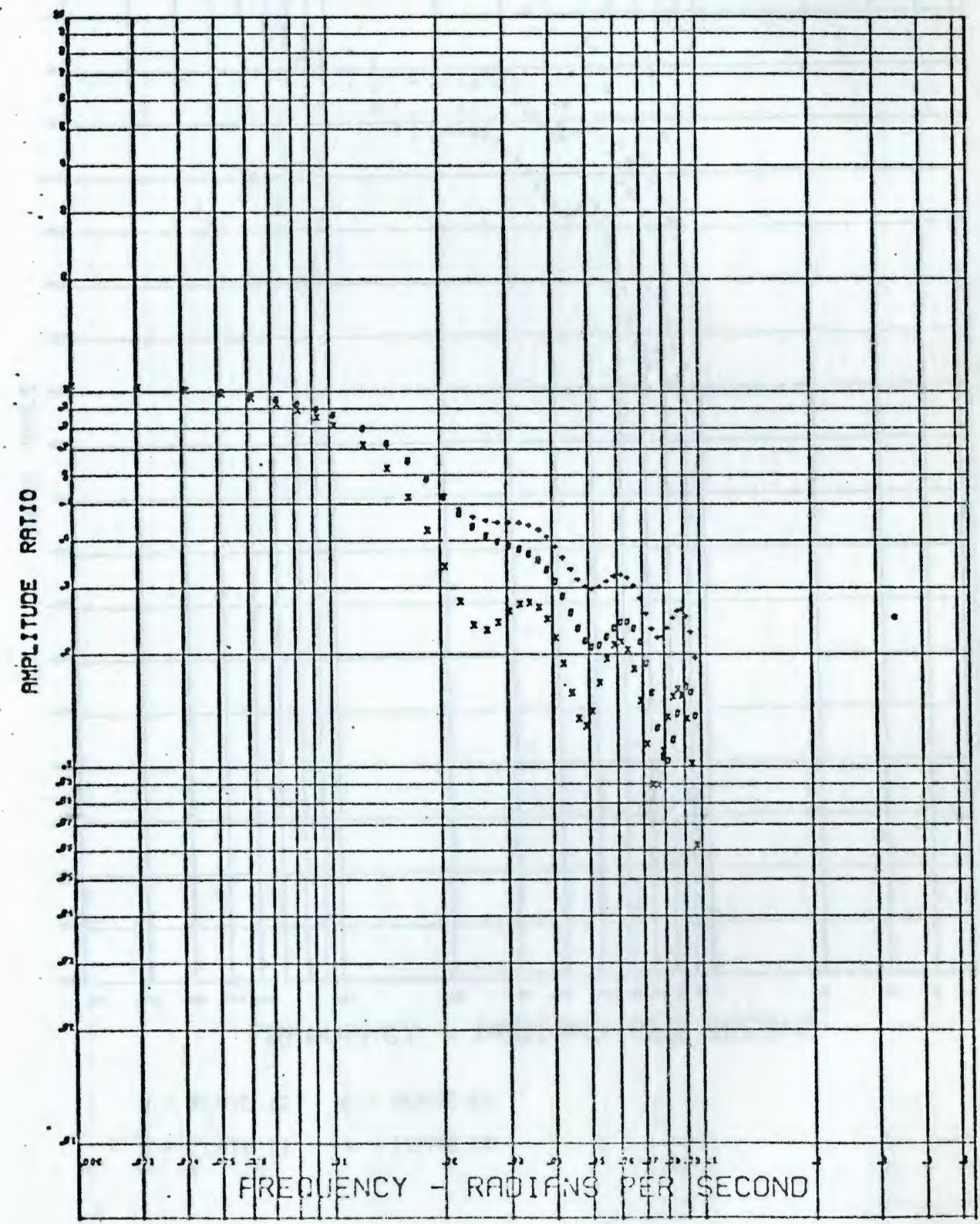


. :

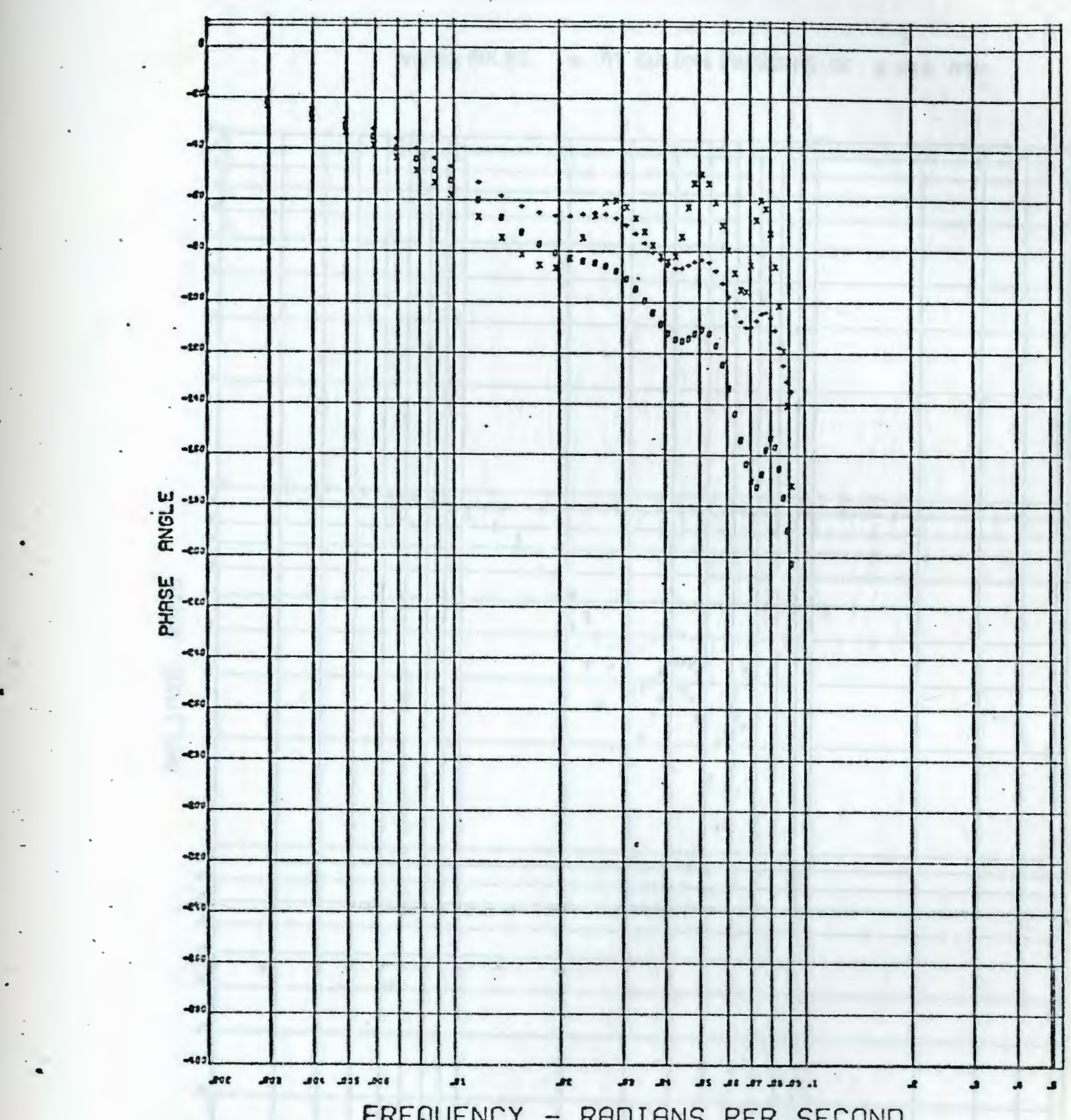

FREQUENCY - RRDIANS PER SECOND

* - plate 16 0-plate 26

$x$ - PlATE $21+$ - FLATE 28 


\section{BODE PLOT}

VAPOR PULSE 5 AT COLUMN PRESSURE OF 0.263 ATM.

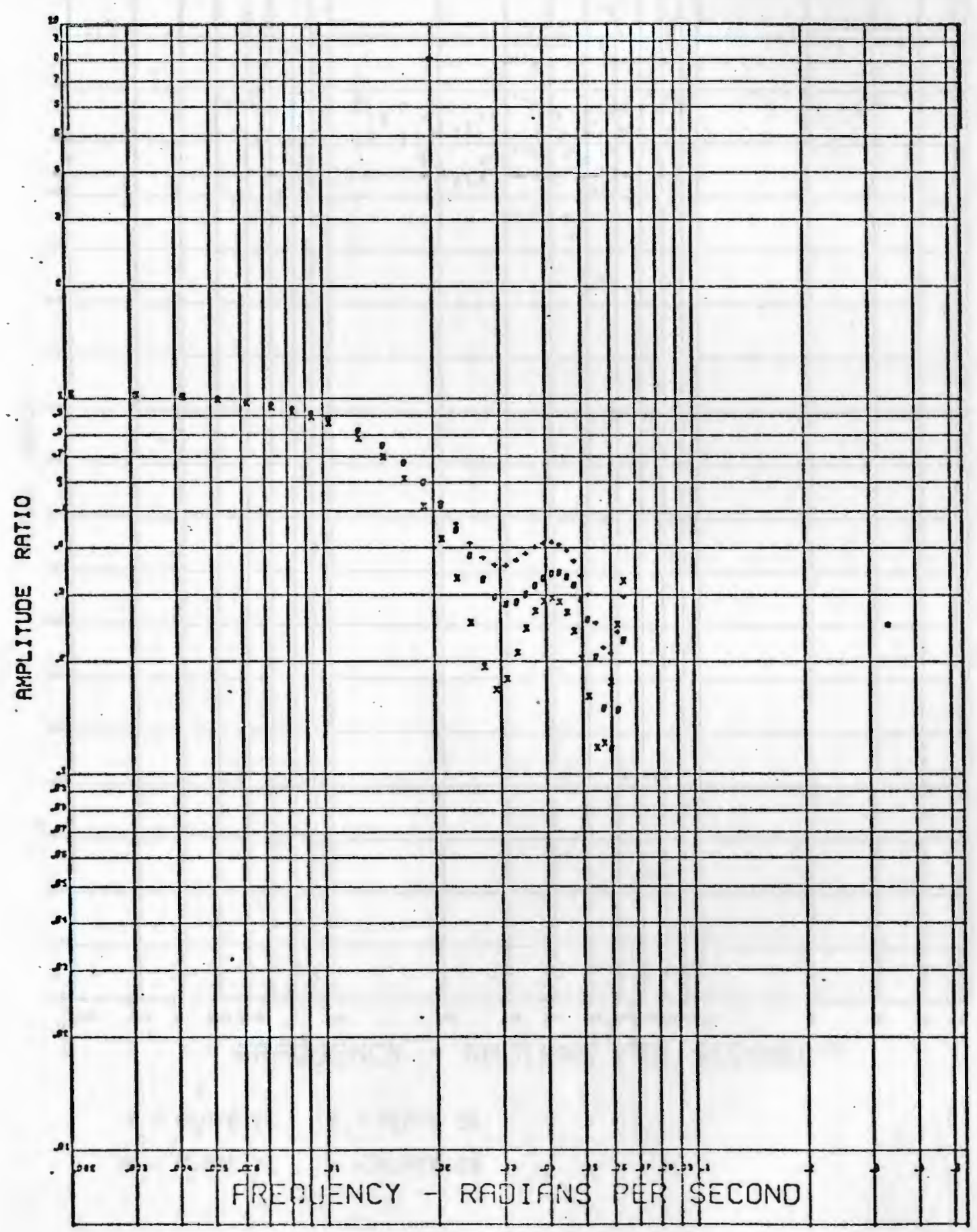




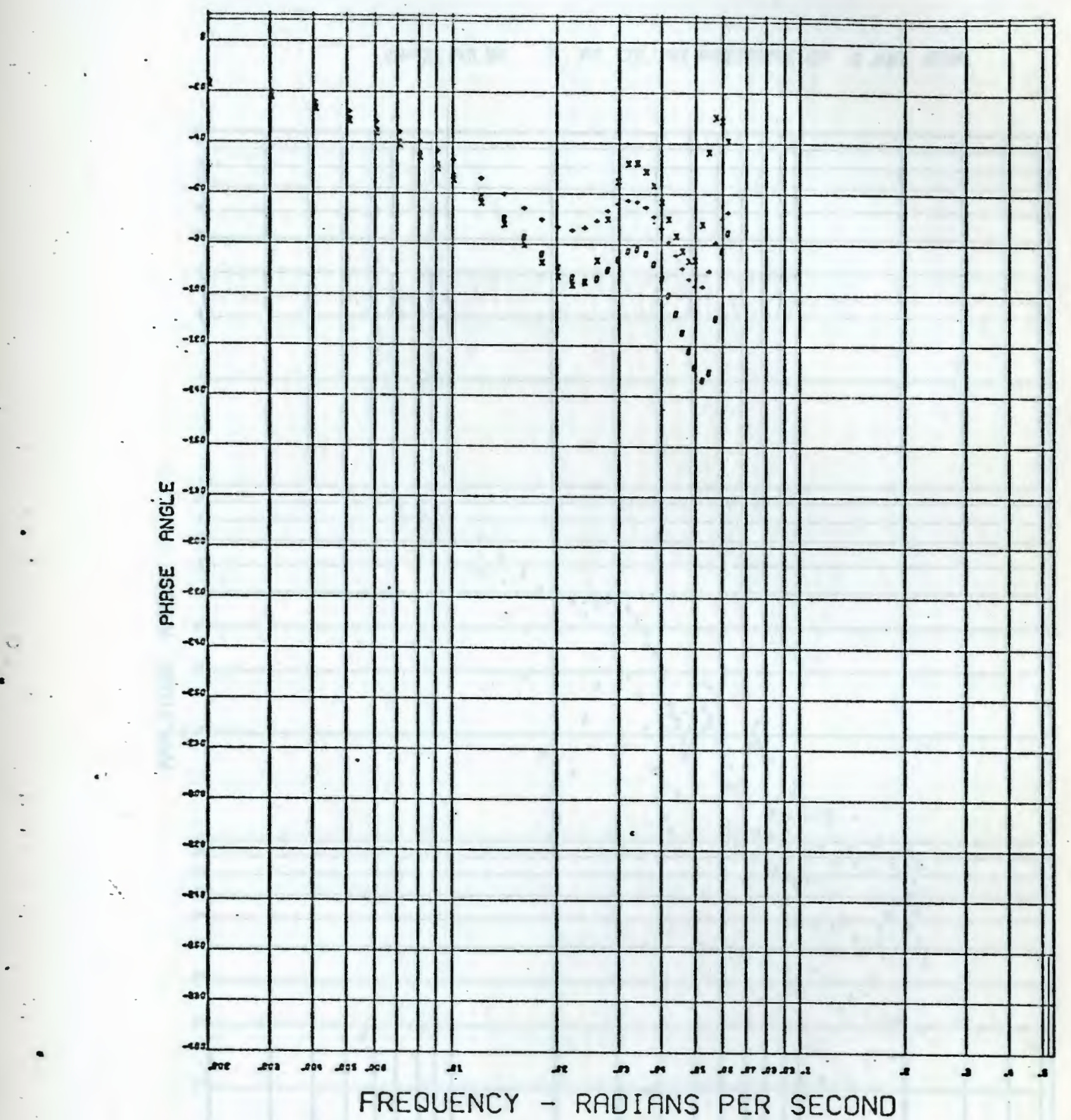

$$
\begin{aligned}
& \text { - Plate } 16 \text { - Plate } 26 \\
& \text { X-Plate } 21 \text { + - Plate } 28
\end{aligned}
$$


$\because$

BODE PLOT

VAFOR PULSE 6 AT COLUMN PRESSURE OF 0.263 ATM.

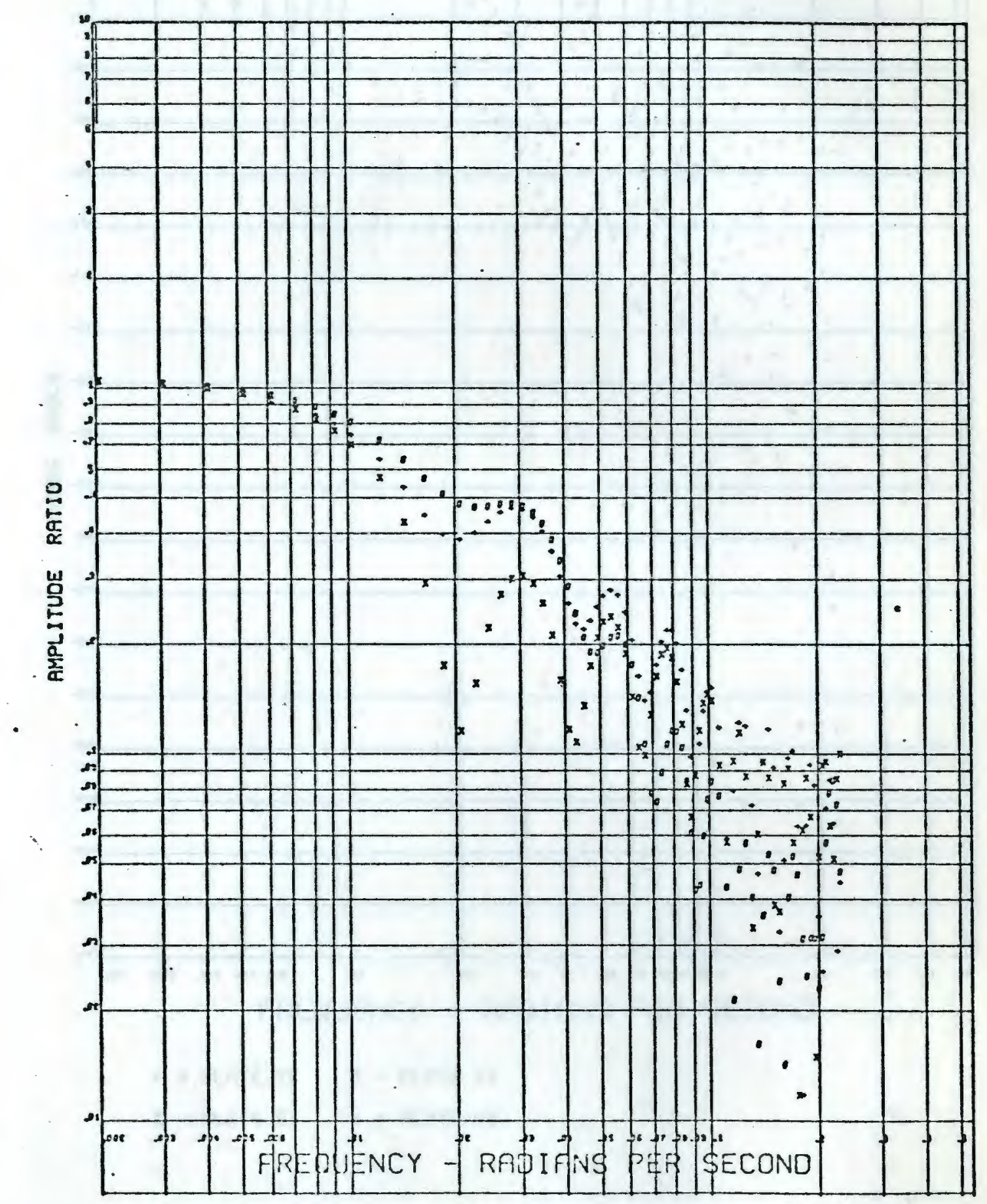




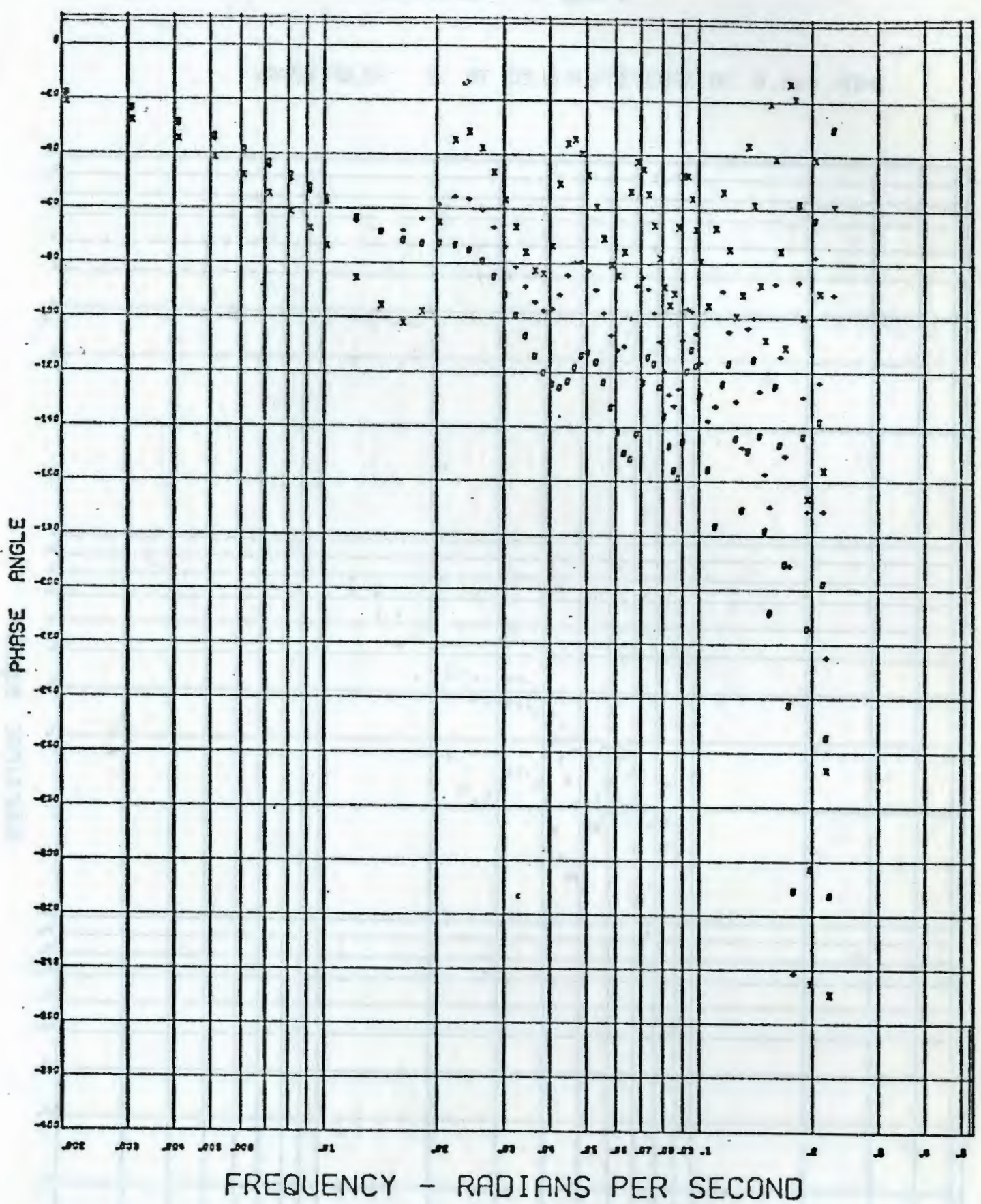

* - plate 16 o - plate 26

X - PLATE 21 + PLATE 28 
BODE PLOT

VAPOR PULSE ? AT COLUMN PRESSURE OF 0.263 ATM.

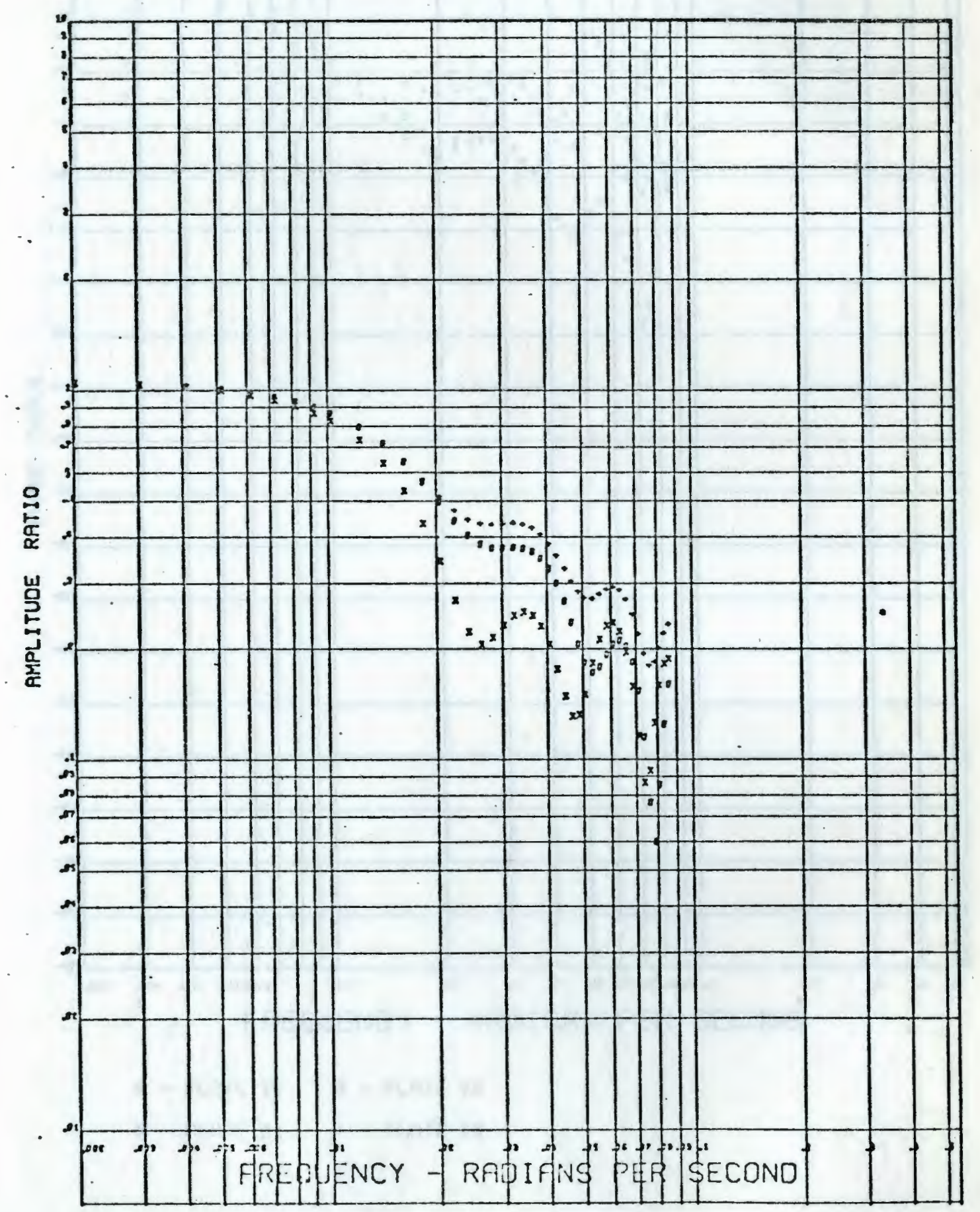





\section{BODE PLOT}

VAPOR PULSE $\&$ AT COLUMN PRESSURE OF 0.263 ATM.

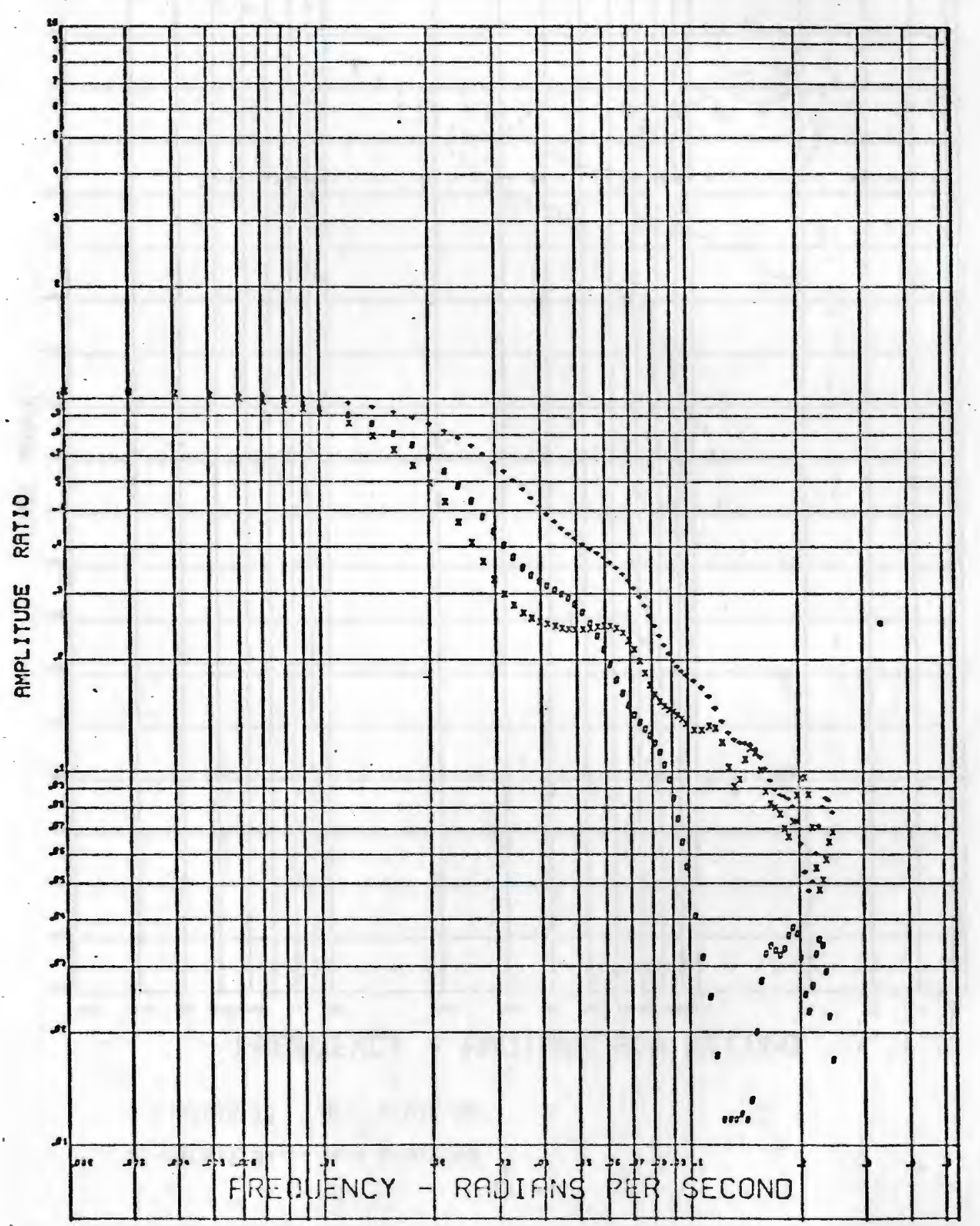




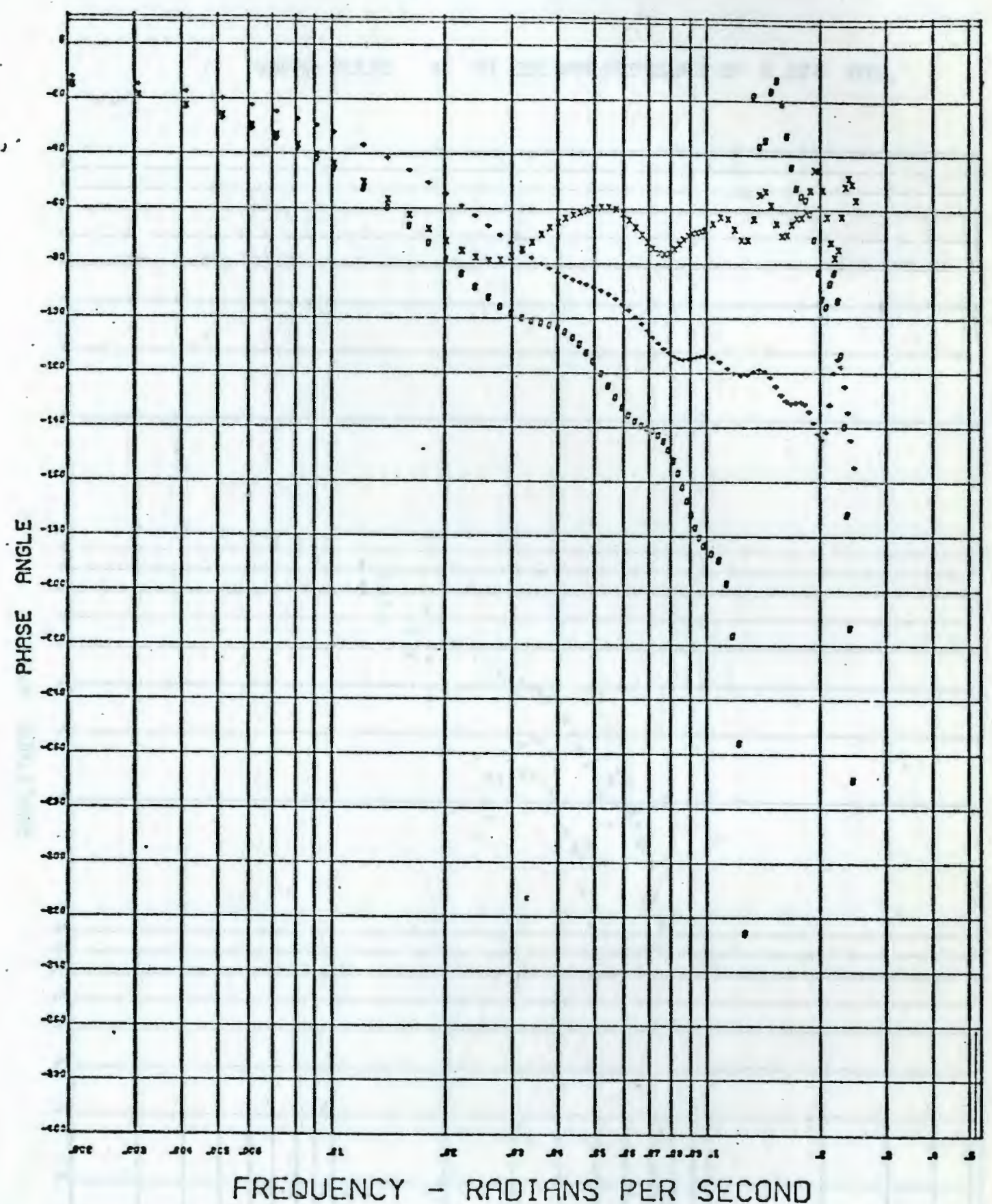

* - plate 16 0 - plate 26

X - plate 21 + - plate 28 
$\therefore$

\section{BODE PLOT}

VAPOR PULSE 9 AT COLUMN PRESSURE OF 0.263 ATM.

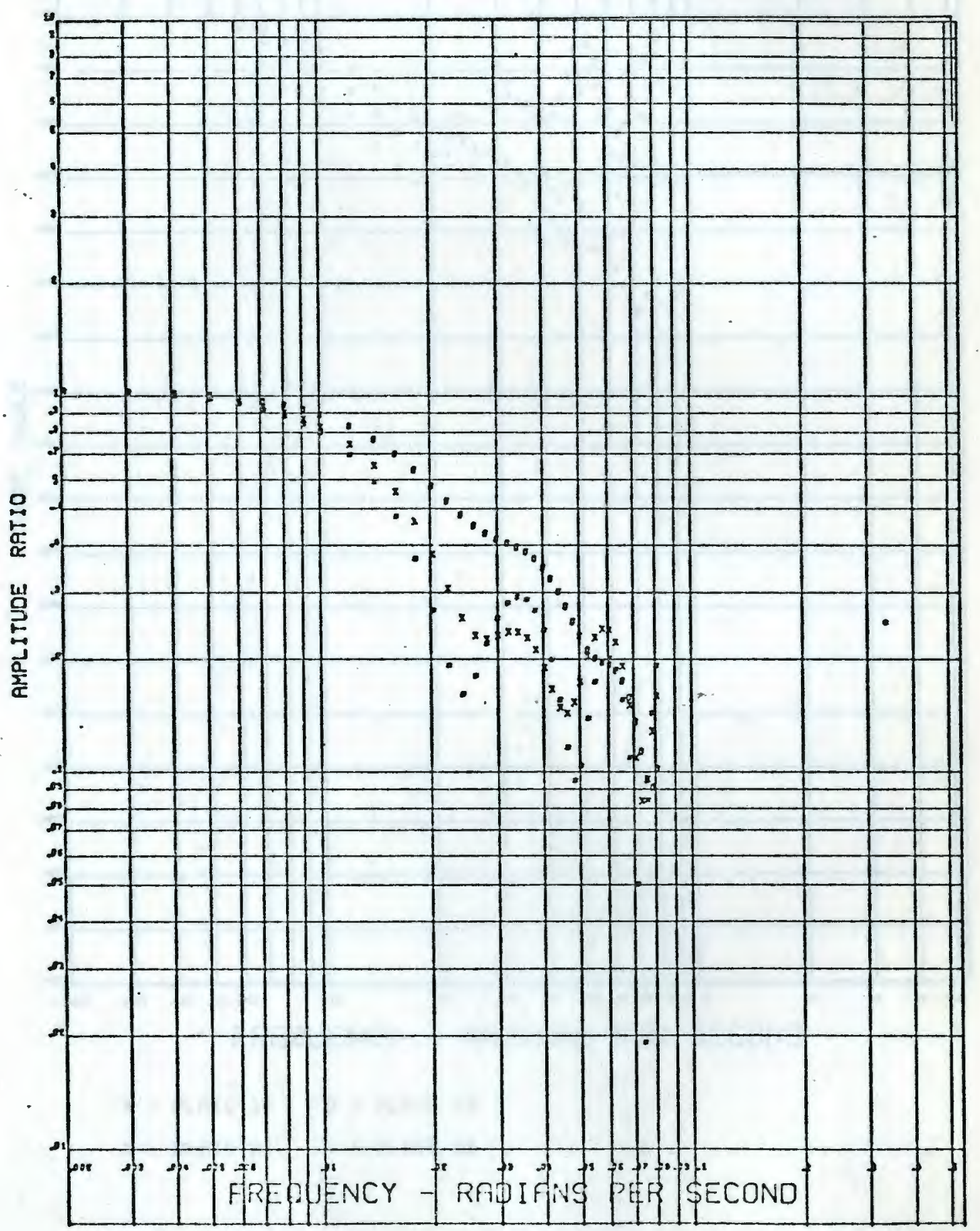




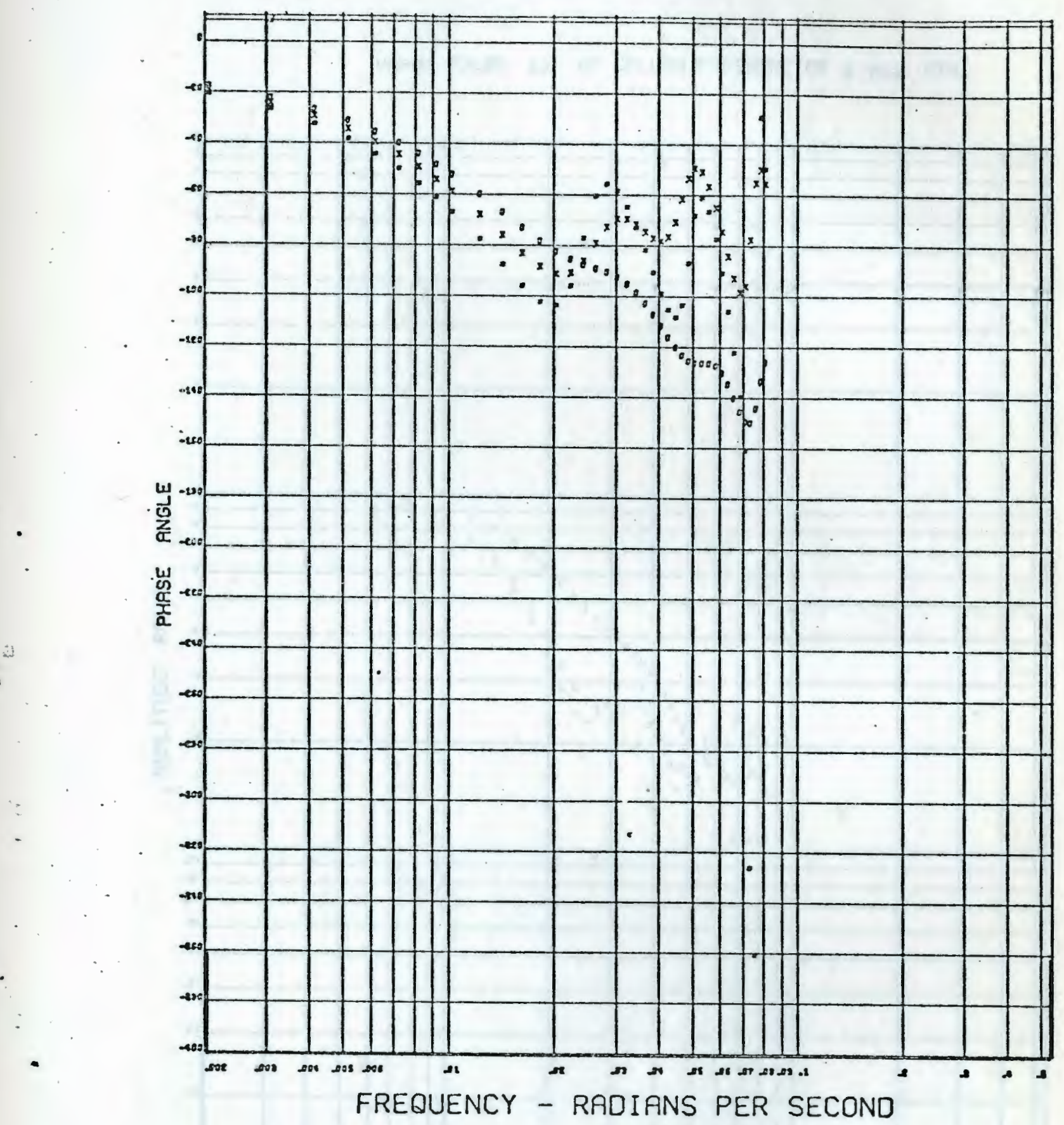

- plate 16 0-plate 26

X-PLATE 21 + PLATE 28 


$$
\begin{aligned}
& \text { BODE PLOT } \\
& \text { BOA }
\end{aligned}
$$

VAPOR PULSE 10 AT COLUMN FRESSURE OF 0.263 ATM.

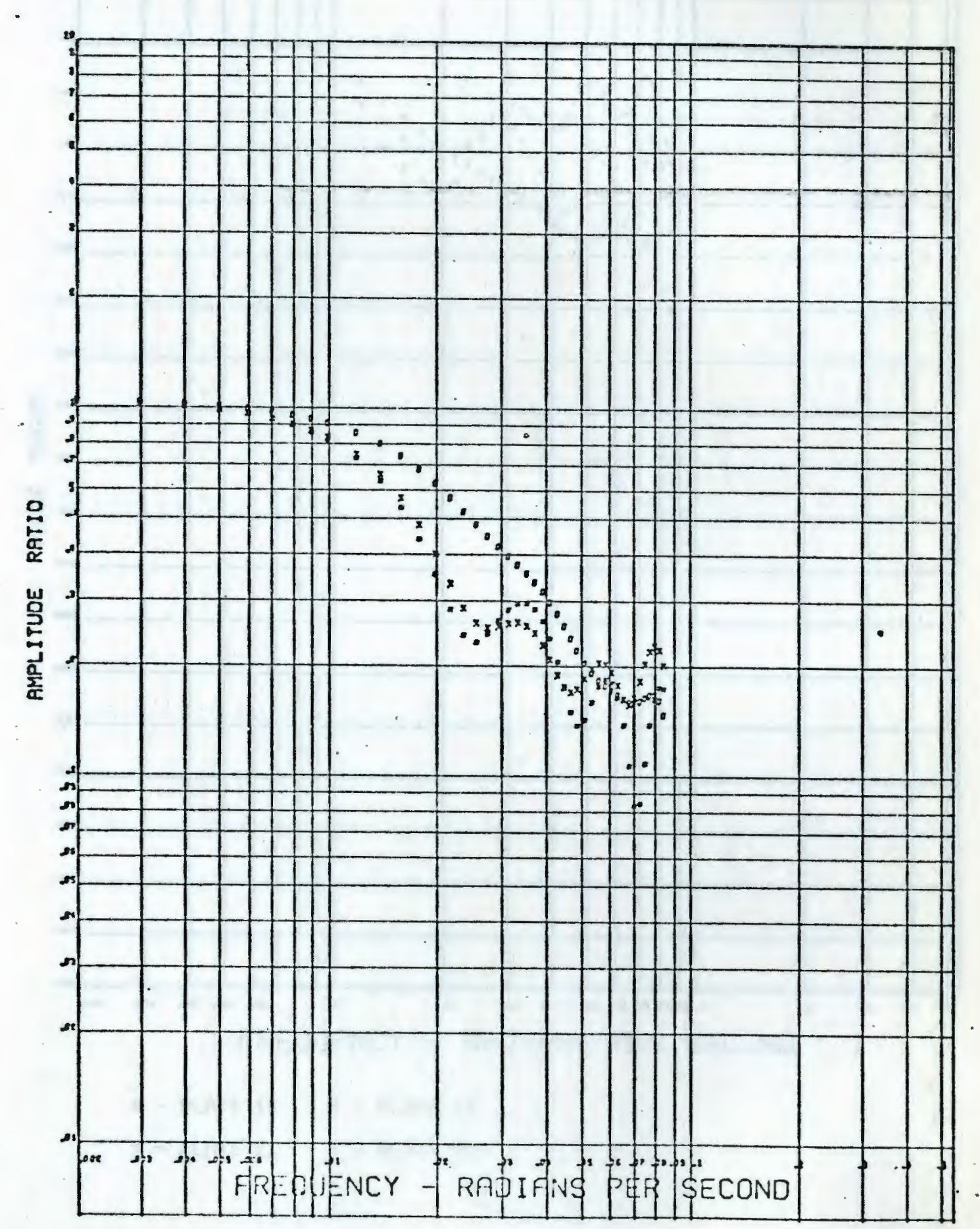



$i$

BODE PLOT

VAPOR PULSE 11 AT COLUMN PRESSURE OF 0.263 ATM.

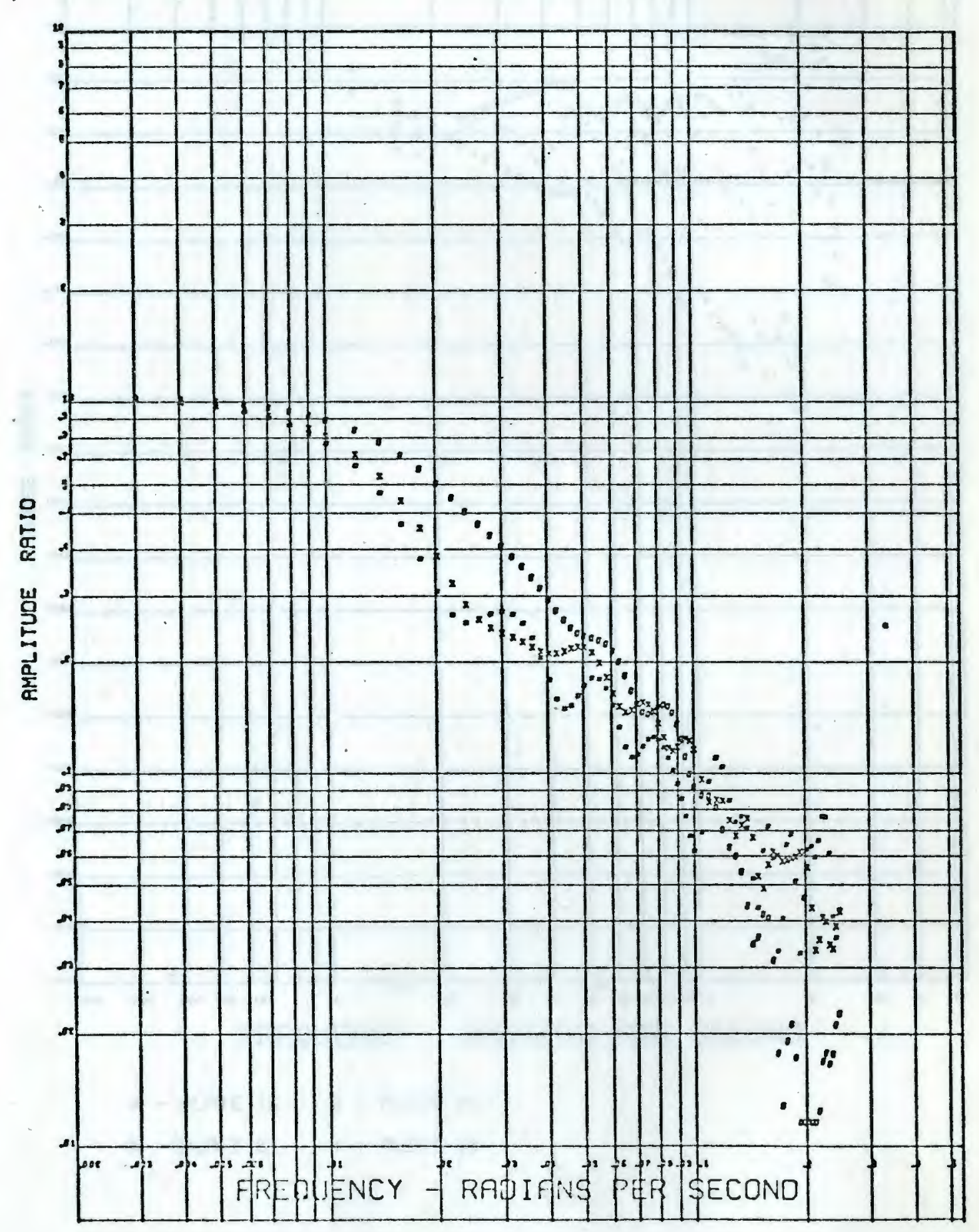




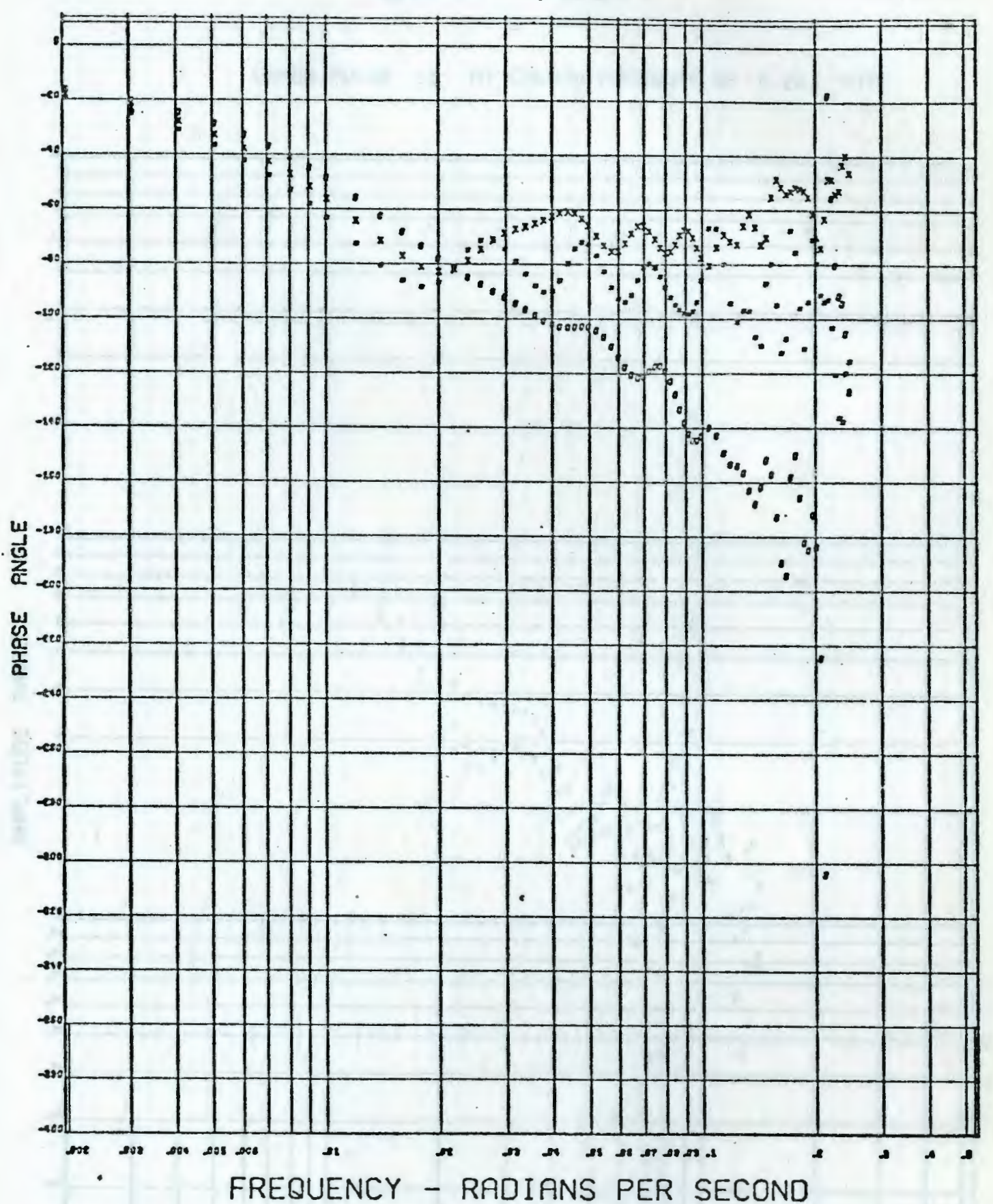

* - plate 16 0 - plate 26

$x$ - Plate 21. + PLATE 28 


\section{BODE PLOT}

VAPOR PULSE 12 RT COLUMN PRESSURE OF 0.263 ATM.

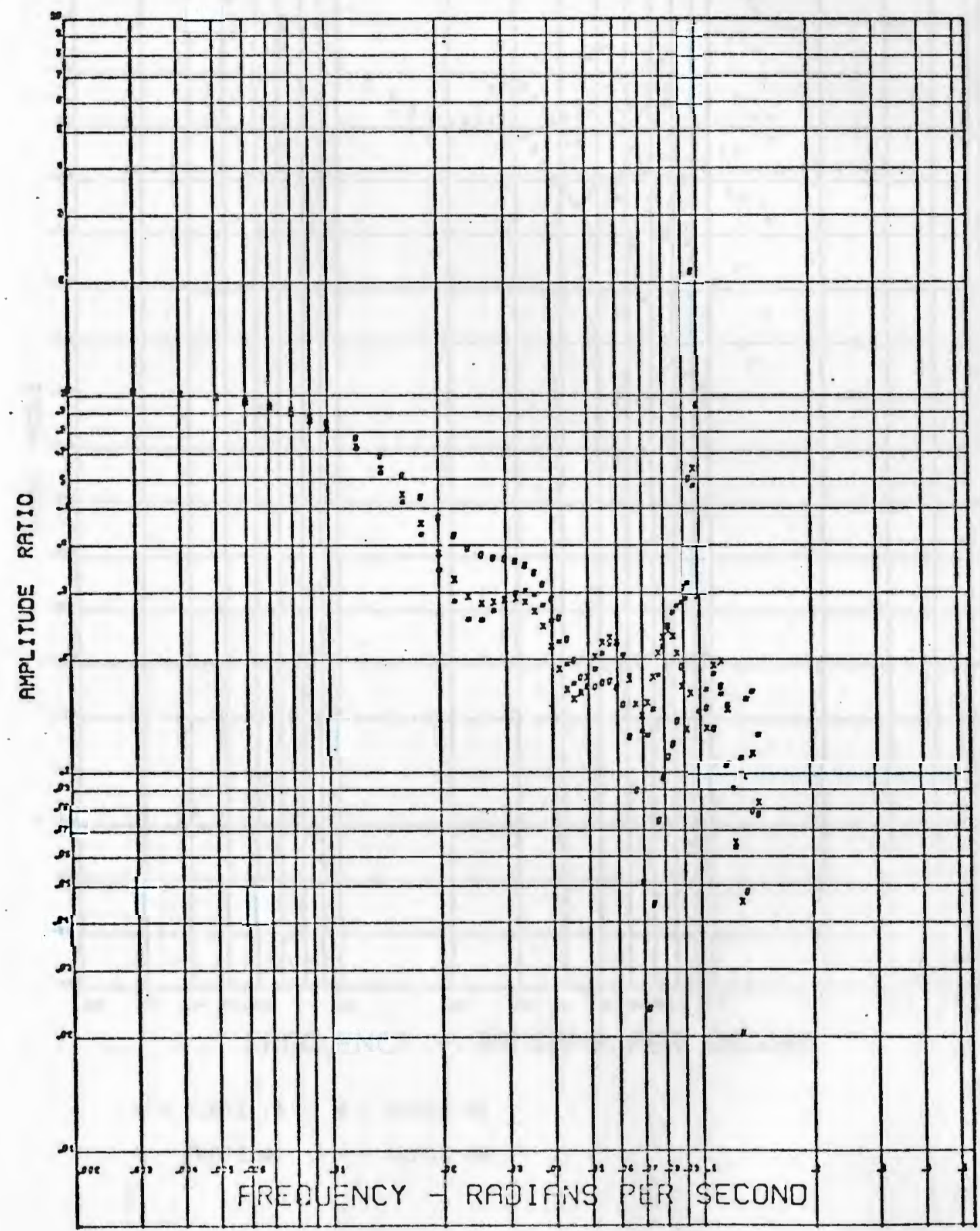




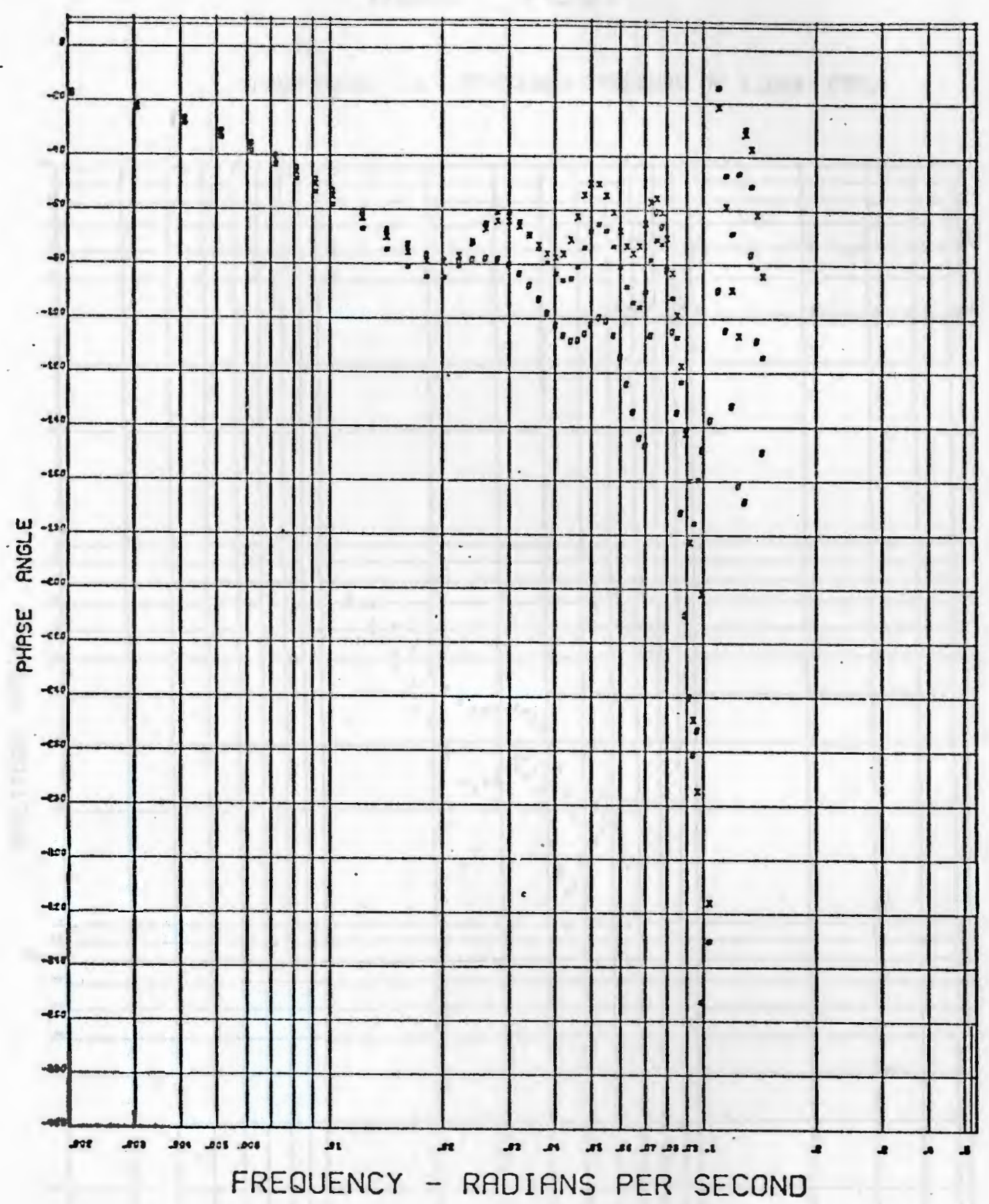

- plate 16 0 - plate 26

X - plate 21 + plate 28 


\section{BODE PLOT}

VAPOR PULSE 13 AT COLUMN PRESSURE OF 0.263 ATM.

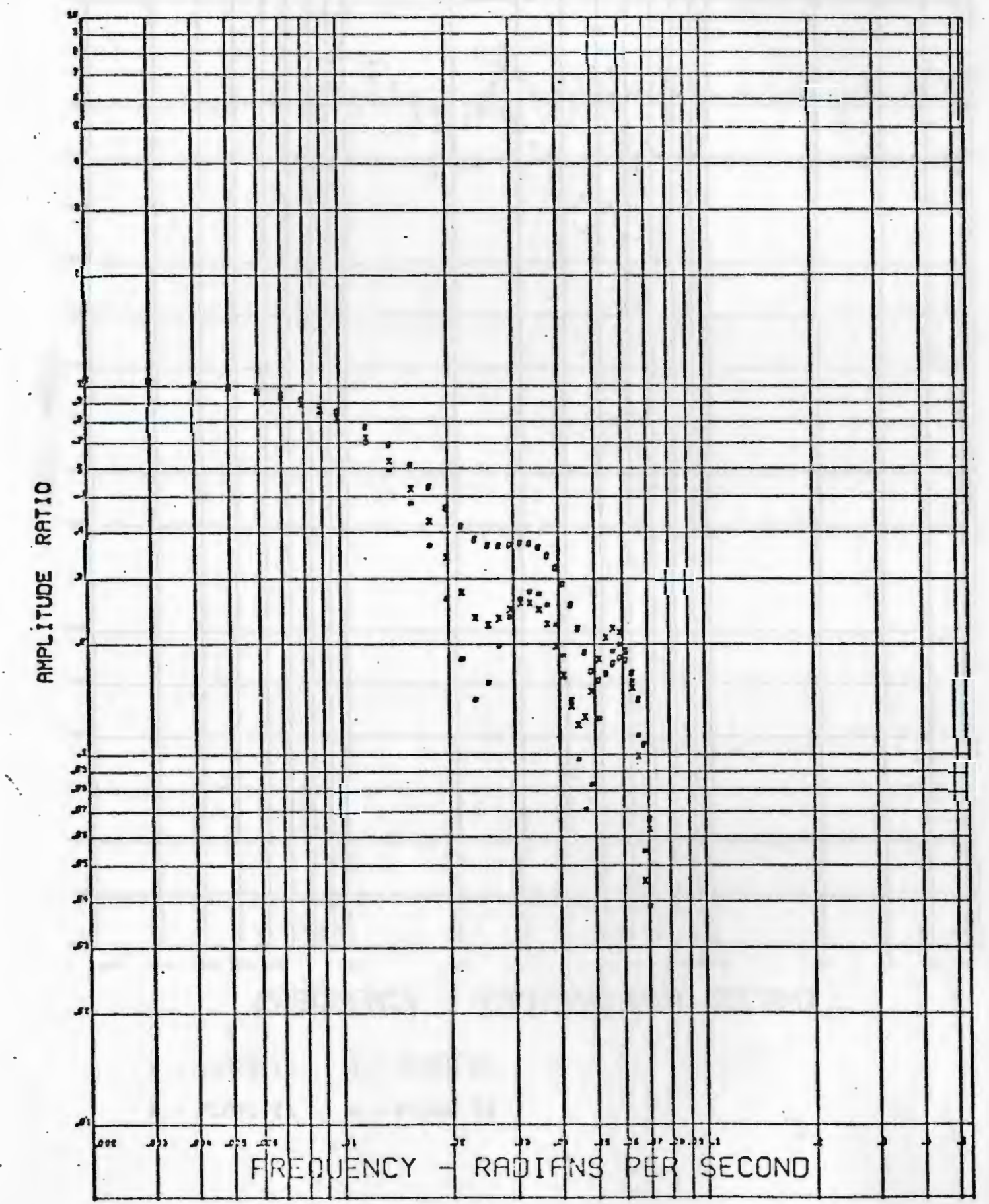




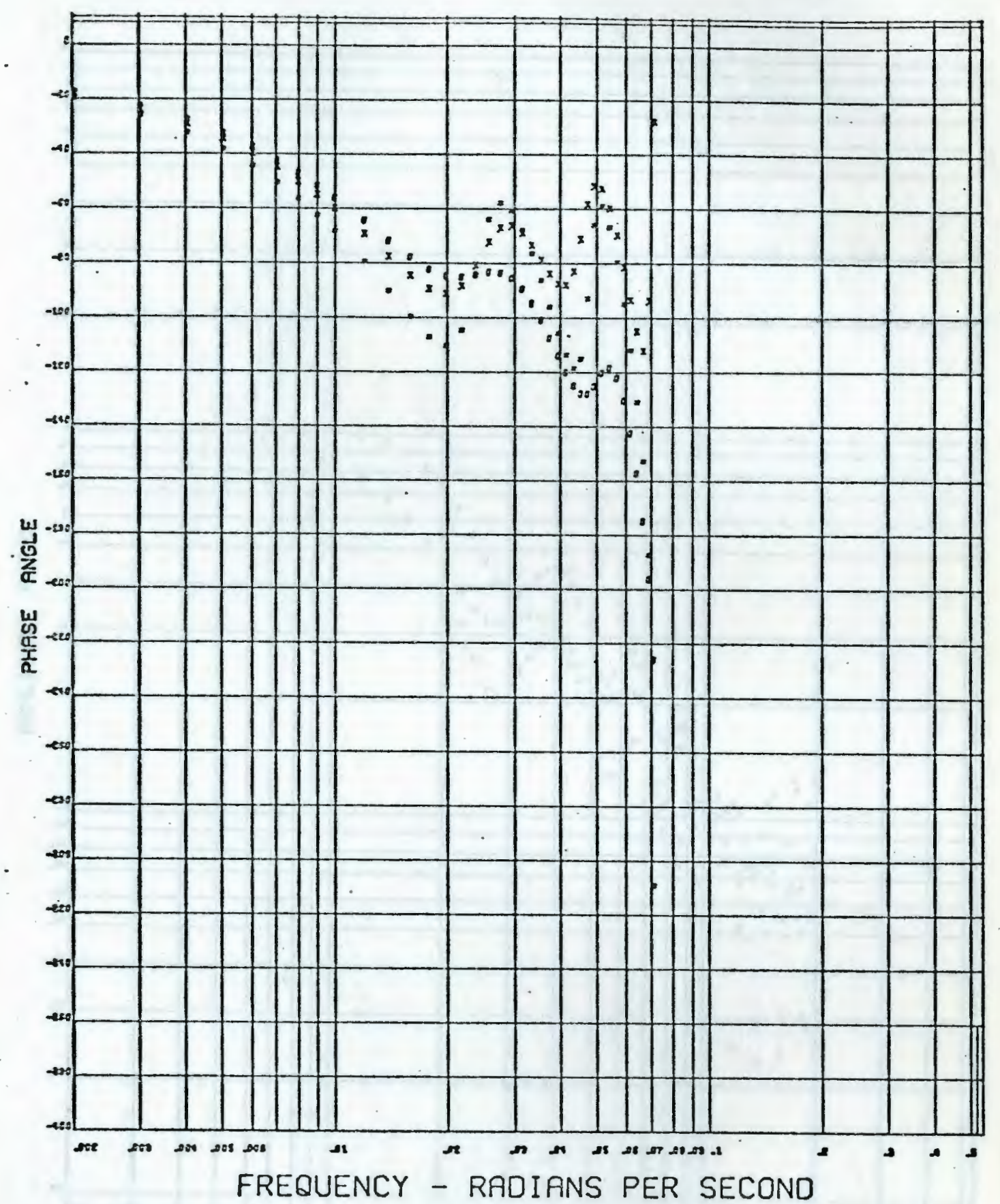

* - plate 16 0 - plate 26

- X - plate 21 + - plate 23 


\section{$\because \quad$ BODE PLOT}

YAPOR PULSE 14 AT COLUMN PRESSURE OF 0.263 ATM.

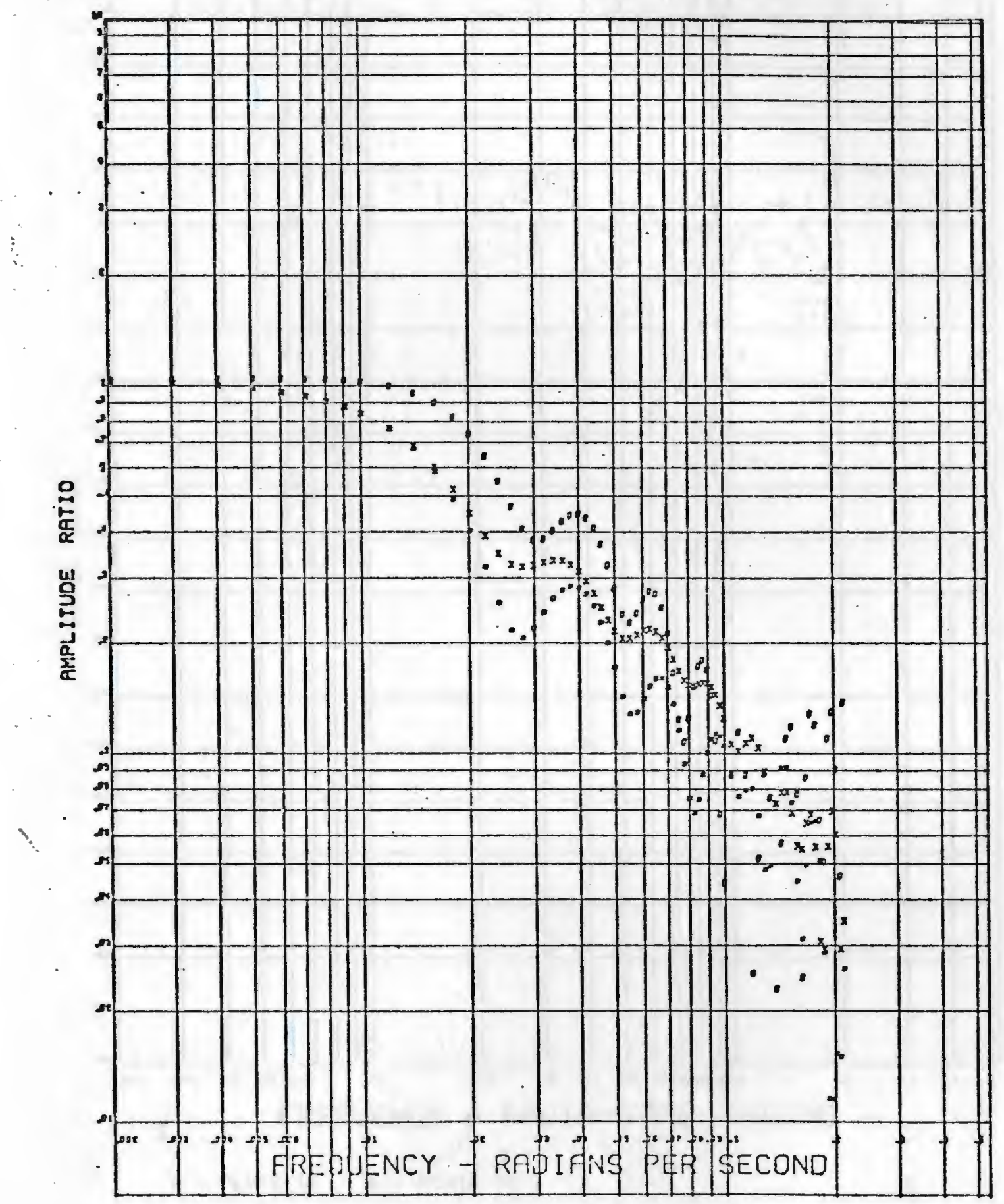


5
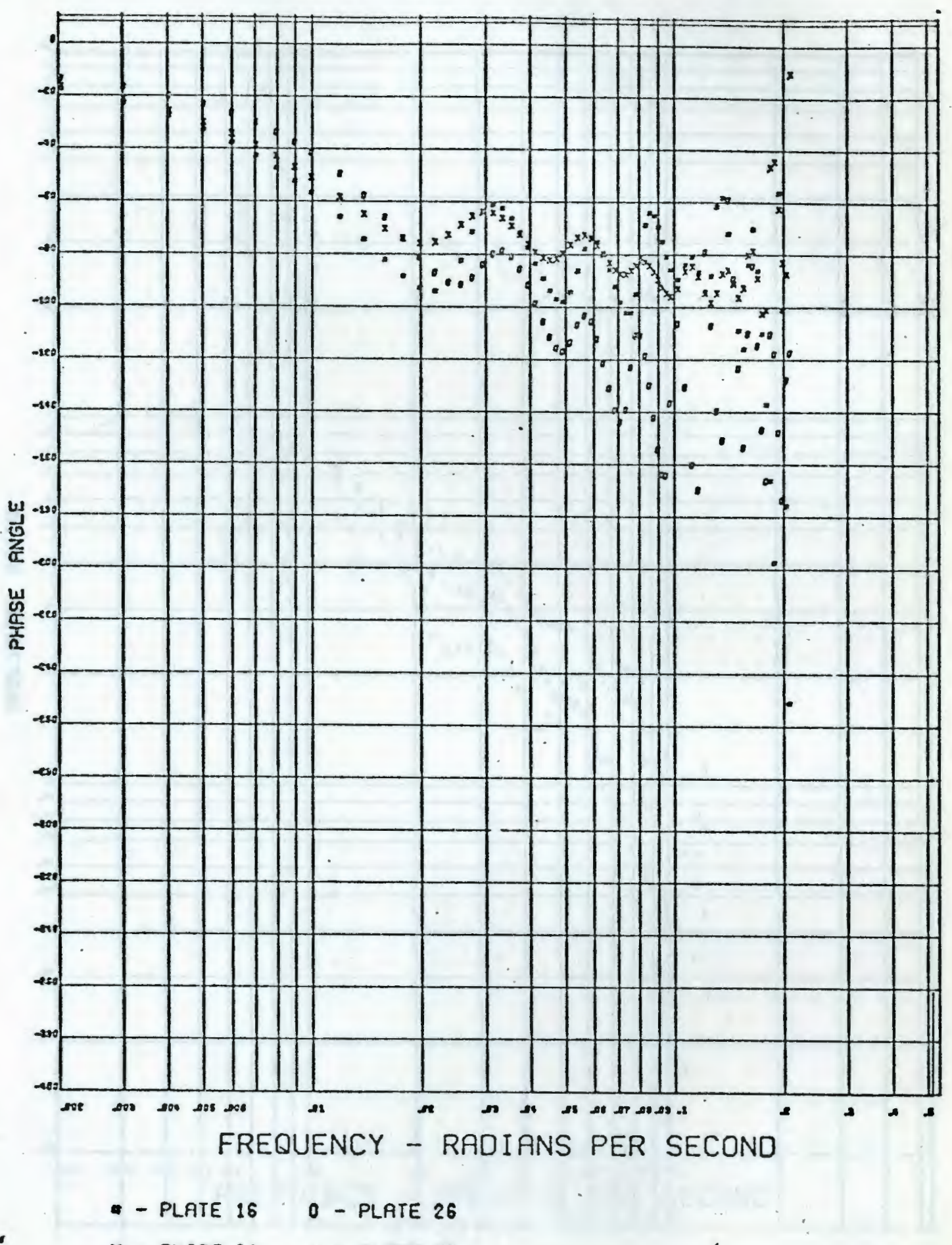

- X - Plate 21. + Plate 28 


\section{. BODE PLOT}

VAPOR PULSE 15 AT COLUMN PRESSURE OF 0.263 ATM.

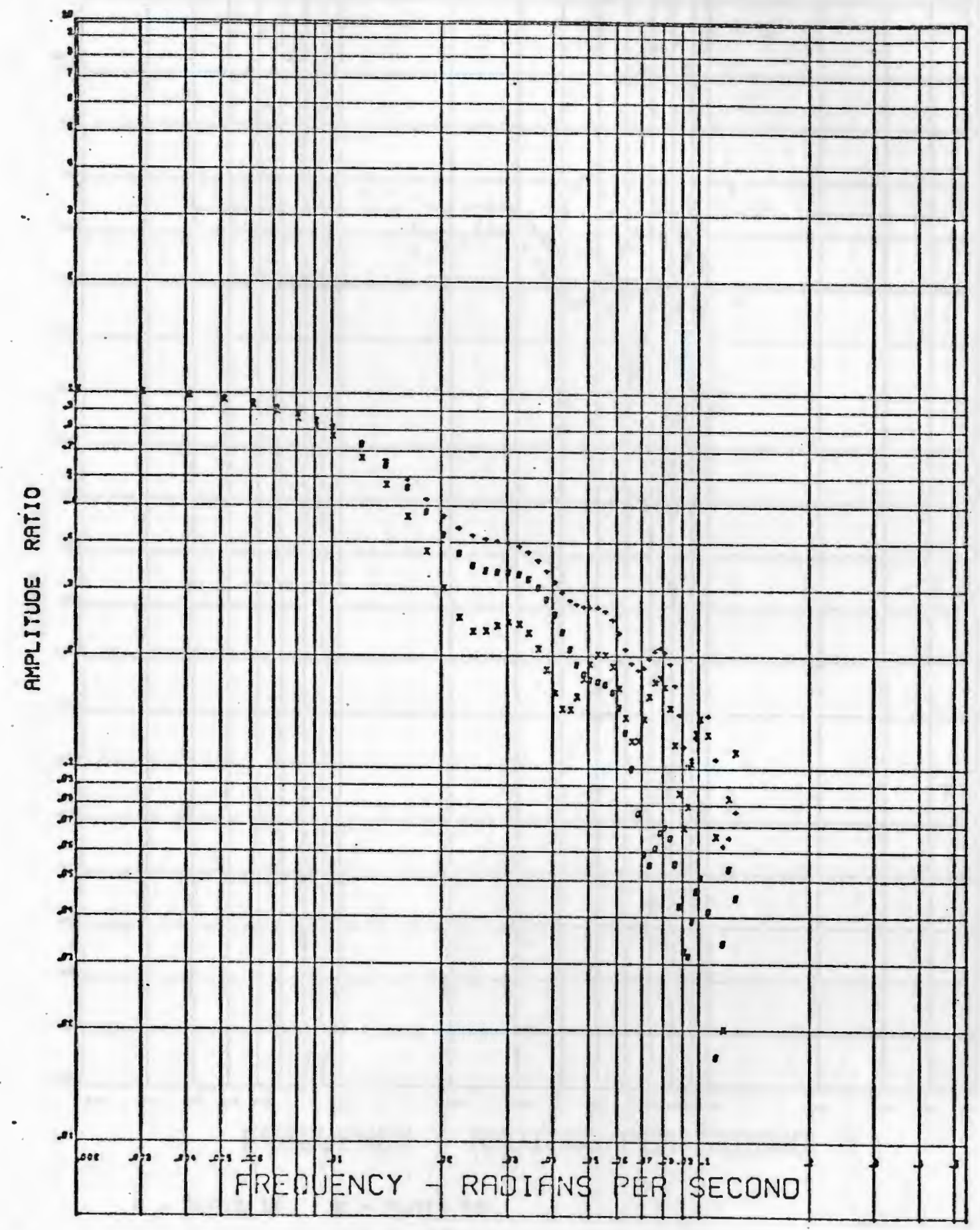




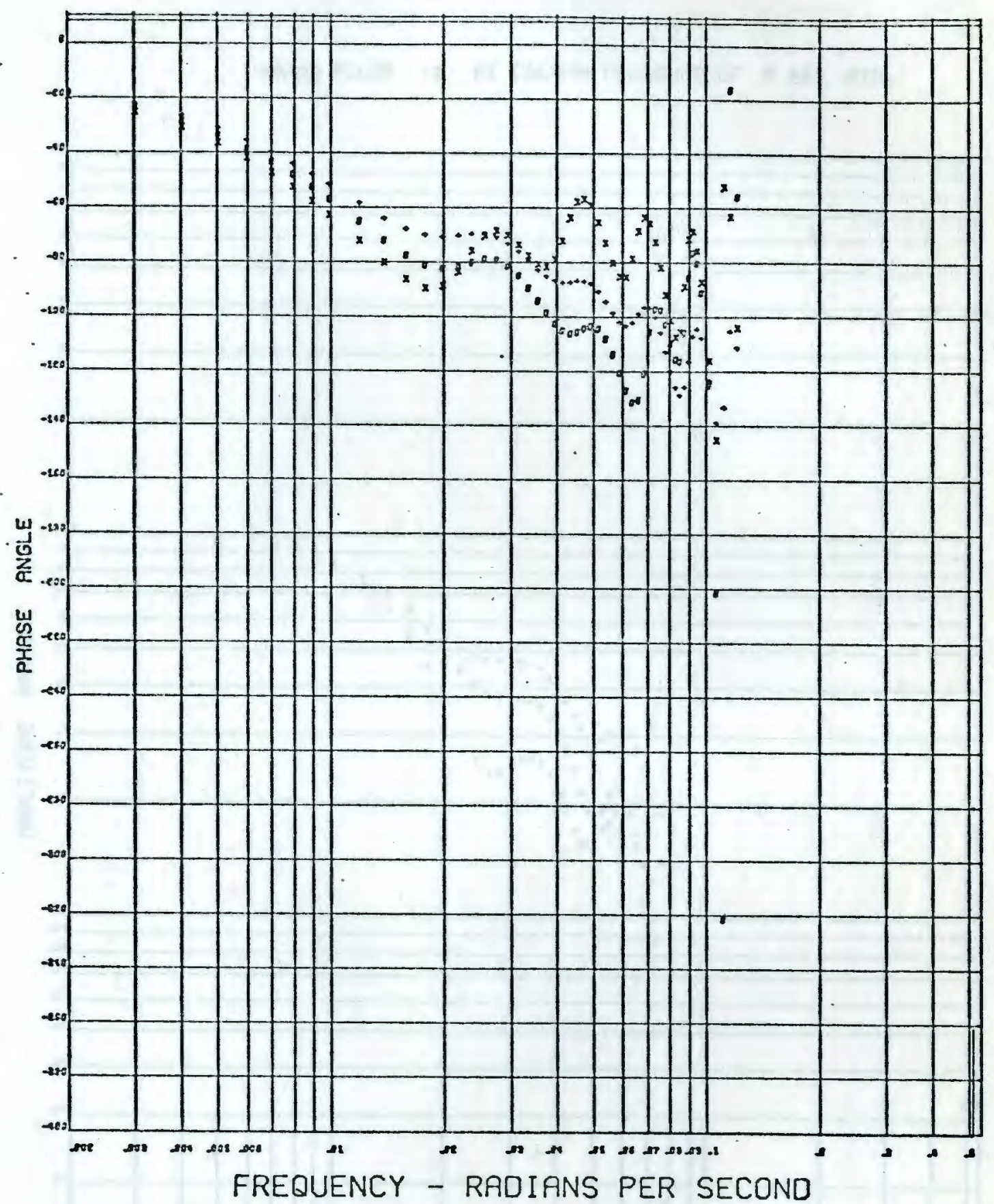

- plate 160 - Plate 26

X - Plate 21. + Plate 28 


$$
5
$$

\section{BODE PLOT}

VAPOR PULSE 16 AT COLUMN PRESSURE OF 0.263 ATM.

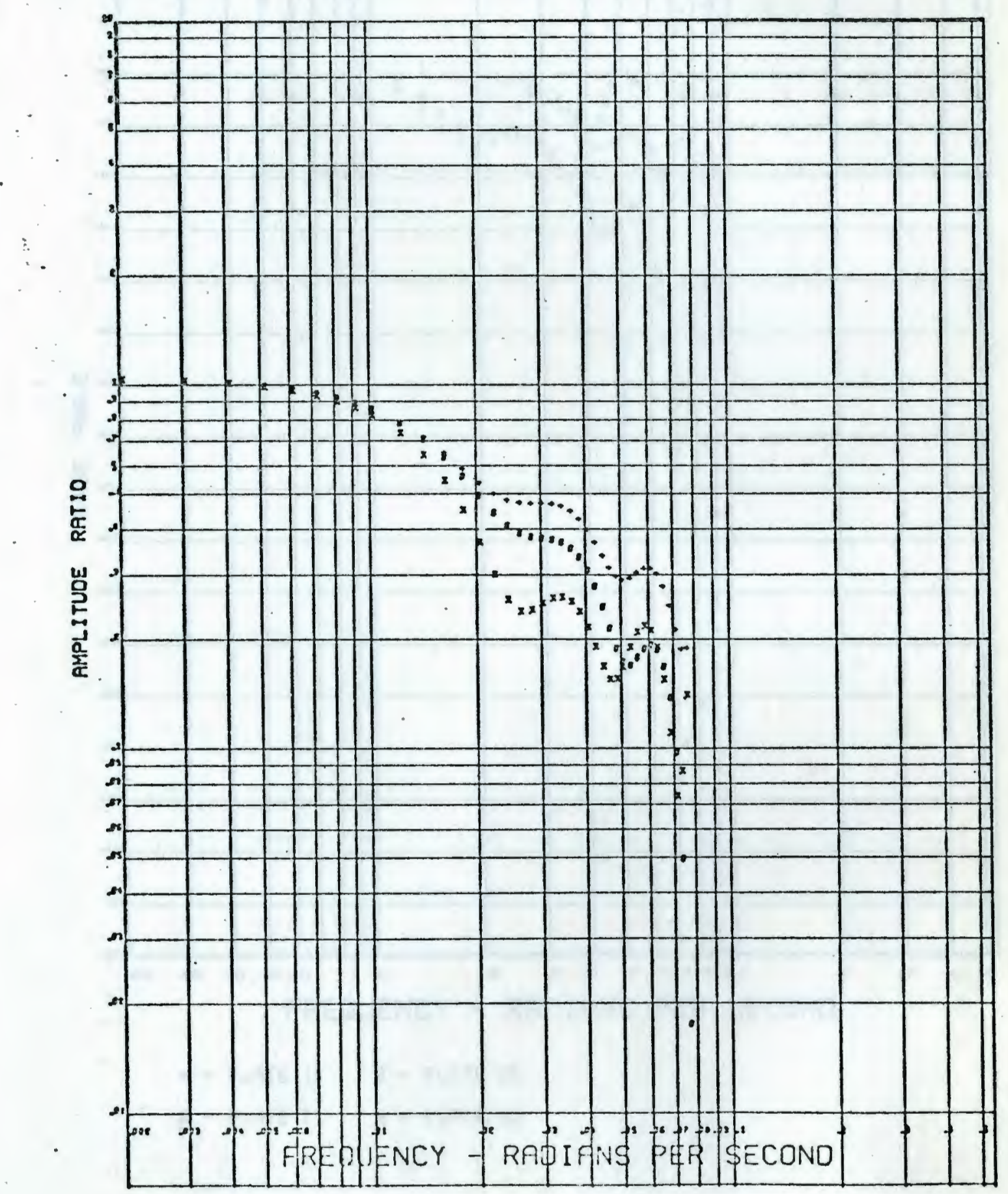




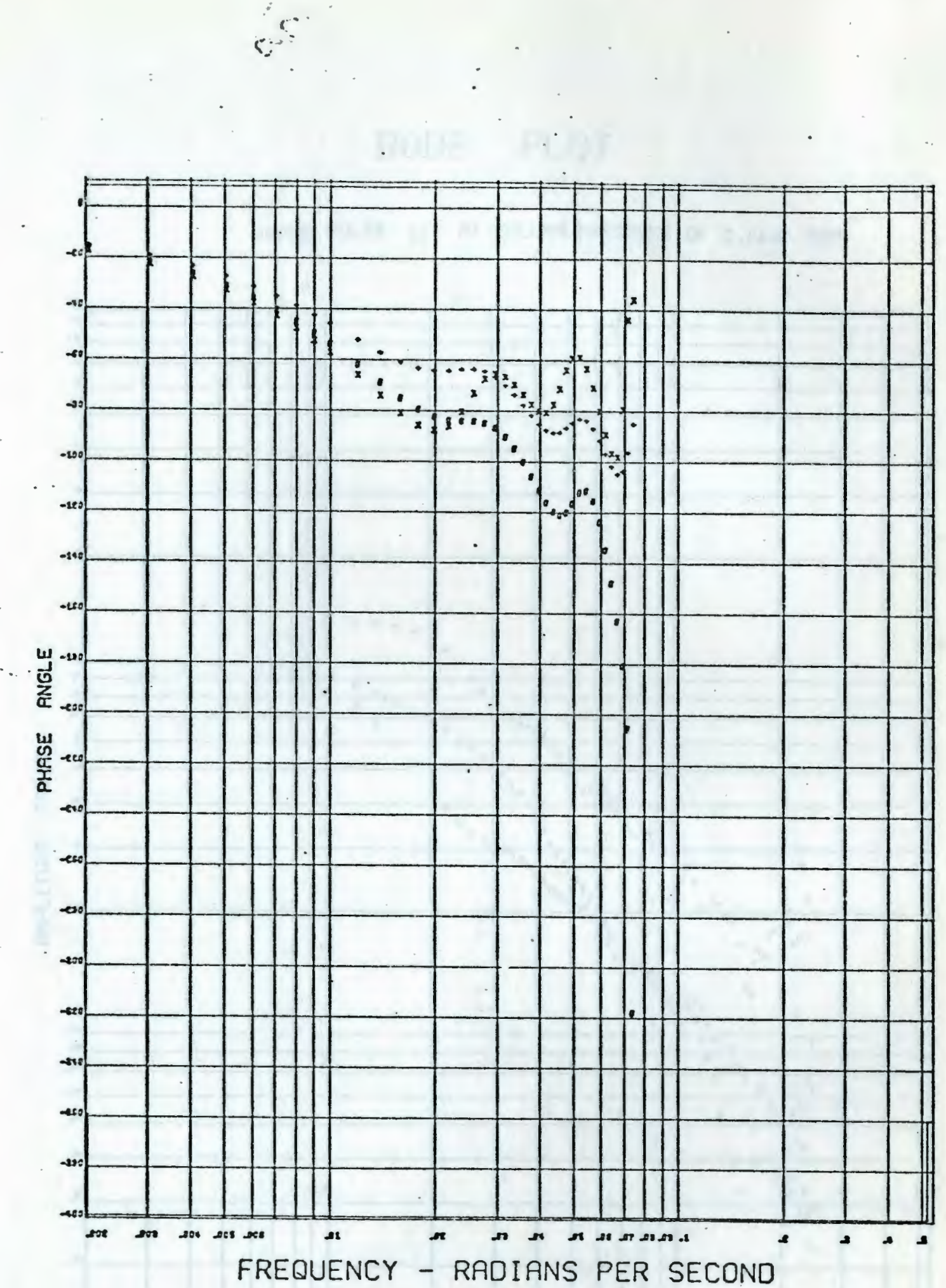

- Plate 16 - plate 26
x-PLate 21. + - plate 28 


\section{BODE PLOT}

VAPOR PULSE 1? AT COLUMN PRESSURE OF 0.263 ATM.

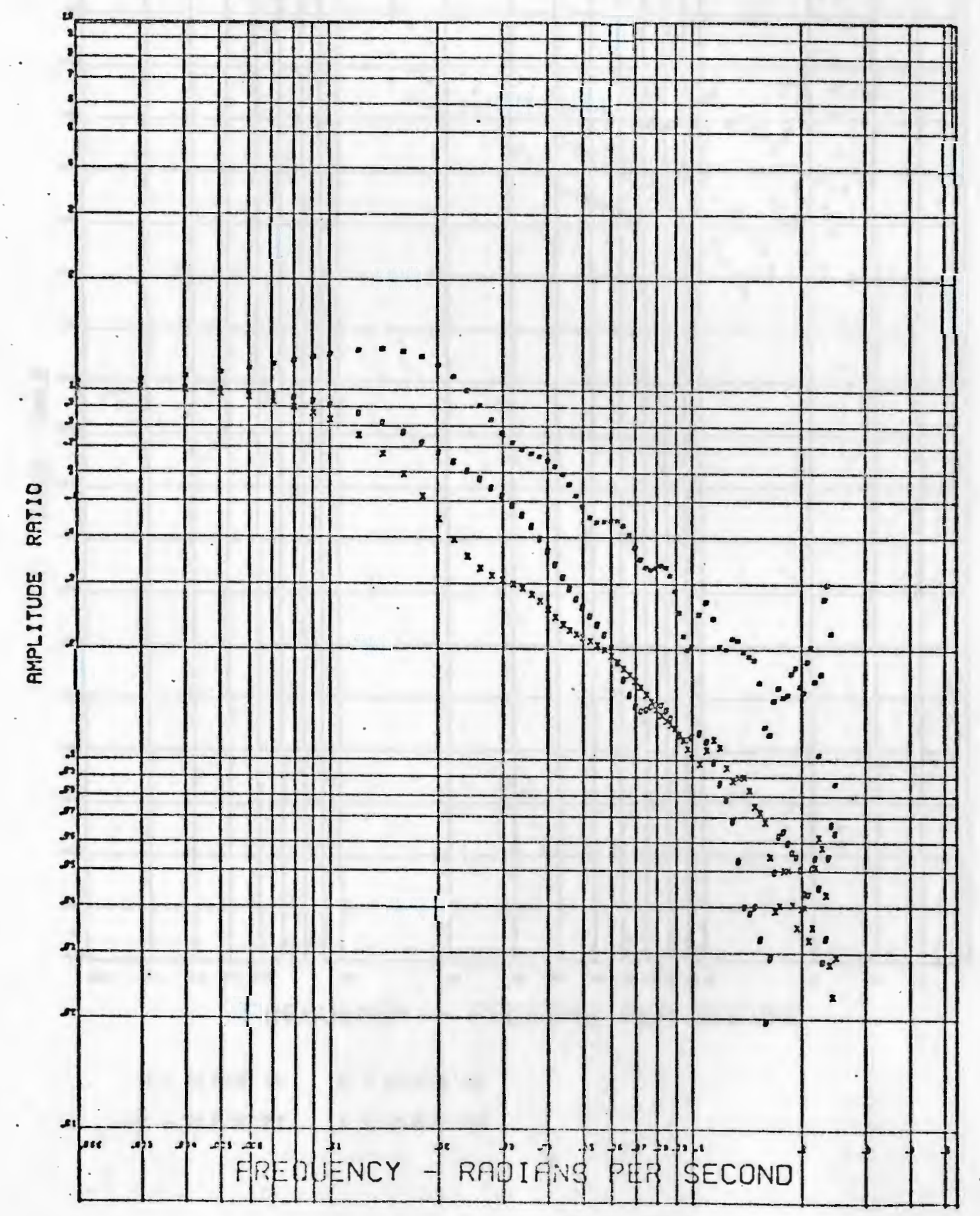




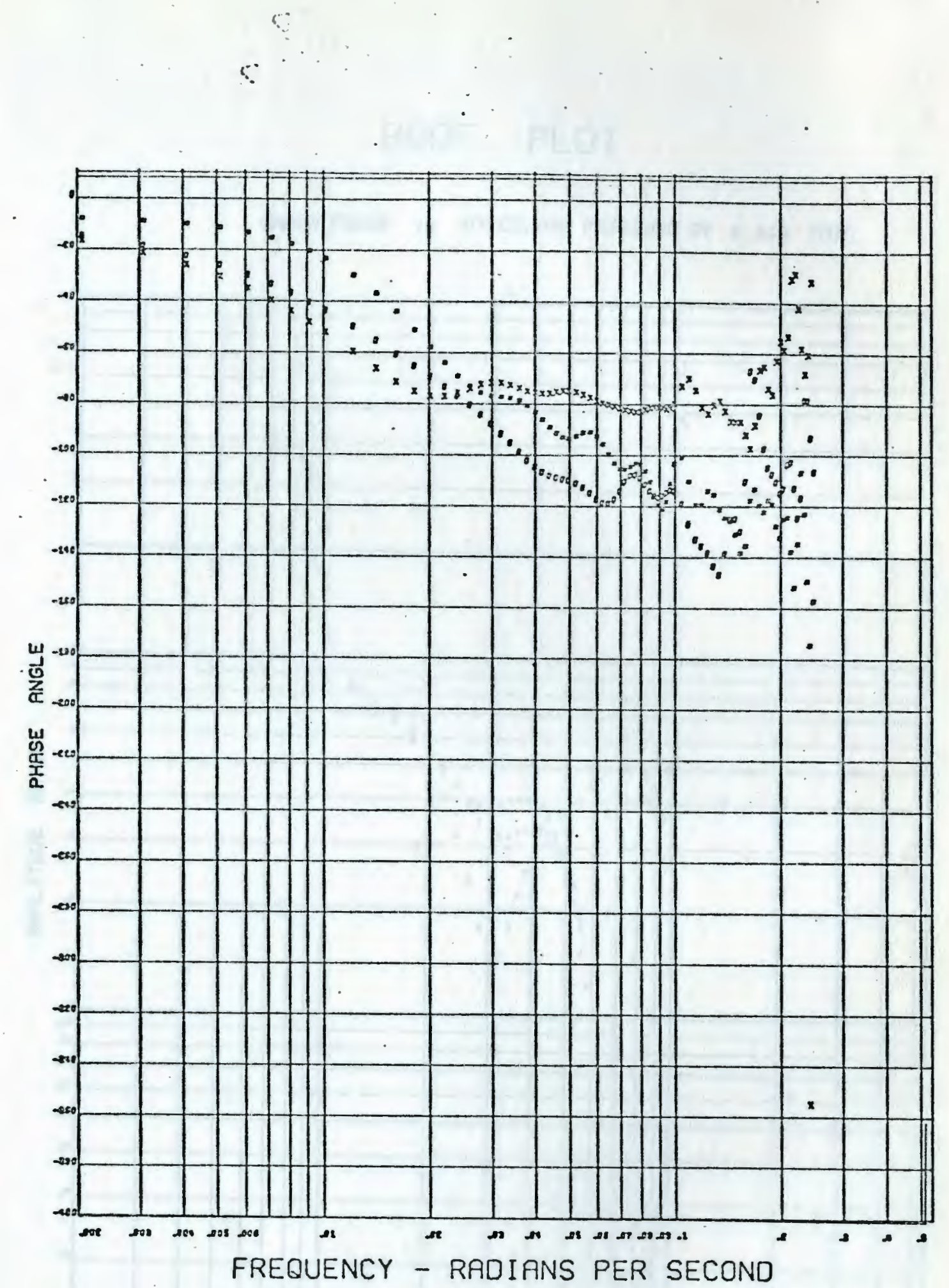

- plate 16 0 - plate 26

. X - plate 21. + - plate 28 


\section{BODE PLOT}

VAPOR PULSE 18 AT COLUMN PRESSURE OF 0.263 ATM.

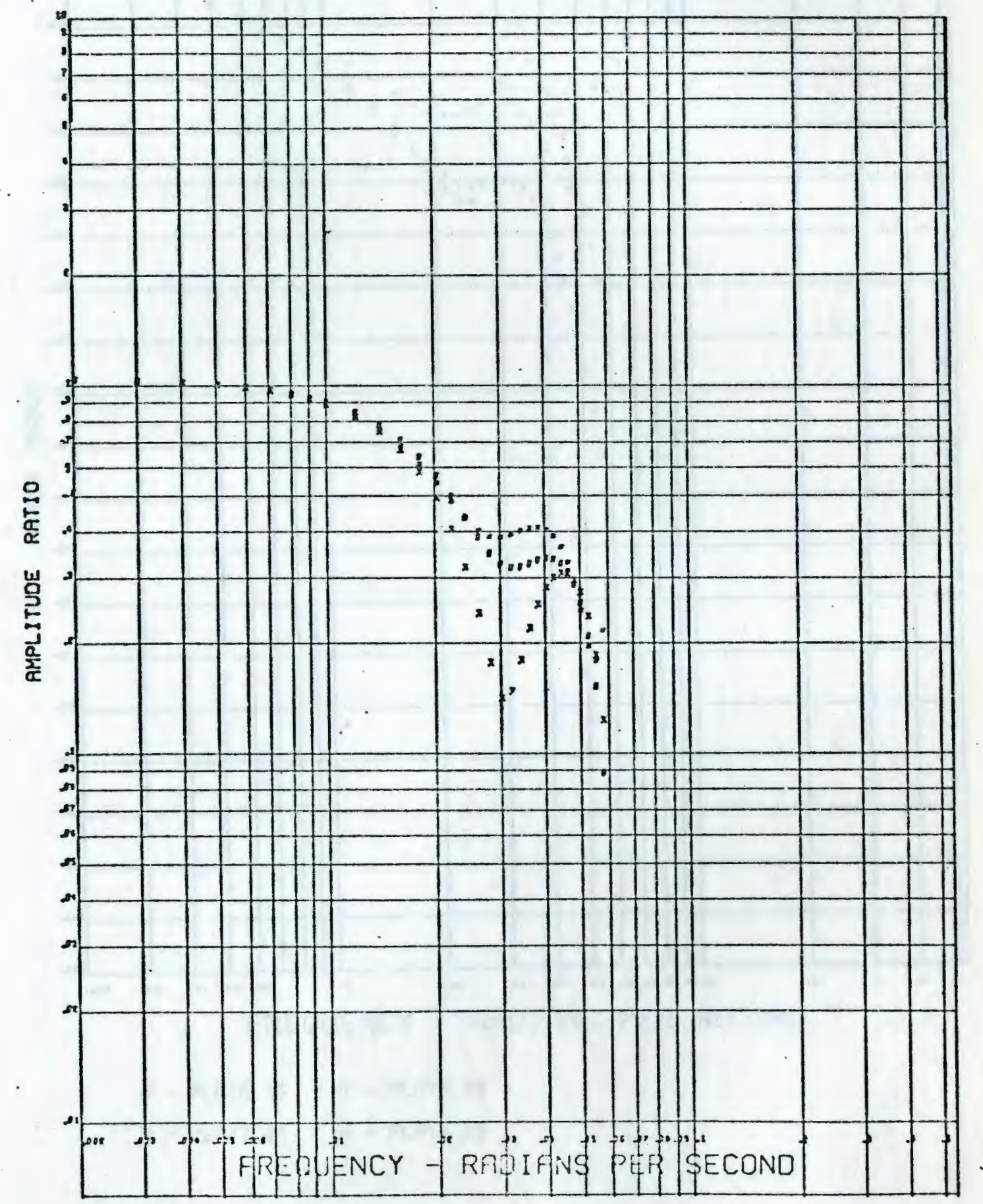




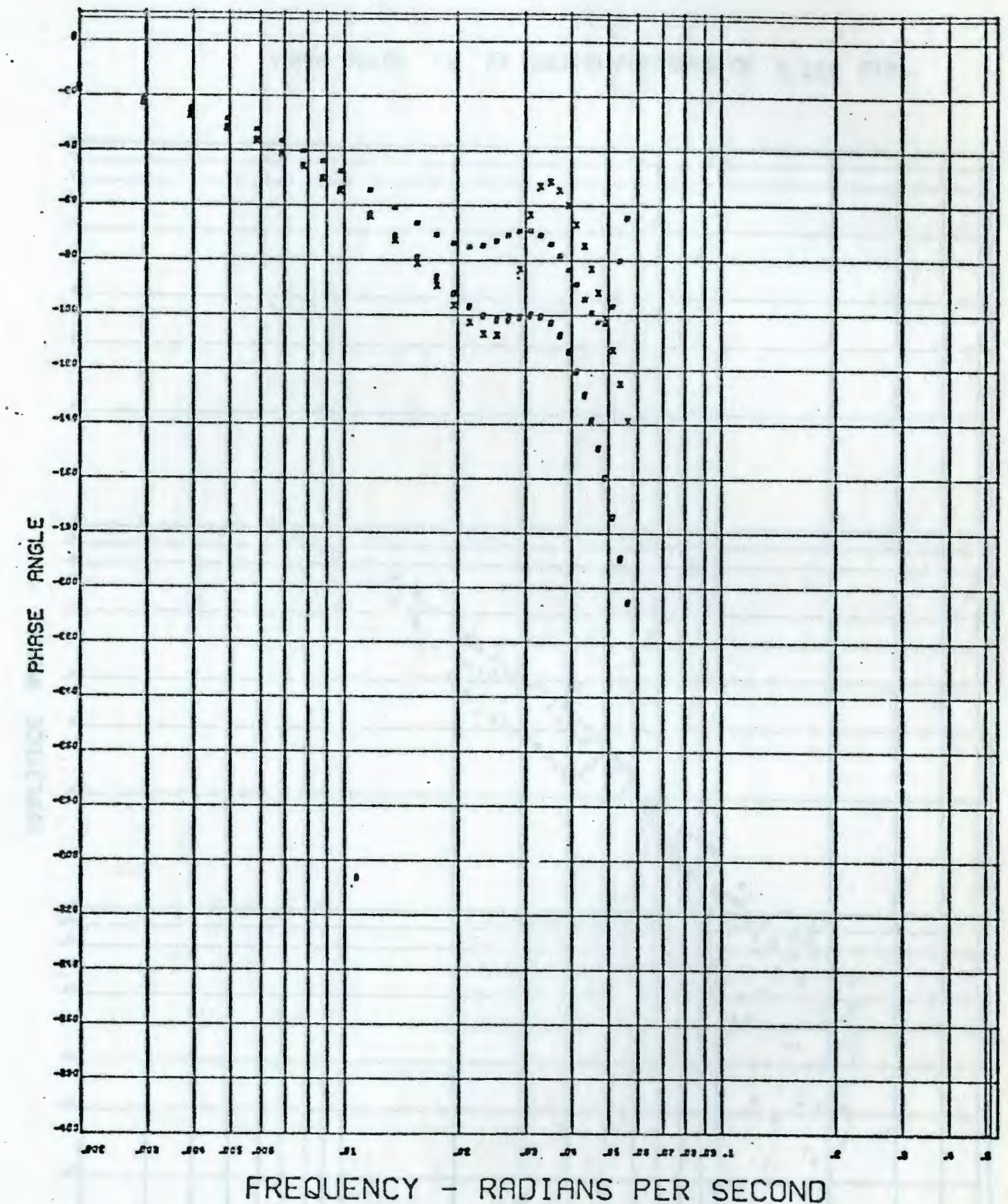

* - plate 16 0 - plate 26

X- Plate 21 + Plate 28 


\section{BODE PLOT}

VAPOR PULSE 19 AT COLUMIN PRESSURE OF 0.263 ATM.

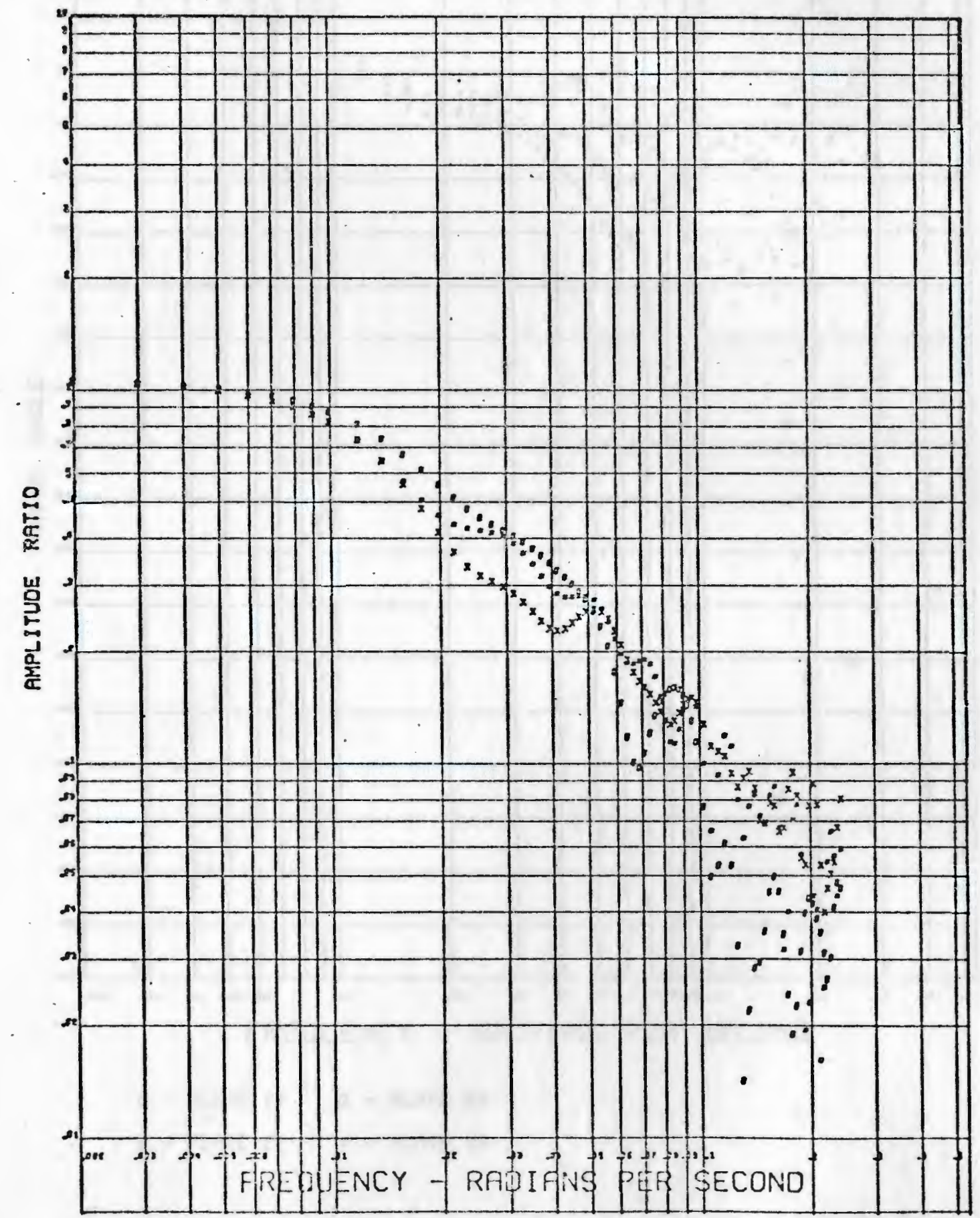




$$
\because
$$

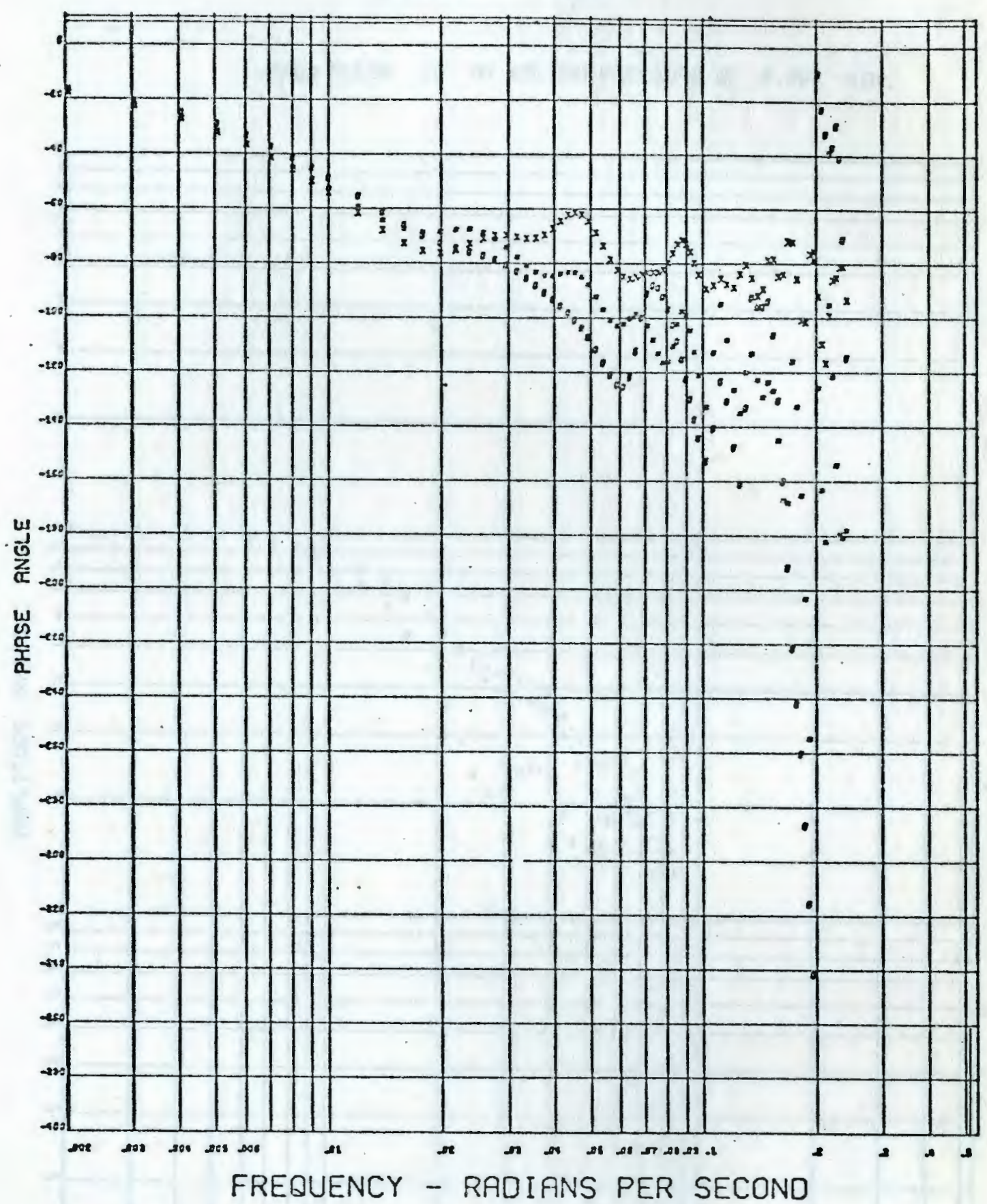

- plate 16 0 - plate 26

X - plate 2\%. + plate 28 


\section{BODE PLOT}

VAPOR PULSE 20 AT COLUMN PRESSURE OF 0.263 ATM.

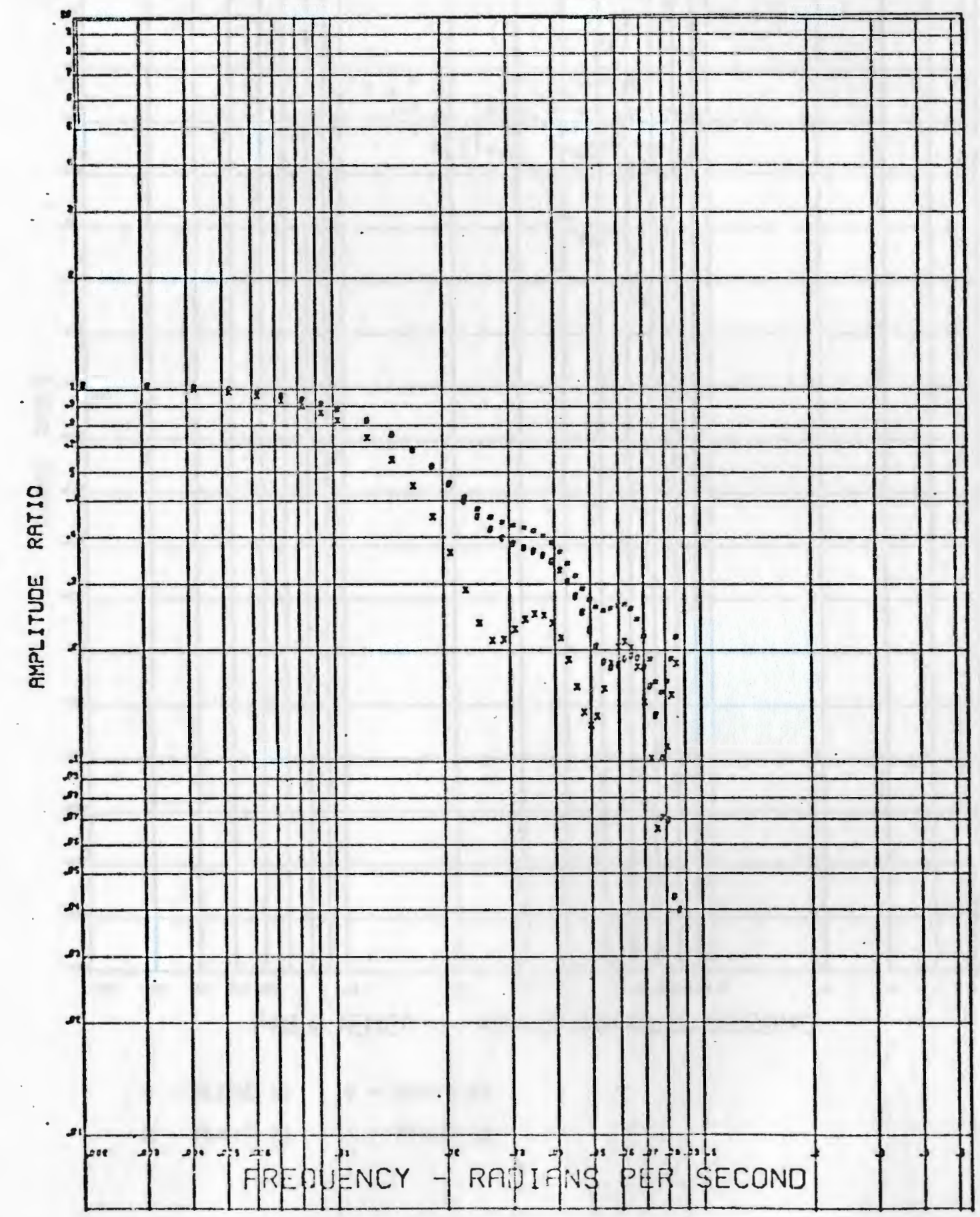


$\because \vdots$

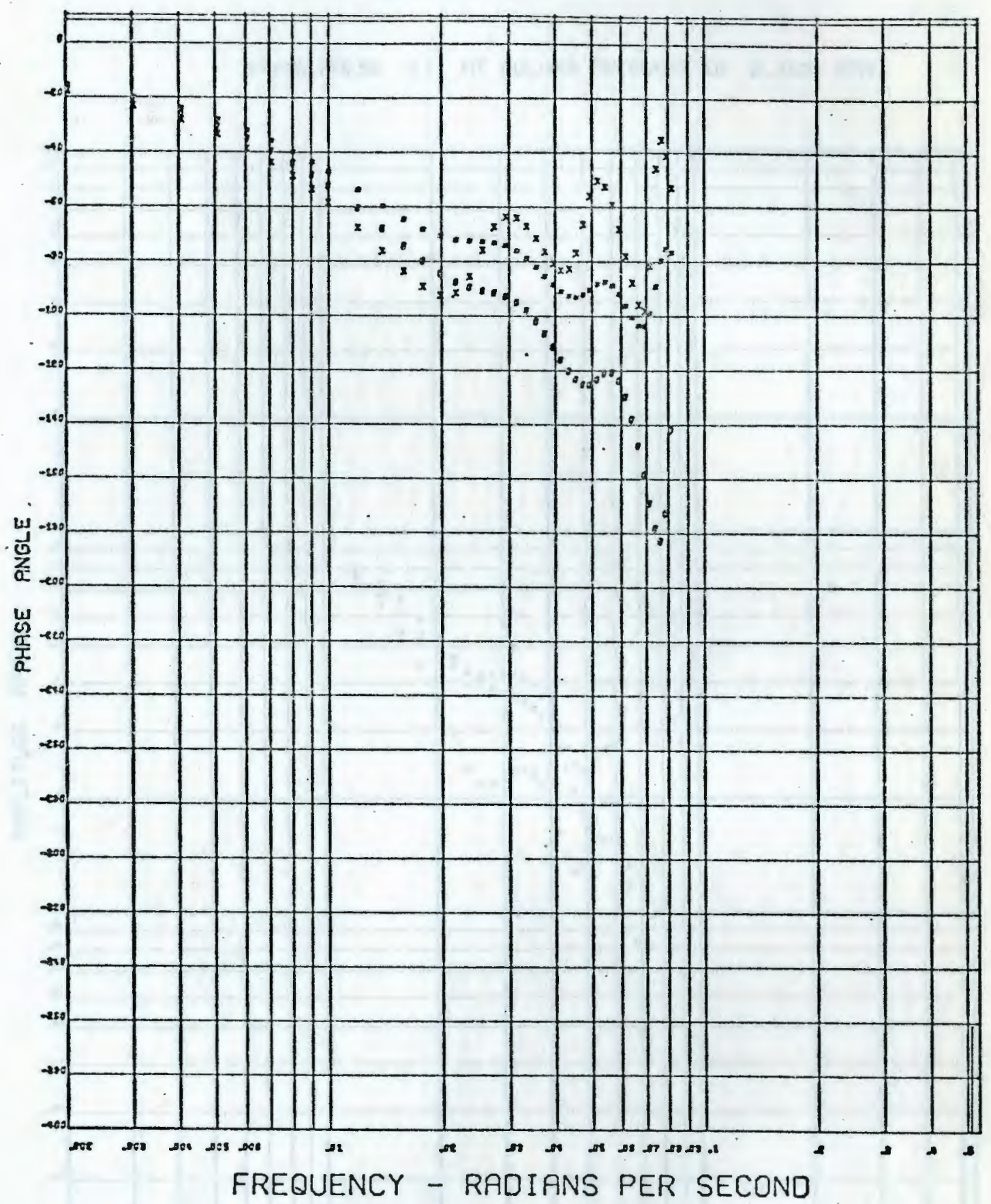

* plate 16 o-plate 26

X - plate 21 + - PLATE 28 


\section{BODE PLOT}

VAPOF PULSE 21 AT COLUMN PRESSURE OF 0.283 ATM.

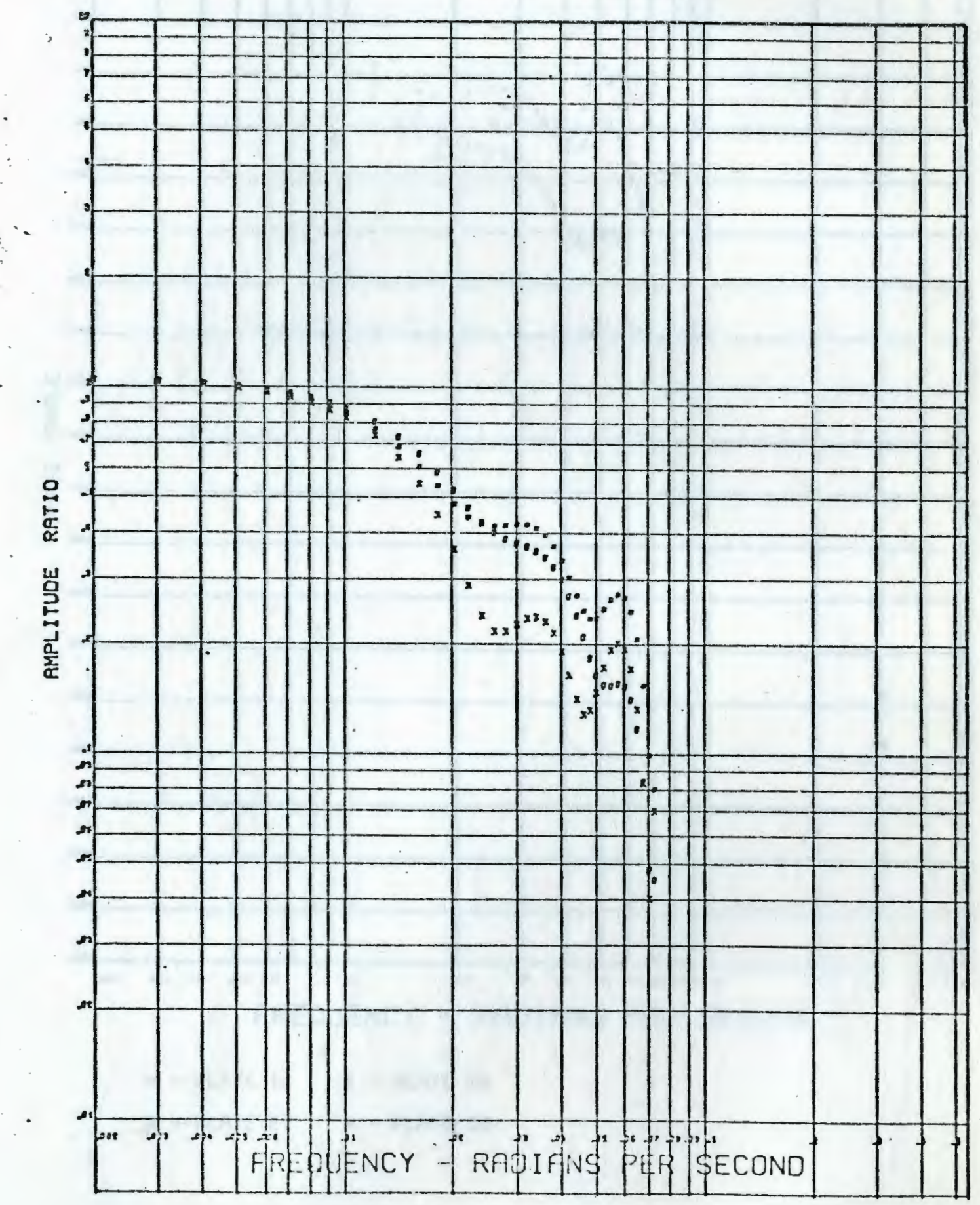


$\checkmark$

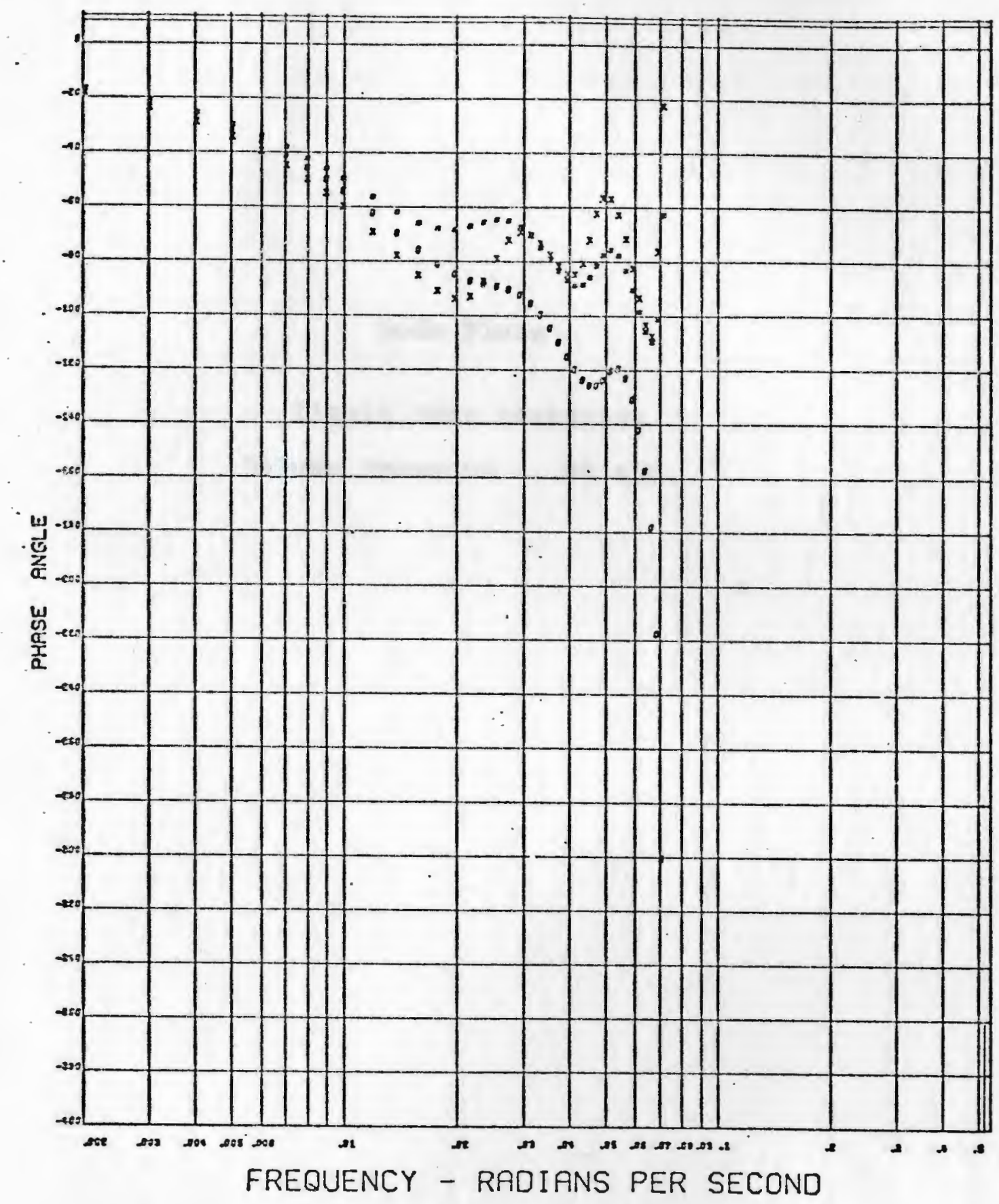

$*$ - PLATE $16 \quad 0$ - PLATE 26
$x$ - PLATE $21 .+-$ PLATE 28 
Bode Plots

Llquid Rate Responses

Column Pressure - .24 atm. 
$\because 6$

BODE PLOT

LIQUID PULSE 2 AT COLUMN PRESSURE OF 0.243 ATM.

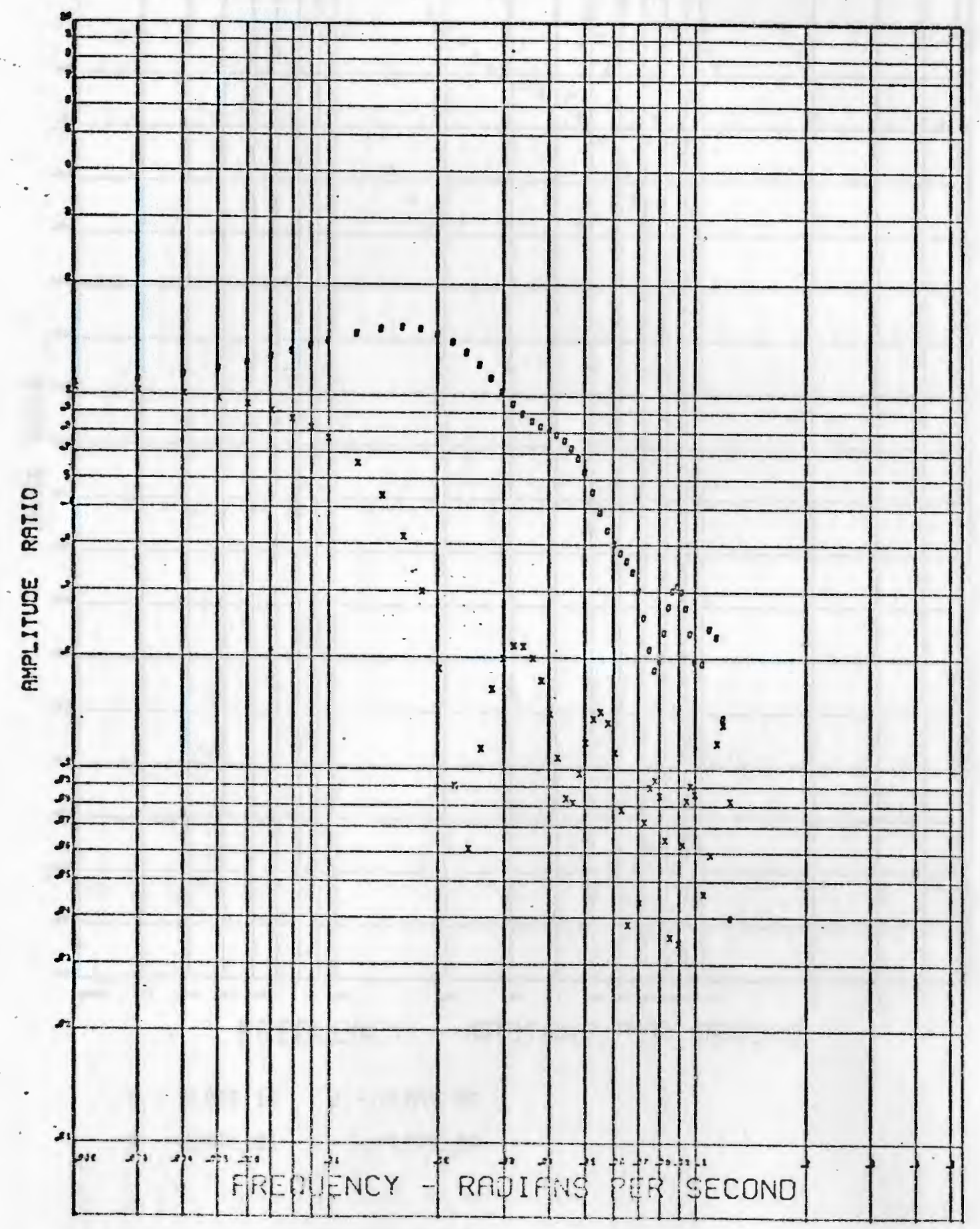




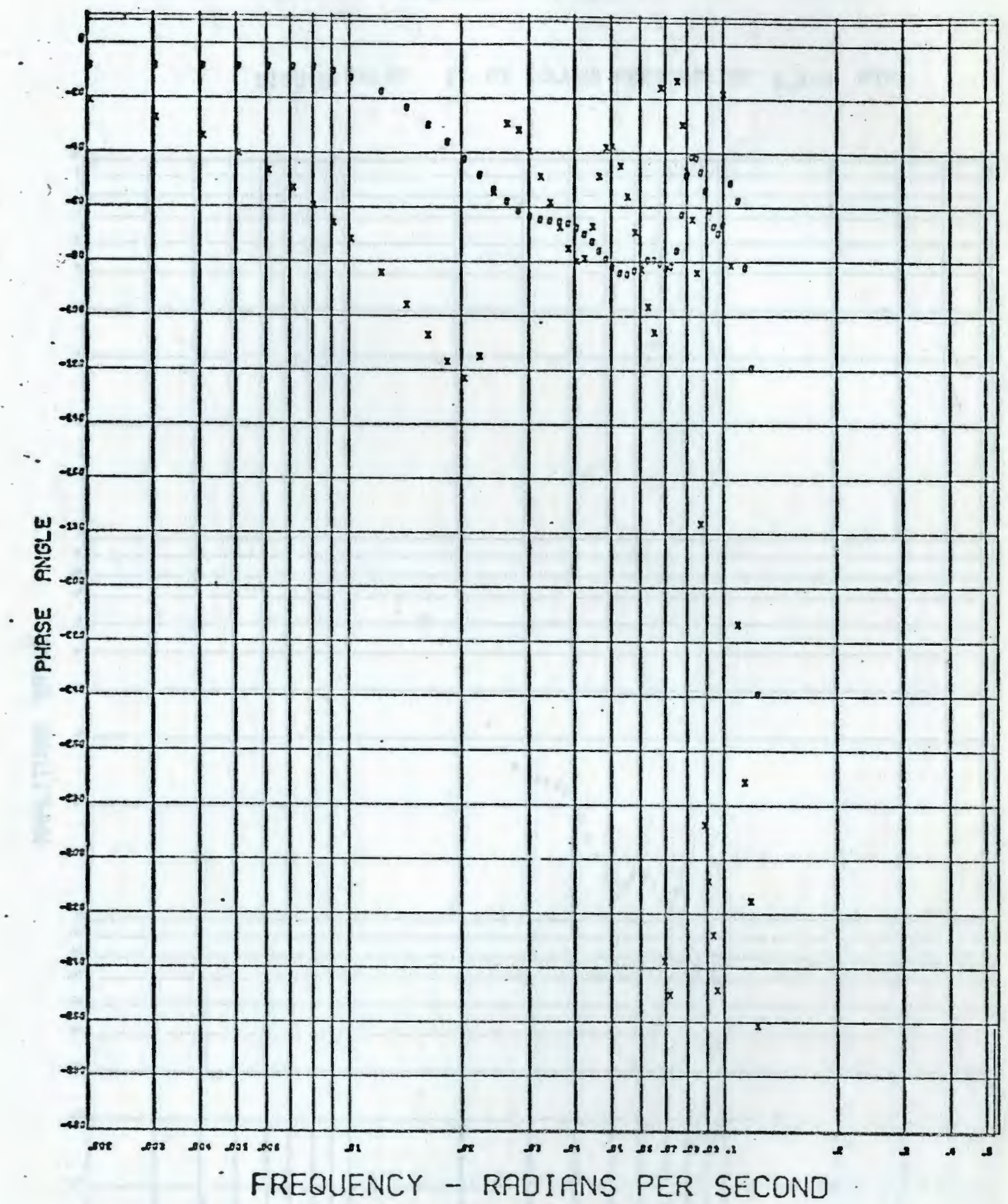

- plate 15 o-plate 26

- X-PLATE 21. + - PLATE 28 


\section{BODE PLOT}

LIQUID PULSE 3 AT COLUMN PRESSURE OF 0.243 ATM.

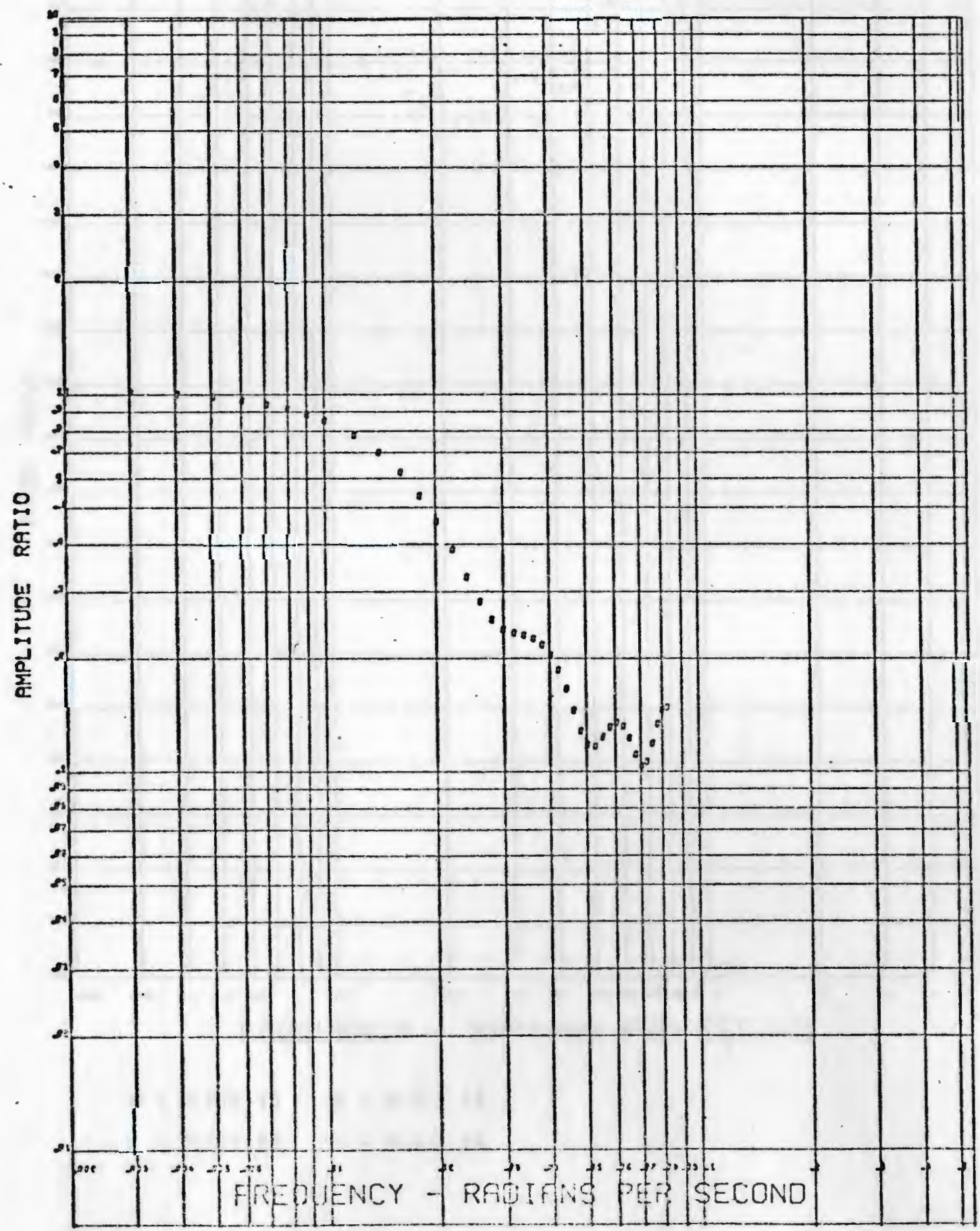




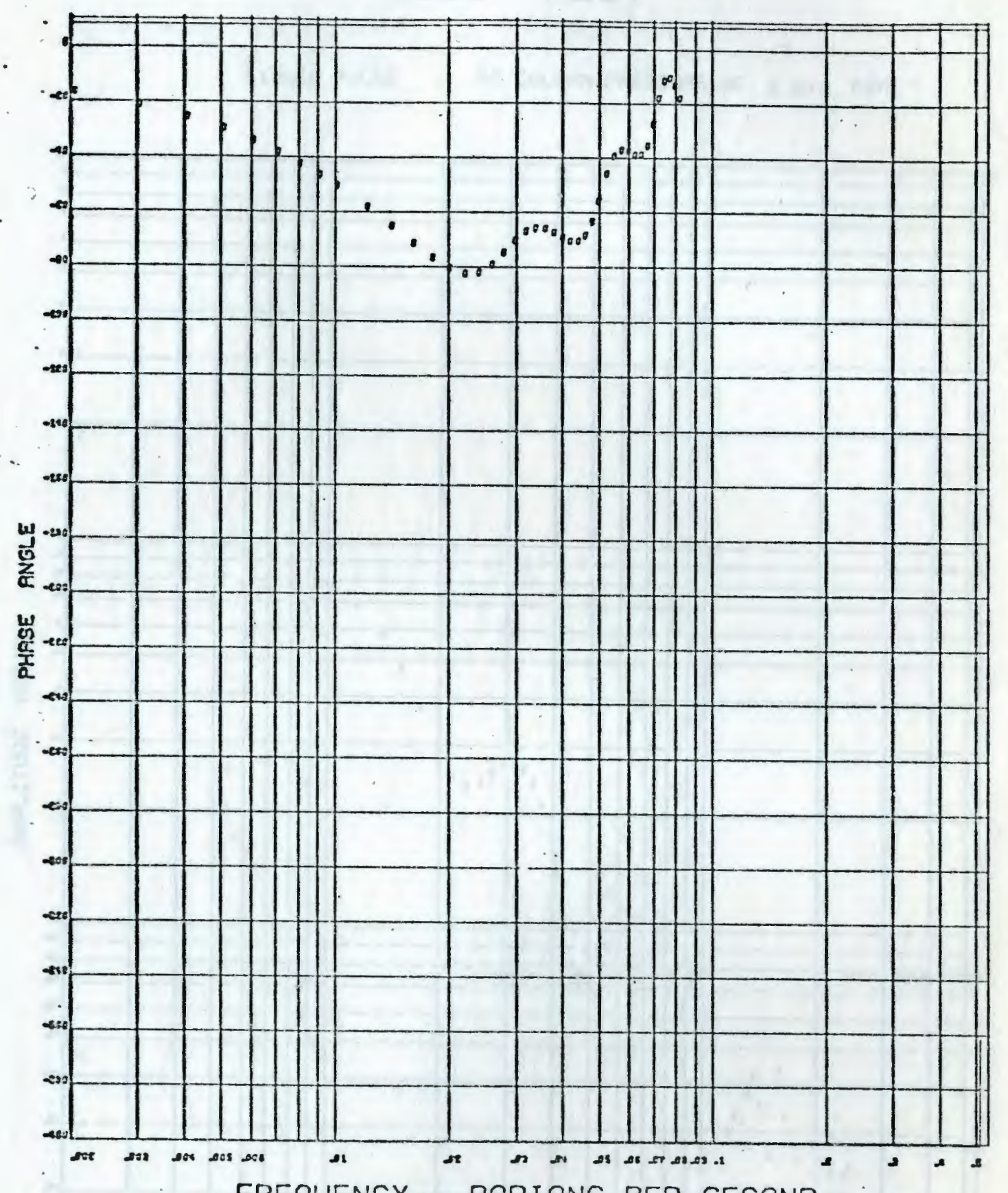

$$
\text { FREQUENCY - RADIANS PER SECOND }
$$

- plate 16 0 -plate 26

$x$ - PLATE 21 . - PLATE 28 
BODE PLOT

LIQUID PULSE 4 AT COLUMN PRESSURE OF 0.243 ATM.

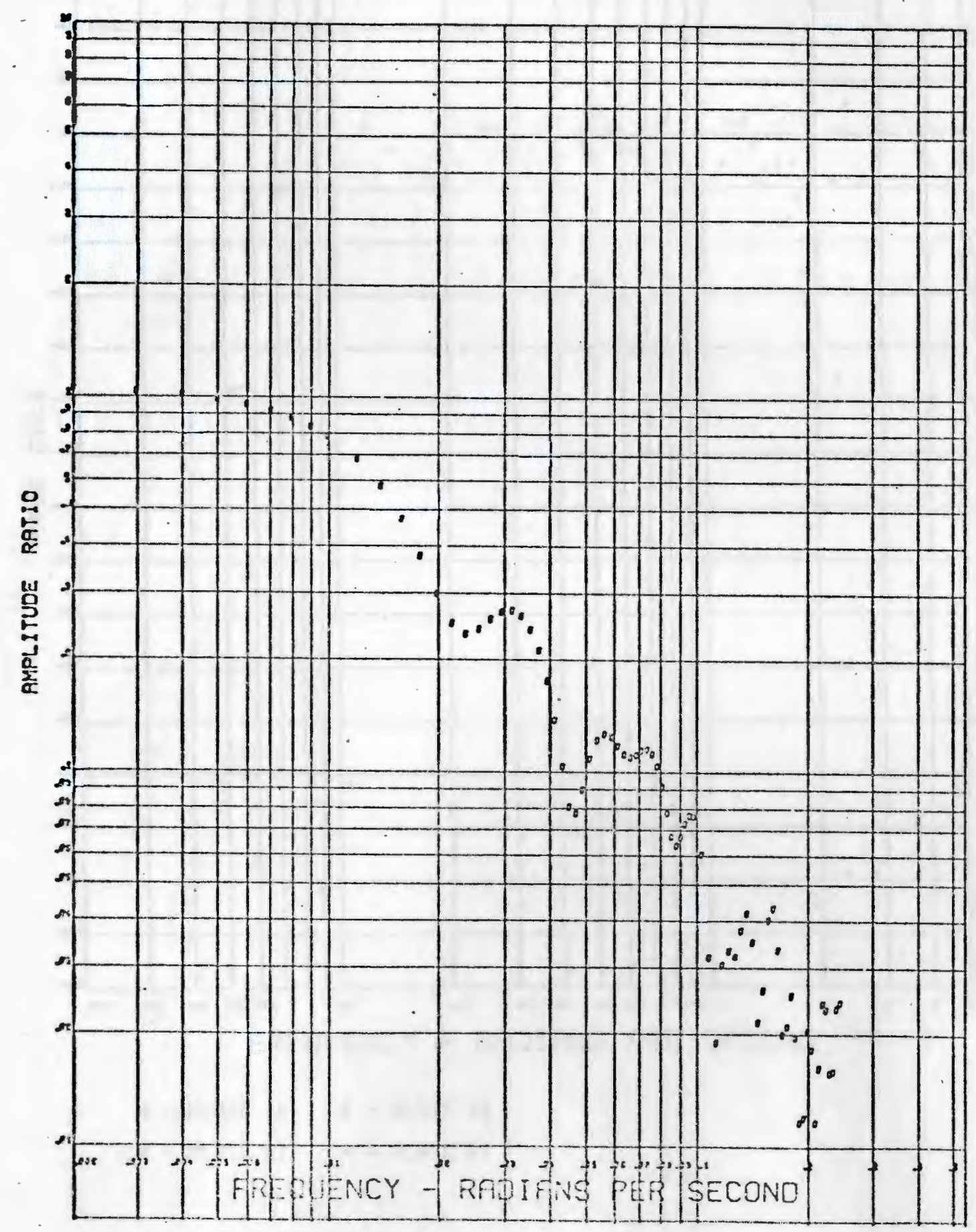



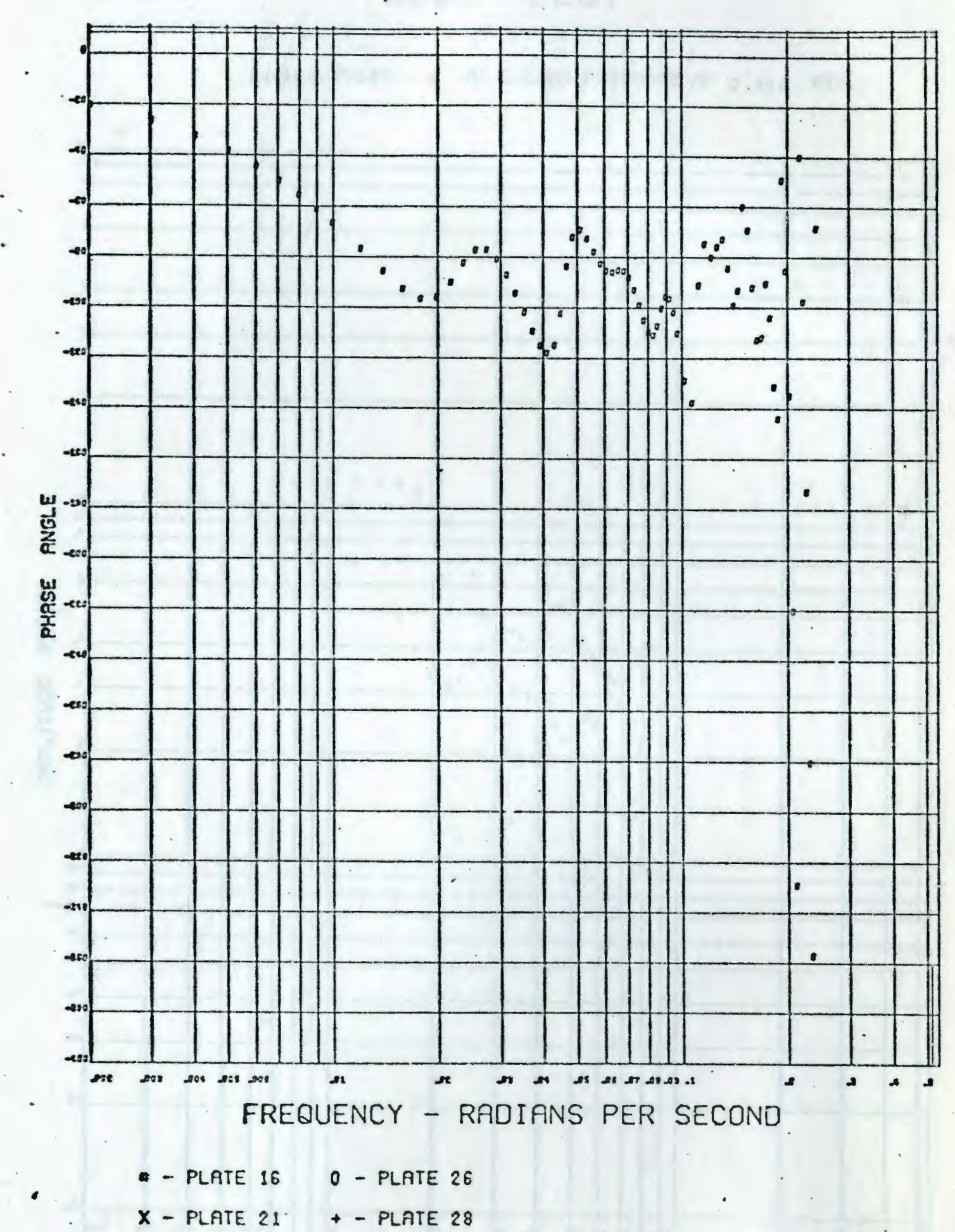


\section{BODE PLOT}

LIQUID PULSE 5 AT COLUMN PRESSURE OF 0.243 RTM.

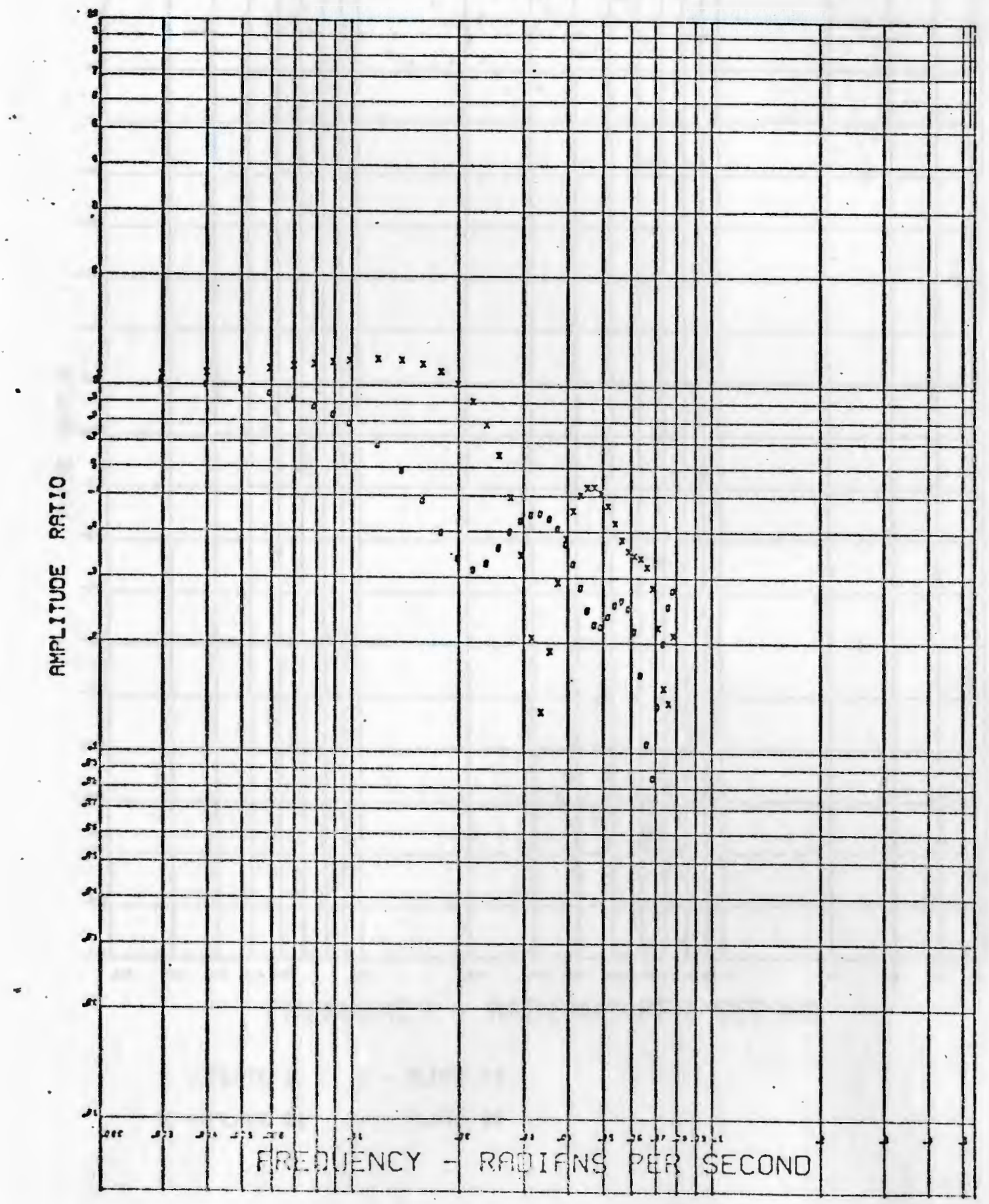




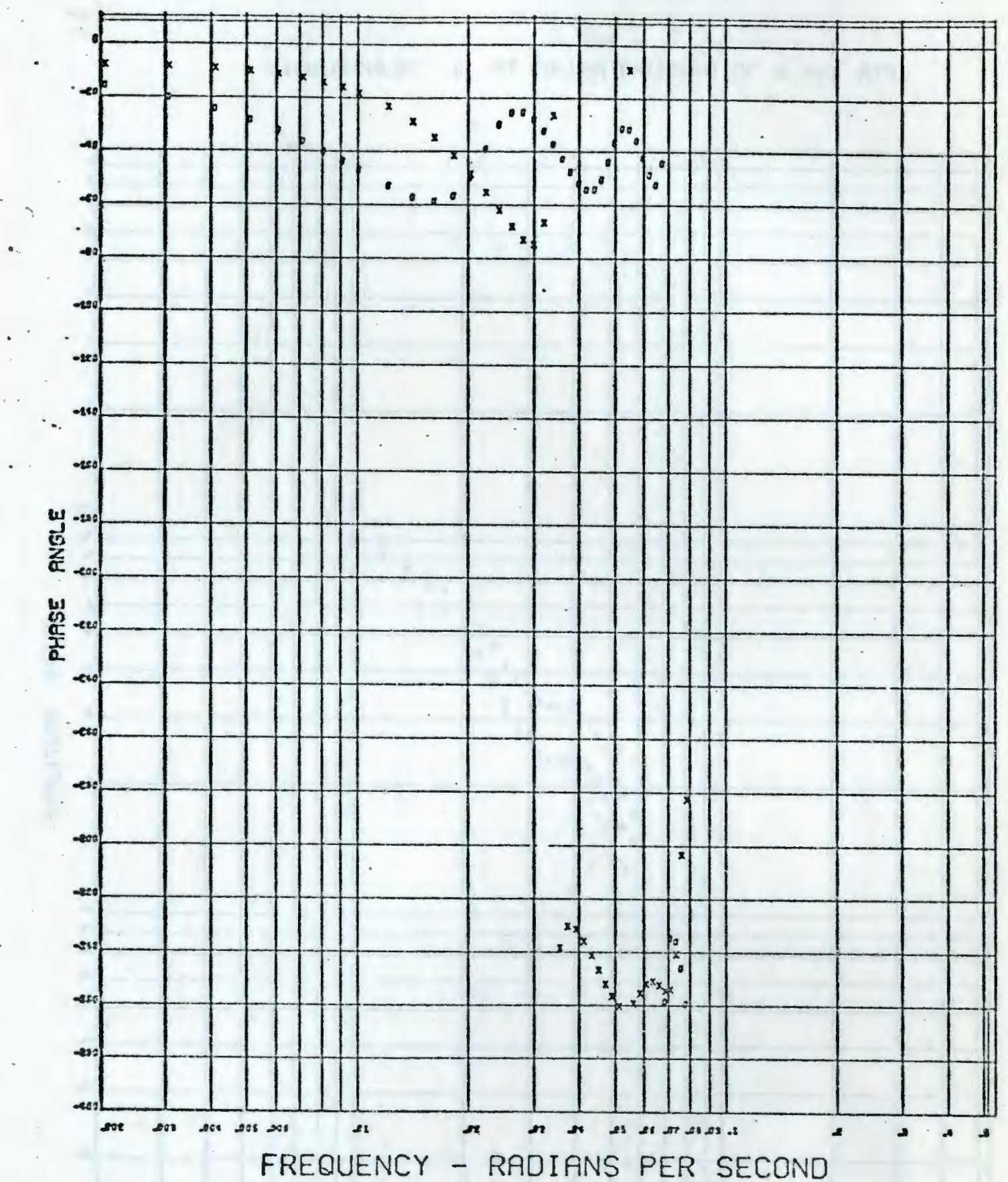

- plate ie o-plate 26

X- plate 21. + PLATE 28 


\section{BODE PLOT}

LIQUIO PULSE 6 AT COLUMN PRESSURE OF 0.243 ATM.

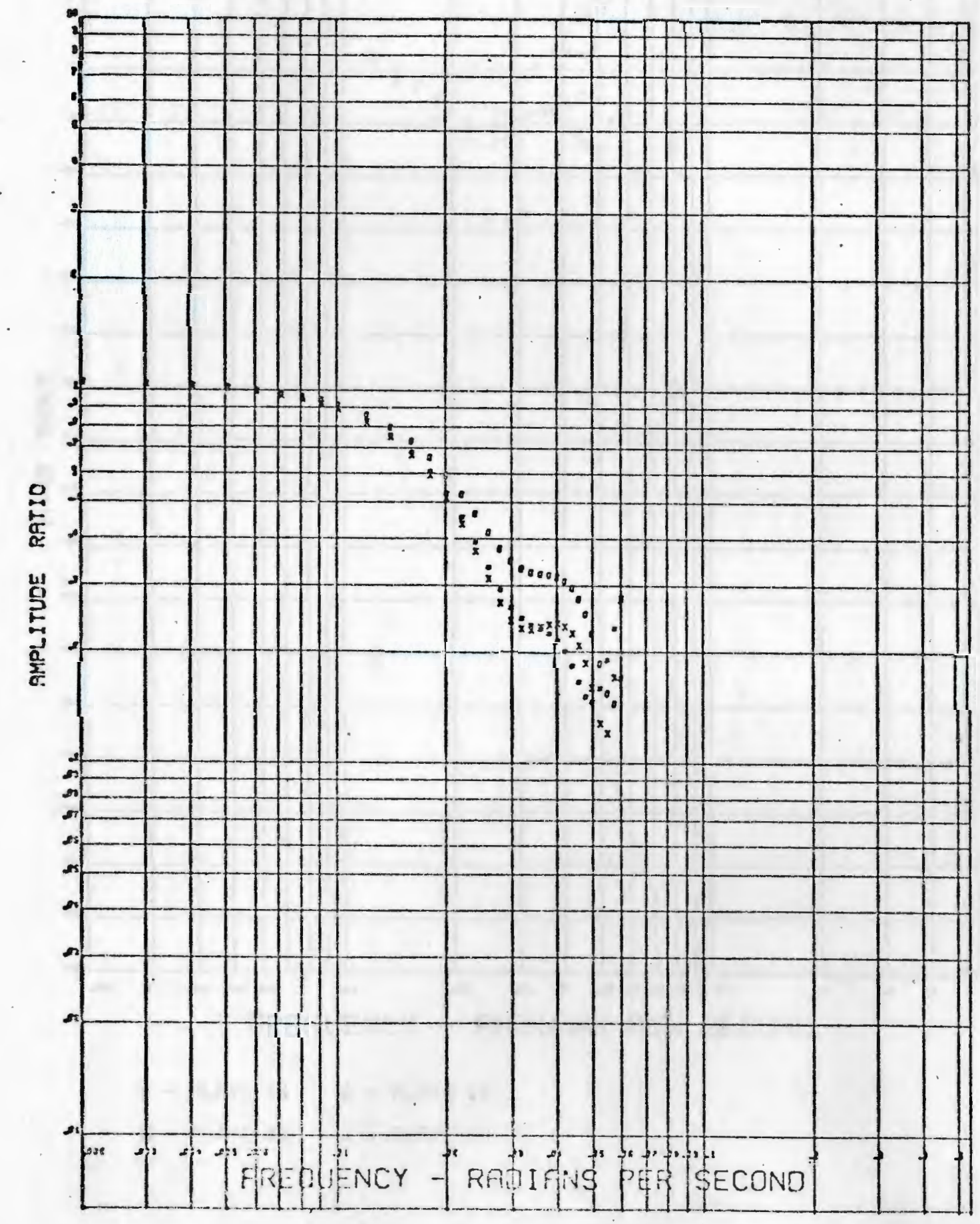




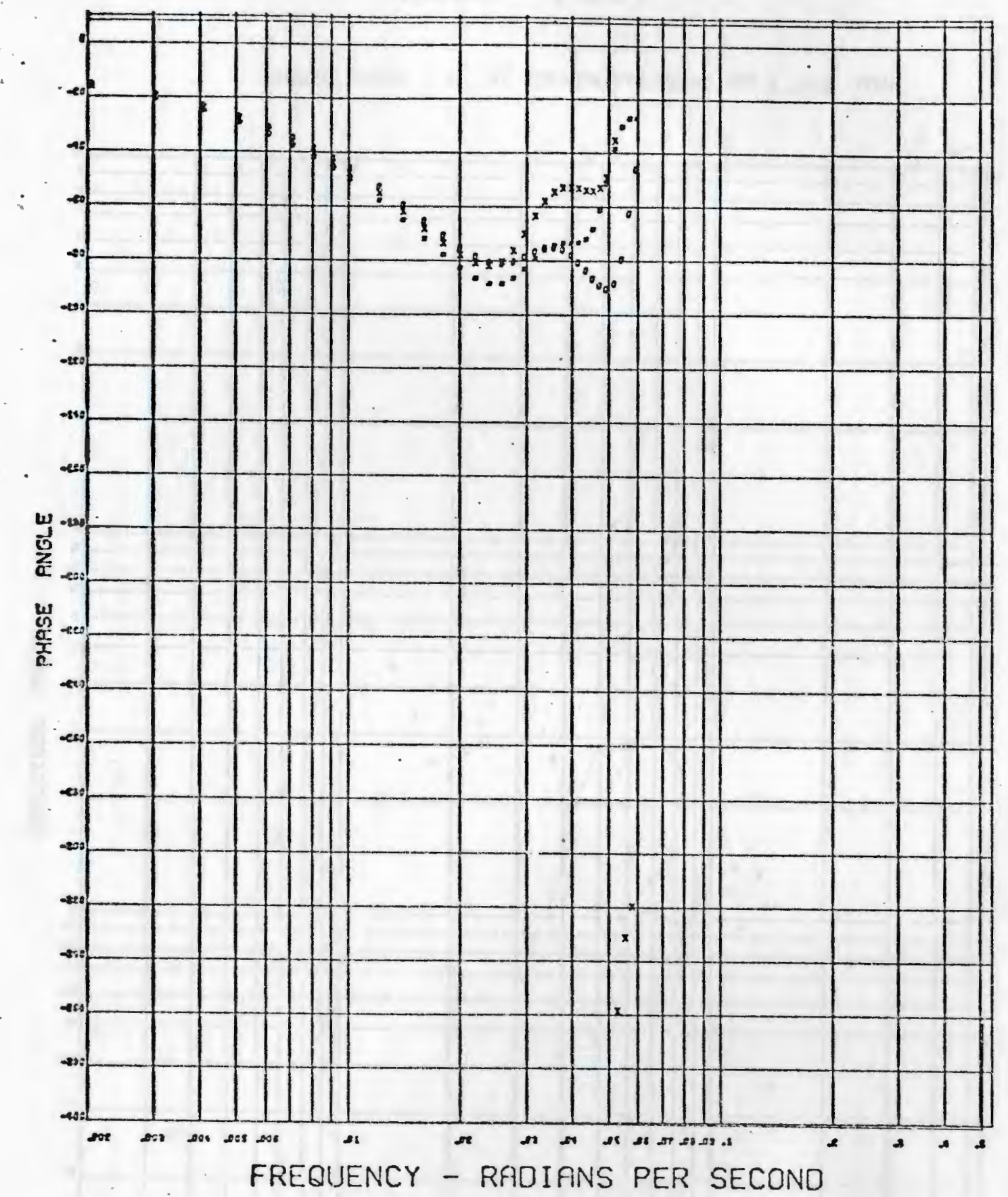

- Plate 16 - Plate 26
$\mathbf{x}$-PLATE $21+$ - Plate 28 


\section{BODE PLOT}

LIQUID PULSE ? AT COLUMN PRESSURE OF 0.243 ATM.

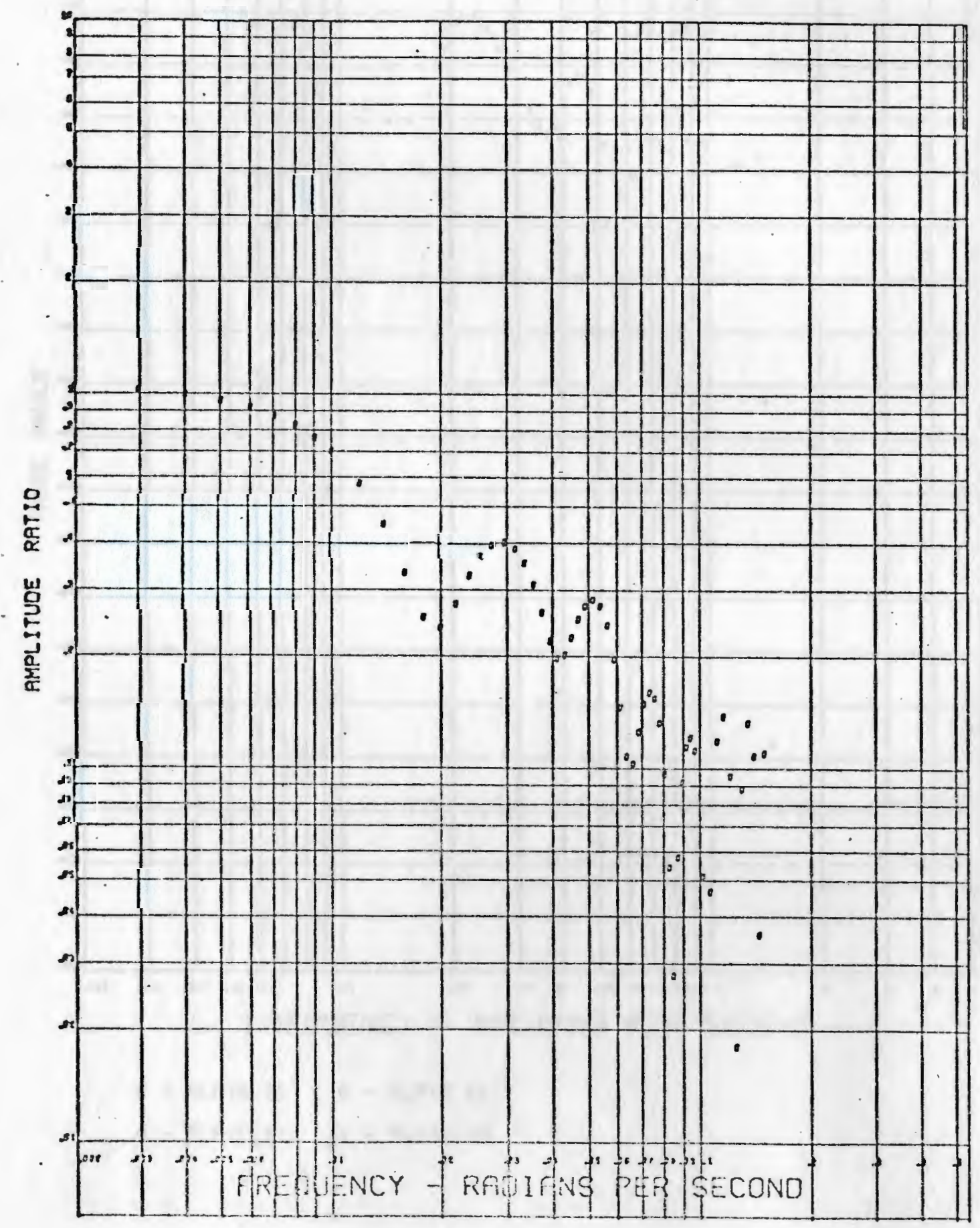




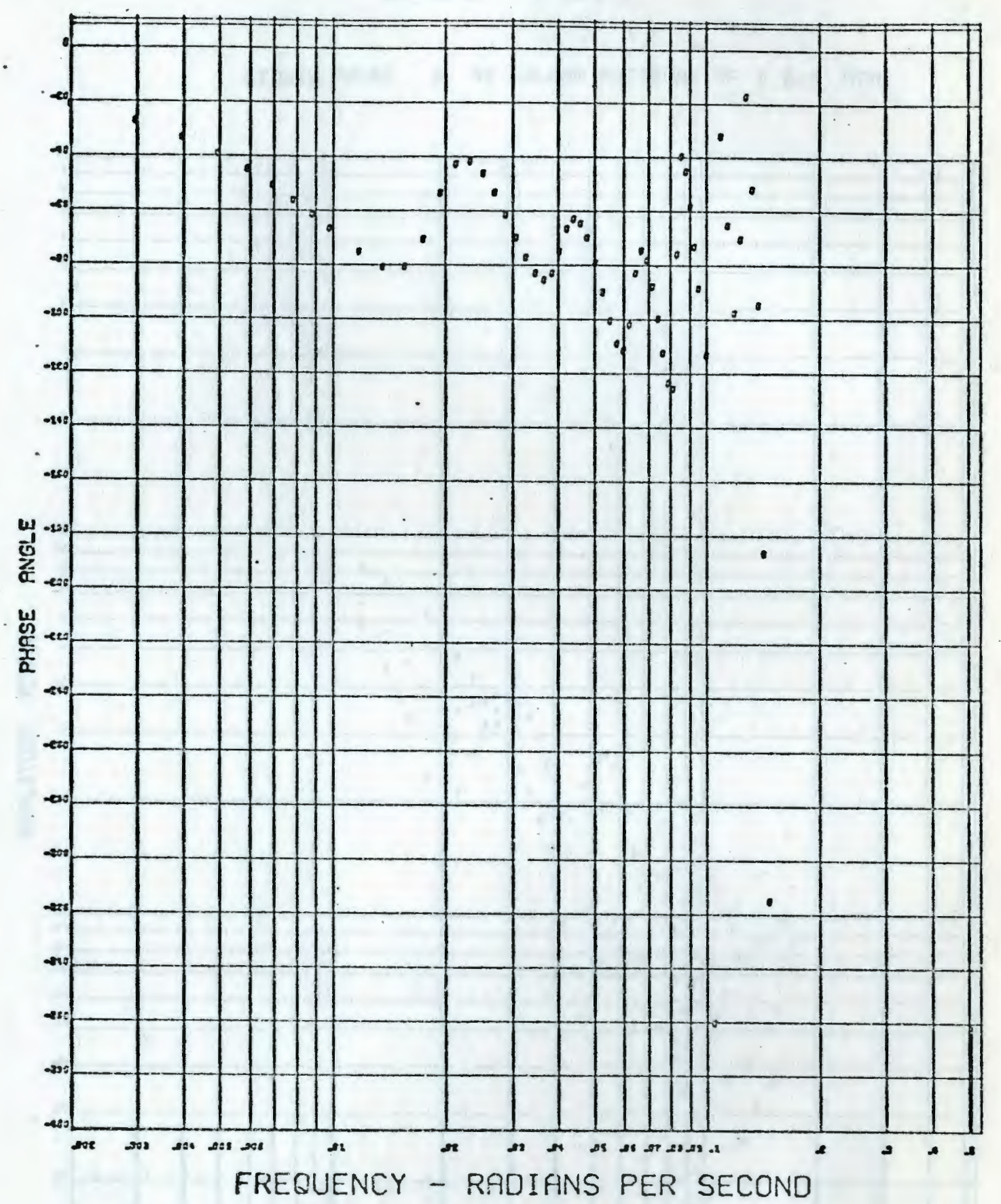

- plate lo 0 - plate 26

X-plate 21. + PL.ate 28 


$$
\text { BODE PLOT }
$$

LIQUID PULSE 8 AT COLUMN PRESSURE OF 0.243 ATM.

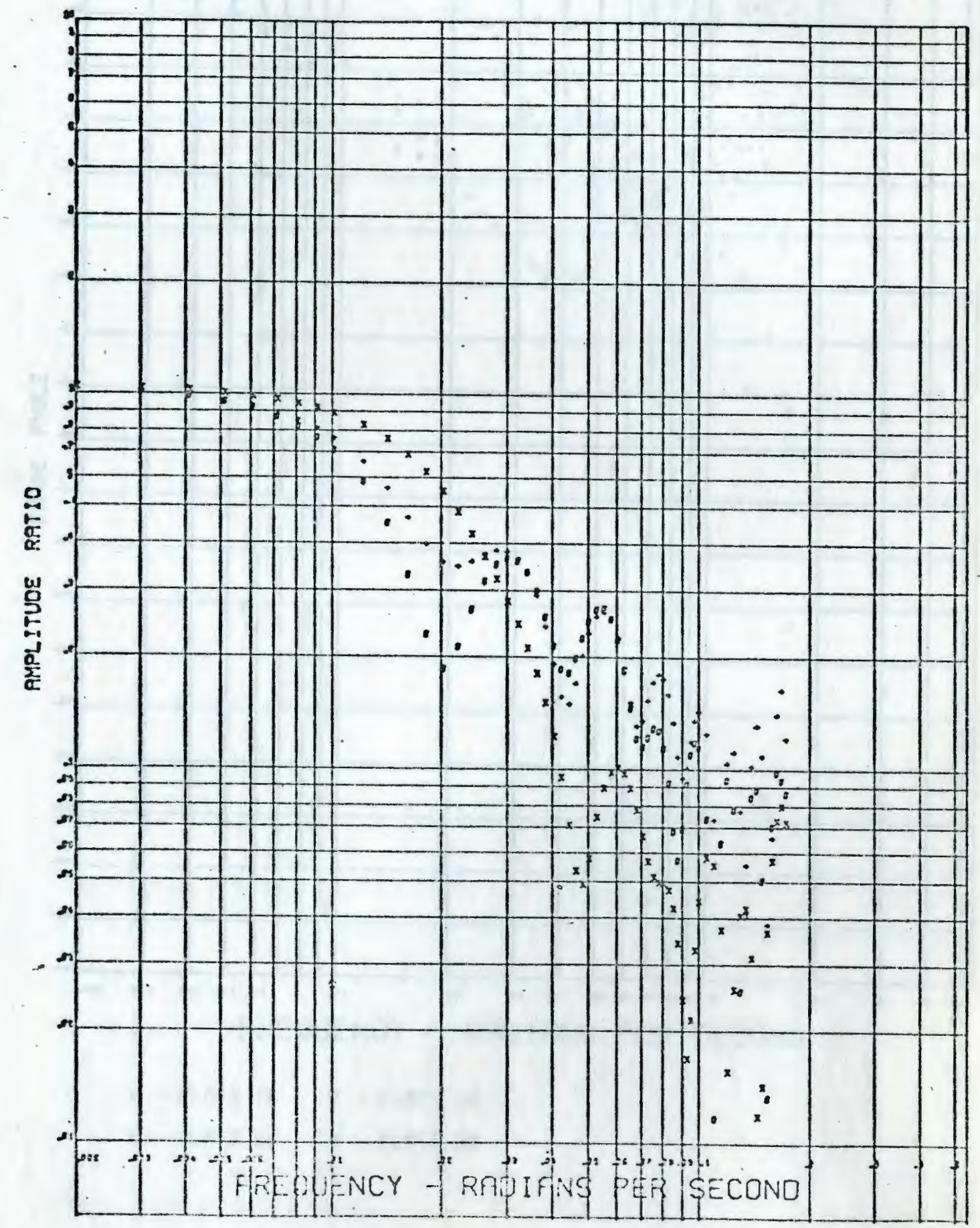




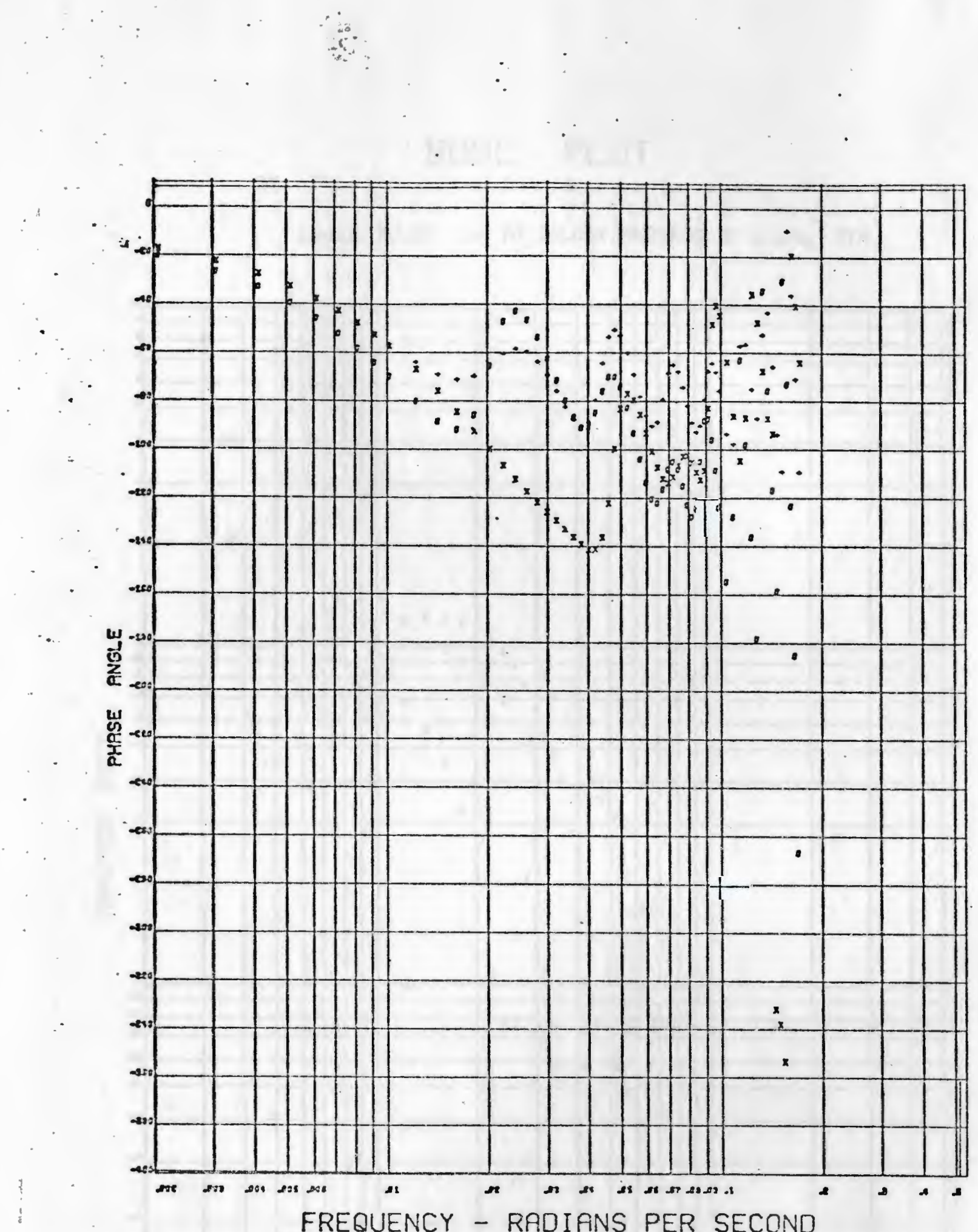

FREQUENCY - RRDIANS PER SECOND

* plate 16 o-plate 26

X - PLATE 2: + - FLRTE 28 


\section{BODE PLOT}

LIQUID PULSE 9 AT COLUMN PRESSURE OF 0.243 ATM.

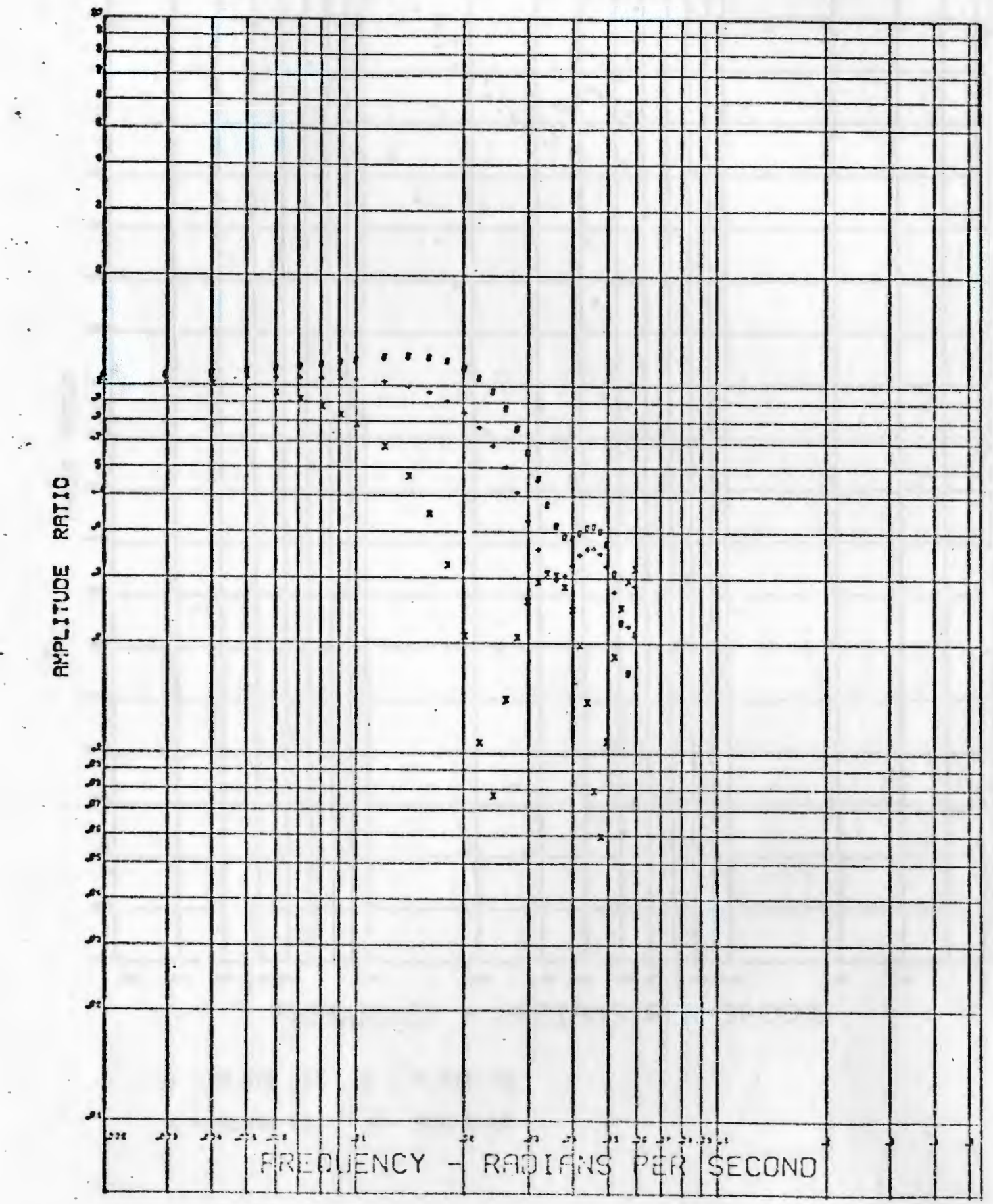




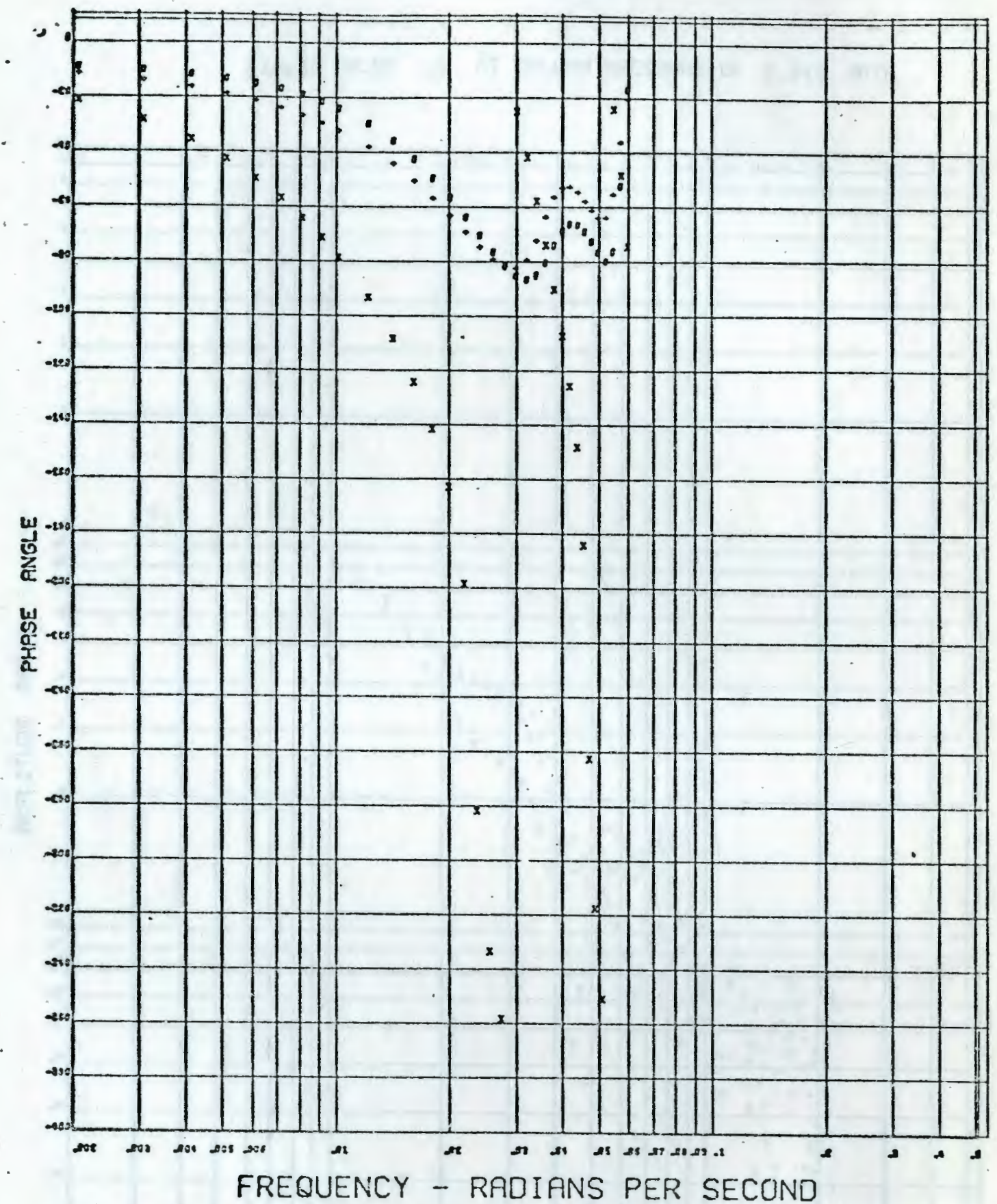

- plate 16 - 0 -plate 26

X-PLATE 21. + PLATE 28 


\section{BODE PLOT}

LIQUIO PLLSE 10 AT COLUMN PRESSURE OF 0.243 ATM.

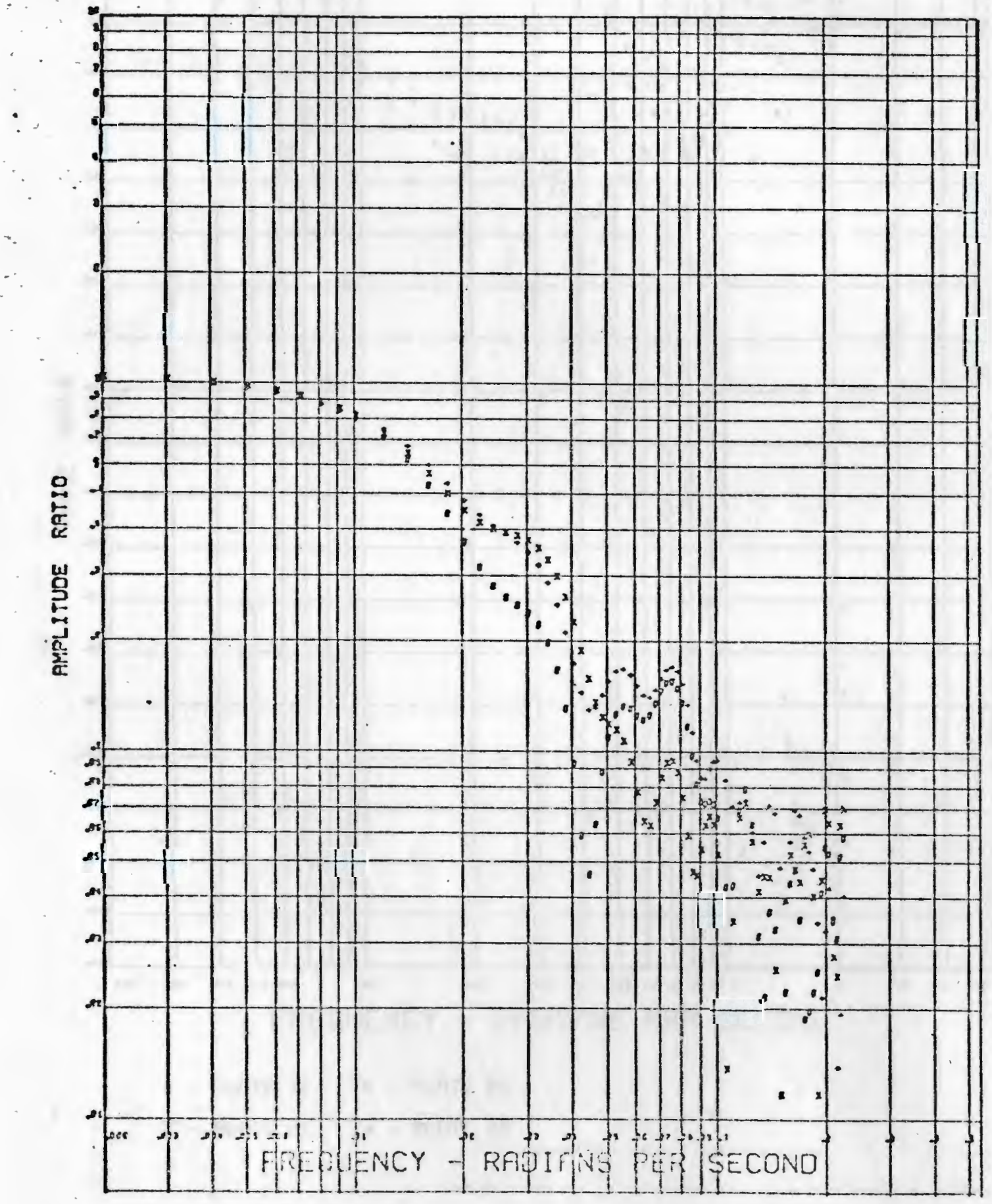




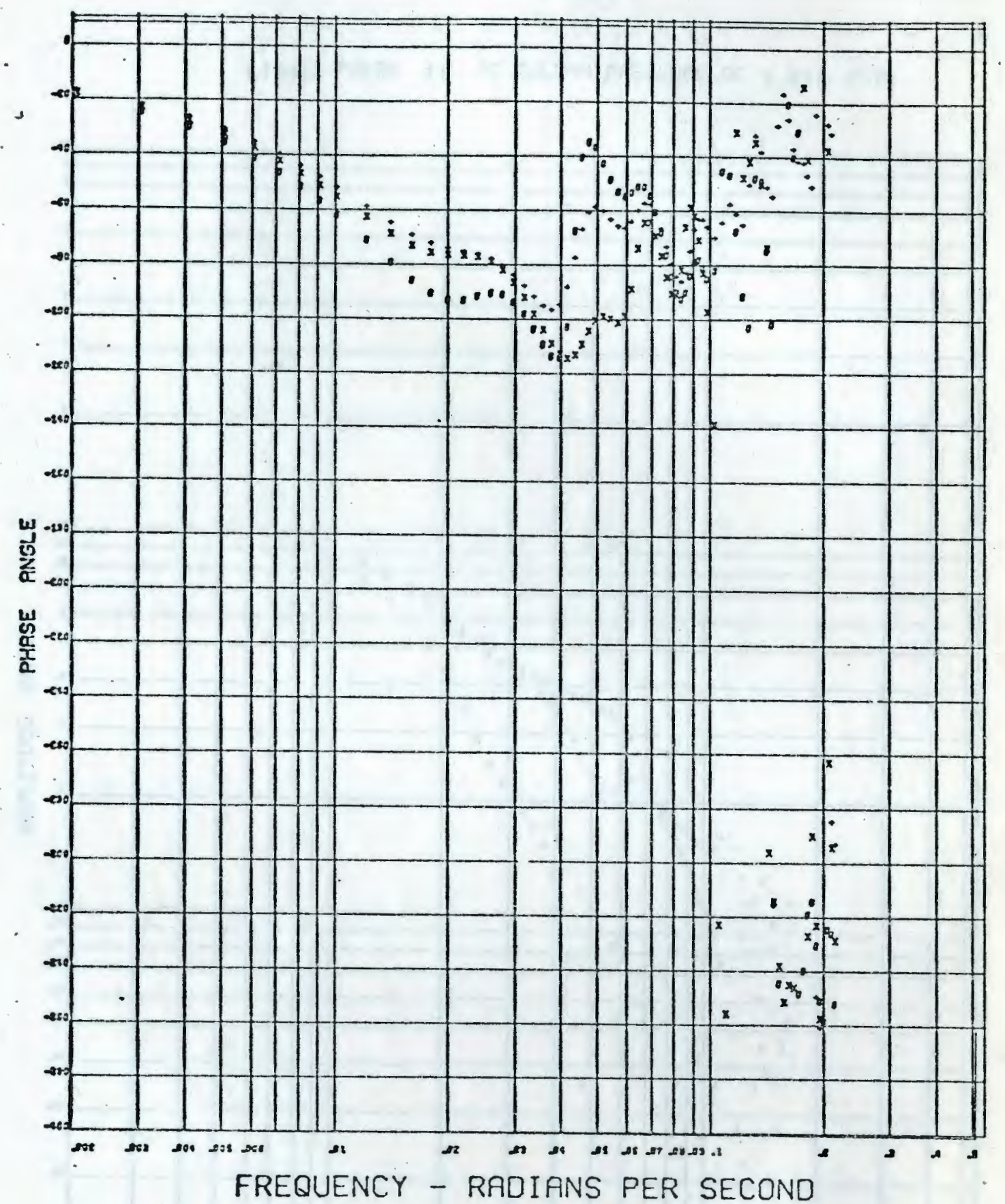

* Plate 15 - Plate 26
x-PLate 21 + PLATE 28 


\section{BODE PLOT}

LIQUTO PULSE 11 AT COLUMN PRESSURE OF 0.243 ATM.

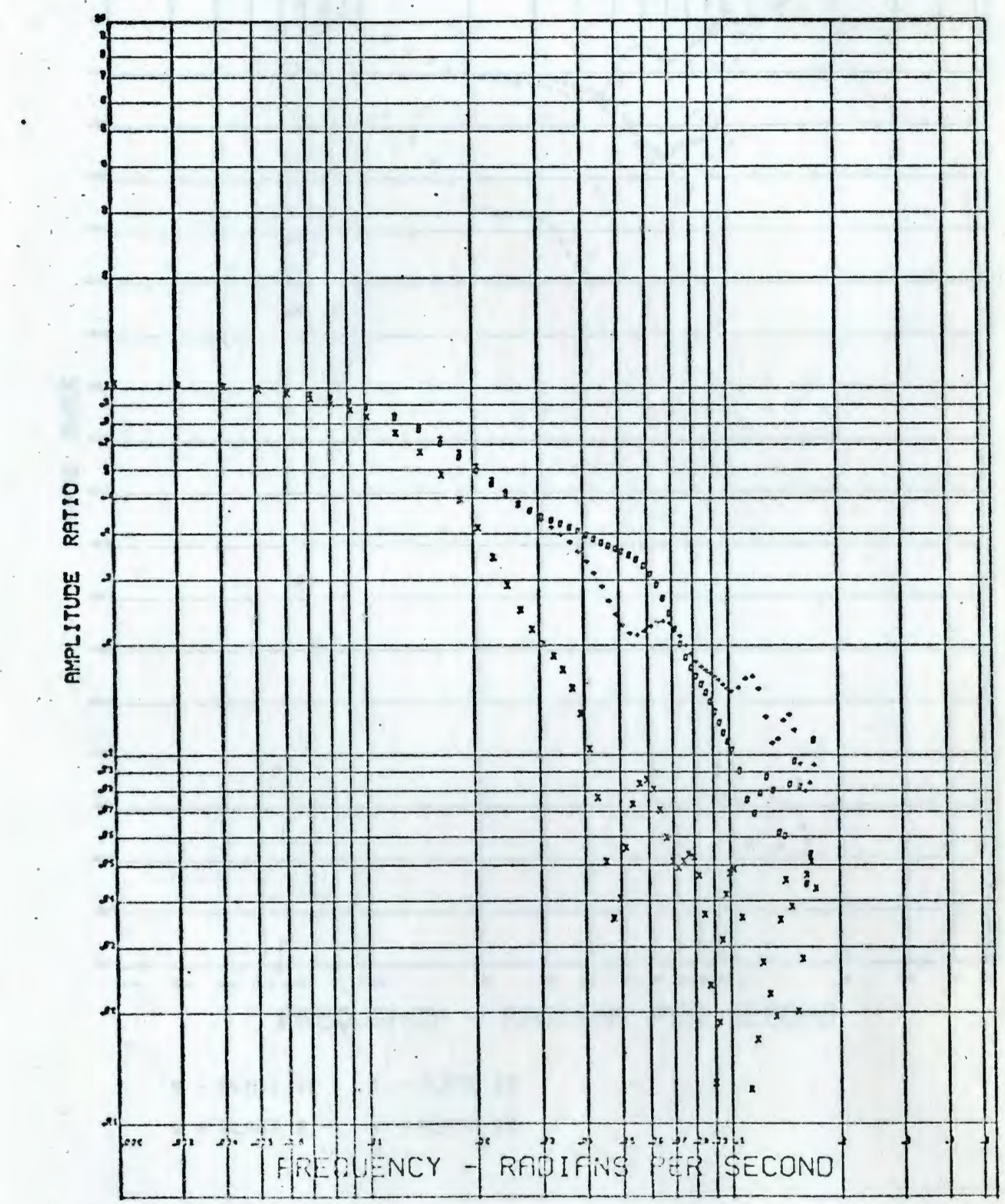




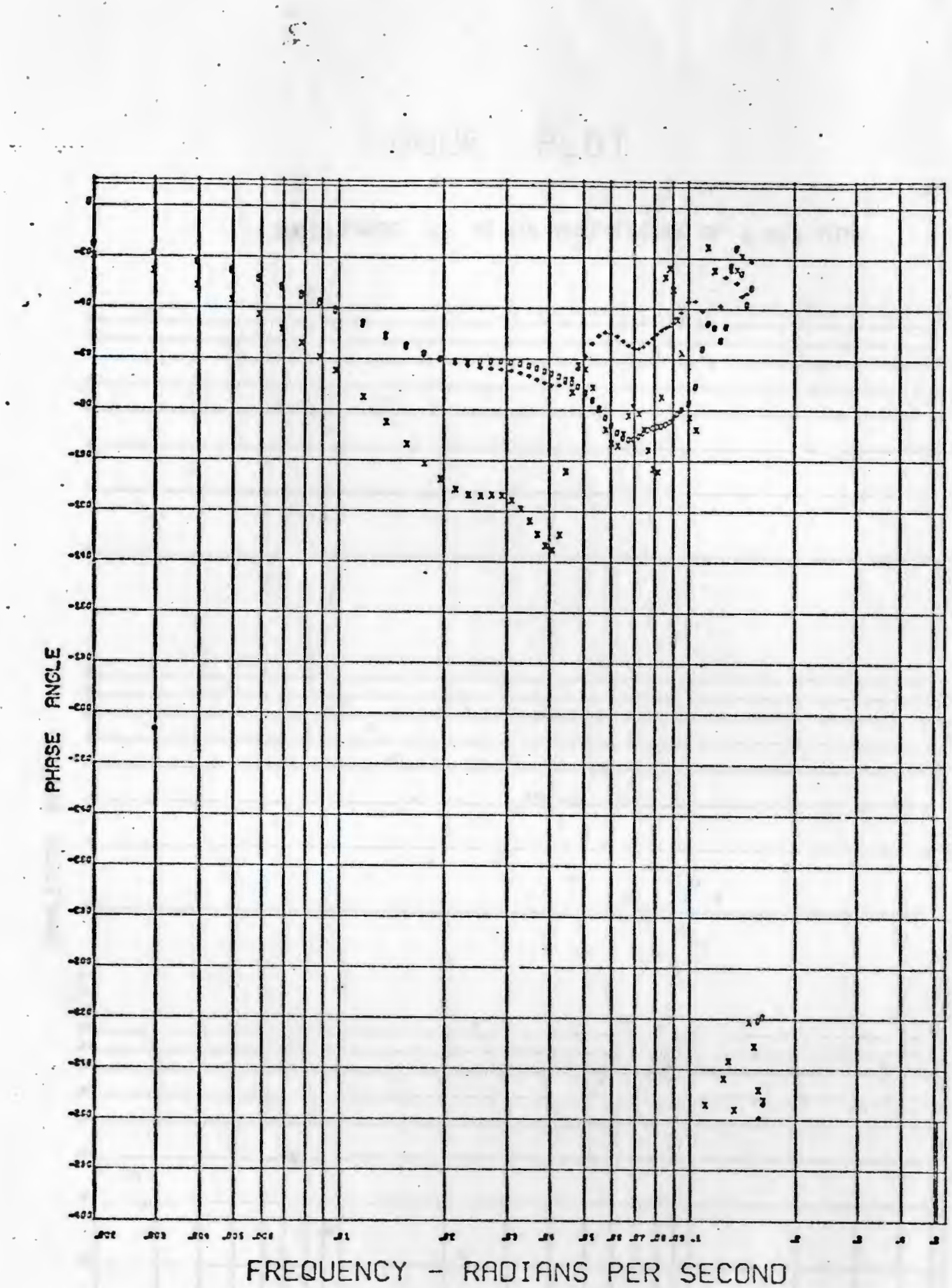

$*$ - PLATE $16 \quad 0$ - PLATE 26
$\quad \times$ - PLATE 21. 


\section{BODE PLOT}

LIQUIO PULSE 13 AT COLUMN PRESSURE OF 0.243 ATM.

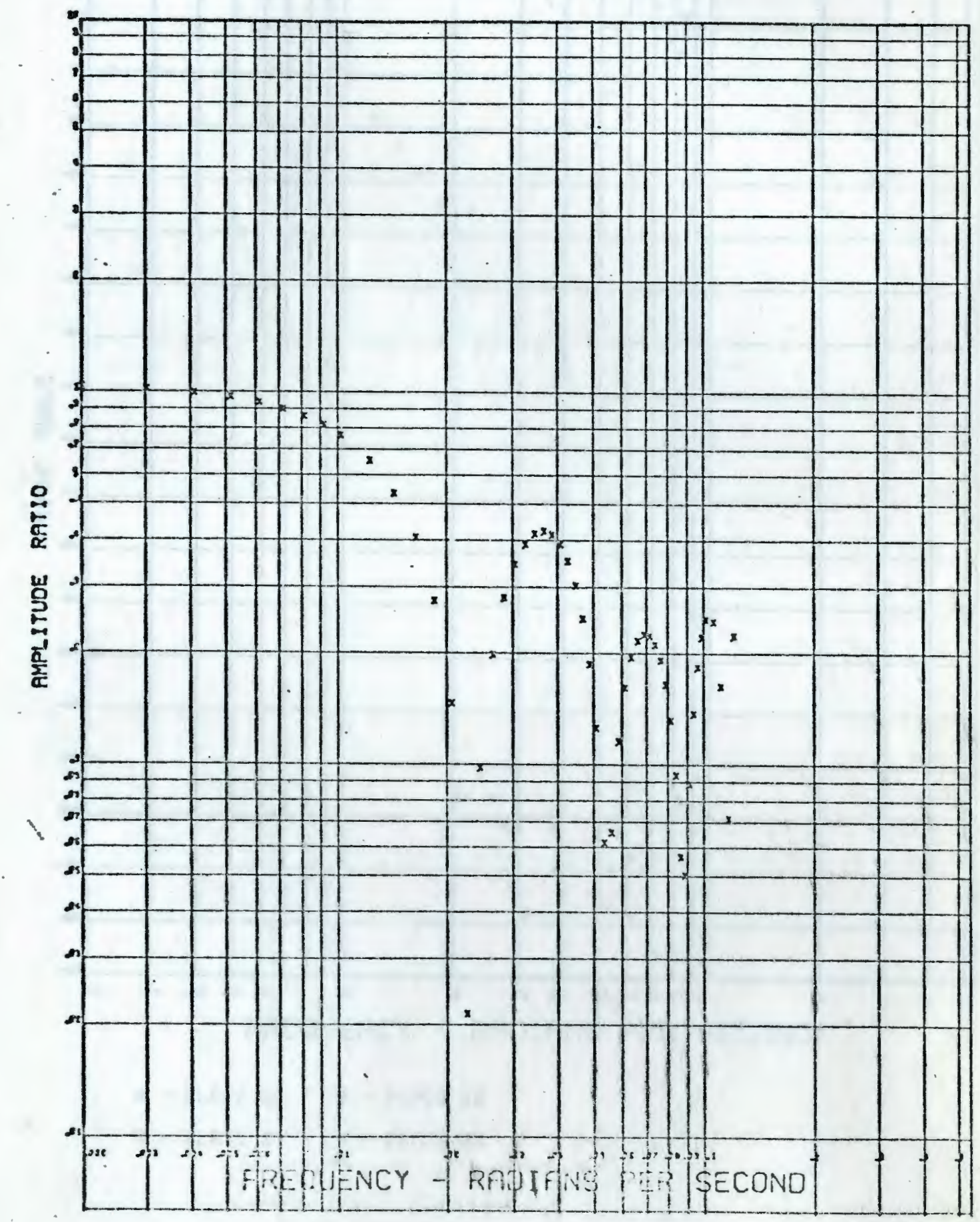



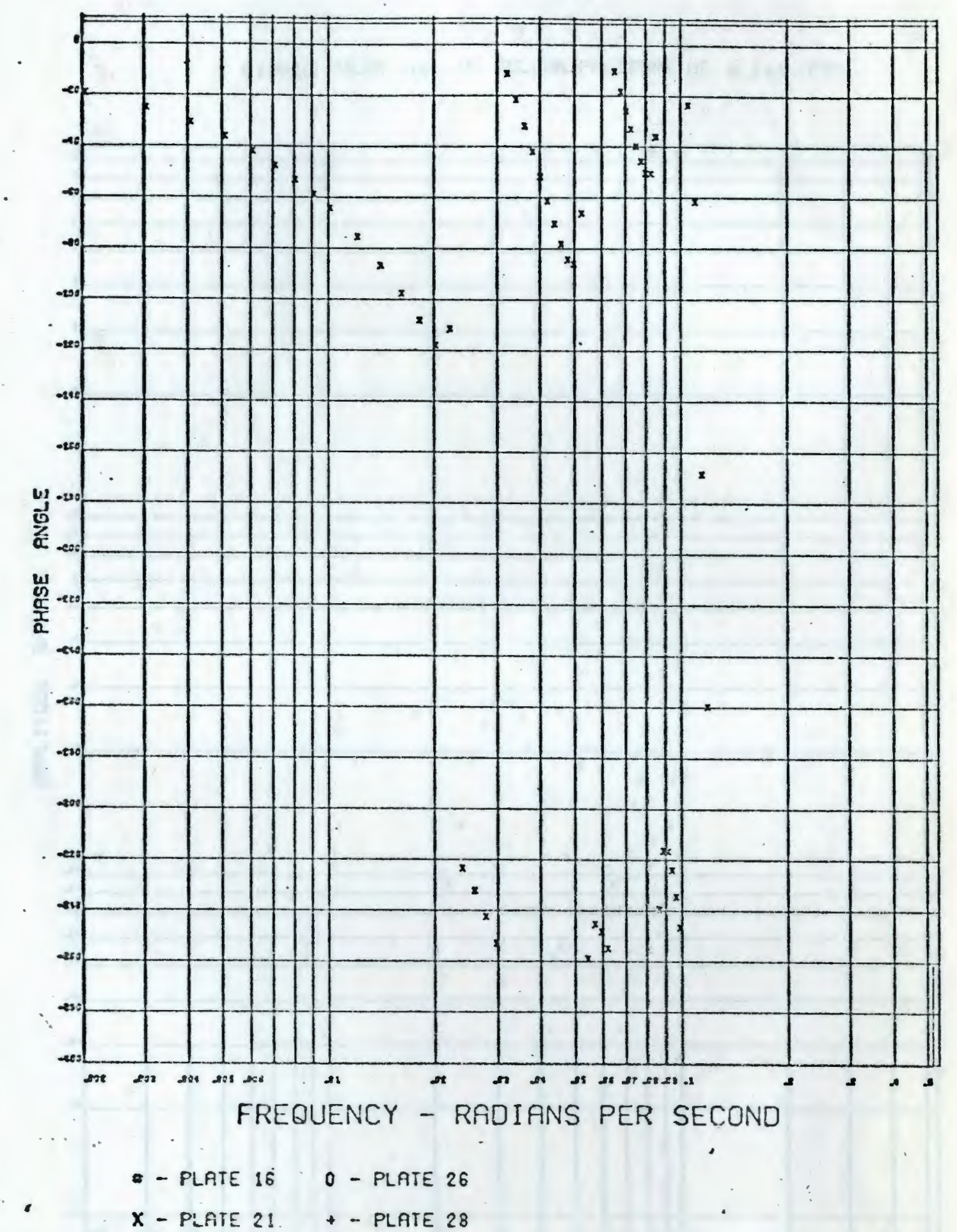


\section{BODE PLOT}

LIQUID PULSE 14 AT COLUMN PRESSURE OF 0.243 RTM.

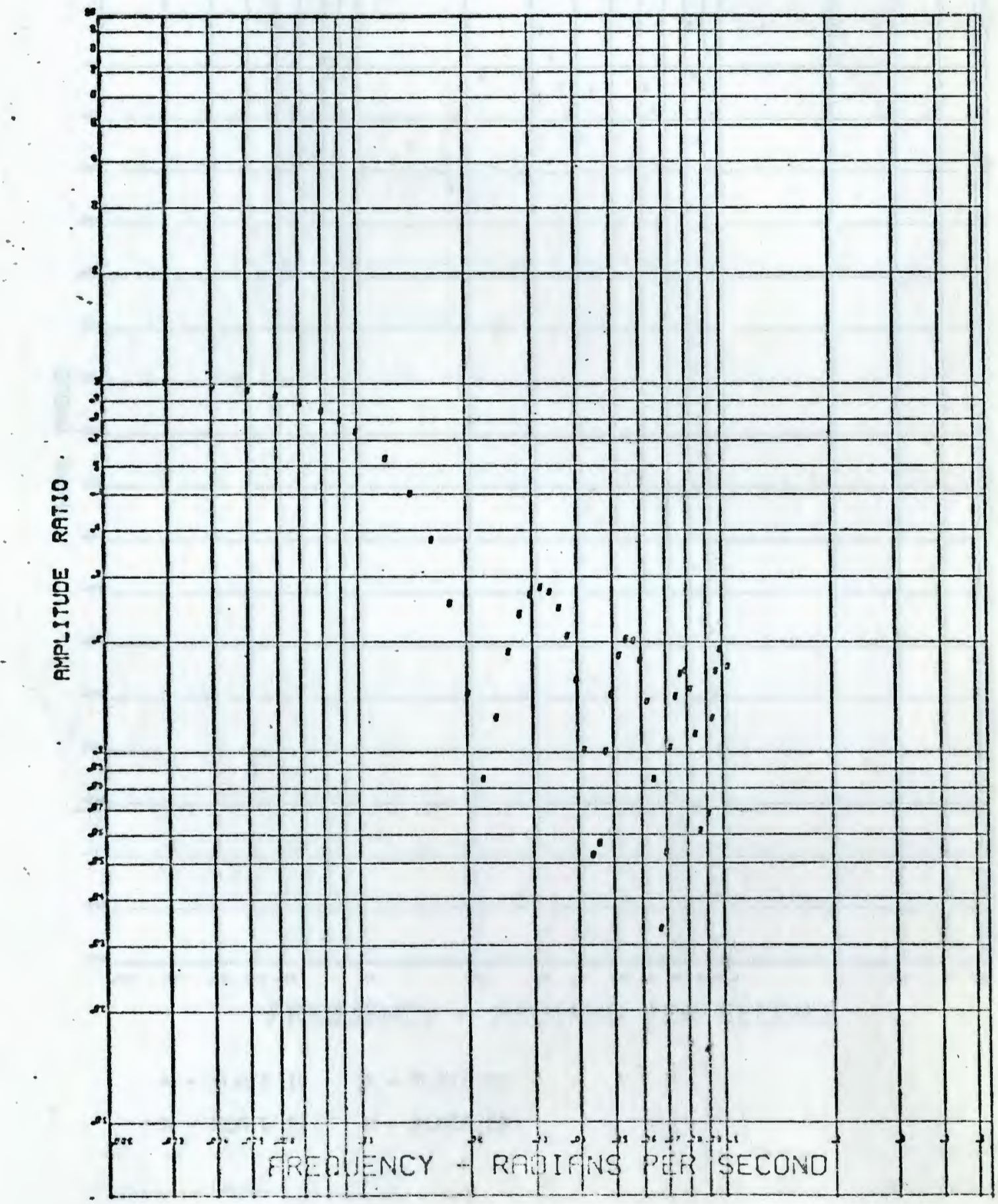




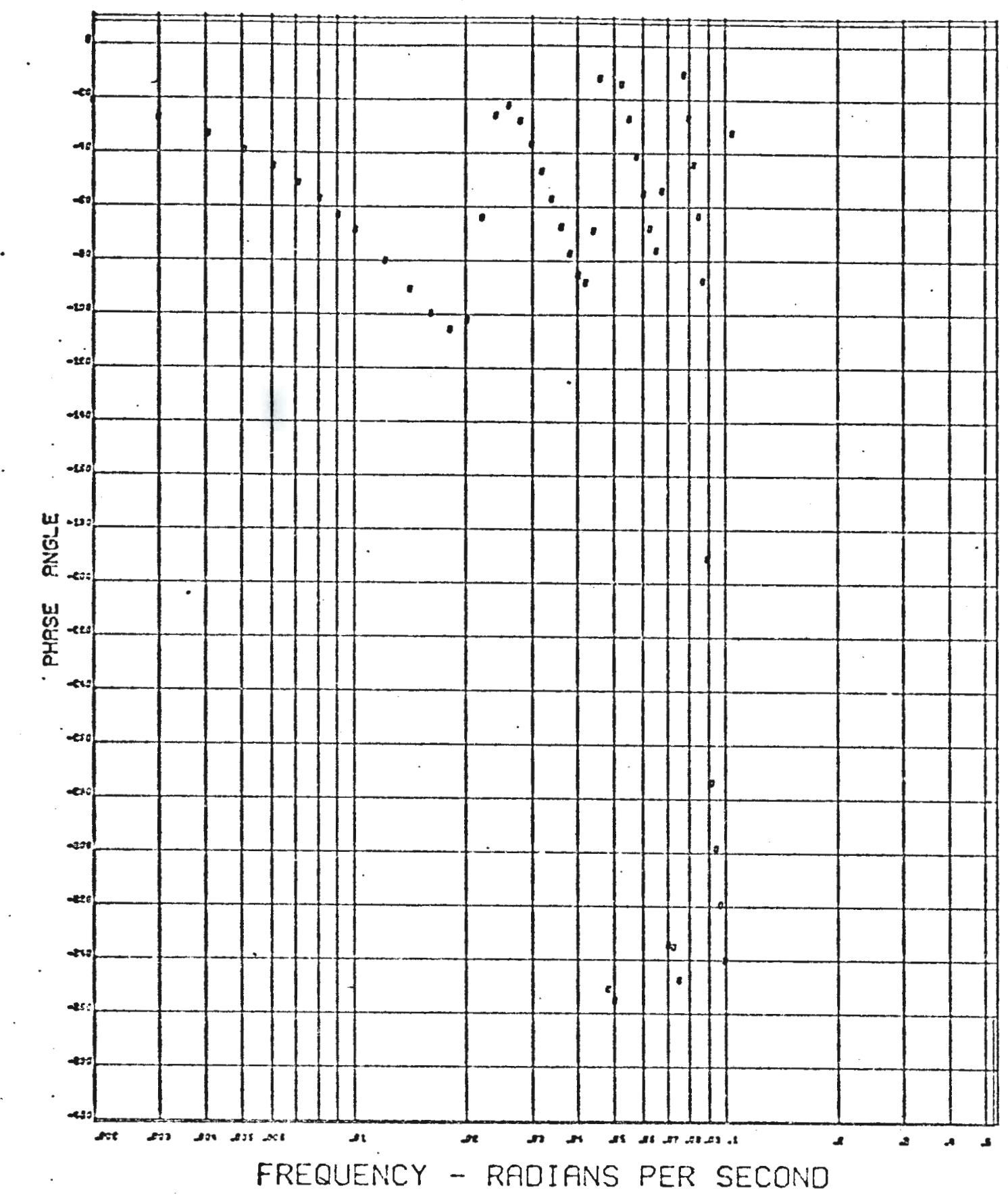


281

Bode Plots

Llquid Concentration Responses

Column Pressure - .26 atm. 


\section{BODE PLOT}

CONCENTRATION PULSE I AT COLUMN PRESSURE OF 0.263 ATM.

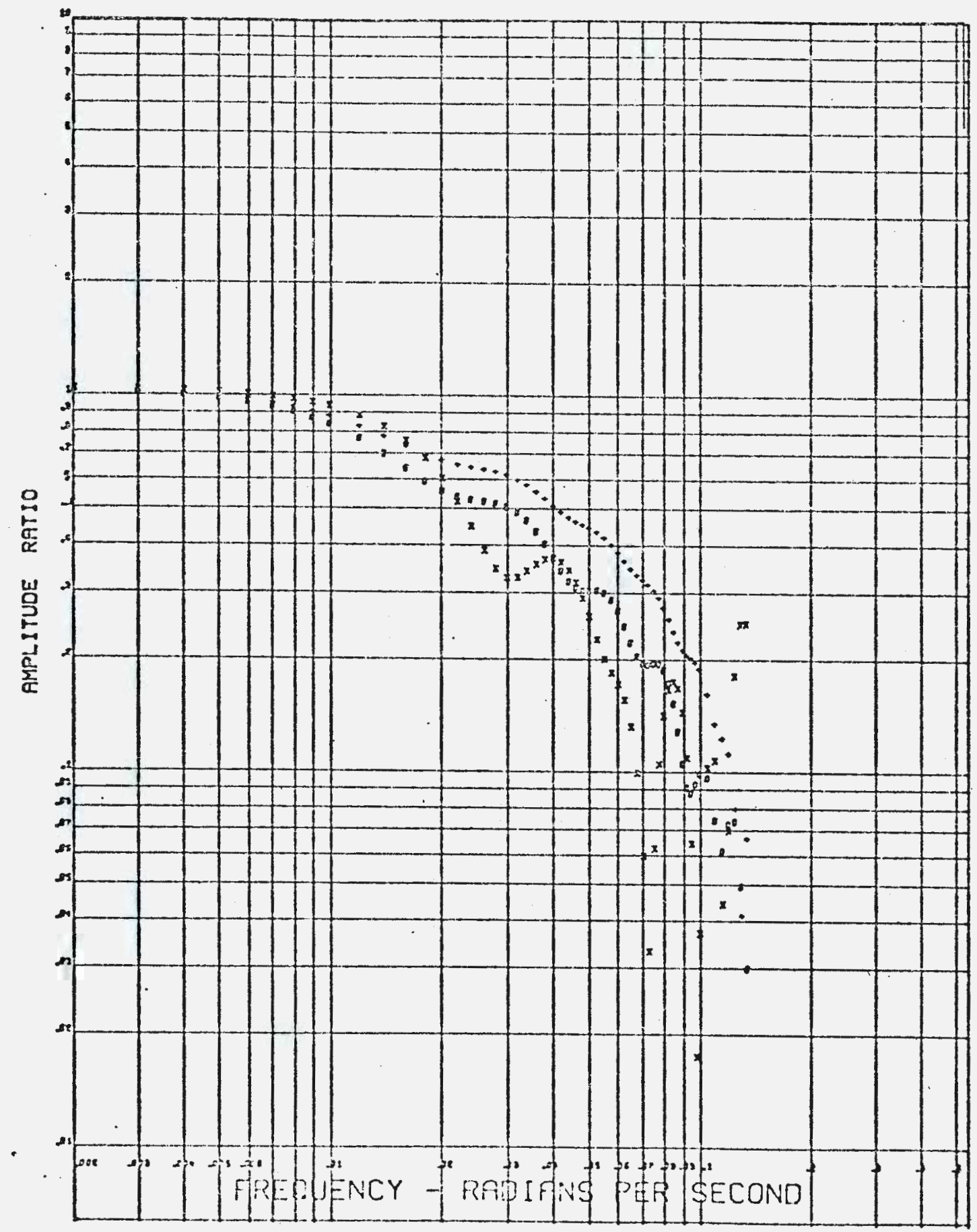




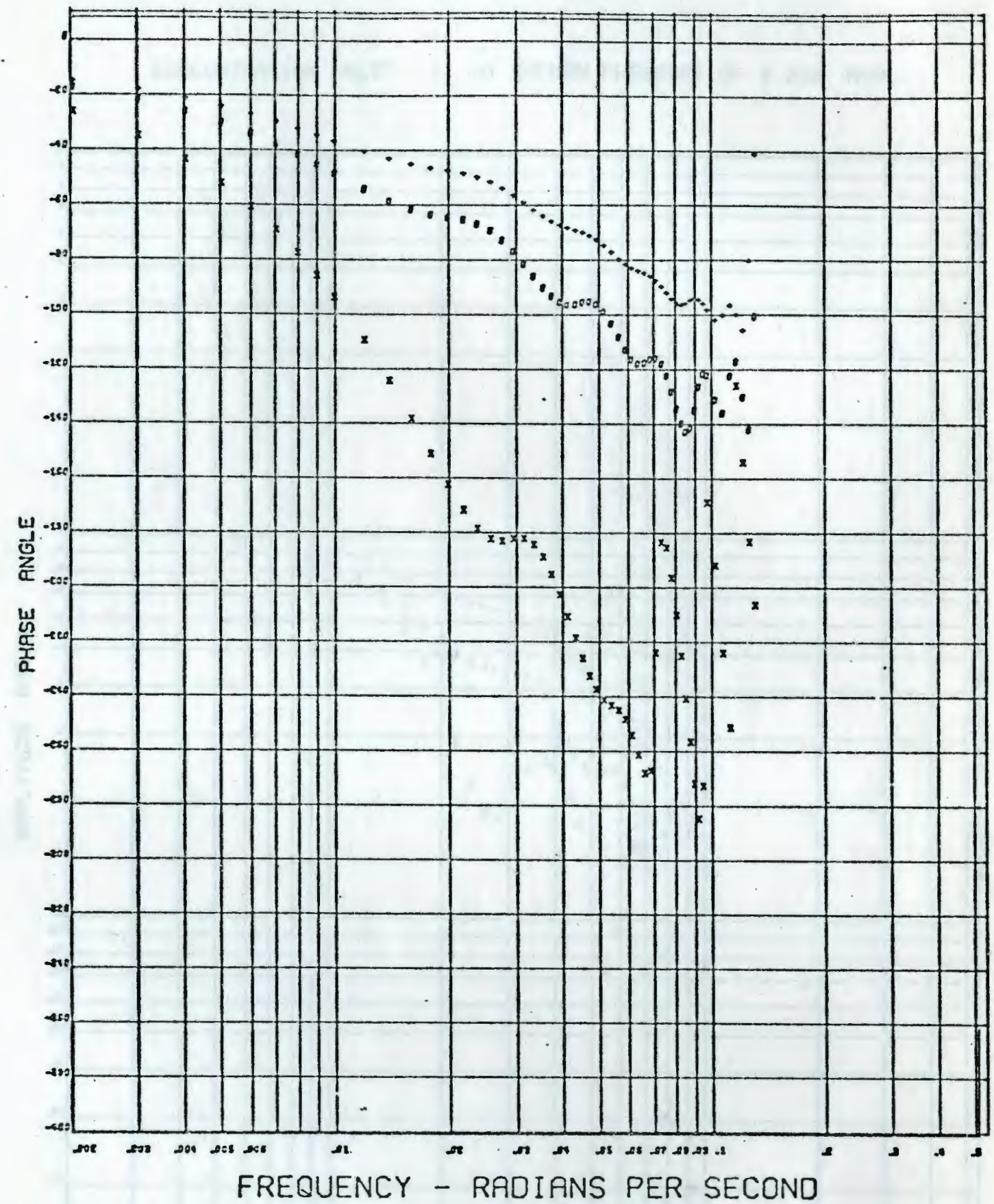

- plate 160 - plate 26

X - plate 21 + - Plate 29 


\section{BODE PLOT}

CONCENTRATION FULSE 2 AT COLUMN PRESSURE OF 0.263 ATM.

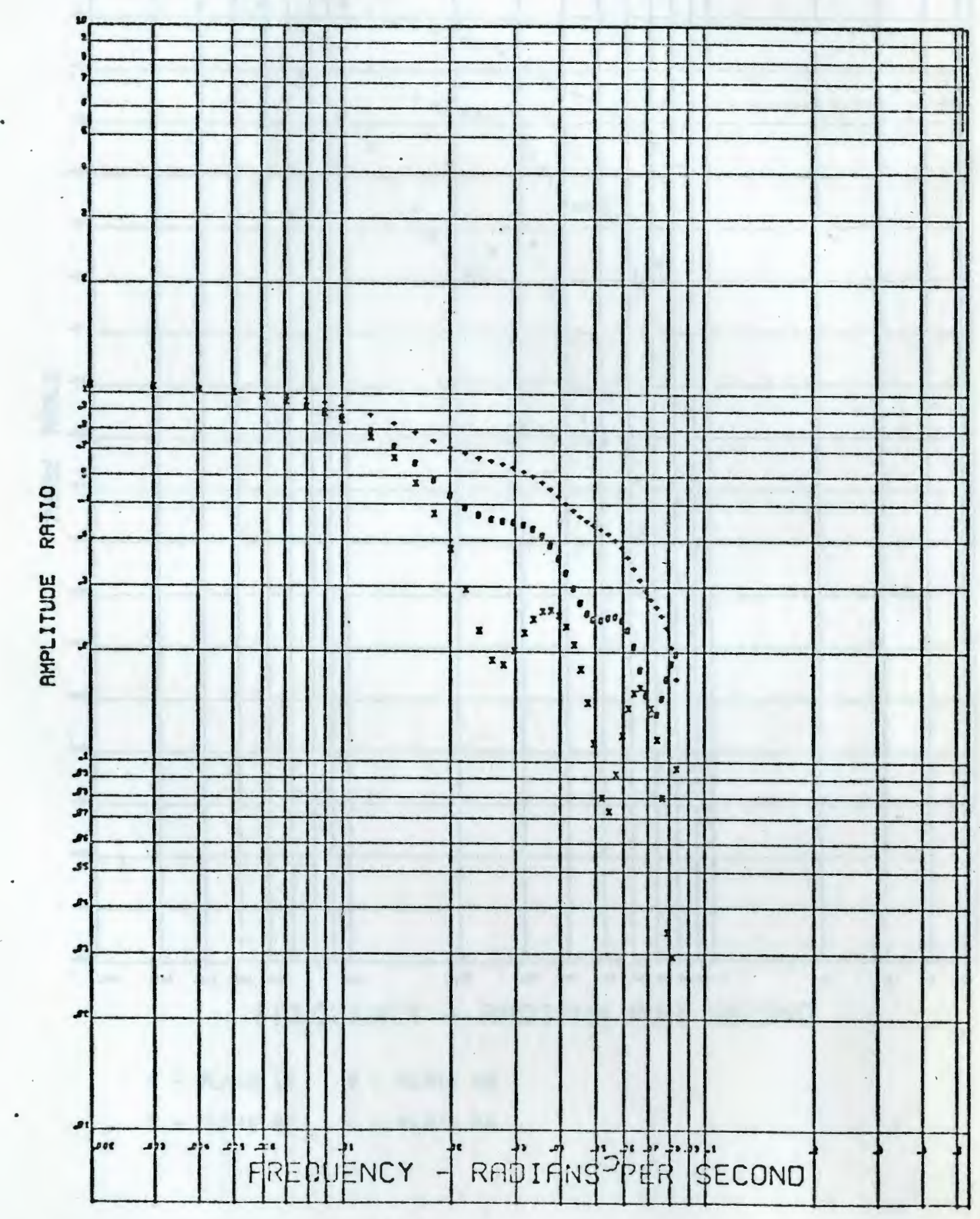




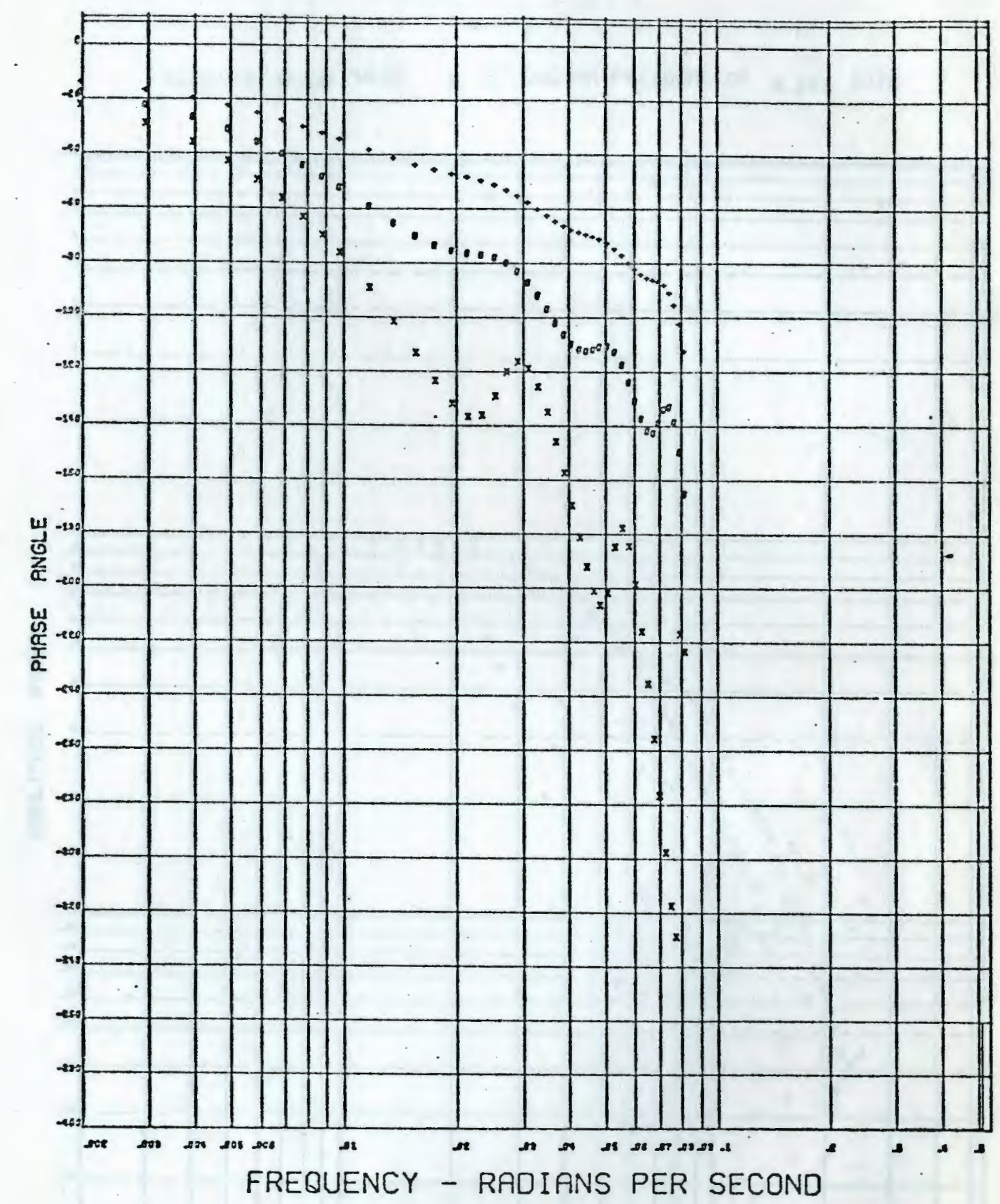

- plate 16 0-plate 26

- $x$ - plate $21 .+$ - plate 28 
BODE PLOT

CONEENTRATION PULSE 3 AT COLUMN PRESSURE OF 0.263 ATM.

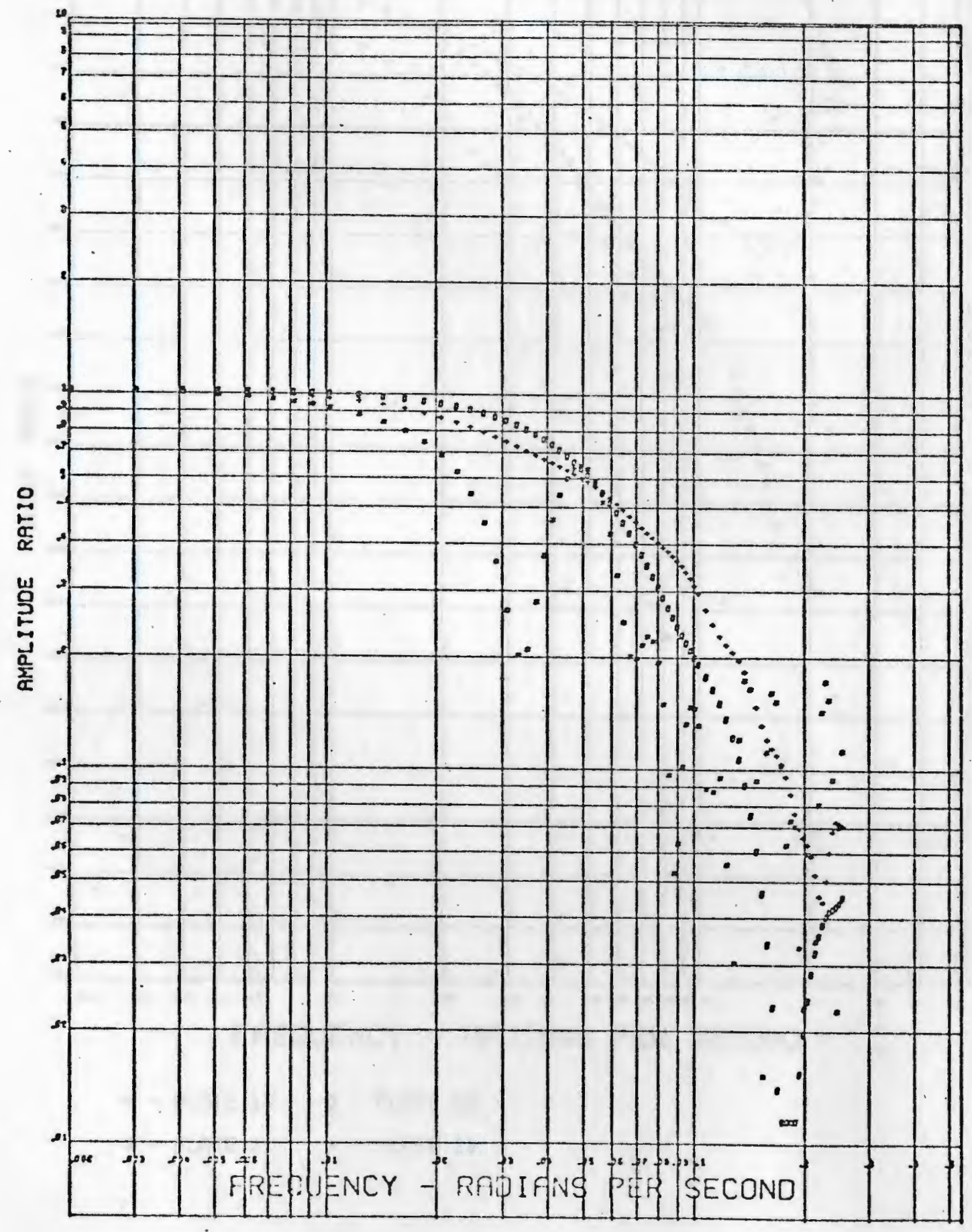




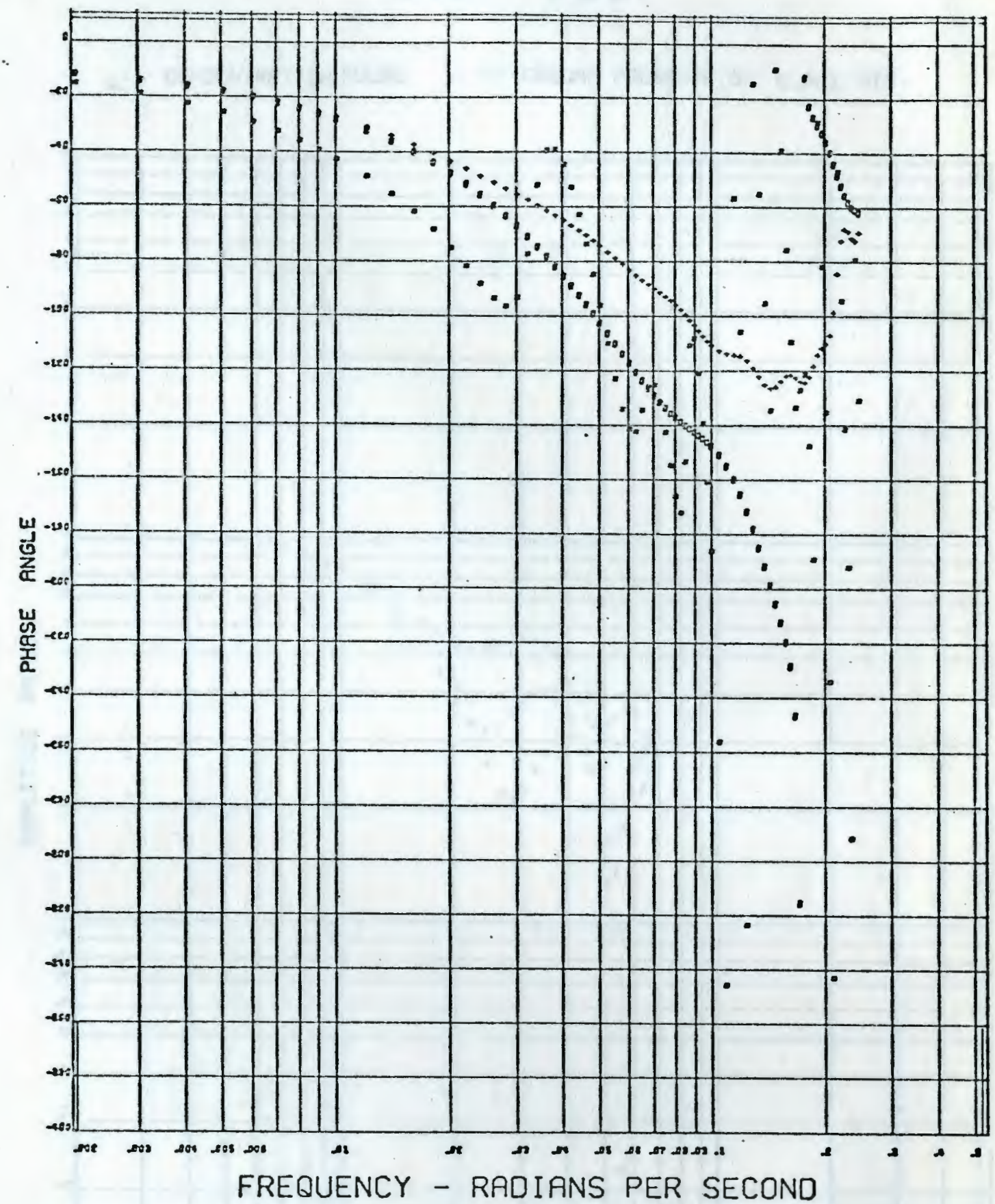

- plate 16 o - plate 26

$x$ - PLATE 21 + - pLATE 28 


\section{BODE PLOT}

$\therefore$ concentration PULSE 4 at COLUMN PRESSURE of 0.263 atM.

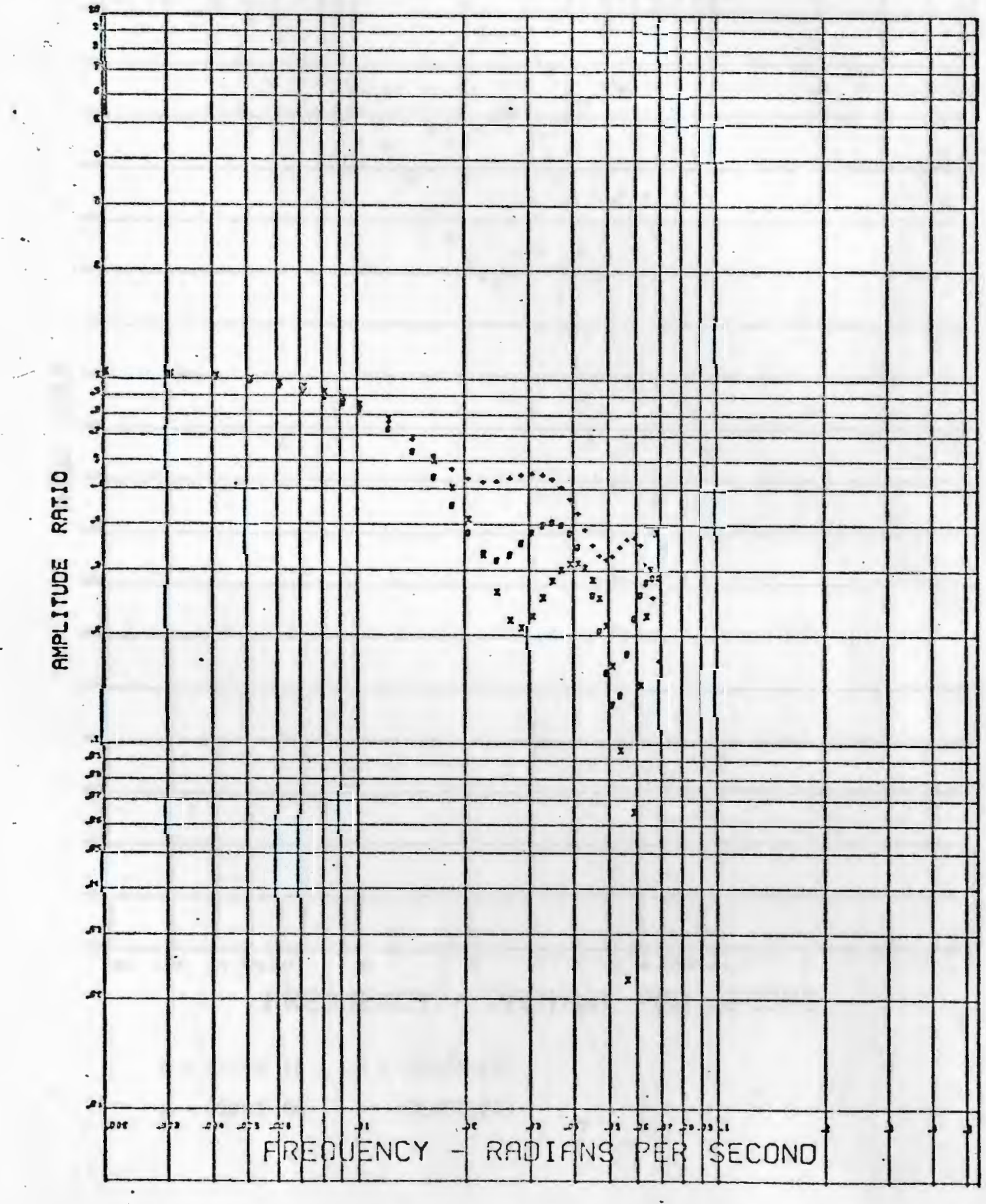




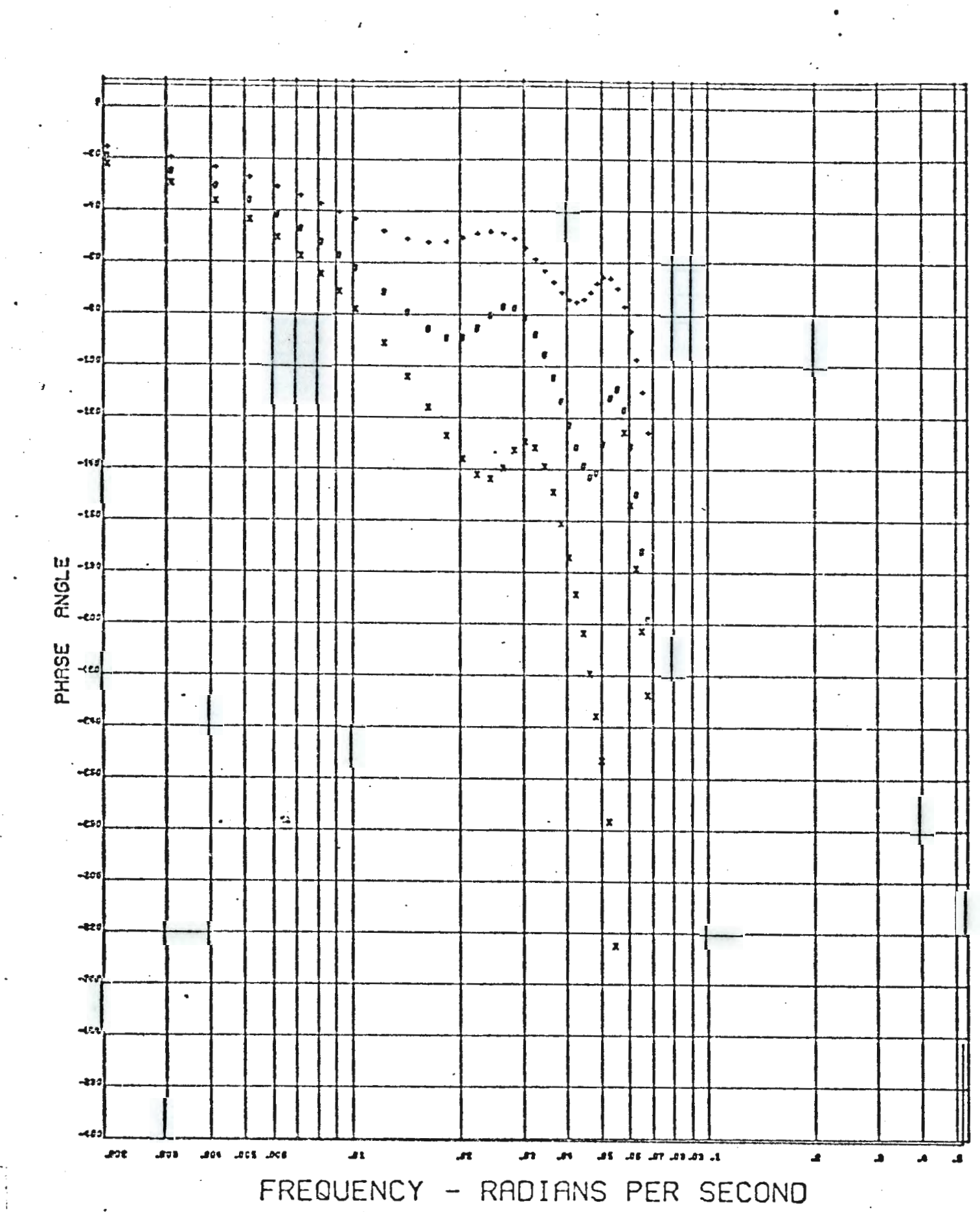

\footnotetext{
- plate 16 - plate 26

X - Plate $21 .+$ - Plate 28
} 


\section{BODE PLOT}

6. CONCENTRATION PULSE 5 AT COLU.MN PRESSURE OF 0.253 atm.

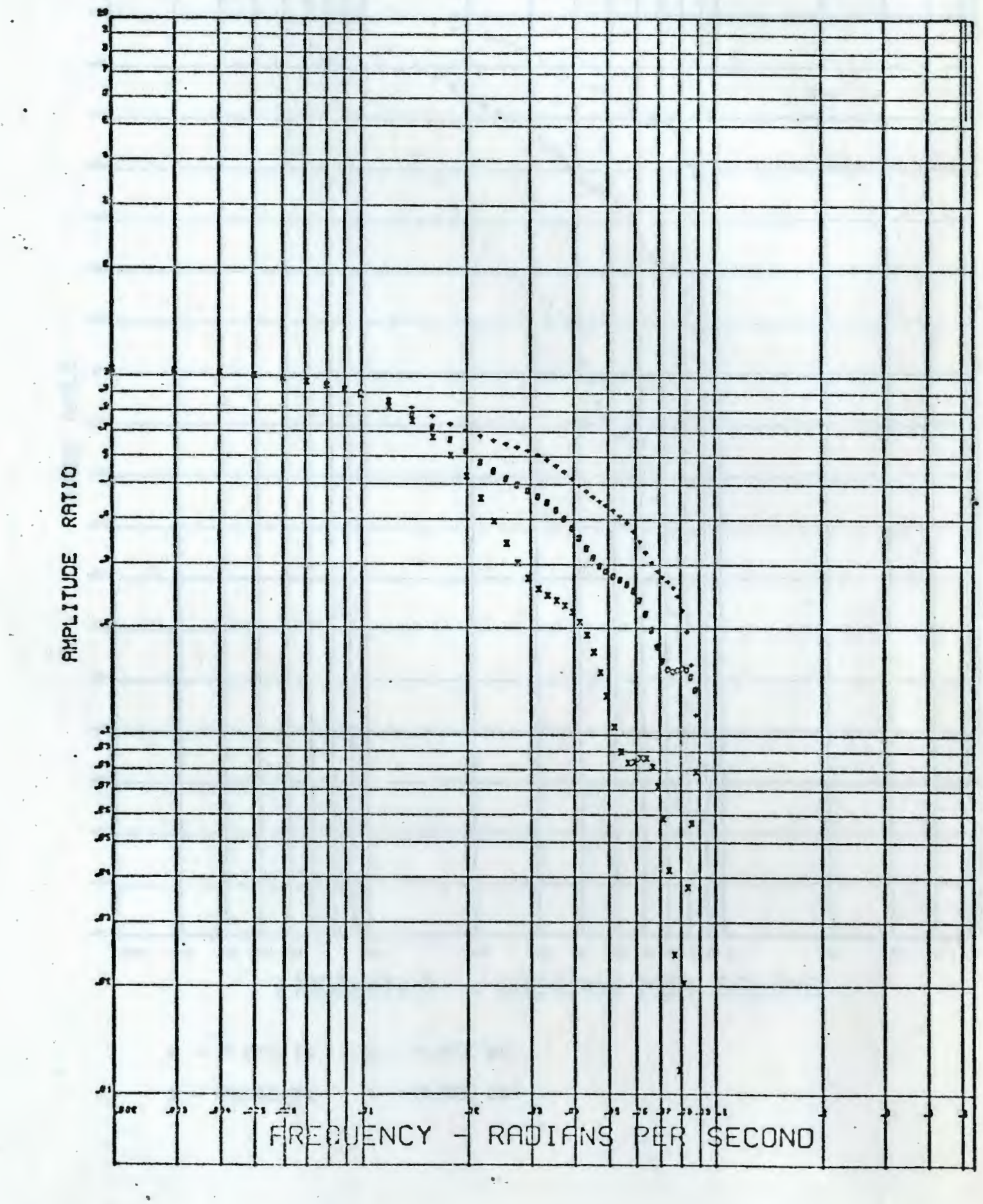




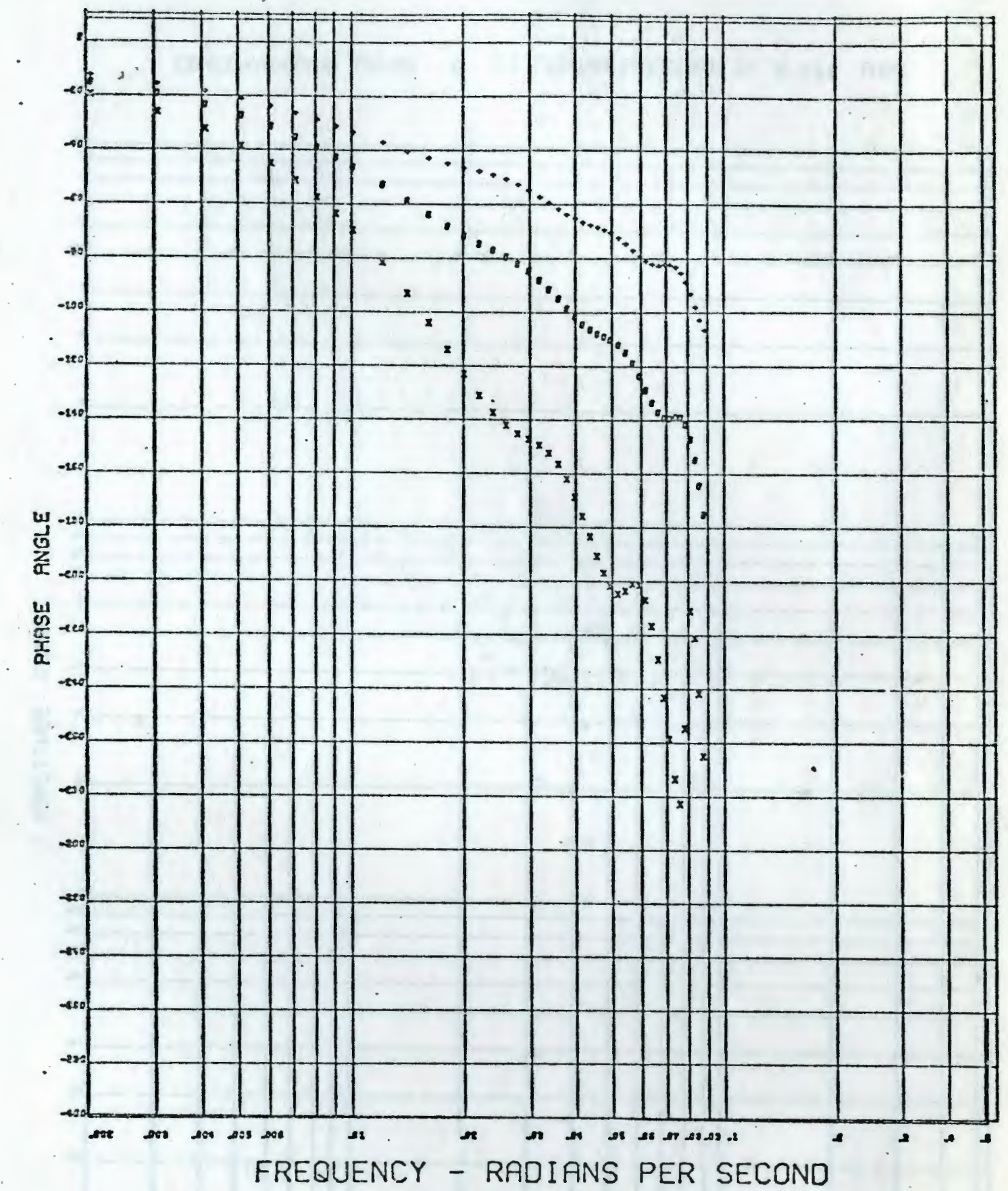

$\begin{array}{ll}\text { * - Plate } 16 & 0 . \text { - Plate } 26 \\ \text { X-PLATE } 21^{\circ} & + \text { - Plate } 28\end{array}$ 


\section{BODE PLOT}

. CONCENTRATion pUlse 6 at column pressure of 0.263 atM.

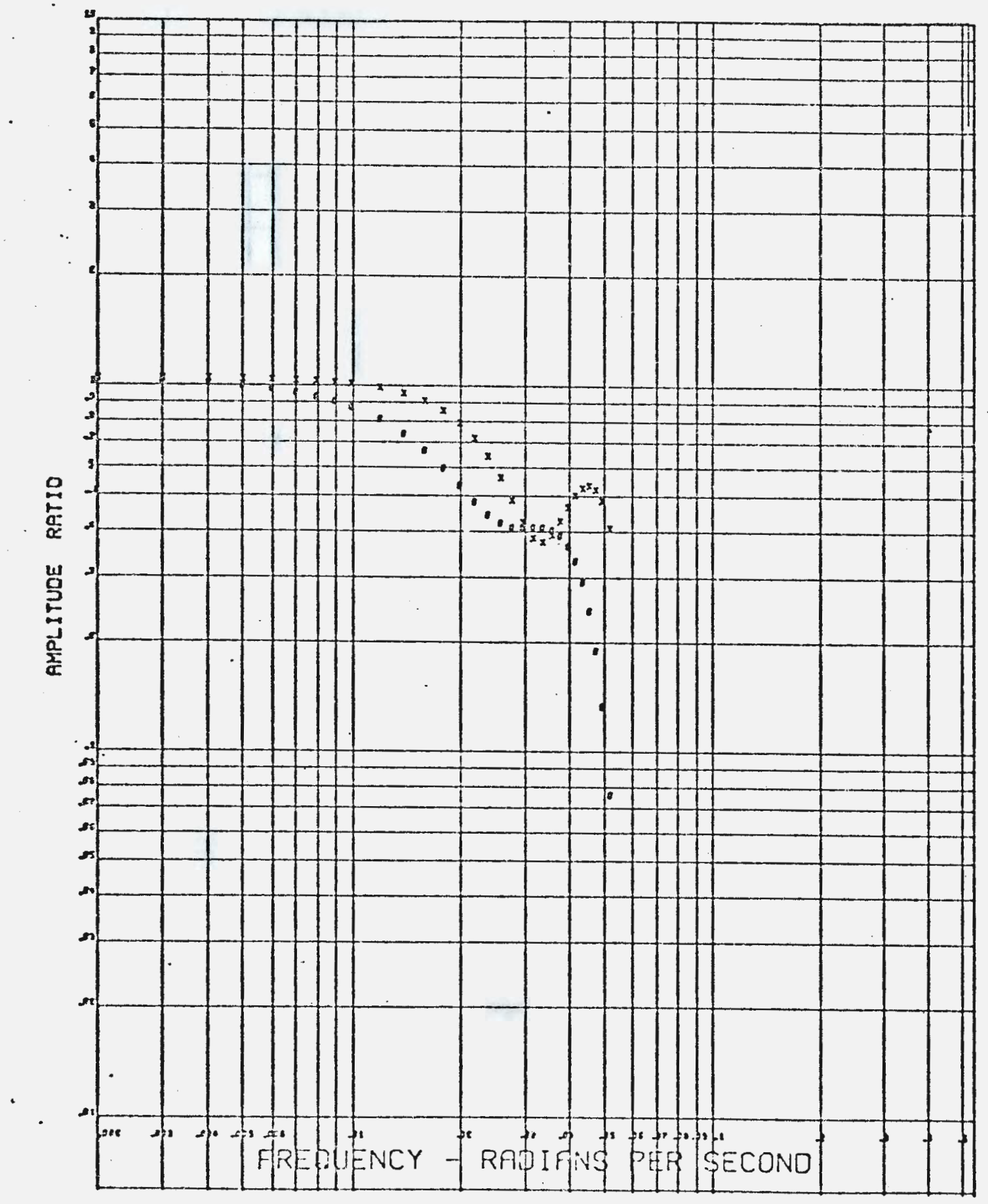




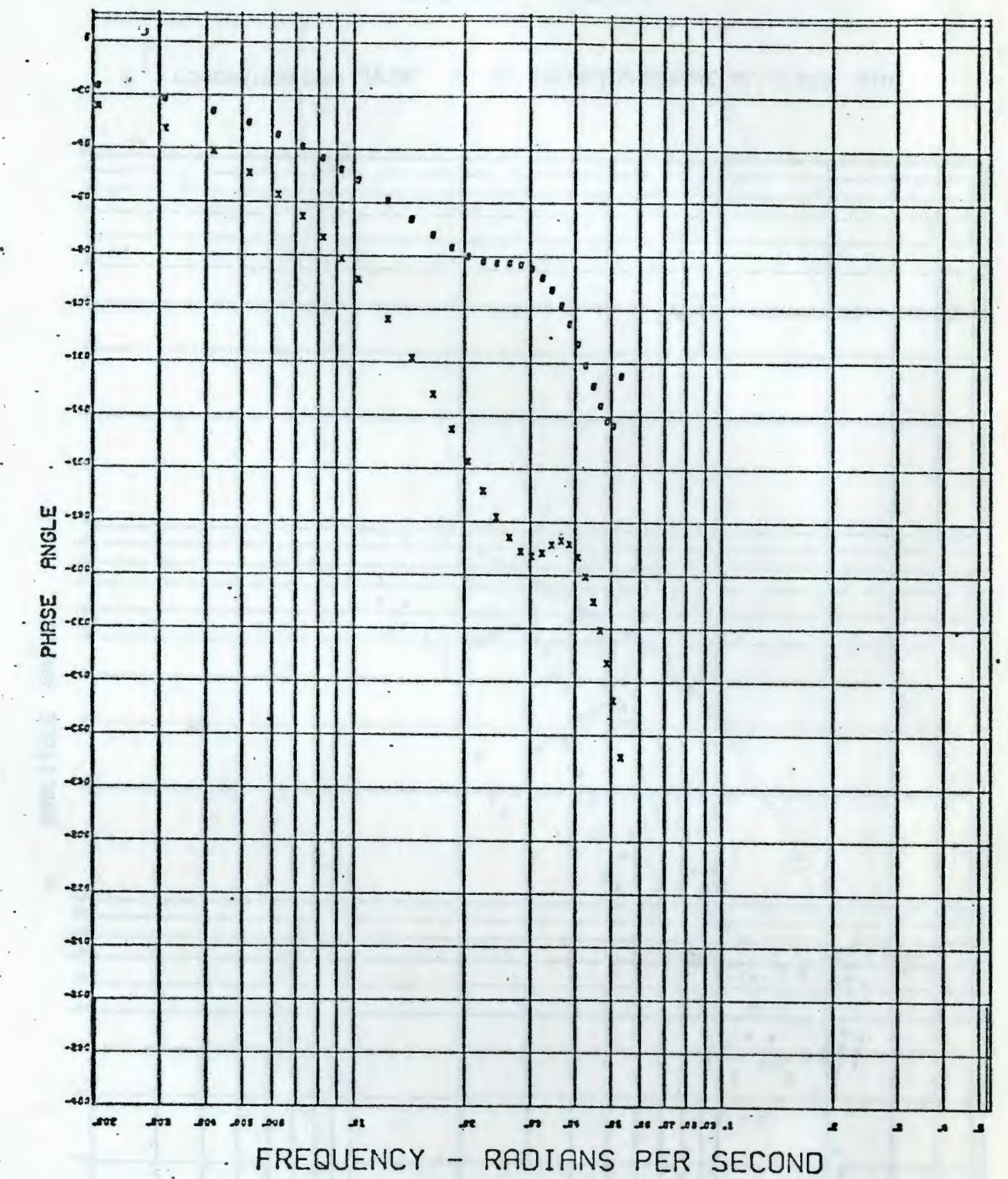

- plate 16 0-plate 26

X - Plate 21 + + plate 28 
* concentration pUlse i at column pressufe of 0.263 atm.

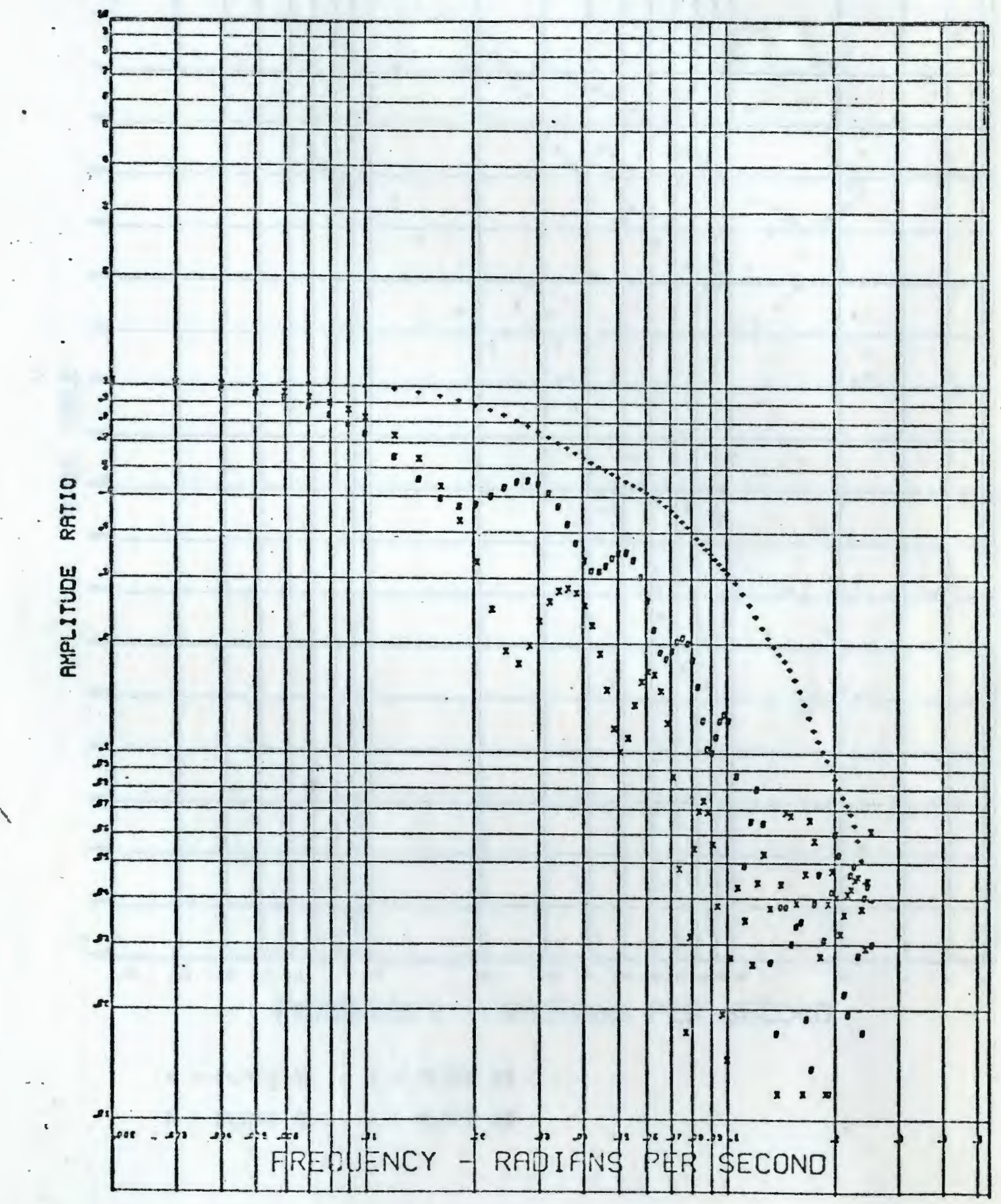



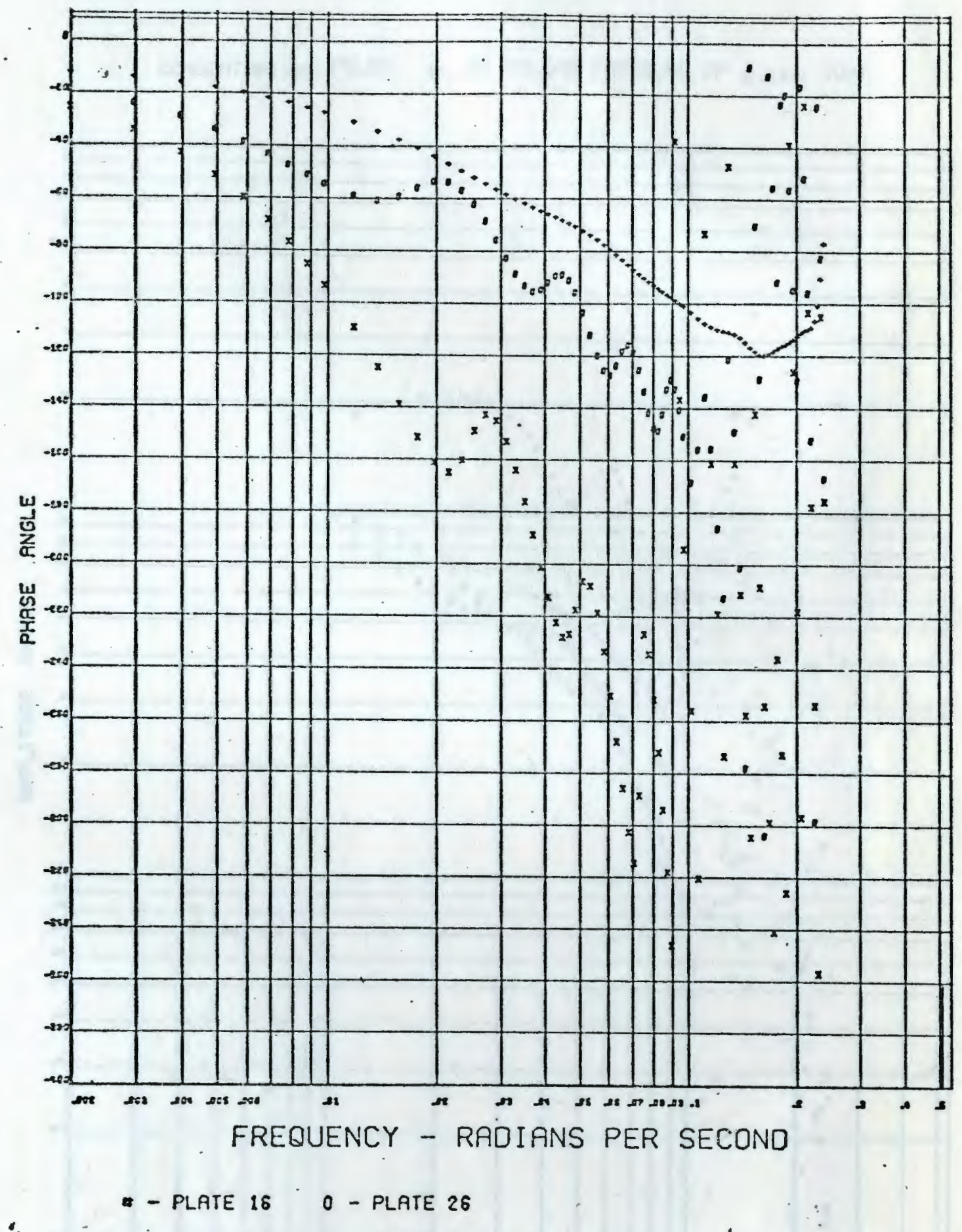

- $x$ - plate 21. + plate 28 
BODE PLOT

$\because$ CONCENTRATION PULSE 8 at COLUMN PRESSURE OF 0.263 ATM.

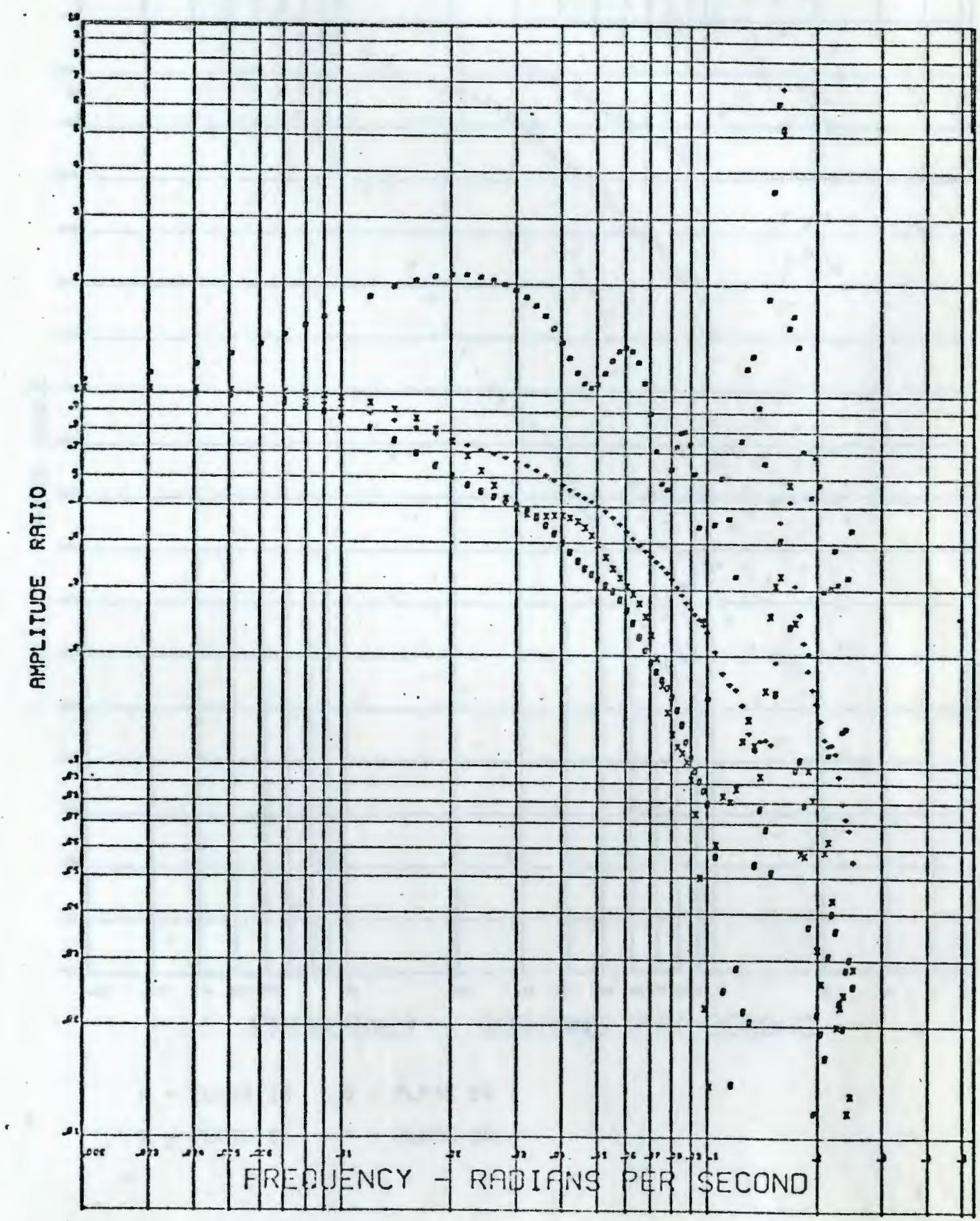




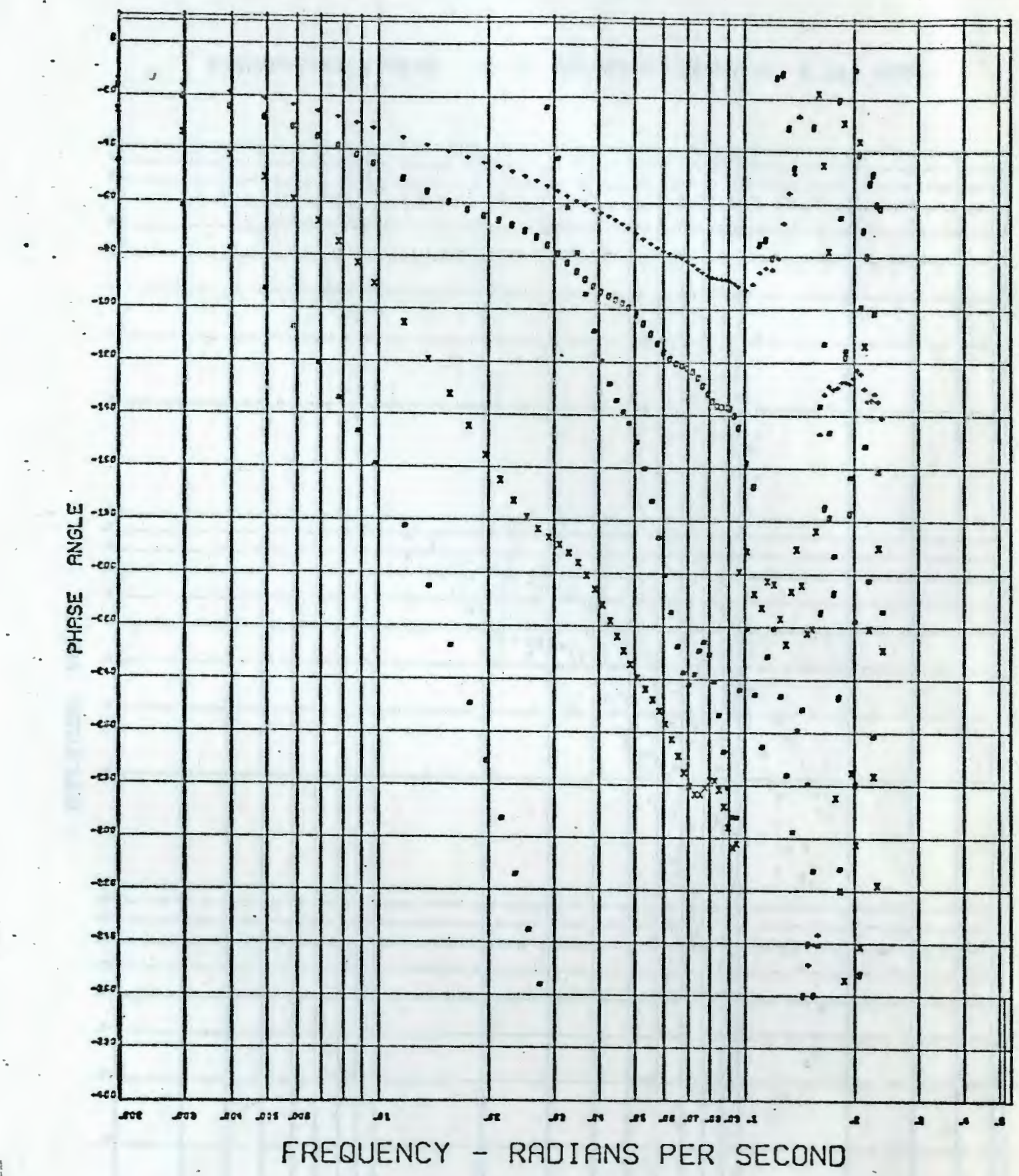

1

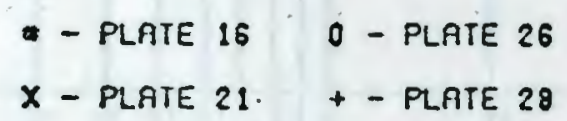




\section{BODE PLOT}

\% concentration Pillse 9 at column pressure of 0.263 atm.

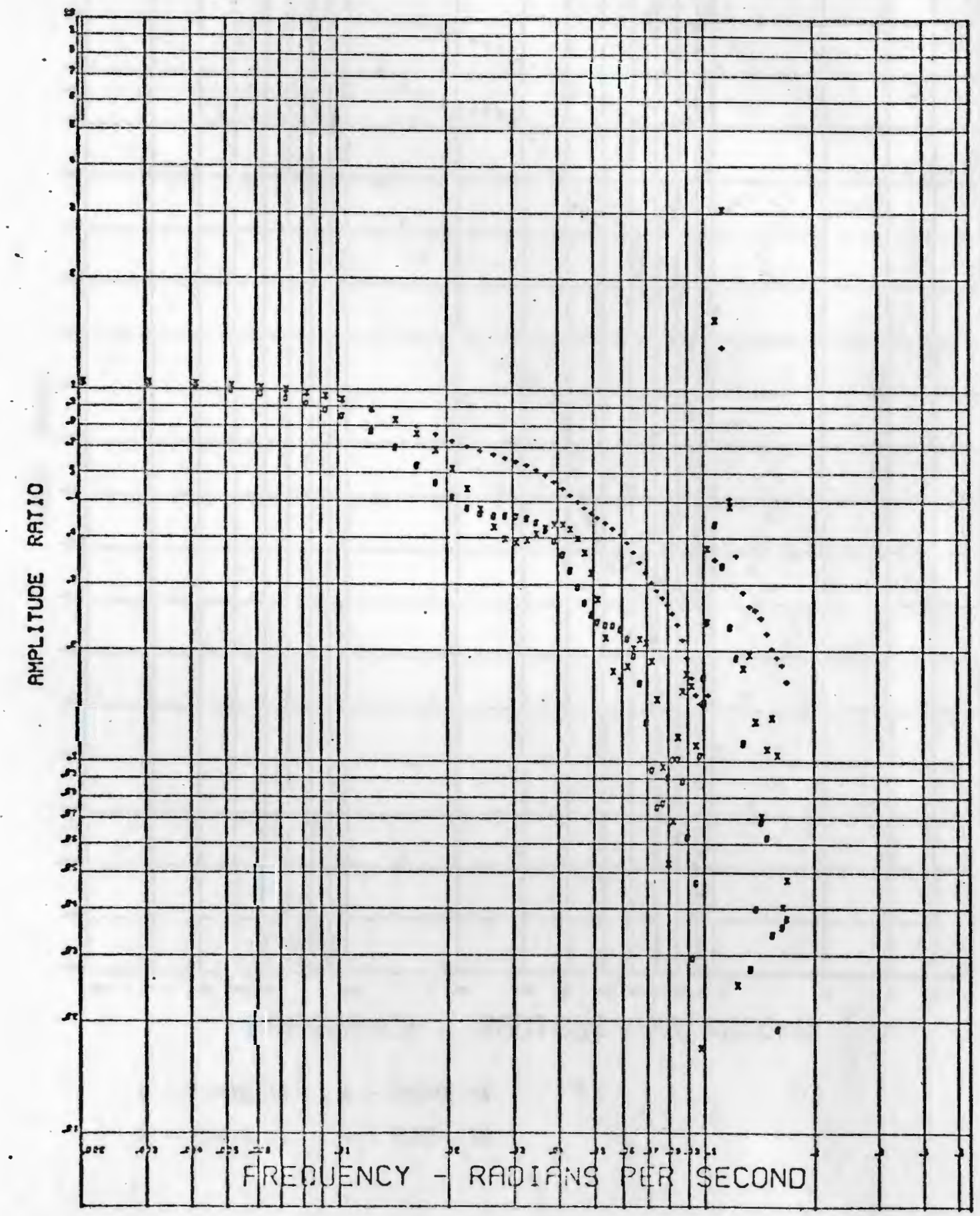



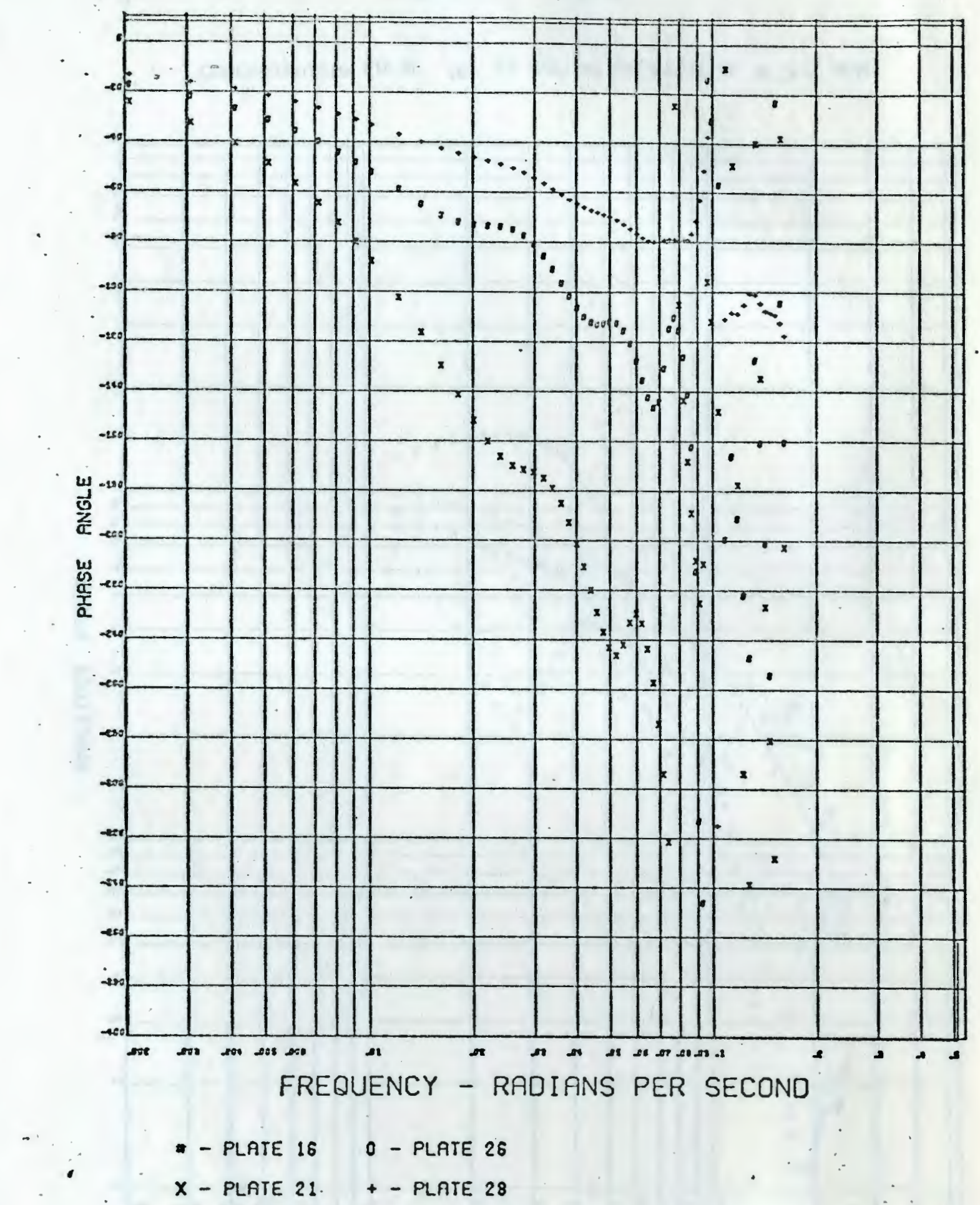


\section{BODE PLOT}

- CONCENTRATION PULSE 10 fT COLUMN PRESSURE of 0.263 atm.

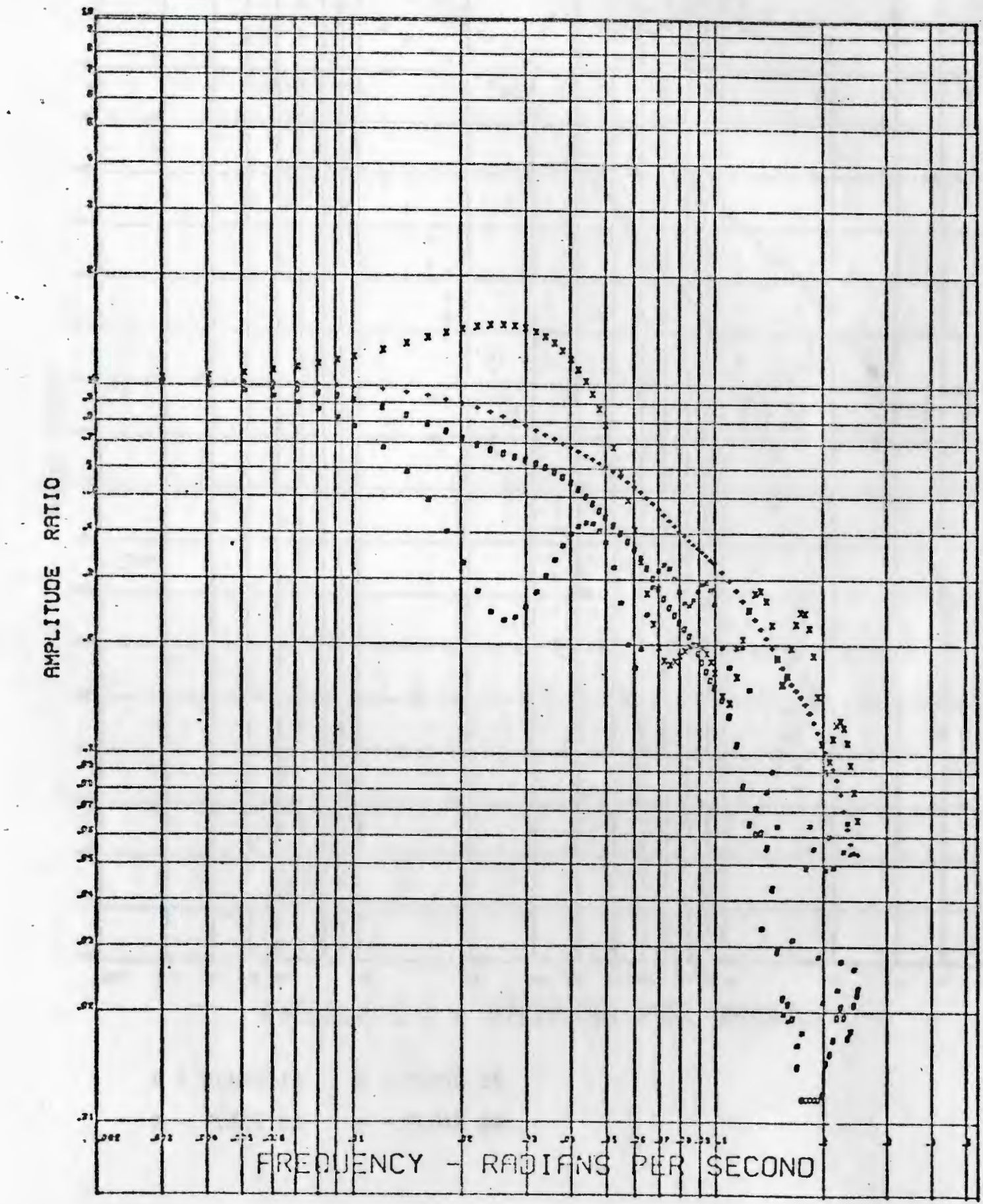




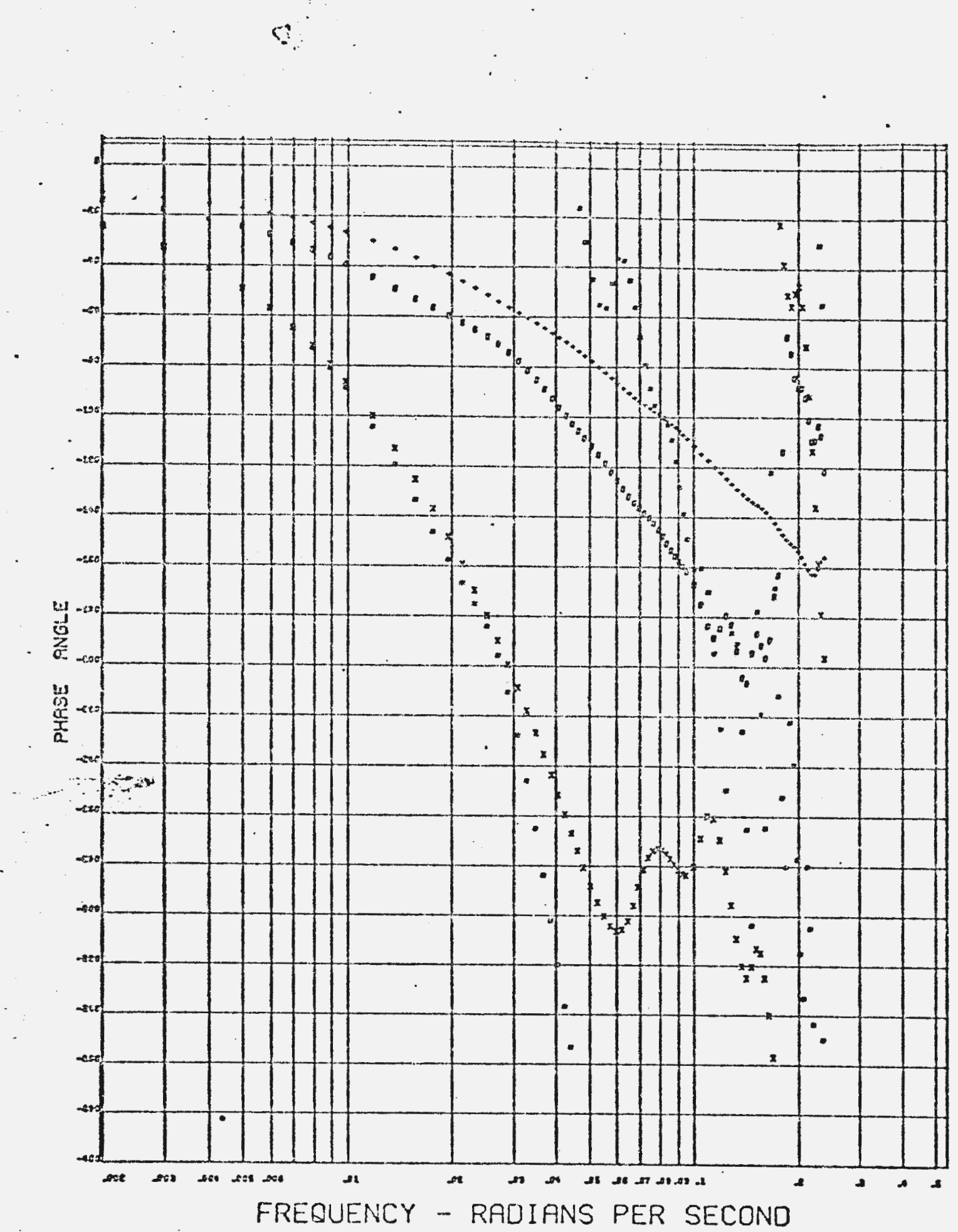

